JOINT TRANSPORTATION RESEARCH PROGRAM

FHWA/IN/JTRP-2007/25

Final Report

POST-CONSTRUCTION EVALUATION OF

LIME-TREATED SOILS

Chulmin Jung

Antonio Bobet

May 2008 


\section{TECHNICAL Summary}

INDOT Research

Technology Transfer and Project Implementation Information

TRB Subject Code: 62-7 Subgrades and Bases

Publication No.: FHWA/IN/JTRP-2007/25, SPR-3007

May 2008

Final Report

\section{POST-CONSTRUCTION EVALUATION OF LIME-TREATED SOILS}

\section{Introduction}

Lime is used to treat weak subgrade soils during construction of highways. A small amount of lime (4 to $7 \%$ ) is used to rapidly dehydrate and modify fine-grained soils. The modification process improves workability and compactability of the soils. Although the lime modification process is primarily aimed at construction expediency, additional effects such as long-term improvement of stiffness and/or strength by pozzolanic and carbonation cementation reactions are expected. Lime treatment has been employed in Indiana over several decades, but the long-term performance of lime-treated soils has not been well quantified and no field tests have been done on roads in service. In addition, there is concern that repeated loading, weathering, change in water content, and potential for lime migration may cause with time a decrease in strength and/ or stiffness of lime-treated subgrade soils. For this reason, engineers do not usually account for the enhanced stiffness that the treatment may provide for pavement design. This results in a conservative design of the asphalt or concrete pavement layers.

\section{Findings}

A comprehensive field investigation was carried out to determine the properties of subgrade soils treated with lime in pavements that had been in service for at least five years. Six sites were selected for the field tests. At each site, SPT, DCPT, and FWD tests were performed to evaluate the in-situ stiffness and/or strength properties of the lime-treated subgrade. Laboratory tests from soil samples taken from the SPT spoon were done to obtain index properties of the lime-treated subgrade and the lime content that remains in the soil. The long-term performance of the lime-treated subgrade at each site was evaluated based on the results of the laboratory and field tests. The evaluation was done by comparing the soil indices and stiffness and/or strength properties of the lime-treated subgrade soil with those of the natural soil. In addition, the lime content of the subgrade and the natural soil were measured to establish the remaining lime in the treated subgrade and detect any leaching in the underlying soil.
The fines content of the original soil was reduced by the addition of lime. The reduction ranged from $20 \%$ to $40 \%$. In general the lime treatment changed the original soil from a silty/clayey soil to a non-plastic silty sand. The CBR longitudinal distribution at each site was obtained from DCPT results. It was found that: (1) the addition of lime to the natural soil has the potential to significantly increase the CBR of the natural soil by as much as $500 \%$ to $1500 \%$; and (2) the results obtained show a very large scatter, both along the length of the road and also with depth.

Quantification of the lime content in the subgrade was done with thermogravimetric (TGA) laboratory tests. The $\mathrm{CaCO}_{3}$, content, which is related to the content of lime that remains in the subgrade, ranges from $1.2 \%$ to $17.5 \%$, with typical values in the range of $5 \%$ to $7 \%$. An important result from the TGA tests, which was confirmed with X-ray diffraction tests, is that the lime was only present in the treated subgrade and not in the natural soil. This provides a strong indication, together with $\mathrm{pH}$ measurements, that there was no leaching of 
the lime out of the subgrade, and thus the treatment remains after 5 to 11 years.

In conclusion, the research has shown the following: (1) the lime remains in the soil even after 11 years of service of the roads; (2) the addition of lime decreases the plasticity of the soil and increases its CBR; and (3) the construction quality observed from the field tests is highly variable.

\section{Implementation}

The recommendations for implementation of the research are based on consensus among INDOT and FHWA personnel, and from industry. In the light of the positive results obtained from the research it is recommended to increase the CBR of LKD-treated subgrade soils by $20-30 \%$ the CBR of the natural, untreated, soil. This increase accounts for the immediate benefits of the engineering properties of the treated soil as well as the long-term benefits. It also considers that the quality control that INDOT has in place today at construction sites has improved over the years.

In the future a further increase of the CBR of the treated subgrade would be appropriate as field data from construction sites is gathered. Such increase needs to be linked to an improvement of quality control during all the phases of the subgrade treatment with LKD that should result in a uniform treatment of the soil along the road. The problems that the research has identified as the source of the non-uniform engineering properties of treated subgrade layers are associated with low reactive lime content of the LKD delivered at the site, which could be related to a long-time storage of the product and/or partial hydration of the lime; and also to non-ideal construction practices including nonoptimal spread, mixing and compaction. Such problems can be identified in the field through systematic testing and an effective quality program, which could include measurements of: (1) the $\mathrm{CaO}$ content of the lime at the site, e.g. using phenolphtaleine; (2) the lime delivered per unit surface; and (3) the density achieved after compaction. Such tests could be complemented by direct measurements of the engineering properties of the subgrade by conducting DCPI and plate load tests. In addition disturbed samples should be taken to the laboratory for identification and lime content tests. Once the road is in service periodic inspections will provide an assessment of the level of performance with time and also as a function of weather conditions.

\section{Contacts}

\section{For more information:}

Prof. Antonio Bobet

Principal Investigator

School of Civil Engineering

Purdue University

West Lafayette IN 47907

Phone: (765) 494-5033

Fax: (765) 494-0395

E-mail: bobet@purdue.edu

\section{Indiana Department of Transportation}

Division of Research

1205 Montgomery Street

P.O. Box 2279

West Lafayette, IN 47906

Phone: (765) 463-1521

Fax: (765) 497-1665

\section{Purdue University}

Joint Transportation Research Program

School of Civil Engineering

West Lafayette, IN 47907-1284

Phone: (765) 494-9310

Fax: (765) 496-7996

E:mail: jtrp@ecn.purdue.edu 
Final Report

FHWA/IN/JTRP-2007/25

\title{
POST-CONSTRUCTION EVALUATION OF LIME-TREATED SOILS
}

\author{
by \\ Chulmin Jung \\ Graduate Research Assistant \\ Purdue University \\ Antonio Bobet \\ Professor \\ Purdue University \\ Nayyar Zia Siddiki \\ Supervisor \\ Indiana Department of Transportation \\ Joint Transportation Research Program \\ Project No. C-36-36UU \\ File No. File No. 6-14-46 \\ SPR-3007 \\ Conducted in Cooperation with the \\ Indiana Department of Transportation \\ and the U.S. Department of Transportation \\ Federal Highway Administration
}

The contents of this report reflect the views of the authors who are responsible for the facts and the accuracy of the data presented herein. The contents do not necessarily reflect the official views or policies of the Indiana Department of Transportation or the Federal Highway Administration at the time of publication. This report does not constitute a standard, specification, or regulation.

\author{
School of Civil Engineering \\ Purdue University \\ May 2008
}


TECHNICAL REPORT STANDARD TITLE PAGE

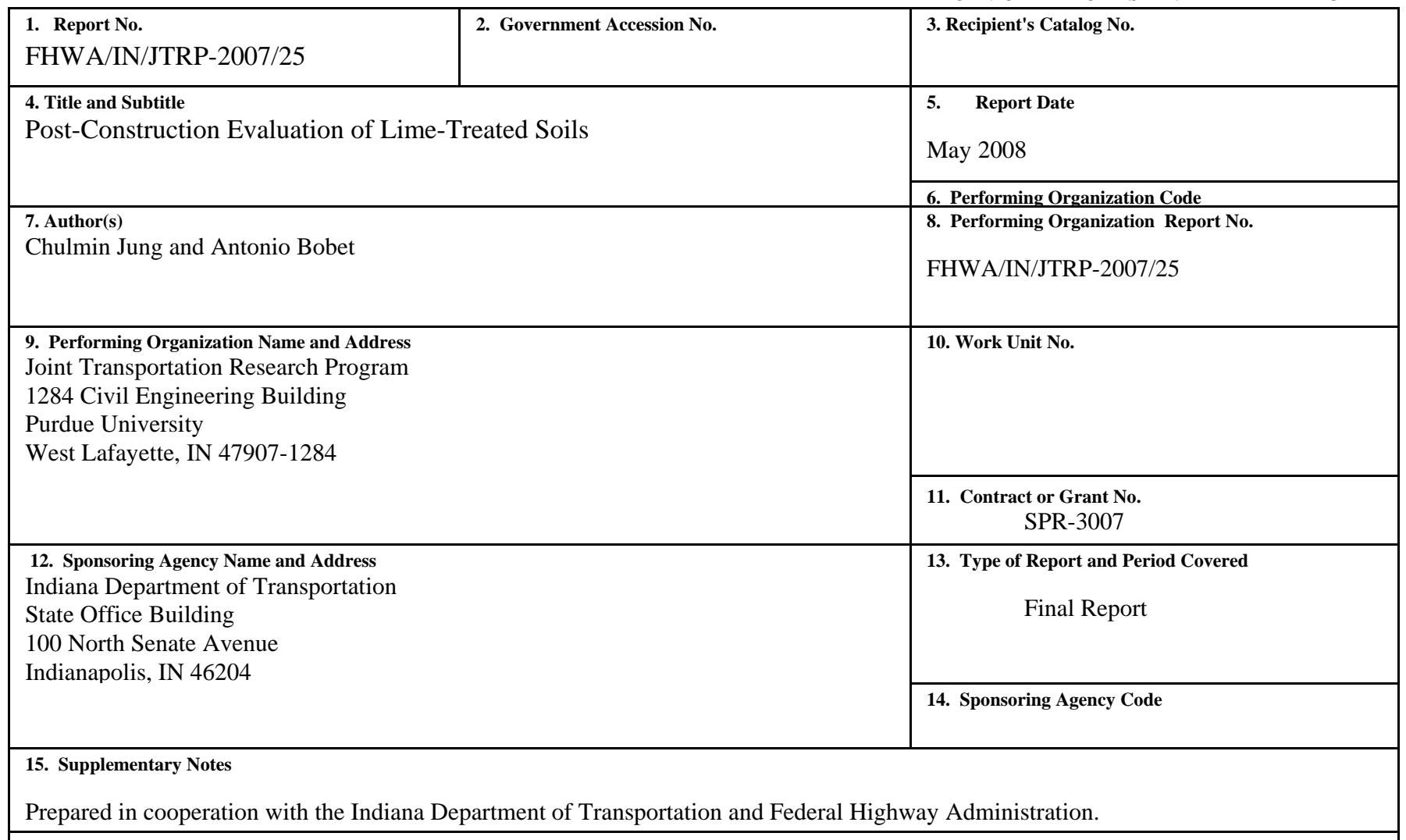

\section{Abstract}

Lime is used to treat weak subgrade soils during construction of highways. A small amount of lime (4 to 7\%) is used to rapidly dehydrate and modify fine grained soils. The modification process improves workability and compactability of the soils. Although the lime modification process is primarily aimed at construction expediency, additional effects such as long-term improvement of stiffness and/or strength by pozzolanic and carbonation cementation reactions are expected. Lime treatment has been employed in Indiana over several decades, but the long-term performance of lime-treated soils has not been well quantified and no field tests have been done on roads in service. A comprehensive field investigation was carried out to determine the properties of subgrade soils treated with lime in pavements that had been in service for at least five years. Six sites were selected for the field tests. At each site, SPT, DCPT, and FWD tests were performed to evaluate the in-situ stiffness and/or strength properties of the lime-treated subgrade. Laboratory tests from soil samples taken from the SPT spoon were done to obtain index properties of the lime-treated subgrade and the lime content that remains in the soil. The long-term performance of the lime-treated subgrade at each site has been evaluated by comparing the soil indices and stiffness and/or strength properties of the lime-treated subgrade soil with those of the natural soil. In addition, the lime content of the subgrade and the natural soil were measured to establish the remaining lime in the treated subgrade and detect any leaching in the underlying soil. The research has shown the following: (1) the lime remains in the soil even after 11 years of service of the road after construction; (2) the addition of lime decreases the plasticity of the soil and increases its CBR; and (3) the construction quality observed from the field tests is highly variable.

\section{Key Words}

Long-term performance, Lime-treated subgrade, Laboratory and field tests, Stiffness and/or strength properties, Lime content, DCP test, FWD test.

\section{Distribution Statement}

No restrictions. This document is available to the public through the National Technical Information Service, Springfield, VA 22161

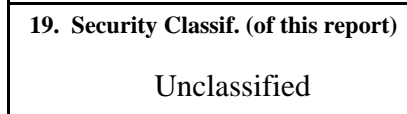

Form DOT F 1700.7 (8-69) 


\section{ACKNOWLEDGEMENTS}

The project (SPR 3007) was funded by the Joint Transportation Research Program of Purdue University in conjunction with the Indiana Department of Transportation and the Federal Highway Administration. The authors acknowledge and appreciate their support and assistance. The authors also are thankful for the input from the Study Advisory Committee members. 


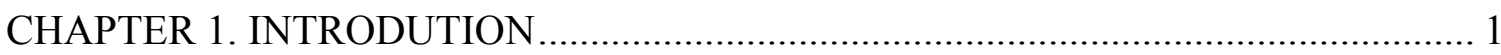

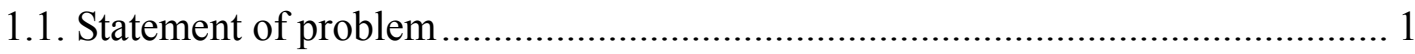

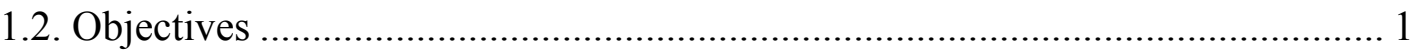

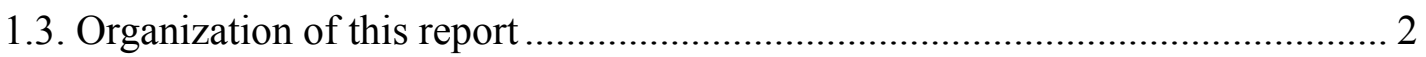

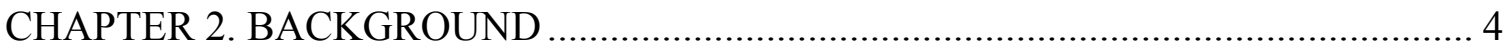

2.1. Chemical reaction of soil-lime mixture …………………….......................... 5

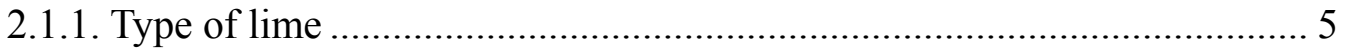

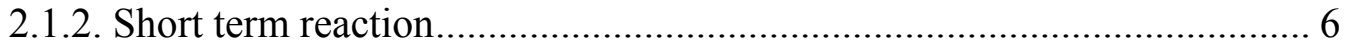

2.1.3. Long term reactions ....................................................................... 8

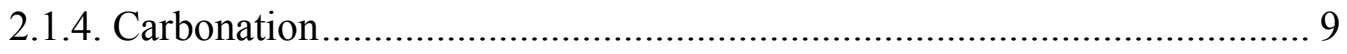

2.2. Engineering properties of lime-treated soils ...................................................... 9

2.2.1. Soil characterization properties........................................................... 9

2.2.2. Strength properties ........................................................................... 13

2.2.3. Stiffness properties......................................................................... 20

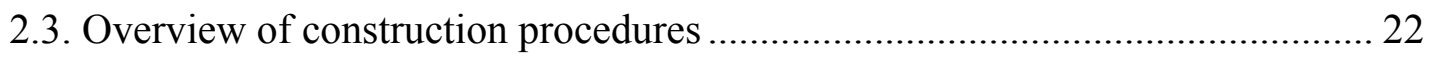

2.3.1. Scarification or initial pulverization of natural soil ................................ 22

2.3.2. Lime spreading.................................................................................. 23

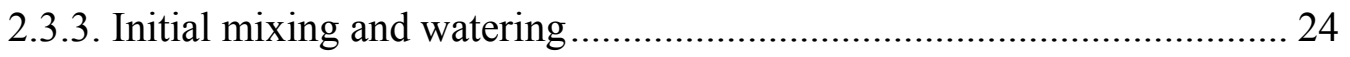

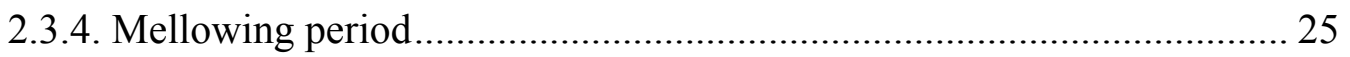

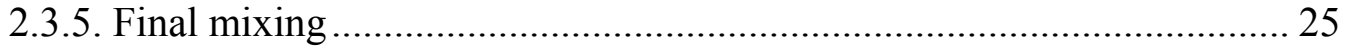




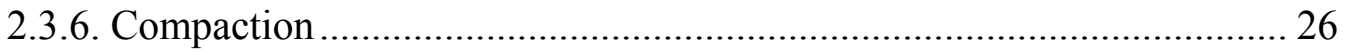

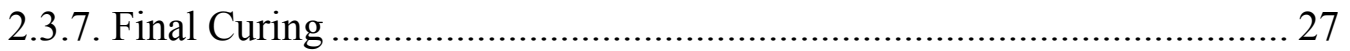

2.4. Factors affecting properties of lime-treated soils............................................. 28

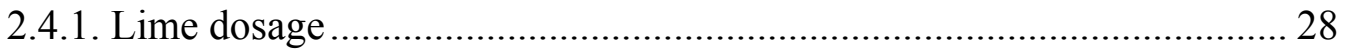

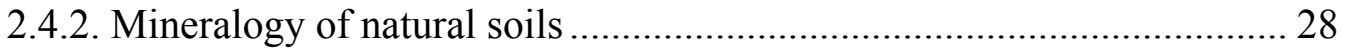

2.4.3. Soil gradation, pulverization, and mixing............................................. 29

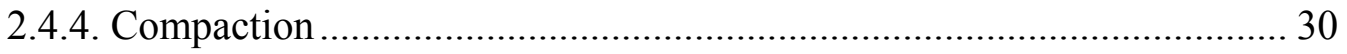

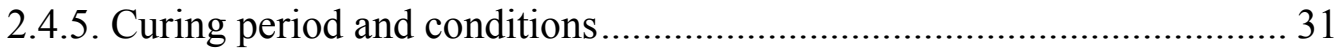

2.5. Design procedures for soil modification or stabilization using lime .................. 31

2.5.1. Indiana Department of Transportation (2002) ......................................... 31

2.5.2. The National Lime Association (1999) .................................................. 32

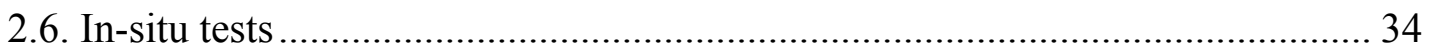

2.6.1. Dynamic Cone Penetrometer Test........................................................... 35

2.6.2. Falling Weight Deflectometer ............................................................... 39

2.7. Post-construction tests for pavement evaluation................................................. 41

2.7.1. General post-construction test............................................................... 41

2.7.2. Post-construction test on lime-treated subgrade ..................................... 42

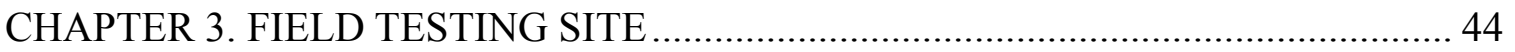

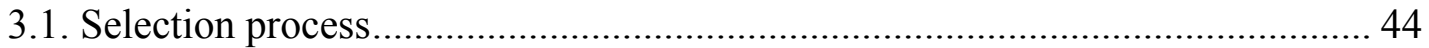

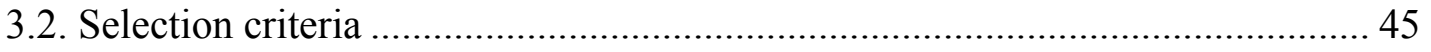

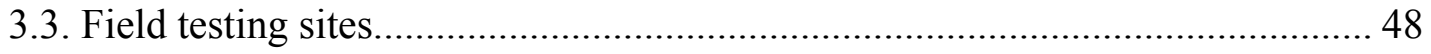

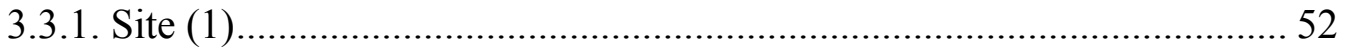




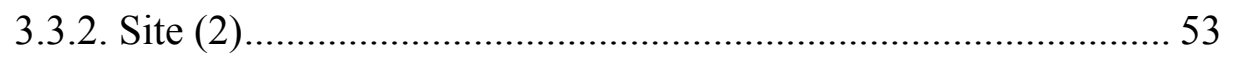

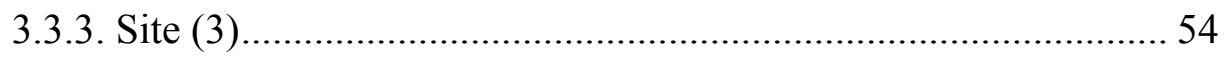

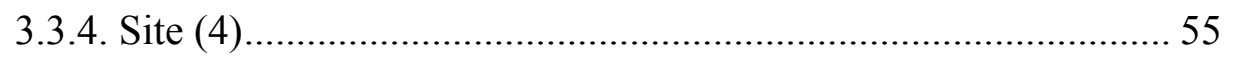

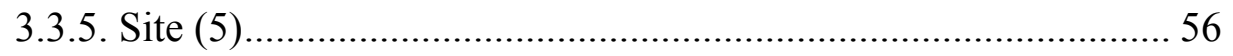

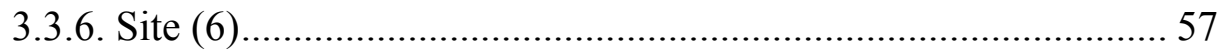

CHAPTER 4. TESTS METHODOLOGY ………………............................... 78

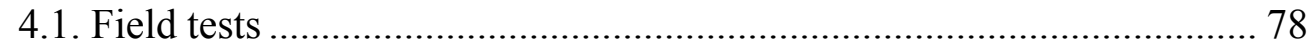

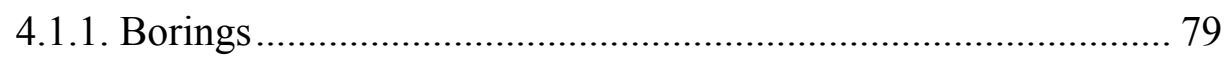

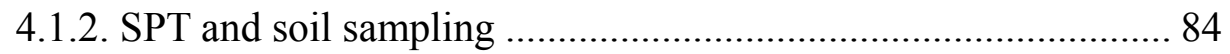

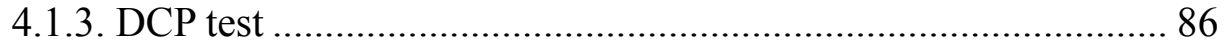

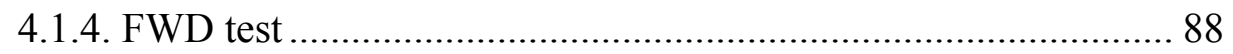

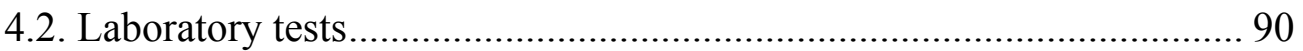

4.2.1. Soil characterization tests .......................................................... 90

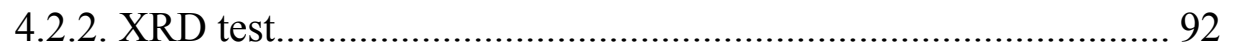

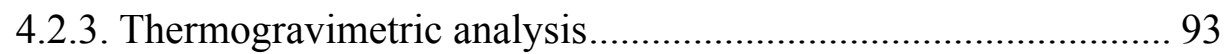

CHAPTER 5. TEST RESULTS AND DISCUSSION ......................................... 95

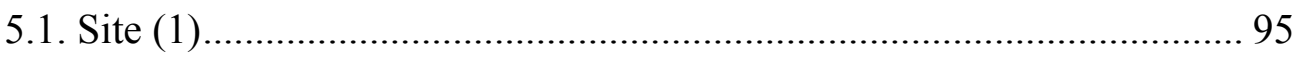

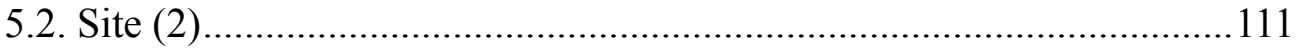

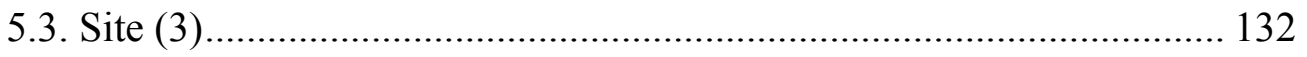

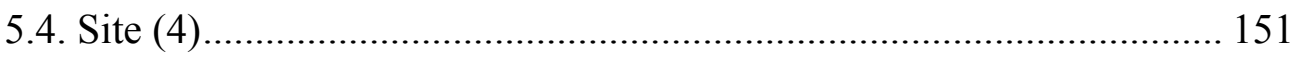

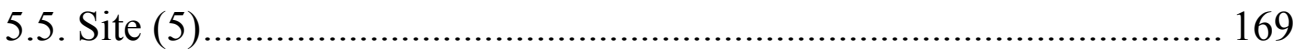




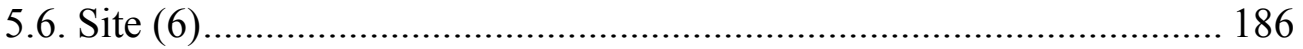

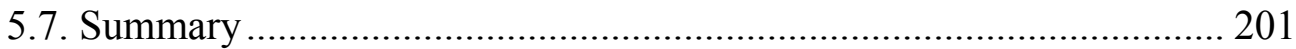

CHAPTER 6. Summary and Conclusions ........................................................ 203

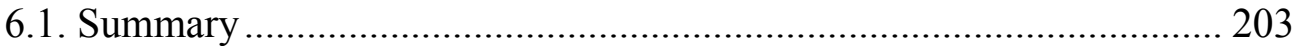

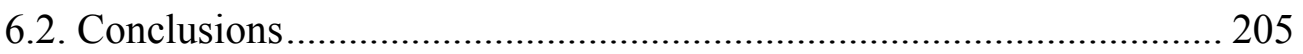

6.3. Recommendations and Implementation.............................................. 213

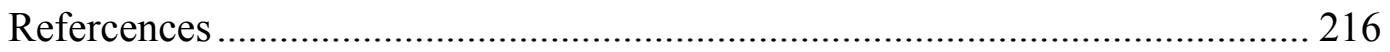

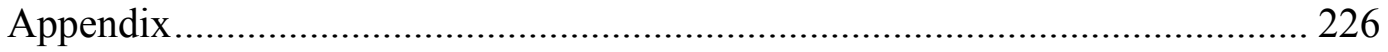




\section{LIST OF FIGURES}

Figure 2.1 Schematic of clay stabilization by cation exchange ............................................... 8

Figure 2.2 Effect of percentage of hydrated lime on the PI of four swelling clays ................... 11

Figure 2.3 Effect of percentage of hydrated lime on PI of soils with high swelling potential ... 11

Figure 2.4 Swelling potential of soil with respect to lime dosage applied ............................... 12

Figure 2.5 Effect of lime treatment on PI of clay in Irbid, Jordan......................................... 12

Figure 2.6 Effect of lime treatment on size fraction of clay in Irbid, Jordan............................ 13

Figure 2.7 Unconfined compressive strengths of soils with different mineralogy.................15

Figure 2.8 Effect of percentage of lime and curing time on the compressibility of a clay soil ..20

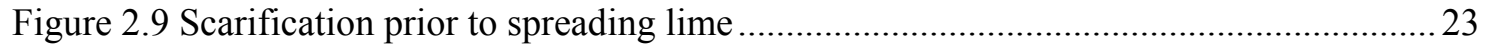

Figure 2.10 Spreading lime using a truck with a mechanical spreader...................................24

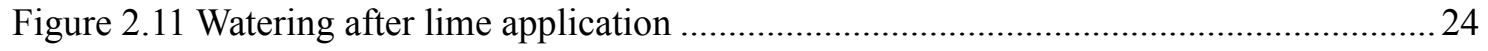

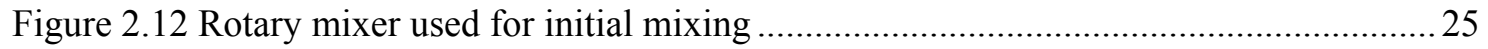

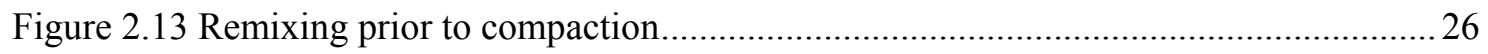

Figure 2.14 Sheepfoot (left) and padfoot (right) rollers used for initial compaction ................27

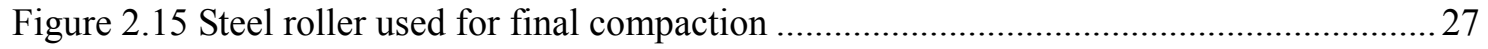

Figure 2.16 Schematic of DCP device (ASTM D 6951-03) .................................................... 36

Figure 2.17 Schematic of typical Falling Weight Deflectometer........................................... 40

Figure 3.1 Geographical location of the six field testing sites................................................50

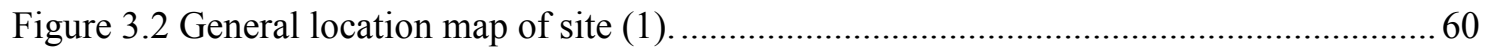

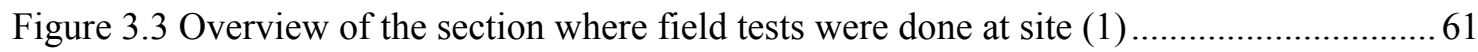

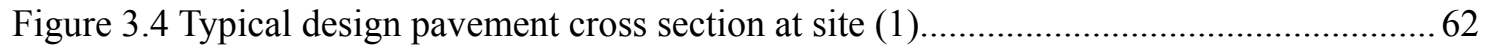




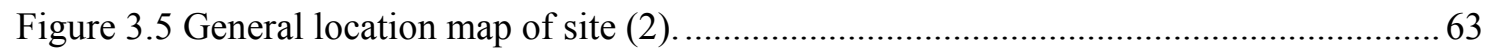

Figure 3.6 Overview of the section where field tests were done at site (2) .............................. 64

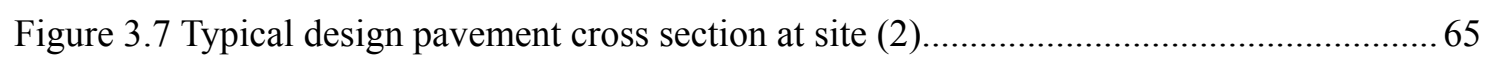

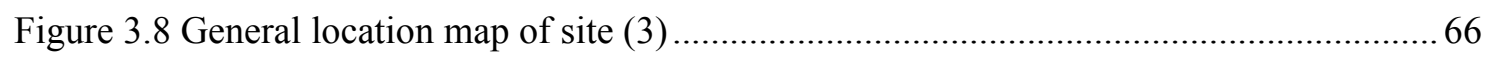

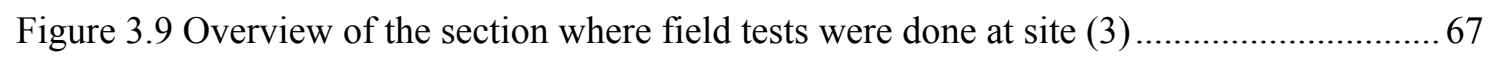

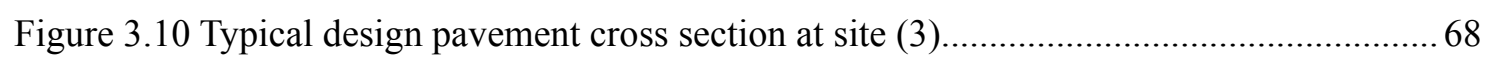

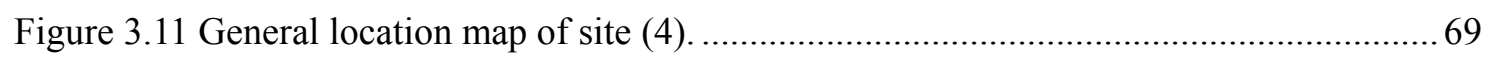

Figure 3.12 Overview of the section where field tests were done at site (4) .......................... 70

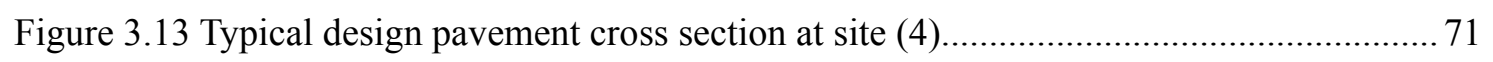

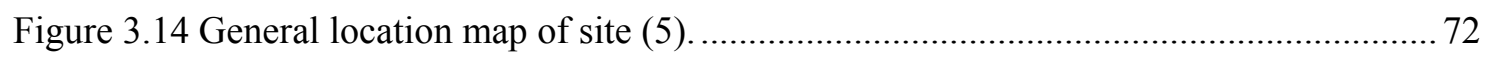

Figure 3.15 Overview of the section where field tests were done at site (5) .......................... 73

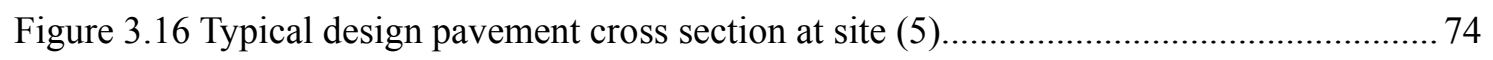

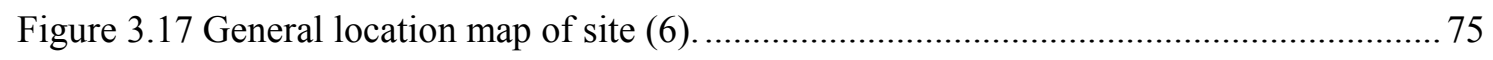

Figure 3.18 Overview of the section where field tests were done at site (6) ........................... 76

Figure 3.19 Typical design pavement cross section at site (6).......................................... 77

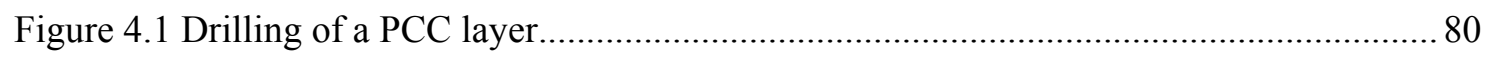

Figure 4.2 Core of a PCC layer at site (5) $(\mathrm{D}=8$ inches and $\mathrm{H}=10$ inches) ............................ 81

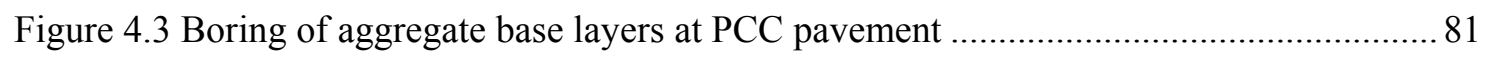

Figure 4.4 Top of upper crushed course aggregate base layer after drilling PCC layer .............82

Figure 4.5 Top of lower aggregate base layer after boring the upper crushed course base layer 82

Figure 4.6 Top of lime-treated subgrade after boring the lower aggregate base layer................ 83

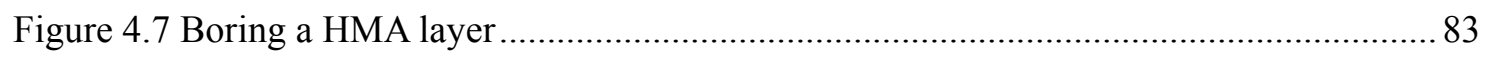

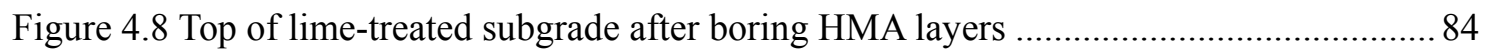


Figure 4.9 boring subgrade soil 84

Figure 4.10 Installation of a standard spoon sampler into a borehole 85

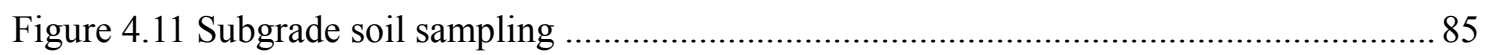

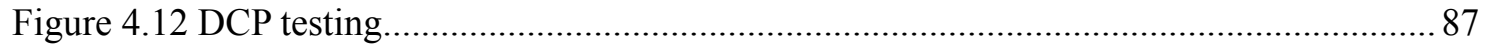

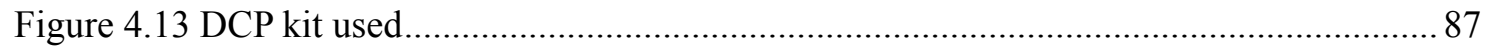

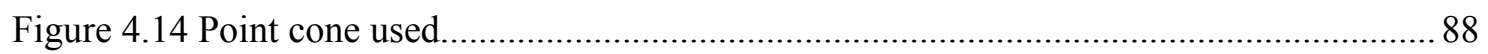

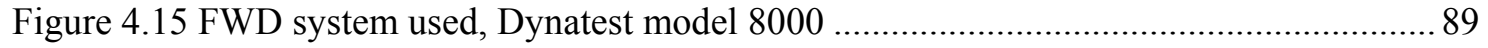

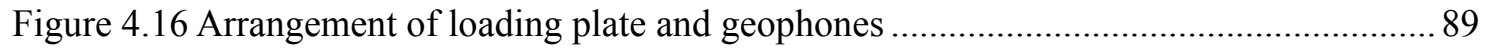

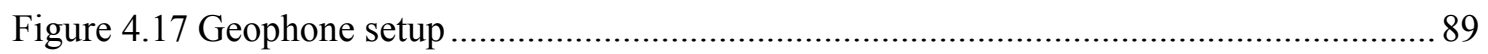

Figure 5.1 Natural water content and soil index properties at site (1) ...................................96

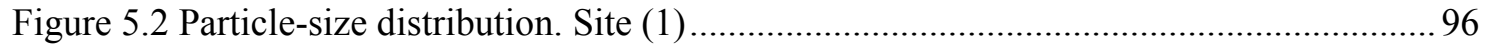

Figure 5.3 DCPT and SPT results with depth at BH-1 (STA. 0 meters). Site (1).....................98

Figure 5.4 DCPT and SPT results with depth at BH-2 (STA. 20 meters). Site (1)....................98

Figure 5.5 DCPT and SPT results with depth at BH-3 (STA. 40 meters). Site (1)....................99

Figure 5.6 DCPT and SPT results with depth at BH-4 (STA. 60 meters). Site (1)...................99

Figure 5.7 CBR of subgrade estimated from DCPT results. Site (1)................................... 101

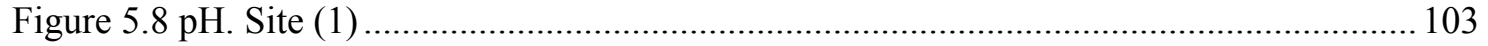

Figure 5.9 XRD pattern for untreated soil sample at BH-3 (STA. 40 meters). Site (1)........... 105

Figure 5.10 XRD pattern for lime-treated soil sample at BH-3 (STA. 40 meters). Site (1) .... 105

Figure 5.11 XRD pattern for lime-treated soil sample taken at a depth of 0 inches below top of

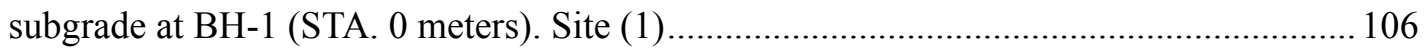

Figure 5.12 XRD pattern for lime-treated soil sample taken at a depth of 4 inches below top of subgrade at BH-1 (STA. 0 meters). Site (1). 106 
Figure 5.13 XRD pattern for lime-treated soil sample taken at a depth of 8 inches below top of subgrade at BH-1 (STA. 0 meters). Site (1). 107

Figure 5.14 XRD pattern for lime-treated soil sample taken at a depth of 12 inches below top of subgrade at BH-1 (STA. 0 meters). Site (1) 107

Figure 5.15 XRD pattern for lime-treated soil sample taken at a depth of 16 inches below top of subgrade at BH-1 (STA. 0 meters). Site (1) 108

Figure 5.16 Weight loss and weight loss rate obtained from TGA from lime-treated and untreated soil samples collected at BH-3 (STA. 40 meters) at site (1) 109

Figure 5.17 Weight loss obtained from TGA from lime-treated soil samples collected at depths of $0,4,8,12$, and 16 inches respectively below top of subgrade, at BH-1 (STA. 0 meters) at site (1) 110

Figure 5.18 Natural water content and soil index properties at site (2). 111

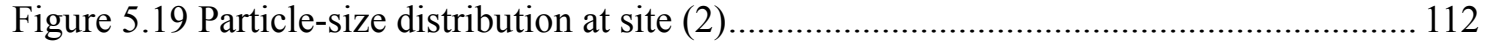

Figure 5.20 DCPT and SPT results with depth at BH-1 (STA. 0 meters). Site (2).................. 114

Figure 5.21 DCPT and SPT results with depth at BH-2 (STA. 20 meters). Site (2)................. 115

Figure 5.22 DCPT and SPT results with depth at BH-3 (STA. 40 meters). Site (2)................ 115

Figure 5.23 DCPT and SPT results with depth at BH-4 (STA. 60 meters). Site (2)................ 116

Figure 5.24 DCPT and SPT results with depth at BH-5 (STA. 80 meters). Site (2)................ 116

Figure 5.25 DCPT and SPT results with depth at BH-6 (STA. 100 meters). Site (2).............. 117

Figure 5.26 DCPT and SPT results with depth at BH-7 (STA. 120 meters). Site (2).............. 117

Figure 5.27 DCPT and SPT results with depth at BH-8 (STA. 140 meters). Site (2).............. 118

Figure 5.28 DCPT and SPT results with depth at BH-9 (STA. 160 meters). Site (2).............. 118

Figure 5.29 DCPT and SPT results with depth at BH-10 (STA. 180 meters). Site (2)............ 119 
Figure 5.30 CBR of subgrade estimated from DCPT results. Site (2) .................................. 119

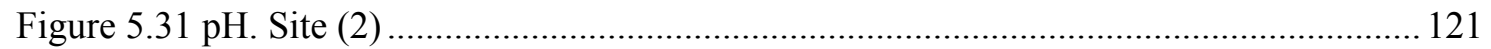

Figure 5.32 XRD pattern for lime-treated soil sample at BH-2 (STA. 20 meters). Site (2) ..... 122

Figure 5.33 XRD pattern for untreated soil sample BH-2 (STA. 20 meters). Site (2).............. 123

Figure 5.34 XRD pattern for lime-treated soil sample at BH-4 (STA. 60 meters). Site (2) ..... 123

Figure 5.35 XRD pattern for lime-treated soil sample at BH-7 (STA. 120 meters). Site (2) ... 124

Figure 5.36 XRD pattern for untreated soil sample at BH-7 (STA. 120 meters). Site (2)........ 124

Figure 5.37 XRD pattern for lime-treated soil sample taken at a depth of 0 inches below top of subgrade at BH-2 (STA. 20 meters). Site (2) 125

Figure 5.38 XRD pattern for lime-treated soil sample taken at a depth of 4 inches below top of subgrade at BH-2 (STA. 20 meters). Site (2) 126

Figure 5.39 XRD pattern for lime-treated soil sample taken at a depth of 8 inches below top of subgrade at BH-2 (STA. 20 meters). Site (2)...... 126

Figure 5.40 XRD pattern for lime-treated soil sample taken at a depth of 12 inches below top of subgrade at BH-2 (STA. 20 meters). Site (2)

Figure 5.41 XRD pattern for lime-treated soil sample taken at a depth of 16 inches below top of subgrade at BH-2 (STA. 20 meters). Site (2)

Figure 5.42 Weight loss and weight loss rate obtained from TGA from lime-treated and natural soil samples collected at BH-2 (STA. 20 meters) at site (2) 128

Figure 5.43 Weight loss and weight loss rate obtained from TGA from lime-treated and natural soil samples collected at BH-4 (STA. 60 meters) at site (2)

Figure 5.44 Weight loss and weight loss rate obtained from TGA from lime-treated and natural soil samples collected at BH-7 (STA. 120 meters) at site (2) 129 
Figure 5.45 Weight loss and weight loss rate obtained from TGA from lime-treated soil samples collected at depths of $0,4,8,12$, and 16 inches below top of subgrade, at BH-2 (STA. 20

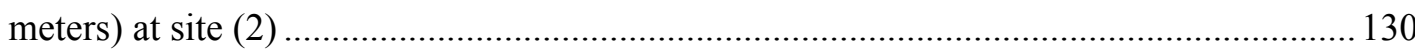

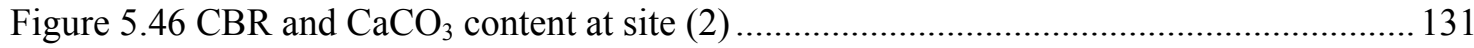

Figure 5.47 Natural water content and soil index properties. Site (3) .................................. 132

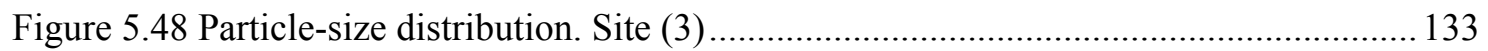

Figure 5.49 DCPT and SPT results with depth at BH-1 (STA. 0 meters). Site (3)................... 134

Figure 5.50 DCPT and SPT results with depth at BH-2 (STA. 20 meters). Site (3)................ 135

Figure 5.51 DCPT and SPT results with depth at BH-3 (STA. 40 meters). Site (3)................ 135

Figure 5.52 DCPT and SPT results with depth at BH-4 (STA. 60 meters). Site (3)................ 136

Figure 5.53 DCPT and SPT results with depth at BH-5 (STA. 80 meters). Site (3)................ 136

Figure 5.54 DCPT and SPT results with depth at BH-6 (STA. 100 meters). Site (3)............... 137

Figure 5.55 DCPT and SPT results with depth at BH-7 (STA. 120 meters). Site (3).............. 137

Figure 5.56 DCPT and SPT results with depth at BH-8 (STA. 140 meters). Site (3)............... 138

Figure 5.57 DCPT and SPT results with depth at BH-9 (STA. 160 meters). Site (3)............... 138

Figure 5.58 DCPT and SPT results with depth at BH-10 (STA. 180 meters).Site (3)............. 139

Figure 5.59 CBR of subgrade estimated from DCPT results. Site (3).................................... 139

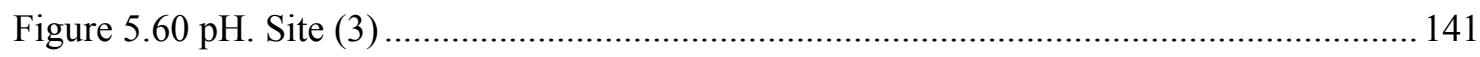

Figure 5.61 XRD pattern for lime-treated soil sample at BH-2 (STA. 20 meters). Site (3) ..... 142

Figure 5.62 XRD pattern for untreated soil sample at BH-2 (STA. 20 meters). Site (3).......... 142

Figure 5.63 XRD pattern for lime-treated soil sample at BH-4 (STA. 60 meters). Site (3) ..... 143

Figure 5.64 XRD pattern for untreated soil sample at BH-4 (STA. 60 meters). Site (3).......... 143

Figure 5.65 XRD pattern for lime-treated soil sample at BH-6 (STA. 100 meters). Site (3) ... 144 
Figure 5.66 XRD pattern for untreated soil sample at BH-6 (STA. 100 meters). Site (3)........ 144

Figure 5.67 XRD pattern for lime-treated soil sample taken at a depth of 0 inches below top of subgrade at BH-4 (STA. 60 meters). Site (3) 145

Figure 5.68 XRD pattern for lime-treated soil sample taken at a depth of 4 inches below top of subgrade at BH-4 (STA. 60 meters). Site (3). 146

Figure 5.69 XRD pattern for lime-treated soil sample taken at a depth of 8 inches below top of subgrade at BH-4 (STA. 60 meters). Site (3). 146

Figure 5.70 XRD pattern for lime-treated soil sample taken at a depth of 12 inches below top of subgrade at BH-4 (STA. 60 meters). Site (3)

Figure 5.71 XRD pattern for lime-treated soil sample taken at a depth of 16 inches below top of subgrade at BH-4 (STA. 60 meters). Site (3).

Figure 5.72 Weight loss and weight loss rate obtained from TGA from lime-treated and natural soil samples collected at BH-2 (STA. 40) at site (3). 148

Figure 5.73 Weight loss and weight loss rate obtained from TGA from lime-treated and natural soil samples collected at BH-4 (STA. 60) at site (3).

Figure 5.74 Weight loss and weight loss rate obtained from TGA from lime-treated and untreated soil samples collected at BH-6 (STA. 100) at site (3).

Figure 5.75 Weight loss and weight loss rate obtained from TGA from lime-treated soil samples collected at depths of $0,4,8,12$, and 16 inches, below top of subgrade at BH-4 (STA. 60 meters) at site (3) 150

Figure 5.76 Natural water content and soil index properties. Site (4) 151

Figure 5.77 Particle-size distribution. Site (4) 152

Figure 5.78 DCPT and SPT results with depth at BH-1 (STA. 0 meters). Site (4) 154 
Figure 5.79 DCPT and SPT results with depth at BH-2 (STA. 20 meters). Site (4)..... 154

Figure 5.80 DCPT and SPT results with depth at BH-3 (STA. 40 meters). Site (4). 155

Figure 5.81 DCPT result with depth at BH-4 (STA. 60 meters). Site (4) ................................ 155

Figure 5.82 DCPT result with depth at BH-5 (STA. 80 meters). Site (4) ................................ 156

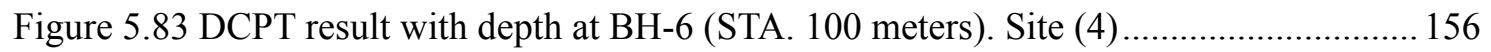

Figure 5.84 DCPT result with depth at BH-7 (STA. 120 meters). Site (4) ............................... 157

Figure 5.85 DCPT result with depth at BH-8 (STA. 140 meters). Site (4) .............................. 157

Figure 5.86 DCPT result with depth at BH-9 (STA. 160 meters). Site (4) .............................. 158

Figure 5.87 DCPT result with depth at BH-10 (STA. 180 meters). Site (4)............................. 158

Figure 5.88 CBR of subgrade estimated from DCPT results. Site (4) .................................... 159

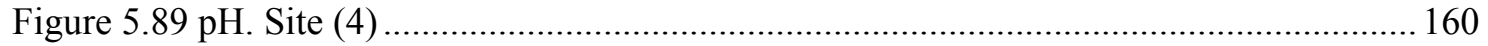

Figure 5.90 XRD pattern for lime-treated soil sample at BH-3 (STA. 40). Site (4) ................. 161

Figure 5.91 XRD pattern for lime-treated soil sample at BH-6 (STA. 100). Site (4) ............... 162

Figure 5.92 XRD pattern for lime-treated soil sample at BH-9 (STA. 160). Site (4) ............... 162

Figure 5.93 XRD pattern for lime-treated soil sample taken at a depth of 0 inch below top of subgrade at BH-9. Site (4) 163

Figure 5.94 XRD pattern for lime-treated soil sample taken at a depth of 4 inches below top of subgrade at BH-9. Site (4)

Figure 5.95 XRD pattern for lime-treated soil sample taken at a depth of 8 inches below top of subgrade at $\mathrm{BH}-9$. Site (4) 164

Figure 5.96 XRD pattern for lime-treated soil sample taken at a depth of 12 inches below top of subgrade at BH-9. Site (4) 164

Figure 5.97 XRD pattern for lime-treated soil sample taken at a depth of 16 inches below top of 
subgrade at BH-9. Site (4) 165

Figure 5.98 Weight loss obtained from TGA from lime-treated and natural soil samples collected at BH-3 (STA. 40 meters) at site (4) 166

Figure 5.99 Weight loss obtained from TGA from lime-treated and natural soil samples collected at BH-6 (STA. 100 meters) at site (4). 166

Figure 5.100 Weight loss obtained from TGA from lime-treated and natural soil samples collected at BH-9 (STA. 160 meters) at site (4). 167

Figure 5.101 Weight loss and weight loss rate obtained from TGA from lime-treated soil samples collected at depths of $0,4,8,12$, and 16 inches, below top of subgrade at BH-9 (STA. 160 meters) at site (3). 167

Figure 5.102 Natural water content and soil index properties. Site (5) 169

Figure 5.103 Particle-size distribution. Site (5) 170

Figure 5.104 DCPT and SPT results with depth at BH-1 (STA. 0 meters). Site (5)................ 172

Figure 5.105 DCPT and SPT results with depth at BH-2 (STA. 20 meters). Site (5)............... 172

Figure 5.106 DCPT and SPT results with depth at BH-3 (STA. 40 meters). Site (5)............... 173

Figure 5.107 DCPT and SPT results with depth at BH-4 (STA. 60 meters). Site (5).............. 173

Figure 5.108 DCPT and SPT results with depth at BH-5 (STA. 80 meters). Site (5).............. 174

Figure 5.109 DCPT and SPT results with depth at BH-6 (STA. 100 meters). Site (5)............. 174

Figure 5.110 DCPT and SPT results with depth at BH-7 (STA. 120 meters). Site (5) ............. 175

Figure 5.111 DCPT and SPT results with depth at BH-8 (STA. 140 meters). Site (5) ............. 175

Figure 5.112 DCPT and SPT results with depth at BH-9 (STA. 160 meters). Site (5) ............. 176

Figure 5.113 DCPT and SPT results with depth at BH-10 (STA. 180 meters). Site (5) .......... 176

Figure 5.114 CBR of subgrade estimated from DCPT results. Site (5) .................................. 177 
Figure $5.115 \mathrm{pH}$. Site (5) 178

Figure 5.116 XRD pattern for lime-treated soil sample at BH-3 (STA. 40 meters). Site (5) ... 179

Figure 5.117 XRD pattern for untreated soil sample at BH-3 (STA. 40 meters). Site (5) ........ 180

Figure 5.118 XRD pattern for lime-treated soil sample at BH-5 (STA. 80 meters). Site (5) ... 180

Figure 5.119 XRD pattern for untreated soil sample at BH-5 (STA. 80 meters). Site (5) ........ 181

Figure 5.120 XRD pattern for lime-treated soil sample at BH-7 (STA. 120 m). Site (5)......... 181

Figure 5.121 XRD pattern for untreated soil sample at BH-7 (STA. 120 m). Site (5) ............. 182

Figure 5.122 Weight loss and weight loss rate obtained from TGA from lime-treated and natural soil samples collected at BH-3 (STA. 40 meters) at site (5)

Figure 5.123 Weight loss and weight loss rate obtained from TGA from lime-treated and natural soil samples collected at BH-5 (STA. 80 meters) at site (5) 183

Figure 5.124 Weight loss and weight loss rate obtained from TGA from lime-treated and untreated soil samples collected at BH-7 (STA. 120 meters) at site (5) 184

Figure 5.125 CBR and lime content of lime-treated subgrade soil at site (5) 184

Figure 5.126 Natural water content and soil index properties. Site (6) 186

Figure 5.127 Particle-size distribution. Site (6) 187

Figure 5.128 DCPT and SPT results with depth at BH-1 (STA. 0 meters). Site (6). 189

Figure 5.129 DCPT and SPT results with depth at BH-2 (STA. 10 meters). Site (6) 189

Figure 5.130 DCPT and SPT results with depth at BH-3 (STA. 20 meters). Site (6). 190

Figure 5.131 DCPT and SPT results with depth at BH-4 (STA. 30 meters). Site (6). 190

Figure 5.132 DCPT and SPT results with depth at BH-5 (STA. 40 meters). Site (6). 191

Figure 5.133 DCPT and SPT results with depth at BH-6 (STA. 60 meters). Site (6). 191

Figure 5.134 DCPT and SPT results with depth at BH-7 (STA. 80 meters). Site (6). 192 
Figure 5.135 DCPT and SPT results with depth at BH-8 (STA. 100 meters). Site (6)............. 192

Figure 5.136 DCPT and SPT results with depth at BH-9 (STA. 120 meters). Site (6)............. 193

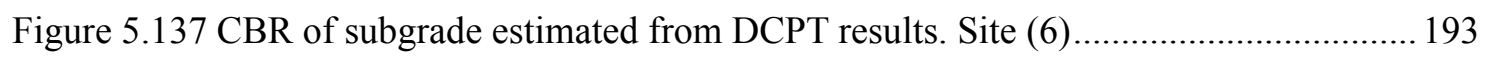

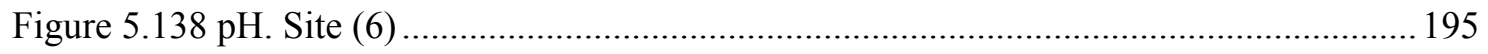

Figure 5.139 XRD pattern for lime-treated soil sample at BH-1 (STA. 0 meters). Site (6) ..... 196

Figure 5.140 XRD pattern for untreated soil sample at BH-1 (STA. 0 meters). Site (6).......... 196

Figure 5.141 XRD pattern for lime-treated soil sample at BH-3 (STA. 30 meters). Site (6) ... 197

Figure 5.142 XRD pattern for untreated soil sample at BH-3 (STA. 30 meters). Site (6)........ 197

Figure 5.143 XRD pattern for lime-treated soil sample at BH-7 (STA. 80 meters). Site (6) ... 198

Figure 5.144 XRD pattern for untreated soil sample at BH-7 (STA. 80 meters). Site (6)....... 198

Figure 5.145 Weight loss and weight loss rate obtained from TGA from lime-treated and natural soil samples collected at BH-1 (STA. 0 meters) at site (6)

Figure 5.146 Weight loss and weight loss rate obtained from TGA from lime-treated and natural soil samples collected at BH-3 (STA. 30 meters) at site (6) 200

Figure 5.147 Weight loss and weight loss rate obtained from TGA from lime-treated and untreated soil samples collected at BH-7 (STA. 80 meters) at site (6) 200

Figure 6.1 CBR of subgrade estimated from DCPT results. Site (1) .....................................209

Figure 6.2 CBR of subgrade estimated from DCPT results. Site (2) ....................................209

Figure 6.3 CBR of subgrade estimated from DCPT results. Site (3) ..................................210

Figure 6.4 CBR of subgrade estimated from DCPT results. Site (4) ....................................210

Figure 6.5 CBR of subgrade estimated from DCPT results. Site (5) ................................... 211

Figure 6.6 CBR of subgrade estimated from DCPT results. Site (6).................................. 211 


\section{CHAPTER 1. INTRODUTION}

\subsection{Statement of problem}

Lime is used to treat weak subgrade soils during construction of highways. A small amount of lime (4 to $7 \%$ ) is used to rapidly dehydrate and modify fine grained soils. The modification process improves workability and compactability of the soils and reduces the potential of swelling and shrinkage by saturating the clay particles with calcium ions. Although the lime modification process is primarily aimed at construction expediency, additional effects such as long-term improvement of stiffness and/or strength by pozzolanic and carbonation cementation reactions are expected. Although lime treatment has been employed in Indiana over several decades, the long-term performance of lime treated soils has not been well quantified and no field tests have been done on roads in service. There is concern that repeated loading, weathering, change in water content, and potential for lime migration may cause with time a decrease in strength and/ or stiffness of lime-treated subgrade soils. For this reason, engineers do not usually account for the enhanced stiffness that the treatment may provide for pavement design. This results in a conservative design of the asphalt or concrete pavement layers.

\subsection{Objectives}

The objectives of the study conducted in this research are:

(1) Investigate long-term durability and performance of lime-treated subgrade 
soils in pavements that have been in service for several years

(2) Determine whether the enhanced stiffness of lime-treated subgrade soils can be factored in pavement design

(3) Determine content of lime that remains in lime-treated subgrade several years after lime treatment and investigate whether there has been leaching from lime-treated subgrade.

(4) Evaluate long term performance of lime-treated subgrades.

\subsection{Organization of this report}

This report consists of five additional chapters. Chapter 2 provides background on the treatment of soils with lime and highlights the techniques used for the treatment and the results obtained. The following is discussed: (1) chemistry of soil-lime mixture: (2) engineering properties of lime-treated soils; (3) construction procedures for lime treatment; (4) identification of factors that affect engineering properties of lime-treated soils; (5) the INDOT design guide; (6) field tests; and (7) post-construction evaluation of lime-treated subgrades. Chapter 3 describes the field testing sites selected for the investigation. The chapter includes: (1) the selection process; (2) the selection criteria; and (3) the field testing sites selected and the preliminary investigation conducted. Chapter 4 provides the methodology used for the field and laboratory tests. The field tests were performed to evaluate in-situ properties of the lime-treated subgrade. Laboratory tests, using in-situ soil samples collected after the SPT, were done to obtain the soil index properties of the lime-treated subgrade and the lime content that remains in the soil. Chapter 5 presents and discusses the results of the field and laboratory tests that were 
performed at each testing site. From the test results, the material and mechanical properties (soil characterization and stiffness and/or strength properties) of the limetreated subgrade soil layer are compared with those of the natural (untreated) soil layer. With the results of the comparison, the long-term performance of the lime-treated subgrade soil is evaluated for each site. In addition leaching is assessed from the lime content data measured from the lime-treated and natural soil samples. Chapter 6 provides a summary of the work done and the conclusions reached. 


\section{CHAPTER 2. BACKGROUND}

The long-term performance of a pavement depends to a very large extent on the properties of the underlying soils (subgrade soil). Unstable soils may cause significant problems to the overlying pavement or other engineering structures. There are typically two mechanisms to improve the subgrade: one simply consists of the replacement of the undesirable material and the other one of the improvement of the soil. Such improvement can be attained either by mechanical means, e.g. compaction, or by chemical treatment. One such chemical treatment is the addition of lime to the soil.

Lime has been used to treat soils to varying degrees depending on the objective to be accomplished. The least amount of lime is used to rapidly dehydrate and modify finegrained soils. The treatment produces a working platform for construction or for temporary roads. Although the modification process is primarily aimed at construction expediency, it has been known that the lime treatment can produce significant structural improvements such as bearing capacity and stiffness.

The chapter provides background on the treatment of soils with lime and highlights the techniques used for the treatment and the results obtained. More specifically, the following is discussed: (1) chemistry of soil-lime mixture: (2) engineering properties of lime-treated soils; (3) construction procedures for lime treatment; (4) identification of factors that affect engineering properties of lime-treated soils; (5) the INDOT design guide; (6) field tests; and (7) post-construction evaluation of lime-treated subgrades. The following sections include information relevant to these 
issues.

\subsection{Chemical reaction of soil-lime mixture}

The practical effects of the treatment of a soil with lime are: (1) improvement of workability and compactability; (2) reduction of swelling and shrinking potentials of the soil by saturating the clay fraction with calcium ions; and (3) increase of strength and/or stiffness of the soil by pozzolanic and carbonation cementation processes.

In this section, the types of lime used are discussed, as well as the short-term and the long-term reactions of the lime with the soil.

\subsubsection{Type of lime}

The types of lime commonly used to treat soils are quicklime, also called calcium oxide $(\mathrm{CaO})$, and hydrated lime, which is called calcium hydroxide $\left(\mathrm{Ca}(\mathrm{OH})_{2}\right)$. Quicklime is produced by chemically transforming calcium carbonate $\left(\mathrm{CaCO}_{3}\right)$, namely limestone, into calcium oxide. Hydrated lime is created when quicklime chemically reacts with water. The hydrated lime reacts with the clay particles and permanently transforms them into a strong cemented matrix.

LKD (Lime Kiln Dust) is an increasingly popular alternative to quicklime and hydrated lime due to its economic benefits. LKD is the finely divided residue that results from the combustion of coal and processing of limestone into lime in a kiln. LKD usually contains a significant amount of lime, alumina, and silica. The amount of lime, silica and alumina in LKD varies, primarily depending on the limestone, fuel, and kiln operations used during the lime manufacturing process. 
The type of lime employed on a road project should be determined considering the lime supply, experience of the contractor, availability of equipment, location of a project -rural or urban- and availability of an appropriate nearby water source. For example, quicklime is excellent for drying wet soils. In addition, quicklime has larger particle sizes than hydrated lime, so dust generation is reduced when quicklime is used. In contrast, hydrated lime particles are fine, so dust may cause a problem in densely populated areas.

\subsubsection{Short term reaction}

Short term reactions of the soil-lime mixture occur within few hours after mixing. These reactions primarily consist of: (1) transformation of calcium oxide into calcium hydroxide due to hydration; and (2) agglomeration and flocculation of clay particles through cation exchange. The short term reactions are sometimes referred to as "soil modification" because they modify the soil to a relatively workable state compared to its original state.

The hydration of calcium oxide $(\mathrm{CaO})$ into calcium hydroxide $\left(\mathrm{Ca}(\mathrm{OH})_{2}\right)$ is an exothermic reaction. The formation of the calcium hydroxide results in the transformation of water from an "available" state into a "bound" state. Since the reaction is exothermic, the heat produced also reduces the water content. As a consequence, the lime-treated soil becomes less plastic and more workable than in the natural (untreated) state.

Clay minerals such as mica, smectite, and chlorite have negatively charged mineral surfaces due to the isomorphic substitution within the mineral structure. The negative charges are balanced with cations such as $\mathrm{Ca}^{2+}, \mathrm{Mg}^{2+}, \mathrm{Na}^{2+}$, and $\mathrm{K}^{+}$. The cations 
are found in their hydrated form like $\mathrm{Ca}(\mathrm{OH})_{2}$. The cation exchange capacity (CEC) of a soil refers to the amount of positively charged ions that a soil can hold. When lime is added to a wet soil, the cations such as $\mathrm{Na}^{+}$and $\mathrm{K}^{+}$, which are adsorbed by the clay surface, are exchanged by the hydrated $\mathrm{Ca}^{2+}$ ions originated from lime. As illustrated in Figure 2.1, the cation exchange induces a reduction of the thickness of double layer, so the soil becomes less susceptible to volume changes with the addition of water. The reduction in thickness of the double layer transforms the structure of clay particles from a flat, parallel structure to a more random edge-faced orientated structure. This process is referred to as flocculation. In addition, weak bonds form at the edge of the clay particles because cementitious material deposits at the clay particle interface. This process is referred to as agglomeration. At this stage, the plastic index of the soil decreases remarkably, and the soil becomes friable and granular, and so the soil becomes more workable and compactable. As previously mentioned, because the phenomenon modifies the behavior of the soil is denoted as "soil modification". Both processes, flocculation and agglomeration, are reported to occur within a few hours after mixing (Prusinski et al., 1999). 


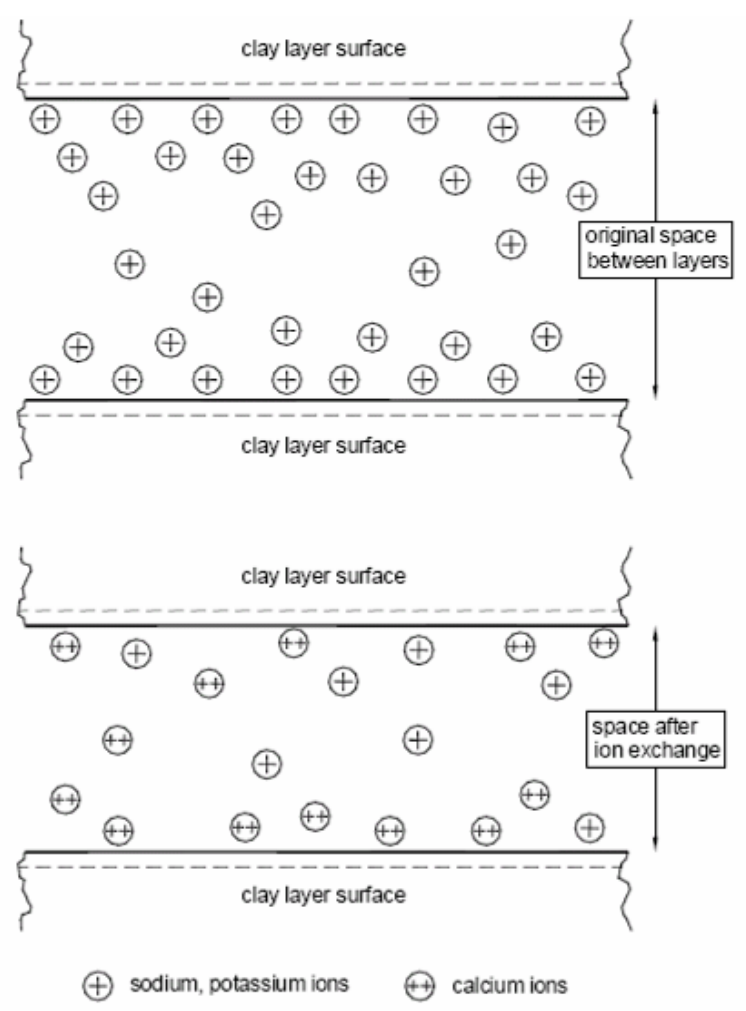

Figure 2.1 Schematic of clay stabilization by cation exchange

\subsubsection{Long term reactions}

One of the effects of cation exchange at the surface of clay particles is an increase of the $\mathrm{pH}$ of the pore water. The increased $\mathrm{pH}$ facilities the dissolution of alumina and silica from the clay minerals. In other words, silica and alumina can more easily be released from the clay mineral. The silica and alumina react with the calcium from the added lime and creates pozzolanic compounds such as calcium-aluminate-hydrate (CAH) and calcium-silicate-hydrates (CSH). The pozzolanic compounds have cementing effects because they bind the soil structure together and increase the strength and/or stiffness of the soil. The process is also referred as solidification. The long-term reaction continues for years, and the strength and/or stiffness of the lime-treated soil increase with time. 


\subsubsection{Carbonation}

Carbonation is another process associated with lime modification, in addition to the short-term and long-term reactions discussed. Carbonation is a chemical process where calcium carbonate $\left(\mathrm{CaCO}_{3}\right)$ is created from the reaction between the lime and the atmospheric carbon dioxide $\left(\mathrm{CO}_{2}\right)$. Diamond and Kinter (1965) reported that the effects of carbonation on the strength of lime-modified soils were negligible. This observation was based on laboratory tests on lime-modified soils.

\subsection{Engineering properties of lime-treated soils}

The engineering properties of lime-treated soils can be categorized into: (1) soil characterization, which include microscopic soil structure, soil classification, and Atterberg limits; (2) strength properties such as unconfined compressive strength; and (3) stiffness properties such as resilient modulus.

\subsubsection{Soil characterization properties}

Natural fine-grained soils often contain significant amounts of thin, platy clay particles. The microstructure of lime-treated soils is distinctly different from the natural soils. Much denser matrices with fewer micropores are observed in the lime-treated soil. Calcium originated from the lime can be detected on the clay particles using Scanning Electron Microscopy (SEM). A pozzolanic compound, calcium-silicate-hydrate (C-S-H), can be also identified in the matrix.

The Plastic Index (PI) is the parameter most commonly used to measure consistency changes of soils due to physicochemical effects produced by changes in 
water content. Holtz (1969) investigated the effect of hydrated lime on the reduction of PI in four active clays (Figure 2.2). It is observed from the figure that as the dosage of lime increases, the PI of the lime-treated soil decreases. Little (1995) presented similar data for four active western clays (Figure 2.3). From the figure, the reduction of PI with increasing lime dosage is confirmed. Reduction in plasticity translates into the improvement of workability and compactability of the soils. The effects of lime treatment on the swelling potential of soils are shown in Figure 2.4 (Basma and Tuncer, 1990). Based on the figure, lime treatment causes a reduction in swelling potential of clays, in addition to a reduction of PI.

Basma and Tuncer (1990) reported that lime treatment affects both the soil classification and the effective size of the soil particles (Figure 2.5 and Figure 2.6). Figure 2.5 shows changes of soil type due to lime treatment. Using the Unified Soil Classification System, a natural soil that was classified as $\mathrm{CH}$ changes into a silty soil, ML, after lime treatment. Figure 2.6 shows changes of percentage of clay-size particles (less than 2 microns) due to lime treatment. After a 28-day curing period and treatment with $8 \%$ lime, the percentage of clay-size particles decreases from about $57 \%$ for the natural soil to less than $2 \%$ for the treated soil. Since lime reacts with the alumina and silica of the clay for years, the physicochemical properties of the soil would continually change with time. 


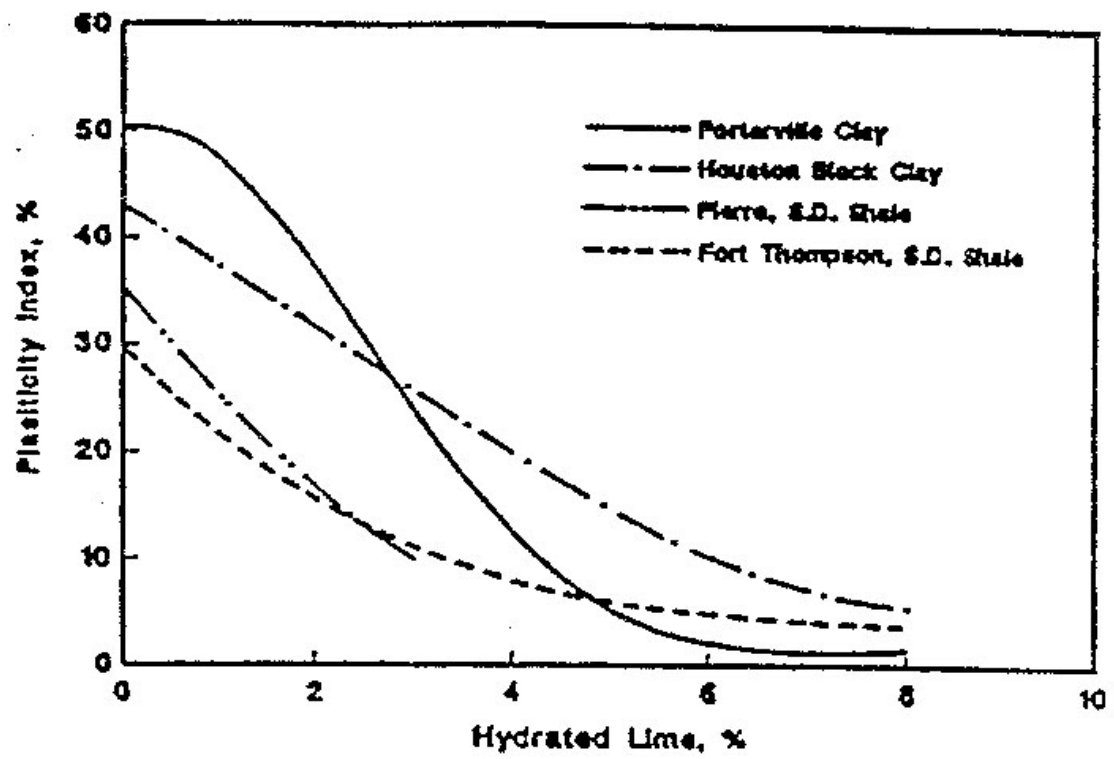

Figure 2.2 Effect of percentage of hydrated lime on the PI of four swelling clays (Holtz, 1969)

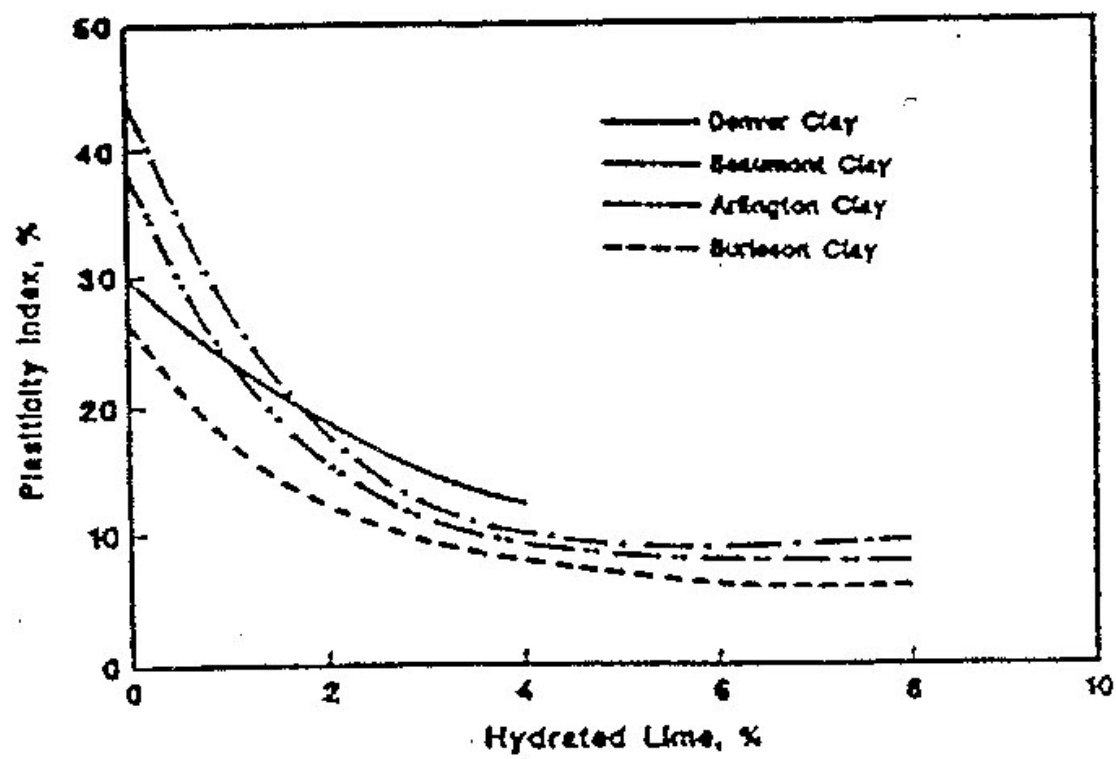

Figure 2.3 Effect of percentage of hydrated lime on PI of soils with high swelling potential (Little, 1995) 


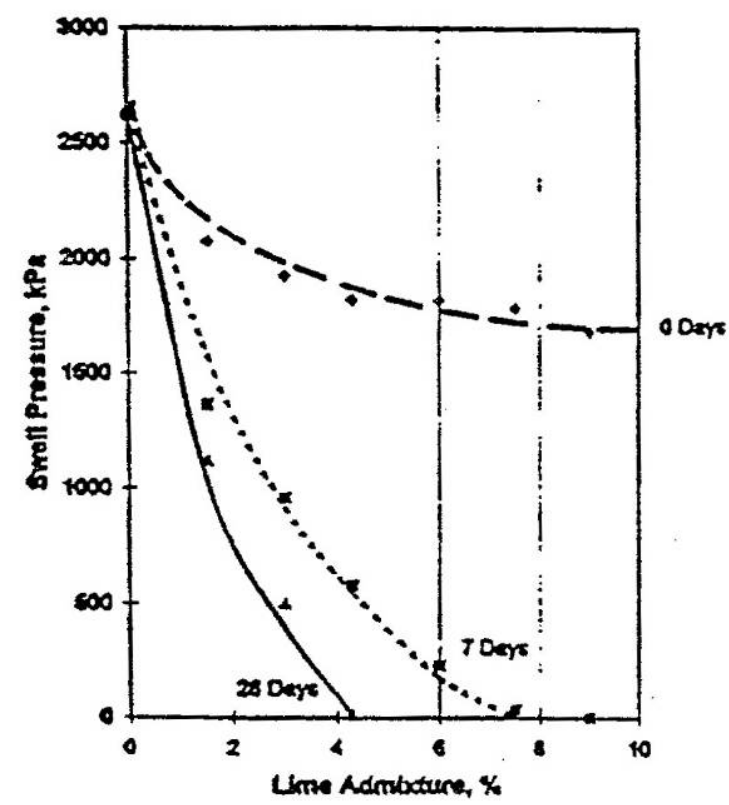

Figure 2.4 Swelling potential of soil with respect to lime dosage applied (Basma and Tuncer, 1990)

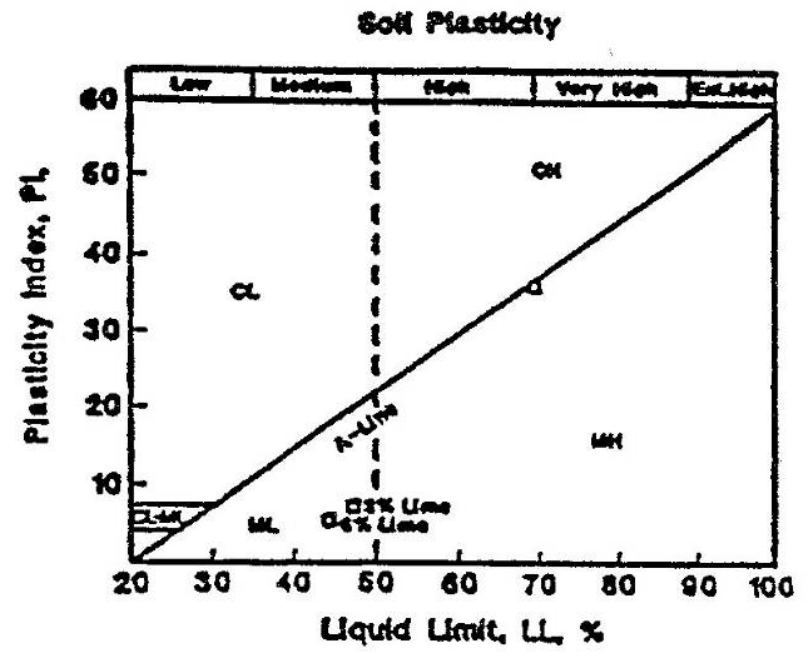

Figure 2.5 Effect of lime treatment on PI of clay in Irbid, Jordan.

(Basma and Tuncer, 1990) 


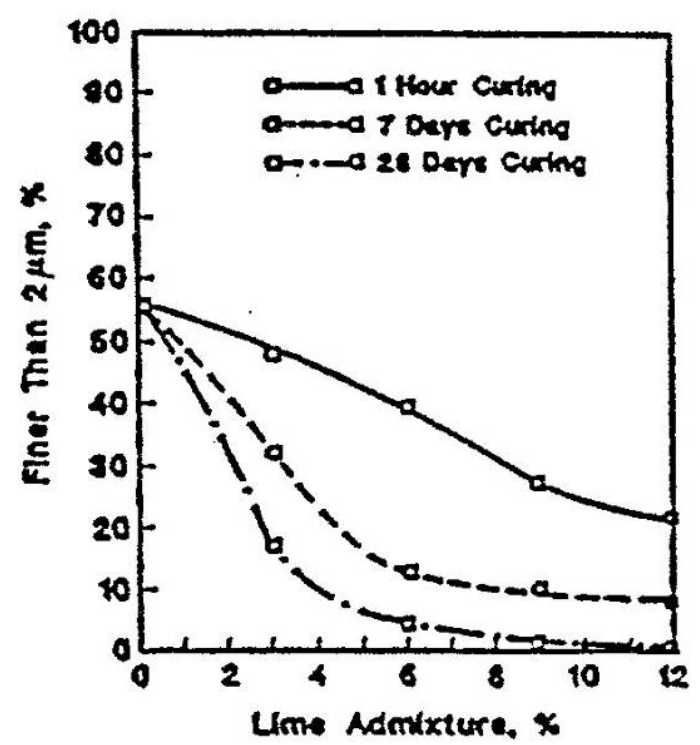

Figure 2.6 Effect of lime treatment on size fraction of clay in Irbid, Jordan. (Basma and Tuncer, 1990)

\subsubsection{Strength properties}

In 1996, the breakout group on subgrade characterization at the workshop on Improved Pavement Design for NCHRP (National Cooperative Highway Research Program) project-1-37A, identified several critical issues for subgrades treated with Portland cement or lime. One of the issues was determination of the stiffness and strength of the lime-treated soil layer as a function of time. They concluded that it was crucial to approximate the rate of stiffness gain, the ultimate (long term) stiffness, and a realistic target of stiffness.

Improvement of shear strength of soils is considered as a significant effect of the lime treatment. It has been known that lime treatment substantially improves shear strength of a soil within a few hours or a few days after intimate mixing. If the soil is cured at suitable temperatures and with the presence of adequate moisture, pozzolanic 
reactions continue to develop in many soils. The reactions result in increasing shear strength of the soil, which may continue for months or even years under appropriate curing conditions.

Thompson (1969) investigated both short-term and long-term shear strength improvements of soils that were pozzolanically reactive (Table 2.1). CBR values were used as a measure of the shear strength. The short-term shear strength improvement results from relatively immediate physicochemical changes of the soils due to the cation exchange reactions and the initial phase of the pozzolanic reactions. The long-term improvement results from the continuous pozzolanic reactions. This can be seen in Table 2.1, which shows that the shear strengths of the treated soils were 100 to $2000 \%$ of those of the natural, untreated soils.

Table 2.2 lists the unconfined compressive strength (UCS) of lime-treated soils for various types of clayey soils with difference percentages of lime, ranging from three to seven percent. UCS of the soil treated with $7 \%$ lime is larger, up to three times, than that of the soil treated with $3 \%$ lime. Table 2.3 summarizes the effects of two different percentages of lime (3\% and $5 \%$ ) at two different curing times (28 days and 360 days) for twelve different California soils. When a soil is treated with $5 \%$ lime, CBR of the soil with a 365-day curing is larger, up to six times, than that of the soil treated with a 28-day curing. Figure 2.7 shows the unconfined compressive strength of six soils, with distinctively different mineralogy, with increasing percentage of lime. From the figure, the UCS of the lime-treated soil substantially increases with increasing quantity of the lime used, and the increase of the UCS also depends on the mineralogy of the natural soil. 


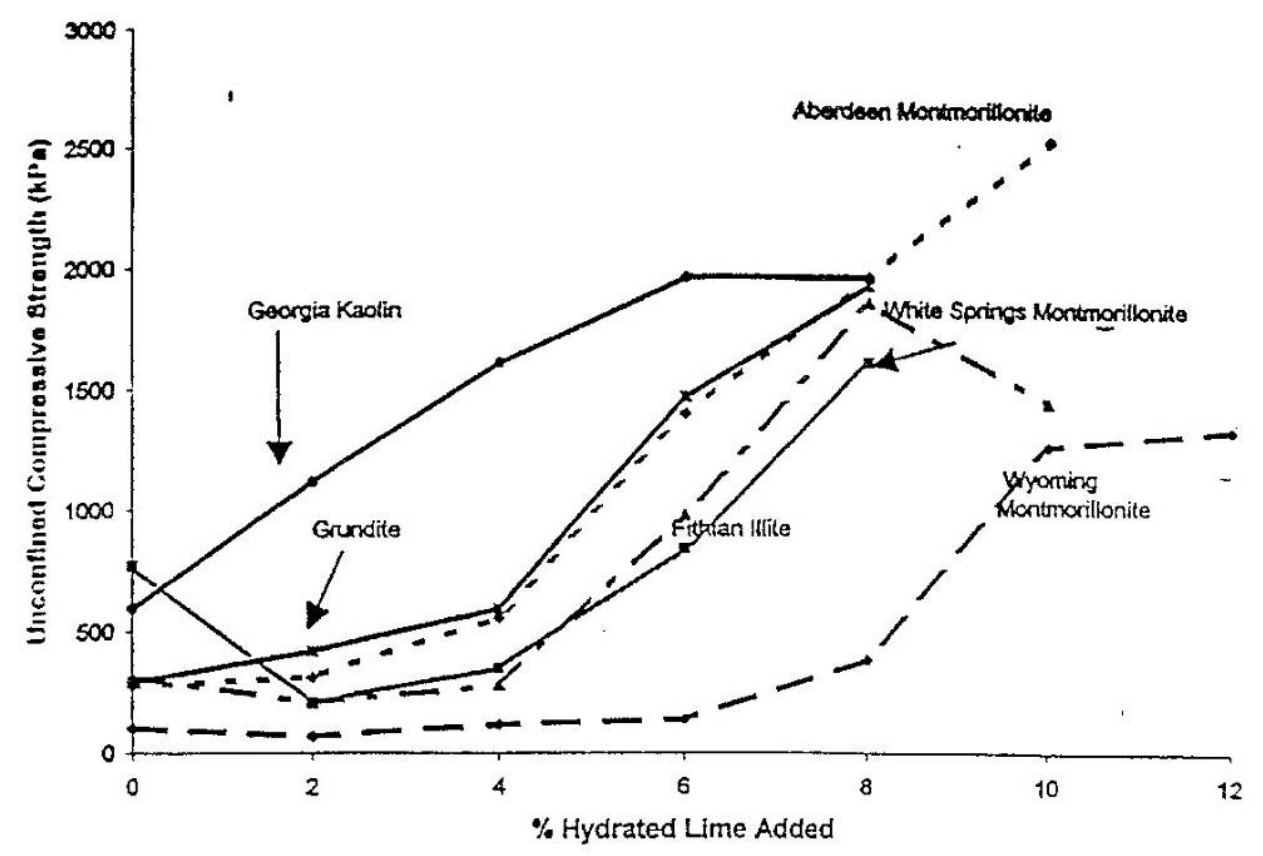

Figure 2.7 Unconfined compressive strengths of soils with different mineralogy. (Eades and Grim, 1963)

Tables 2.2 and 2.3 and Figure 2.7 indicate that there are three factors that affect the level of compressive strength gain: (1) the reactivity of the clay; (2) the percentage of lime used; and (3) the time and conditions of curing. The soil should be reactive with lime to provide substantial compressive strength improvement. This means that the alumina and silica in the clay should be free to react with calcium. The curing time required to activate and drive the pozzolanic reactions varies widely depending on the mineralogy of the soil and the presence of other compounds within the soil that may interfere with the reaction process.

A faster strength development with increasing temperature has been reported in lime-treated soils. Dumbleton and Ross (1960) studied the strength development of heavy clay, silty clay, and sand treated with lime, within the temperature range between $32^{\circ} \mathrm{F}$ 
and $113^{\circ} \mathrm{F}$. For a cohesive soil, the increase of strength per degree increase of curing temperature was larger at higher curing temperatures. For sand, the strength increase by an increase of curing temperature was uniform within the range of temperatures covered. Temperature facilitates the reaction of the soil with the lime and thus the rate of strength development. 
Table 2.1 CBR values of natural and lime-treated soils illustrating the short-term effects of the treatment (Thomson, 1969)

\begin{tabular}{|c|c|c|c|c|c|c|c|c|}
\hline \multirow{3}{*}{ Soil } & \multirow{3}{*}{$\begin{array}{l}\text { Soil } \\
\text { Type }\end{array}$} & \multicolumn{2}{|c|}{ Natural soil } & \multirow{3}{*}{$\begin{array}{l}\text { Lime } \\
(\%)\end{array}$} & \multicolumn{4}{|c|}{ Soil-lime mixture } \\
\hline & & \multirow{2}{*}{$\begin{array}{c}\text { CBR } \\
(\%)\end{array}$} & \multirow{2}{*}{$\begin{array}{c}\text { Swell } \\
(\%)\end{array}$} & & \multicolumn{2}{|c|}{ No curing } & \multicolumn{2}{|c|}{48 hour curing } \\
\hline & & & & & CBR & Swell & CBR & Swell, \\
\hline \multicolumn{9}{|c|}{ Reactive Soils } \\
\hline Accretion Gley 2 & $\mathrm{CL}$ & 2.6 & 2.1 & 5 & 15.1 & 0.1 & 351.0 & 0.0 \\
\hline Accretion Gley 3 & $\mathrm{CL}$ & 3.1 & 1.4 & 5 & 88.1 & 0.0 & 370.0 & 0.1 \\
\hline Bryce B & $\mathrm{CH}$ & 1.4 & 5.6 & 3 & 20.3 & 0.2 & 197.0 & 0.0 \\
\hline $\begin{array}{c}\text { Champaign Co. } \\
\text { Till }\end{array}$ & $\begin{array}{l}\mathrm{CL}- \\
\mathrm{CH}\end{array}$ & 6.8 & 0.2 & 3 & 10.4 & 0.5 & 85.0 & 0.1 \\
\hline Cisne B & $\mathrm{CH}$ & 2.1 & 0.1 & 5 & 14.5 & 0.1 & 150.0 & 0.1 \\
\hline Cowden B & $\mathrm{CH}$ & 7.2 & 1.4 & 3 & - & - & 98.5 & 0.0 \\
\hline Cowden C & $\mathrm{CL}$ & 4.5 & 0.8 & 3 & 27.4 & 0.0 & 243.0 & 0.0 \\
\hline Darwin B & $\mathrm{CH}$ & 1.1 & 8.8 & 5 & 7.7 & 1.9 & 13.6 & 0.1 \\
\hline East St. Louis & $\mathrm{CH}$ & 1.3 & 7.4 & 5 & 5.6 & 2.0 & 17.3 & 0.1 \\
\hline Fayette C & CL & 1.3 & 0.0 & 5 & 32.4 & 0.0 & 295.0 & 0.1 \\
\hline Illinoian B & $\mathrm{CL}$ & 1.5 & 1.8 & 3 & 29.0 & 0.0 & 274.0 & 0.0 \\
\hline Illinoian Till & CL & 5.9 & 0.3 & 3 & 18.0 & 0.9 & 213.0 & 0.1 \\
\hline Sable B & $\mathrm{CH}$ & 1.8 & 4.2 & 3 & 15.9 & 0.2 & 127.0 & 0.0 \\
\hline \multicolumn{9}{|c|}{ Non-Reactive Soil } \\
\hline Fayette B & CL & 4.3 & 1.1 & 3 & 10.5 & 0.0 & 39.0 & 0.0 \\
\hline Tama B & $\mathrm{CH}$ & 2.6 & 2.0 & 3 & 4.5 & 0.2 & 9.9 & 0.1 \\
\hline Miami B & $\mathrm{CL}$ & 2.9 & 0.08 & 3 & 12.7 & 0.0 & 14.5 & 0.0 \\
\hline
\end{tabular}


Table 2.2 Unconfined compressive strength of natural and lime-treated soils from Arizona, Colorado, Idaho, Illinois, Texas, and Utah (Thompson, 1969; Little et. al, 1987)

\begin{tabular}{|c|c|c|c|c|}
\hline \multirow[t]{2}{*}{ Soil } & \multirow{2}{*}{$\begin{array}{l}\text { Unified Soil } \\
\text { Classification }\end{array}$} & \multicolumn{3}{|c|}{ Compressive Strength, $\mathrm{kPa}$} \\
\hline & & 3\% Lime & $5 \%$ Lime & 7\% Lime \\
\hline Arlington, TX & $\mathrm{CH}$ & 1750 & 2450 & 4550 \\
\hline Beaumont, TX & $\mathrm{CH}$ & 490 & 700 & 1400 \\
\hline Burleson, TX & $\mathrm{CH}$ & 1050 & 1540 & 2170 \\
\hline Victoria, TX & $\mathrm{CH}$ & 700 & 1330 & 1820 \\
\hline Denver, CO & $\mathrm{CL}$ & 2100 & 2800 & 2750 \\
\hline Nogalis, AZ & CL & - & - & 2400 \\
\hline Prescott, AZ & $\mathrm{CL}$ & - & - & 2700 \\
\hline Boise, ID & CL & - & - & 3560 \\
\hline Salt Lake City, & $\mathrm{CH}$ & - & - & 5200 \\
\hline Salt Lake City, & $\mathrm{CL}$ & - & 5400 & -- \\
\hline Bryce A, IL & $\mathrm{MH}$ & 301 & 406 & 371 \\
\hline Bryce A, IL & $\mathrm{CH}$ & 1407 & 1484 & 1351 \\
\hline Cisne B, IL & $\mathrm{CH}$ & 749 & 1330 & 1323 \\
\hline Drummer A, IL & ML & 203 & 343 & 224 \\
\hline Drummer B, IL & $\mathrm{CH}$ & 1302 & 1064 & 1022 \\
\hline Fayette A, IL & ML & 259 & 322 & 343 \\
\hline Fayette B, IL & $\mathrm{CL}$ & 763 & 798 & 791 \\
\hline Fayette C, IL & $\mathrm{CL}$ & 959 & 1295 & 875 \\
\hline Accreton Gley, & $\mathrm{CL}$ & 1841 & 1729 & 1981 \\
\hline Huey B, IL & CL & 1561 & 1512 & 1631 \\
\hline Huey D, IL & $\mathrm{CL}$ & 1554 & 1253 & 1379 \\
\hline Illinoian Till, & $\mathrm{CL}$ & 1050 & 1302 & 1001 \\
\hline Loam Till, IL & $\mathrm{MH}$ & 1204 & 1288 & 1218 \\
\hline Davidson B, IL & $\mathrm{MH}$ & 1386 & 1876 & 2268 \\
\hline Greenville, IL & $\mathrm{CL}$ & 3185 & 3619 & 3857 \\
\hline NorfolK B, IL & $\mathrm{SC}$ & 2429 & 2947 & 2324 \\
\hline Clalitos, IL & $\mathrm{MH}$ & 798 & 931 & 921 \\
\hline
\end{tabular}


Table 2.3 Effect of curing time on the unconfined compressive strength of twelve California soils (Doty and Alexander, 1978)

\begin{tabular}{|c|c|c|c|c|c|c|}
\hline \multirow{3}{*}{ Soil } & & \multirow{2}{*}{$\begin{array}{c}\text { AASHTO } \\
\text { Classification }\end{array}$} & \multirow{2}{*}{ P.I. } & \multicolumn{2}{|c|}{ Unconfined compressive strength (kPa) } \\
\cline { 4 - 7 } & & & $\begin{array}{c}28 \text {-day } \\
\text { Cure }\end{array}$ & $\begin{array}{c}360 \text {-day } \\
\text { Cure }\end{array}$ & $\begin{array}{c}\text { 28-day } \\
\text { Cure }\end{array}$ & $\begin{array}{c}360 \text {-day } \\
\text { Cure }\end{array}$ \\
\hline 1 & A-6(10) & 14 & 1120 & 1540 & 840 & 4270 \\
\hline 2 & A-6(10) & 11 & 2730 & 3570 & 2800 & 9870 \\
\hline 3 & A-7-5(20) & 30 & 1960 & 2170 & 3850 & 8470 \\
\hline 4 & A-2-4 & NP & 700 & 700 & 770 & 1260 \\
\hline 5 & A-7-6(20) & 30 & 2450 & 4480 & 1820 & 11550 \\
\hline 6 & A-7-5(13) & 15 & 490 & 490 & 1540 & 1540 \\
\hline 7 & A-4(5) & 7 & 560 & 1960 & 840 & 2800 \\
\hline 8 & A-6 & 14 & 3780 & 5250 & 3850 & 11060 \\
\hline 9 & A-4 & 7 & 2940 & 7700 & 2450 & 13300 \\
\hline 10 & A-7-5(20) & 22 & 2800 & 5810 & 2100 & 8400 \\
\hline 11 & A-4(2) & 10 & 1925 & 6300 & 1470 & 7700 \\
\hline 12 & A-7-5(20) & 22 & 2520 & 3640 & 3570 & 7070 \\
\hline
\end{tabular}

Based on laboratory consolidation test results on lime-treated soil samples, Uddin et al. (2002) reported that lime treatment alters the strength and deformation characteristics of soft clays, from a normally consolidated to an overconsolidated state. He showed that the lime treatment substantially increased the overconsolidation pressure of the clay. Figure 2.8 demonstrates the effect of lime treatment and curing time on consolidation. The figure shows that the samples with the higher lime content exhibit lower compressibility. Also the increase of curing time reduces the compressibility of the clay. Uddin et al. (2002) noted that the reduced deformation response might be significant for a subgrade layer subjected to consolidation under either a moving or static wheel load. 


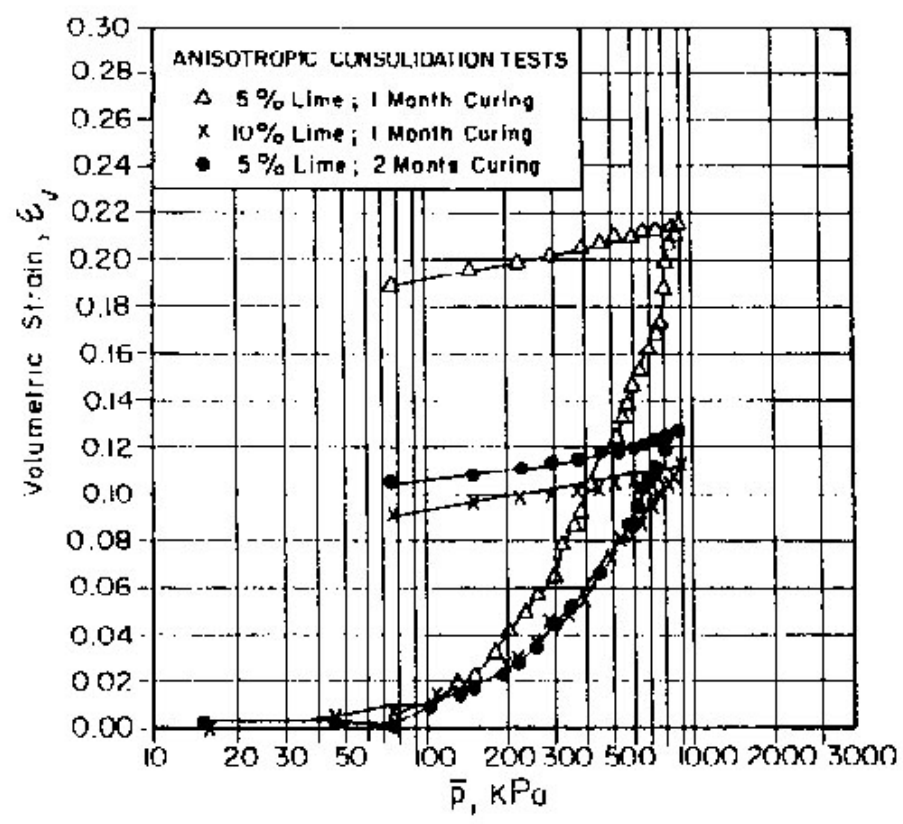

Figure 2.8 Effect of percentage of lime and curing time on the compressibility of a clay soil (Uddin, 2002)

\subsubsection{Stiffness properties}

The 1986 AASHTO Guide has specified that the resilient modulus should be the parameter used for characterizing subgrades. In 2003, the AASHTO published the standard for the resilient modulus test for granular and fine grained soils as T-30799(2003) "the Resilient Modulus of Soils and Aggregate Materials". The resilient modulus test provides a basic relationship between stress and strain of pavement materials. The stress-strain relationship is used for structural analysis of layered pavement systems. $M_{R}$ is determined from a repeated triaxial compression test by dividing the axial stress by the amplitude of the recoverable axial strain. In other words, $M_{R}$ is defined as the ratio of deviator stress, $\sigma_{d}$, and the recoverable strain, $\varepsilon_{\mathrm{r}}$. The laboratory test procedures for resilient modulus of subgrades have been revised and 
simplified over the years, so they may be considered now complete. It is advisable to collect and test a large number of samples to obtain results of statistical importance.

Since the resilient modulus test is performed in the laboratory, there is always the question of duplicating the in situ environmental conditions in the field. As an alternative to the laboratory estimates, the resilient modulus may be obtained directly by backcalculation of results of deflection tests in the field or indirectly through correlations with penetration tests results such as DCP (Dynamic Cone Penetrometer) and CPT (Cone Penetration Test). Recognizing the importance of in-situ tests, the AASHTO Design Guide recommended Falling Weight Deflectometer (FWD) tests for pavement evaluation. The FWD delivers a transient force impulse to the pavement surface that simulates a moving wheel load in both magnitude and duration. The deflection data obtained from the FWD tests are used to evaluate the in-situ stiffness of the pavement. The test is nondestructive and is conducted in a few minutes. Computer program codes for the backcalculation of the deflection data are easily available. Because of the nature of the test and its simple interpretation, the FWD test is gaining acceptance among highway engineers.

The DCP test consists of a steel rod with a steel cone attached to one end, which is driven into the pavement structure or subgrade using a sliding hammer. The material strength is measured by the penetration per hammer blow. The DCP test may be useful when the moduli back-calculated from falling weight deflectometer (FWD) data are in question; for example when the asphalt concrete is less than $76 \mathrm{~mm}$ thick or when shallow bedrock is present (Little et al., 1995). These two situations often cause a misinterpretation of FWD data. The DCP can be used to increase the accuracy of the 
measurements. In addition, it is not possible to conduct a FWD test directly on a weak subgrade or base layers since the resulting large deflection may exceed the equipment's calibration limit.

Little et al. (1996) conducted DCP and FWD tests on pavements with lime-treated subgrades that were in service. Based on the test results, they concluded that the limetreated subgrades provided a level of stiffness and strength that is similar to that of an unbounded aggregated base. They also suggested that the lime-treated subgrades should be assigned AASHTO structural coefficients in the same range as unbounded aggregate bases. Yusuf et al. (2001) also reported that the stiffness ratio between lime-treated subgrades and natural untreated subgrades was in the range of 11 to 33.

\subsection{Overview of construction procedures}

The review on the construction procedures used to apply lime to natural soils may be useful to identify those factors that affect the long-term performance of lime-treated subgrades. The construction methods used for lime modification and lime stabilization are similar. Generally, lime stabilization requires more lime and a more thorough processing and job control than lime modification.

Construction often includes the following procedures: (1) scarification or initial pulverization of the natural soil; (2) lime spreading; (3) mixing and watering; (4) mellowing; (5) final mixing; (6) compaction; and (7) curing.

\subsubsection{Scarification or initial pulverization of natural soil}

Prior to adding lime to a subgrade soil, the subgrade is scarified to a specified 
depth and then partially pulverized or broken into parts (Figure 2.9). The scarified and pulverized subgrade provides more surface contact area between the lime and the soil particles.

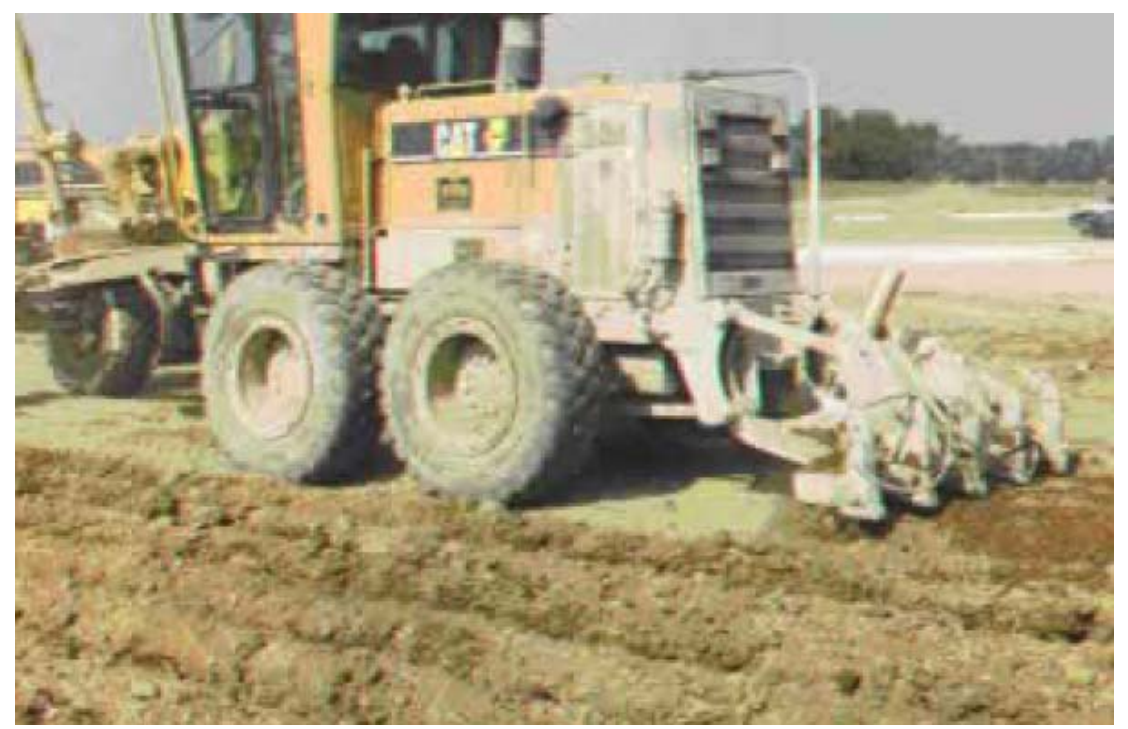

Figure 2.9 Scarification prior to spreading lime (National Lime Association, 2004)

\subsubsection{Lime spreading}

Lime should be spread on the natural subgrade evenly with a constant thickness. Two methods are commonly used to spread lime: (1) simple method with a self-unloading truck; and (2) combined method with gravitational lime drop and spread. The selfunloading trucks or trailers can evenly distribute lime pneumatically or mechanically. Trucks with mechanical spreaders are commonly used (Figure 2.10). With the combined method, the lime is gravitationally dropped on the natural subgrade with bottom dump tankers and clam shell bottom drop trailers; afterwards the lime is evenly spread with a motor grader. 


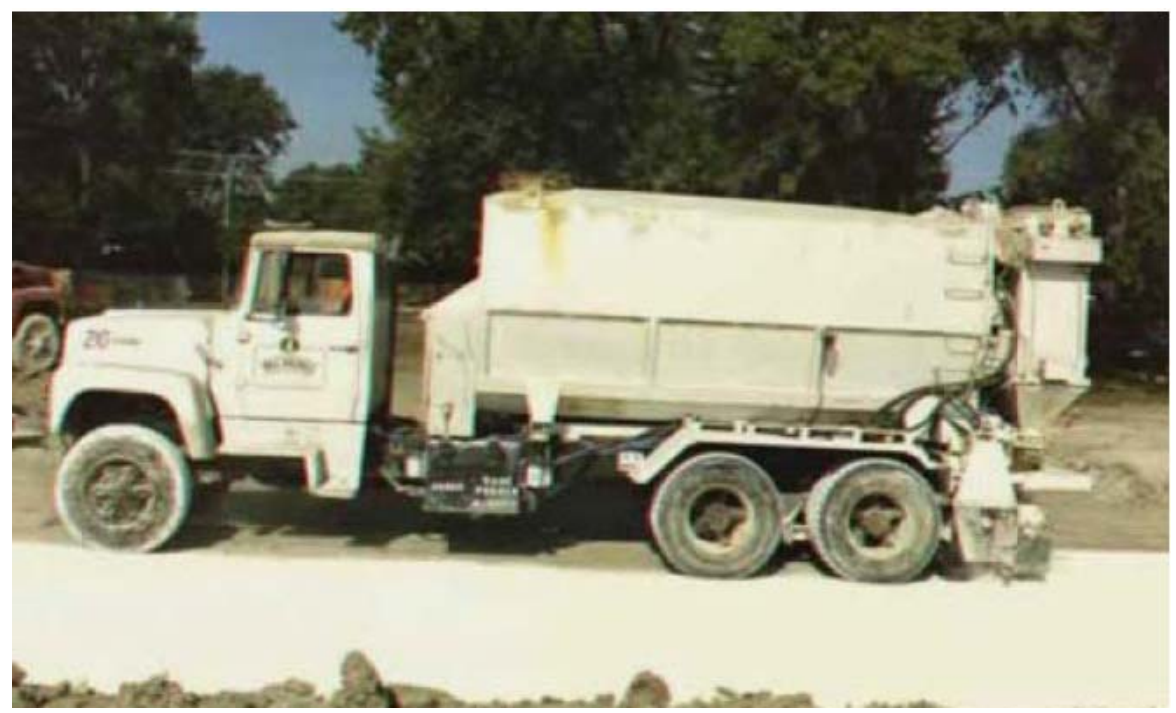

Figure 2.10 Spreading lime using a truck with a mechanical spreader. (National Lime Association, 2004)

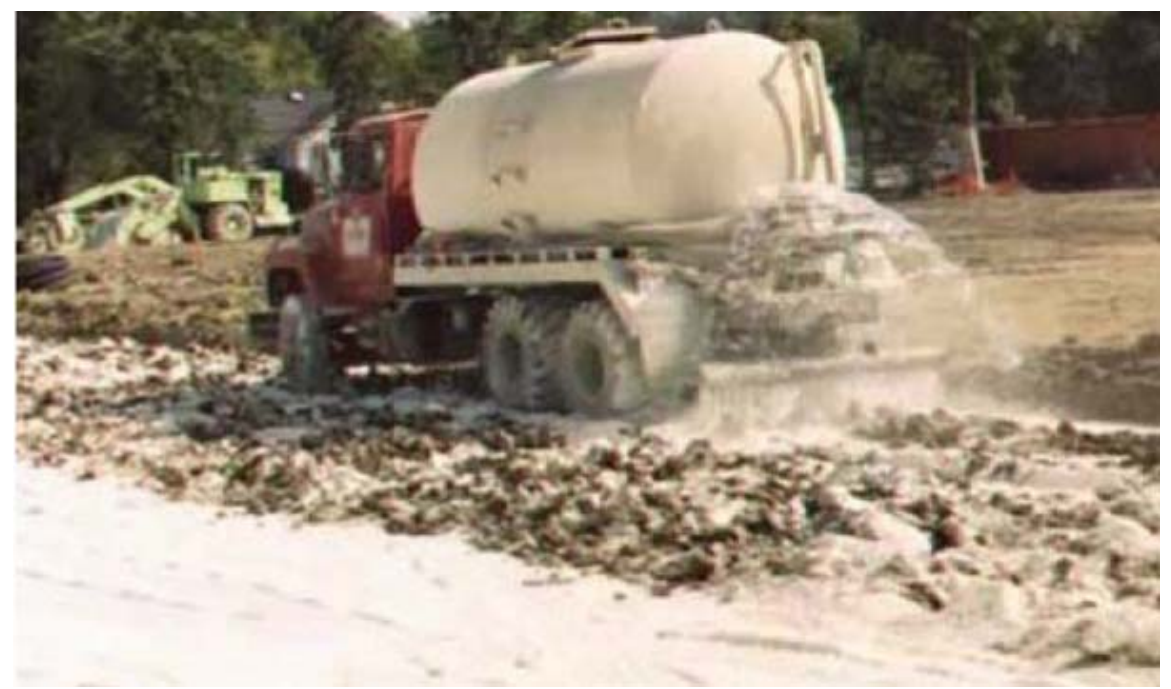

Figure 2.11 Watering after lime application (National Lime Association, 2004)

\subsubsection{Initial mixing and watering}

Initial mixing is required to distribute lime throughout the soil. During or immediately after mixing, water should be added to initiate the chemical reaction between soil and lime (Figure 2.11). Rotary mixers are employed to guarantee thorough 
mixing of the lime, soil and water (Figure 2.12).

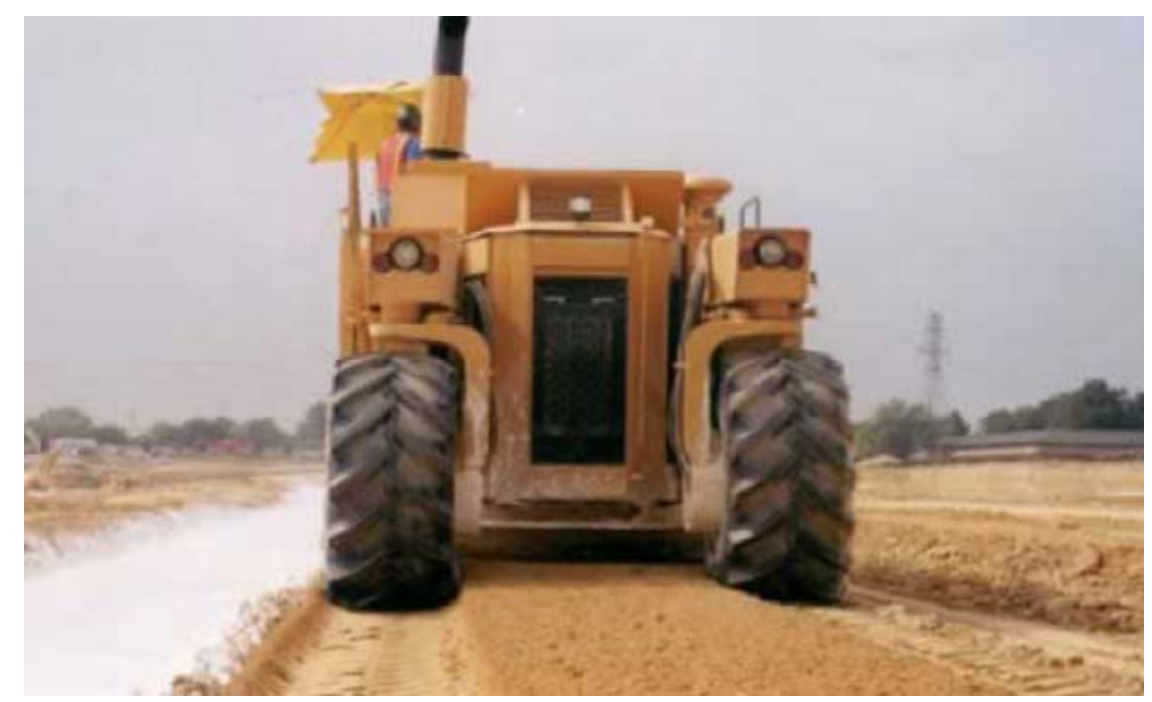

Figure 2.12 Rotary mixer used for initial mixing (National Lime Association, 2004)

\subsubsection{Mellowing period}

To expedite the chemical reaction of soil and lime, the soil-lime mixture should be left undisturbed for a sufficient period of time (mellowing period). The duration of the mellowing period is based on engineering judgment depending on soil type, and it is typically one to seven days.

\subsubsection{Final mixing}

After the mellowing period, the treated soil is remixed before compaction. With the remixing, the lime is thoroughly distributed throughout the soil (Figure 2.13). Additional water may be needed during the final mixing, prior to compaction, to bring the soil to three percent above optimum moisture content. 


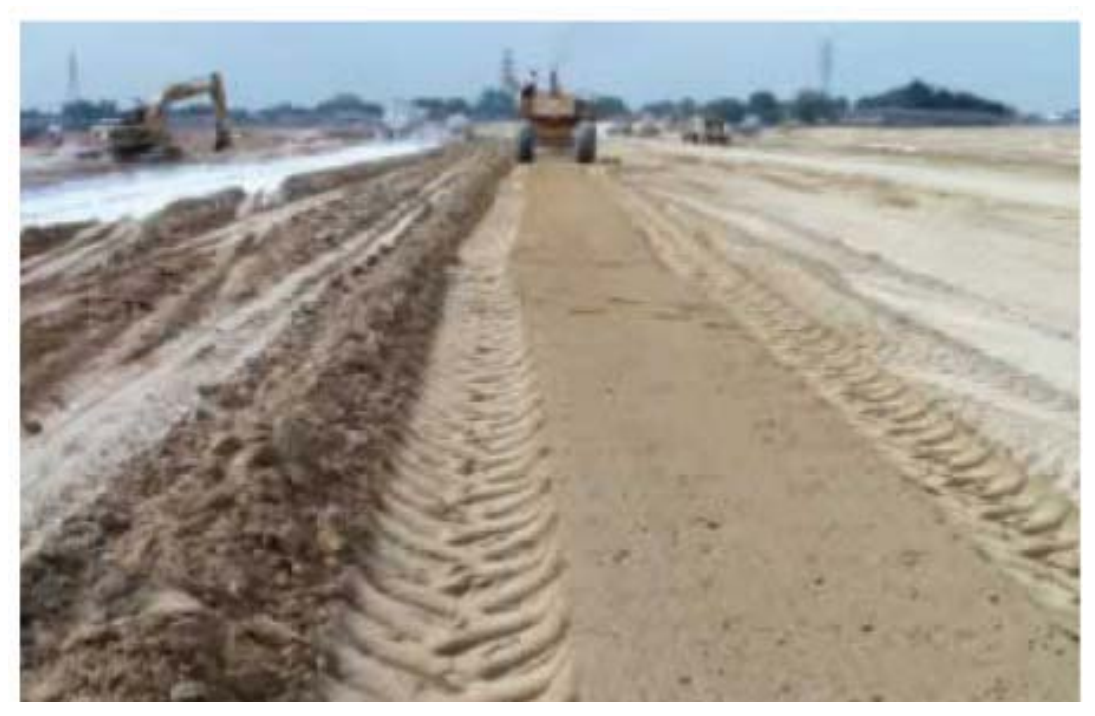

Figure 2.13 Remixing prior to compaction (National Lime Association, 2004)

\subsubsection{Compaction}

The soil-lime mixture is compacted to a density required by the project specification, typically at least 95 percent of the maximum density obtained from a laboratory compaction test. The AASHTO T-99 test, "the standard method of test for moisture-density relations of soils using a $2.5 \mathrm{~kg}$ rammer and a $305 \mathrm{~mm}$ drop," is used. The value of the maximum density is determined from the Proctor curve obtained with a representative sample of the soil-lime mixture. The compaction equipment is selected considering the depth of the soil to be treated and to meet specifications. The compaction can be accomplished in one lift using heavy vibratory padfoot rollers or using a combination of sheepfoot and light vibratory padfoot rollers (Figure 2.14). Final compaction is obtained using a steel wheel roller, as shown in Figure 2.15. 

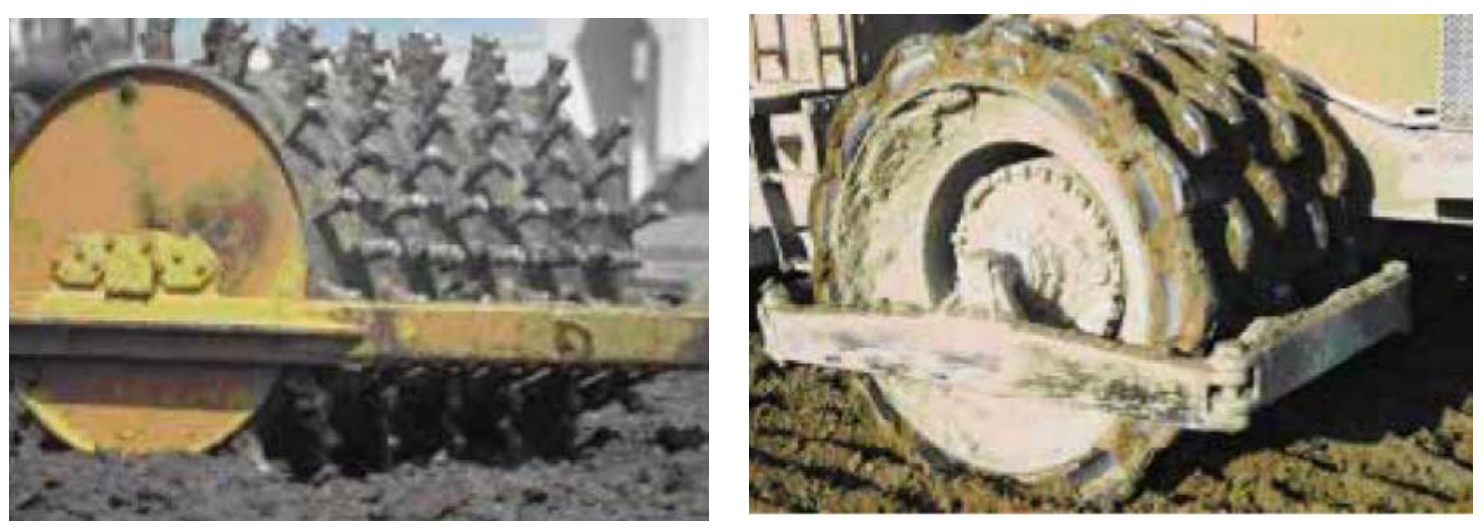

Figure 2.14 Sheepfoot (left) and padfoot (right) rollers used for initial compaction (National Lime Association, 2004)

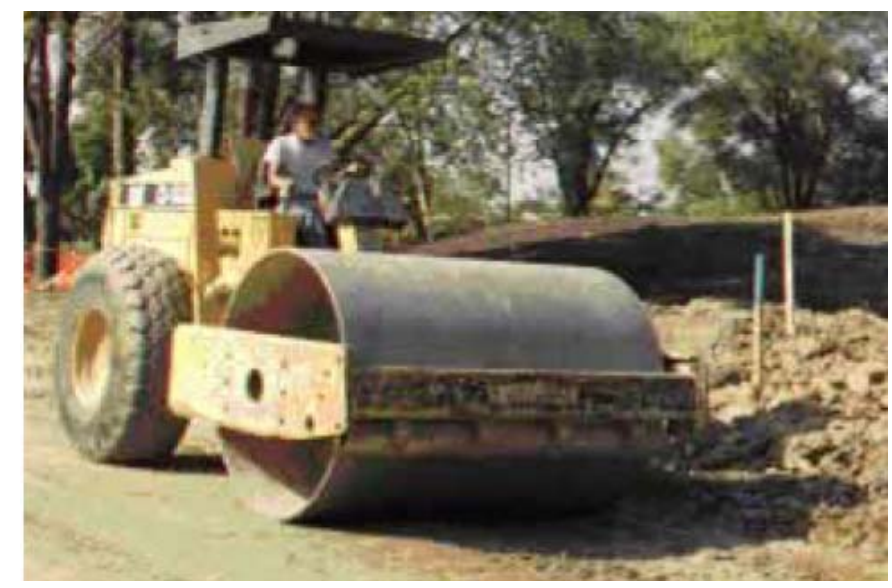

Figure 2.15 Steel roller used for final compaction (National Lime Association, 2004)

\subsubsection{Final Curing}

Prior to place the subbase on the subgrade, the compacted subgrade should be hardened enough such that loaded dump trucks can operate without rutting the soil. The top of the lime-treated subgrade, before placing the subbase, is kept moist to induce strength gain. This is the curing step, and it can be done in two ways. One is moist curing, which consists of keeping the top of the subgrade in a moist condition using light 
sprinkling of water and rolling when necessary. The second way is membrane curing, which involves sealing the top with a bituminous emulsion.

\subsection{Factors affecting properties of lime-treated soils}

The engineering properties of lime-treated soils depend on the following factors: (1) lime dosage; (2) mineralogy of the natural soil; (3) soil gradation, pulverization and mixing; (4) compaction; and (5) curing period and conditions. The following provides a discussion of these factors.

\subsubsection{Lime dosage}

With increasing the amount of lime added to a clay soil, the soil becomes more granular and the Plastic Index reduces. There is a lower limit of lime dosage below which mixing uniformity cannot be achieved with normal construction operations. The minimum percentage of lime is usually determined from the Eades and Grim procedure. The procedure is based on $\mathrm{pH}$ measurements. The amount of lime necessary to achieve a $\mathrm{pH}$ of 12.4 is considered to be the minimum. The dosage of lime applied to treat a soil may be also determined based on reduction of Plastic Index and/or improvement of strength properties such unconfined compressive strength. INDOT's design guide recommends that the lime dosage necessary for chemical treatment of a subgrade is determined from the Eades and Grim procedures.

\subsubsection{Mineralogy of natural soils}

As previously discussed, reduction of the Plastic Index (PI) of lime-treated soils 
and short-term strength gain occur due to cation exchange between the soil and the lime and due to short-term pozzolanic reactions. In addition long-term strength gain of the treated soils occurs due to time-dependent pozzolanic reactions. Both the cation exchange and the pozzolanic reactions are affected directly by the mineralogy of the natural soil. To expect short-term and long-term strength gains of a soil with lime treatment, the soil particles should be able to exchange cations and be pozzolanically reactive.

The presence of organic matter affects the lime chemical reactions with the soil. Organic compounds of low weight generally act as a retarder against soil-lime reaction, and the strength gain is usually poor (Winterkorn, 1942).

\subsubsection{Soil gradation, pulverization, and mixing}

The surface area and the size distribution of soil particles affect the physicochemical reactions between the soil and the lime. This is o because the chemical reactions are facilitated as more surface area of the soil particles is exposed. From a mechanical point of view, gradation and shape of the soil particles determines the degree of interlocking and packing density of the soil particles, which strongly influence the unit weight of the compacted soil. A well-graded dense soil, when treated with lime, reaches higher shear and compressive strengths than a poorly graded or loose soil.

The majority of soil modification or stabilization research has been performed on finely pulverized soil samples (100\% passing No. 4 sieve). The presence of larger particles may affect the short- term or long-term reactions, and so in the field care should be taken to pulverize the soil to the extent where the physical and chemical processes can take place. Mixing in the laboratory and in the field is a necessary operation to distribute 
the lime efficiently and uniformly within the soil. The mixing sequence, duration, and time between mixing and compaction all affect the engineering properties of the treated soil.

\subsubsection{Compaction}

The soil is essentially a mixture of solid particles, water and air. For a specific compactive effort at a certain moisture content, the solid particles attain their closest packing or highest density. As a consequence, both the moisture and compactive effort are critical to achieve the target soil density.

There are two well-known laboratory compaction methods: (1) standard proctor test (ASTM D 698 AASHTO T 99); and (2) modified Proctor test (ASTM D 1557 and AASHTO T 180). In each test compaction is performed at varying moisture contents in steel molds. A standard hammer dropped from a standard height a number of predetermined times provides the specified energy delivered to the soil in each test. The standard and modified Proctor tests differ from each other by the number of lifts used to prepare the samples and by the compactive effort applied $\left(600 \mathrm{kN}-\mathrm{m} / \mathrm{m}^{3}\right.$ for the standard Proctor test and $27,000 \mathrm{kN}-\mathrm{m} / \mathrm{m}^{3}$ for the modified Proctor test). Dry density and moisture content are determined and plotted at the end of every test. The peak of the curve of the dry density and water content corresponds to the maximum dry density and the optimum moisture content. These values are often used in construction specifications.

Kennedy et al. (1987) performed unconfined compressive tests on lime-treated soil samples obtained at different compactive efforts (standard and modified Proctor compactions). From the test results, it was reported that the higher compactive effort 
substantially increased (approximately by a factor of 4) the unconfined compressive strength of the lime-treated soil.

\subsubsection{Curing period and conditions}

As previously discussed, the long-term strength gain of lime-treated soils is affected by the curing time and curing conditions. When a soil is treated with lime in the field, after the initial mixing the soil-lime mixture is let undisturbed for one to seven days to expedite the chemical reactions. In addition, before placing the subbase, the top of the lime-treated subgrade is kept moist to allow access of the lime to water to facilitate hydration. The curing period thus facilitates short-term reactions. With time after treatment and as the road is in service, pozzolanic reactions continue to occur, and so it is expected that the engineering properties of the soil would improve with time. For this to happen, it is necessary that the soil remains moist. This is however the case in most projects as the subgrade is protected by the layers of pavement.

\subsection{Design procedures for soil modification or stabilization using lime}

In this section, the INDOT design procedure is reviewed. In addition, a design protocol proposed by the National Lime Association is introduced, which shows a new trend on the design of lime treatment.

\subsubsection{Indiana Department of Transportation (2002)}

INDOT's design guide on the lime treatment of a subgrade specifies design procedures for soil modification and stabilization respectively. 
The percentage of lime of 3 to $10 \%$ is used for soil modification and stabilization. For soil modification, hydrated lime or quicklime and lime by-products are used within the range of $4 \pm 0.5 \%$ and $5 \pm 1 \%$ by weight of natural soil. The optimum content of lime or lime by-products required for modification or stabilization of the soil should be determined by the following procedure:

(1) Perform mechanical and physical tests on the natural soil.

(2) Determine $\mathrm{pH}$ of both the soil and lime.

(3) Determine the optimum lime content using the Eades and Grim $\mathrm{pH}$ test. The test specifies that a sufficient amount of lime is to be added to the soil to obtain a $\mathrm{pH}$ of 12.4 or equal to the $\mathrm{pH}$ of the lime itself. A graph is plotted between $\mathrm{pH}$ and lime percentage. The optimum lime content is the one associated with the maximum $\mathrm{pH}$ of the soil-lime mixture.

(4) Atterberg limit tests are performed on the soil-lime mixtures.

(5) Compaction is performed in accordance with AASHTO T99 to samples at the optimum soil-lime mixture.

\subsubsection{The National Lime Association (1999)}

The National Lime Association has proposed a new laboratory mixture design and testing protocol to ensure that the properties needed to meet structural demands are achieved and that lime-treated mixtures are durable. The protocol is different from existing procedures since it considers durability as well as strength as parameters to characterize the soil-lime mixtures. Durability is evaluated by measuring the resistance of the soil-lime mixture with moisture and freeze-thaw cycles. 
The mixture design and testing protocol are summarized as follows:

(1) Classify a soil to screen the soil for potential of reactivity with lime. A soil may be a candidate for lime stabilization if the soil has more than $25 \%$ passing the No. 200 sieve and a plasticity index of at least 10. Soils with organic contents exceeding one percent by weight are difficult to react with lime or may require uneconomical quantities of lime for soil stabilization. Soluble sulfates of a soil should be less than 0.3 percent by weight in a 10:1, water-to-soil solution.

(2) Perform the Eades and Grim $\mathrm{pH}$ test to determine the approximate optimum lime content. The test identifies the lime content required to satisfy immediate lime-soil reactions.

(3) Determine the moisture-density relation of the lime-treated soil according to protocols such as AASHTO T-99, T-180, ASTM D 698, D 1557, Texas Method 113A, and so on. Prepare samples for strength and moisturesensitivity testing at their optimum moisture content. Cure all samples for 7 days at $40^{\circ} \mathrm{C}$ in plastic bags to retain sufficient moisture. Previous studies have demonstrated that this period of accelerated curing promotes a strength representative of long term curing. Following curing, subject the samples to capillary soak for 24 hours before strength testing. The capillary soak consists of placing the sample wrapped in a wet absorptive fabric on a porous stone.

(4) Determine unconfined compressive strength of the lime-soil mixture.

(5) Determine the resilient modulus in accordance with AASHTO T 294-94. A rapid triaxial tester $(\mathrm{RaTT})$ can be used to determine the resilient modulus 
instead of AASHTO T 294-94, which is more time-consuming and materialintensive.

(6) Evaluate moisture sensitivity by obtaining the dielectric value (DV). The DV, measured by the tube suction test, is a measure of how much moisture a base, subbase, or subgrade will absorb through capillary rise and the state of bonding of the absorbed moisture. Low DVs indicate the presence of tightly absorbed and well-arranged water molecules.

However, the design protocol does not present an allowable range of the values of the parameters required for the mixture design, such as unconfined compressive strength, resilient modulus, and moisture sensitivity.

\subsection{In-situ tests}

Laboratory tests conforming to AASHTO T-307 are necessary to obtain the resilient modulus, which is a measure of the deformation characteristics of the subgrade. The resilient modulus is obtained by conducting repeated triaxial tests on reconstituted or undisturbed cylindrical specimens of the subgrade soils. Because of the complexities of the test and the difficulties in specimen preparation, it is always difficult to extrapolate the laboratory results to in situ conditions. As a consequence, field tests are perceived as a more reliable means to assess the actual properties of the soils. The most common field tests are SPT (standard penetration tests), DCP (dynamic cone penetration) and FWD (falling weight deflectometer). The following sections provide a summary review of the DCP and FWD tests. 


\subsubsection{Dynamic Cone Penetrometer Test}

The DCP (Dynamic Cone Penetrometer) was developed in 1956, in South Africa as an in-situ pavement evaluation technique for evaluating the strength of pavement layers. Since then, the device has been extensively used in South Africa, the United Kingdom, the United States, Australia, and in many other countries. The main advantages of the DCP include its simplicity, portability, cost effectiveness, and the ability to provide rapid measurement of the in-situ strength of pavement layers. The DCP has also been proven to be useful for quality control during construction.

\section{Dynamic Cone Penetrometer test (ASTM D 6951-03)}

The DCP consists of a steel rod with a steel cone attached to one end, which is driven into a pavement structure or a subgrade using a sliding hammer (Figure 2.16). The soil strength is measured by the penetration, usually in millimeters or inches, per hammer blow.

The ASTM D 6951 specifies a standard method for the use of the dynamic cone penetrometer in shallow pavement applications. The cone has a pointed angle of $60^{\circ}$, and a diameter of $20 \mathrm{~mm}(0.79 \mathrm{in}$.$) . The weight of the hammer is 8 \mathrm{~kg}(17.7 \mathrm{lb})$, and the drop height is $575 \mathrm{~mm}(22.6$ in.). 


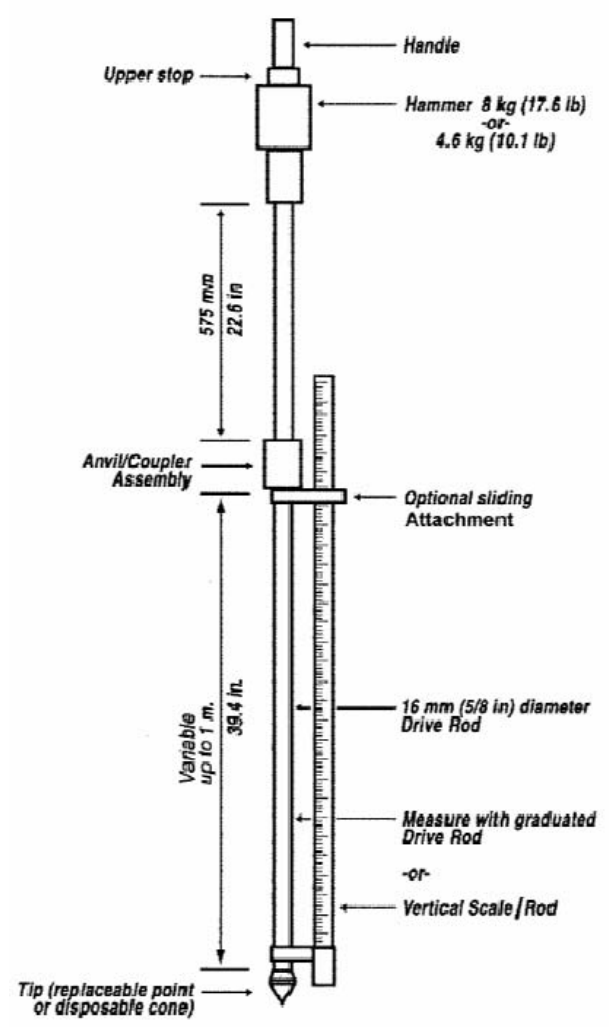

Figure 2.16 Schematic of DCP device (ASTM D 6951-03)

\section{Application of DCP}

Some applications of the DCP test include correlations with CBR, unconfined compressive strength, resilient modulus, and shear strength. The DCP test has been used for performance evaluation of pavement layers and quality control of fill compaction.

Extensive research has been performed to develop empirical relations between DCP penetration resistance and CBR values. Based on the results of past studies, many of the relationships between DCP and CBR have the following form:

$$
\log (C B R)=a+b \log (D C P I)
$$

Where DCPI $=$ DCP penetration resistance $(\mathrm{mm} / \mathrm{blow}) ; \mathrm{a}=$ constant that ranges 
from 2.44 to 2.60 ; and $b=$ constant that ranges from -1.07 to -1.16 . A summary of some of these correlations is presented in Table 2.4. In this research, an equation proposed by Webster et. al. (1992) is used to estimate CBR values of a subgrade from DCP test results.

Table 2.4 Correlations between DCPI and CBR

\begin{tabular}{|c|c|c|}
\hline Correlation Equation & Tested soil & Reference \\
\hline $\log (C B R)=2.56-1.16 \log (D C P I)$ & $\begin{array}{l}\text { Granular and } \\
\text { cohesive }\end{array}$ & Livneh(1987) \\
\hline $\log (C B R)=2.55-1.14 \log (D C P I)$ & $\begin{array}{l}\text { Granular and } \\
\text { cohesive }\end{array}$ & Harison (1987) \\
\hline $\log (C B R)=2.45-1.12 \log (D C P I)$ & $\begin{array}{l}\text { Granular and } \\
\text { cohesive }\end{array}$ & Livneh et al. (1992) \\
\hline $\log (C B R)=2.46-1.12 \log (D C P I)$ & Various soil types & Webster et al. (1992) \\
\hline $\log (C B R)=2.62-1.27 \log (D C P I)$ & Unknown & Kleyn (1975) \\
\hline $\log (C B R)=2.44-1.07 \log (D C P I)$ & $\begin{array}{l}\text { Aggregate base } \\
\text { course }\end{array}$ & Ese et al. (1995) \\
\hline $\log (C B R)=2.60-1.07 \log (D C P I)$ & $\begin{array}{l}\text { Aggregate base } \\
\text { course and cohesive }\end{array}$ & NCDOT (1998) \\
\hline $\log (C B R)=2.53-1.14 \log (D C P I)$ & $\begin{array}{l}\text { Piedmont residual } \\
\text { soil }\end{array}$ & Coonse (1999) \\
\hline
\end{tabular}

Several equations have been provided to correlate DCPI directly with resilient modulus $\left(\mathrm{M}_{\mathrm{R}}\right)$. Hassan (1996) suggested the following correlation:

$$
M_{R}(p s i)=7013.065-2040.783 \ln (D C P I)
$$

Where, DCPI is in inches per blow.

George and Uddin (2000) provided correlations between DCPI and $M_{R}$ as a 
function of moisture content, liquid limit and density. They also provided correlations between DCPI and $\mathrm{M}_{R}$. For fine-grained soils, the correlation is:

$$
M_{R}(p s i)=532.1 D C P I^{-0.492}
$$

For coarse-grained soils, the correlation is:

$$
M_{R}(p s i)=235.3 D C P I^{-0.475}
$$

Where, DCPI is in inches per blow.

Based on laboratory studies, McElvaney and Djatnika (1991) indicated that DCPI values can be correlated with the unconfined compressive strength of soil-lime mixtures, and provided probabilistic correlations between DCPI and unconfined compressive strength.

The DCP test has been also used to verify the resilient modulus obtained from Falling Weight Deflectometer (FWD) tests on roads with lime-treated base and subbase.

\section{Factors Affecting DCP results}

Kleyn and Savage (1982) indicated that DCPI results are affected by moisture content, gradation, density, and plasticity. Hassan (1996) reported that for fine-grained soils moisture content, soil type, dry density and confining pressure affect the DCPI, and for coarse-grained soils the coefficient of uniformity and confining pressures are important.

Livneh et al. (1995) conducted a comprehensive study on the effects of vertical confinement on DCPI results on pavement layers. According to the study, vertical 
confinement does not affect DCPI results on rigid pavement layers, while the vertical confinement does affect the DCPI results of granular subgrades underlying asphalt pavement. The confinement effects usually result in a decrease in the DCP values.

Because the DCP device may not be completely vertical while penetrating through the soil, the penetration resistance may be higher due to side friction. A higher resistance may also occur when penetrating into a collapsible granular material. This effect is usually small in cohesive soils. Livneh (2000) suggested to use a factor to correct DCPI results for side friction.

\subsubsection{Falling Weight Deflectometer}

Non-destructive tests on pavements, especially deflection tests, have been vital to evaluate the structural capacity of pavement layers.

The FWD (Falling Weight Deflectometer) test is based on delivering a transient impulse to the surface of a pavement. The transient impulse simulates a moving wheel load in both magnitude and duration. By changing the weight and the height of the weight drop, different impulse forces are generated. Geophones placed on the pavement surface at different distances from the point of weight drop are used to measure deflections. The deflection data are used to calculate the in-situ stiffness of individual pavement layers. Figure 2.17 shows a schematic of a typical FWD load impulse and the geophone response. When the falling weight drops, the impulse generates body waves and surface waves. The geophone sensors pick up the vertical velocity produced by the pulse. A single analog integration of the signal gives the deflection with time, and a backcalculation technique is used to analyze the deflection data. The load plate geometry, 
pavement thickness, and estimated layer moduli are used to generate a theoretical deflection basin. The theoretical deflections are compared with the measured deflections, and the error is computed. If the error is not within a specified tolerance, the process is repeated with revised layer moduli values until the two deflection basins are considered to be sufficiently close or until the modulus for any given layer reaches a given limit.

One fundamental difference between the DCP test and the FWD test is that the first one is a destructive test, as the pavement layers have to be cored to reach the subgrade and the FWD test is non-destructive. Also, the DCP test is more time demanding and is more expensive. However the DCP test provides a direct measure of the properties of the subgrade wile the FWD gives an indirect measure.

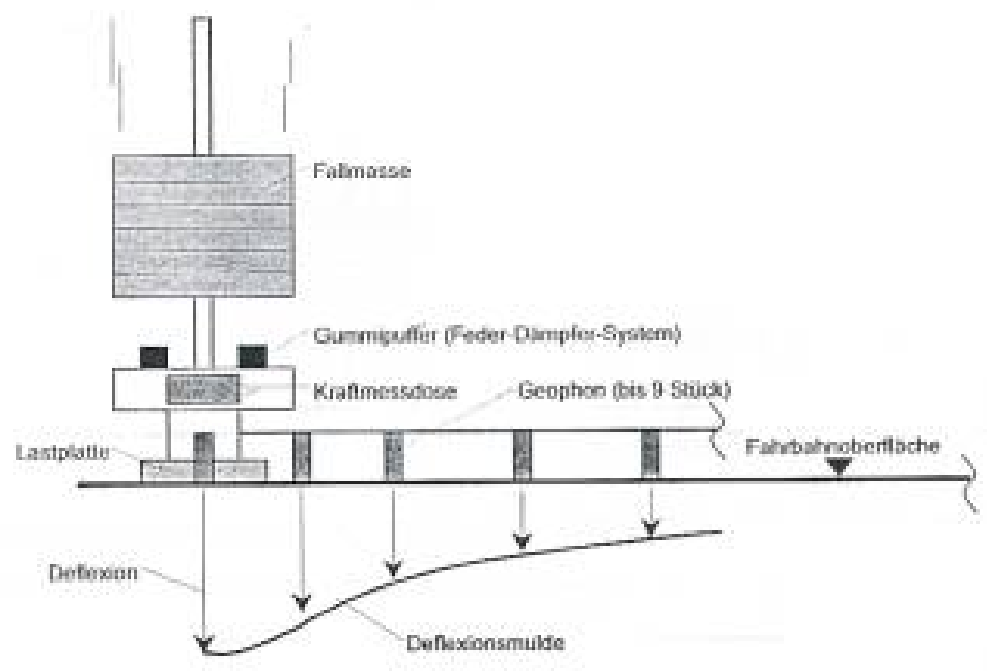

Figure 2.17 Schematic of typical Falling Weight Deflectometer 


\subsection{Post-construction tests for pavement evaluation}

\subsubsection{General post-construction test}

Pavement evaluation techniques usually involve measurement of deflections at the surface of the pavement with non-destructive tests (Dynaflect, Benkelmann beam and falling weight deflectometer). From the measurements, the elastic modulus of each pavement layer is back-calculated. AASHTO Design Guide (1993) recommends FWD tests. Since FWD is a nondestructive test that can be conducted in a few minutes and several back-calculation programs are available, FWD is gaining acceptance among highway engineers. However, the back-analysis is not straightforward because it requires knowledge of the actual geometry of the layered pavement.

Generally, FWD tests are conducted to: (1) obtain stiffness of pavement layers including the subgrade; (2) predict the remaining life of the pavement; and (3) to determine the overlay thickness required to repair a structural deficiency. Asphalt highway pavements are usually tested on the outer wheel path of the outer traffic lane; this places the test at one to two feet from the lane edge. On concrete highway pavements, FWD tests are usually done on the slab interior at the middle of the outer lane.

Typical testing intervals for highway pavements are between 100 and $500 \mathrm{ft}$ (between about 50 and 10 points per mile). Results of FWD tests tend to become more variable with time. A longer testing interval is appropriate for younger pavements, and a shorter interval is more appropriate for older pavements

Livneh and Ishai (1987) reported that, to develop a reliable pavement evaluation processes, non-destructive test results need to be correlated and calibrated with physical 
measurements of the pavement layers. They suggested that the correlations and/or calibrations may be achieved by conducting destructive tests like DCP tests in a borehole that penetrates the pavement layers including the subgrade. The DCP test may be an effective tool to assess subsurface pavement conditions and strength because of its portability, simplicity, and ability to rapidly provide in-situ strength of the pavement layers and subgrade. The DCP test does not require excavation of the existing pavement as in in-situ CBR and plate bearing tests do. The DCP results can be used to correlate or verify the FWD test results.

\subsubsection{Post-construction test on lime-treated subgrade}

There have been few studies on post-construction evaluation of lime-treated subgrades with DCP tests. The reason is because the DCP is a destructive test. Many more studies on long-term evaluation of lime-treated subgrades have been done using FWD tests. The FWD back-calculation analysis requires the layer geometry of the pavement and "initial" or seed values of the moduli of each of the pavement layers. While most pavement layers have well defined ranges for their stiffness, this is not usually the case for lime-treated subgrades. As the initial estimates may have a significant influence on the results of the back-calculation, a source of uncertainty may be introduced. The DCP is then an attractive alternative to complement and verify the FWD test results.

Little et al. (1996) evaluated long-term performance of lime-treated subgrades in road pavements in Texas using DCP and FWD tests. The stiffness obtained from correlations with DCP tests was compared with the stiffness back-calculated with FWD 
measurements. Based on the field test results, the authors reported that the stiffness of the lime-treated subgrade increased to more than 300 percent of that of the natural subgrade. Yusuf et al. (2001) performed DCP and FWD tests to evaluate lime-treated subgrades in four road pavements in Mississippi. It was reported by the authors that the ratio of the stiffness of the lime-treated and the natural subgrade was in a range between 4 and 20 and between 12 and 33, from the FWD and the DCP results respectively. 


\section{CHAPTER 3. FIELD TESTING SITE}

The main objective of this study is to evaluate the long-term performance of limetreated subgrades by conducting field tests on roads that have been in service for several years. The selection of the field testing sites is a critical issue for the evaluation. This chapter includes: (1) the selection process; (2) the selection criteria; and (3) the field testing sites selected and the preliminary investigation conducted.

\section{1. $\underline{\text { Selection process }}$}

On September 16, 2005, there was a meeting attended by Dr. Daehyeon Kim and Mr. Nayyar Zia Siddiki (INDOT), and Prof. Antonio Bobet and Mr. Chul Min Jung (Purdue University) at INDOT's Materials \& Testing office in Indianapolis. At the meeting it was decided to request to INDOT's District engineers information regarding roads where the subgrade had been treated with lime and which had been already in service for several years. At the end of September 2005, an electronic mail was sent to the Construction Engineers of the six Districts of INDOT, requesting such information. Based on the information obtained from the field engineers, ten projects were initially selected.

In December 2005, all available documents regarding the ten projects initially selected were reviewed with INDOT personnel at Material and Testing Division, INDOT. The following documents were evaluated: (1) official letters communicated between INDOT's main office and INDOT's District or a contractor; (2) design plans; 
and (3) geotechnical investigation data including boring logs, laboratory and field test data on subgrade soil. Information that could not be obtained at Material \& Testing Division was requested again to the corresponding District engineers. Road construction projects with insufficient information were removed from the selection list. The process was repeated until a sufficient number of projects were finally found satisfying the selection criteria.

\section{2. $\underline{\text { Selection criteria }}$}

The field testing sites were selected based on the following considerations: (1) location of the road project in the State of Indiana; (2) class of the road; (3) year when lime treatment was done; (4) type of lime used; (5) type of pavement; (6) availability of information necessary for post-construction evaluation; and (7) traffic and safety control. The following provides details regarding the selection criteria.

\section{Location of road construction project}

The testing sites should be representative of existing roads in Indiana, and should be well distributed over the State of Indiana. Indiana Department of Transportation (INDOT) has six Districts: (1) LaPorte District, in charge of Northwest Indiana; (2) Fort Wayne District, in charge of Northeast Indiana; (3) Crawfordsville District, in charge of West Central Indiana; (4) Greenfield District, in charge of East Central Indiana; (5) Vincennes District, in charge of Southwest Indiana; and (6) Seymour District, in charge of Southeast Indiana. In addition, traffic characteristics such as road-use, traffic volumes, and traffic density change across the state. Weather conditions are also different 
depending on geographic location. As a result, it was decided that the sites should be representative at least of existing roads in North, Central, and South Indiana.

\section{Class of road}

The class of a road is determined by traffic volume and is also associated with different availability of design and construction information. In Indiana, highway roads are classified as: (1) Interstate Highway Road; (2) US Highway Road; (3) State Road (SR); and (4) County or City Road (CR). Interstate highway roads are excluded as testing sites because of safety and traffic disruption due to their high traffic volume. For similar reasons, County roads are not included because of their smaller volume and density of traffic. In addition County roads tend to have a smaller amount of information available regarding design and construction. As a result, US Highway Roads and State Roads are selected.

\section{Year when lime treatment was done}

The year when lime treatment was done is a critical criterion for the site selection. As previously discussed, pozzolanic reactions and carbonation cementation processes in lime-treated soils continue for years. This process contributes to an increase in the stiffness and/or the strength of a soil with time. In addition, considering that this study is aimed at the long-term evaluation of lime-treated subgrades, it was decided to limit the testing site to roads constructed before 2002, which provides a minimum of 5 years in service. 


\section{Type of lime}

This study focuses on pavements with the subgrades treated with LKD (Lime Kiln Dust). Quicklime $(\mathrm{CaO})$ and hydrated lime $\left(\mathrm{Ca}(\mathrm{OH})_{2}\right)$ have been widely used throughout the US. However in Indiana LKD is increasingly being employed due to its economic benefits (Kim and Siddiki, 2004). LKD usually contains a significant amount of lime, alumina, and silica. The amount of lime, silica and alumina in LKD varies, depending on the limestone, fuel, and kiln operations used during the manufacturing process.

\section{Type of pavement}

In Indiana, lime modification has been adopted as a special subgrade treatment for PCC (Portland Cement Concrete) and HMA (Hot Mixed Asphalt) pavements, and so both types of pavements are chosen for field tests. In addition, few studies have been done on lime modification of subgrade soils under PCC. In accordance, it was decided to test both PCC and HMA pavements with lime-treated subgrades

\section{Information availability for preliminary investigation}

The roads to be tested should have sufficient geotechnical information generated during design and construction such that soil properties before and after treatment with lime could be compared. The following information was deemed necessary: (1) pavement type and configuration; (2) location and length of the road section where the subgrade was treated; (3) year when the treatment was done; (4) type and content of lime used; and (5) geotechnical properties of the subgrade natural soil. 


\section{$\underline{\text { Traffic and safety control for a field testing }}$}

Field tests are performed on roads in service. Therefore, traffic and safety control are absolutely necessary during testing to ensure the safety of the crew performing the test as well as the users of the road. For this reason, it was decided to exclude Interstate roads.

\subsection{Field testing sites}

The location of the six field testing sites selected is shown in Figure 3.1. The road projects chosen were: (1) Des. 62050 (R-22364) on US 30 in Lake County; (2) Des. 9901900 (R-25555) on SR 49 in Porter County; (3) Des. 9118711 (R-23126) on SR 67 in Delaware County; (4) Des. 9133550 (R-25819) on US 231 in Montgomery County; (5) Des. 63260 (R-24568) on SR 69 in Posey County; and (6) Des. 9774201 (R-25919) on SR 67 in Knox County. Des. is the designation number given by INDOT to a road construction project. R- is the contract number used between a contractor and INDOT.

Table 3.1 shows details of each site. The table contains: (a) designation number of the road project selected; (b) contract number of the project; (c) County where the project was done and INDOT District that has jurisdiction for the project; (d) name of road; (e) type of pavement and total number of driving lanes; (f) type of lime used and design thickness of lime-treated subgrade; (g) geographical location of the road project, denoted in terms of reference post (RP) number, and the total length of the project; and (h) year when the lime treatment was done.

Sites (1) and (2) are located in Northern Indiana; sites (3) and (4) in Central Indiana, and sites (5) and (6) in Southern Indiana. As a result, the sites are considered 
representative of the roads encountered across the State of Indiana. Lime treatment was done in all the sites before 2002. Sites (1) and (5) have PCC pavement while sites (2), (3), (4), and (6) have HMA pavement. Sites (1) and (4) are on US Highways while sites (2), (3), (5) and (6) are on Indiana State Roads. At each site, subgrades were designed to improve the original soil with $5 \%$ of LKD and with 16 inches of the lime-treated subgrade.

More details are presented in this section focusing on: (1) geographical location of each site; (2) pavement configuration; (3) information on lime treatment; and (4) soil characterization and stiffness properties of the natural subgrade obtained from existing geotechnical investigation data. 


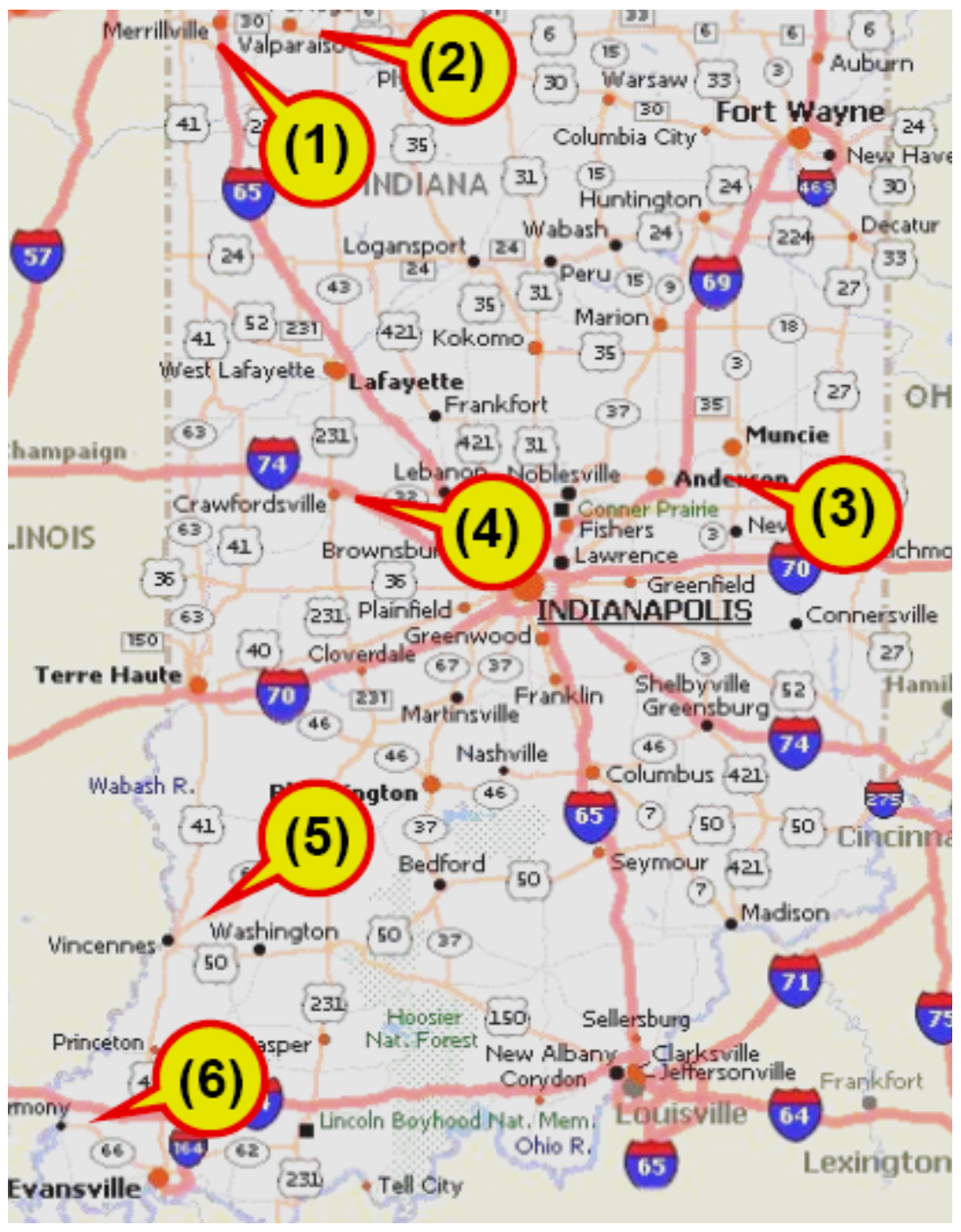

Figure 3.1 Geographical location of the six field testing sites 
Table 3.1 Details of testing sites

\begin{tabular}{|c|c|c|}
\hline Site & $\begin{array}{l}\text { - Project number } \\
\text { - Contract number } \\
\text { - County (District) } \\
\text { - Road name }\end{array}$ & $\begin{array}{l}\text { - Type of pavement / No. of driving lanes } \\
\text { - Type of lime / Thickness of treated subgrade } \\
\text { - Location and length of treated section } \\
\text { - Year when lime treatment was done }\end{array}$ \\
\hline (1) & $\begin{array}{l}\text { - Des. } 62050 \\
\text { - R-22364 } \\
\text { - Lake (Laporte) } \\
\text { - US } 30\end{array}$ & $\begin{array}{l}\text { - PCC pavement with } 4 \text { lanes } \\
-5 \% \text { LKD / } 16 \text { in. } \\
\text { - RP 4+0.550 RP } 4+0.970,0.42 \text { miles } \\
-1997\end{array}$ \\
\hline (2) & $\begin{array}{l}\text { - Des } 9901900 \\
\text { - R-25555 } \\
\text { - Porter (Laporte) } \\
\text { - SR } 49\end{array}$ & $\begin{array}{l}\text { - HMA pavement with } 4 \text { lanes } \\
\text { - } 5 \% \text { LKD / } 16 \text { in. } \\
\text { - RP } 30+0.330 \sim \text { RP } 35+0.500,5.2 \text { miles } \\
\text { - } 2002\end{array}$ \\
\hline (3) & $\begin{array}{l}\text { - Des. } 9118711 \\
\text { - R-23126 } \\
\text { - Delaware (Greenfield) } \\
\text { - SR } 67\end{array}$ & $\begin{array}{l}\text { - HMA pavement with } 4 \text { lanes } \\
\text { - } 5 \% \text { LKD / } 16 \text { in. } \\
\text { - RP142+0.489 RP } 146+0.600,4.1 \text { miles } \\
\text { - } 1999\end{array}$ \\
\hline (4) & $\begin{array}{l}\text { - Des. } 9133550 \\
\text { - R-25819 } \\
\text { - Montgomery (Crawfordsville) } \\
\text { - US } 231\end{array}$ & $\begin{array}{l}\text { - HMA pavement with } 4 \text { lanes } \\
\text { - } 5 \% \text { LKD / } 16 \text { in. } \\
\text { - RP } 41+0.505 \sim \text { RP } 45+0.178,3.7 \text { miles } \\
\text { - } 2002\end{array}$ \\
\hline (5) & $\begin{array}{l}\text { - Des. } 63260 \\
\text { - R-24568 } \\
\text { - Posey (Vincennes) } \\
\text { - SR } 69\end{array}$ & $\begin{array}{l}\text { - PCC pavement with } 2 \text { lanes } \\
\text { - } 5 \% \text { LKD / } 16 \text { in. } \\
\text { - RP } 13+0.55 \sim \text { RP } 17+0.05,3.5 \text { miles } \\
\text { - } 1996\end{array}$ \\
\hline (6) & $\begin{array}{l}\text { - Des. } 9774201 \\
\text { - R-25919 } \\
\text { - Knox (Vincennes) } \\
\text { - SR } 67\end{array}$ & $\begin{array}{l}\text { - HMA pavement with } 2 \text { lanes } \\
-5 \% \text { LKD / } 16 \text { in. } \\
\text { - RP 4+0.39 RP 10+0.79, } 6.4 \text { miles } \\
-2002\end{array}$ \\
\hline
\end{tabular}




\subsubsection{Site (1)}

Site (1) is located along US 30 in Schererville, Lake County, Indiana. The road has the heaviest traffic of all six sites. The site begins 2485 feet West of the intersection of US 30 and Cline avenue (RP 4+0.55), and runs easterly along US 30, to 285 feet West of the intersection of US30 and Cline avenue (RP 4+0.97); see Figure 3.2. RP is the "Reference Post" number given first by the mile and then by the fraction of the mile to the one-thousandth precision; it is used to identify the location of a certain point along a road. The site has a total length of 0.66 kilometers and the road has four lanes (Figure $3.3)$.

The site has PCC pavement. The design pavement cross section consists of, from the top of the pavement: (1) PCC layer with thickness of 11 inches; (2) 100\% crushed coarse aggregate subbase layer with size \#8 and thickness of 4 inches; (3) compacted aggregate base layer with size \#53 and thickness of 6 inches on top of the subgrade which has a thickness of 16 inches (Figure 3.4).

Lime treatment was done in 1997 only at a section on the westbound road, which ranges from RP4+0.77 to RP4+0.87. The design quantity of lime was $5 \%$ LKD by dry weight of soil. The design thickness of the lime treated subgrade soil was 16 inches $(40 \mathrm{~cm})$

The natural subgrade soil at the site was characterized, before field testing, based on existing geotechnical data, which are included in the Appendix; see also Table 3.2. The soil was a fine grained soil with $83 \%$ passing No. 200 sieve. The soil had a Liquid Limit (LL) of $34 \%$, a Plastic Limit (PL) of $18 \%$, and a Plastic Index (PI) of 16. Based on the soil particle distribution and the soil index properties, the soil is classified as A-6, 
following the AASHTO classification system, and as CL under the Unified Soil Classification System. The soil had pH 7.6. From existing boring logs, the subgrade soil had $16 \%$ of water content and SPT number (N) of 8 (Figure A.1 (a)). From a correlation between SPT N-value and CBR (Livneh, 1989), the estimated CBR of the natural subgrade was 6.5 (Table 3.2).

\subsubsection{Site (2)}

Site (2) is located along SR 49 in Valparaiso, Porter County, Indiana. The road interconnects US 30 (E-W direction) and the Indiana Toll Road, I-90 (E-W direction). The site begins $0.97 \mathrm{~km}$ North of the centerline of US30 (RP 30+0.330), and runs northwesterly along SR 49, to $1.98 \mathrm{~km}$ South of the centerline of US6 (RP 35+0.500). See Figure 3.5. The site has a total length of 8.3 kilometers $(5.17 \mathrm{miles})$, and the road has four lanes (Figure 3.6).

The site has HMA pavement. As seen in the design drawing of the pavement configuration, the cross section of the pavement consists of, from the top of the pavement: (1) $75 \mathrm{~kg} / \mathrm{m}^{2}$ of HMA surface layer with $9.5 \mathrm{~mm}$ size of crushed stone; (2) 165 $\mathrm{kg} / \mathrm{m}^{2}$ of HMA intermediate layer with $19 \mathrm{~mm}$ size of crushed stone; (3) $900 \mathrm{~kg} / \mathrm{m}^{2}$ of HMA base layer with $25 \mathrm{~mm}$ size of crushed stone, placed on top the subgrade (Figure 3.7). A $60 \mathrm{~kg} / \mathrm{m}^{2}$ of HMA layer approximately represents a HMA layer with a thickness of one inch. The site has totally 19-in thick HMA pavement layer including the surface, intermediate, and base layers.

Lime modification was done in 2002 with a design value of $5 \%$ LKD by dry weight of soil and for the entire length of the project. The design thickness of the lime- 
treated subgrade soil was 16 inches $(40 \mathrm{~cm})$.

The natural subgrade soil at the site was characterized based on existing geotechnical data, also included in the Appendix. A summary of the results is included in Table 3.2. The soil was a fine grained soil with $75 \%$ passing No. 200 sieve. The soil had a LL of 34, a PL of 16, and a PI of 18. Based on the soil particle distributions and the soil index properties, the soil is classified as A-6 following the AASHTO classification system, and as CL under the Unified Soil Classification System. The soil had $\mathrm{pH} 4.8$. From existing boring logs, the subgrade soil had $19 \%$ of water content and SPT number (N) of 8 (Figure A.1 (b)). The estimated CBR is 6.5 (Table 3.2).

\subsubsection{Site (3)}

Site (3) is located along SR 67 in the South of Muncie, Delaware County, Indiana. The site begins 255 meters East of CR 600W (RP 142+0.489), and runs easterly and northerly along SR 67, to 441 meters Northeast of CR 400S (RP 146+0.600), as shown in Figure 3.8. The site has a total length of 6.3 kilometers and the road has four lanes (Figure 3.9).

The site has HMA pavement. The design pavement cross section included, from the top of the pavement: (1) $60 \mathrm{~kg} / \mathrm{m}^{2}$ of HMA surface layer with $9.5 \mathrm{~mm}$ size of crushed stone; (2) $120 \mathrm{~kg} / \mathrm{m}^{2}$ of HMA intermediate layer with $19 \mathrm{~mm}$ size of crushed stone; (3) $170 \mathrm{~kg} / \mathrm{m}^{2}$ of HMA base layer with $25 \mathrm{~mm}$ size of crushed stone; (4) $250 \mathrm{~kg} / \mathrm{m}^{2}$ of HMA base layer with $25 \mathrm{~mm}$ size of crushed stone; and (5) $210 \mathrm{~kg} / \mathrm{m}^{2}$ of HMA base layer with $25 \mathrm{~mm}$ size of crushed stone constructed on top of the subgrade (Figure 3.10).

Lime modification was done in 1999 with a design value of $5 \%$ LKD by dry 
weight of soil and along the entire project. The design thickness of lime treated subgrade soil was 16 inches $(40 \mathrm{~cm}) \cdot 230$ Geotechnical investigation data at site (3) was not available.

\subsubsection{Site (4)}

Site (4) is located along US 231 in Crawfordsville, Montgomery County, Indiana. The road crosses downtown Crawfordsville. The site begins 0.84 miles South of the centerline of CR 150S (RP 175+0.560), and runs northerly along US 231, to 0.29 miles South of the centerline of US 136 (RP 177+0.810). See Figure 3.11. The site has a total length of 3.7 kilometers and the road has four lanes (Figure 3.12).

The site has HMA pavement. As seen in the design plans, the pavement consists of, from the top of the pavement: (1) $75 \mathrm{~kg} / \mathrm{m}^{2}$ of HMA surface layer with $9.5 \mathrm{~mm}$ size of crushed stone; (2) $165 \mathrm{~kg} / \mathrm{m}^{2}$ of HMA intermediate layer with $19 \mathrm{~mm}$ size of crushed stone; (3) $240 \mathrm{~kg} / \mathrm{m}^{2}$ of HMA base layer with $25 \mathrm{~mm}$ size of crushed stone; (4) $140 \mathrm{~kg} / \mathrm{m}^{2}$ of HMA base layer with $19 \mathrm{~mm}$ size of crushed stone; and (5) $210 \mathrm{~kg} / \mathrm{m}^{2}$ of HMA base layer with $25 \mathrm{~mm}$ size of crushed stone, on top of the lime-treated subgrade soil (Figure $3.13)$.

Lime modification was done in 2002 with a design value of $5 \%$ LKD by dry weight of soil. The treatment was applied to the entire length of the project. The design thickness of the lime-treated subgrade soil was 16 inches $(40 \mathrm{~cm})$.

The natural subgrade soil at the site was characterized using existing geotechnical investigation data. The data can be found in the Appendix; see also Table 3.2. The soil was a fine grained soil with $56 \%$ passing No. 200 sieve. The soil had a LL of 33, a PL of 
24, and a PI of 9. Based on the soil particle distributions and the soil index properties, the soil is classified as A-4 following the AASHTO classification system, and as ML under the Unified Soil Classification System. The soil had pH 5.8. From existing boring logs, the subgrade soil had $27 \%$ of water content and SPT number (N) of 7 (Figure A.1 (d)). The estimated CBR of the soil is 6.0. (Table 3.2).

\subsubsection{Site (5)}

Site (5) is located along SR 69 in Mt. Vernon, Posey County, Indiana (Figure 3.14). The site begins at the intersection of SR 62 with CR 400E (RP 13+0.550) and runs northwesterly along SR 69 to 0.76 miles South of the centerline of CR 400S (RP $17+0.050$ ). The site has a total length of 5.7 kilometers and the road has two lanes (Figure $3.15)$.

The site has the PCC pavement designed identical to that of site (1). The design, from the top of the pavement, consisted of: (1) PCC surface layer with a thickness of 10 inches; (2) $100 \%$ crushed coarse aggregate subbase layer with a size of \#8 and a thickness of 4 inches; (3) compacted aggregate base layer with a size of \#53 and a thickness of 3 inches (Figure 3.16).

Lime modification was done in 1996. This is the oldest site, with a length of time in service of 11 years before testing. The design lime-treatment was $5 \%$ LKD by dry weight of soil and included the entire project. The design thickness of lime treated subgrade soil was 16 inches $(40 \mathrm{~cm})$.

From existing geotechnical investigation data, the natural subgrade was a fine grained soil with $97 \%$ passing No. 200 sieve. The soil had a LL of 33, a PL of 21, and a 
PI of 12. Based on the soil particle distributions and the soil index properties, the soil is classified as A-4 following the AASHTO classification system, and as CL under the Unified Soil Classification System. The soil had pH 6.7. From existing boring logs, the subgrade soil had $20 \%$ of water content and SPT number $(\mathrm{N})$ of 8 (Figure A.1 (e)). The estimated CBR is 6.5 .

\subsubsection{Site (6)}

Site (6) is located along SR 67, linking Bruceville to Bickell in Knox County, Indiana. The site begins 200 meters Southwest of the centerline of Washington street in Bruceville (RP 4+0.390), and runs northeasterly along SR 67, to just West of CR 800E in Bickell (RP 10+0.790); see Figure 3.17. The site has a total length of 10.3 kilometers and the road has two lanes (Figure 3.18).

The site has HMA pavement. The design pavement cross section included, from the top of the pavement: (1) $90 \mathrm{~kg} / \mathrm{m}^{2}$ of HMA surface layer with $9.5 \mathrm{~mm}$ size of crushed stone; (2) $50 \mathrm{~kg} / \mathrm{m}^{2}$ of HMA intermediate layer with $19 \mathrm{~mm}$ size of crushed stone; (3) 180 $\mathrm{kg} / \mathrm{m}^{2}$ of HMA base layer with $25 \mathrm{~mm}$ size of crushed stone; (4) $165 \mathrm{~kg} / \mathrm{m}^{2}$ of HMA base layer with $25 \mathrm{~mm}$ size of crushed stone; and (5) $180 \mathrm{~kg} / \mathrm{m}^{2}$ of HMA base layer with 25 mm size of crushed stone, followed by the lime-subgrade soil (Figure 3.19).

Lime modification was done in 2002 with a design value of $5 \%$ LKD by dry weight of soil and for the entire length of the project. The design thickness of the subgrade was 16 inches $(40 \mathrm{~cm})$.

Based on existing geotechnical investigation, the soil was a fine grained soil with 93 \% passing No. 200 sieve. The soil had a Liquid Limit (LL) of 26, a Plastic Limit (PL) 
of 22, and a Plastic Index (PI) of 4. The soil is classified as A-4 following the AASHTO classification system, and as ML under the Unified Soil Classification System. The soil had $\mathrm{pH}$ 6.4. From existing boring logs, the subgrade soil had $23 \%$ of water content and SPT number $(\mathrm{N})$ of 8 (Figure A.1 (f)). The estimated CBR is 6.5 . 
Table 3.2 Soil characterization and strength properties of the natural subgrade soils at the six sites.

(The results are obtained from existing geotechnical investigation data prior to the field testing)

\begin{tabular}{|c|c|c|c|c|c|c|}
\hline & Site (1) & Site (2) & Site (3) & Site (4) & Site (5) & Site (6) \\
\hline $\begin{array}{l}\text { Unified Soil } \\
\text { Classification }\end{array}$ & $\mathrm{CL}$ & CL & - & ML & $\mathrm{CL}$ & ML \\
\hline $\begin{array}{c}\text { AASHTO } \\
\text { Classification }\end{array}$ & A-6 & A-6 & - & A-4 & A-6 & A-4 \\
\hline \#200 passing (\%) & 83 & 75 & - & 56 & 97 & 93 \\
\hline Liquid limit (\%) & 34 & 34 & - & 33 & 33 & 26 \\
\hline Plastic limit (\%) & 18 & 16 & - & 24 & 21 & 22 \\
\hline Plastic index & 16 & 18 & - & 9 & 12 & 4 \\
\hline Water content $(\%)$ & 16 & 19 & - & 27 & 20 & 23 \\
\hline $\mathrm{pH}$ & 7.6 & 4.8 & - & 5.8 & 6.7 & 6.4 \\
\hline SPT number & 8 & 8 & - & 7 & 8 & 8 \\
\hline Estimated CBR & 6.5 & 6.5 & - & 6 & 6.5 & 6.5 \\
\hline
\end{tabular}




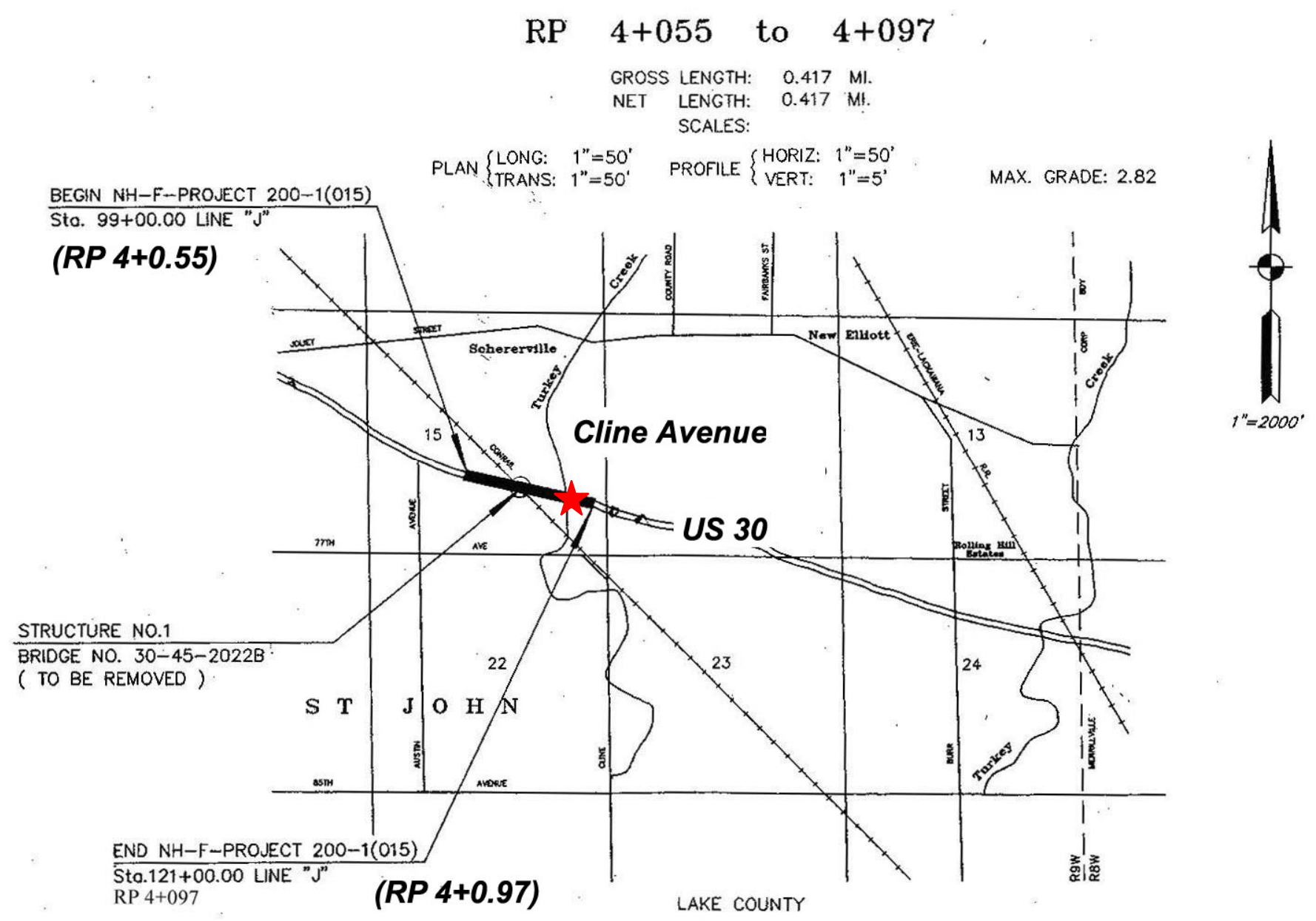

Figure 3.2 General location map of site (1) (modified from a design plan of the project).

The star indicates the location of the section where field tests were done. 


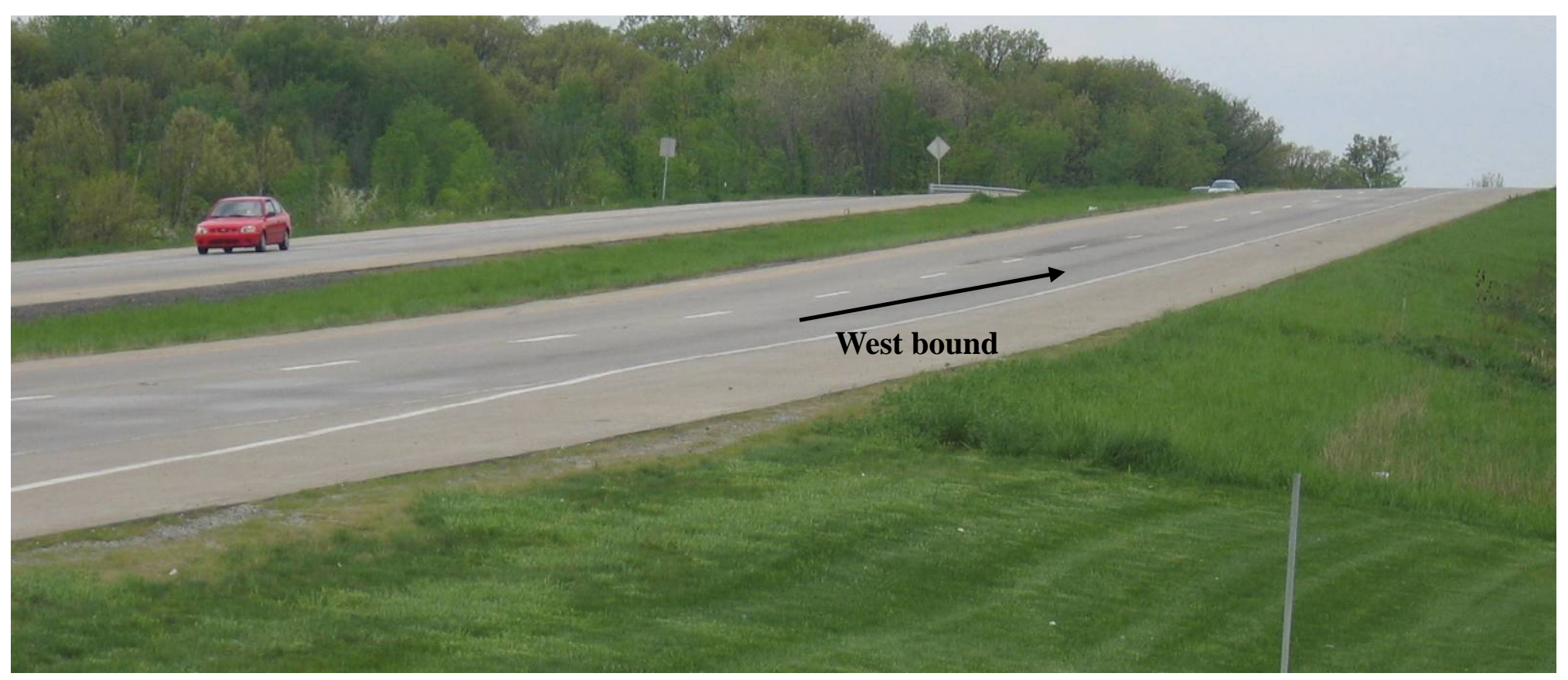

Figure 3.3 Overview of the section where field tests were done at site (1) 


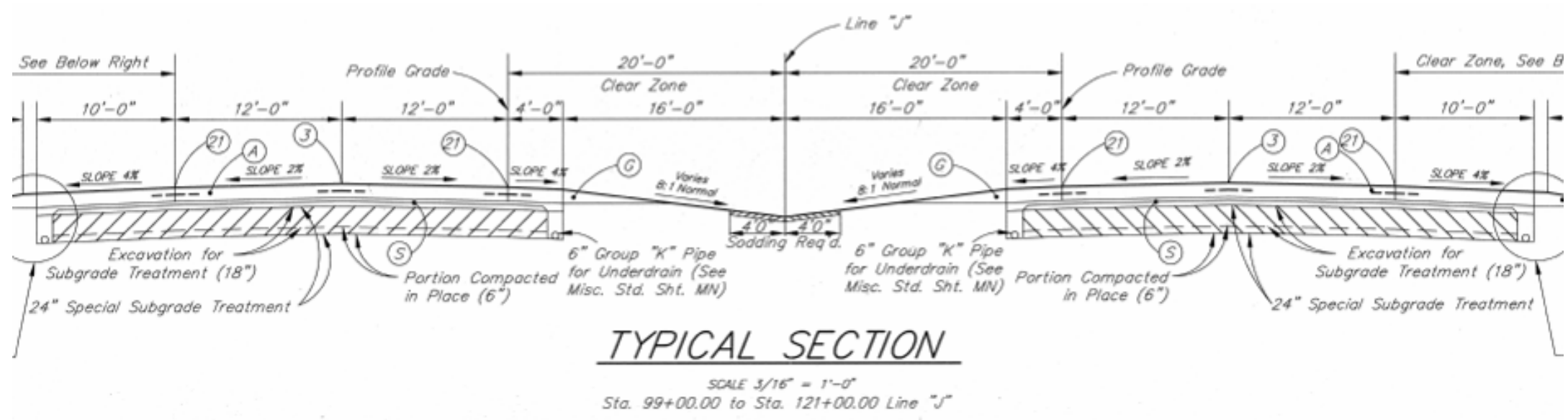

(A) 11 in. Portland Cement Concrete Pavement

(D) 440\#/Sys. Bituminous Mixture for Approaches, $\mathrm{LV}$ on 4" Compacted Aggregate

(E) $440 \# /$ Sys. Bituminous Mixture for Approaches, LV on 8 " Compacted Aggregate Base

(G) Compacted Aggregate Base, No. 53

(5) 4" of $100 \%$ Crushied "Coarse Aggregate, \# 8 on 6" of Compacted Aggregate, Type "O", Size \# 53

(3) Longitudinal Joint

(27) Longitudinal Construction Joint

Figure 3.4 Typical design pavement cross section at site (1) 


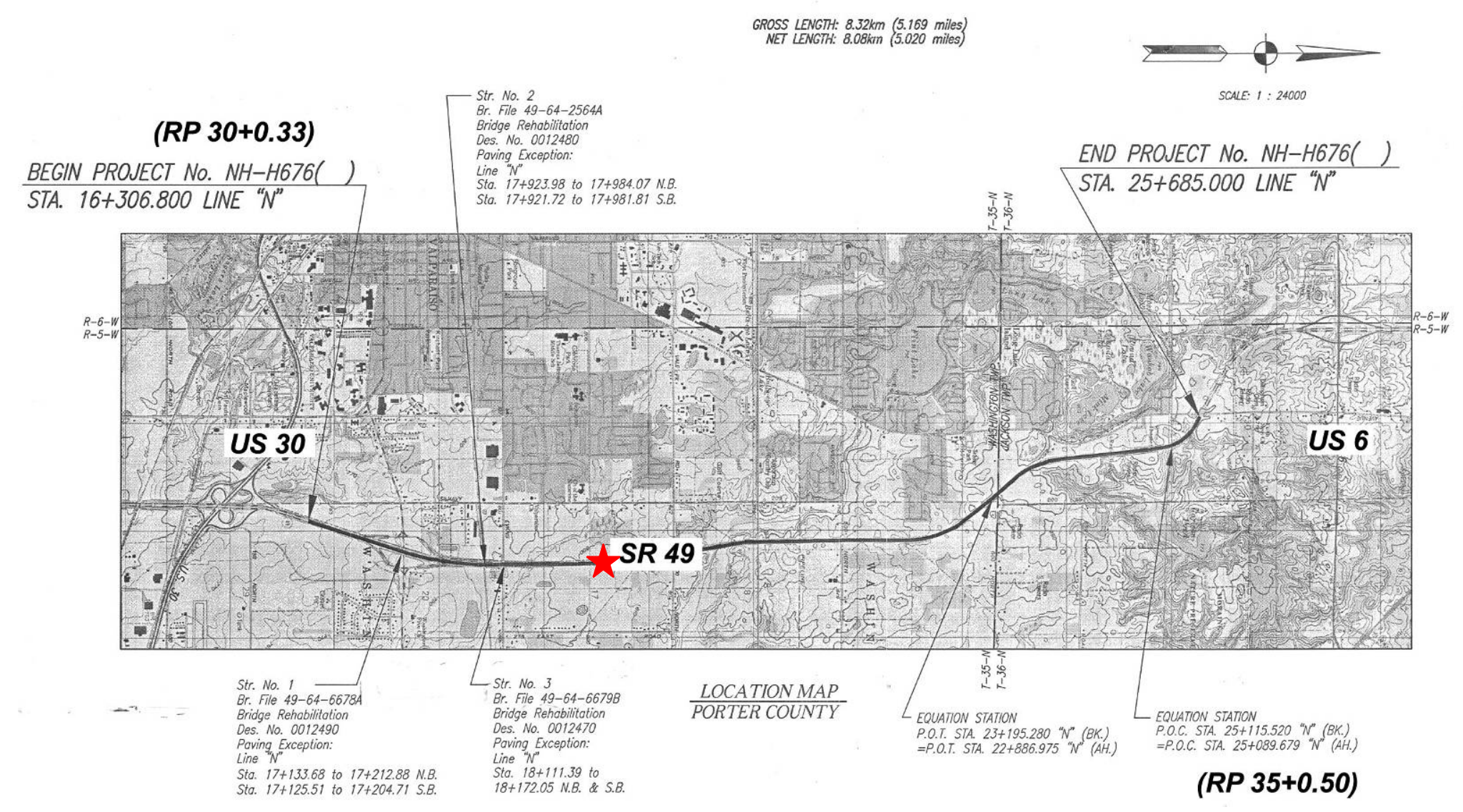

Figure 3.5 General location map of site (2) (modified from a design plan of the project).

The star indicates the location of the section where field tests were done. 


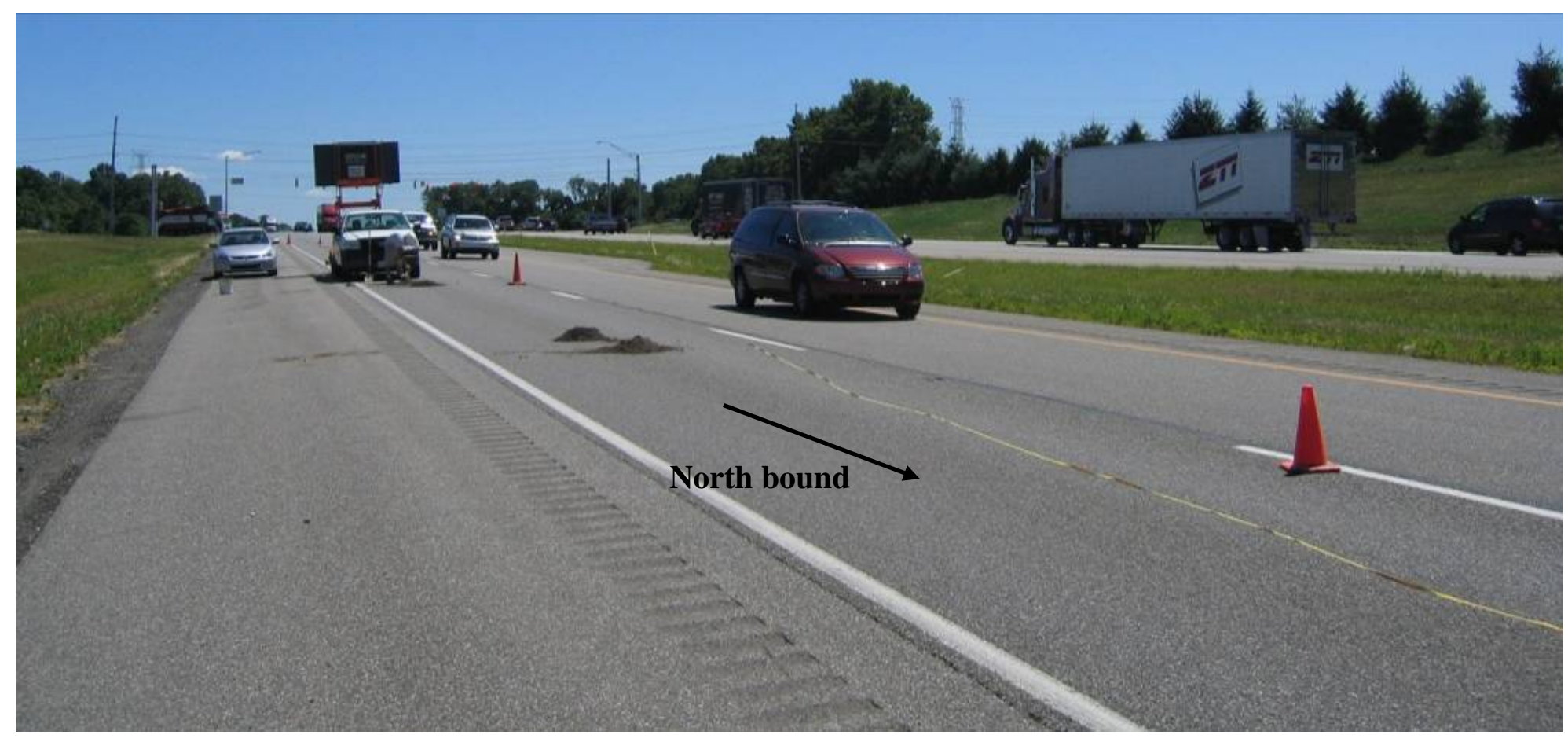

Figure 3.6 Overview of the section where field tests were done at site (2) 

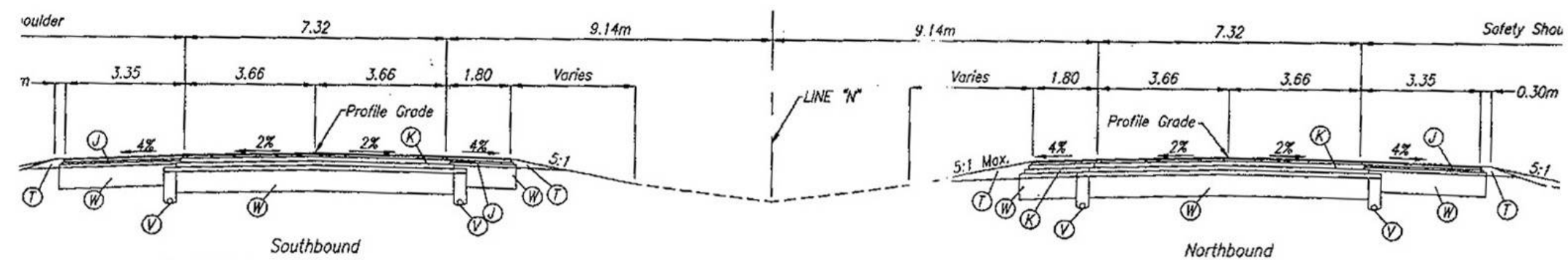

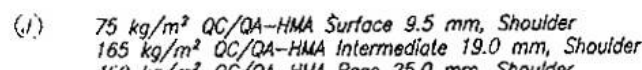

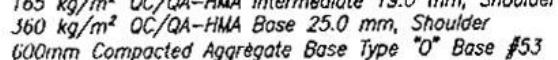

(K) $7 ., \mathrm{kg} / \mathrm{m}^{2}$ OC/OA-HMA Surface $9.5 \mathrm{~mm}$, Moinline

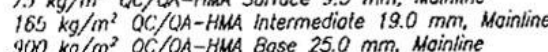

$75 \mathrm{~kg} / \mathrm{m}^{2}$ OC/OA-HMA Surfoce $9.5 \mathrm{~mm}$, Moinline $16.5 \mathrm{~kg} / \mathrm{m}^{2}$ OC/OA-HAC Intermediate $19.0 \mathrm{~mm}$, Moinline $480 \mathrm{~kg} / \mathrm{m}^{2} \mathrm{OC} / \mathrm{cm}$ lik4 Bose $250 \mathrm{~mm}$, Moinline

(17) $75 \mathrm{~kg} / \mathrm{m}^{2}$ OC/OA-HAMA Surfoce $9.5 \mathrm{~mm}$, Shoulder Vuriable (Min. $165 \mathrm{~kg} / \mathrm{m}^{2}$ ) OC/OA-HMA Intermediote $19.0 \mathrm{~mm}$, Shoulder Vurialtio BOse OC/OA HMA Base $25.0 \mathrm{~mm}$. Shoulder

(i) $75 \mathrm{~kg} / \mathrm{m}^{2}$ aC/OA-HMA Surfoce $9.5 \mathrm{~mm}$, Shoulder

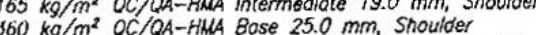
600 inm Compacted Aggregate Bose Type " 0 " Base $\$ 53$

(K) $7.5 \mathrm{~kg} / \mathrm{m}^{2}$ QC/OA-HMA Surface $9.5 \mathrm{~mm}$, Moinline $165 \mathrm{~kg} / \mathrm{m}^{2}$ QC/ LA-HMA Intermediote $19.0 \mathrm{~mm}$, Moinline
$900 \mathrm{~kg} / \mathrm{m}^{2}$ QC $/ O A-H M A$ Base $25.0 \mathrm{~mm}$, Mointine

(ii) $75 \mathrm{~kg} / \mathrm{m}^{2}$ QC/OA-HMA Surfoce $9.5 \mathrm{~mm}$, Mointine $165^{3} \mathrm{~kg} / \mathrm{m}^{2}$ OC/OA-HAS intermediate $19.0 \mathrm{~mm}$, Mointine

(112) $\quad 75 \mathrm{~kg} / \mathrm{m}^{2}$ QC/OA-HMCs Surfoce $9.5 \mathrm{~mm}$, Shoulder Vurioblts (Min. $165 \mathrm{~kg} / \mathrm{m}^{2}$ ) OC/OA-HMA Intermediote $19.0 \mathrm{~mm}$, Shoulder Virrichlo Bose OC/OA HMA Base $25.0 \mathrm{~mm}$, Shoulder

Figure 3.7 Typical design pavement cross section at site (2) 


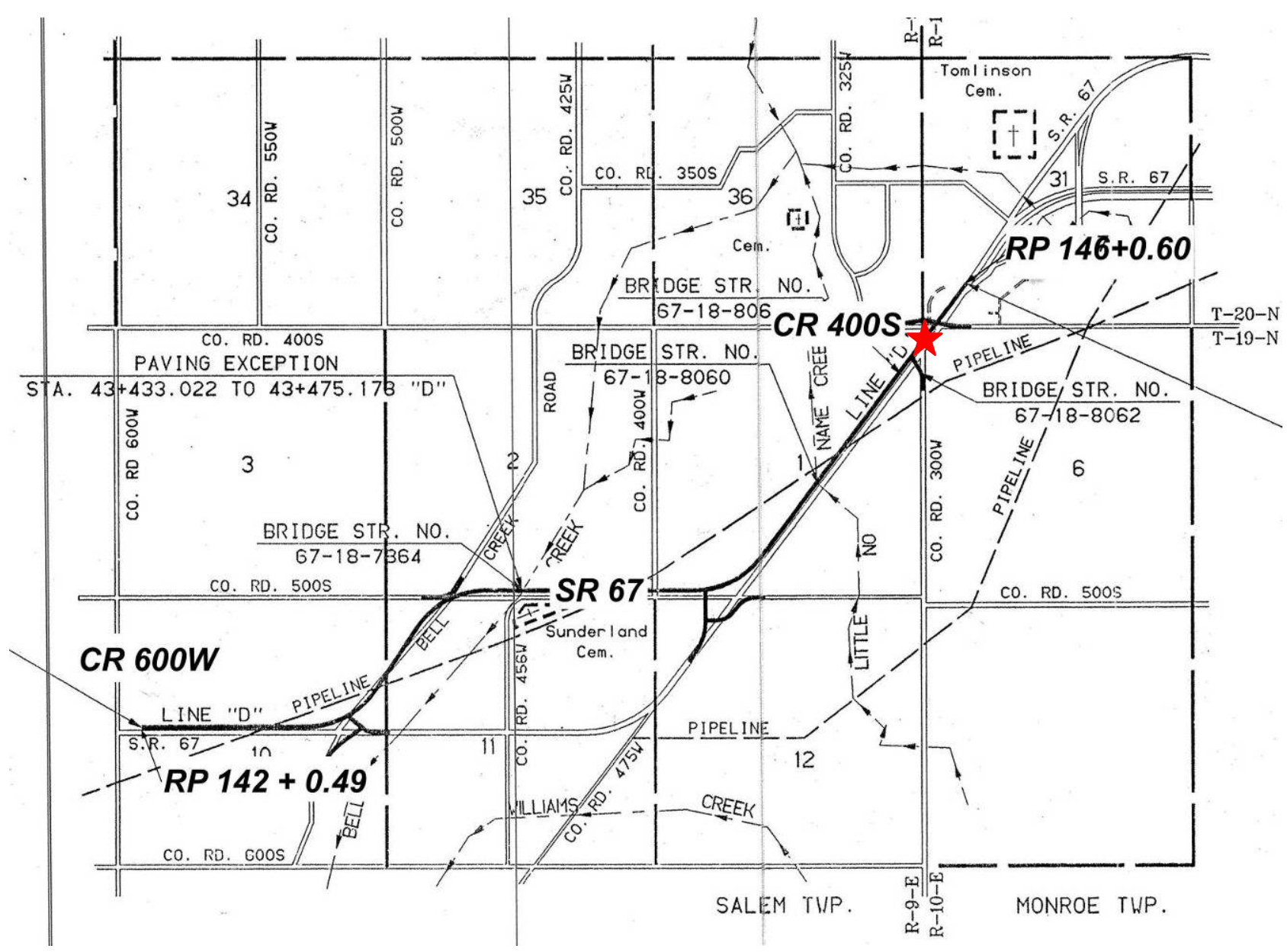

Figure 3.8 General location map of site (3) (modified from a design plan of the project).

The star indicates the location of the section where field tests were done. 


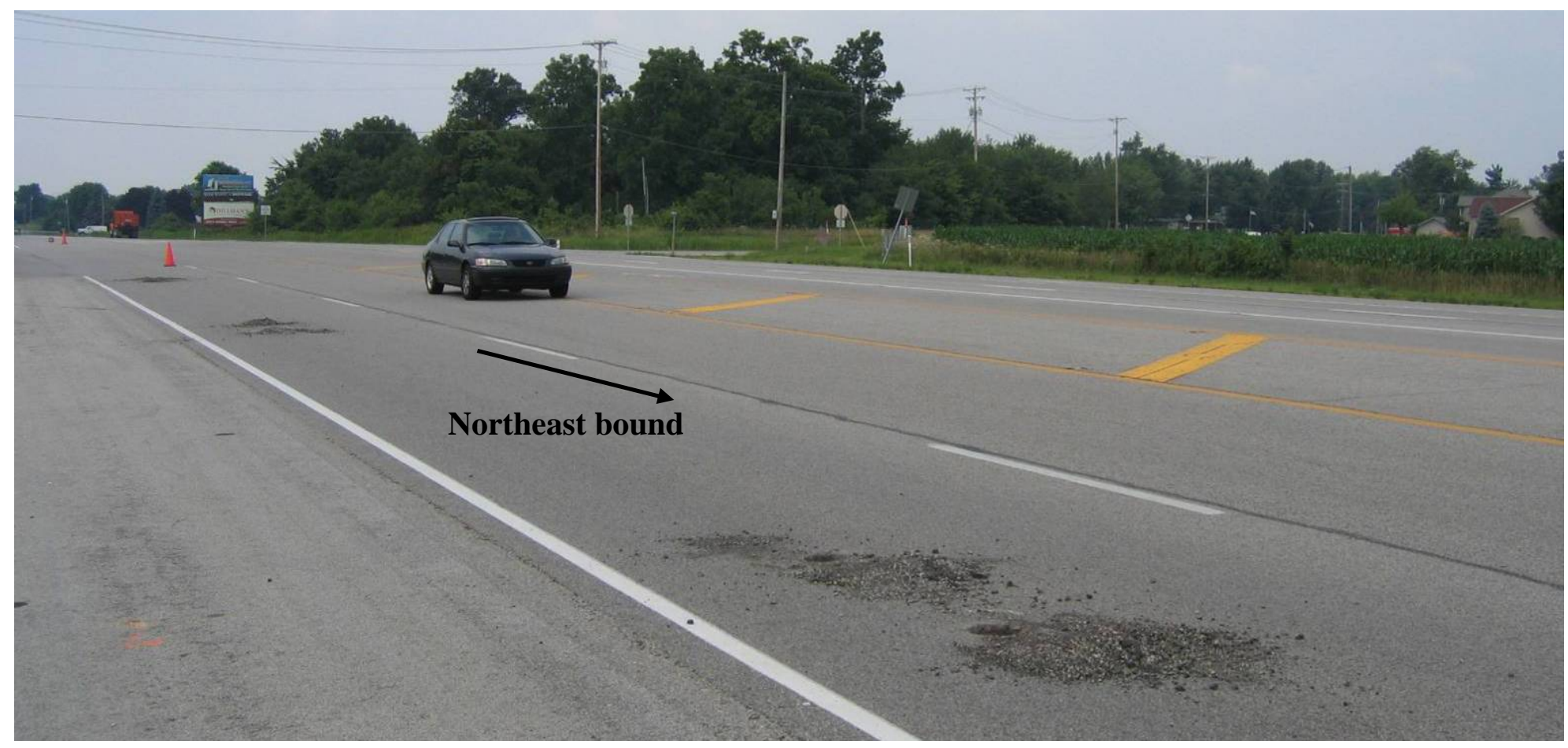

Figure 3.9 Overview of the section where field tests were done at site (3) 


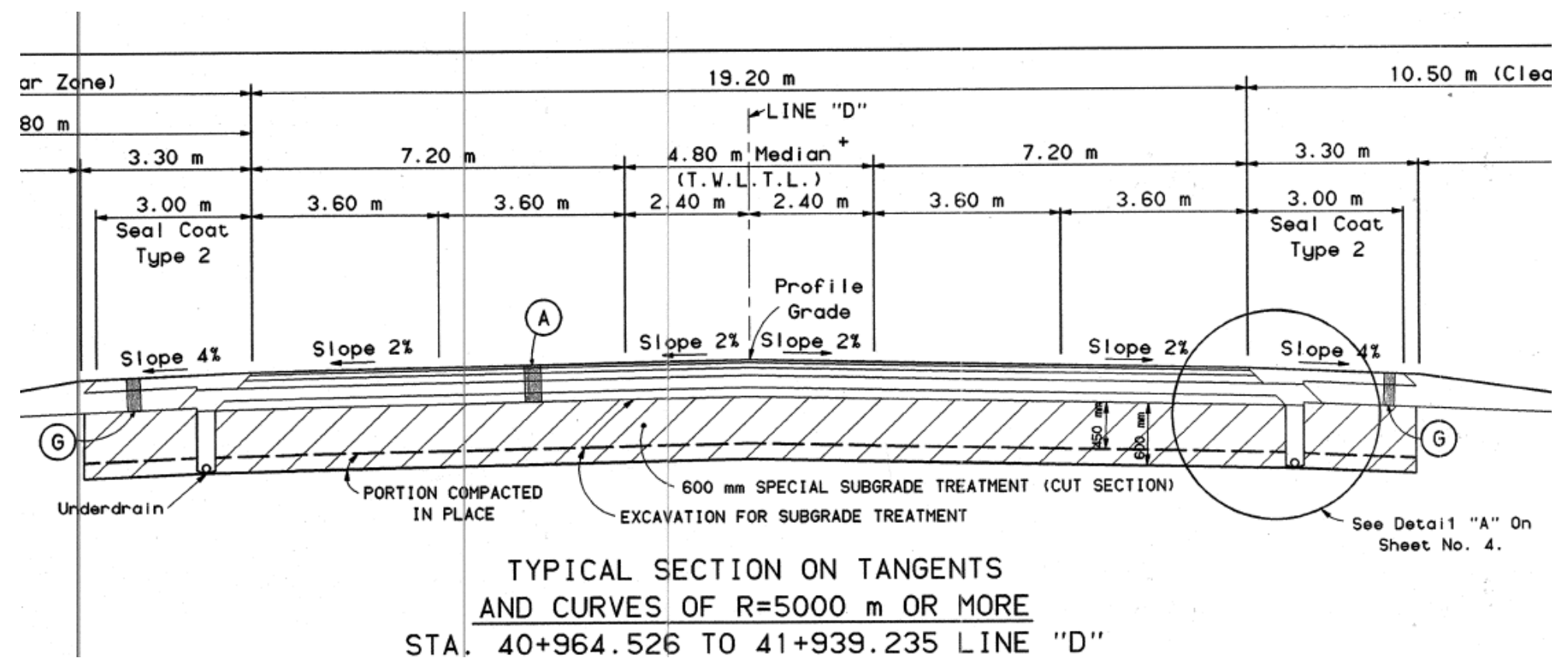

\section{LEGEND}

(A) $60 \mathrm{~kg} / \mathrm{m}^{2}$ QC/QA-HMA Surface $9.5 \mathrm{~mm}$, Mainline on

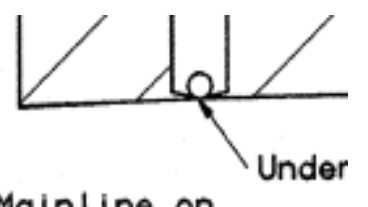

(A) $120 \mathrm{~kg} / \mathrm{m}^{2}$ QC/QA-HMA Intermediate $19 \mathrm{~mm}$, Mainline on $270 \mathrm{~kg} / \mathrm{m}^{2}$ QC/QA-HMA Base $25.0 \mathrm{~mm}$, Mainl ine on

$250 \mathrm{~kg} / \mathrm{m}^{2}$ HMA Base C25.0 mm, Mainl ine on

$210 \mathrm{~kg} / \mathrm{m}^{2}$ QC/QA-HMA Base $25.0 \mathrm{~mm}$, Mainl ine

Figure 3.10 Typical design pavement cross section at site (3) 


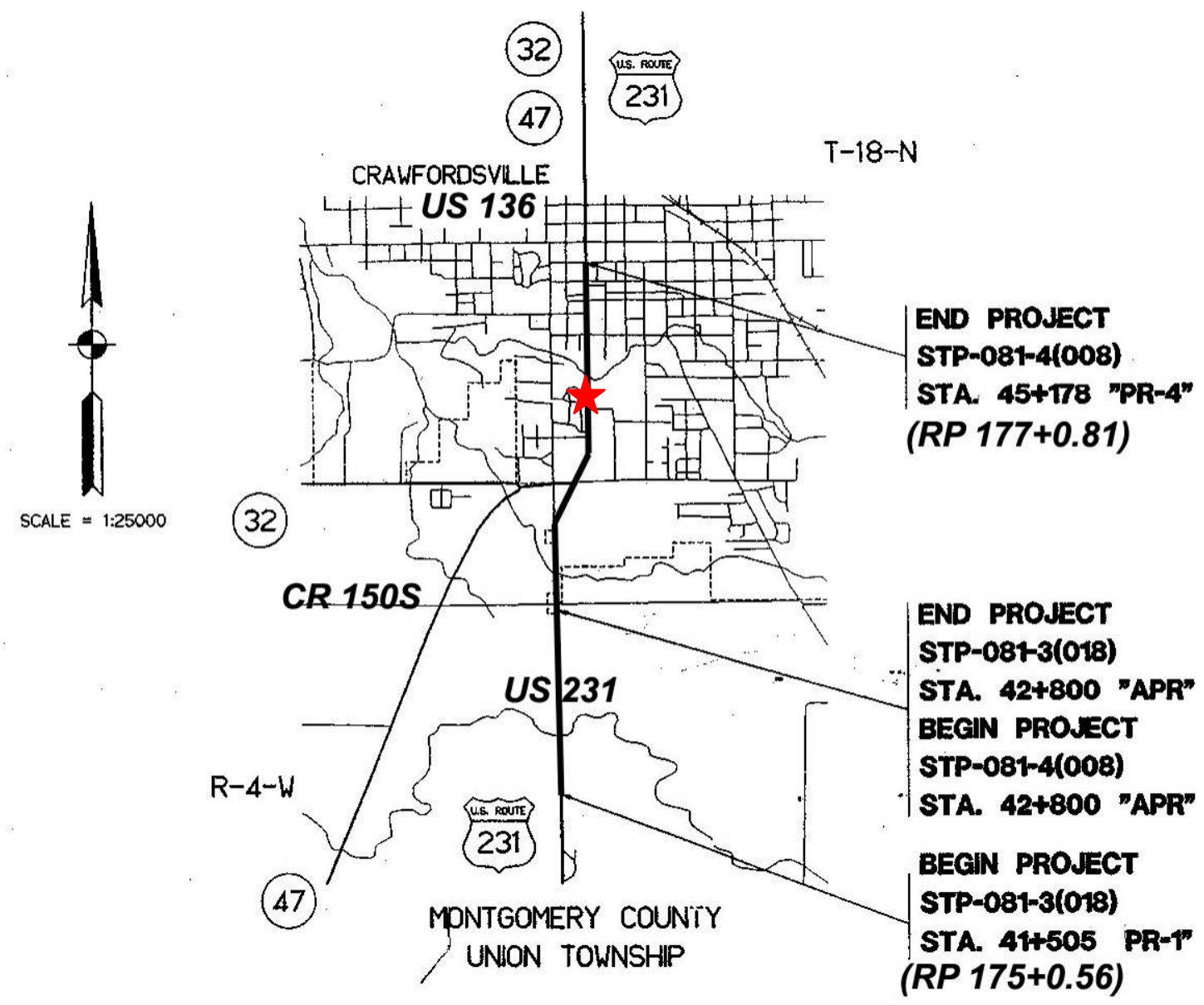

Figure 3.11 General location map of site (4) (modified from a design plan of the project).

The star indicates the location of the section where field tests were done. 


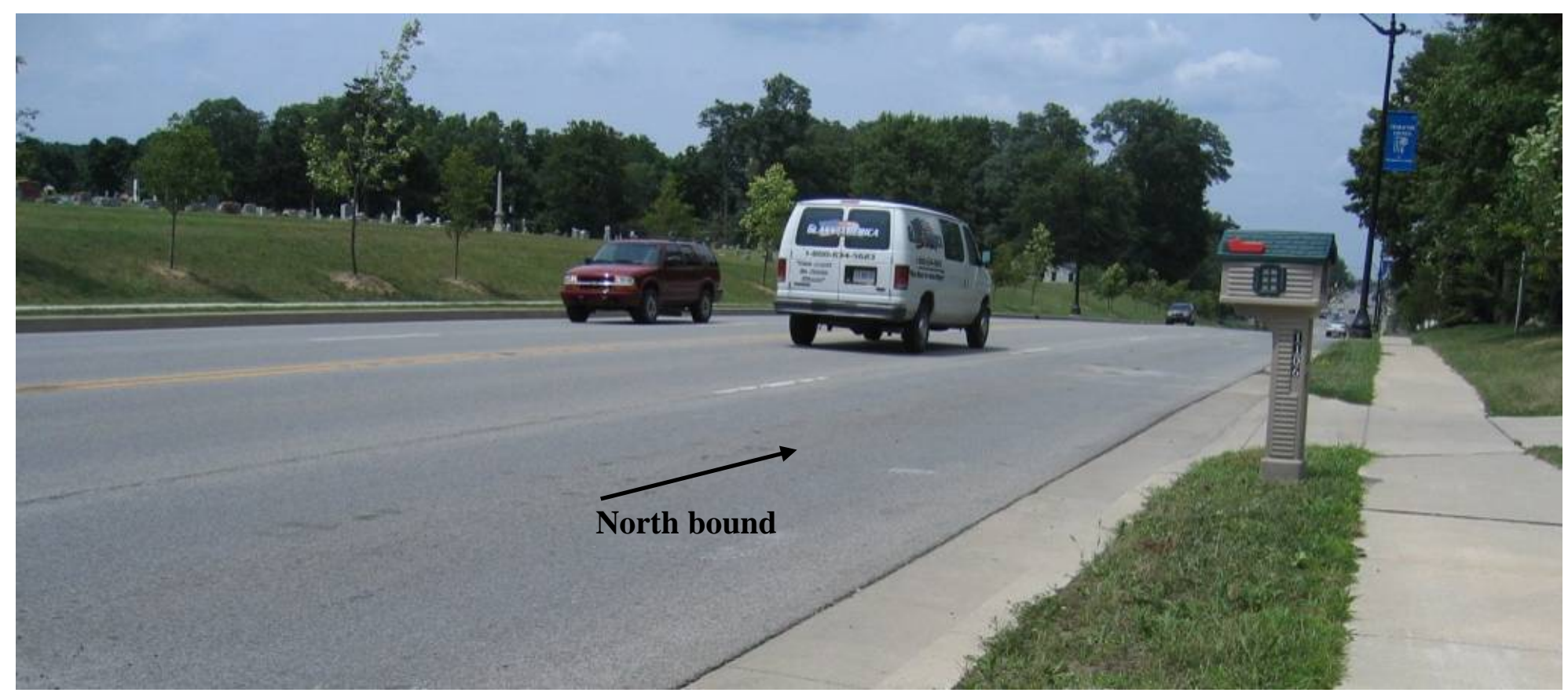

Figure 3.12 Overview of the section where field tests were done at site (4) 


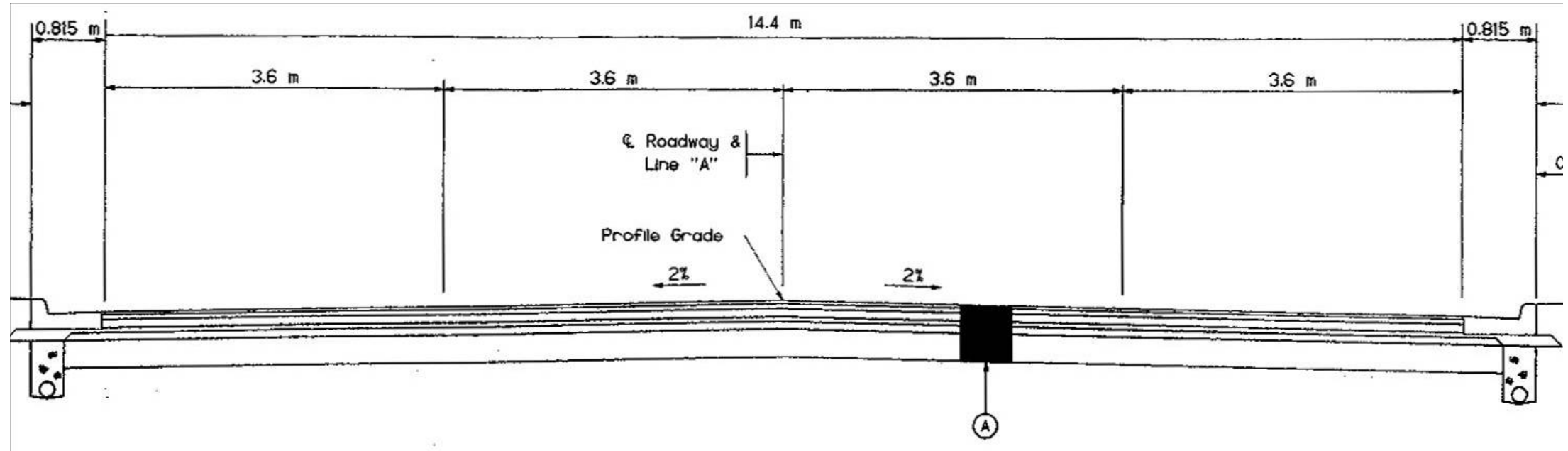

18sing Areas

TYPICAL TANGENT SECTION

Sta. $43+972$ to $44+378$ ' $A$ '

Sta. $44+448$ to $44+607$ "A"

(A) $75 \mathrm{~kg} / \mathrm{m}^{2}$ QC/QA PG Binder HMA Surface $9.5 \mathrm{~mm}$, Mainline, on

$165 \mathrm{~kg} / \mathrm{m}^{2}$ QC/QA PG Binder HMA Intermediate $19.0 \mathrm{~mm}$, Mainline, on

$240 \mathrm{~kg} / \mathrm{m}^{2}$ QC/QA PG Binder HMA Base $25.0 \mathrm{~mm}$, Mainline, on

$140 \mathrm{~kg} / \mathrm{m}^{2}$ HMA Intermediate C $19.0 \mathrm{~mm}$, Malnline, on

$210 \mathrm{~kg} / \mathrm{m}^{2}$ QC/QA PG Binder HMA Base $25.0 \mathrm{~mm}$, Malnilne, on

$400 \mathrm{~mm}$ Chemical Modification.

Figure 3.13 Typical design pavement cross section at site (4) 


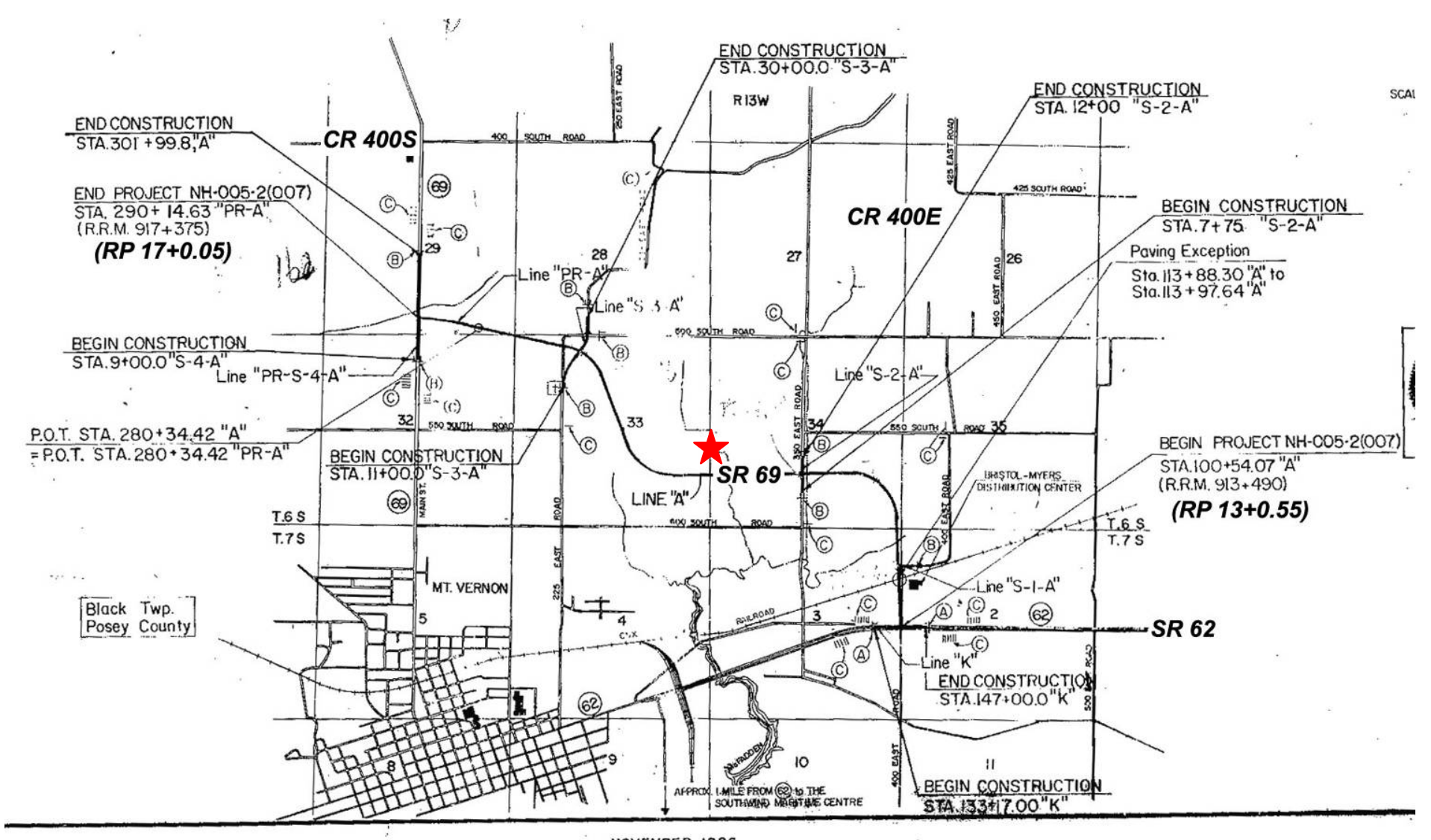

NOVEMBER 1986

Figure 3.14 General location map of site (5) (modified from a design plan of the project).

The star indicates the location of the section where field tests were done. 


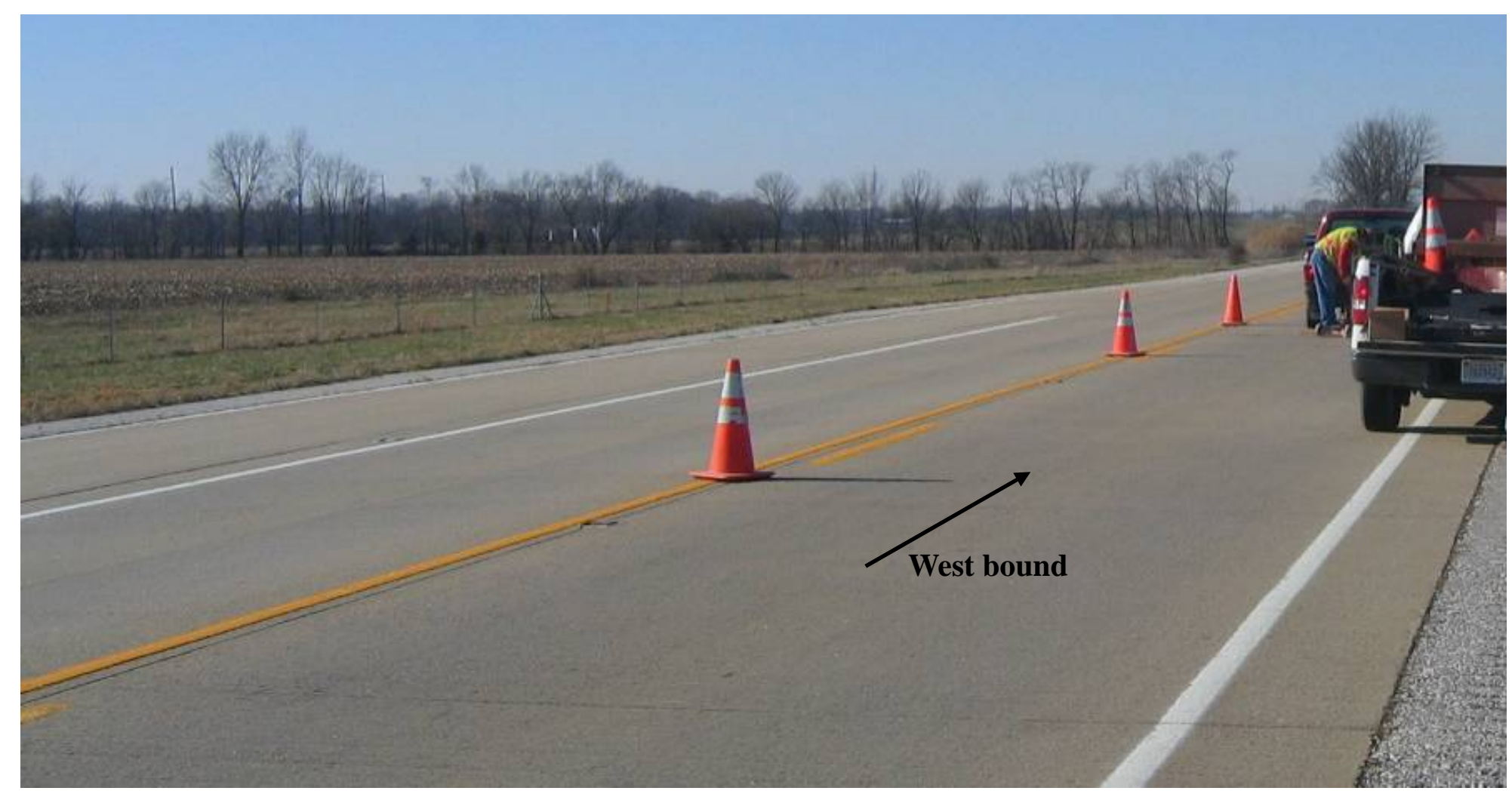

Figure 3.15 Overview of the section where field tests were done at site (5) 


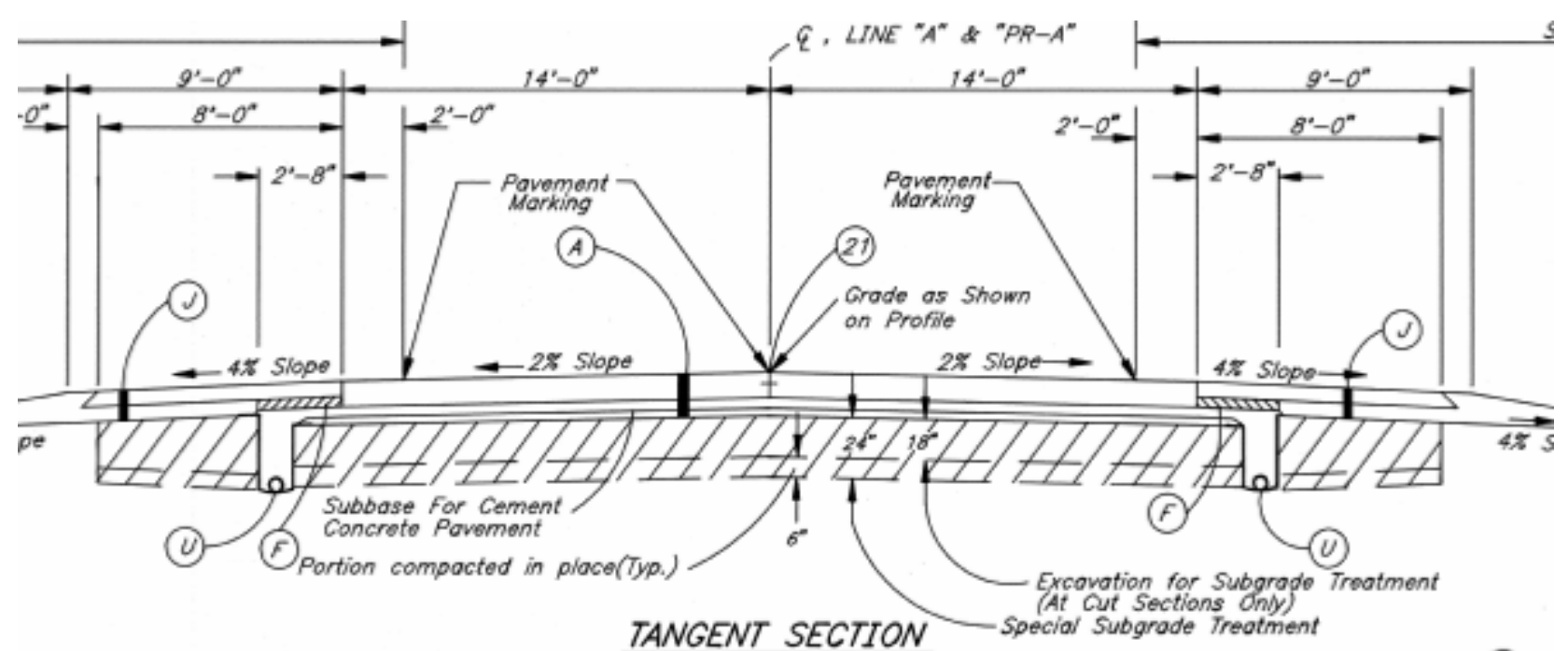

TANGENT SECTION Special Subgrade Treotment (4) Inch Plain Jointed Cement Concrete Pavement w/ $20^{\prime}-O^{*}$ Iype "D- ${ }^{*}$
Contraction Jaint Spacing (perpendicular to centerline) on Subbase for Cement concrete Pavement (4 Inches 100x Crushed Caarse Aggregate size 18 on 3 Inches Compacted Aggregate for Base, "O", size No. 53.)

(J) $680 \mathrm{f} / \mathrm{syd}$ Bituminous Base 50, LV, w/Bituminous Corrugations on 6 Inches of Compacted Aggregote for Base, "O", Na. 5 .

(F) Bituminous Coated Aggregate Base No. 5.

(4) Underdrain (For Add") Details, See Typ, Section Sheet Na. $3 \& 5$ Misc. Std Sheet "MN)

(W) Compacted Aggregate For Base, "O", Na. 53

(21) Longitudinal Construction Joint (See Std. Sheet "A", Joints)

(26) Sodding

Figure 3.16 Typical design pavement cross section at site (5) 


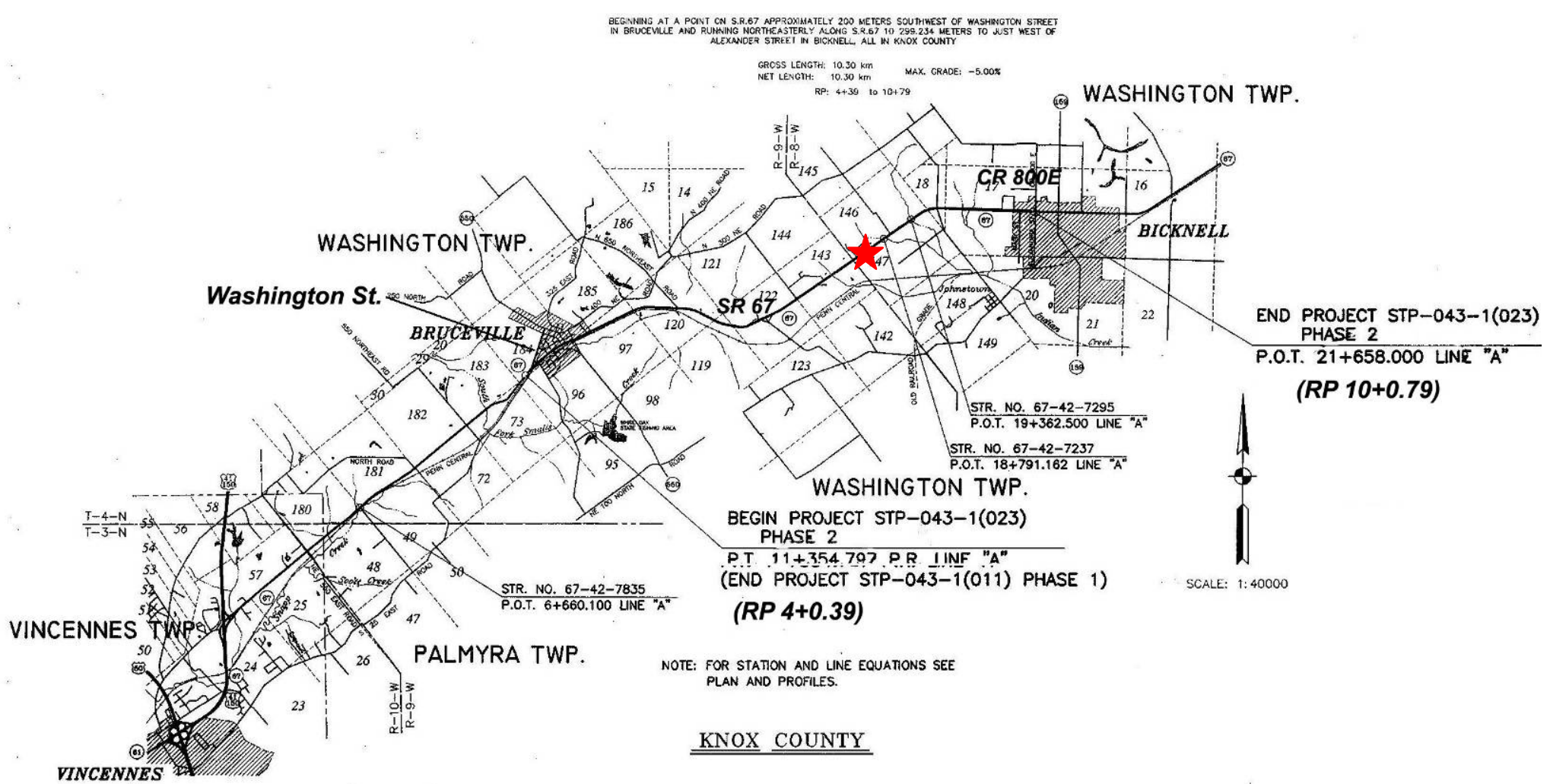

Figure 3.17 General location map of site (6) (modified from a design plan of the project).

The star indicates the location of the section where field tests were done. 


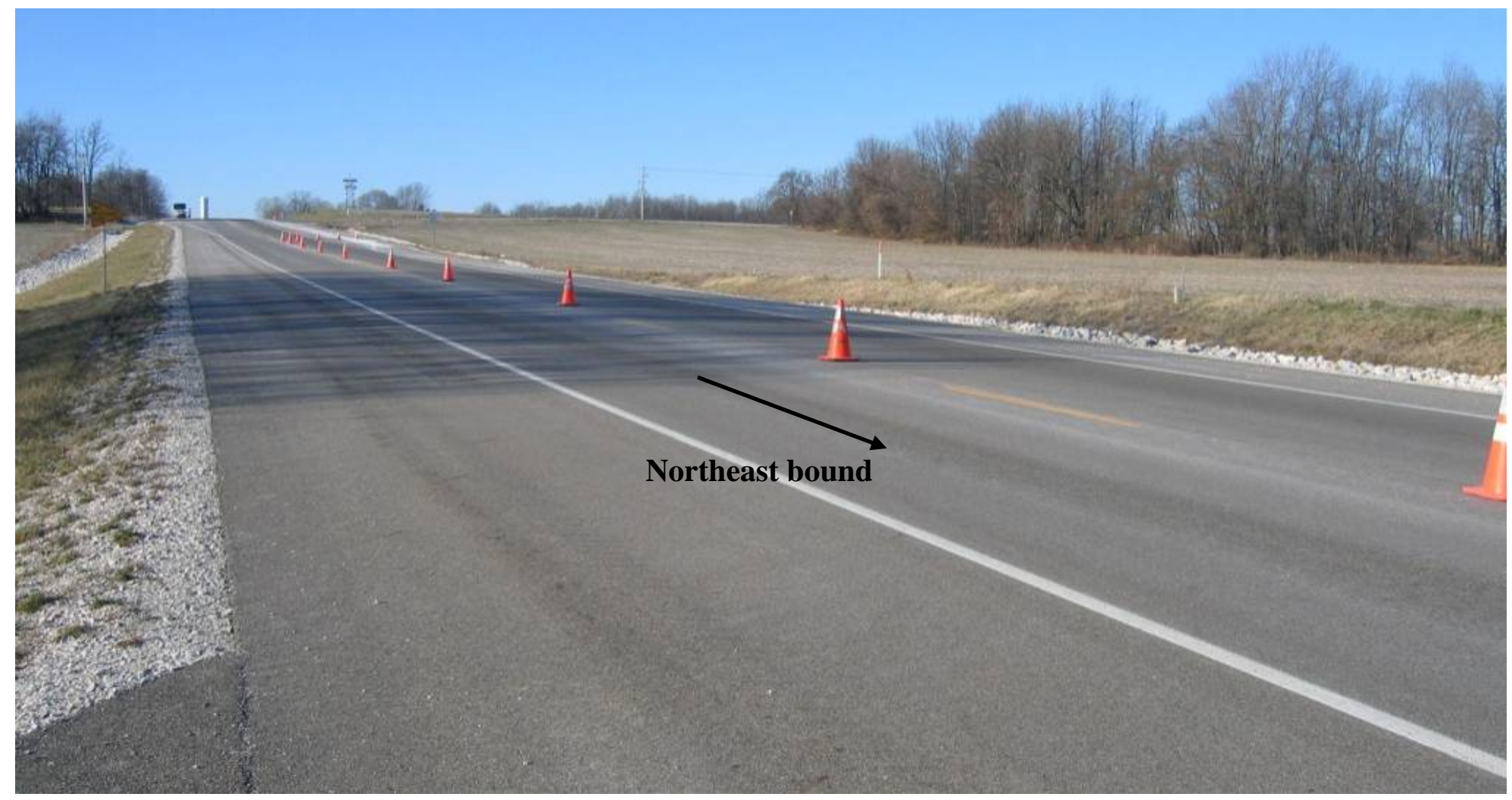

Figure 3.18 Overview of the section where field tests were done at site (6) 


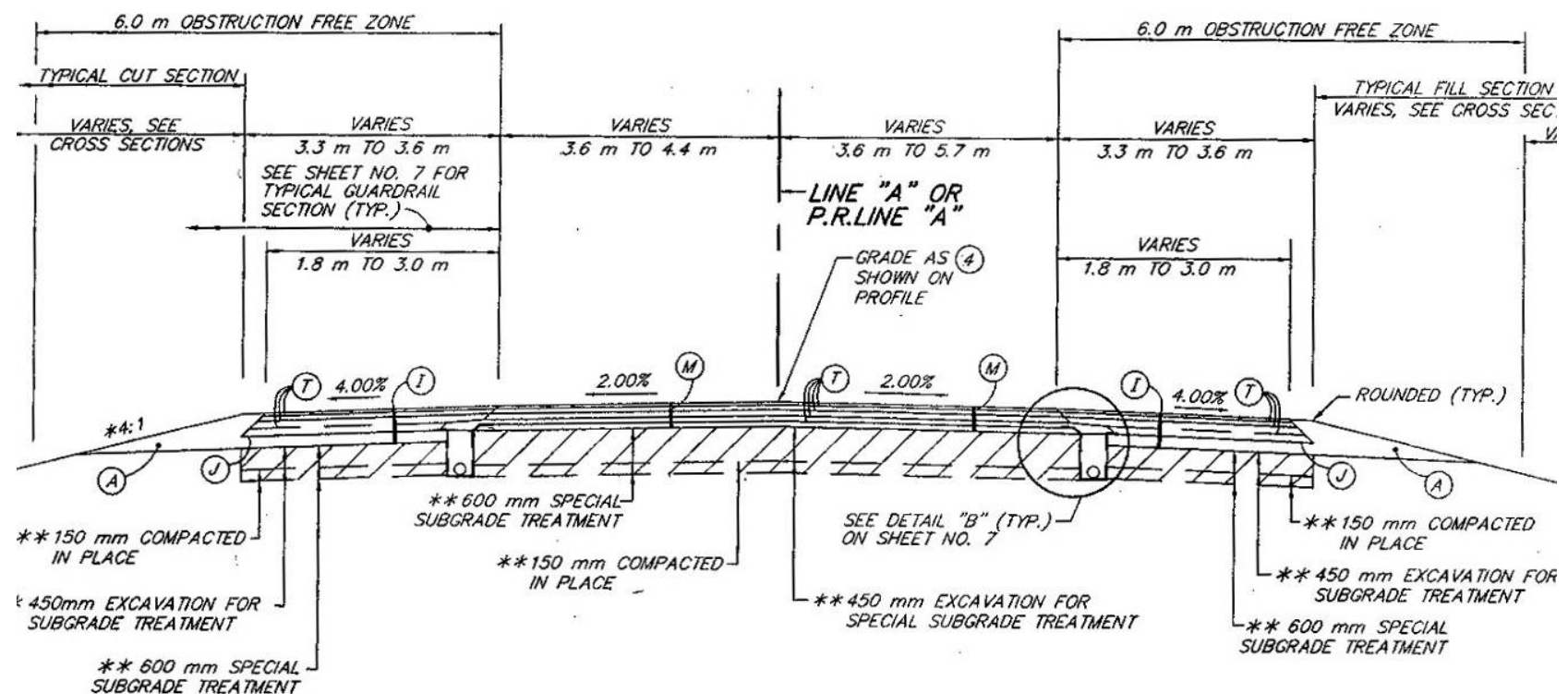

\section{LEGEND}

(A) COMPACTED AGGREGATE FOR BASE, O. SIZE NO. 53

(I) $90 \mathrm{~kg} / \mathrm{m}^{2}$ HIMA SURFACE $9.5 \mathrm{~mm}$ MAINLINE WTH 1900

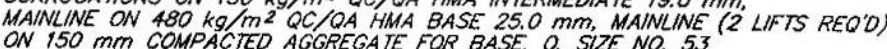

(D) ASPHALT MATERIAL FOR PRIME COAT

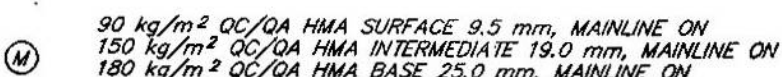
$180 \mathrm{~kg} / \mathrm{m}^{2}$ QC $/ Q A$ HMA BASE $25.0 \mathrm{~mm}$, MAINLINE ON $165 \mathrm{~kg} / \mathrm{m}^{2}$ HNAA BASE C25.0 $\mathrm{mm}$, MAINLINE ON

(T) ASPHALT MATERIAL FOR TACK COAT

Figure 3.19 Typical design pavement cross section at site (6) 


\section{CHAPTER 4. TESTS METHODOLOGY}

At all the six testing sites selected, the field tests: SPT, DCPT, and FWD were performed to evaluate in-situ properties of the lime-treated subgrade. In addition, laboratory tests, using in-situ soil samples collected after the SPT, were done to obtain the soil index properties of the lime-treated subgrade and the lime content that remains in the soil. In this chapter, the methodology used for the field and laboratory tests is discussed.

\subsection{Field tests}

FWD tests were first conducted at all six sites. To complement the FWD test, subgrade soil sampling, SPT and DCPT were conducted also at each site. The geographical location of the field testing sections is presented in terms of RP (Reference Post) number of the road at each site (Table 4.1).

The FWD tests were performed by Division of Research of INDOT. The soil sampling, SPT, and DCPT were performed by Alt \& Witzig Engineering Company, and the tests were supervised by Chul Min Jung. Sites (5) and (6) were tested with SPT and DCPT on Dec. $5^{\text {th }}$ and $8^{\text {th }}, 2006$ respectively. Sites (3), (4), and (2) were tested consecutively on July $9^{\text {th }}, 10^{\text {th }}$, and $11^{\text {th }}, 2007$, respectively. Site (6) was finally tested on Aug. $8^{\text {th }}, 2007$. 
Table 4.1 Field testing section at each site

\begin{tabular}{|c|c|}
\hline Site & \multicolumn{1}{|c|}{ Field testing section } \\
\hline Site (1) & RP $4+0.78-4+0.86$ on West bound US 30 in Lake Co. \\
\hline Site (2) & RP $32+0.30-32+0.27$ on North bound SR 49 in Porter Co. \\
\hline Site (3) & RP $146+0.00-146+0.12$ on Northeast bound SR 67 in Delaware Co. \\
\hline Site (4) & RP $177+0.20-177+0.32$ on North bound US 231 in Montgomery Co. \\
\hline Site (5) & RP $14+0.70-14+0.82$ on West bound SR 69 in Posey Co. \\
\hline Site (6) & RP $8+0.00-8+0.12$ on Northeast bound SR 67 in Knox Co. \\
\hline
\end{tabular}

\subsubsection{Borings}

Ten borings were performed at sites (2) to (6) at an interval of approximately $66 \mathrm{ft}$ $(20 \mathrm{~m})$ where DCP tests were done. Another ten borings were performed near the previous borings for SPT and soil sampling. In other words, different boreholes were used for SPT and DCPT. The distance between a SPT borehole and the nearest DCPT borehole was about 2 meters. At site (1), five borings for SPT and four for DCPT were conducted because of safety issues associated with the large traffic density of the road.

Sites (1) and (5) have PCC pavement, and so the PCC layer, which was about 11in thick at site (1) and about 10-in thick at site (5), was first drilled using a drilling machine with a diameter of 8 inches (Figure 4.1). The core of the PCC layer is shown in Figure 4.2. Afterwards the upper and lower base layers were bored (Figure 4.3). The upper base layer was 4-in thick at both sites, and consisted of $100 \%$ crushed coarse aggregate with size \#8 (Figure 4.4). The lower base layer was 6-in thick at site (1) and 3-in thick at site (5). The lower base layer consisted of compacted aggregate with size 
\#53 (Figure 4.5). The top of the subgrade was observed in the boreholes after boring the lower aggregate base layer (Figure 4.6).

Sites (2), (3), (4) and (6) have HMA pavement. The pavement, in detail, consists of a HMA surface layer, HMA intermediate, and HMA base layers. Crushed course aggregate or aggregate bases were not used at the sites. The total thickness of the HMA layer was about 19 inches at site (2), 15 inches at site (3), 14 inches at site (4), and 13 inches at site (6). The layer was not drilled but directly bored due to the low strength of the pavement (Figure 4.7). The top of the subgrade was observed in the borehole after boring the HMA layer (Figure 4.8). SPT tests were performed on the lime-treated subgrade soil as well as at the natural soil below the subgrade. Additional boring was done to reach these layers (Figure 4.9).

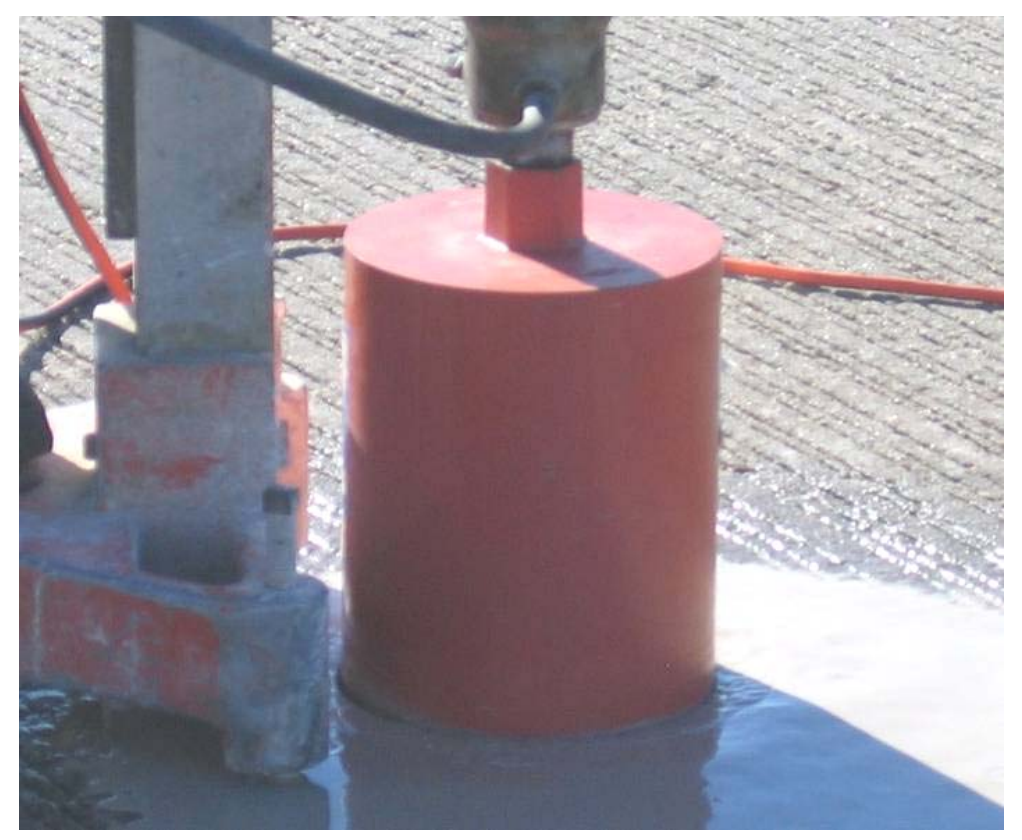

Figure 4.1 Drilling of a PCC layer 


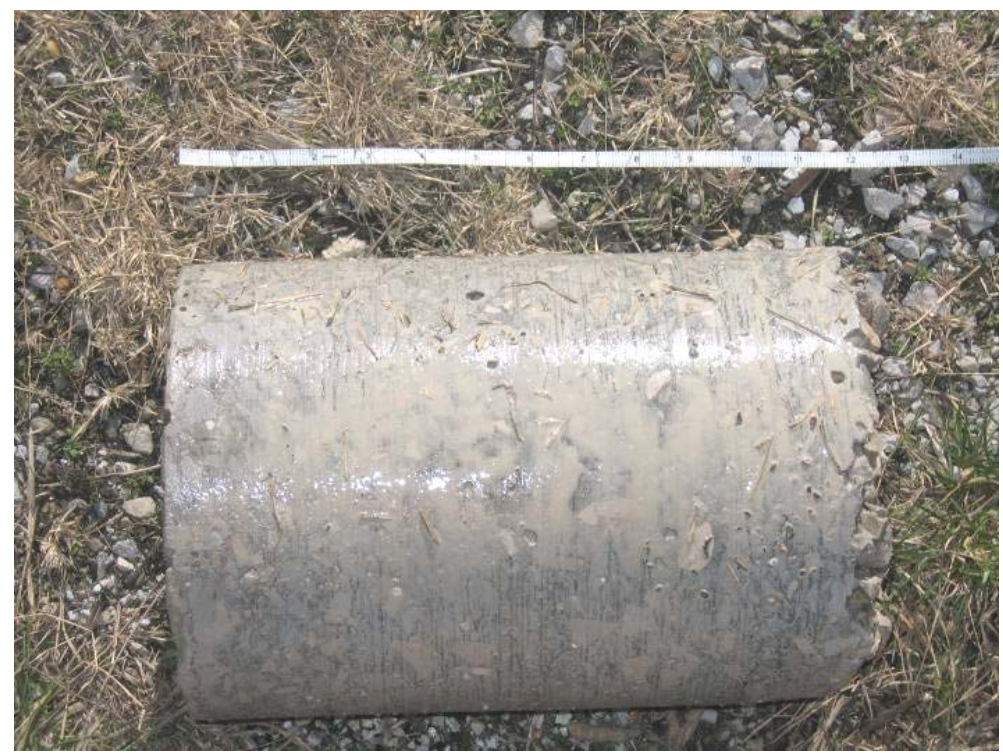

Figure 4.2 Core of a PCC layer at site (5) $(\mathrm{D}=8$ inches and $\mathrm{H}=10$ inches)

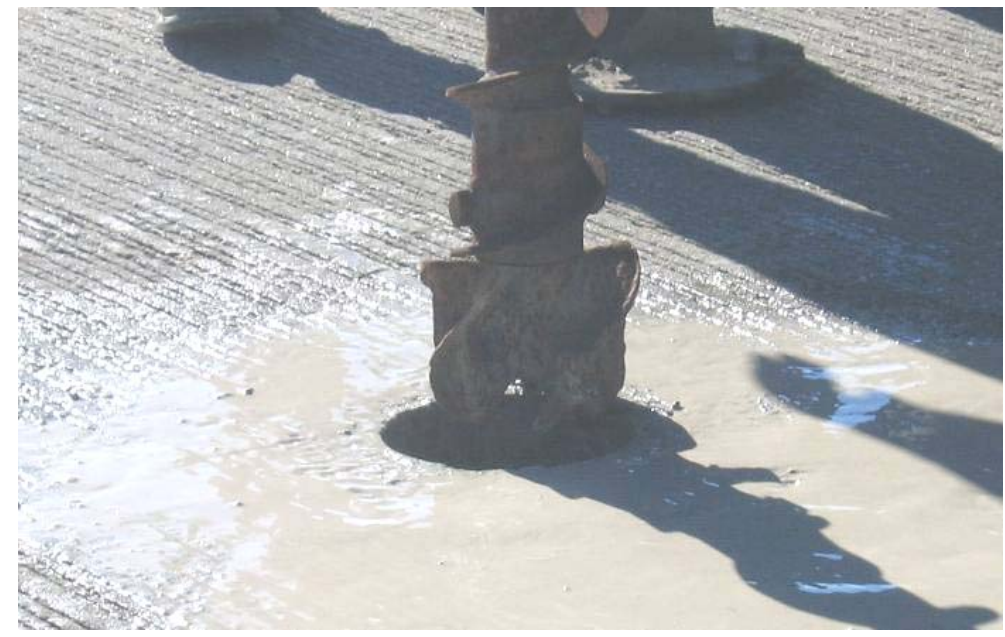

Figure 4.3 Boring of aggregate base layers at PCC pavement 


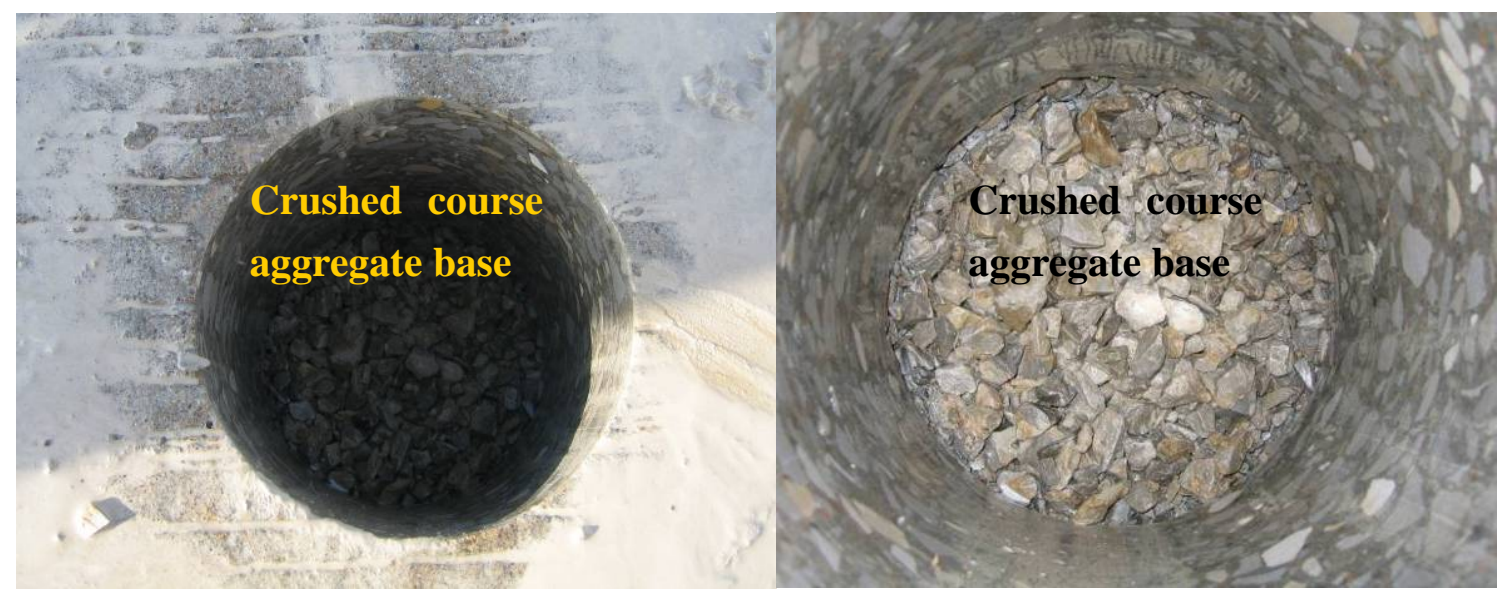

Figure 4.4 Top of upper crushed course aggregate base layer after drilling PCC layer

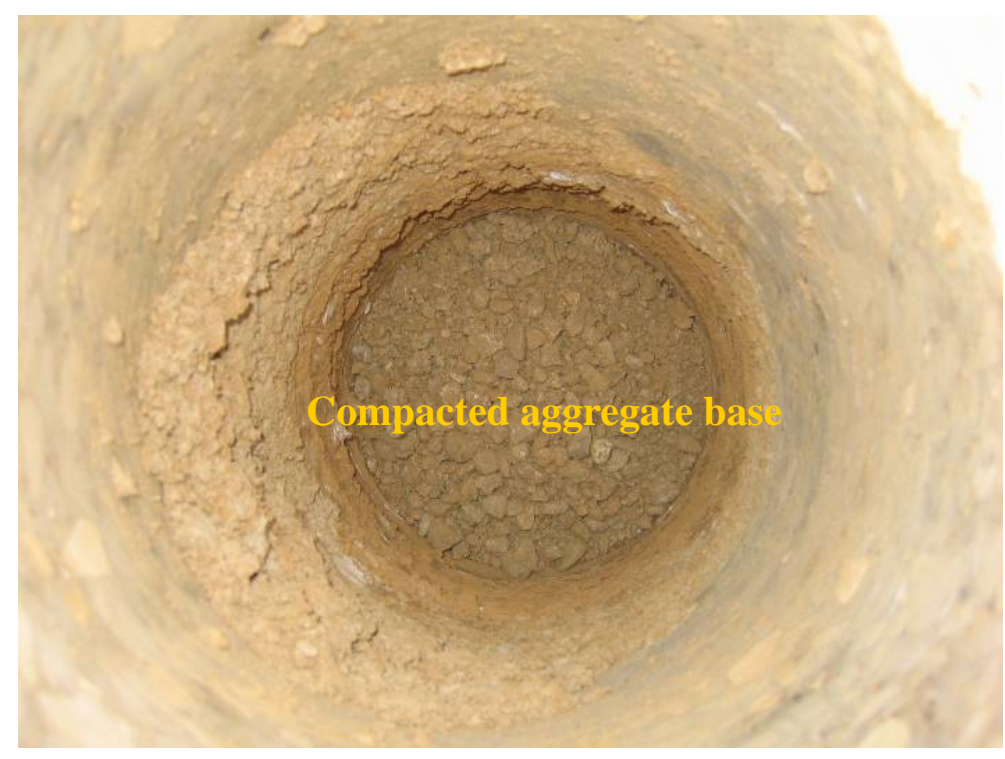

Figure 4.5 Top of lower aggregate base layer after boring the upper crushed course base layer 


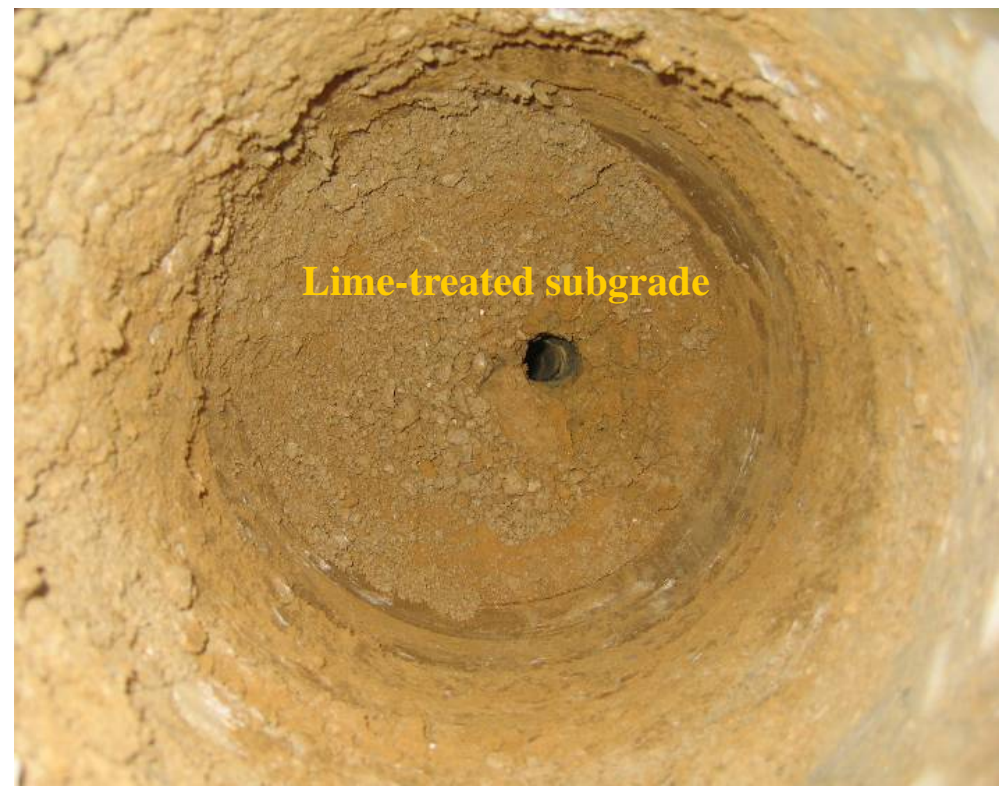

Figure 4.6 Top of lime-treated subgrade after boring the lower aggregate base layer

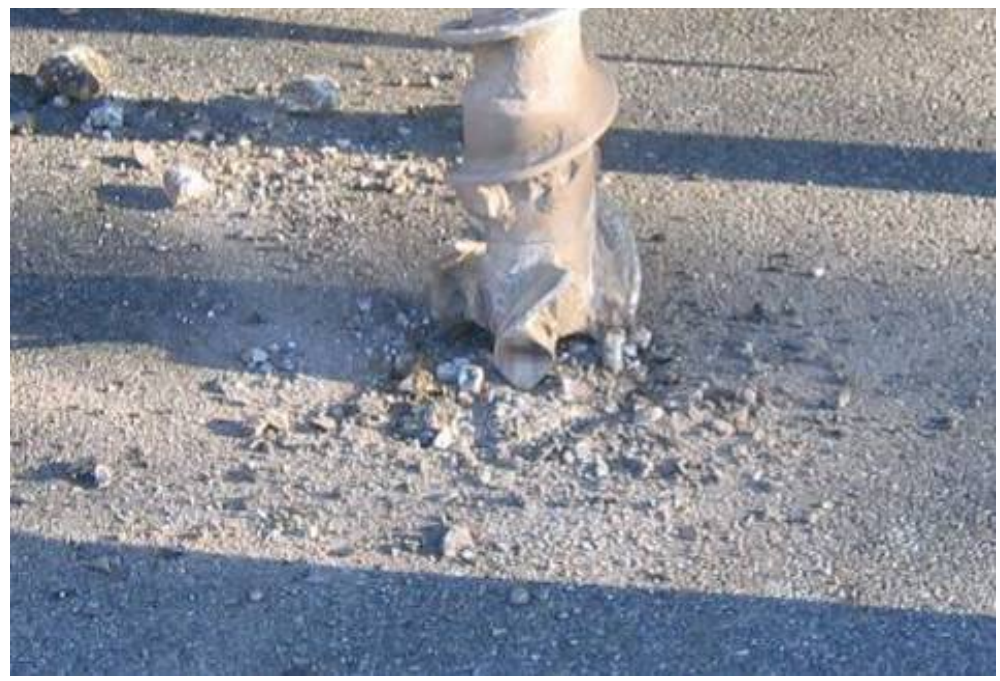

Figure 4.7 Boring a HMA layer 


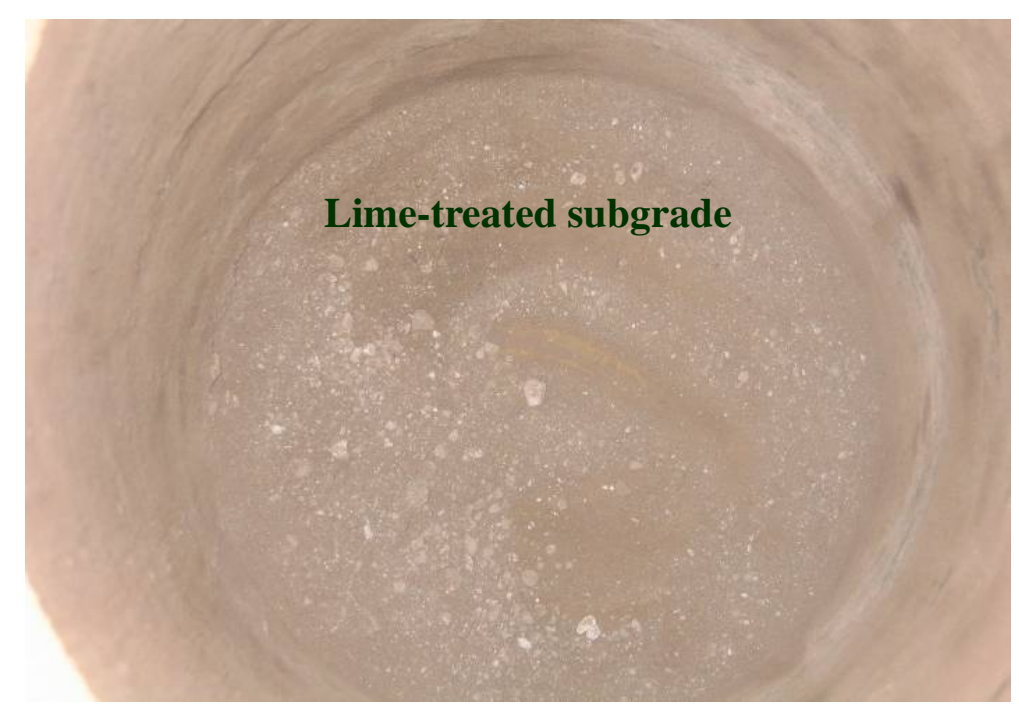

Figure 4.8 Top of lime-treated subgrade after boring HMA layers

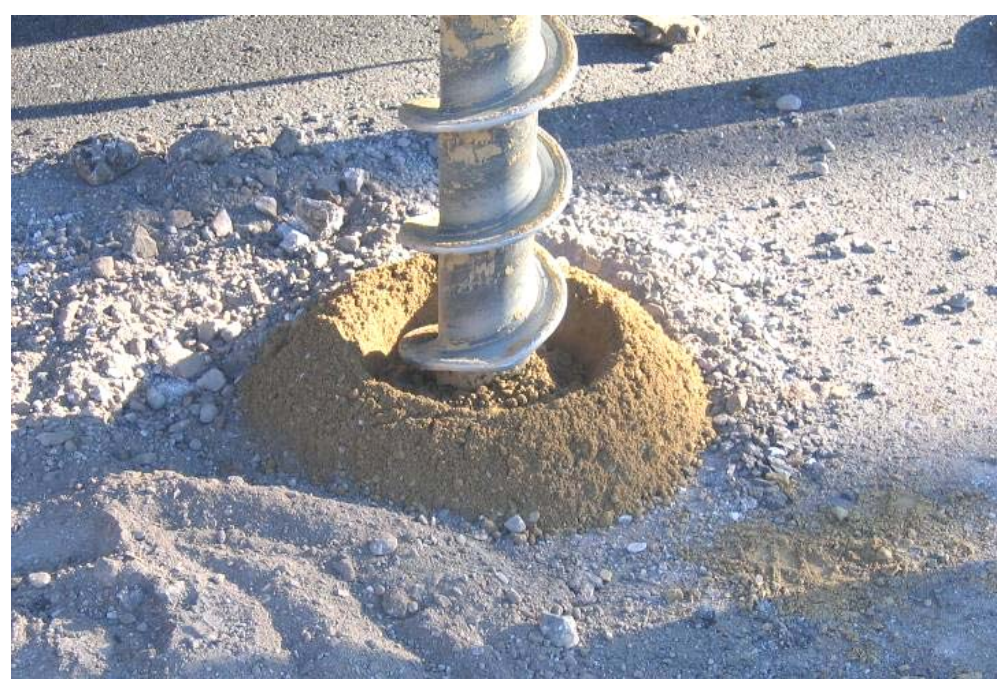

Figure 4.9 boring subgrade soil

\subsubsection{SPT and soil sampling}

The objectives of SPT were mostly to obtain samples for laboratory tests, and to a smaller extent to compare SPT results with DCP data. The SPT and soil samplings were conducted in ten boreholes at site (2) to (6) and in five boreholes at site (1). The interval between boreholes for the SPT was about $66 \mathrm{ft}$. Three SPT's were run in each borehole, 
and three soil samples were taken at intervals of $1.5 \mathrm{ft}$ from the top of the subgrade. Figure 4.10 shows placement of the standard spoon sampler into a borehole. A disturbed soil sample was obtained after the SPT (Figure 4.11).

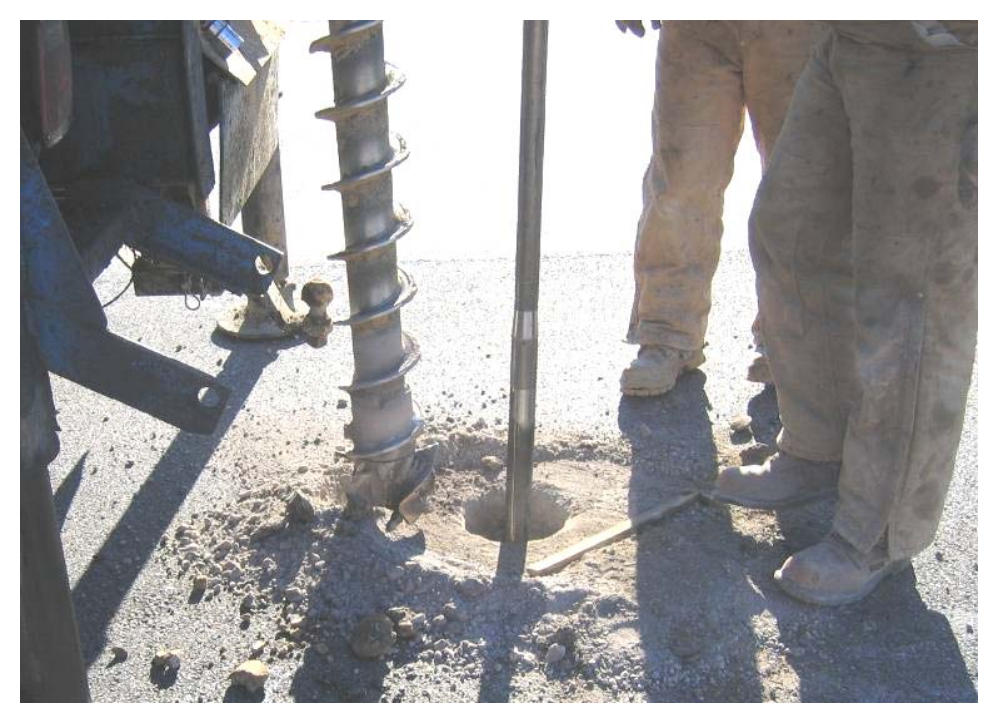

Figure 4.10 Installation of a standard spoon sampler into a borehole

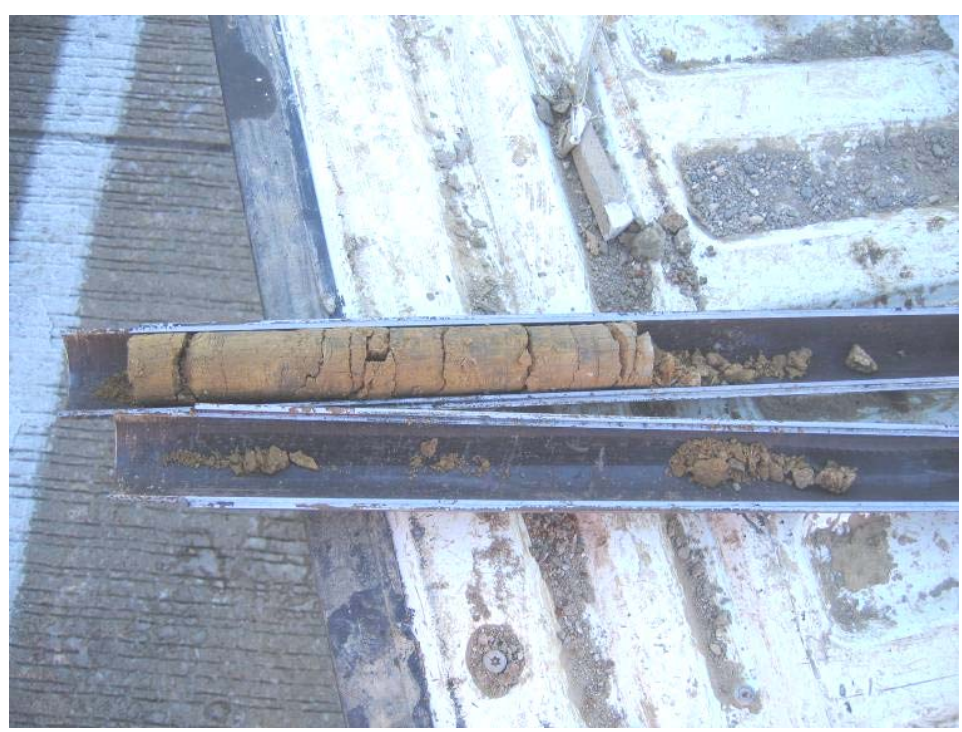

Figure 4.11 Subgrade soil sampling 


\subsubsection{DCP test}

DCP tests were performed to complement FWD tests, as well as to evaluate directly the stiffness of the lime-treated subgrades. Ten DCP tests were conducted at about $60 \mathrm{ft}$ intervals at sites (2) to (6), and four DCP tests were conducted with the same spacing at site (1). DCP blow counts were recorded for every 2-inch penetration of the cone into the subgrade. In each borehole, the DCP tests started at the top of the subgrade, and terminated after a penetration in the soil of about 30 inches (Figure 4.12). The cone penetrated through the theoretical 16 in thickness of the lime-treated subgrade soil layer, and continued over an additional depth of 14 inches into the natural (untreated) subgrade soil.

The K-100 Deluxe Kit model, manufactured by Kessler Soils Engineering Inc., was used for the DCP tests (Figure 4.13). A steel point (with flats for tightening) was attached to one end of the DCP and was driven into the subgrade by dropping an 8-kg stainless steel sliding hammer (Figure 4.14). The angle of the point was 60 degrees, and the diameter of the base of the point was 0.790 inches. 


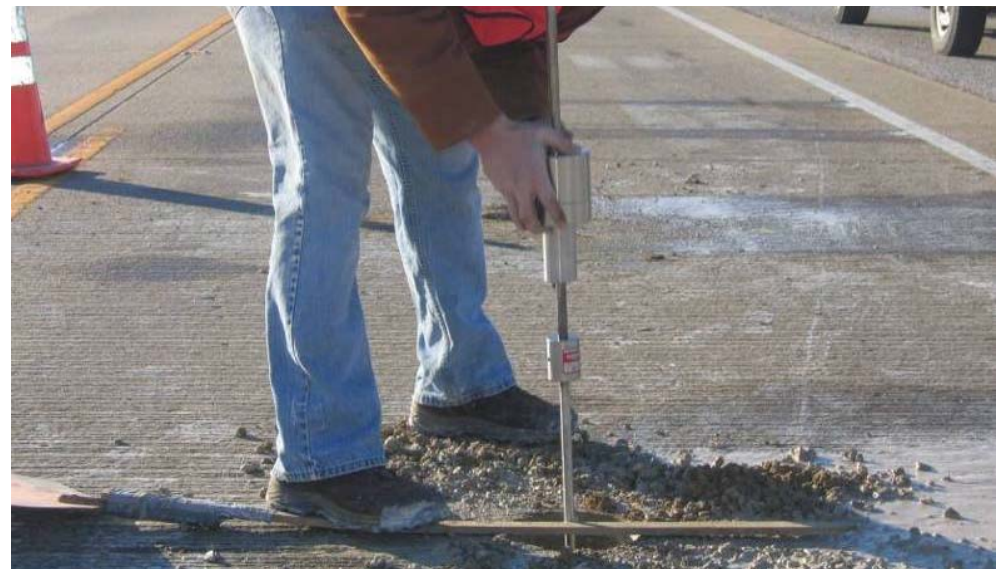

Figure 4.12 DCP testing

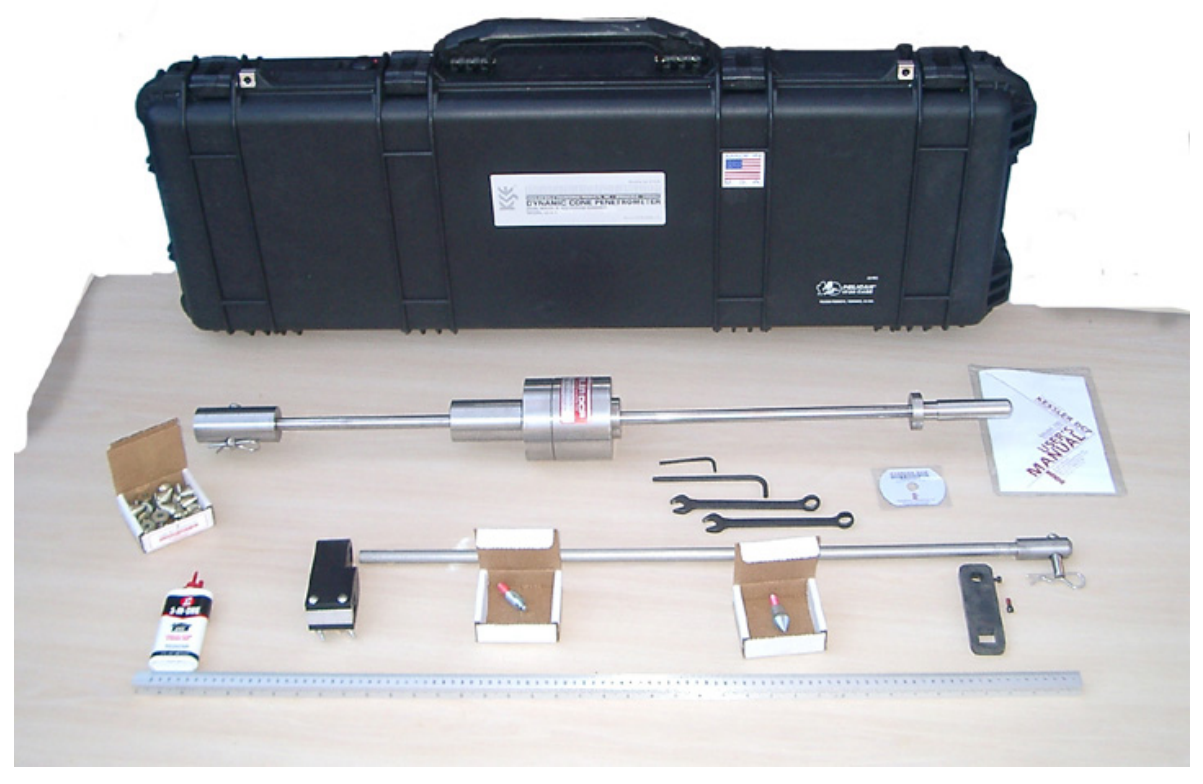

Figure 4.13 DCP kit used 


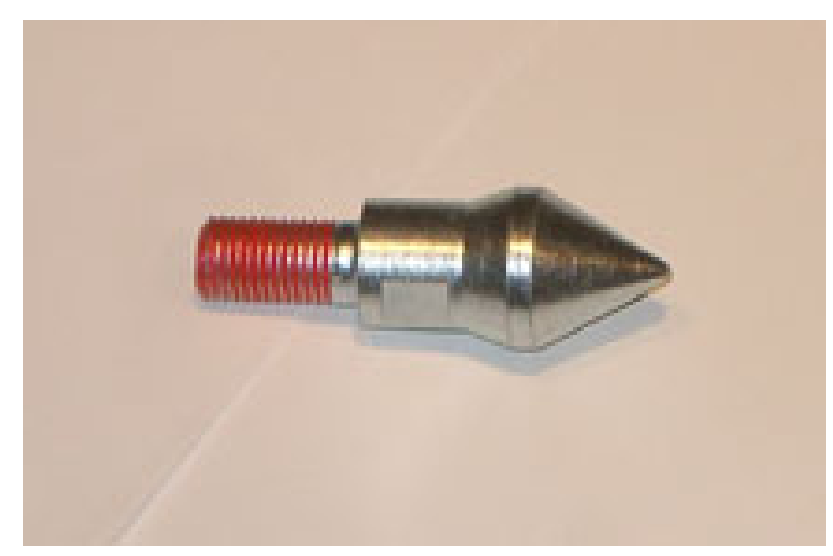

Figure 4.14 Point cone used

\subsubsection{FWD test}

FWD tests were conducted to obtain the in-situ $\mathrm{M}_{\mathrm{R}}$ of the lime-treated subgrade and of the original, untreated subgrade. The Dynatest model 8000 was used for FWD tests (Figure 4.15). The data processing code, ELMOD5, developed by Dynatest, was used for back-calculation of FWD deflection data.

FWD tests were conducted at about 30 - $\mathrm{ft}$ intervals on a $600 \mathrm{ft}$ length segment at each site. A pulse force was generated from a loading plate with the shape of a half-sine wave and a peak force of approximately $8,000 \mathrm{lb}$. The radius of the loading plate was 5.9 inches. Nine geophone sensors were used to obtain the deflection basin curve of the pavement (Figure 4.16). The sensors were positioned such that they were aligned with the center of the loading plate (Figure 4.17 and Table 4.2). 


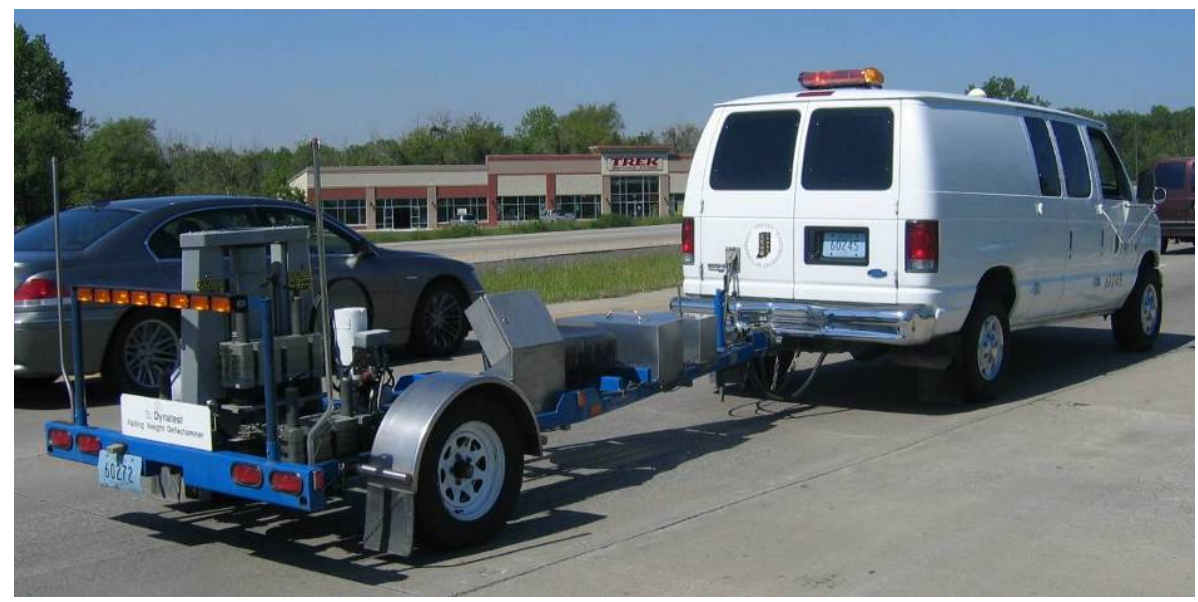

Figure 4.15 FWD system used, Dynatest model 8000

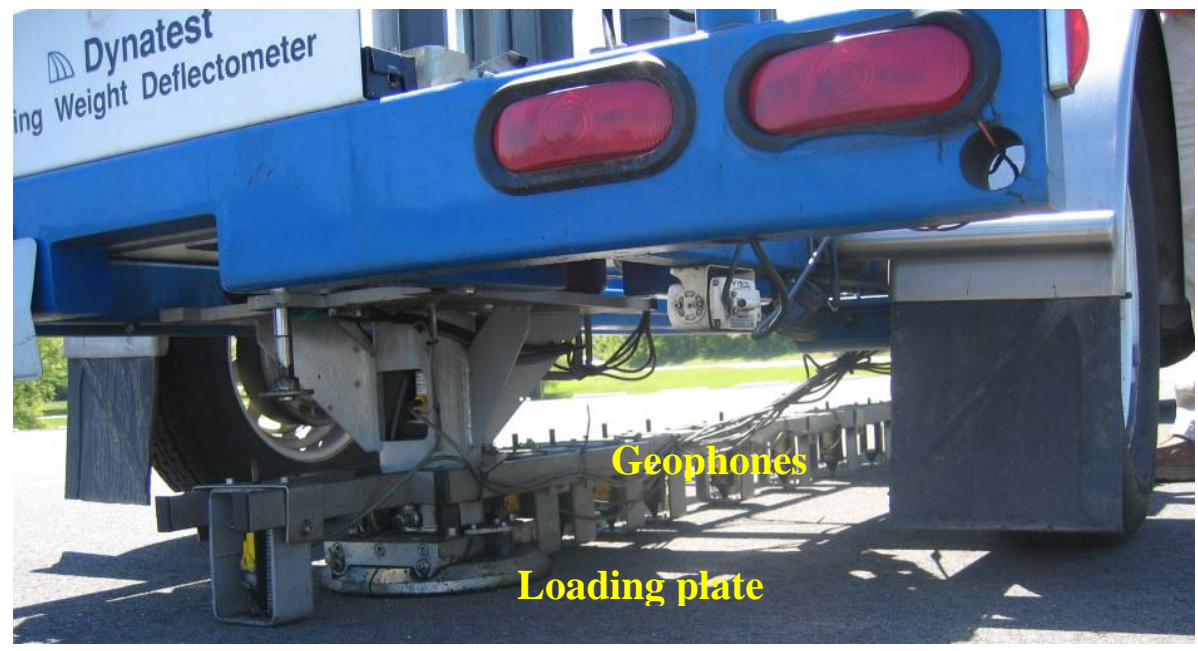

Figure 4.16 Arrangement of loading plate and geophones

\section{Loading plate}

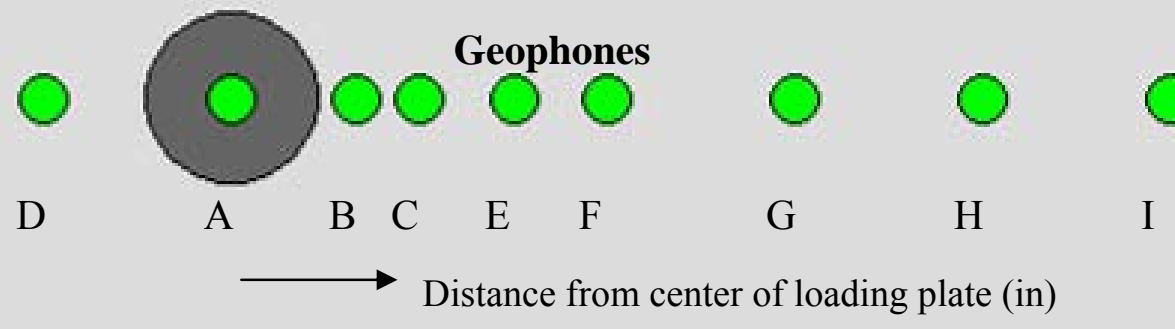

Figure 4.17 Geophone setup 
Table 4.2 Position of geophones

\begin{tabular}{|c|c|c|c|c|c|c|c|c|c|}
\hline Geophone & A & B & C & D & E & F & G & H & I \\
\hline $\begin{array}{c}\text { Distance from } \\
\text { center of loading } \\
\text { plate (in.) }\end{array}$ & 0 & 8 & 12 & -12 & 18 & 24 & 36 & 48 & 60 \\
\hline
\end{tabular}

\subsection{Laboratory tests}

FWD and DCP test results provide information on the strength and stiffness of the lime-treated subgrade, but not on the type of soil. The index properties of the lime-treated subgrade are evaluated from laboratory tests using the soil samples collected in the field. XRD (X-Ray Diffraction) and TGA (Thermogravimetric Analysis) tests were conducted to investigate mineralogy and chemical properties of the lime-treated subgrade and of the natural soil underneath.

\subsubsection{Soil characterization tests}

Laboratory tests were performed on both the lime-treated and untreated subgrade soils to evaluate the following soil index properties: natural water content, particle-size distribution, Atterberg limits, $\mathrm{pH}, \mathrm{XRD}$, and TGA.

\section{(1) Natural water content}

To investigate the horizontal uniformity of the subgrade, the natural water content was determined from all boreholes in each site. The water content of a soil sample was measured in accordance with ASTM D 2216-05. The soil sample was 
weighed and was oven-dried at $105^{\circ} \mathrm{C}$ for 24 hours. The dried sample was then reweighed. The difference in weight was divided by the weight of the dry soil, which provides the water content.

\section{(2) Particle size distribution}

To investigate the change in particle-size distribution of the subgrade soils due to lime treatment from their original (untreated) state and to classify the soils, wet sieving tests were conducted following ASTM D 422-63. Each soil sample was sieved through a series of sieves with progressively smaller screen sizes to determine the soil's particle size distribution.

\section{(3) Atterberg limits}

To investigate the change in plasticity of the subgrade soil from its original (untreated) state due to lime treatment, and to classify the soil, the plastic limit (PL) and the liquid limit (LL) were determined. This was done following ASTM D 4318. The soil that passes through a No. 40 sieve was used for the determination of the PL and LL.

The soil is classified based on its particle size distribution and Atterberg limits, following the Unified Soil Classification System (USCS) or the AASHTO classification.

(4) $p H$

The $\mathrm{pH}$ of the soil was determined at all boreholes in each site to evaluate 
whether there is any degradation or migration of lime with time. The $\mathrm{pH}$ was measured in accordance with ASTM D 4972-01. Ten grams of air-dried soil that passed through a No. 10 sieve was mixed with $10 \mathrm{~mL}$ of water. One hour after mixing, the $\mathrm{pH}$ of the soil sample was measured using a calibrated $\mathrm{pH}$ meter.

\subsubsection{XRD test}

X-ray diffraction (XRD) tests were performed to identify the minerals present in a soil sample. The focus of the tests was on the identification of the minerals associated with the chemical reactions of the soil with lime. The tests were conducted on the fraction of the soil that passes No 200 sieve. A SIMENS D500, an X-ray diffractometer, was used for this study.

X-ray diffraction is a method to investigate the organization of solids at the atomic scale. Soil minerals consist of three-dimensional arrays of atoms that are arranged in regularly spaced planes, which are probed by the X-rays. X-ray diffraction in minerals occurs in accordance with Bragg's law:

$$
n \lambda=2 d \sin \theta
$$

Where $\lambda$ is the wavelength of the X-ray, $d$ is the interplanar spacing, $\theta$ is the critical angle for constructive interference of scattered rays, and $\mathrm{n}$ is an integer. Each mineral has a peculiar distance between planes of atoms, so it has a distinctive diffraction angle, which can be identified with the tests.

From the XRD test results, the presence of calcium oxide $(\mathrm{CaO})$, calcium 
hydroxide $\left(\mathrm{Ca}(\mathrm{OH})_{2}\right)$, or calcium carbonate $\left(\mathrm{Ca}(\mathrm{CO})_{3}\right)$ in a soil sample can be identified. Note that with this test the minerals are identified, but the test cannot provide a quantitative estimate of the mineral in the sample.

\subsubsection{Thermogravimetric analysis}

TGA (Thermogravimetric Analysis) tests were performed to the in-situ soil samples to determine the content of lime that remains in the soil and to evaluate if there is any degradation or migration of lime with time.

TGA was done with soil samples collected from three different borehole locations at each site. The TGA test was conducted to both the lime-treated subgrade and to the underlying untreated natural soil. A soil sample that was collected at a location 8-in deep below the top of a subgrade was used as representative of the lime-treated subgrade. A soil sample that was collected at a location 30-in deep below the top of a subgrade was used as representative of the untreated natural soil. In addition, the lime content was vertically measured at one borehole at each site using the soil samples collected at five different depths, namely $0,4,8,12$, and 16 inches deep below the top of a lime-treated subgrade.

The lime content of a lime-treated subgrade was determined comparing the TGA result of the lime-treated subgrade soil with that of the underlying (untreated) soil. It has to be mentioned that the results include the total lime content of the soil, but cannot distinguish the reactive from the non-reactive portion of the lime used in the original treatment.

A TGA-2050 (manufactured by TA Instruments), thermogravimetric analyzer, was 
used for this study. Ten mg of soil were placed in the furnace of the analyzer and then heated in a nitrogen gas at a rate of $10^{\circ} \mathrm{C} / \mathrm{min}$ from room temperature to $1000{ }^{\circ} \mathrm{C}$. The weight loss curve of the soil with temperature is obtained from the test. Different minerals decompose at well defined temperatures. At $550{ }^{\circ} \mathrm{C}$, calcium hydroxide $\left(\mathrm{Ca}(\mathrm{OH})_{2}\right)$, a hydrated form of lime, decomposes into calcium oxide $(\mathrm{CaO})$ and water $\left(\mathrm{H}_{2} \mathrm{O}\right)$. At $650 \sim 800{ }^{\circ} \mathrm{C}$, calcium carbonate $\left(\mathrm{Ca}(\mathrm{CO})_{3}\right)$, which may be created by a carbonation of $\mathrm{Ca}(\mathrm{OH})_{2}$ in the lime-treated subgrade soil, decomposes into calcium oxide $(\mathrm{CaO})$ and carbon dioxide $\left(\mathrm{CO}_{2}\right)$. 


\section{CHAPTER 5. TEST RESULTS AND DISCUSSION}

The results of the field and laboratory tests that were performed at each testing site are presented and discussed in this chapter. From the test results, the material and mechanical properties (soil characterization and stiffness and/or strength properties) of the lime-treated subgrade soil layer are compared with those of the natural (untreated) soil layer. With the results of the comparison, the long-term performance of the limetreated subgrade soil is evaluated for each site. In addition leaching is assessed from the lime content data measured from the lime-treated and natural soil samples.

\subsection{Site (1)}

\section{Soil characterization properties}

Figure 5.1 shows the natural water content and soil index properties of the limetreated subgrade and natural (untreated) soil, which are determined from laboratory tests using the samples collected at different borehole locations at site (1). The water content of the lime-treated and untreated soils is determined using samples taken approximately at 8-in and 30-in depths, respectively, below the top of the subgrade. The water content of the lime-treated subgrade ranges from $22 \%$ to $25 \%$ while the natural soil below the subgrade ranges from $15 \%$ to $21 \%$. The water contents of the lime-treated subgrade soil layer are to some extent higher than those of the natural subgrade soil layer. 


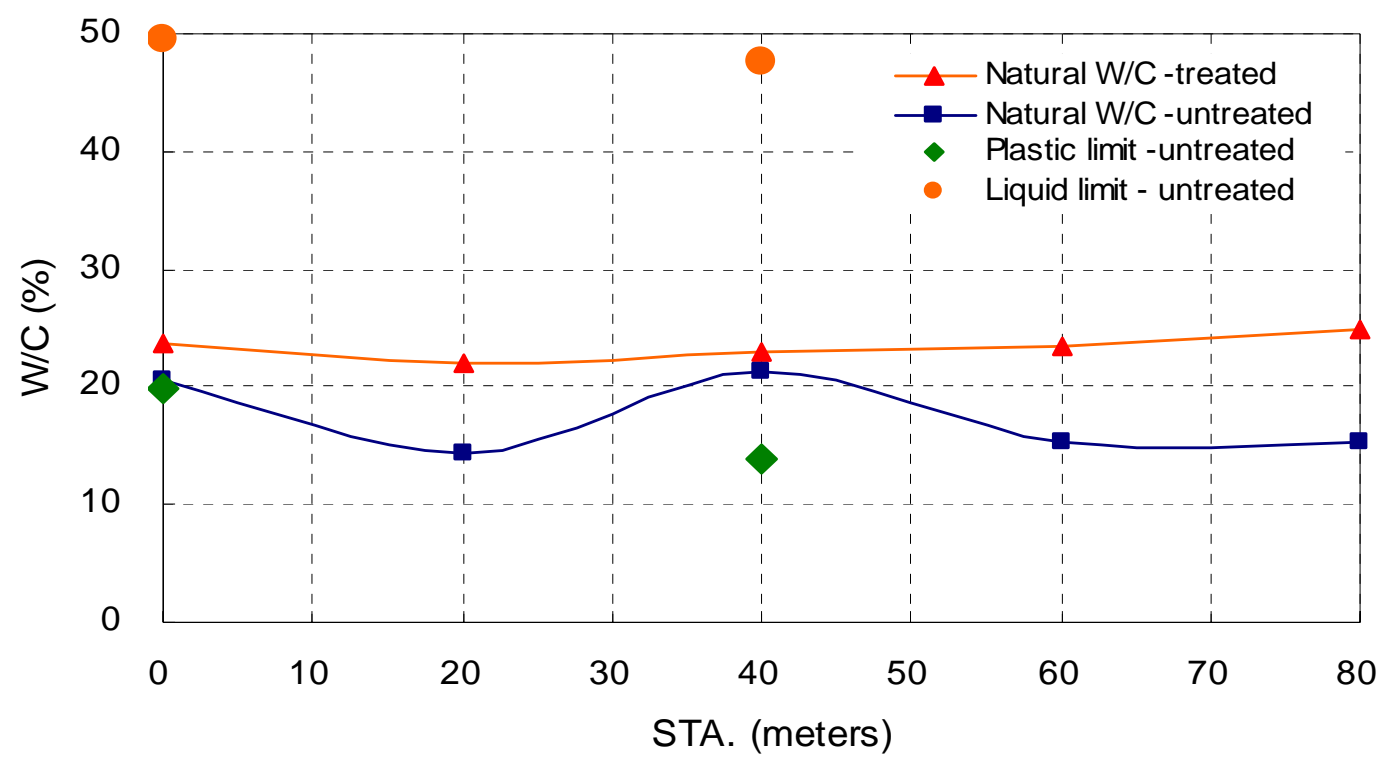

Figure 5.1 Natural water content and soil index properties at site (1)

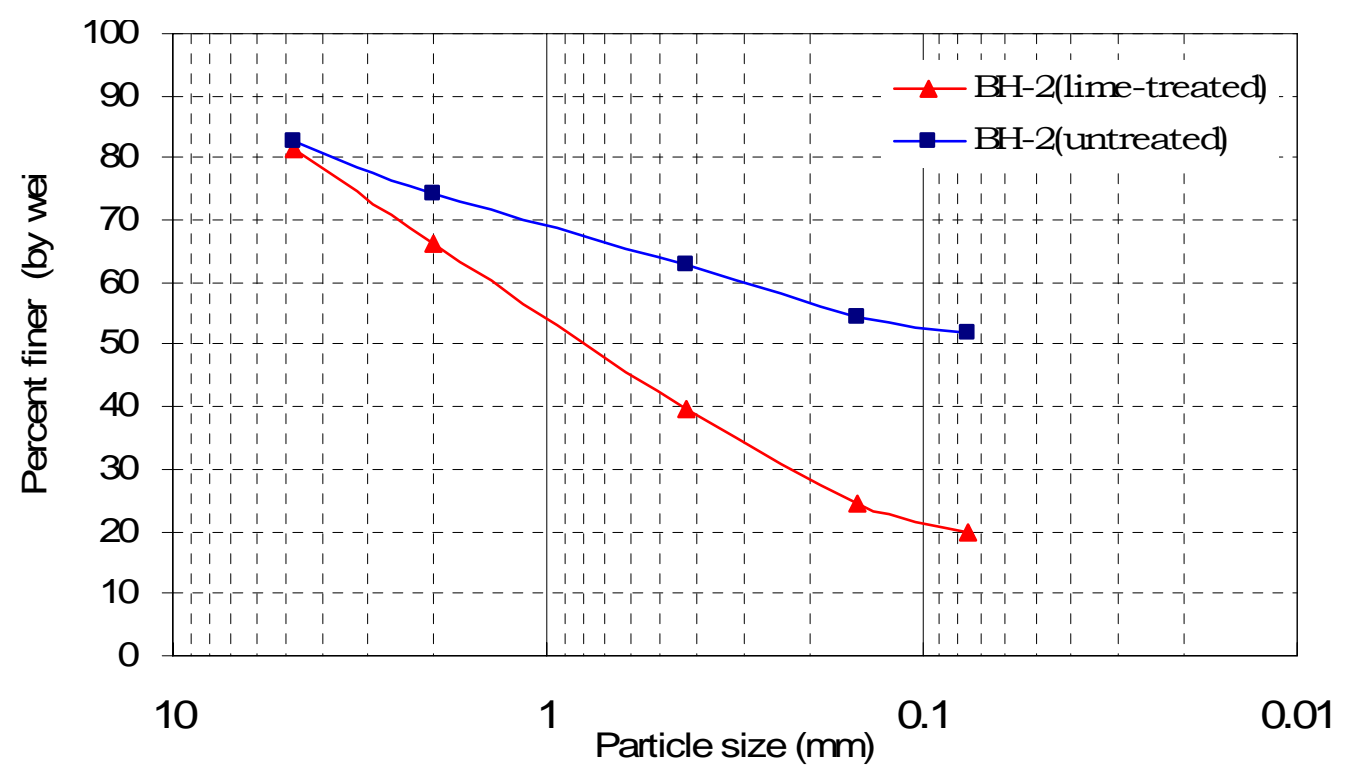

Figure 5.2 Particle-size distribution. Site (1)

Figure 5.2 shows the particle-size distribution obtained from wet sieving tests using both the lime-treated and the natural soil samples. The amount passing the No. 200 sieve is $20 \%$ and $52 \%$ for the lime-treated and natural soil, respectively. Atterberg limits 
performed on the soils show that the lime-treated subgrade soil is non-plastic, because the soil cannot be rolled into a 3-mm thread. The natural (untreated) soil has a Plastic Limit (PL) of 17, a Liquid Limit (LL) of 48, and a Plastic Index (PI) of 31. Based on the laboratory results, the lime-treated subgrade soil is classified as SM following USCS (Unified Soil Classification System), or A-1-b in accordance with the AASHTO classification. The natural soil is classified as CL and A-7-5, respectively.

Based on the soil index properties and particle-size distribution (Figure 5.1 and Figure 5.2), the lime treatment at the site appears to have been successful as the soil was modified from a low-plasticity clay to a silty sand.

\section{Stiffness and/or strength properties}

The stiffness of the soil is determined by two methods: One through an indirect method using the results from the FWD tests. The other method, directly from SPT and DCP tests. For the indirect method, the $\mathrm{M}_{\mathrm{R}}$ of the natural soil and the lime-treated subgrade soil layers is obtained from back-calculation of FWD deflection data. The $M_{R}$ of the lime-treated and the untreated natural subgrade layer is 79 and $26 \mathrm{ksi}$, respectively, resulting in an increase of the $\mathrm{M}_{\mathrm{R}}$ by a factor of $200 \%$.

Figure $5.3 \sim$ Figure 5.6 show DCPI (Dynamic Cone Penetration Index) and SPI (Standard Penetration Index) with depth of penetration at all the four boreholes done at the site. For example, Figure 5.3 plots DCPI and SPI with depth at BH-1 (STA. 0 meters at site (1)). We chose this figure because it shows more clearly some of the features that are discussed in the following comments. 


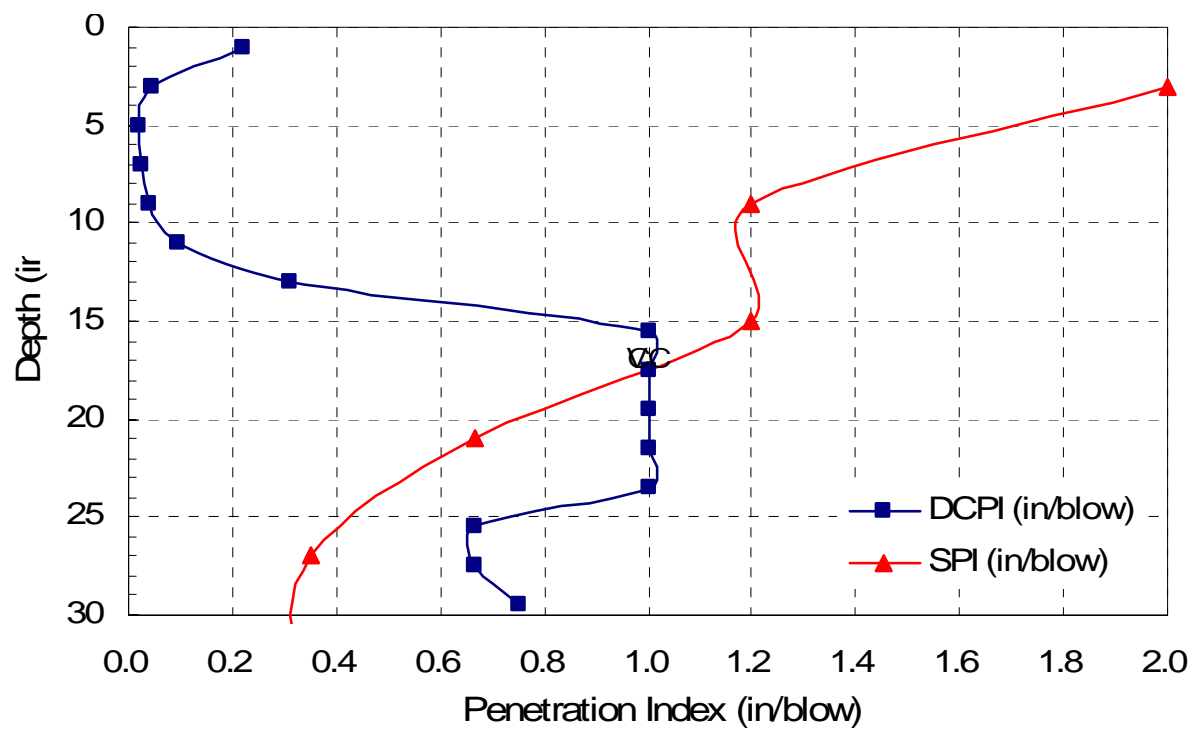

Figure 5.3 DCPT and SPT results with depth at BH-1 (STA. 0 meters). Site (1)

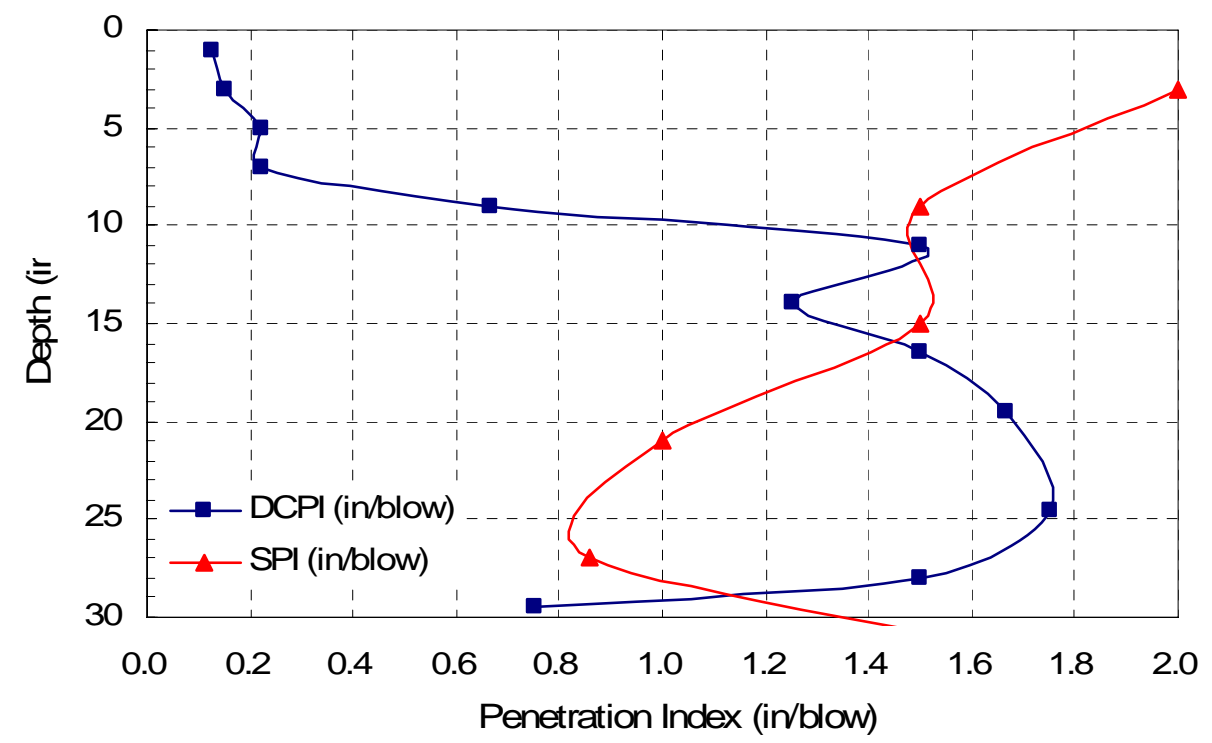

Figure 5.4 DCPT and SPT results with depth at BH-2 (STA. 20 meters). Site (1) 


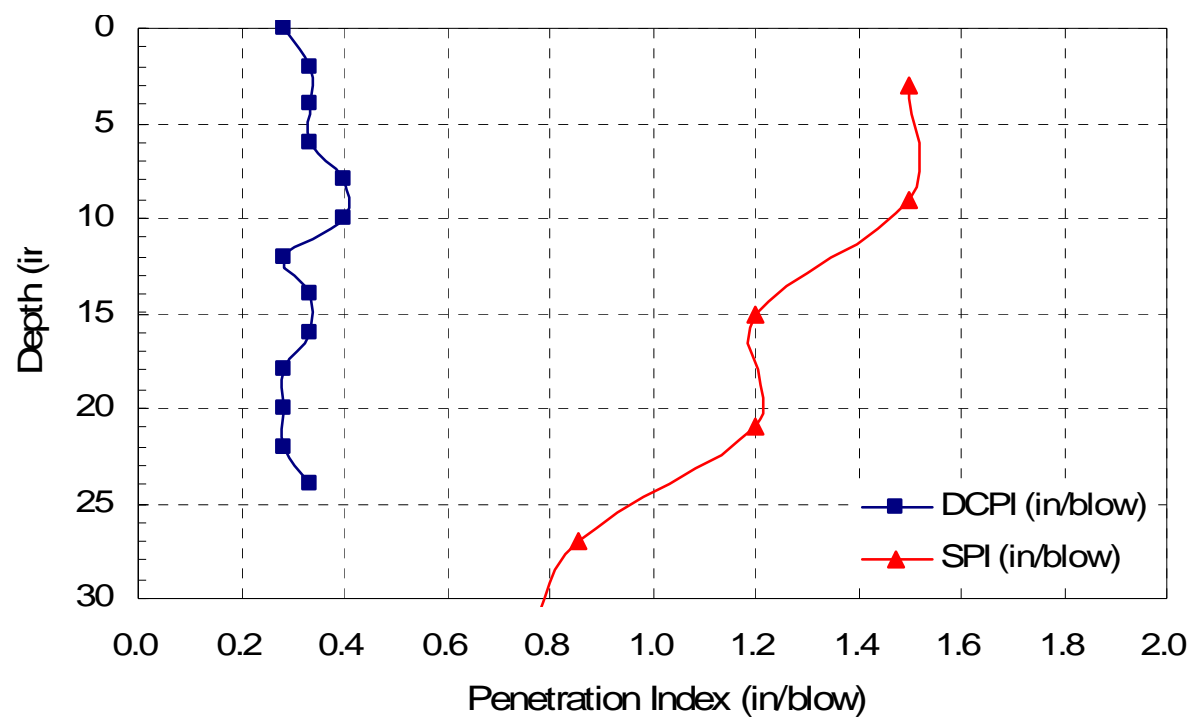

Figure 5.5 DCPT and SPT results with depth at BH-3 (STA. 40 meters). Site (1)

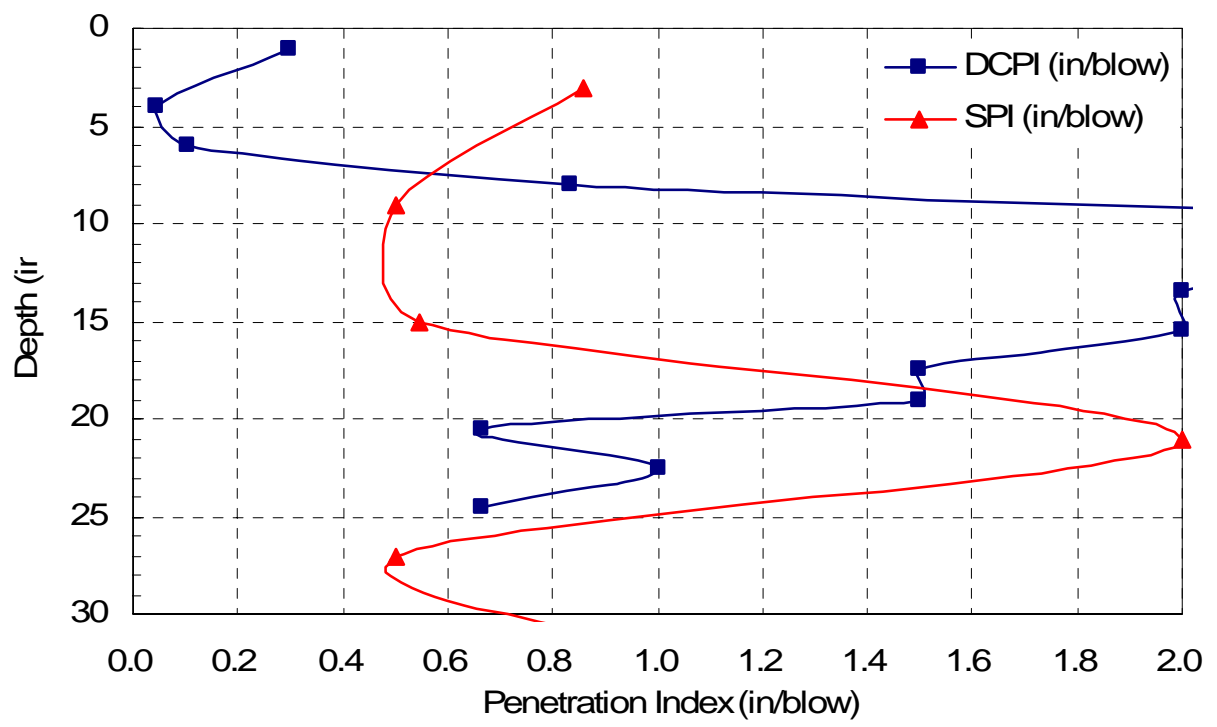

Figure 5.6 DCPT and SPT results with depth at BH-4 (STA. 60 meters). Site (1)

The DCPI was $0.22 \mathrm{in} / \mathrm{blow}$ at the top of the subgrade and less than $0.05 \mathrm{in} / \mathrm{blow}$ at depths of 3 to 11 inches below the top of the subgrade. At a depth of 15 inches the DCPI was $1.0 \mathrm{in} / \mathrm{blow}$. In the figure, there are two clear layers that show a considerable difference of DCPI values: (1) an upper layer, where the DCPIs are to some extent 
constant with a smaller value; and (2) a lower layer, where the DCPIs are considerably larger than those measured on the upper layer. This is interpreted as an increase in strength and/ or stiffness of the upper subgrade layer due to lime-treatment. Note that in the plots the DCP values measured just at the top of subgrade are larger than those immediately below. The difference is attributed to the inevitable disturbance of the soil near the top of the subgrade during the boring operations. The observations made for Figure 5.3 are also found in Figure 5.4 and Figure 5.6. However, in the distributions of DCPI with depth at BH-2 (STA. 20 meters) and BH-4 (STA. 60 meters), the thickness of the upper layer with a constant, small value of DCPIs, is smaller than in BH-1 (STA. 0 meters). In Figure 5.5, a stiffness gain of the subgrade due to lime treatment is not observed.

Figure $5.3 \sim$ Figure 5.6 also plot results of SPT tests. The trend of the SPT test results with depth does not compare well with the DCP tests. In addition, there are fewer data points and so the resolution is smaller than DCP, which is due to the larger depth involved in each SPT test. In other words, the SPT blow counts were measured every 6 inches while DCP blow counts every 2 inches. Because of the high resolution of DCP tests, and also because they correlate very well with stiffness properties of the soil, they are used to obtain estimates of CBR. 


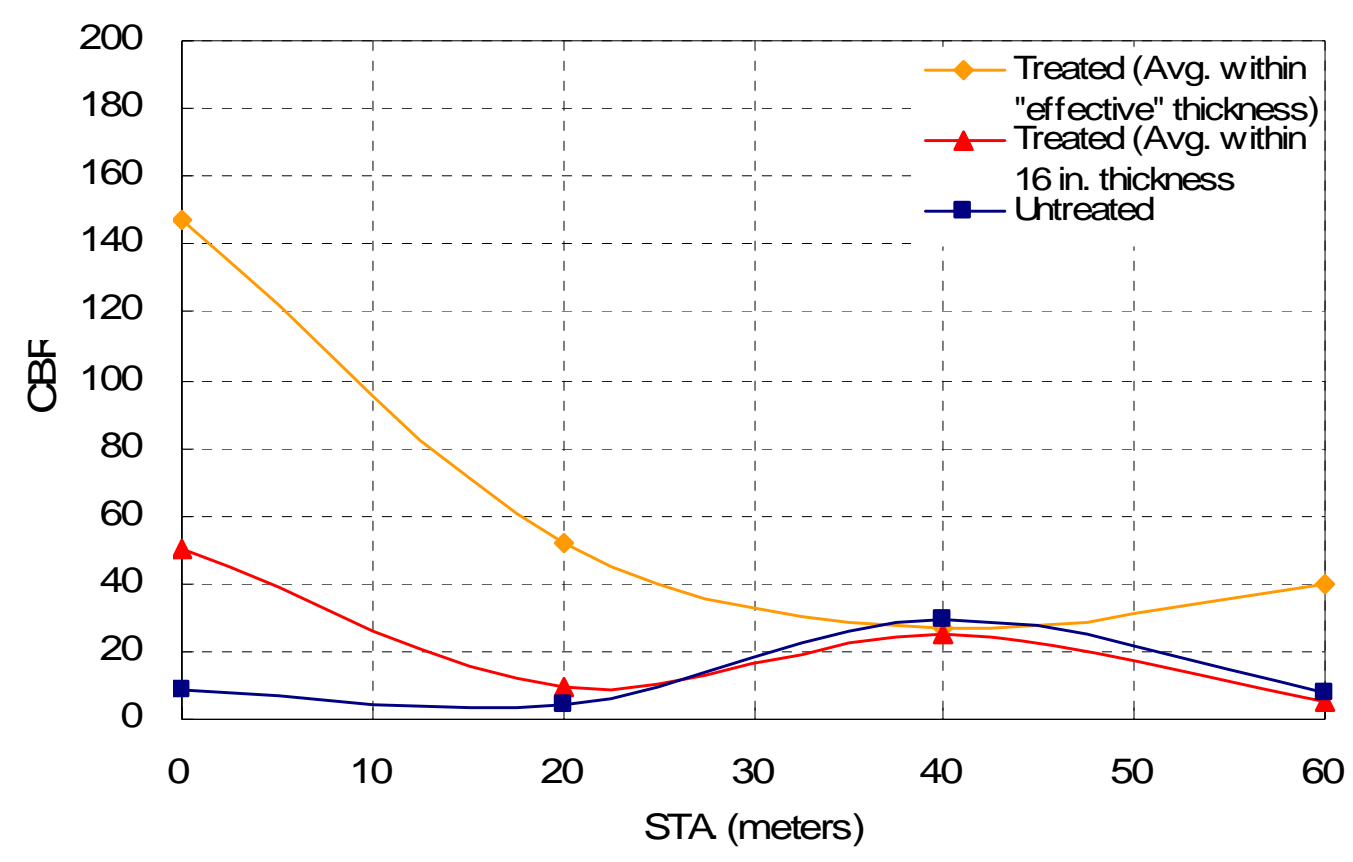

Figure 5.7 CBR of subgrade estimated from DCPT results. Site (1)

Figure 5.7 plots the longitudinal distribution of CBR for both lime-treated and natural soil layers. The CBR values are obtained with a correlation of DCPI and CBR (Webster et al., 1992), which was discussed in chapter 2. There are two curves in the figure to describe the CBR values of the treated soil, in an attempt to quantify how uniform the treatment was. The top curve is obtained by averaging, at each location, the DCPI values over the "effective thickness" of treatment. The effective thickness is defined as the thickness of the lime-treated subgrade soil layer with approximately constant DCPI values less than 0.2 inches/blow. The bottom curve results from average of the DCPI values over the theoretical 16 inches thickness of the lime-treated subgrade. The third curve plots the DCPI values of the natural (untreated) soil. For example, going back to Figure 5.3, the average DCPI values of the lime-treated subgrade layer calculated within the "effective" thickness are $0.07 \mathrm{in} / \mathrm{blow}$, and over the entire thickness of 16 
inches are $0.19 \mathrm{in} / \mathrm{blow}$. The calculated average value of the untreated subgrade is 0.87 in/blows. From the correlation between DCPI and CBR, the estimated CBR of the limetreated subgrade is 147 for the "effective thickness", 50 for the entire 16-inch layer, and 9 for the natural soil. In the same manner, the CBR of the lime-treated and untreated soil layers were determined at the other borehole locations.

From Figure 5.7, it is observed between the two borehole locations BH-1 (STA. 0 meters), and BH-2 (STA. 20 meters) that: (1) the CBR of the natural soil layer ranges between 5 and 9; (2) the CBR of the lime-treated subgrade soil layer, calculated within the effective thickness of the layer, ranges between 52 and 147, which results in an increase of the CBR by a factor of 1000 and $1500 \%$; (3) the CBR of the lime-treated subgrade soil layer, calculated within a thickness of 16 inches below the top of the subgrade, ranges between 9 and 50, which results in a increase of CBR of 100 and $450 \%$; and (4) the distance between the two curves of the treated soil is a measure of the difference between the design and the actual depth of treatment. Figure 5.7 shows that there is an increase of the stiffness of the soil with treatment, and that such increase can be substantial while it also shows a very large and significant variability. At BH-3 (STA. 40 meters), the increase of the stiffness and/or strength of the subgrade due to lime treatment is not observed. Note that the natural (untreated) subgrade soil has a large value of CBR $(=30)$. From the observations, it may be inferred that the natural soil was not appropriately pulverized or mixed with the lime because of the already high strength of the natural subgrade soil. The same appears to be the case for the following stations. 


\section{Lime content}

Figure 5.8 shows the $\mathrm{pH}$ values of both the lime-treated subgrade and natural soil, which are determined at the boreholes drilled at the site. The lime-treated and natural (untreated) soil samples, which were collected approximately at depths of 8 and 30 inches respectively below the subgrade, were used for the $\mathrm{pH}$ tests. The lime-treated subgrade soil has a $\mathrm{pH}$ ranging from 9.4 to 10.9 while the untreated soil has a $\mathrm{pH}$ ranging from 7.8 to 8.3. The increase of $\mathrm{pH}$ denotes the presence of lime. Note that the lime-treated subgrade at BH-3 (STA. 40 meters) has a $\mathrm{pH}$ of 9.4 that is the lowest value.

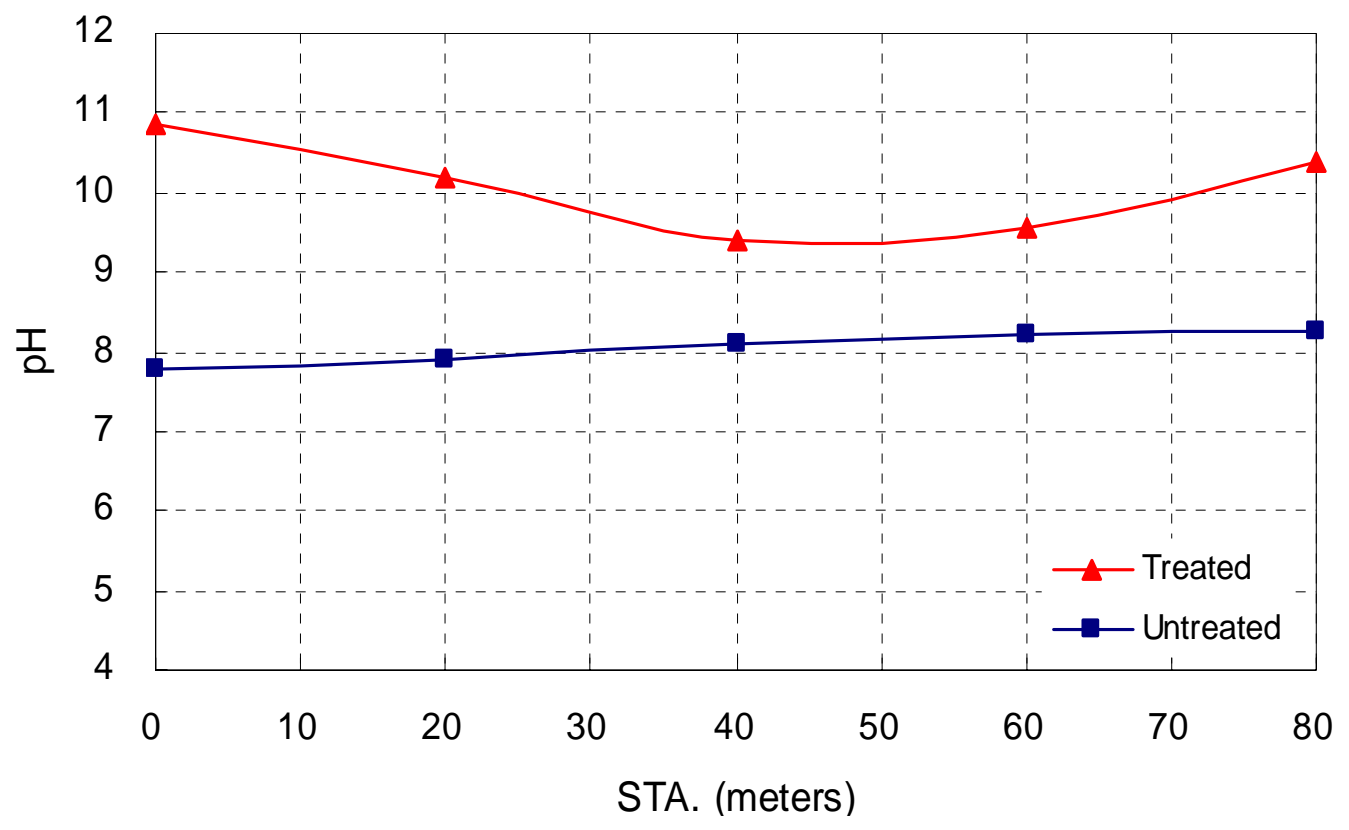

Figure $5.8 \mathrm{pH}$. Site (1)

Figure 5.9 and Figure 5.10 show the results of XRD tests from the lime-treated and natural soil samples taken at BH-3 (STA. 40 meters). The lime-treated and natural soil samples, which were collected approximately at depths of 4 and 30 inches respectively below the top of the subgrade, were used for the XRD tests. The existence of 
calcium carbonate $\left(\mathrm{CaCO}_{3}\right)$ in the lime-treated subgrade is observed in the XRD results. The fact that the source of the $\mathrm{CaCO}_{3}$ is from the added lime is confirmed by the observation that the mineral was not found in the natural soil. As discussed in Chapter 4, $\mathrm{CaCO}_{3}$ is created by the reaction of calcium hydroxide $\left(\mathrm{Ca}(\mathrm{OH})_{2}\right)$ with carbon dioxide $\left(\mathrm{CO}_{2}\right)$. Quantification of the amount of lime is done through thermo-gravimetric analyses (TGA). In Figure 5.9, which shows the XRD pattern for the untreated soil sample taken at BH-3 (STA. 40 meters), it is observed that the XRD pattern does not have a peak at critical X-ray refraction angles of $\mathrm{CaCO}_{3}$. However, in Figure 5.10 that plots a XRD pattern for a lime-treated soil sample taken at BH-3, it is observed that the XRD pattern has a peak at the critical angles of $\mathrm{CaCO}_{3}$. From the observations on the XRD patterns for the lime-treated and natural soil samples, the existence of $\mathrm{CaCO}_{3}$ that results from the added lime is confirmed. In addition, it appears that there has been no leaching of the lime from the lime-treated subgrade since no lime is found on the natural soil.

Figure $5.11 \sim$ Figure 5.15 show the XRD pattern for the lime-treated soil samples collected at depths of $0,4,8,12$, and 16 inches below the top of the subgrade at $\mathrm{BH}-1$ (STA. 0 meters). The XRD tests are done to investigate lime contents with depth in the lime-treated subgrade. Figure 5.11 shows the XRD pattern for the lime-treated soil sample collected immediately below the top of the subgrade. In the figure, the XRD pattern has a little peak at the critical refraction angles of $\mathrm{CaCO}_{3}$, but the intensity decreases with increasing depths below the top of the subgrade, which indicates the reduction of the added lime with depth in the lime treated subgrade. Quantification of the lime content is determined from TGA tests 

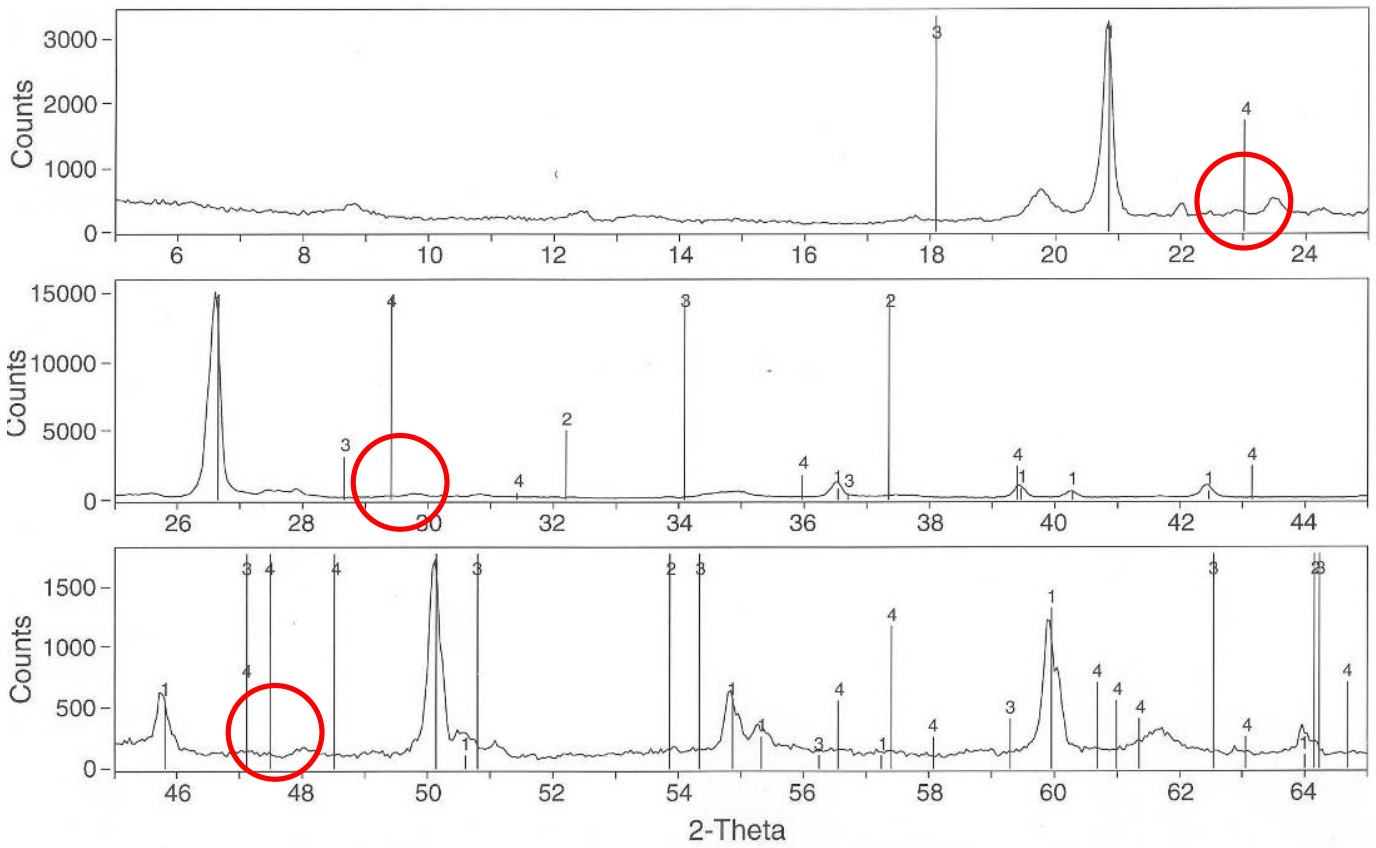

1> 33-1161: Quartz, syn - SiO2

2> 37-1497: Lime, syn - CaO

3> 04-0733: Portlandite, syn - $\mathrm{Ca}(\mathrm{OH}) 2$

4> 05-0586: Calcite, syn - CacO3

Figure 5.9 XRD pattern for untreated soil sample at BH-3 (STA. 40 meters). Site (1)
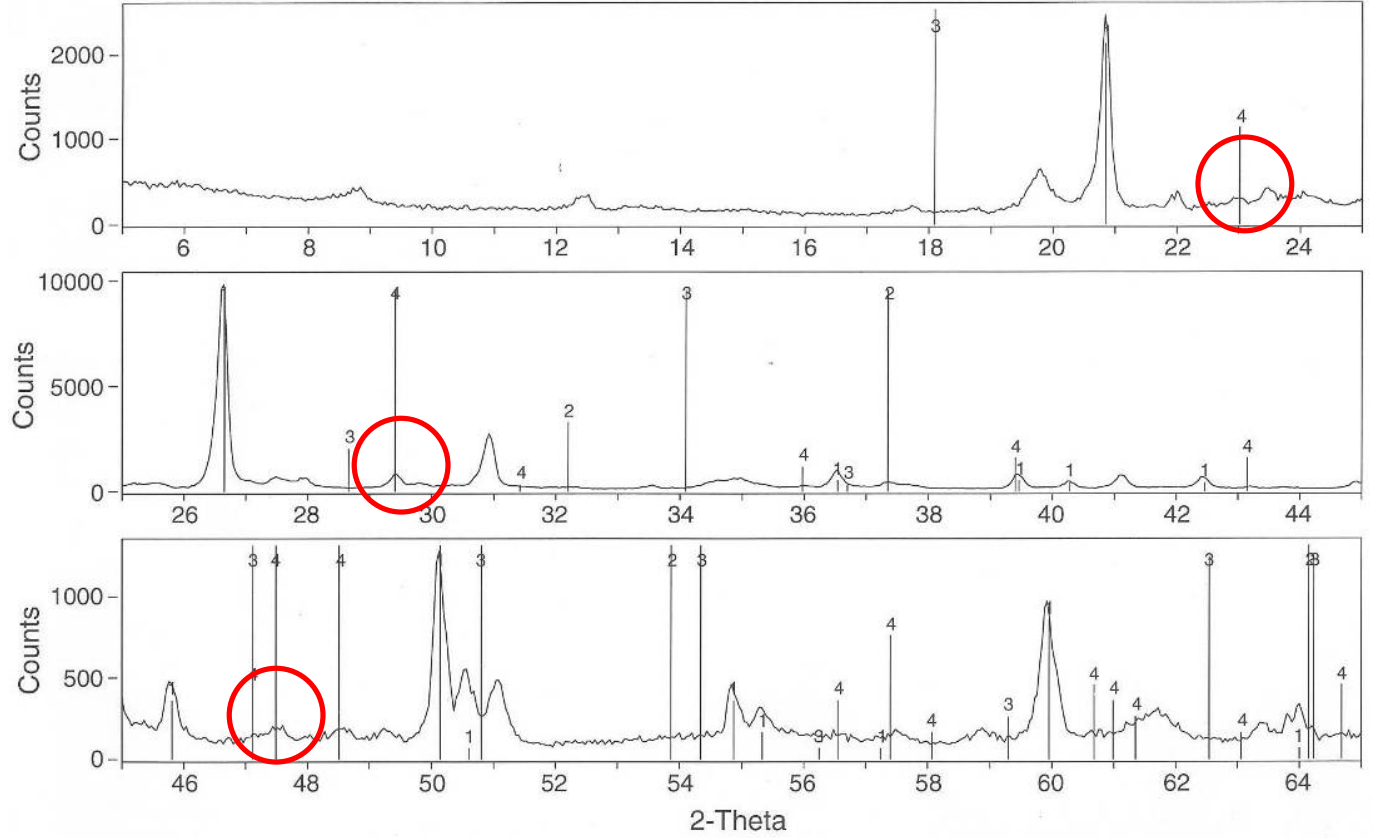

1> 33-1161: Quartz, syn - SiO2

2> 37-1497: Lime, syn - CaO

3> 04-0733: Portlandite, syn - $\mathrm{Ca}(\mathrm{OH}) 2$

4> 05-0586: Calcite, syn - $\mathrm{CaCO} 3$

Figure 5.10 XRD pattern for lime-treated soil sample at BH-3 (STA. 40 meters). Site (1) 

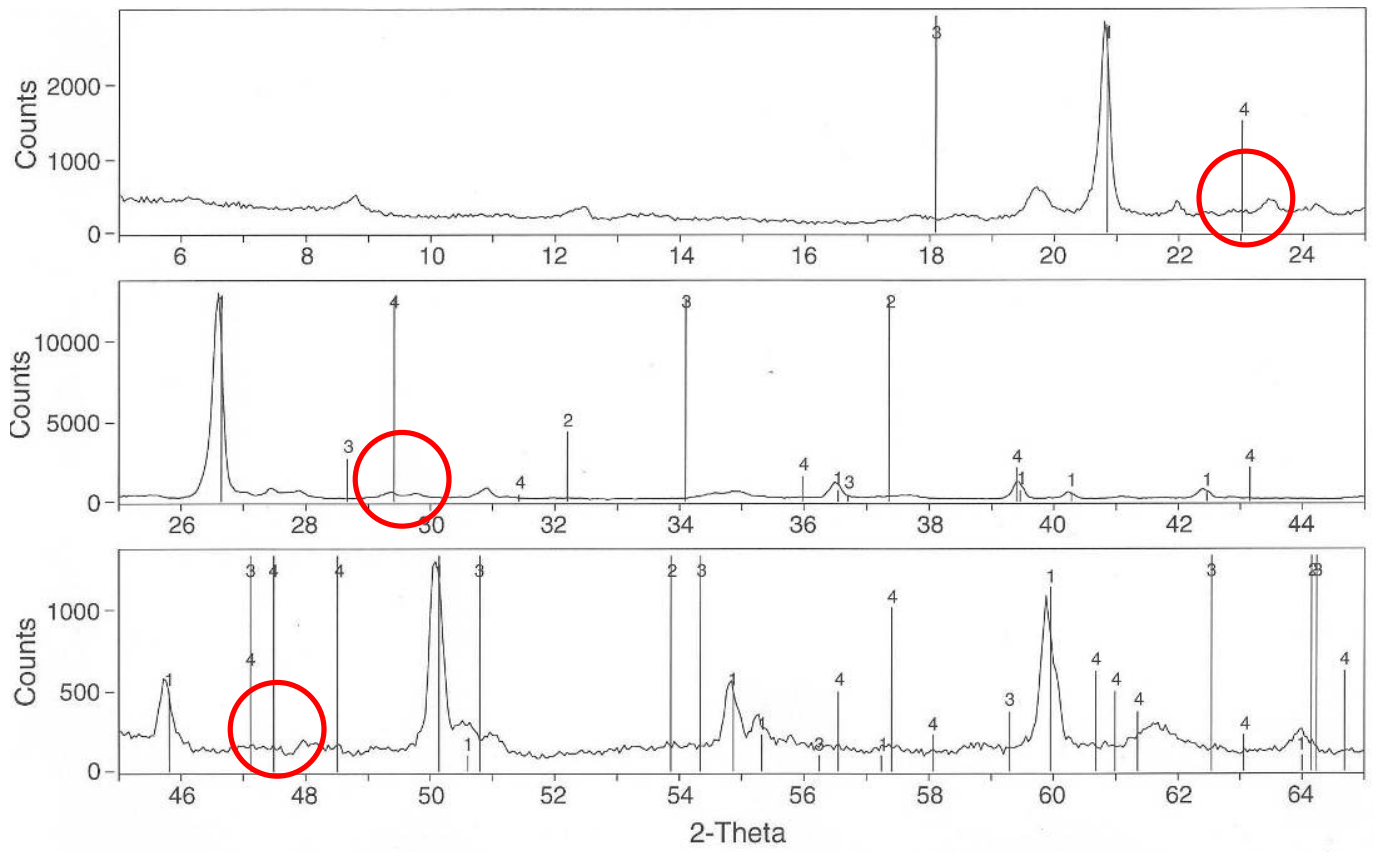

1> 33-1161: Quartz, syn - SiO2

3> 04-0733: Portlandite, syn - $\mathrm{Ca}(\mathrm{OH}) 2$

2> 37-1497: Lime, syn - CaO

4> 05-0586: Calcite, syn - CaCO3

Figure 5.11 XRD pattern for lime-treated soil sample taken at a depth of 0 inches below top of subgrade at BH-1 (STA. 0 meters). Site (1)
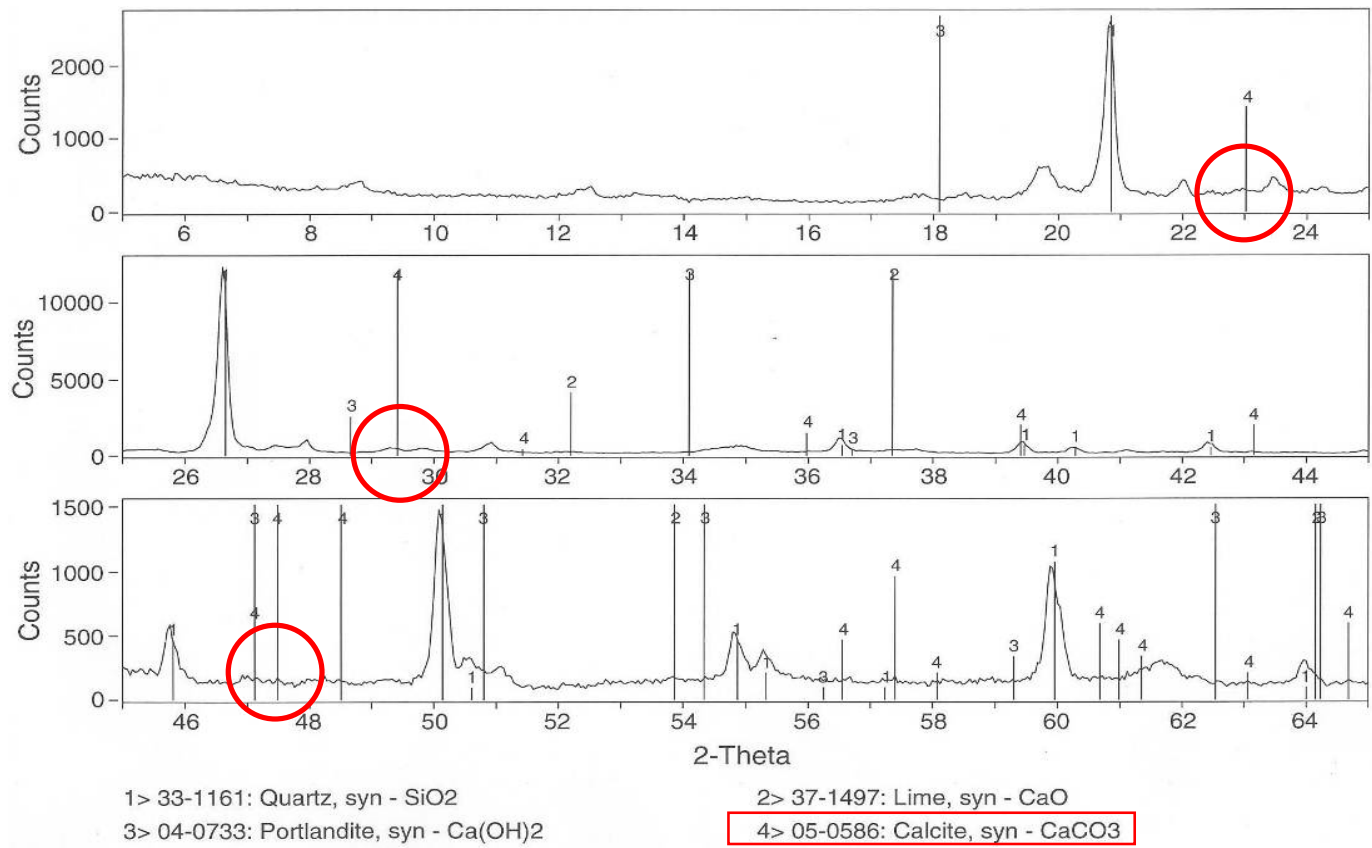

Figure 5.12 XRD pattern for lime-treated soil sample taken at a depth of 4 inches below top of subgrade at BH-1 (STA. 0 meters). Site (1) 

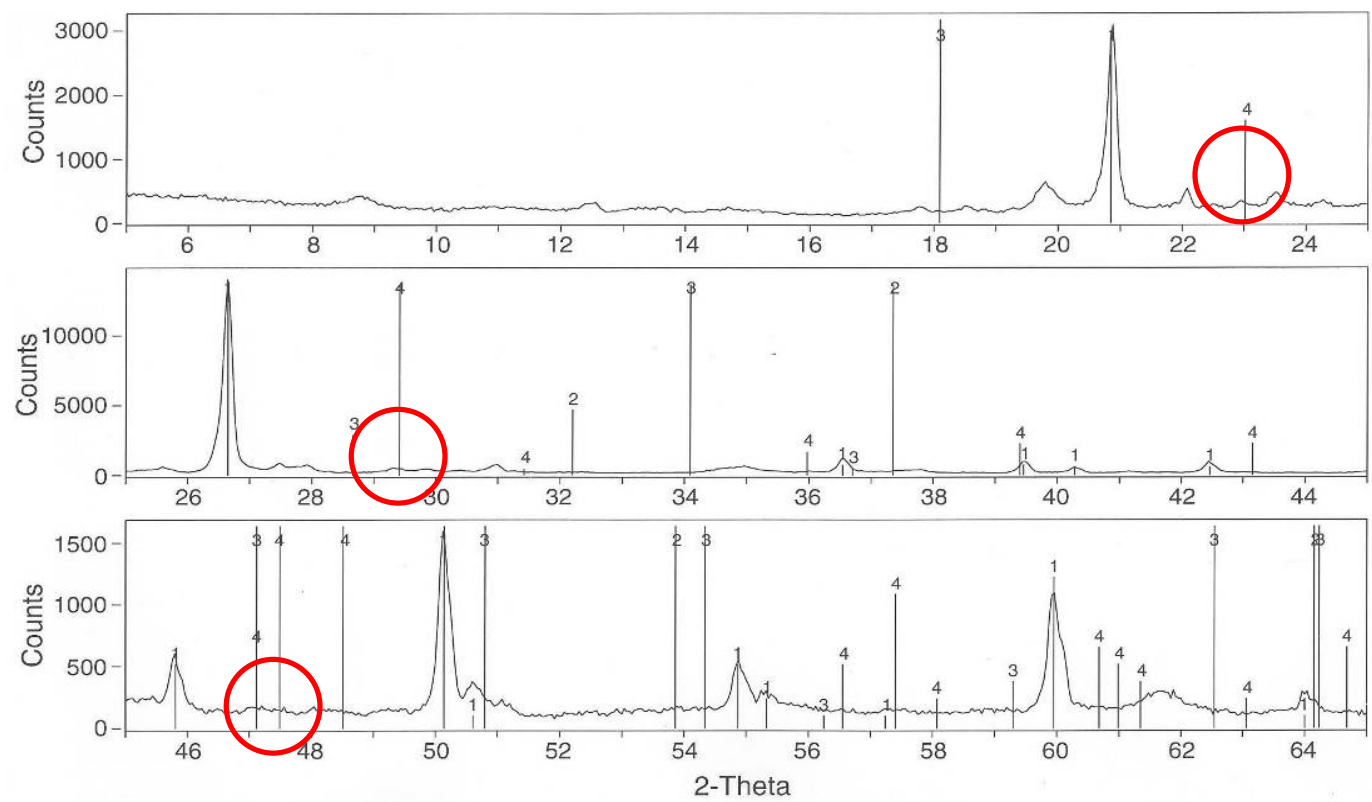

1> 33-1161: Quartz, syn - SiO2

3> 04-0733: Portlandite, syn - $\mathrm{Ca}(\mathrm{OH}) 2$

2> 37-1497: Lime, syn - CaO

4> 05-0586: Calcite, syn - CaCO3

Figure 5.13 XRD pattern for lime-treated soil sample taken at a depth of 8 inches below top of subgrade at BH-1 (STA. 0 meters). Site (1)
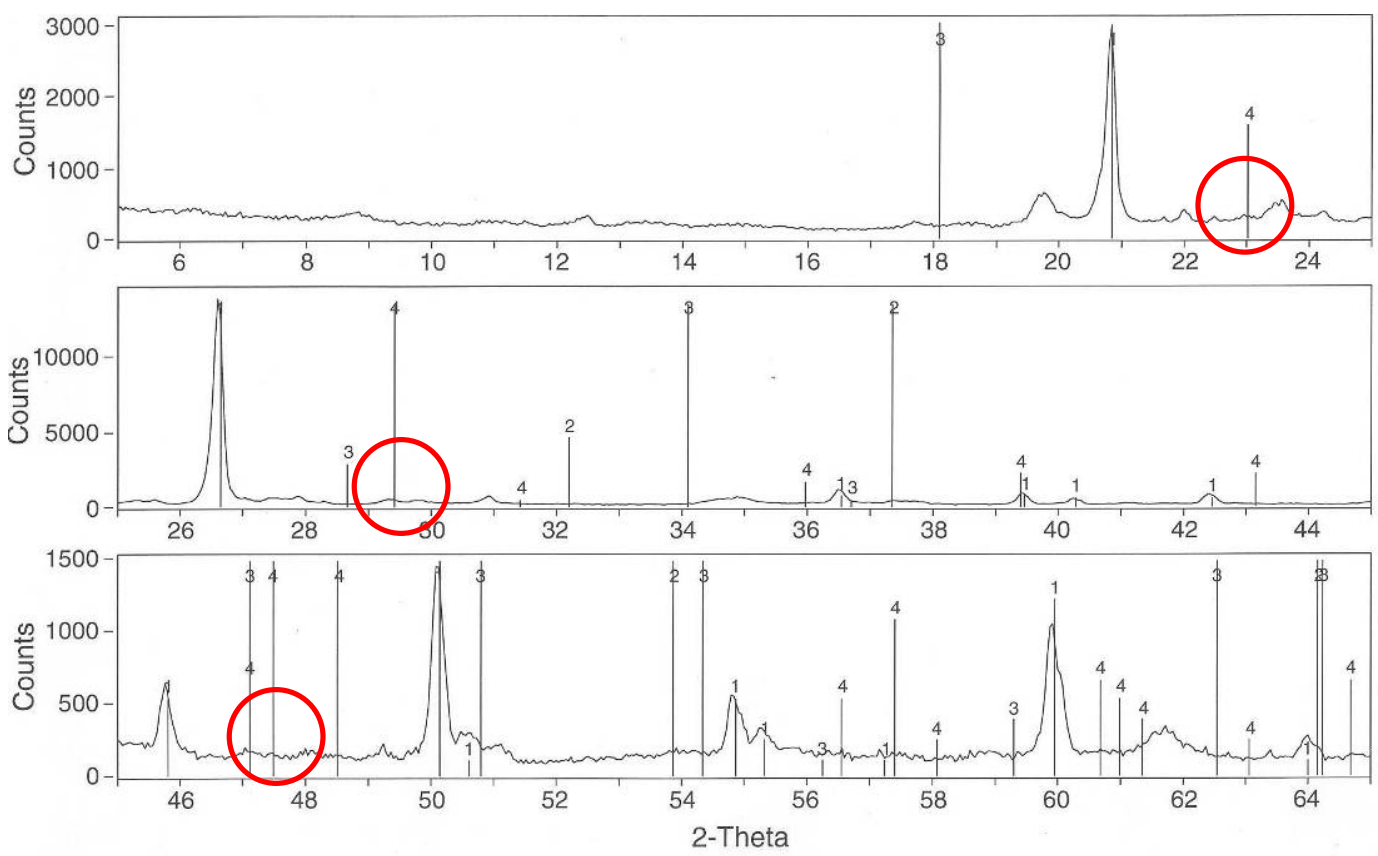

1> 33-1161: Quartz, syn - SiO2

2> 37-1497: Lime, syn - CaO

3> 04-0733: Portlandite, syn - $\mathrm{Ca}(\mathrm{OH}) 2$

4> 05-0586: Calcite, syn - CaCO3

Figure 5.14 XRD pattern for lime-treated soil sample taken at a depth of 12 inches below top of subgrade at BH-1 (STA. 0 meters). Site (1) 

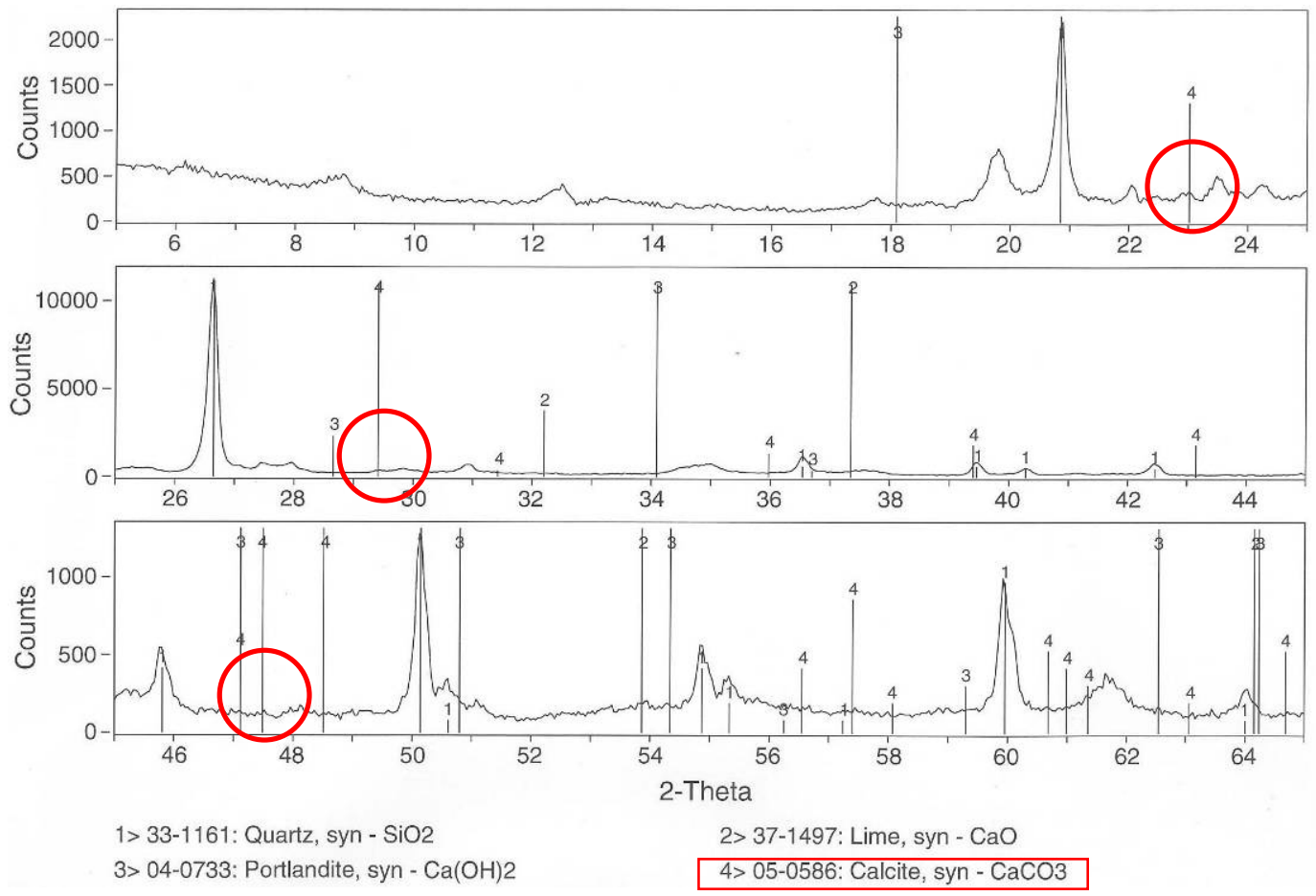

Figure 5.15 XRD pattern for lime-treated soil sample taken at a depth of 16 inches below top of subgrade at BH-1 (STA. 0 meters). Site (1)

Figure 5.16 shows the results of TGA tests of the lime-treated and natural soil samples. The figure shows that the weight of the natural soil decreases uniformly with increasing temperature while the weight of the treated soil has a sharp decrease within a range of temperatures between 650 and $800{ }^{\circ} \mathrm{C}$. This is the temperature range where $\mathrm{CaCO}_{3}$ decomposes into $\mathrm{CaO}$ and $\mathrm{CO}_{2}$, and so the weight loss represents the $\mathrm{CaCO}_{3}$ content. LKD typically has an available lime content of 30 to $60 \%$ in the form of $\mathrm{CaO}$, $\mathrm{MgO}$ and $\mathrm{Ca}(\mathrm{OH})_{2}$. Considering that $5 \% \mathrm{LKD}$ was used for the lime-treatment at site (1), the lime-treated subgrade should have a lime content of 1.5 to $3 \%$. From the figure, the calculated amount of $\mathrm{CaCO}_{3}$ is $7.0 \%$. Note that all the lime in LKD may not be reactive since $\mathrm{CaCO}_{3}$ may remain during the fabrication process. The amount of $\mathrm{CaCO}_{3}$ depends on the limestone, fuel, and kiln operations used during the lime manufacturing process. 
Figure 5.17 shows TGA results of the lime-treated soil samples collected at depths of 0,4 , 8,12 , and 16 inches below the top of the subgrade at BH-1 (STA. 0 meters). In the figure, the calculated amount of $\mathrm{CaCO}_{3}$ decreases from $2.4 \%$ at the top of the lime-treated subgrade to $0 \%$ at 16-in. depth below the top. Going back to Figure 5.3, the DCPI curve with depth at BH-1 presents a large value of DCPI (implying a low strength) at 16-in. depth, which may be caused by the absence of lime at this depth.

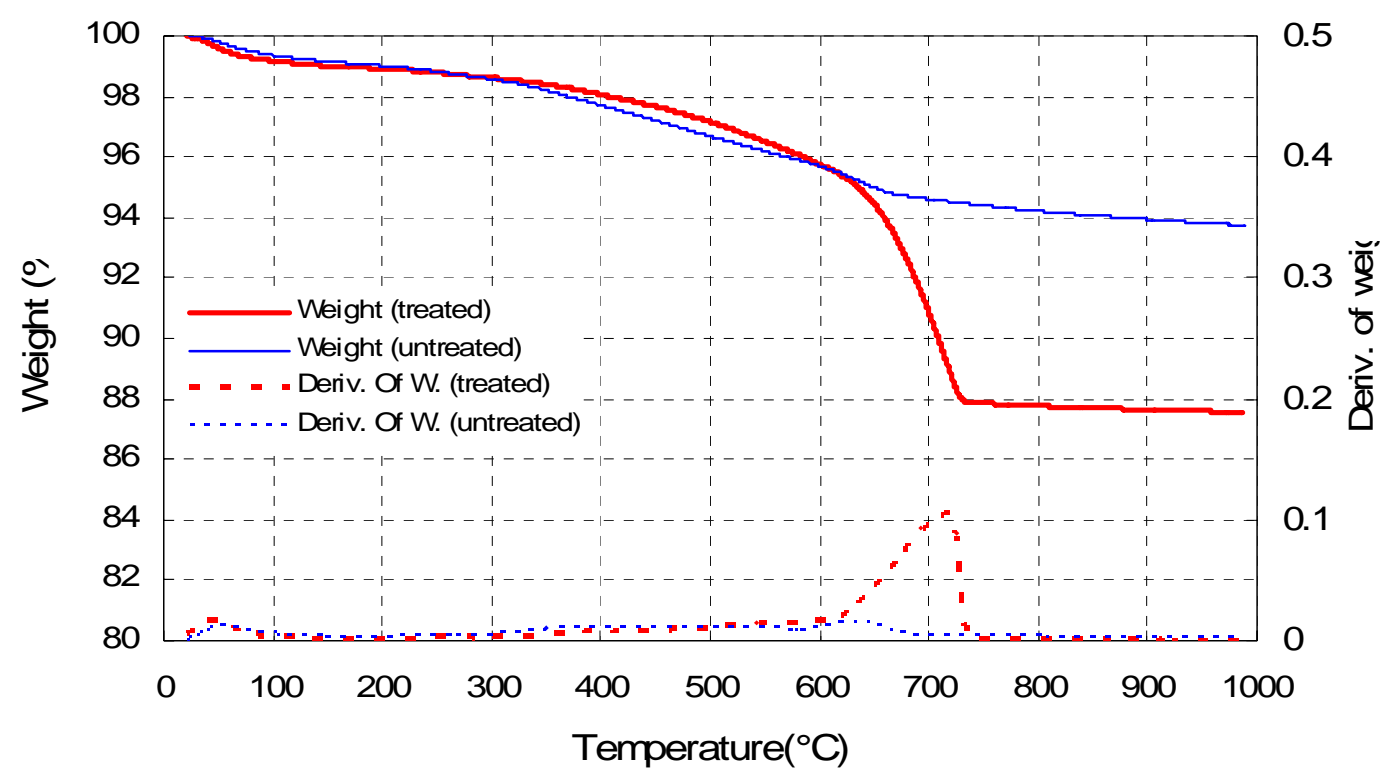

Figure 5.16 Weight loss and weight loss rate obtained from TGA from lime-treated and untreated soil samples collected at BH-3 (STA. 40 meters) at site (1) 


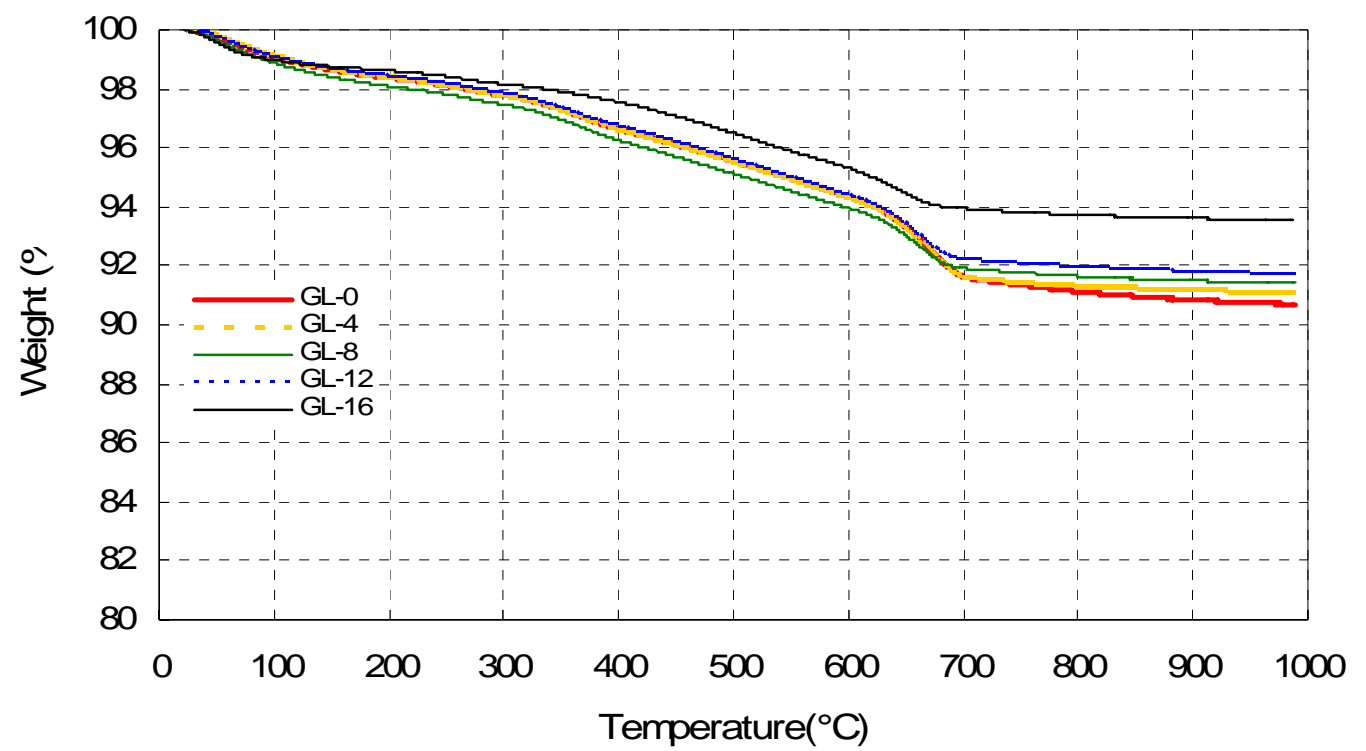

Figure 5.17 Weight loss obtained from TGA from lime-treated soil samples collected at depths of $0,4,8,12$, and 16 inches respectively below top of subgrade, at BH-1 (STA. 0 meters) at site (1)

The amount of $\mathrm{CaCO}_{3}$ calculated for the lime-treated soil sample collected at $\mathrm{BH}-$ 1 (STA. 0 meters) is $2.4 \%$ (determined at 4 -in. depth) while the amount of $\mathrm{CaCO}_{3}$ is $7.0 \%$ for the treated sample collected at BH-3 (STA. 40 meters). On the other hand, going back to Figure 5.7, the stiffness and/or strength of the lime-treated subgrade at BH1 is larger than that determined at BH-3. From the laboratory and field test results, it appears that, at site (1), there is little correlation between the stiffness and/or strength of subgrade and the added lime. The results suggest that there are factors other than lime dosage that affect the stiffness; for example percentage of active lime, construction quality and compaction, to name a few. 


\subsection{Site (2)}

\section{Soil characterization properties}

Figure 5.18 plots the natural water content and soil index properties of the limetreated subgrade and natural (untreated) soil. The soil characterization properties are determined from laboratory tests using the soil samples collected at different borehole locations at site (2). The soil samples taken at about 8-in and 30-in depths below the top of the subgrade are used to determine the natural water content of the lime-treated and untreated soil. The water content of the lime-treated subgrade ranges from $13 \%$ to $20 \%$ while the water content of the natural soil ranges from $10 \%$ and $19 \%$. The difference in water content between the treated and untreated soils can be considered within experimental error.

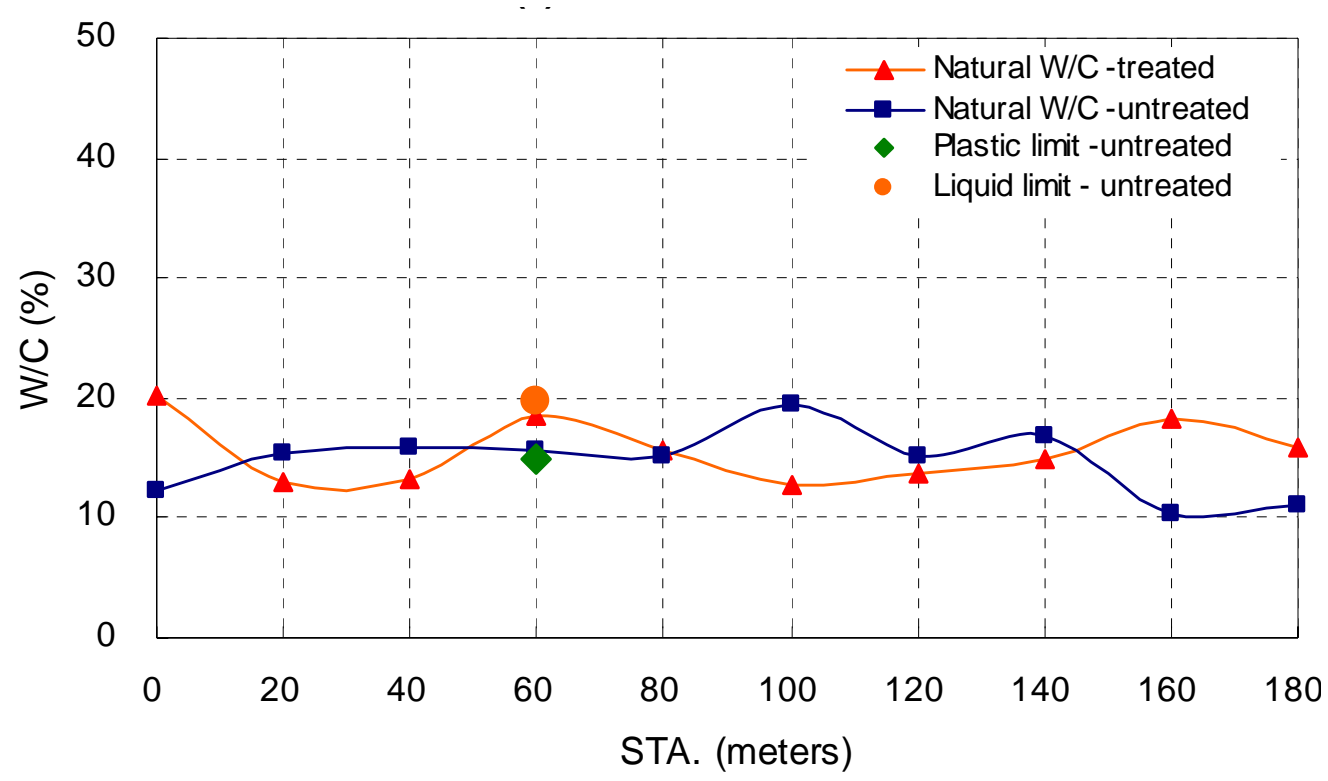

Figure 5.18 Natural water content and soil index properties at site (2) 
The soil index properties of the lime-treated and natural soil are determined at three borehole locations (BH-4, 7, and 9). At BH-4 (STA. 60 meters), the natural (untreated) soil has a Plastic Limit (PL) of 15, a Liquid Limit (LL) of 20, and a Plastic Index (PI) of 5. However, Atterberg limit tests on the natural soil samples taken at $\mathrm{BH}-7$ (STA. 120 meters) and BH-9 (STA. 160 meters) show that the natural soil (not treated) is non-plastic because the soil cannot be rolled into $3-\mathrm{mm}$ threads. The same result is obtained for the lime-treated soil samples taken at the same borehole locations (BH-5, 7, and 9).

Figure 5.19 shows the particle-size distribution obtained from wet sieving tests of the lime-treated and the natural soil samples taken at BH-8 (STA. 140 meters). The amount passing the No. 200 sieve is $38 \%$ and $18 \%$ for the lime-treated and natural soil, respectively.

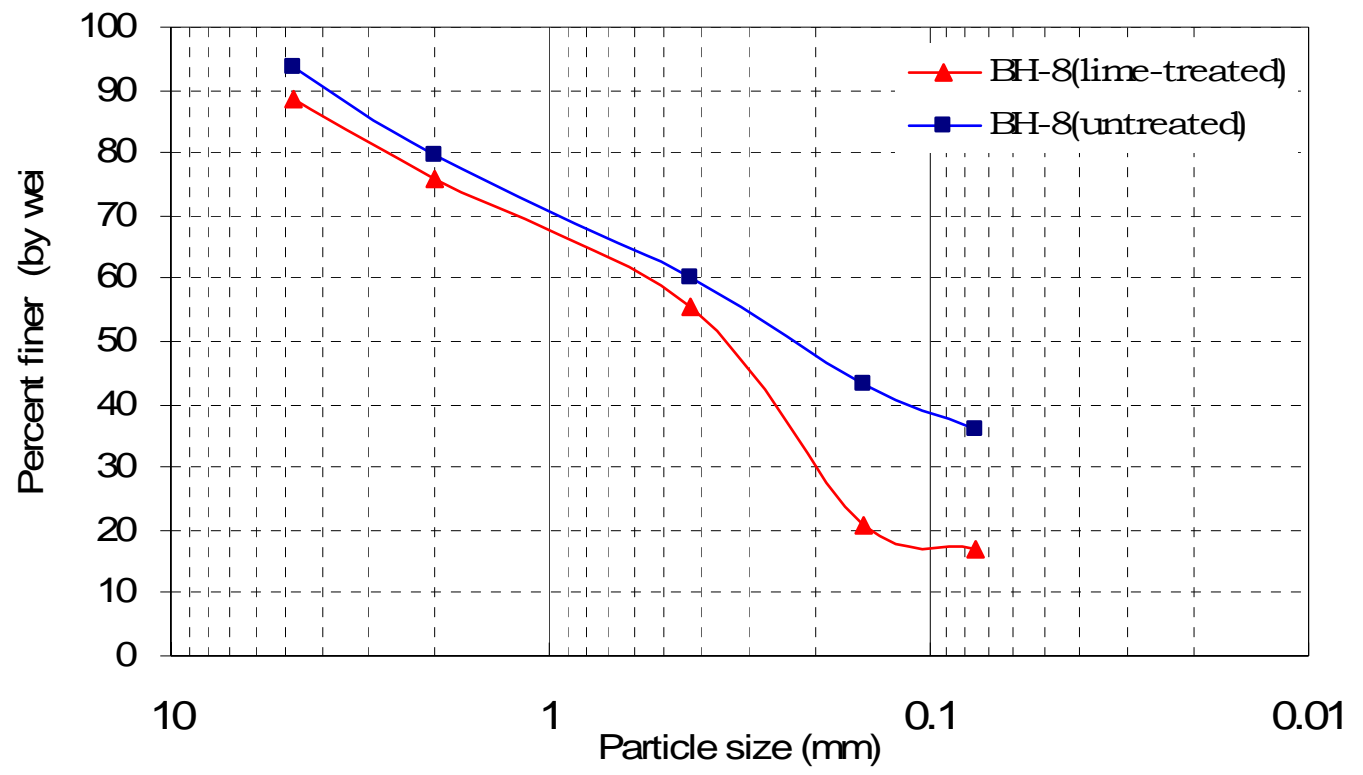

Figure 5.19 Particle-size distribution at site (2) 
Based on the laboratory results, the lime-treated subgrade soil is classified as SM following USCS (Unified Soil Classification System), or A-2-4 in accordance with the AASHTO classification. The natural soil is classified as SM and A-4, respectively.

Results from the soil characterization tests indicate that the natural soil did not contain sufficient clay particles to have a good reaction with the lime. However the soil has become a bit more granular after the lime-treatment.

\section{Stiffness and/or strength properties}

From the back-calculation of the deflection data obtained from the FWD test at site (2), the $M_{R}$ of the lime-treated and the untreated natural subgrade layer is 284 and 45 ksi, respectively, resulting in an increase of the $\mathrm{M}_{\mathrm{R}}$ by a factor of $530 \%$.

Figure 5.20 Figure 5.29 show DCPI (Dynamic Cone Penetration Index) and SPI (Standard Penetration Index) with depth of penetration at all the ten boreholes done at the site. In the discussion regarding DCPI results at site (1), it was mentioned that there are two layers with a considerable difference of DCPI values, which is caused by the increase in stiffness and/or strength due to lime-treatment. This is also confirmed at site (2). For example, in Figure 5.28, that plots DCPI and SPI with depth at BH-9 (STA. 160 meters), the DCPI was $0.5 \mathrm{in} / \mathrm{blow}$ at the top of the subgrade and less than $0.2 \mathrm{in} / \mathrm{blow}$ at depths between 1.5 and 16 inches below the top of the subgrade. At a depth of 20 inches the DCPI increases to $1.25 \mathrm{in} / \mathrm{blow}$. The figure confirms the existence of the two layers in the subgrade that are distinguished by their considerably difference of DCPI values. This is due to the lime treatment. As previously discussed, the DCPI measured just at the top of subgrade is larger than immediately below, which is caused by the inevitable disturbance 
of the soil near the top of the subgrade during the boring operations. The two observations made for Figure 5.28 are also found in the other figures, within the variability associated with field tests. The figures also plot the results of SPT tests. In contrast to the SPT results at site (1), the SPT test results at site (2) have a trend similar to that obtained from DCP tests. However, as mentioned before, there are fewer data points and so the resolution is smaller than DCP, which is due to the larger depth involved in each SPT test. In addition, there have been a larger number of correlation studies between DCPI and CBR than between SPT and CBR. As a consequence, DCPI is used to estimate the CBR of the subgrade.

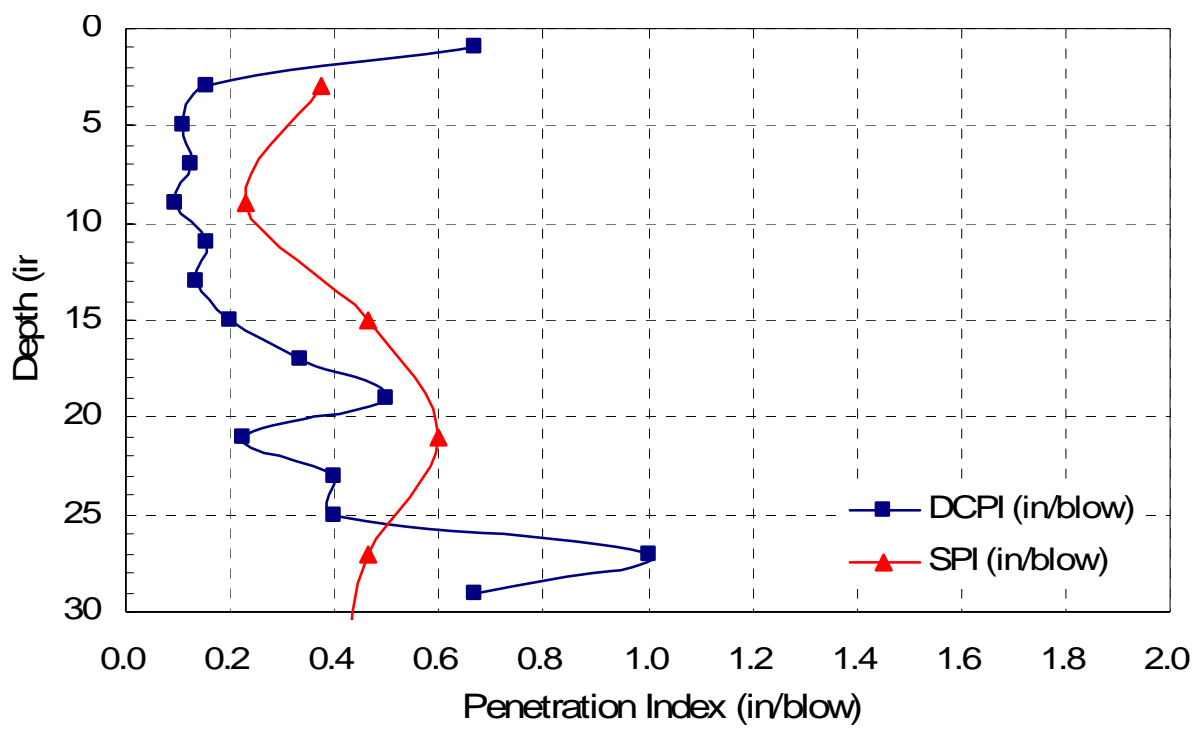

Figure 5.20 DCPT and SPT results with depth at BH-1 (STA. 0 meters). Site (2) 


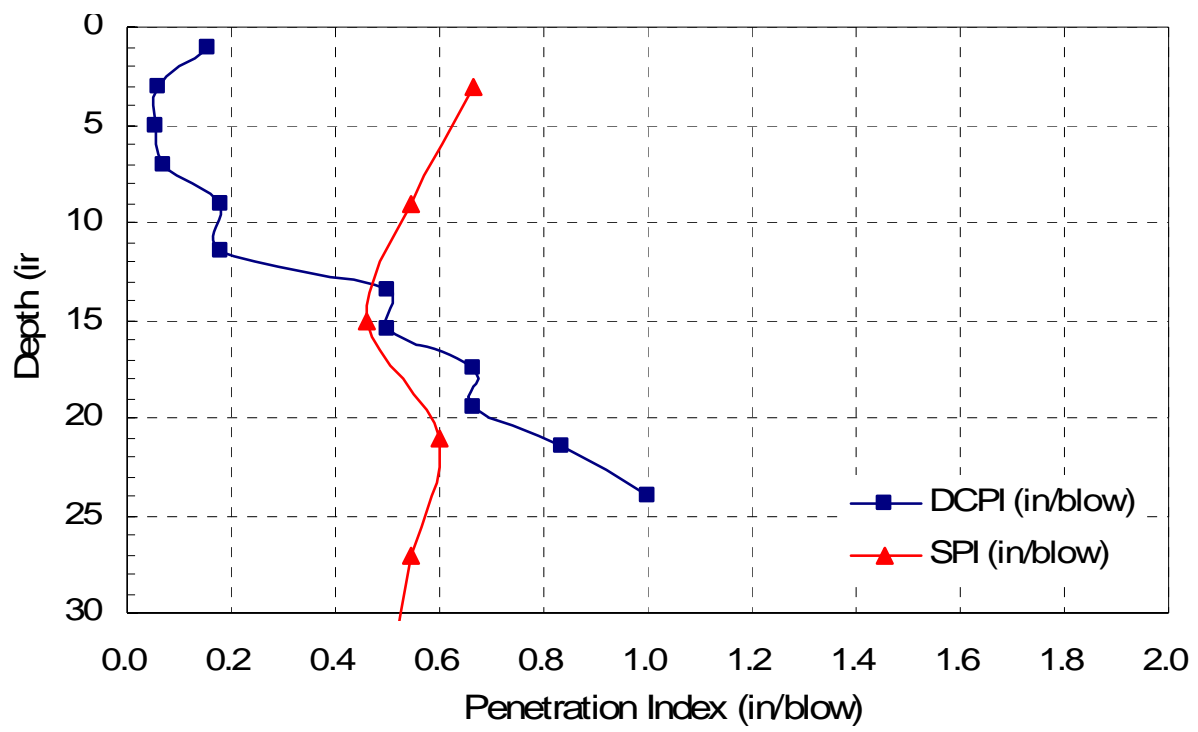

Figure 5.21 DCPT and SPT results with depth at BH-2 (STA. 20 meters). Site (2)

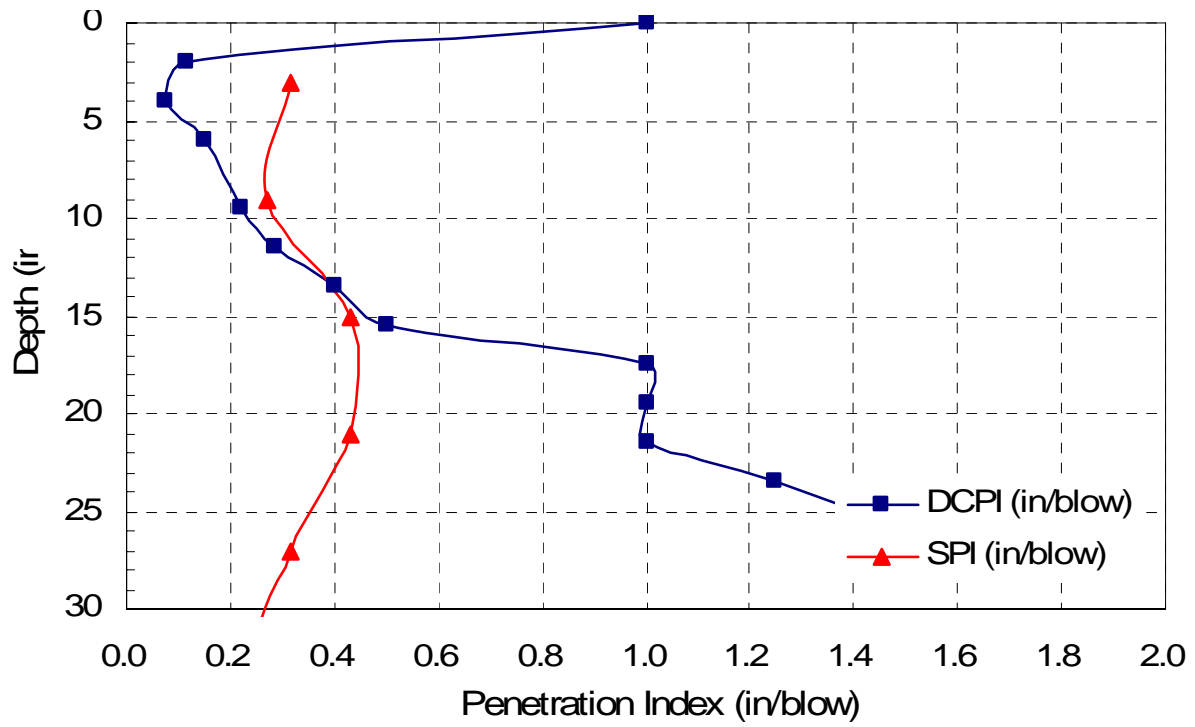

Figure 5.22 DCPT and SPT results with depth at BH-3 (STA. 40 meters). Site (2) 


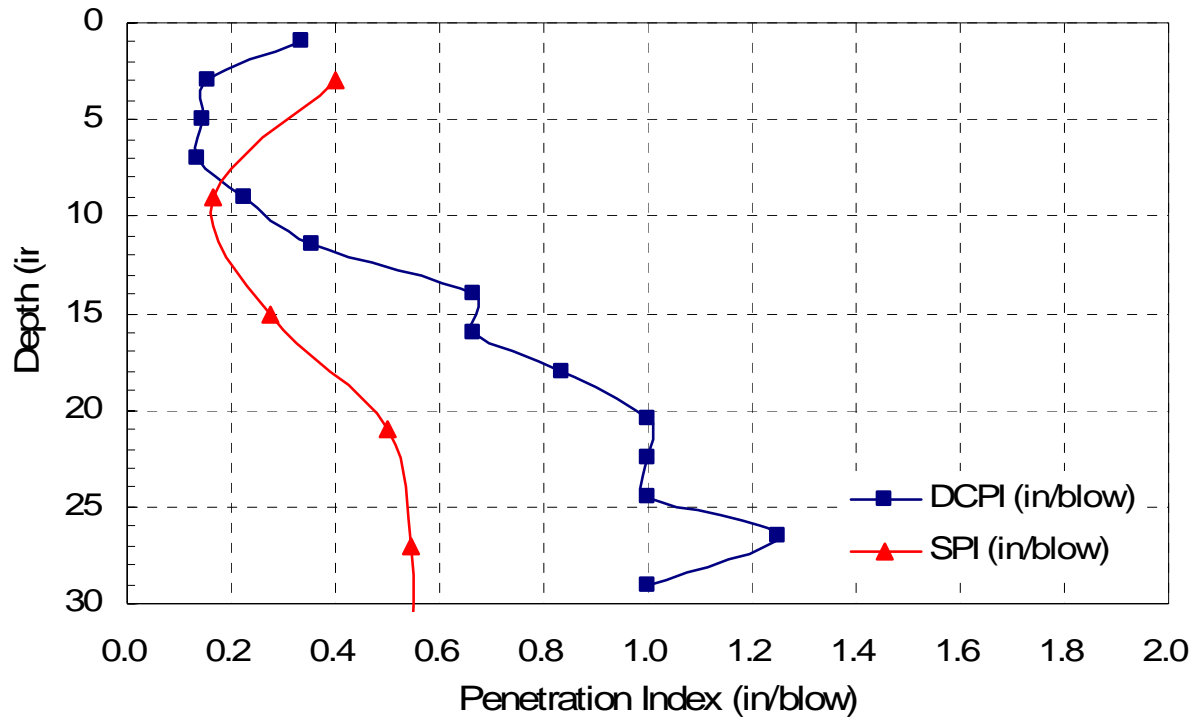

Figure 5.23 DCPT and SPT results with depth at BH-4 (STA. 60 meters). Site (2)

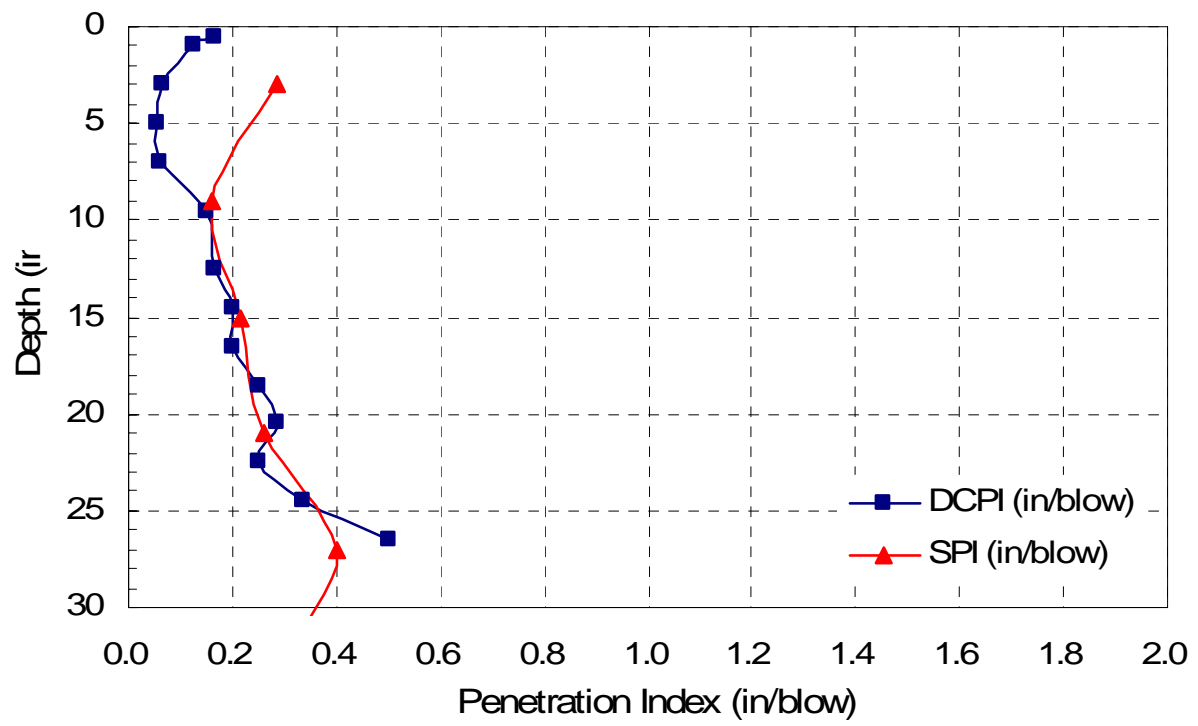

Figure 5.24 DCPT and SPT results with depth at BH-5 (STA. 80 meters). Site (2) 


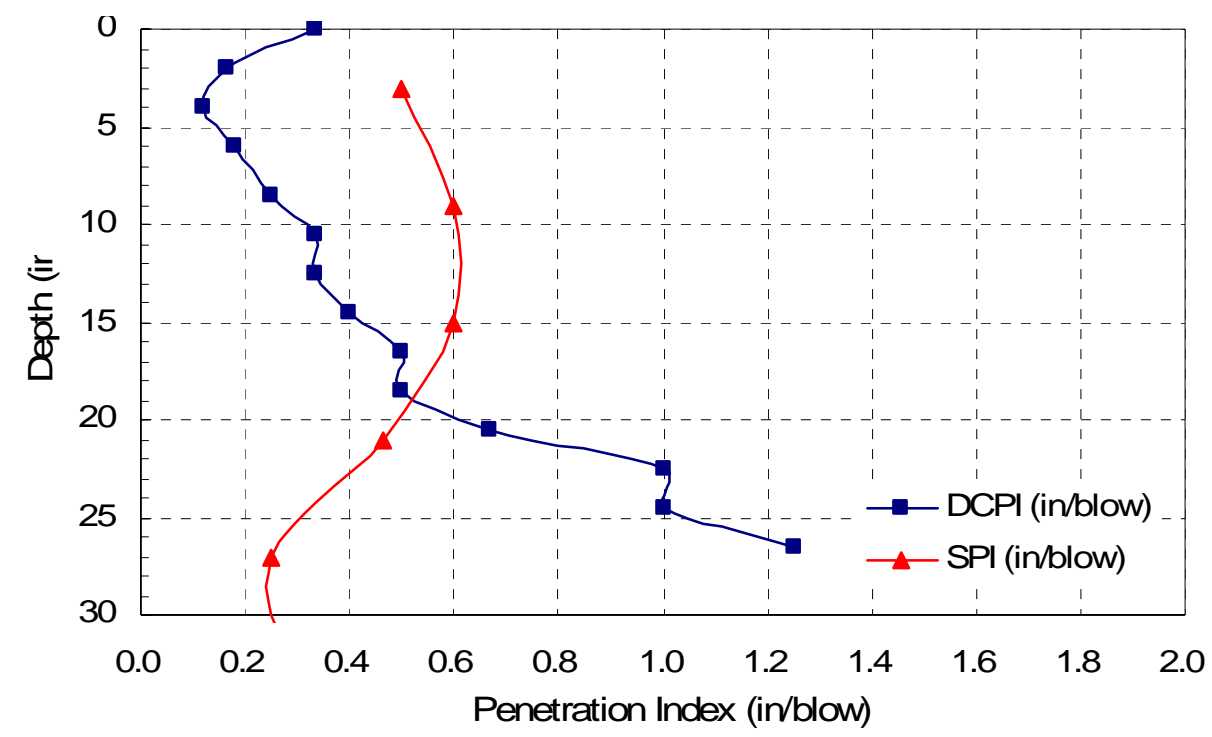

Figure 5.25 DCPT and SPT results with depth at BH-6 (STA. 100 meters). Site (2)

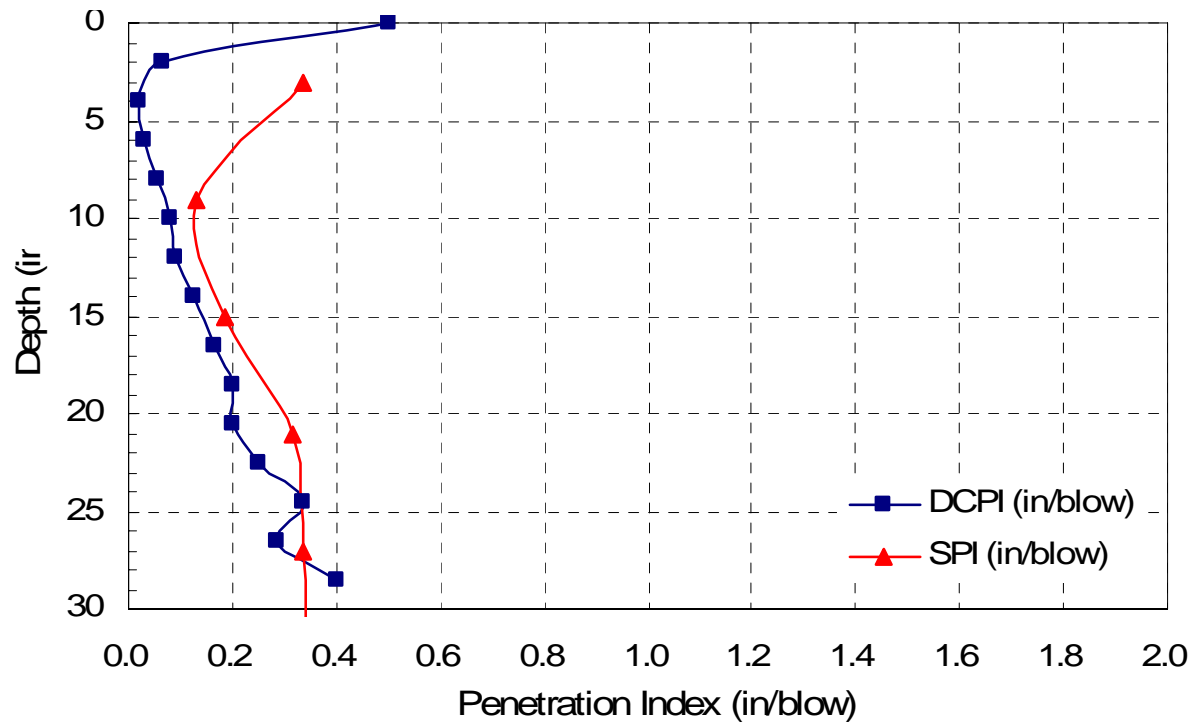

Figure 5.26 DCPT and SPT results with depth at BH-7 (STA. 120 meters). Site (2) 


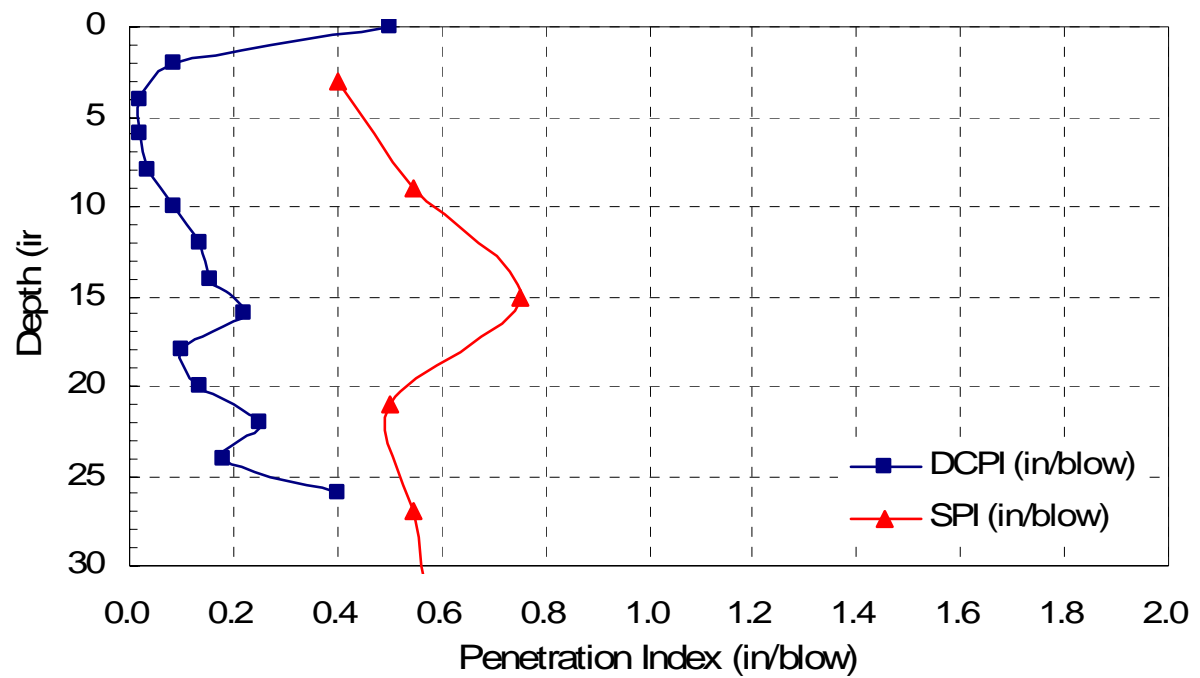

Figure 5.27 DCPT and SPT results with depth at BH-8 (STA. 140 meters). Site (2)

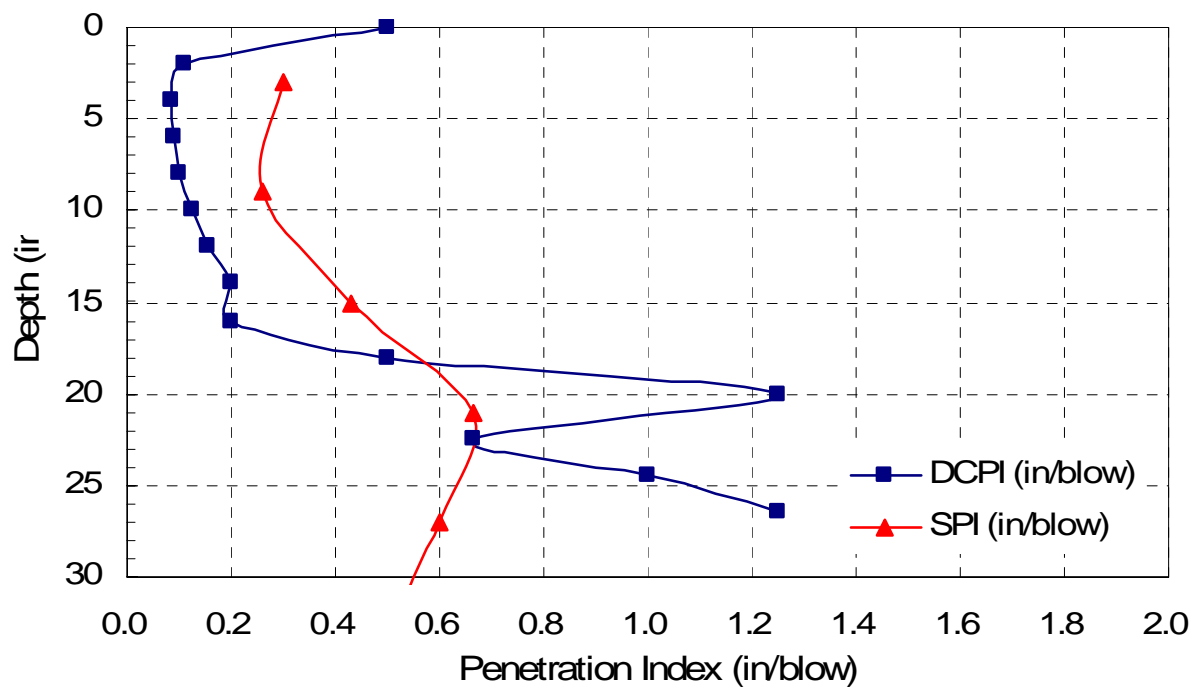

Figure 5.28 DCPT and SPT results with depth at BH-9 (STA. 160 meters). Site (2) 


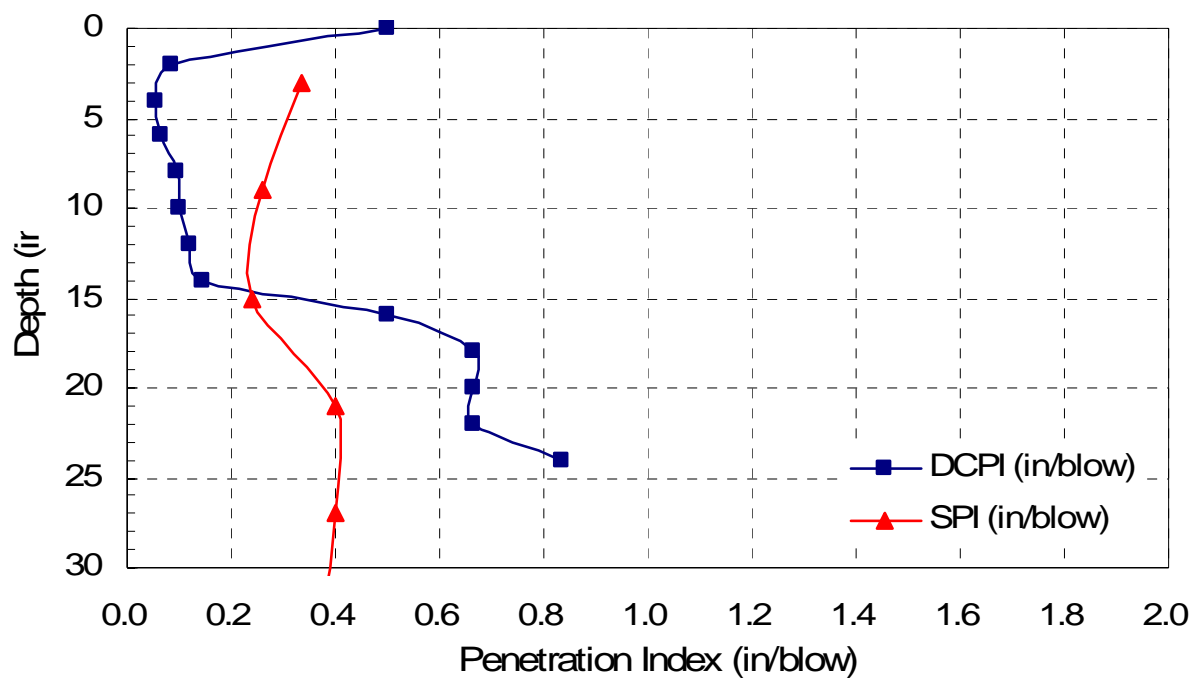

Figure 5.29 DCPT and SPT results with depth at BH-10 (STA. 180 meters). Site (2)

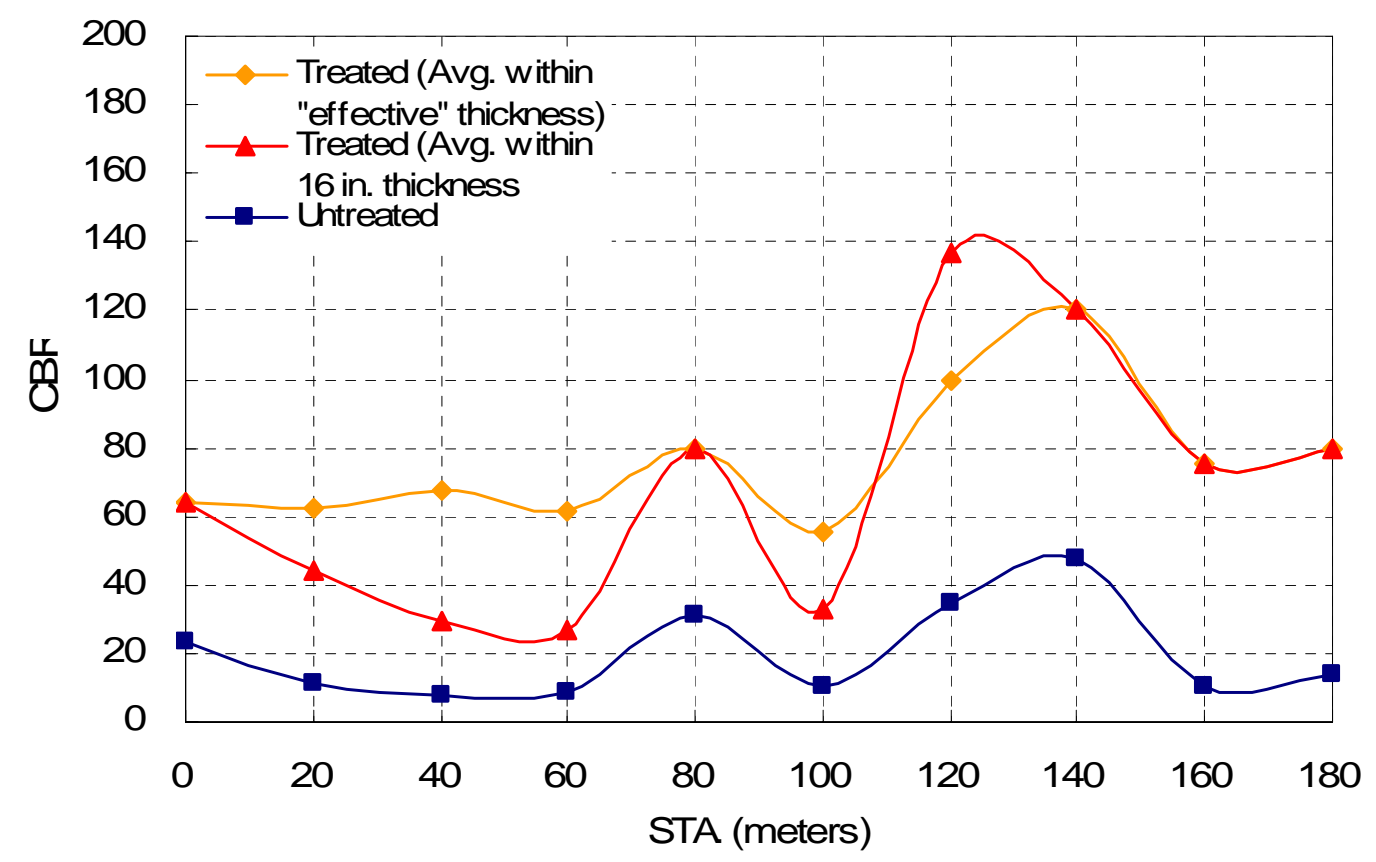

Figure 5.30 CBR of subgrade estimated from DCPT results. Site (2) 
Figure 5.30 plots the longitudinal distribution of CBR for both the lime-treated and natural soil layers. The CBR at each borehole location is determined based on a correlation of DCPI and CBR (Webster et al., 1992). To describe the CBR values of the lime-treated soil, the two values of the CBR are plotted: (1) the average value of DCPI's over the "effective thickness" (defined as the thickness of the lime-treated subgrade soil layer with approximately constant DCPI values less than 0.2 inches/blow); and (2) the average value of DCPI's over the theoretical 16- in thickness of the lime-treated subgrade.

For example, going back to Figure 5.28, the average DCPI value of the limetreated subgrade layer calculated within the "effective" thickness is the same $(=0.13$ inches/blow) as the average DCPI value over the entire thickness of 16 inches. The result of having the same two average values of DCPI represents that the lime treatment was uniform over the 16-in thickness. From the correlation between DCPI and CBR, the estimated CBR of the lime-treated subgrade is 75.5. At BH-7 (STA. 120 meters), the estimated CBR calculated within the effective thickness of the layer is smaller than the estimated CBR calculated within the thickness of 16 inches. This means that the effective thickness of the lime-treated subgrade is larger than 16 inches.

From Figure 5.30, it is observed that: (1) the CBR of the natural soil layer ranges between 7 and 47; (2) the CBR of the lime-treated subgrade soil layer, calculated within the effective thickness of the layer, ranges between 26 and 137, which results in an increase of the CBR by a factor of $150 \%$ to $810 \%$; (3) the CBR of the lime-treated subgrade soil layer, calculated within a thickness of 16 inches below the top of the subgrade, ranges between 55 and 120, which results in an increase of the CBR by a factor of $150 \%$ to $660 \%$; and (4) the distance between the two curves of the treated soil is a 
measure of the difference between the design and the actual depth of treatment.

While Figure 5.30 shows that there is an increase of the stiffness of the soil with treatment, and that such increase can be very substantial, it also shows significant variability.

\section{Lime content}

Figure 5.31 shows the $\mathrm{pH}$ values of both the lime-treated subgrade and natural soil, which are determined from samples taken at the boreholes drilled at the site. The lime-treated subgrade soil has a $\mathrm{pH}$ ranging from 9.4 to 11.2 while the untreated soil has a $\mathrm{pH}$ ranging from 7.3 to 8.4 . The increase of $\mathrm{pH}$ denotes the presence of lime.

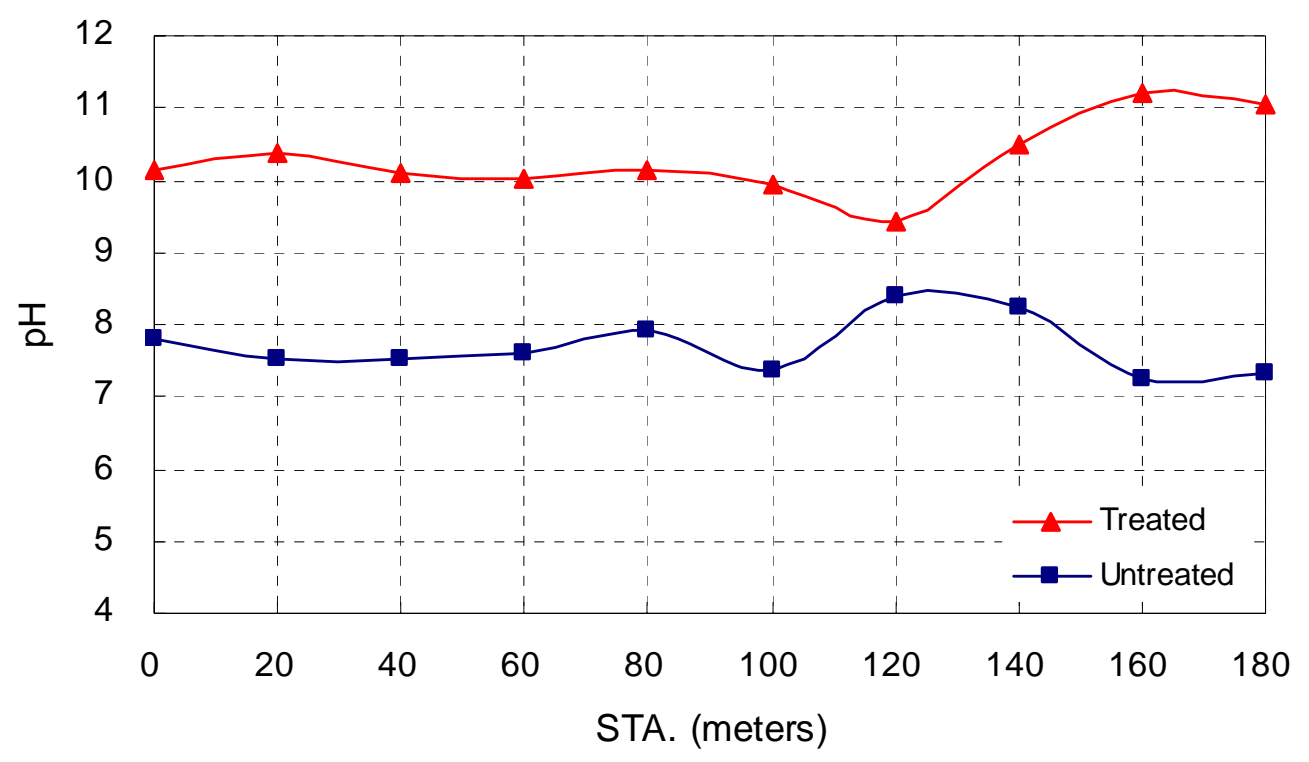

Figure $5.31 \mathrm{pH}$. Site (2)

Figure $5.32 \sim$ Figure 5.36 show the results of XRD tests from the lime-treated and natural soil samples at $\mathrm{BH}-2,4$, and 7, respectively. The lime-treated and natural soil samples were taken approximately at depths of 4 and 30 inches $r$ below the top of the 
subgrade. As discussed in Chapter $4, \mathrm{CaCO}_{3}$ is created by the reaction of calcium hydroxide $\left(\mathrm{Ca}(\mathrm{OH})_{2}\right)$ with carbon dioxide $\left(\mathrm{CO}_{2}\right)$. The existence of calcium carbonate $\left(\mathrm{CaCO}_{3}\right)$ in the lime-treated subgrade is observed in the XRD results.. The observation that the $\mathrm{CaCO}_{3}$ is not found in the natural soil confirms the fact that the source of the $\mathrm{CaCO}_{3}$ comes from the added lime. It also indicates that there is no leaching of the lime from the subgrade to the lower soil layer. In Figure 5.32, which shows a XRD pattern for a lime-treated soil sample taken at BH-2 (STA. 20 meters), it is observed that there is a peak at the critical X-ray refraction angles of $\mathrm{CaCO}_{3}$.. However, in Figure 5.33 that plots the XRD pattern for the untreated soil sample taken at BH-2, it is observed that the XRD pattern does not have a peak at the critical angles of $\mathrm{CaCO}_{3}$. The same results are found in the other figures.
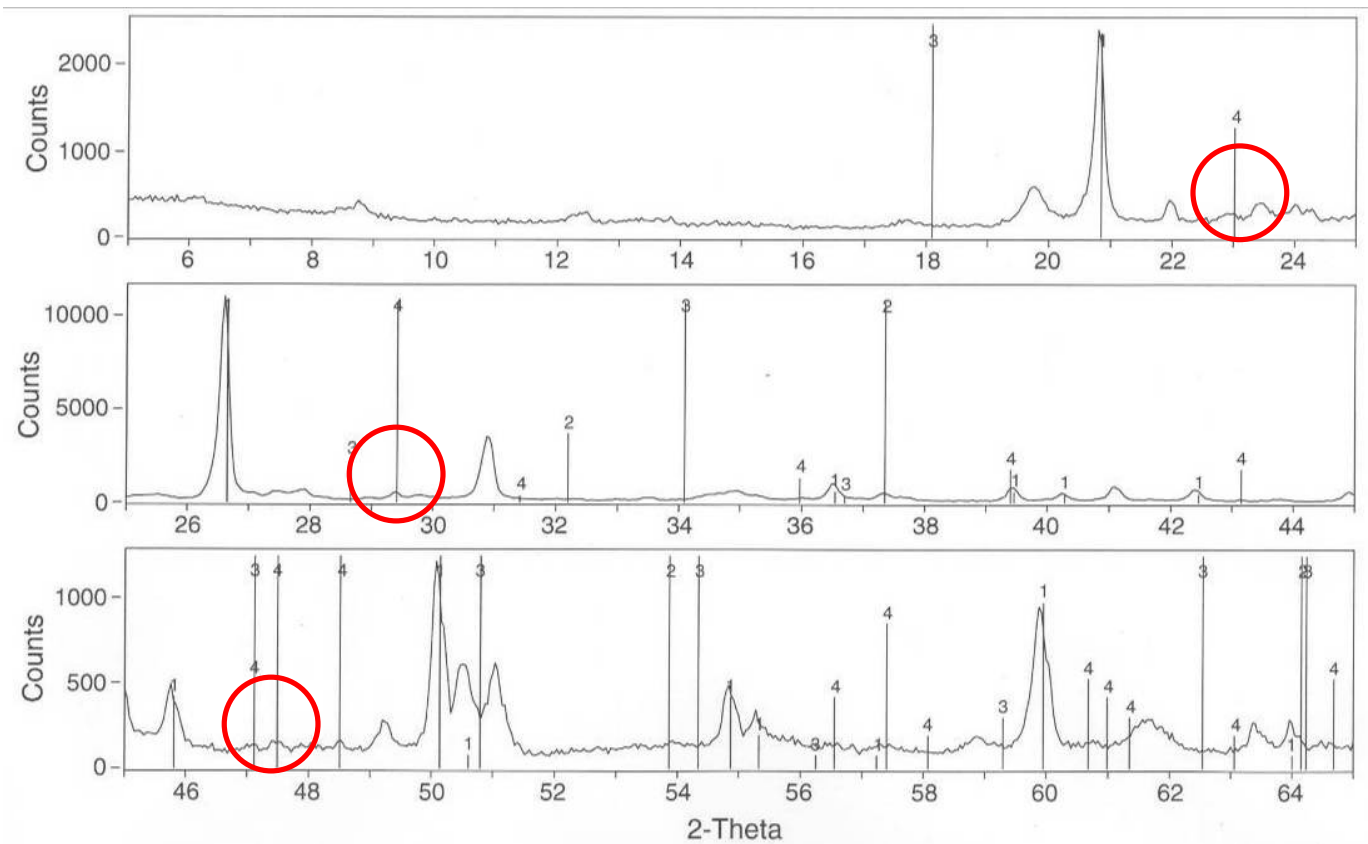

1> 33-1161: Quartz, syn - SiO2 3> 04-0733: Portlandite, syn - $\mathrm{Ca}(\mathrm{OH}) 2$

2> 37-1497: Lime, syn - CaO 4> 05-0586: Calcite, syn - $\mathrm{CaCO} 3$

Figure 5.32 XRD pattern for lime-treated soil sample at BH-2 (STA. 20 meters). Site (2) 

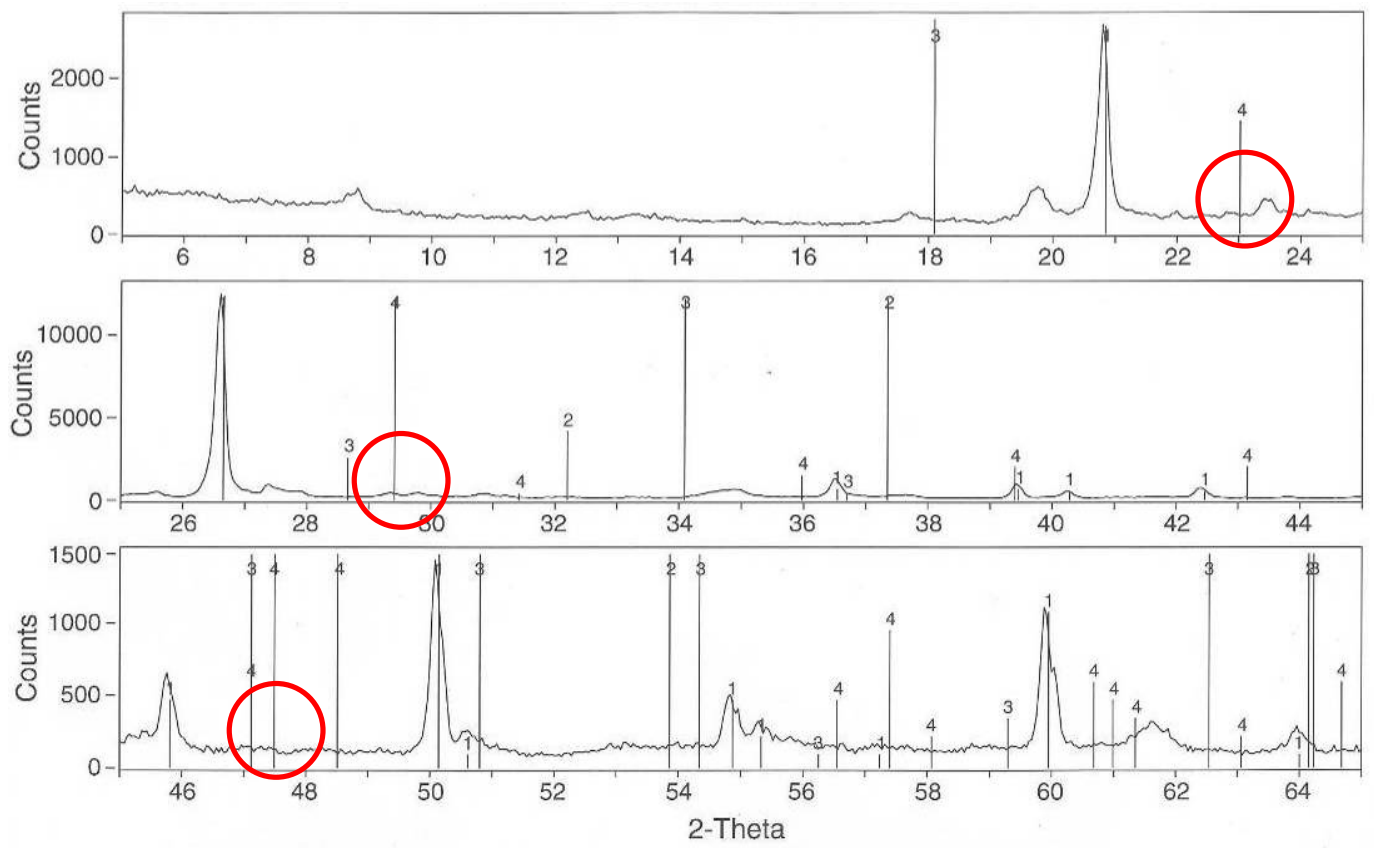

1> 33-1161: Quartz, syn - SiO2

2> 37-1497: Lime, syn - CaO

3> 04-0733: Portlandite, syn - $\mathrm{Ca}(\mathrm{OH}) 2$

4> 05-0586: Calcite, syn - CaCO3

Figure 5.33 XRD pattern for untreated soil sample BH-2 (STA. 20 meters). Site (2)
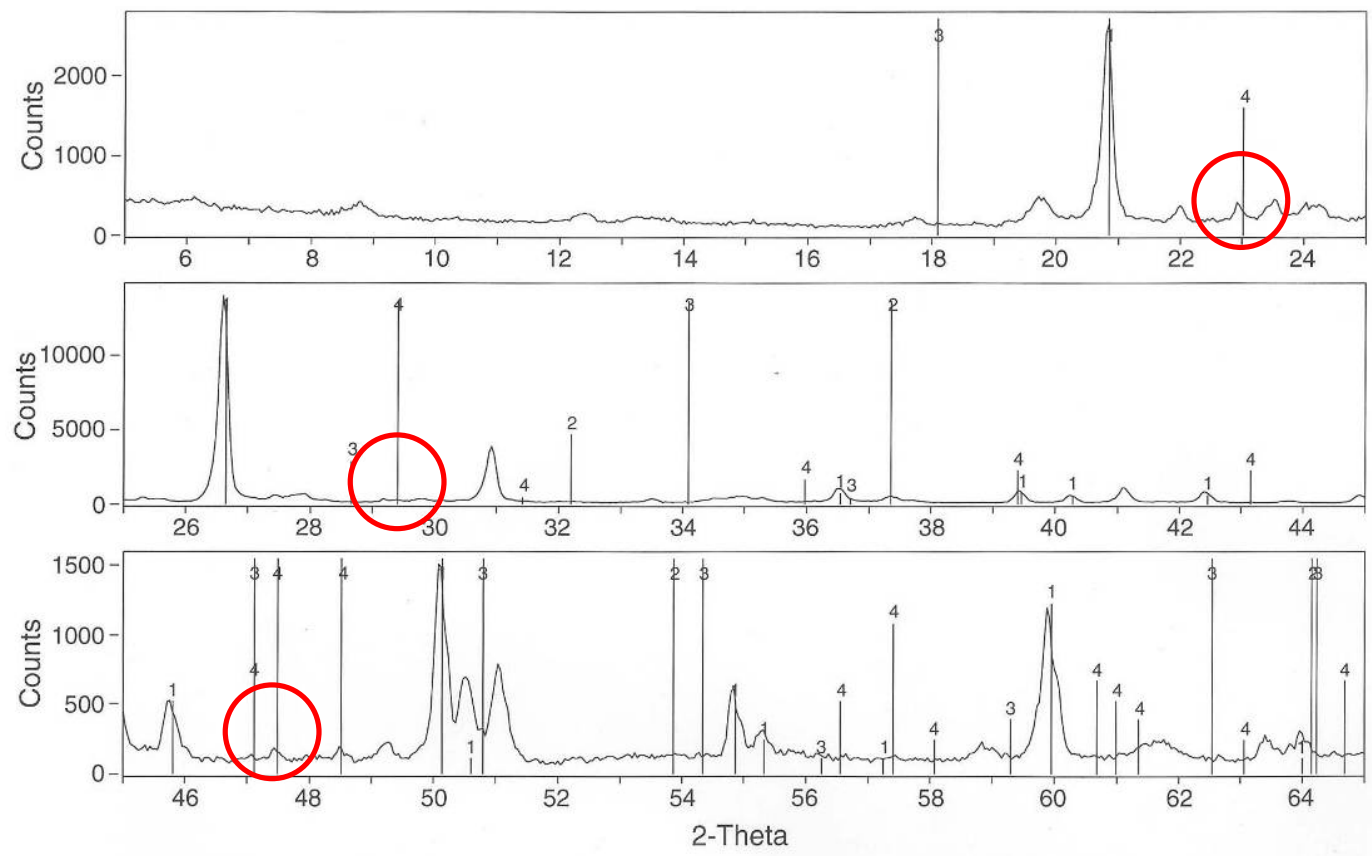

1> 33-1161: Quartz, syn - SiO2

3> 04-0733: Portlandite, syn - $\mathrm{Ca}(\mathrm{OH}) 2$

2> 37-1497: Lime, syn - CaO

4> 05-0586: Calcite, syn - $\mathrm{CaCO} 3$

Figure 5.34 XRD pattern for lime-treated soil sample at BH-4 (STA. 60 meters). Site (2) 

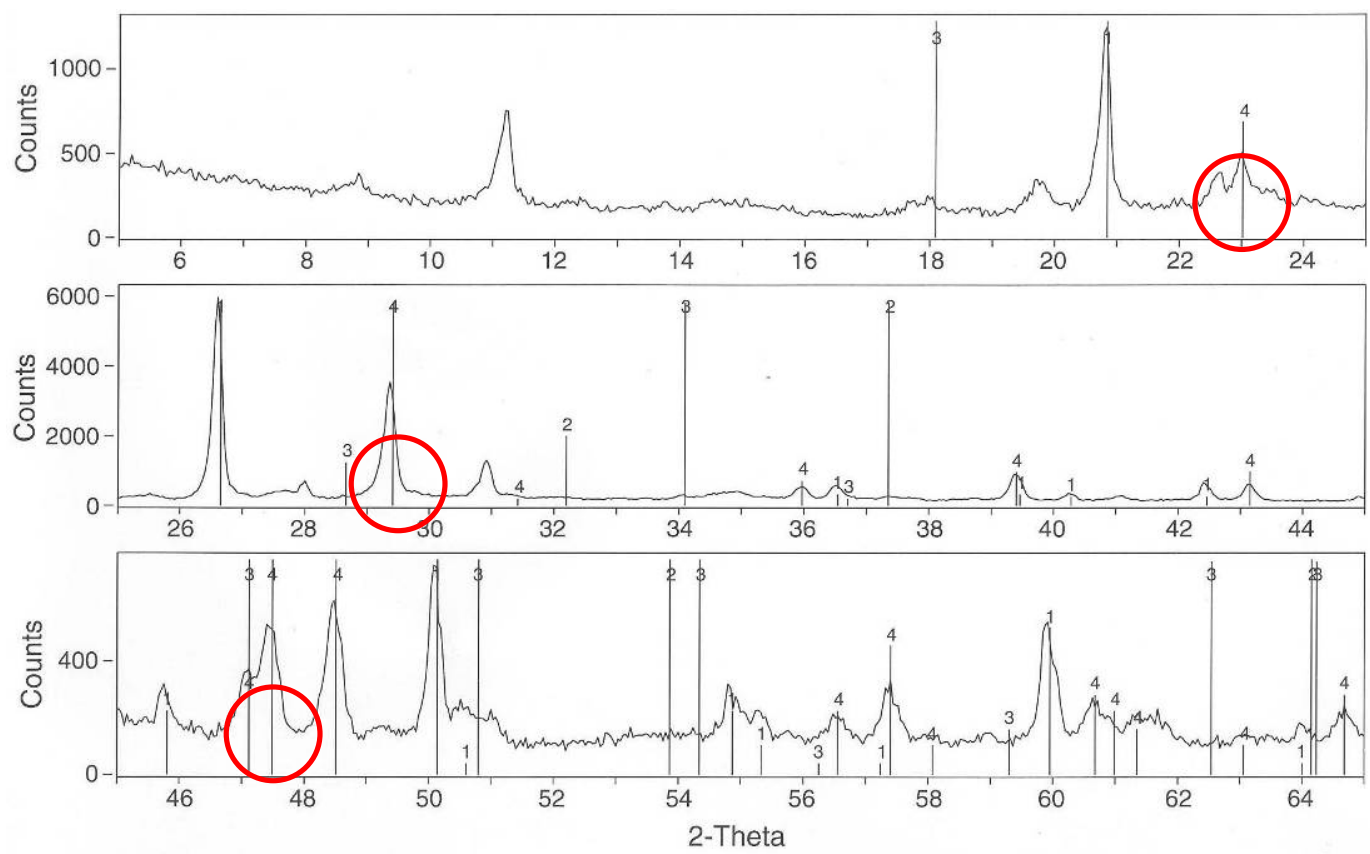

1> 33-1161: Quartz, syn - SiO2

3> 04-0733: Portlandite, syn - $\mathrm{Ca}(\mathrm{OH}) 2$

2> 37-1497: Lime, syn - CaO

4> 05-0586: Calcite, syn - CaCO3

Figure 5.35 XRD pattern for lime-treated soil sample at BH-7 (STA. 120 meters). Site (2)
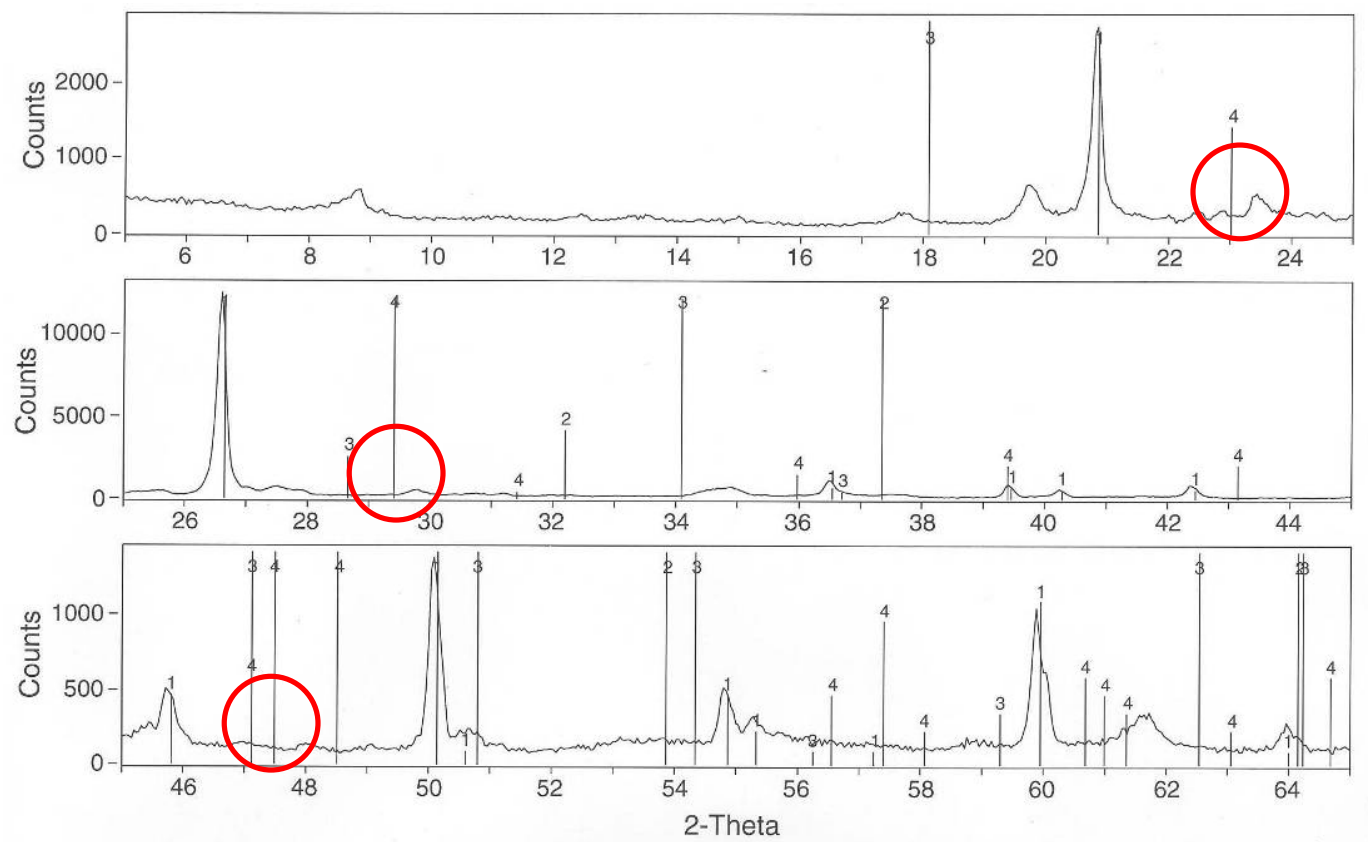

1> 33-1161: Quartz, syn - SiO2

2> 37-1497: Lime, syn - CaO

3> 04-0733: Portlandite, syn - $\mathrm{Ca}(\mathrm{OH}) 2$

4> 05-0586: Calcite, syn - CaCO3

Figure 5.36 XRD pattern for untreated soil sample at BH-7 (STA. 120 meters). Site (2) 
Figure $5.37 \sim$ Figure 5.41 show the XRD pattern for the lime-treated soil samples collected at depths of $0,4,8,12$, and 16 inches below the top of the subgrade at $\mathrm{BH}-2$ (STA. 20 meters). The XRD tests were done to investigate the distribution of lime with depth. In all the figures, the XRD pattern has a small peak at the critical refraction angles of $\mathrm{CaCO} 3$.
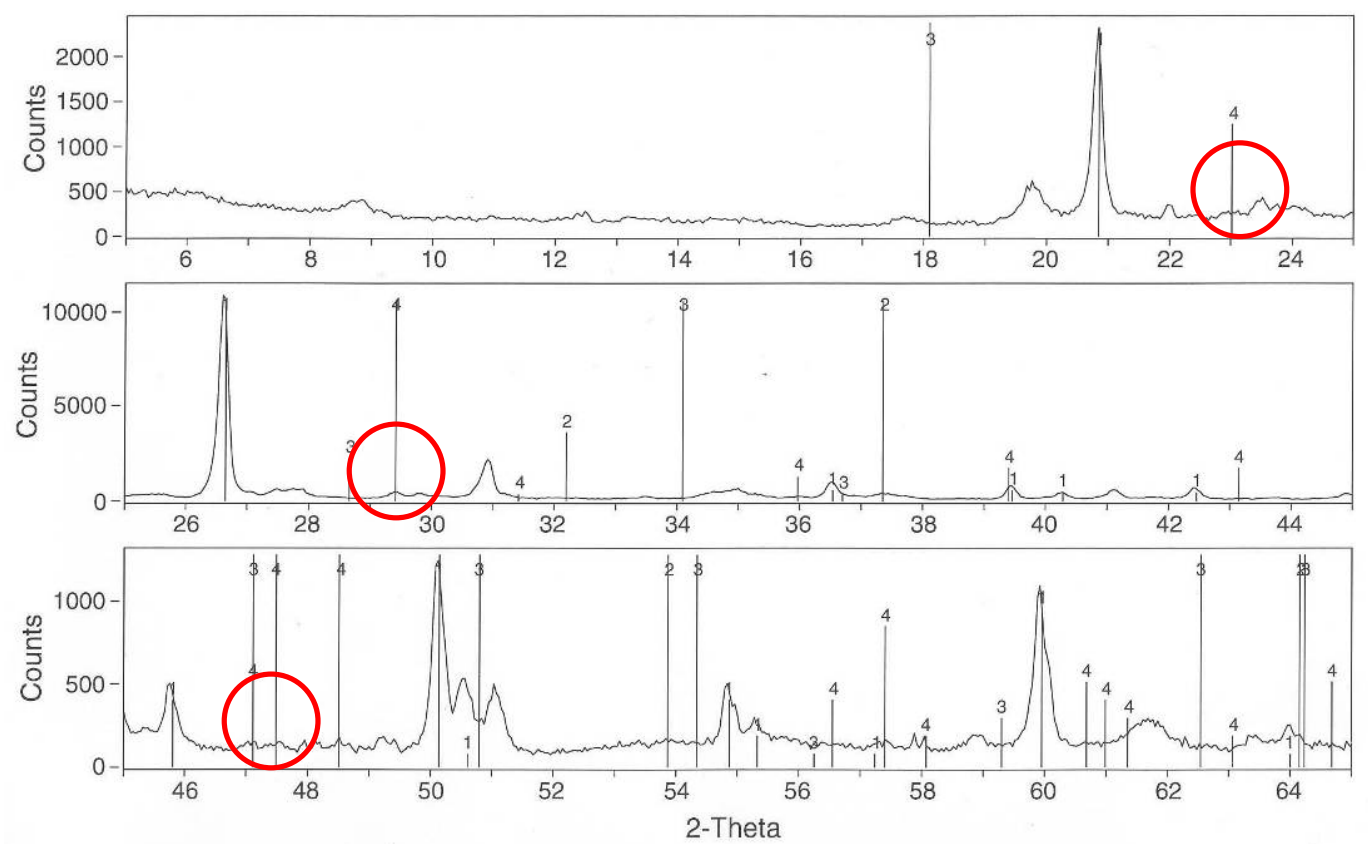

1> 33-1161: Quartz, syn - SiO2 3> 04-0733: Portlandite, syn - $\mathrm{Ca}(\mathrm{OH}) 2$

2> 37-1497: Lime, syn - CaO 4> 05-0586: Calcite, syn - CaCO3

Figure 5.37 XRD pattern for lime-treated soil sample taken at a depth of 0 inches below top of subgrade at BH-2 (STA. 20 meters). Site (2) 

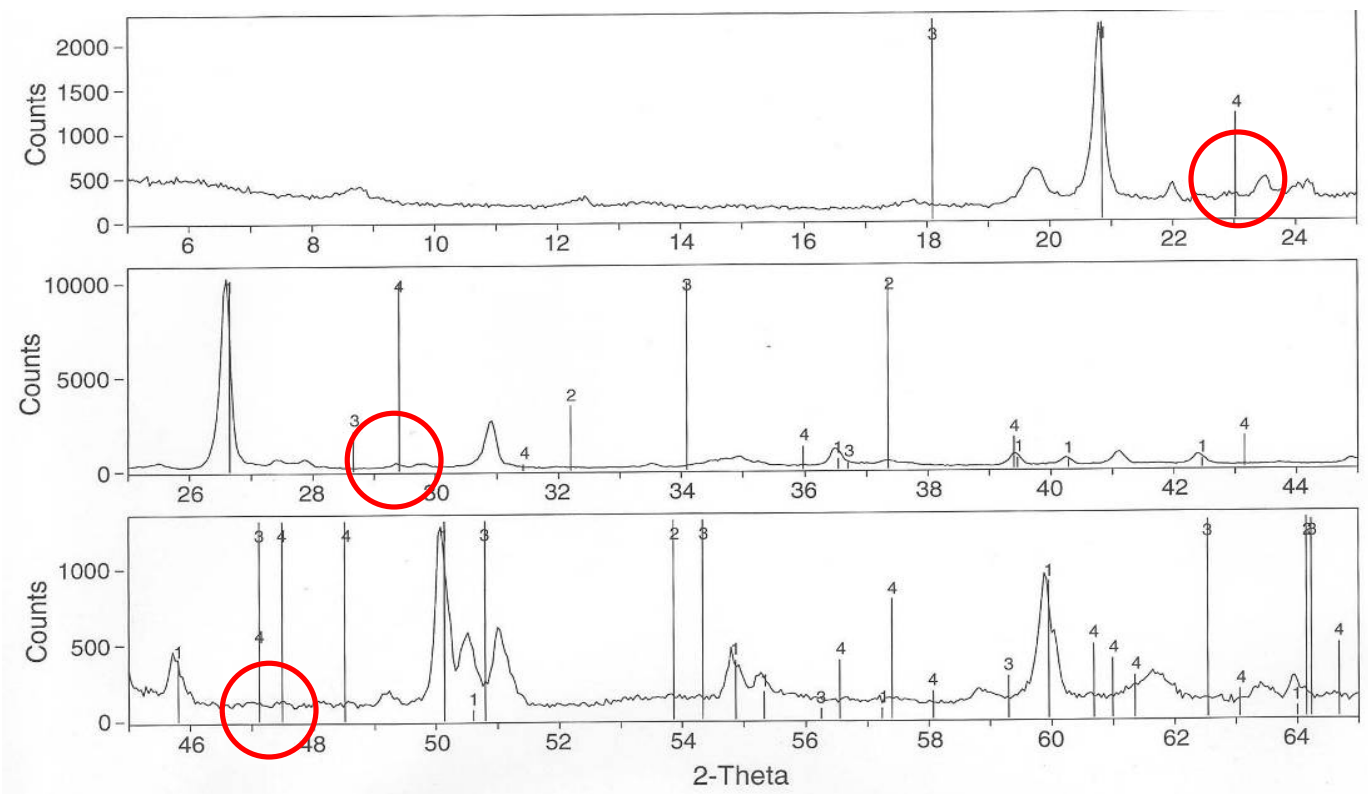

1> 33-1161: Quartz, syn - SiO2

2> 37-1497: Lime, syn - CaO

3> 04-0733: Portlandite, syn - $\mathrm{Ca}(\mathrm{OH}) 2$

4> 05-0586: Calcite, syn - $\mathrm{CaCO} 3$

Figure 5.38 XRD pattern for lime-treated soil sample taken at a depth of 4 inches below top of subgrade at BH-2 (STA. 20 meters). Site (2)
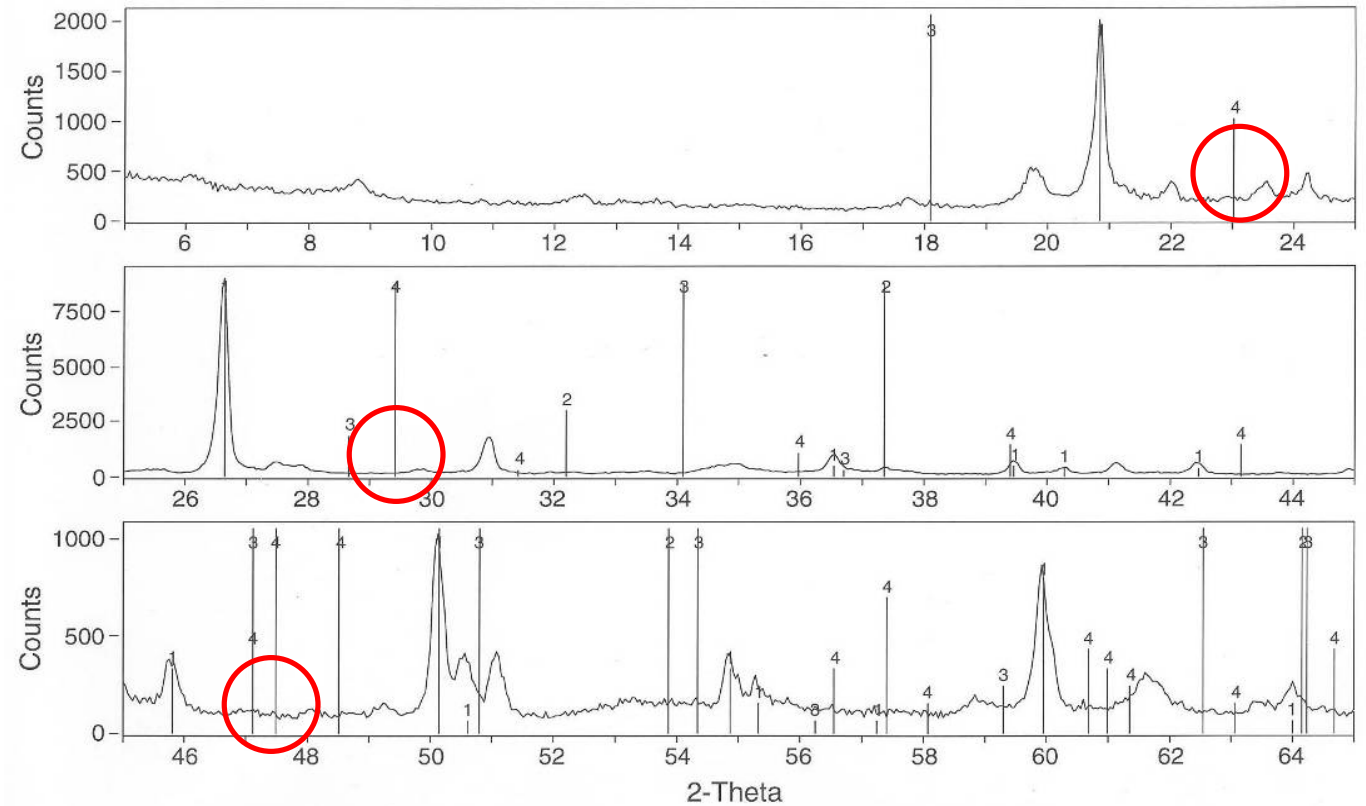

1> 33-1161: Quartz, syn - SiO2

3> 04-0733: Portlandite, syn - $\mathrm{Ca}(\mathrm{OH}) 2$

2> 37-1497: Lime, syn - CaO

4> 05-0586: Calcite, syn - CaCO3

Figure 5.39 XRD pattern for lime-treated soil sample taken at a depth of 8 inches below top of subgrade at BH-2 (STA. 20 meters). Site (2) 

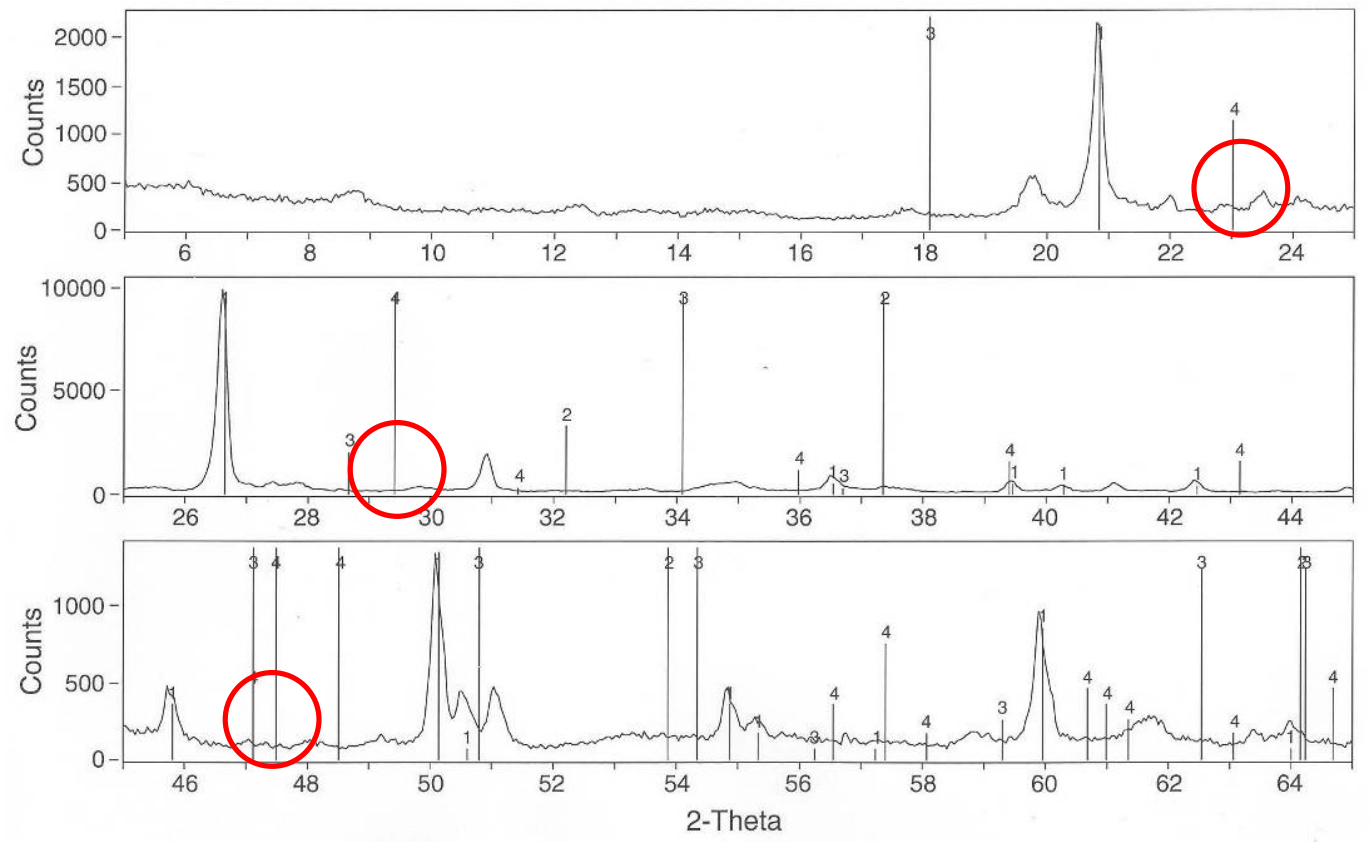

1> 33-1161: Quartz, syn - SiO2

3> 04-0733: Portlandite, syn - $\mathrm{Ca}(\mathrm{OH}) 2$

2> 37-1497: Lime, syn - CaO

4> 05-0586: Calcite, syn - CaCO3

Figure 5.40 XRD pattern for lime-treated soil sample taken at a depth of 12 inches below top of subgrade at BH-2 (STA. 20 meters). Site (2)
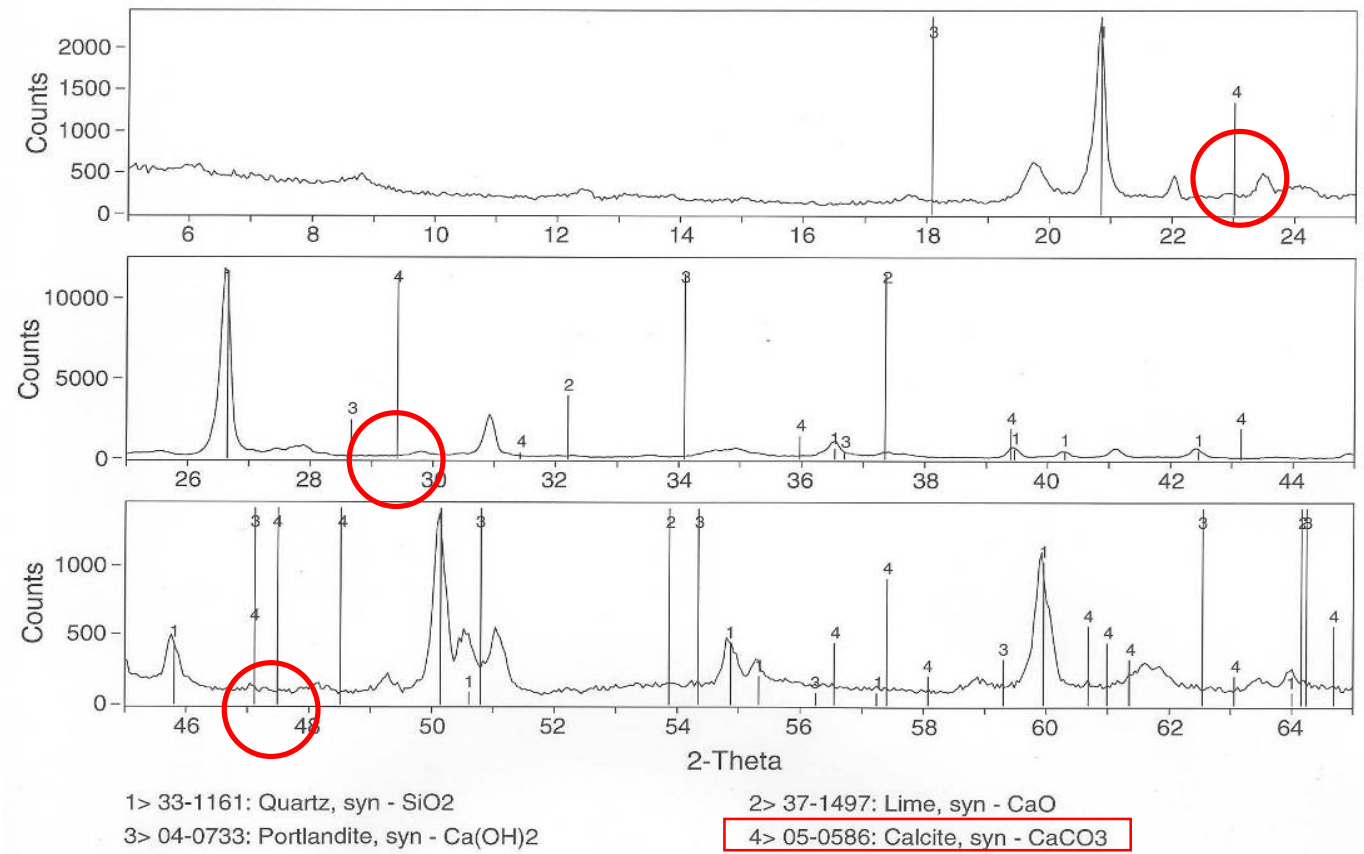

Figure 5.41 XRD pattern for lime-treated soil sample taken at a depth of 16 inches below top of subgrade at BH-2 (STA. 20 meters). Site (2) 
Figure $5.42 \sim$ Figure 5.44 plot the results of TGA tests on the lime-treated and natural soil samples. Considering that 5\% LKD was used at site (2), the lime-treated subgrade should have a lime content of 1.5 to $3 \%$. From the figure, the calculated amount of $\mathrm{CaCO}_{3}$, is 7, 9.5, and $10 \%$ at BH-2 (STA. 20 meters), BH-4 (STA. 60 meters), and BH-7 (STA. 120 meters), respectively. From the TGA results at site (2), the amount of the added LKD would be more than $5 \%$. This appears to indicate that in the lime used there was a substantial quantity of non-reactive $\mathrm{CaCO}_{3}$.

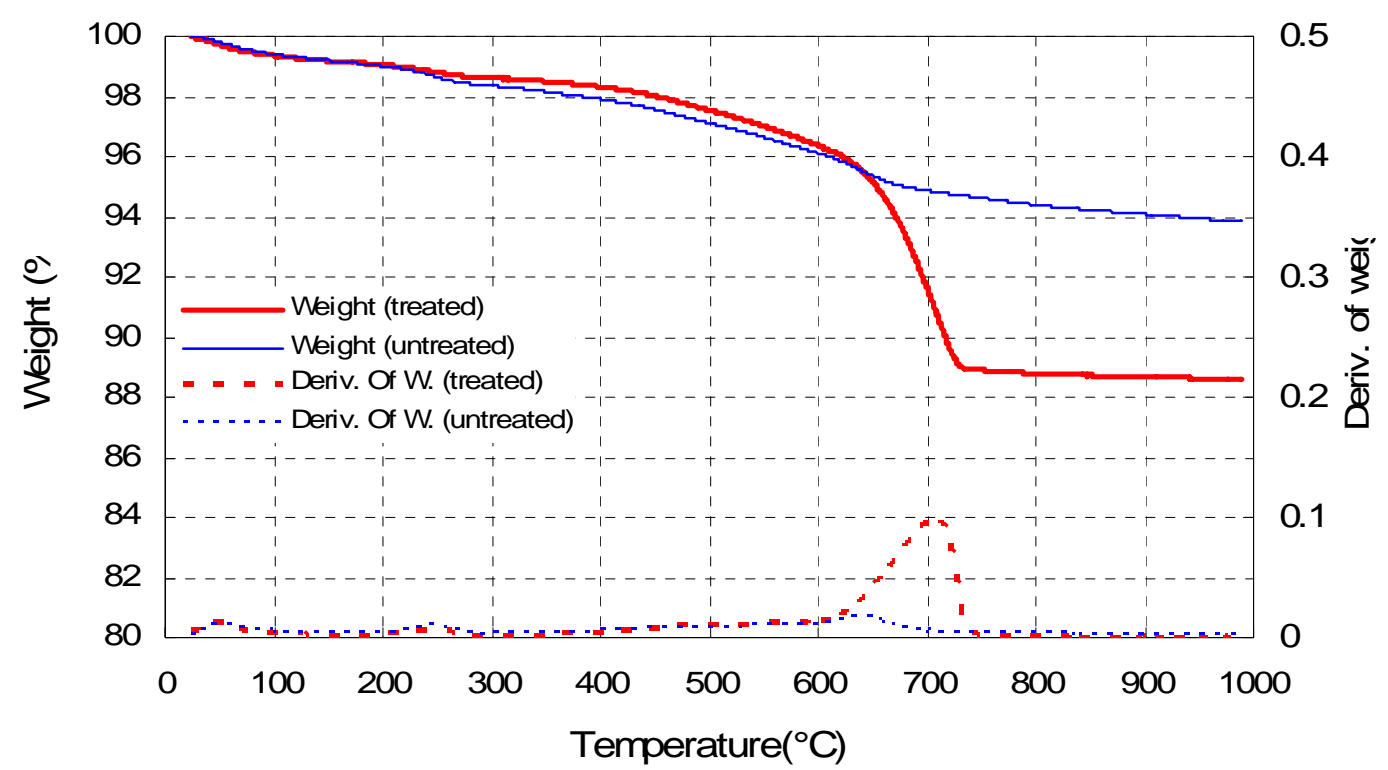

Figure 5.42 Weight loss and weight loss rate obtained from TGA from lime-treated and natural soil samples collected at BH-2 (STA. 20 meters) at site (2) 


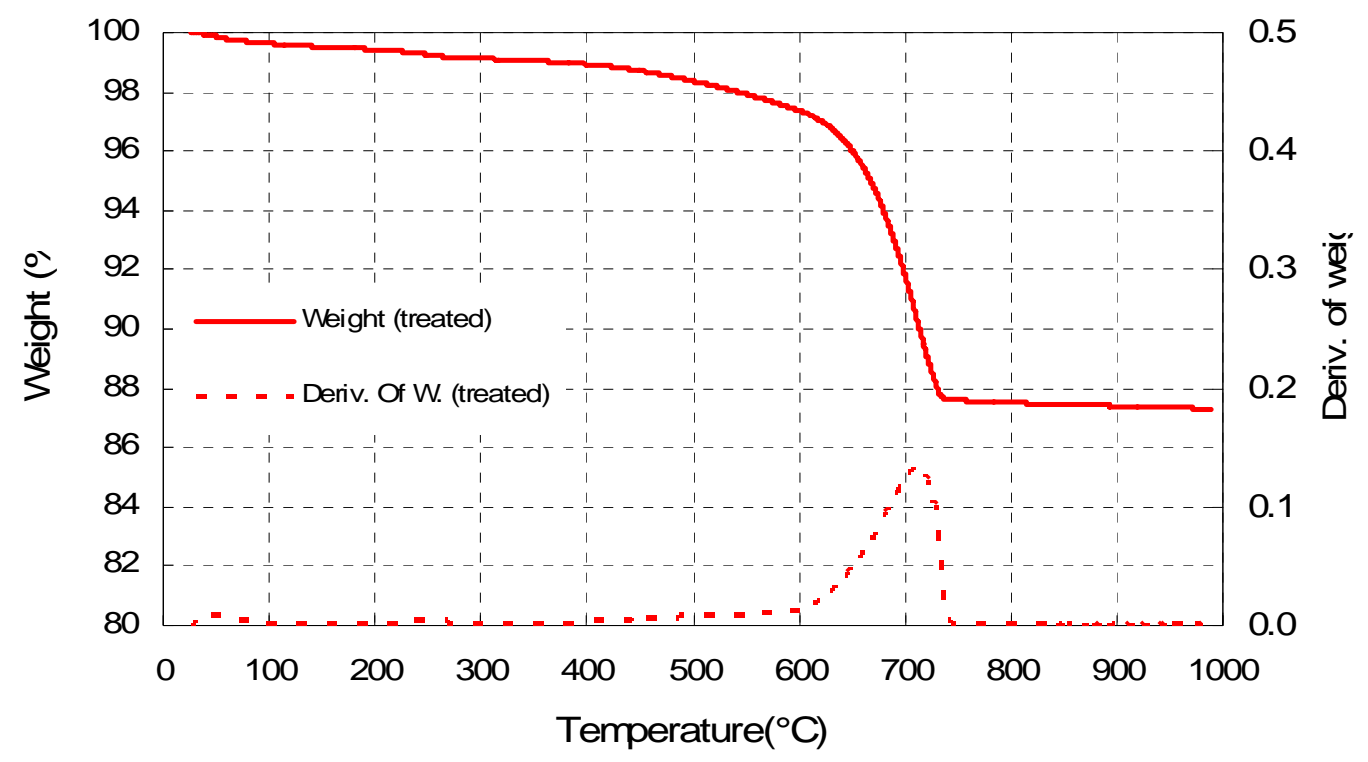

Figure 5.43 Weight loss and weight loss rate obtained from TGA from lime-treated and natural soil samples collected at BH-4 (STA. 60 meters) at site (2)

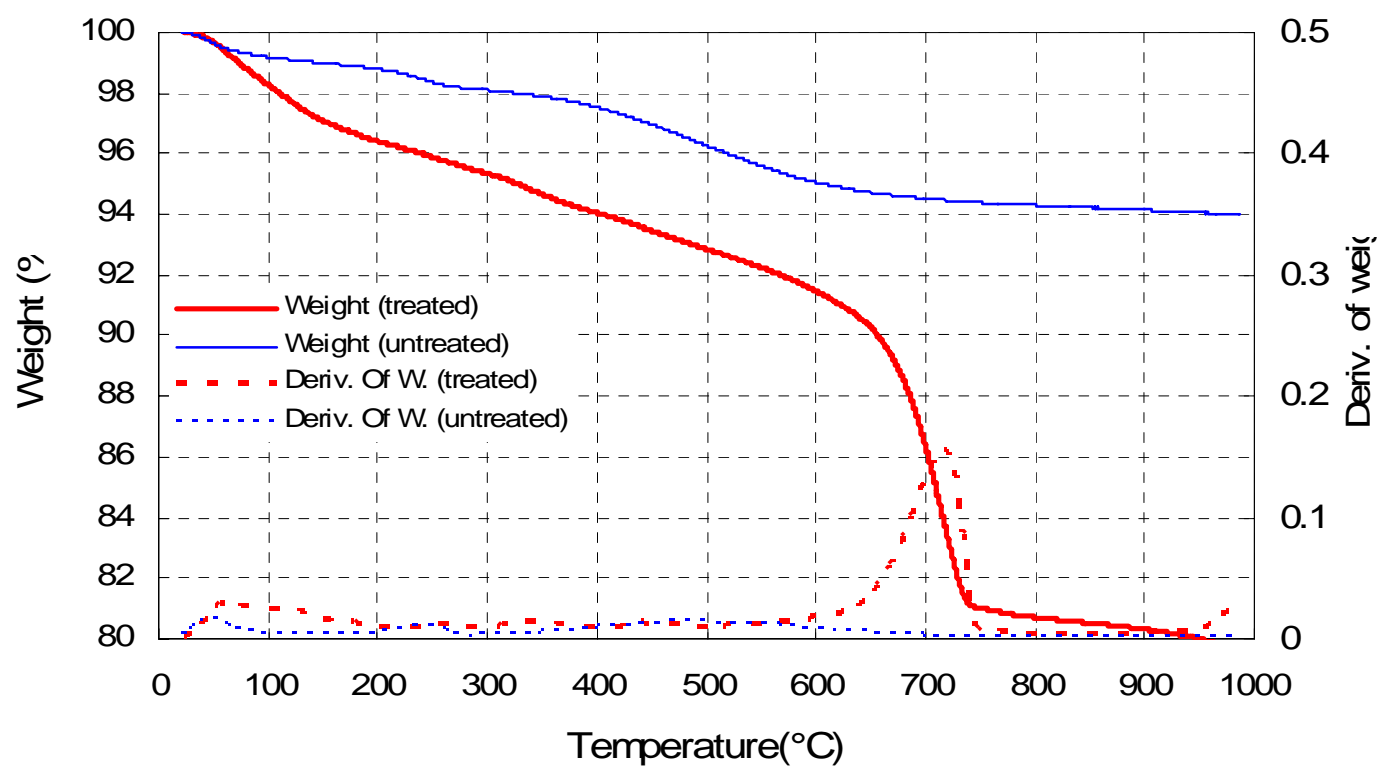

Figure 5.44 Weight loss and weight loss rate obtained from TGA from lime-treated and natural soil samples collected at BH-7 (STA. 120 meters) at site (2) 


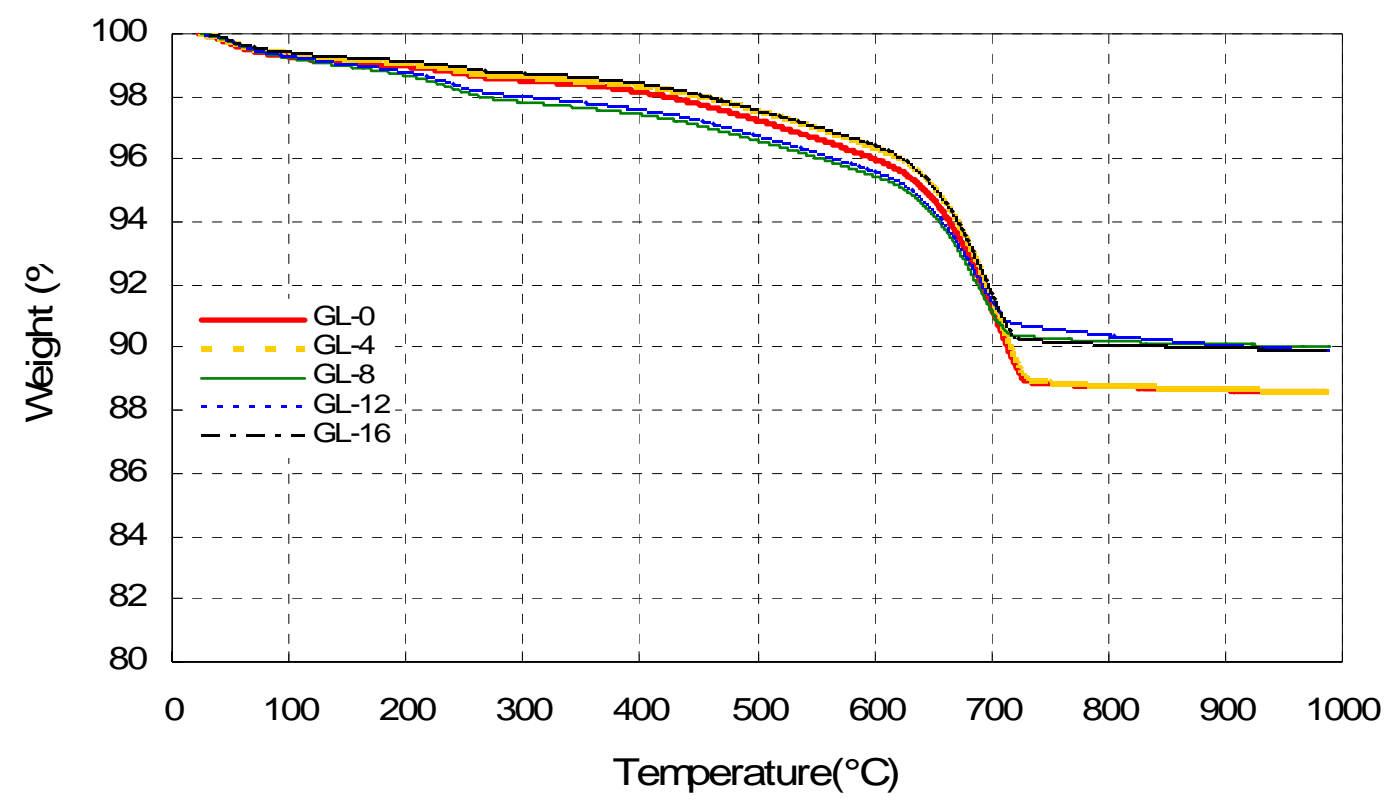

Figure 5.45 Weight loss and weight loss rate obtained from TGA from lime-treated soil samples collected at depths of $0,4,8,12$, and 16 inches below top of subgrade, at BH-2

(STA. 20 meters) at site (2)

Figure 5.45 shows TGA results of the lime-treated soil samples that are collected at depths of $0,4,8,12$, and 16 inches below the top of the subgrade at BH-2 (STA. 20 meters). The amount of $\mathrm{CaCO}_{3}$ decreases a little from $7 \%$ at the top of the subgrade to $5.5 \%$ at 16 -in. depth. Since a significant amount of $\mathrm{CaCO}_{3}$ is found even at 16 -in. it appears that in this job the lime was well mixed with the natural soil through the entire thickness of 16 inches. This agrees well with the DCPI plots in Figures 5.20 to \%.30.

The $\mathrm{CaCO}_{3}$ content is plotted together with $\mathrm{CBR}$ in Figure 5.46 in an attempt to determine whether there is a strong correlation between lime dosage and CBR. From the figure, it appears that there exists some correlation between $\mathrm{CaCO}_{3}$ and $\mathrm{CBR}$, but the correlation is not strong. As already mentioned in the discussion for site (1), other factors such as percentage of active lime, construction quality and compaction, may also have a strong effect. 


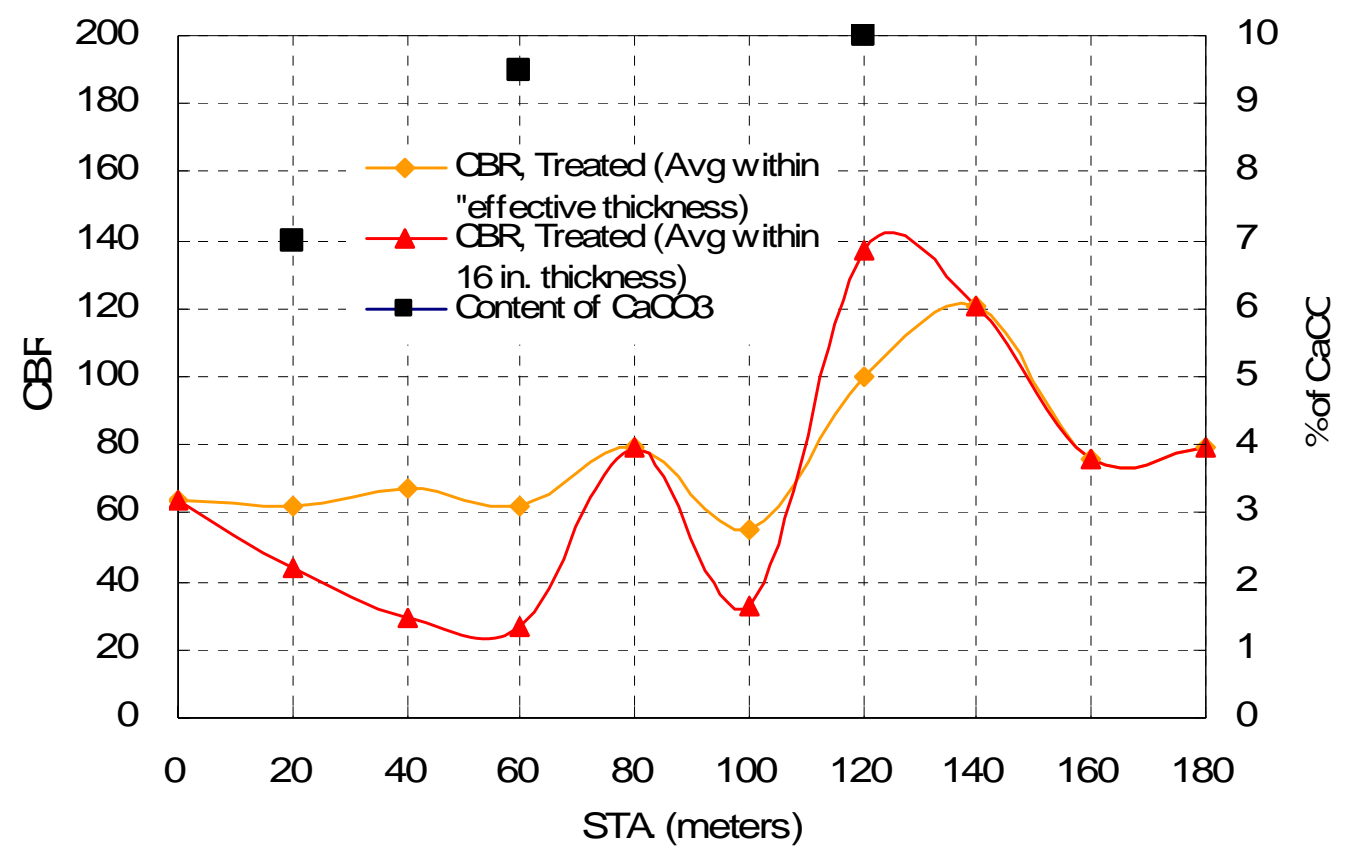

Figure 5.46 CBR and $\mathrm{CaCO}_{3}$ content at site (2)

The laboratory and field tests results indicate that the lime still remains in the subgrade after five years of service, and that the lime-treated subgrade still has the engineering properties gained with the addition of the lime. In addition, given the lime content found in the laboratory analyses, it appears that there has been no leaching of the lime from the subgrade to the natural soil. 


\subsection{Site (3)}

\section{Soil characterization properties}

Figure 5.47 shows the natural water content and soil index properties of the limetreated subgrade and natural soil determined at site (3). The water content of the limetreated and untreated soils is determined from samples taken at approximately 8 -in and 30-in depths, respectively, below the top of the subgrade. The water content of the limetreated subgrade ranges between 10 and $19 \%$ while the natural soil between 17 and $25 \%$. The water content of the lime-treated subgrade is lower than the natural soil.

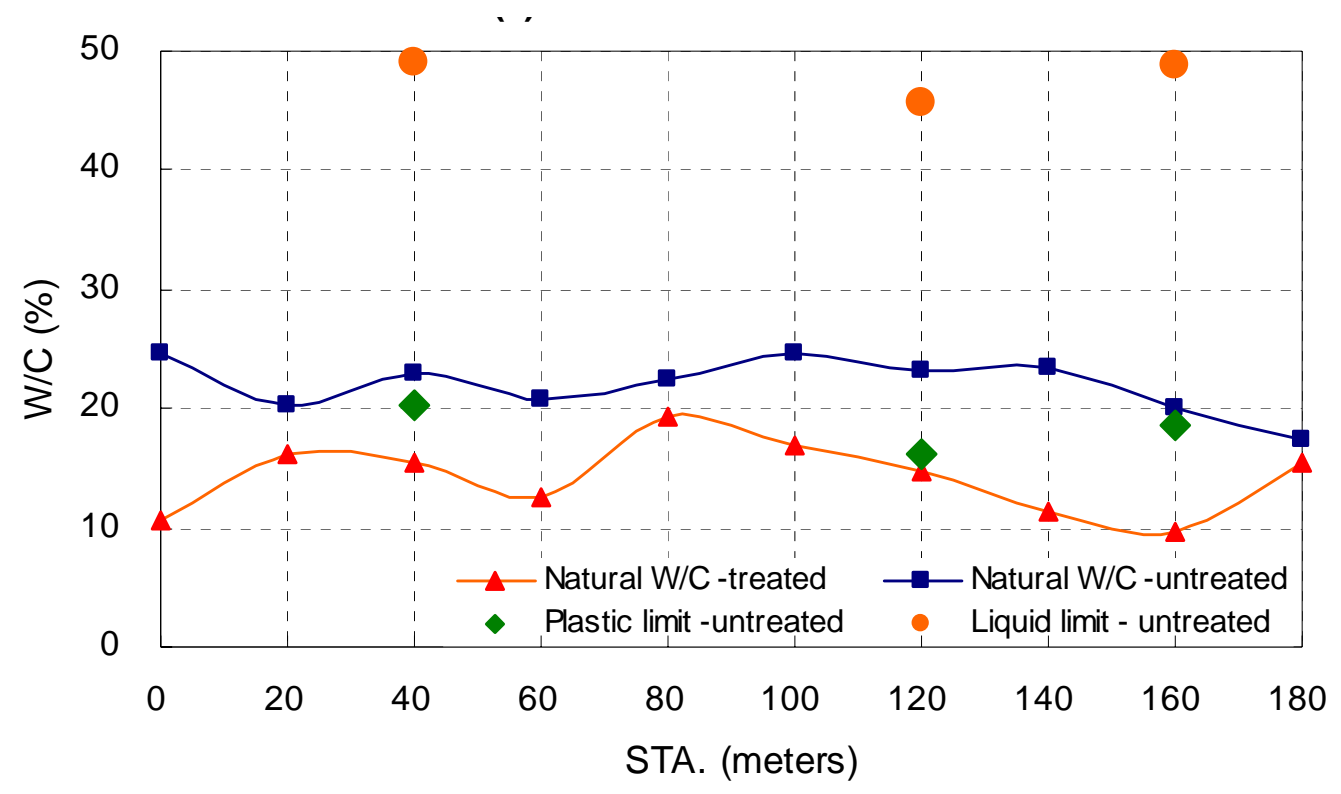

Figure 5.47 Natural water content and soil index properties. Site (3) 


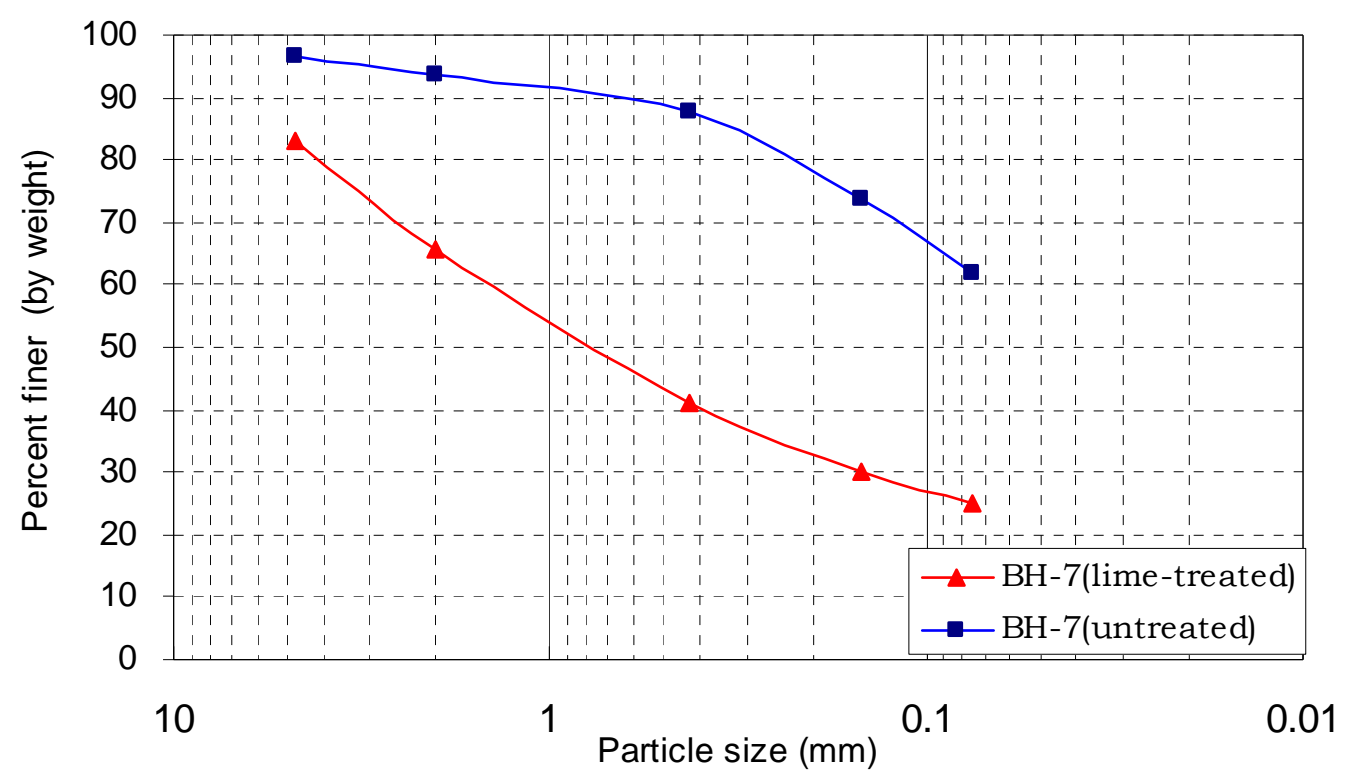

Figure 5.48 Particle-size distribution. Site (3)

Figure 5.48 shows the particle-size distribution from wet sieving tests on both the lime-treated and the natural soil. The amount passing the No. 200 sieve is $25 \%$ for the soil with lime and $62 \%$ for the natural soil. Atterberg limit tests indicate that the limetreated subgrade soil is non-plastic. The natural (untreated) soil has a Plastic Limit (PL) of 19, a Liquid Limit (LL) of 47, and a Plastic Index (PI) of 29. Based on the laboratory results, the lime-treated subgrade soil is classified as SM following USCS (Unified Soil Classification System), or A-2-4 in accordance with the AASHTO classification. The natural soil is classified as CL and A-7-6, respectively. Hence the soil was modified from a low-plasticity clay to a silty sand.

\section{Stiffness and/or strength properties}

The $\mathrm{M}_{\mathrm{R}}$ of the subgrade is $56 \mathrm{ksi}$ and of the natural soil is $28 \mathrm{ksi}$ from backcalculation of the deflection data obtained from the FWD tests at the site. The FWD 
results show an increase of the $\mathrm{M}_{\mathrm{R}}$ of the treated subgrade by a factor of $100 \%$.

Figure $5.49 \sim$ Figure 5.58 show DCPI (Dynamic Cone Penetration Index) and SPI (Standard Penetration Index) with depth of penetration at all the ten boreholes done at the site. From Figure 5.49, Figure 5.50, and Figure 5.55, the effective thickness of the limetreated subgrade soil layer is 8, 10, and 6 inches at BH-1, 2, and 7 (STA. 0, 20, and 120 meters), respectively. There is no evidence at the other locations that the treatment has been successful.

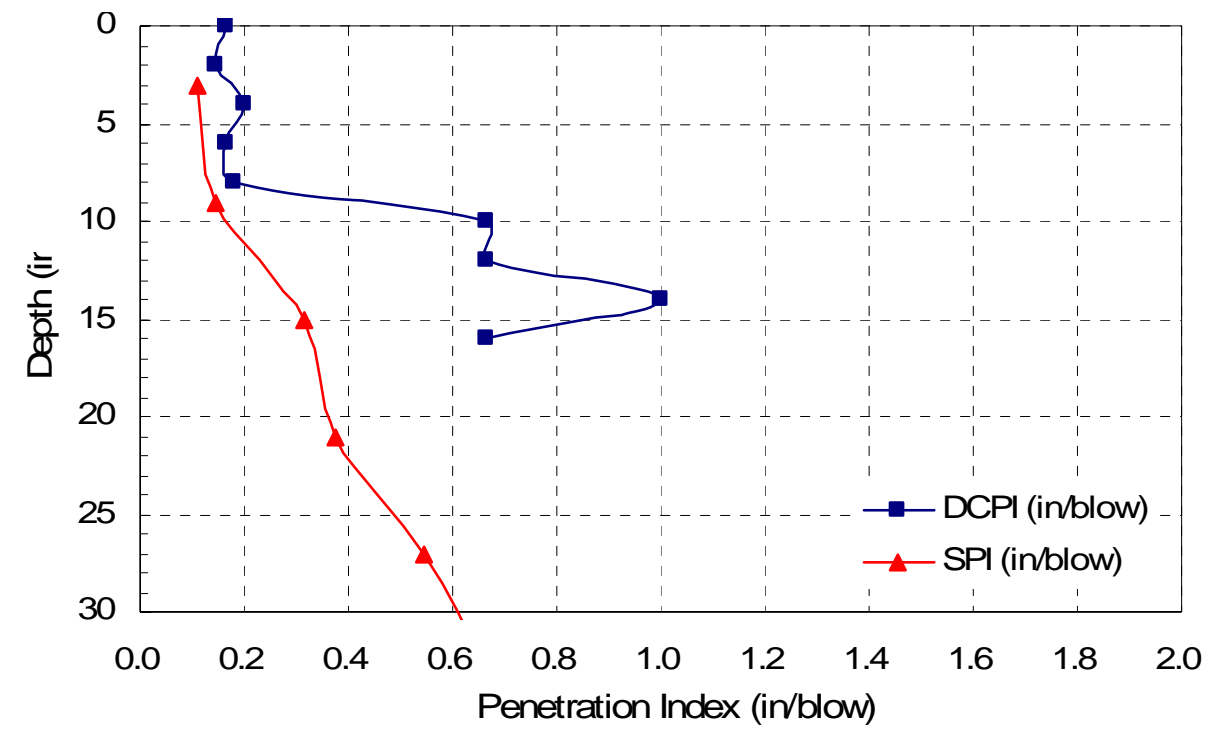

Figure 5.49 DCPT and SPT results with depth at BH-1 (STA. 0 meters). Site (3) 


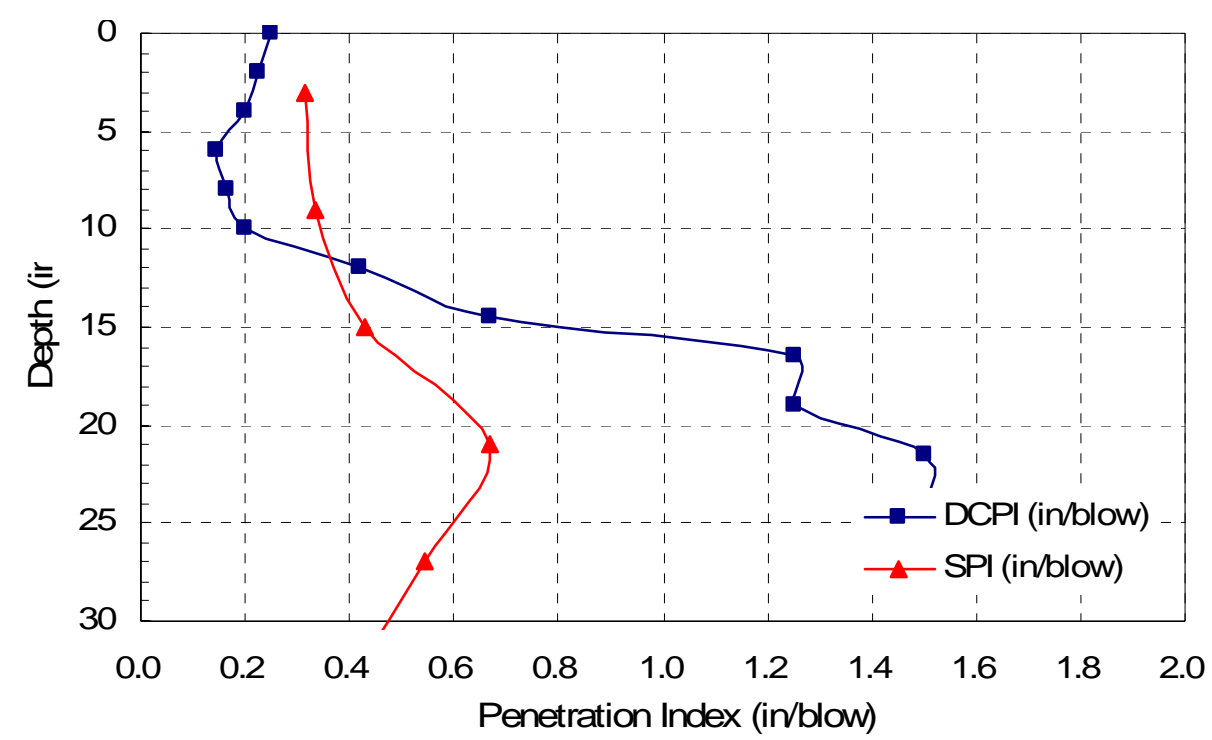

Figure 5.50 DCPT and SPT results with depth at BH-2 (STA. 20 meters). Site (3)

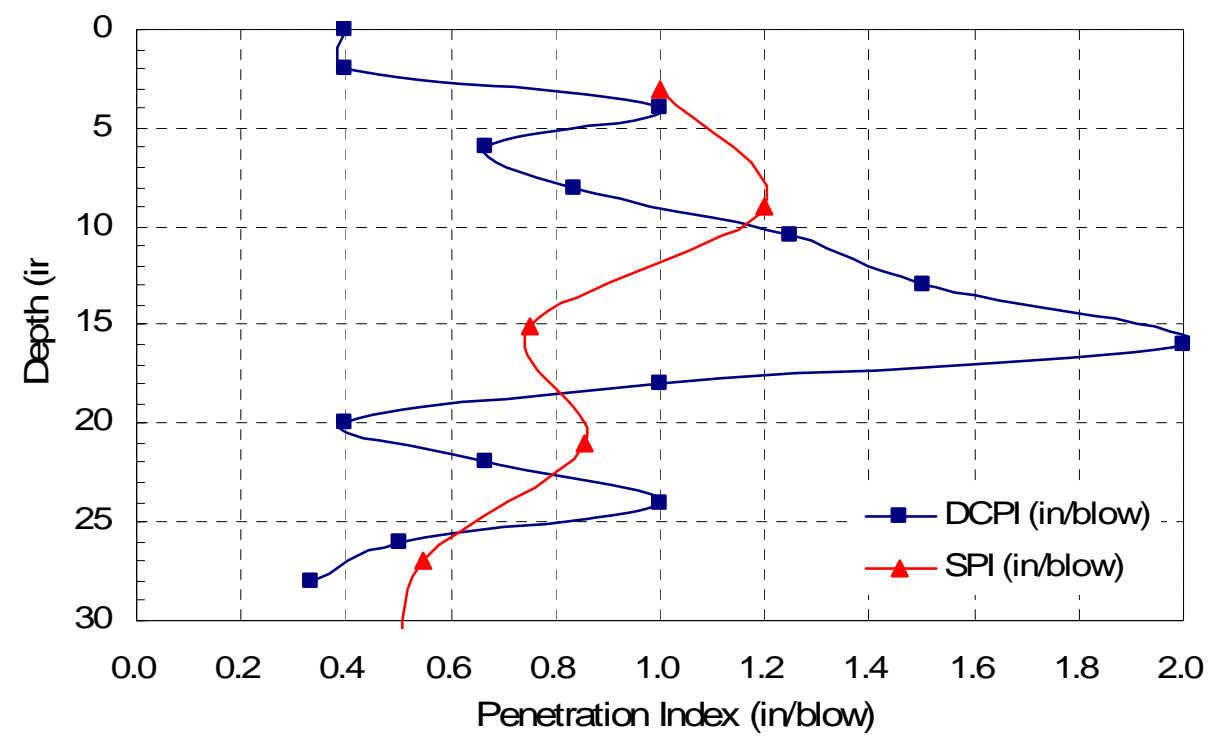

Figure 5.51 DCPT and SPT results with depth at BH-3 (STA. 40 meters). Site (3) 


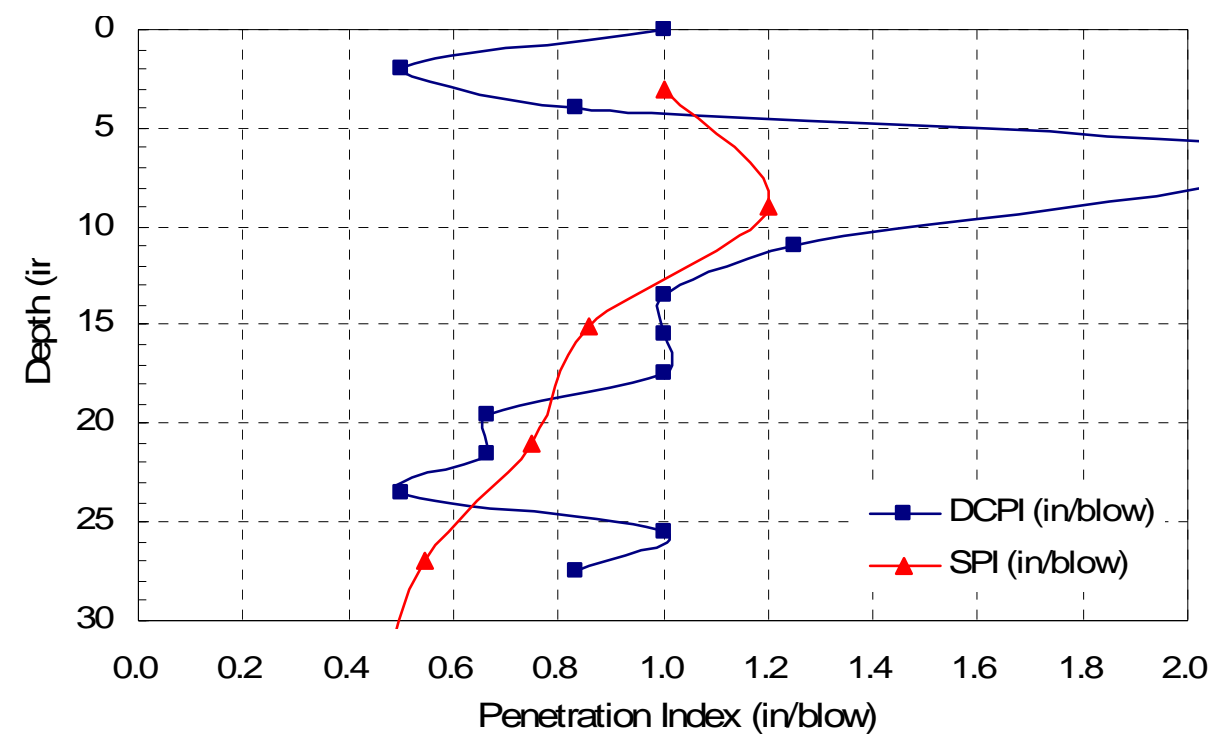

Figure 5.52 DCPT and SPT results with depth at BH-4 (STA. 60 meters). Site (3)

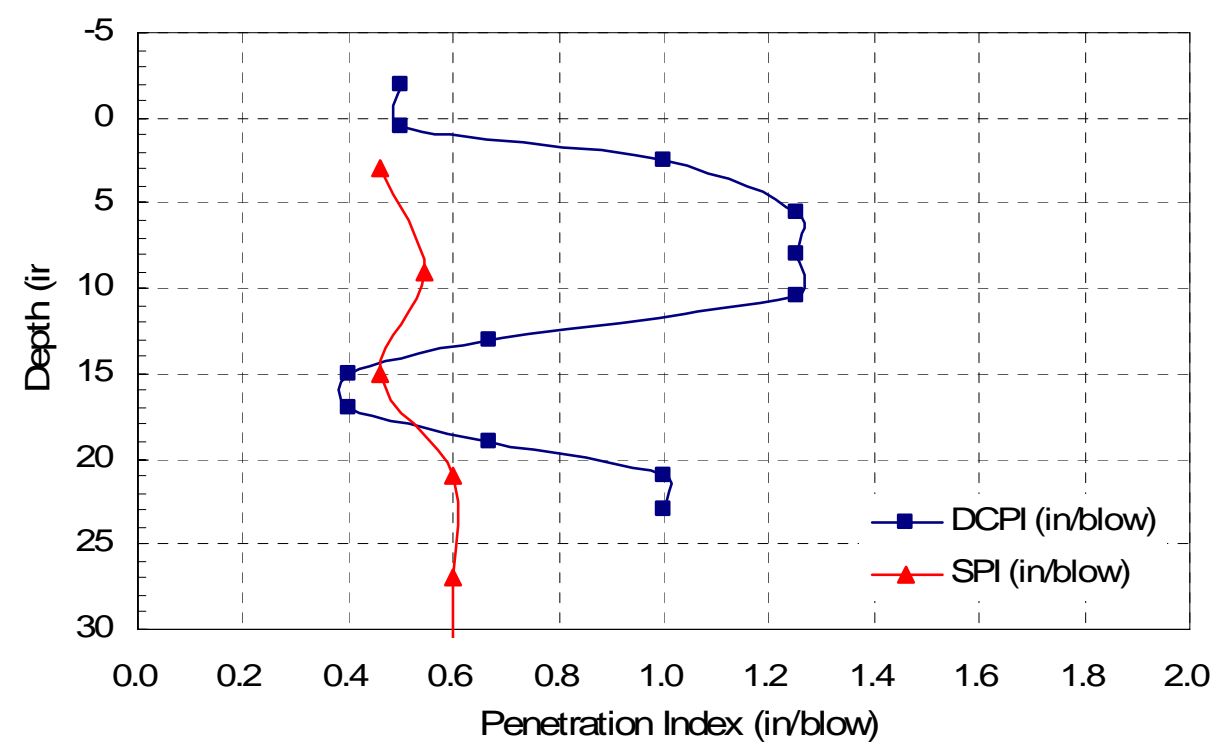

Figure 5.53 DCPT and SPT results with depth at BH-5 (STA. 80 meters). Site (3) 


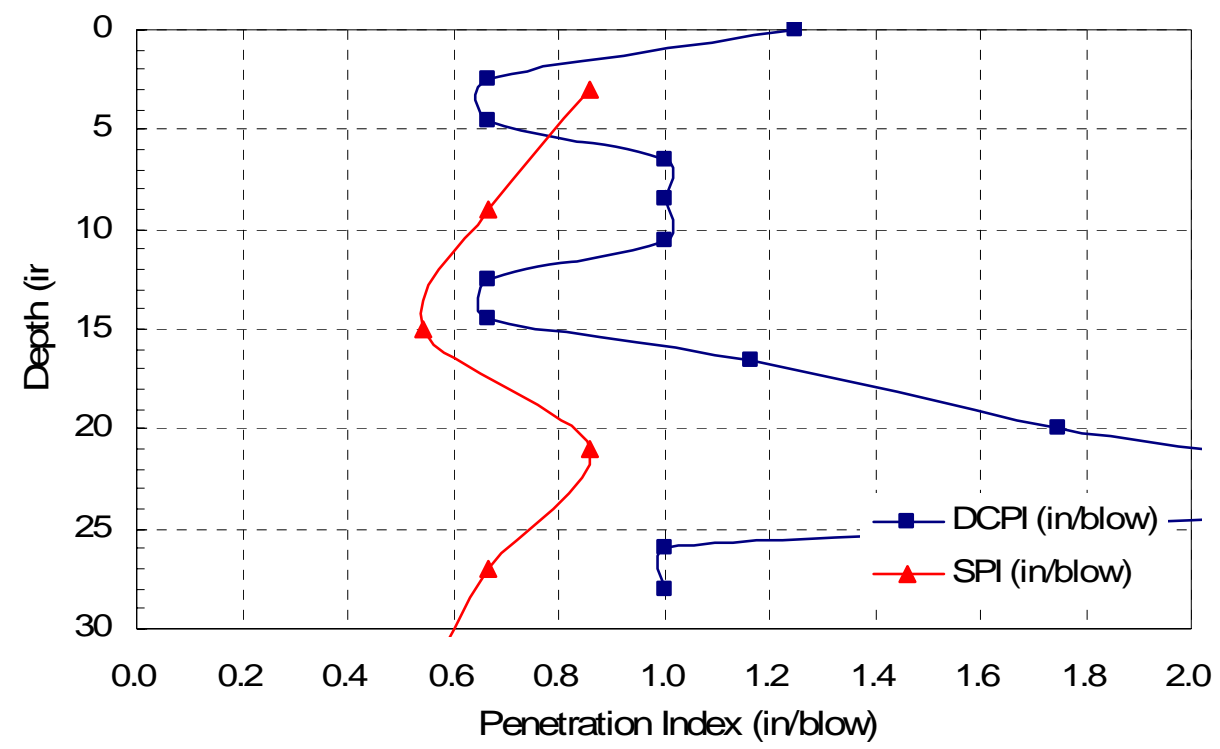

Figure 5.54 DCPT and SPT results with depth at BH-6 (STA. 100 meters). Site (3)

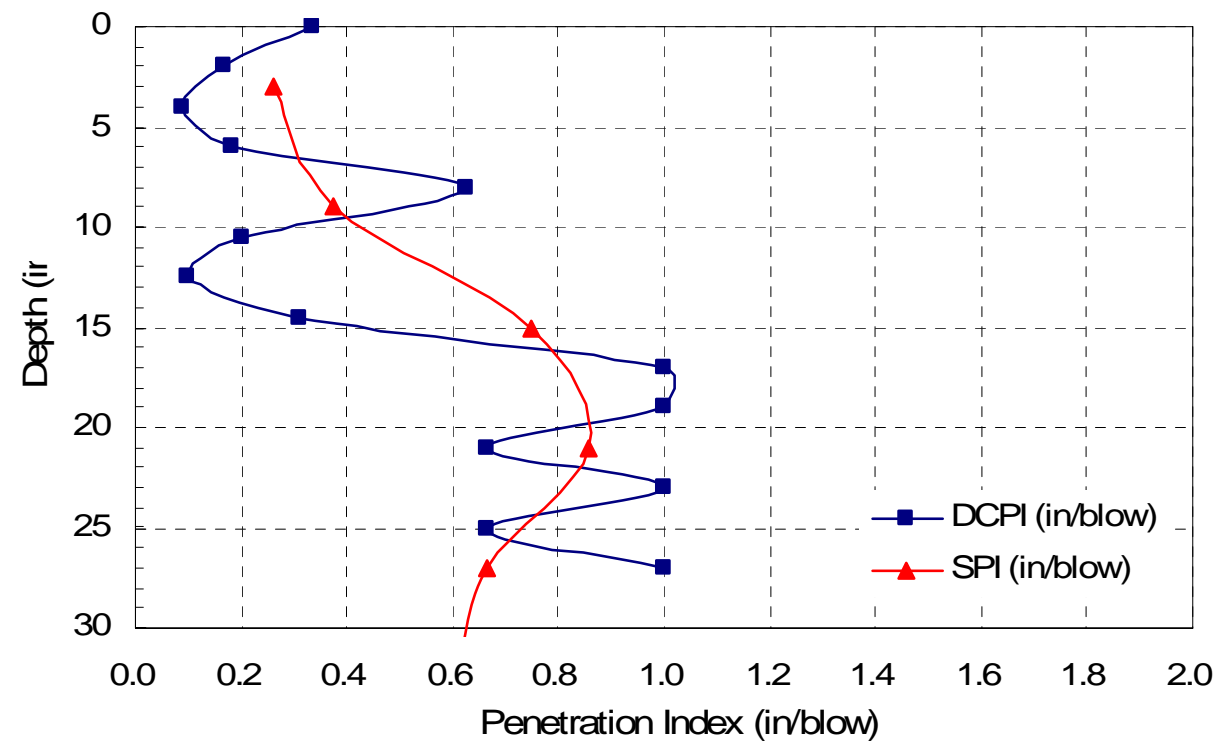

Figure 5.55 DCPT and SPT results with depth at BH-7 (STA. 120 meters). Site (3) 


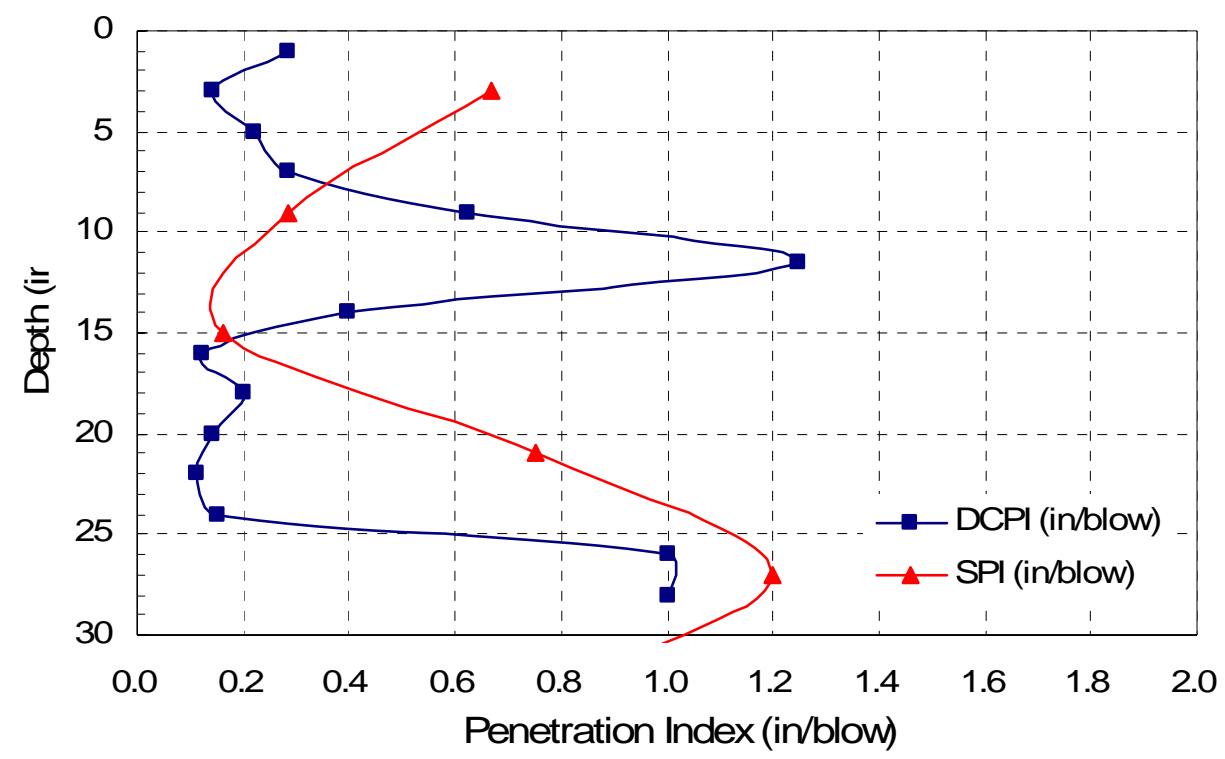

Figure 5.56 DCPT and SPT results with depth at BH-8 (STA. 140 meters). Site (3)

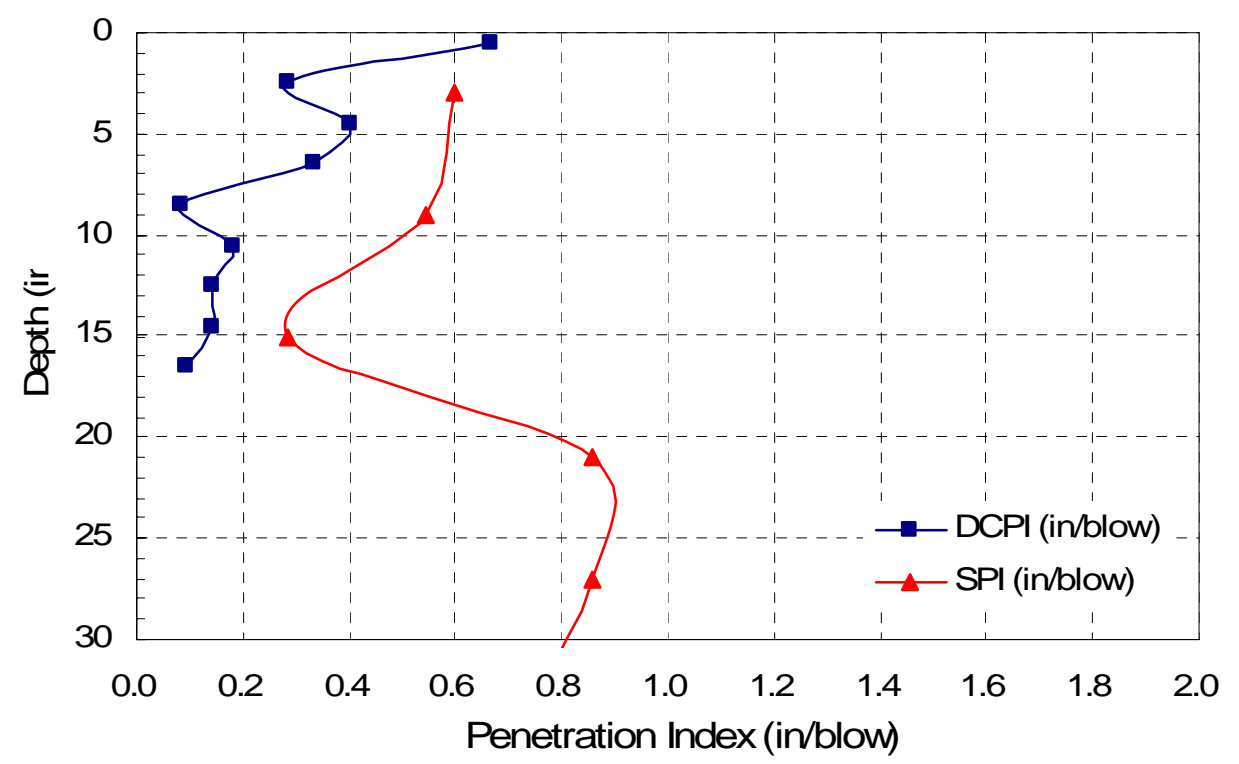

Figure 5.57 DCPT and SPT results with depth at BH-9 (STA. 160 meters). Site (3) 


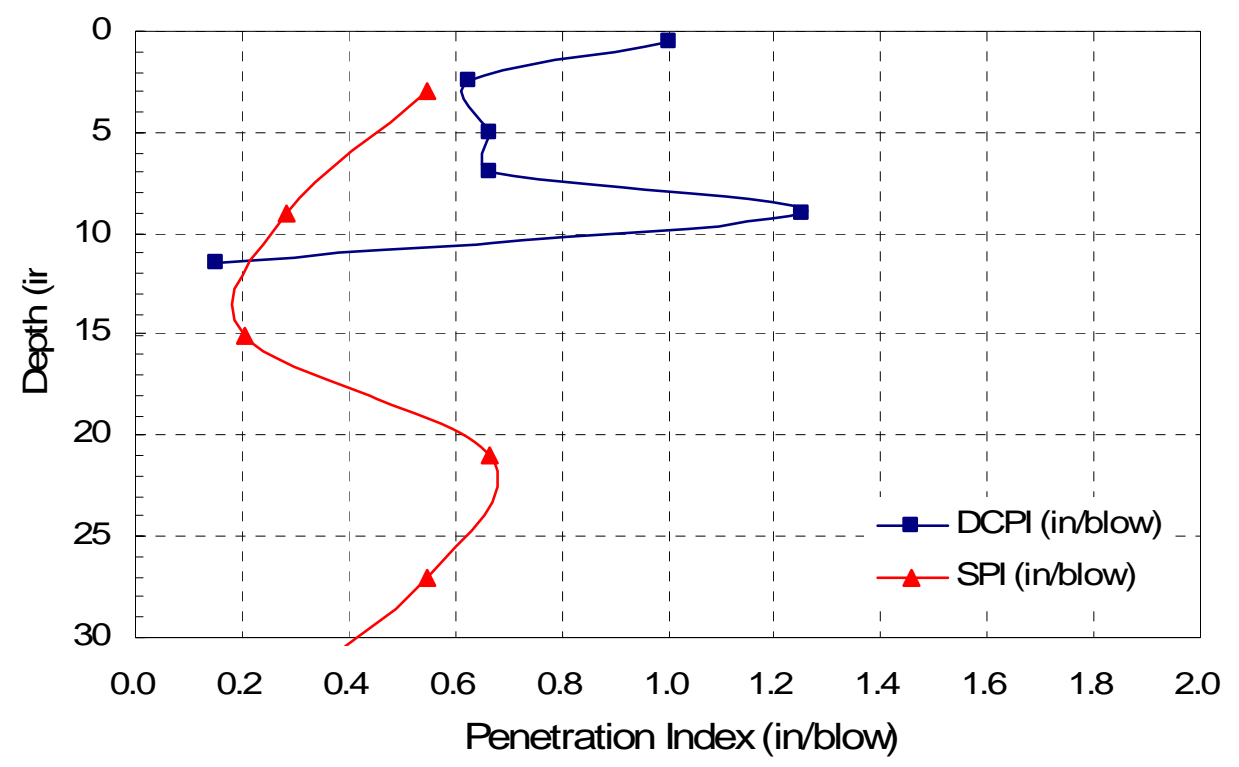

Figure 5.58 DCPT and SPT results with depth at BH-10 (STA. 180 meters).Site (3)

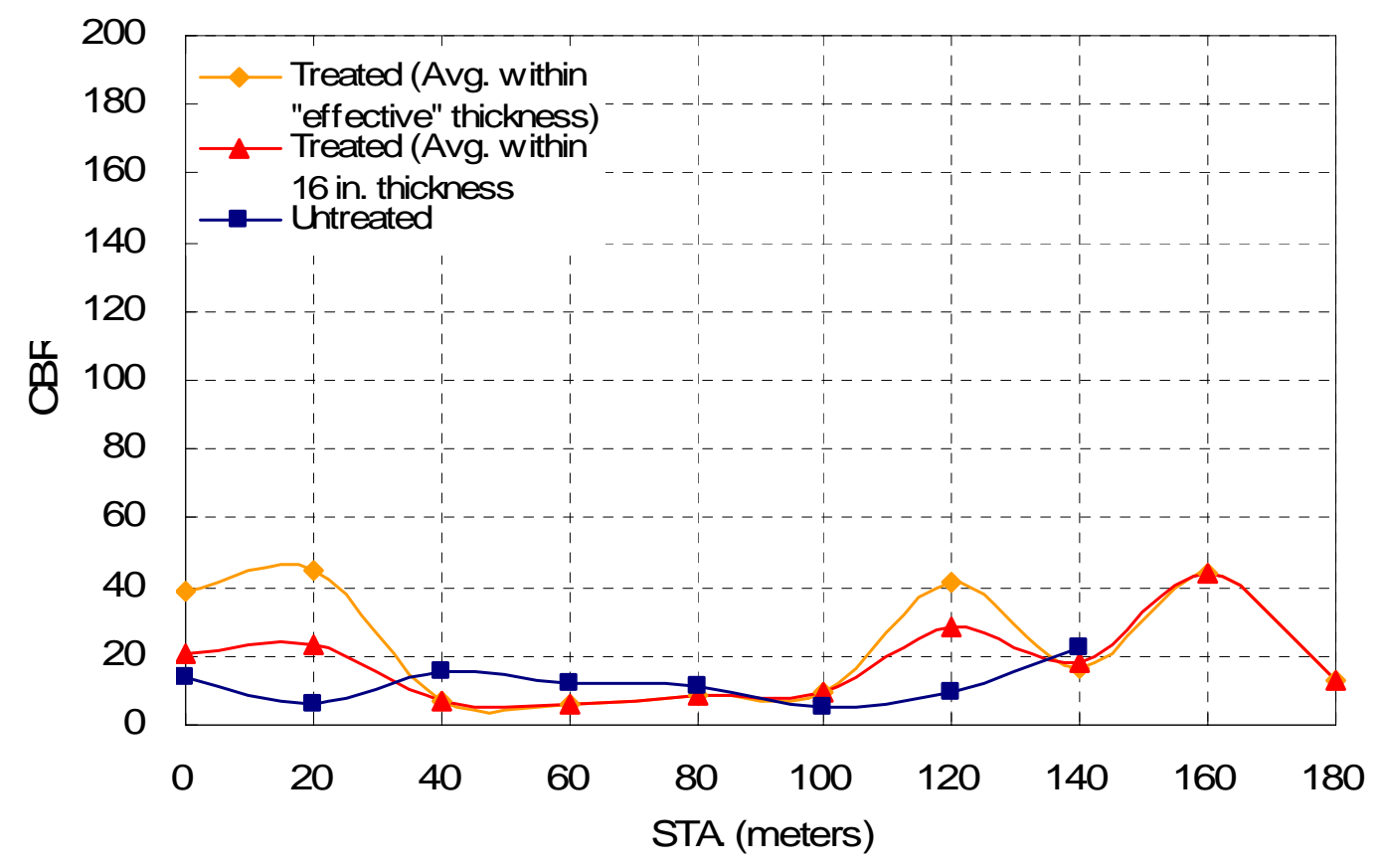

Figure 5.59 CBR of subgrade estimated from DCPT results. Site (3)

Figure 5.59 plots the longitudinal distribution of CBR of the lime-treated and natural soil layers. The CBR values are obtained with a correlation of DCPI and CBR 
(Webster et al., 1992), which was discussed in chapter 2. At the locations BH-1, 2 and 7 (STA. 0, 20, and 120 meters) the CBR of the natural subgrade soil layer ranges from 6 to 14, while the CBR of the lime-treated subgrade soil, calculated within the effective thickness of the layer, ranges between 38 and 45, which results in an increase of the CBR by a factor of $170 \%$ to $630 \%$. Also the average CBR over the theoretical 16 inches thickness of the subgrade ranges between 21 and 28, which results in an increase of CBR of 50 to $280 \%$. At all other locations, from STA 40 to 100 and from 140 to 180 , it appears that the treatment, if any, was not successful.

\section{Lime content}

Figure 5.60 shows the $\mathrm{pH}$ values of both the lime-treated subgrade and natural soil. The lime-treated subgrade soil has a $\mathrm{pH}$ ranging from 8.6 to 10.9 while the untreated soil has a $\mathrm{pH}$ ranging from 7.2 to 8.1 . The increase of $\mathrm{pH}$ denotes the presence of lime. Note that the lime-treated subgrade soil layer only has a high value of a $\mathrm{pH}$ (about 11) between STA. 120 meters $\sim$ STA 180 meters. 


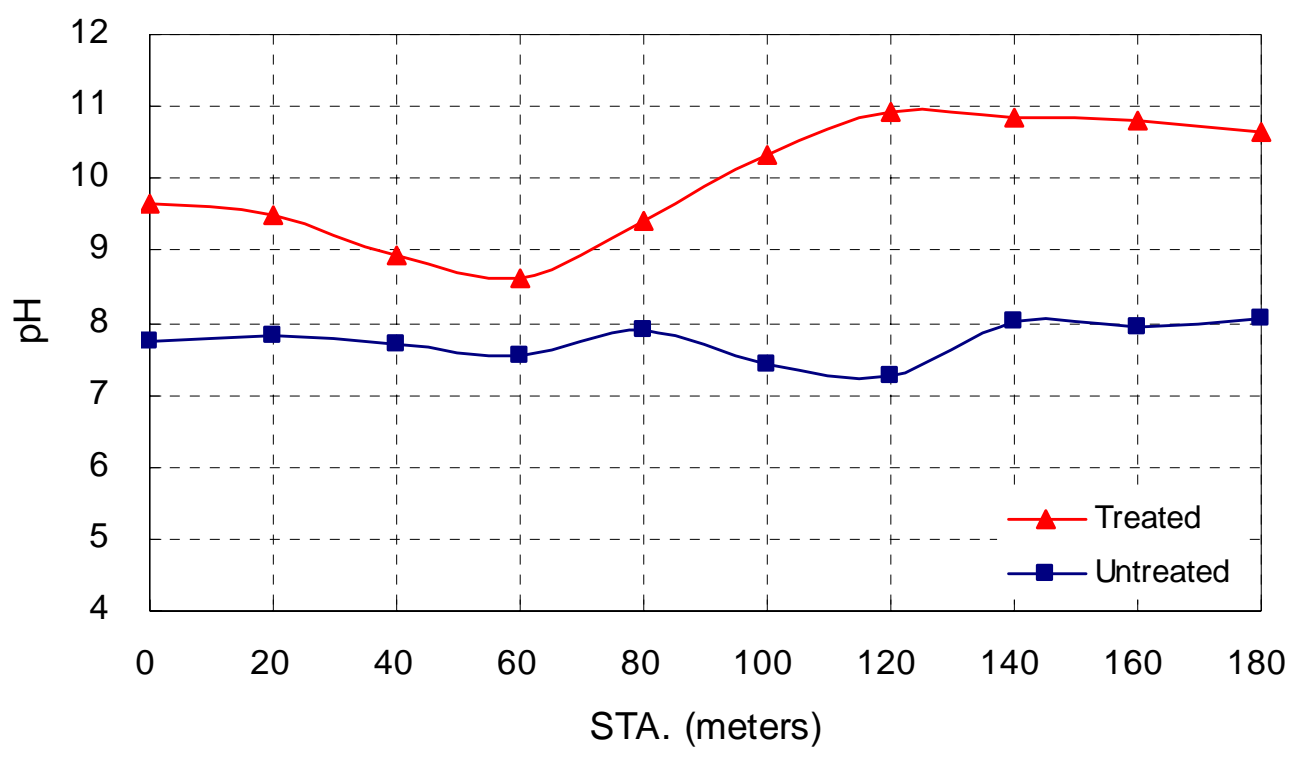

Figure $5.60 \mathrm{pH}$. Site (3)

Figure $5.61 \sim$ Figure 5.66 show the results of XRD tests from the lime-treated and natural soil samples at BH-2 (STA. 20 meters), BH-4 (STA. 60 meters), and BH-6 (STA. 100 meters), respectively. The lime-treated and natural soil samples were taken approximately at depths of 4 and 30 inches respectively below the top of the subgrade. In the figures, the existence of calcium carbonate $\left(\mathrm{CaCO}_{3}\right)$ is observed in the lime-treated subgrade while the existence of $\mathrm{CaCO}_{3}$ is not observed in the natural soil. The observation that the $\mathrm{CaCO}_{3}$ is not found in the natural soil confirms the fact that the source of the mineral comes from the added lime. 

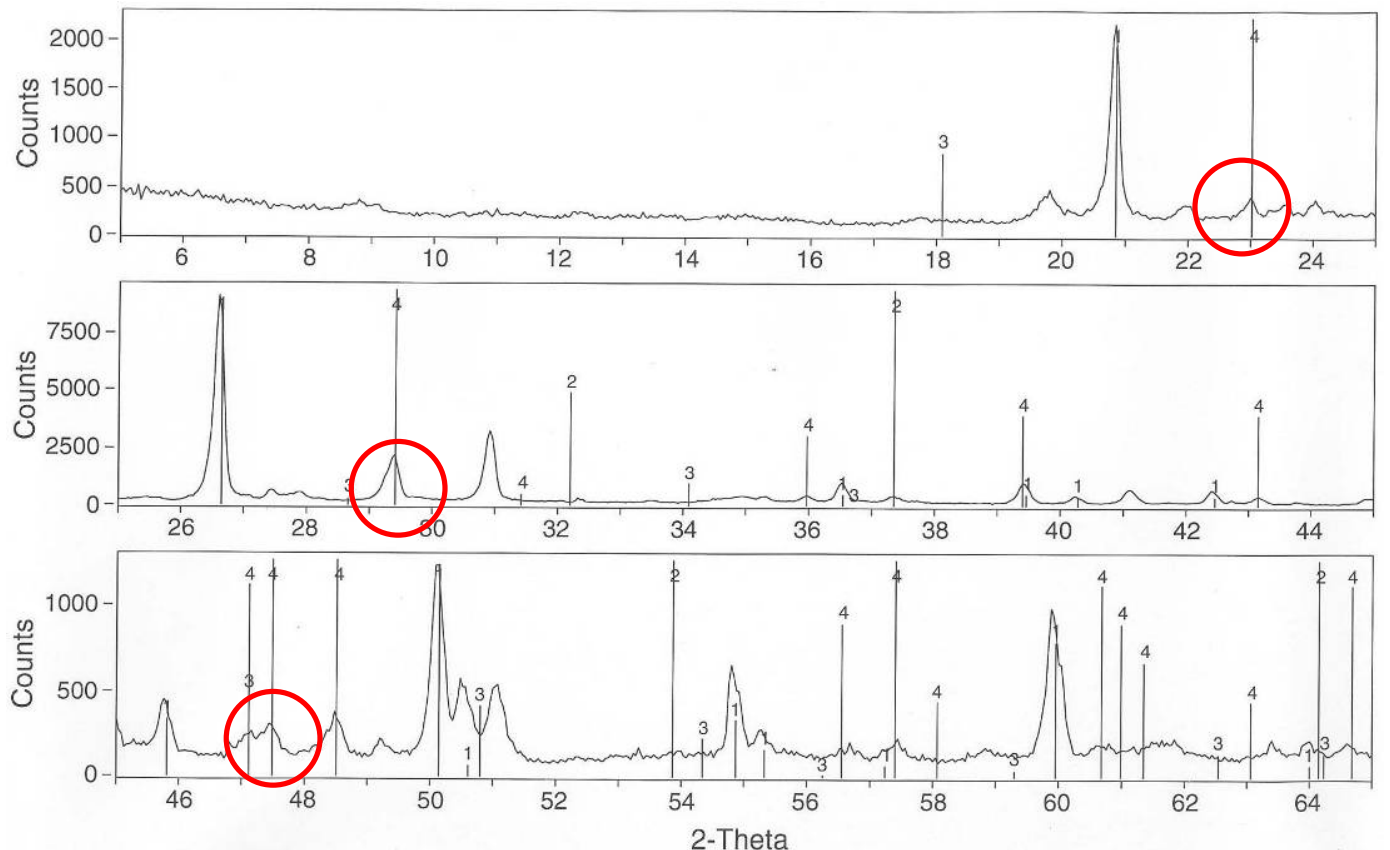

1> 33-1161: Quartz, syn - SiO2

3> 04-0733: Portlandite, syn - $\mathrm{Ca}(\mathrm{OH}) 2$

2> 37-1497: Lime, syn - CaO

4> 05-0586: Calcite, syn - CaCO3

Figure 5.61 XRD pattern for lime-treated soil sample at BH-2 (STA. 20 meters). Site (3)
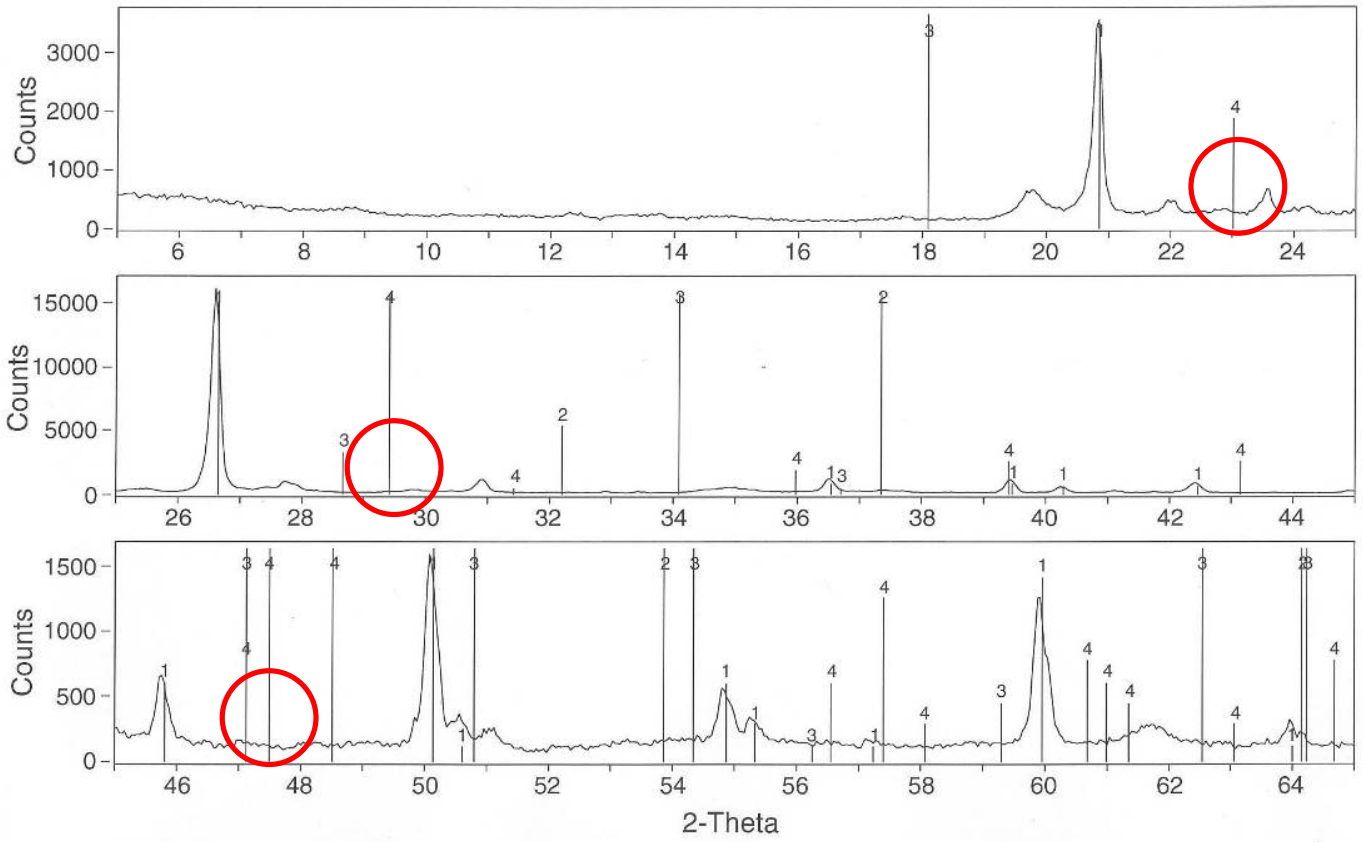

1> 33-1161: Quartz, syn - $\mathrm{SiO} 2$

2> 37-1497: Lime, syn - CaO

3> 04-0733: Portlandite, syn - $\mathrm{Ca}(\mathrm{OH}) 2$

4> 05-0586: Calcite, syn - CaCO3

Figure 5.62 XRD pattern for untreated soil sample at BH-2 (STA. 20 meters). Site (3) 

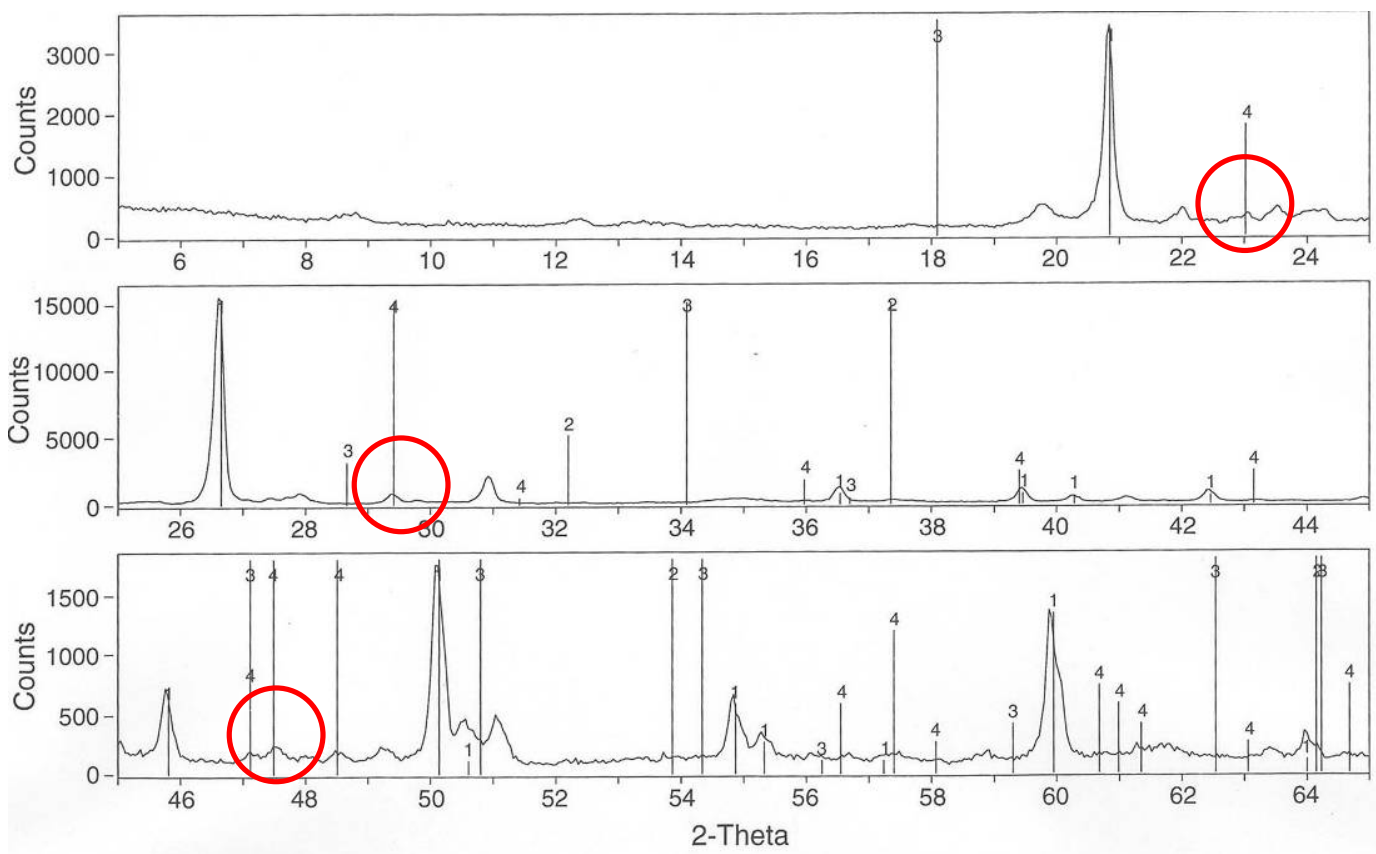

1> 33-1161: Quartz, syn - SiO2

2> 37-1497: Lime, syn - CaO

3> 04-0733: Portlandite, syn - $\mathrm{Ca}(\mathrm{OH}) 2$

4> 05-0586: Calcite, syn - CaCO3

Figure 5.63 XRD pattern for lime-treated soil sample at BH-4 (STA. 60 meters). Site (3)
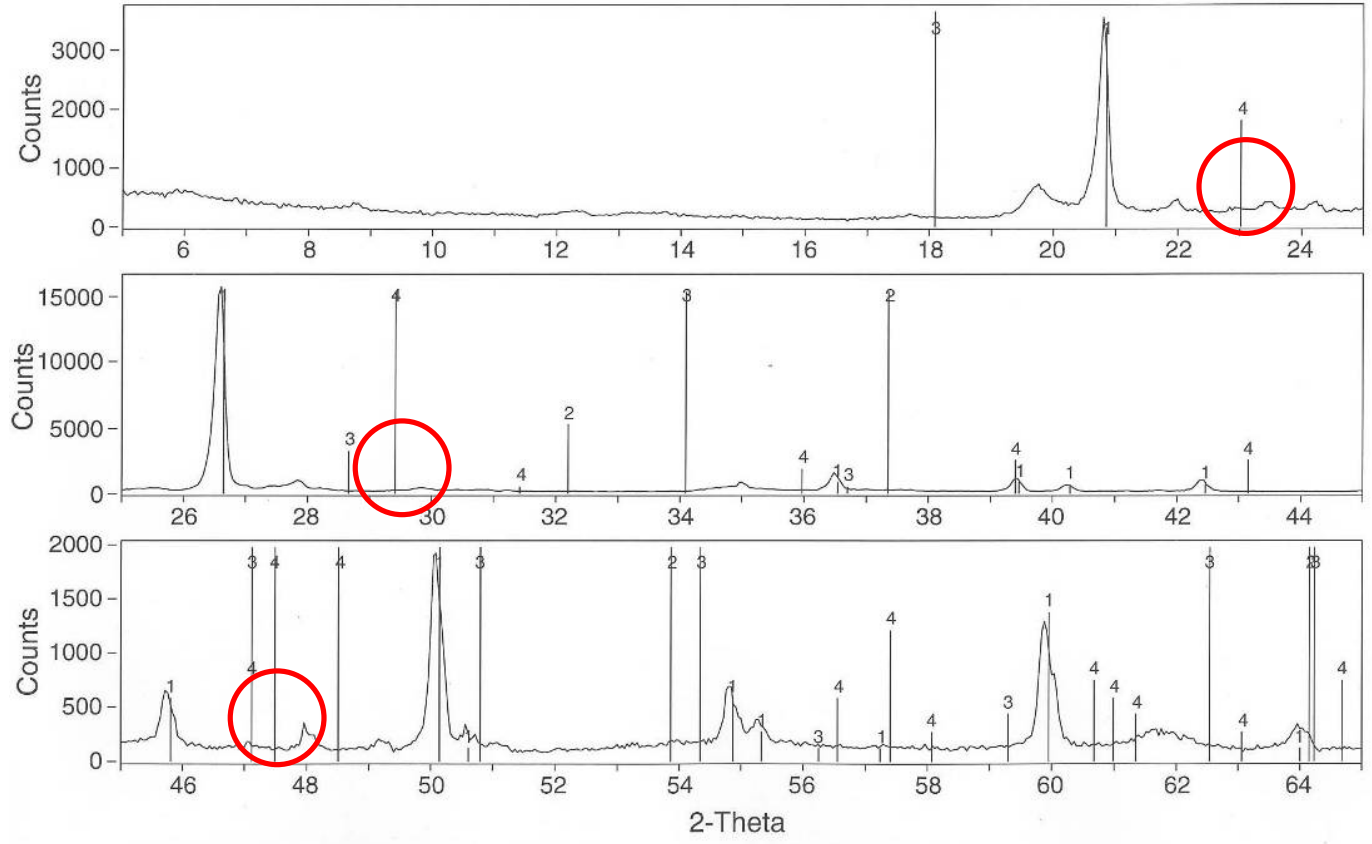

1> 33-1161: Quartz, syn - SiO2

3> 04-0733: Portlandite, syn - $\mathrm{Ca}(\mathrm{OH}) 2$

2> 37-1497: Lime, syn - CaO

4> 05-0586: Calcite, syn - CaCO3

Figure 5.64 XRD pattern for untreated soil sample at BH-4 (STA. 60 meters). Site (3) 

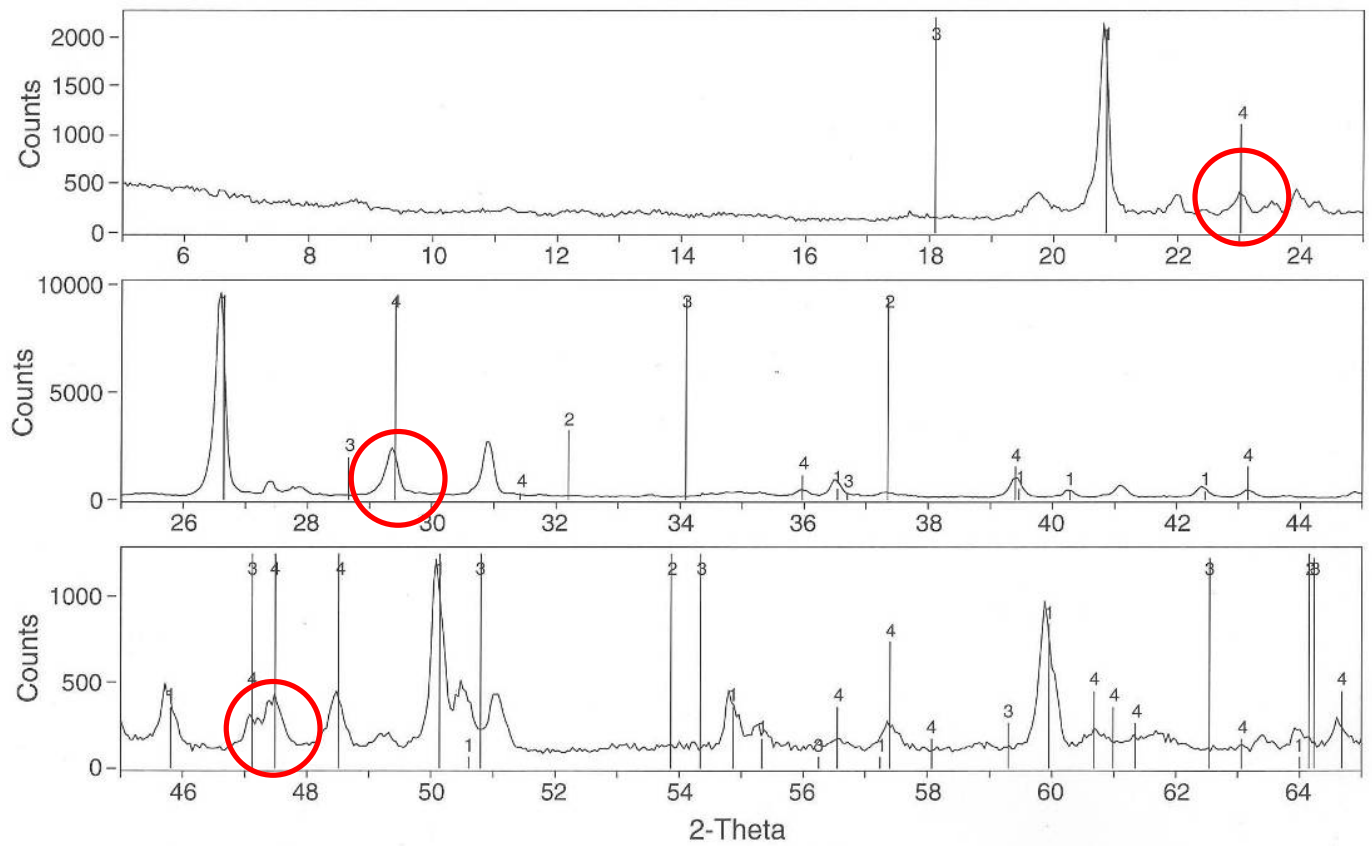

1> 33-1161: Quartz, syn - SiO2

2> 37-1497: Lime, syn - CaO

3> 04-0733: Portlandite, syn - $\mathrm{Ca}(\mathrm{OH}) 2$

4> 05-0586: Calcite, syn - CaCO3

Figure 5.65 XRD pattern for lime-treated soil sample at BH-6 (STA. 100 meters). Site (3)
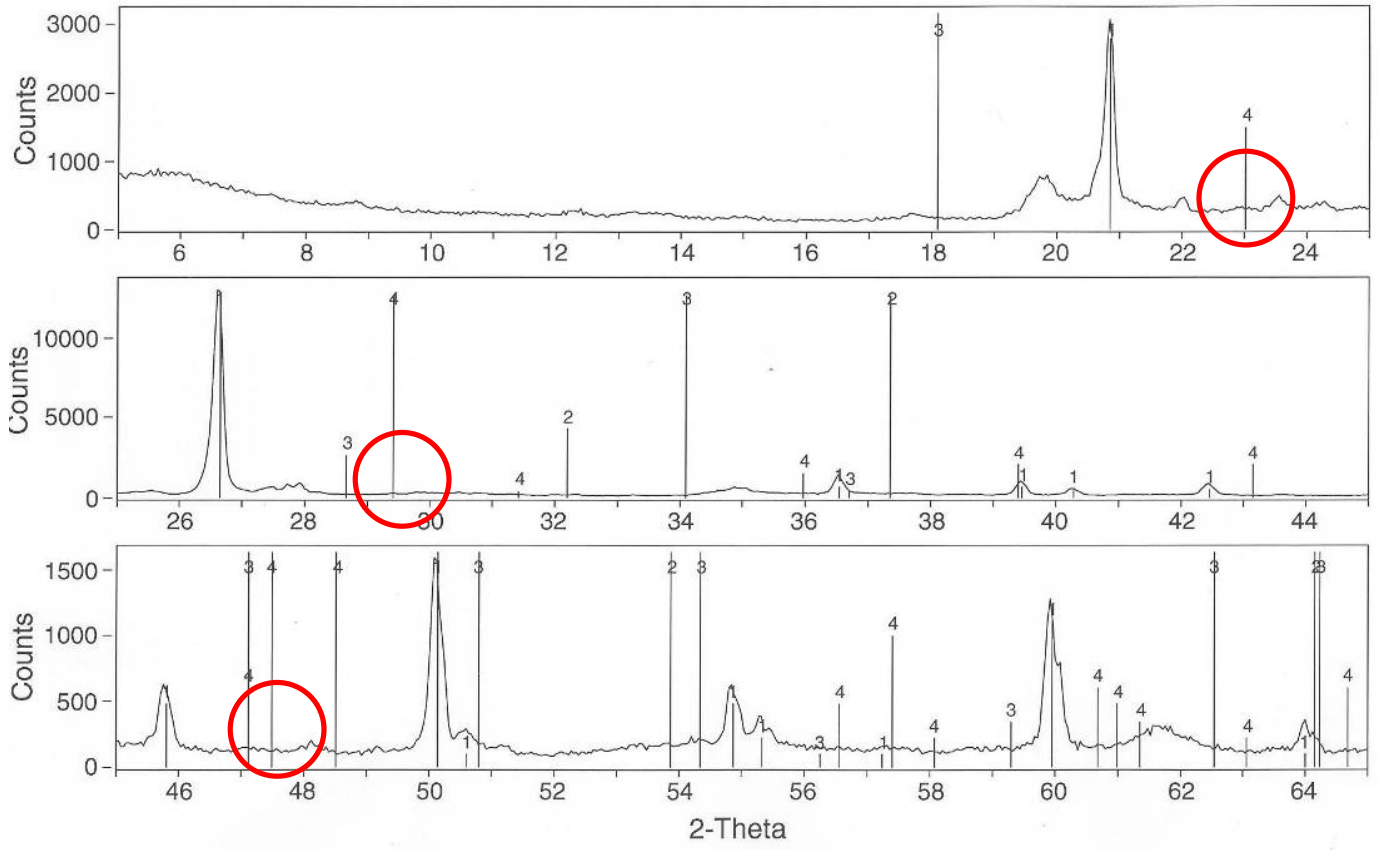

1> 33-1161: Quartz, syn - SiO2

2> 37-1497: Lime, syn - CaO

3> 04-0733: Portlandite, syn - $\mathrm{Ca}(\mathrm{OH}) 2$

4> 05-0586: Calcite, syn - CaCO3

Figure 5.66 XRD pattern for untreated soil sample at BH-6 (STA. 100 meters). Site (3) 
Figure $5.67 \sim$ Figure 5.71 show the XRD pattern for the lime-treated soil samples collected at depths of $0,4,8,12$, and 16 inches below the top of the subgrade at $\mathrm{BH}-4$ (STA. 20 meters). In the figures, the XRD pattern has a peak at the critical refraction angles of $\mathrm{CaCO}_{3}$ at depths of 0,4 , and 8 inches below the top of the subgrade. The intensity of the peak decreases with depth. At depths of 12 and 16 inches, the XRD pattern does not have a peak at the critical angles, which indicates that $\mathrm{CaCO}_{3}$ does not exist below a depth of 12 inches.
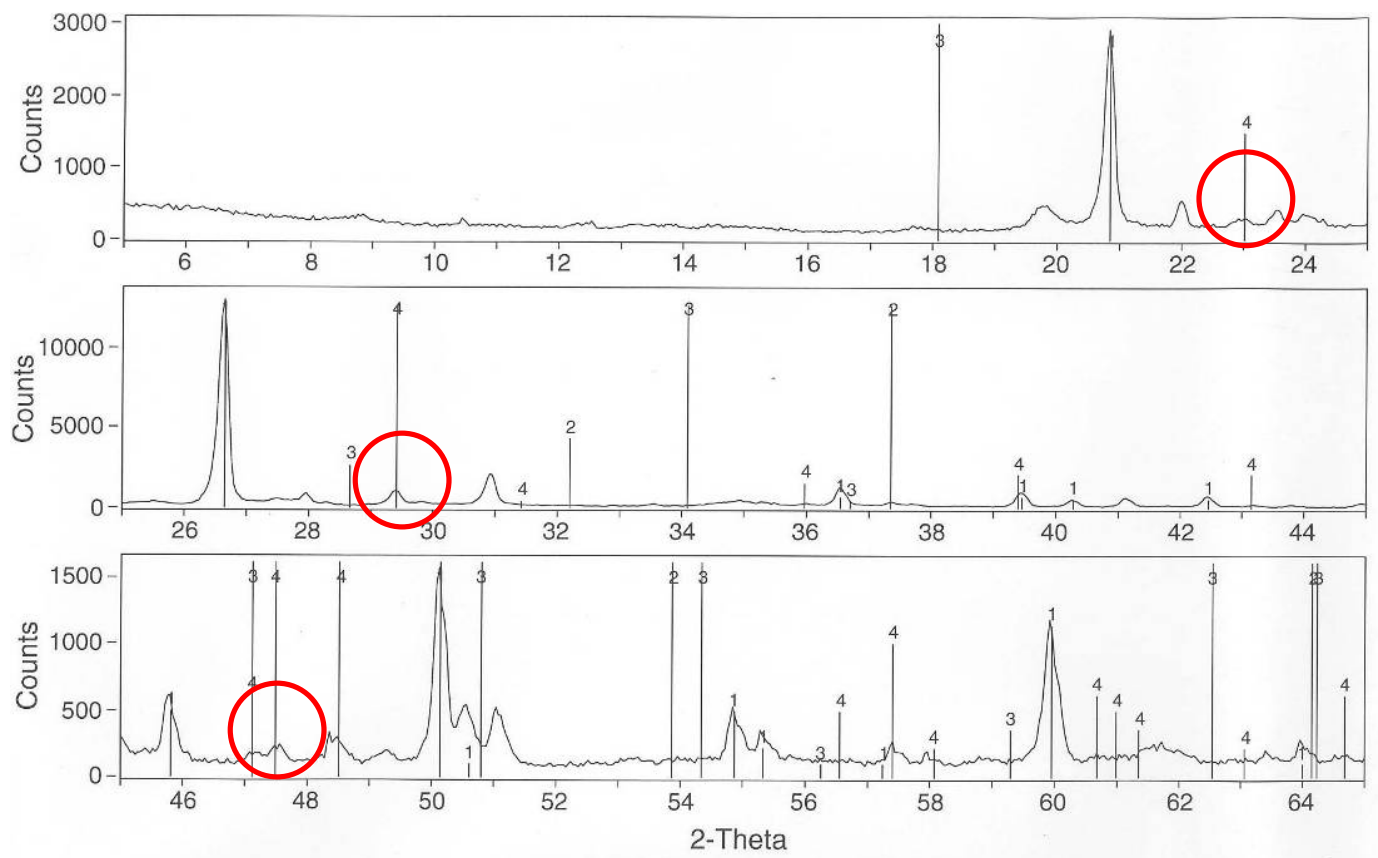

1> 33-1161: Quartz, syn - SiO2

2> 37-1497: Lime, syn - $\mathrm{CaO}$

3> 04-0733: Portlandite, syn - $\mathrm{Ca}(\mathrm{OH}) 2$

4> 05-0586: Calcite, syn - $\mathrm{CaCO} 3$

Figure 5.67 XRD pattern for lime-treated soil sample taken at a depth of 0 inches below top of subgrade at BH-4 (STA. 60 meters). Site (3) 

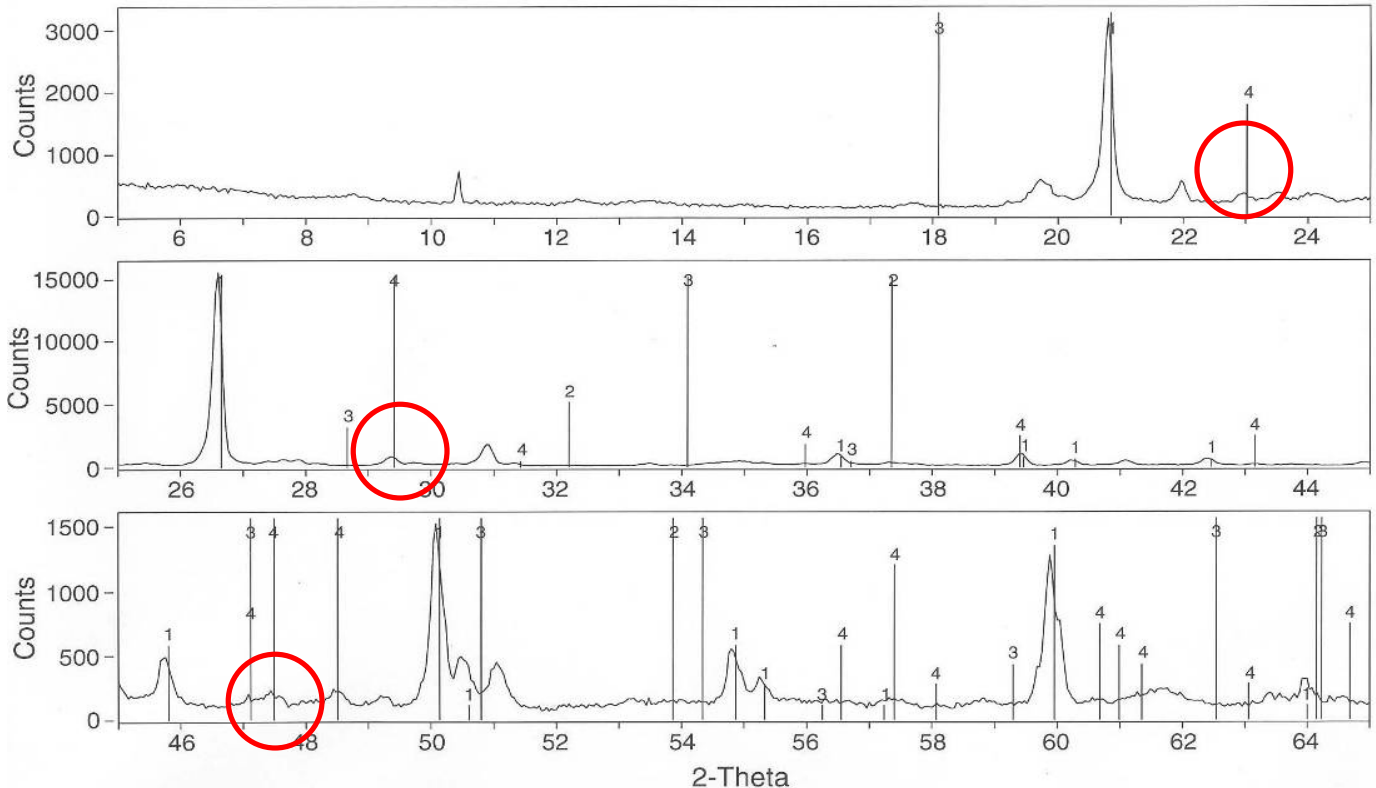

1> 33-1161: Quartz, syn - SiO2

3> 04-0733: Portlandite, syn - $\mathrm{Ca}(\mathrm{OH}) 2$

2> 37-1497: Lime, syn - CaO

4> 05-0586: Calcite, syn - CaCO3

Figure 5.68 XRD pattern for lime-treated soil sample taken at a depth of 4 inches below top of subgrade at BH-4 (STA. 60 meters). Site (3)
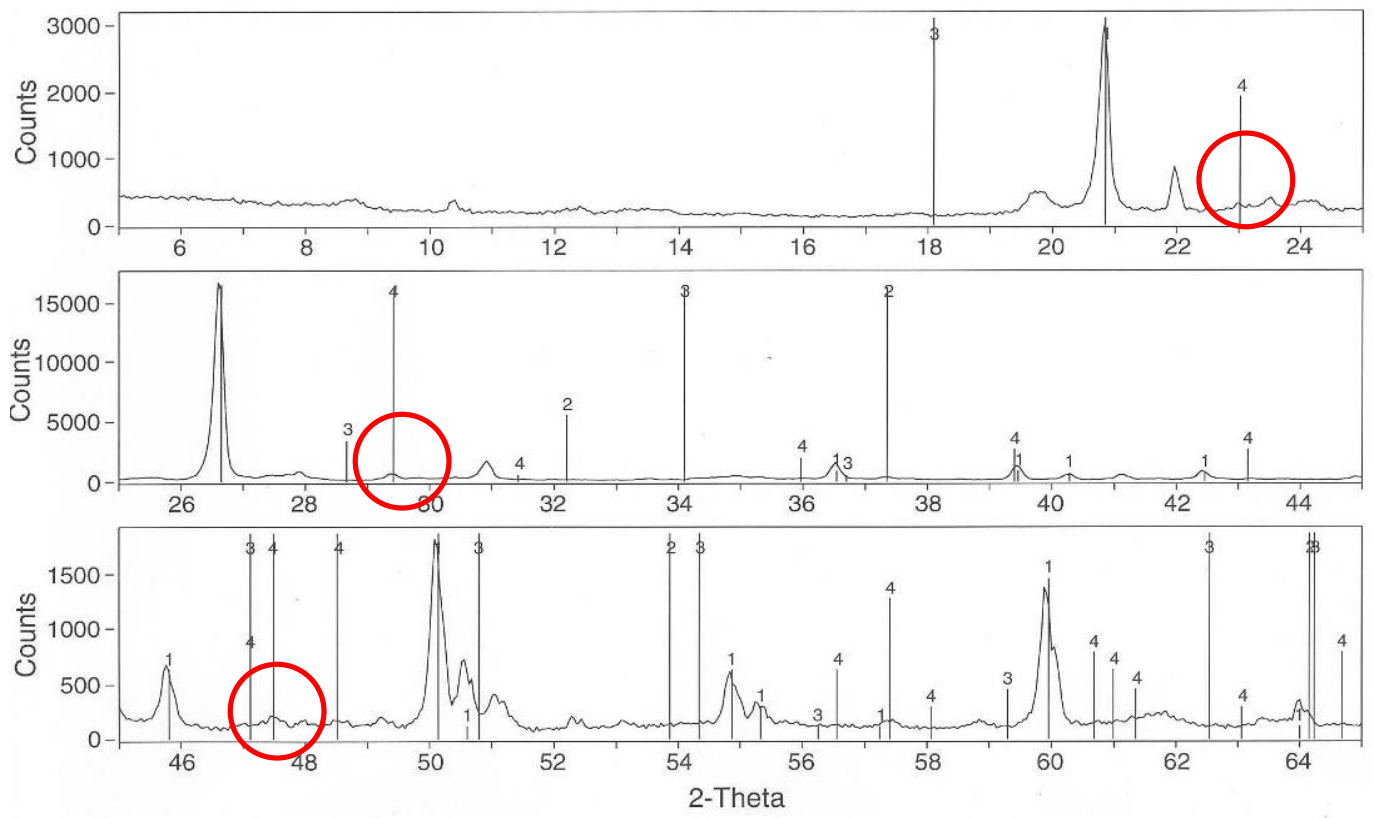

1> 33-1161: Quartz, syn - SiO2

2> 37-1497: Lime, syn - CaO

3> 04-0733: Portlandite, syn - $\mathrm{Ca}(\mathrm{OH}) 2$

4> 05-0586: Calcite, syn - CaCO3

Figure 5.69 XRD pattern for lime-treated soil sample taken at a depth of 8 inches below top of subgrade at BH-4 (STA. 60 meters). Site (3) 

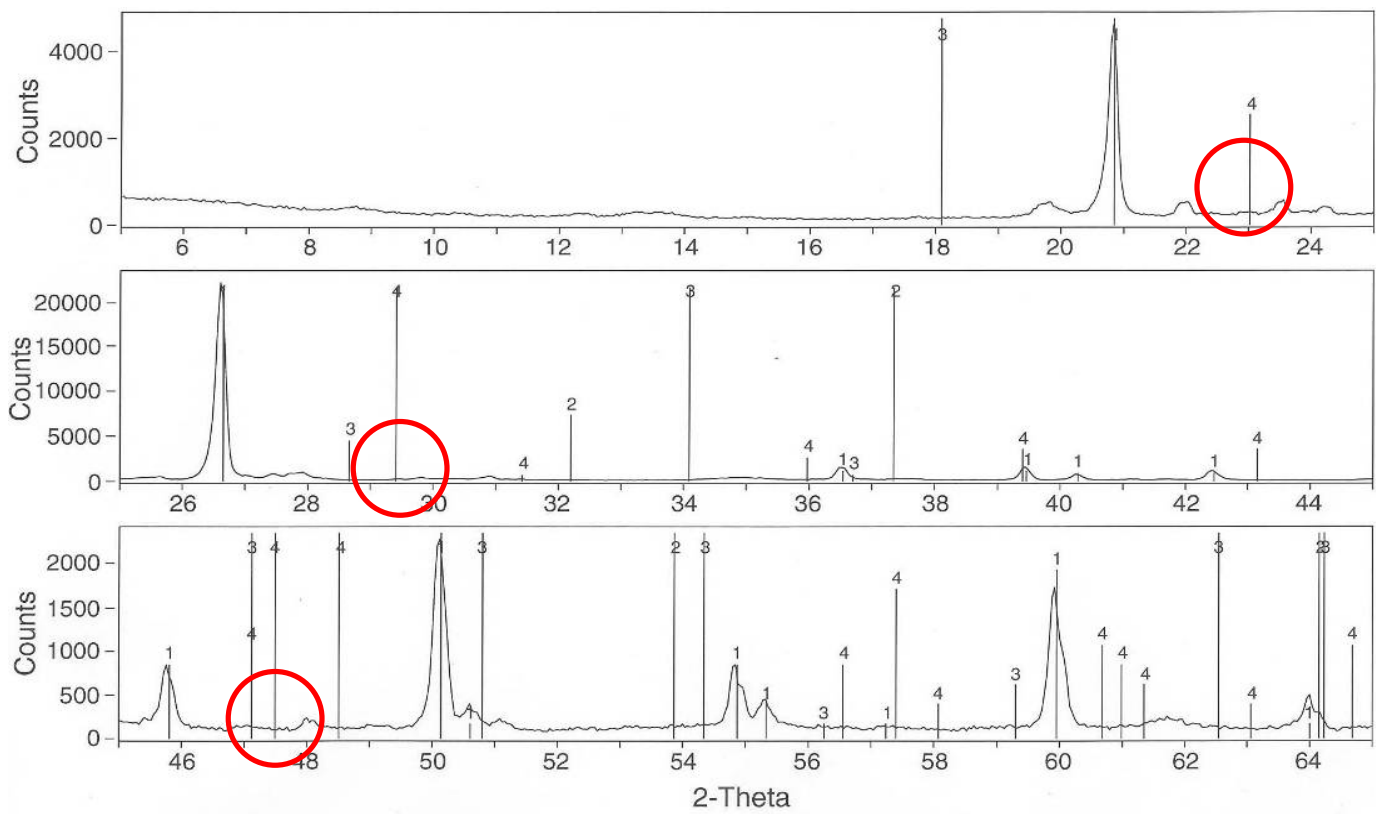

1> 33-1161: Quartz, syn - SiO2

2> 37-1497: Lime, syn - CaO

3> 04-0733: Portlandite, syn - $\mathrm{Ca}(\mathrm{OH}) 2$

4> 05-0586: Calcite, syn - $\mathrm{CaCO} 3$

Figure 5.70 XRD pattern for lime-treated soil sample taken at a depth of 12 inches below top of subgrade at BH-4 (STA. 60 meters). Site (3)
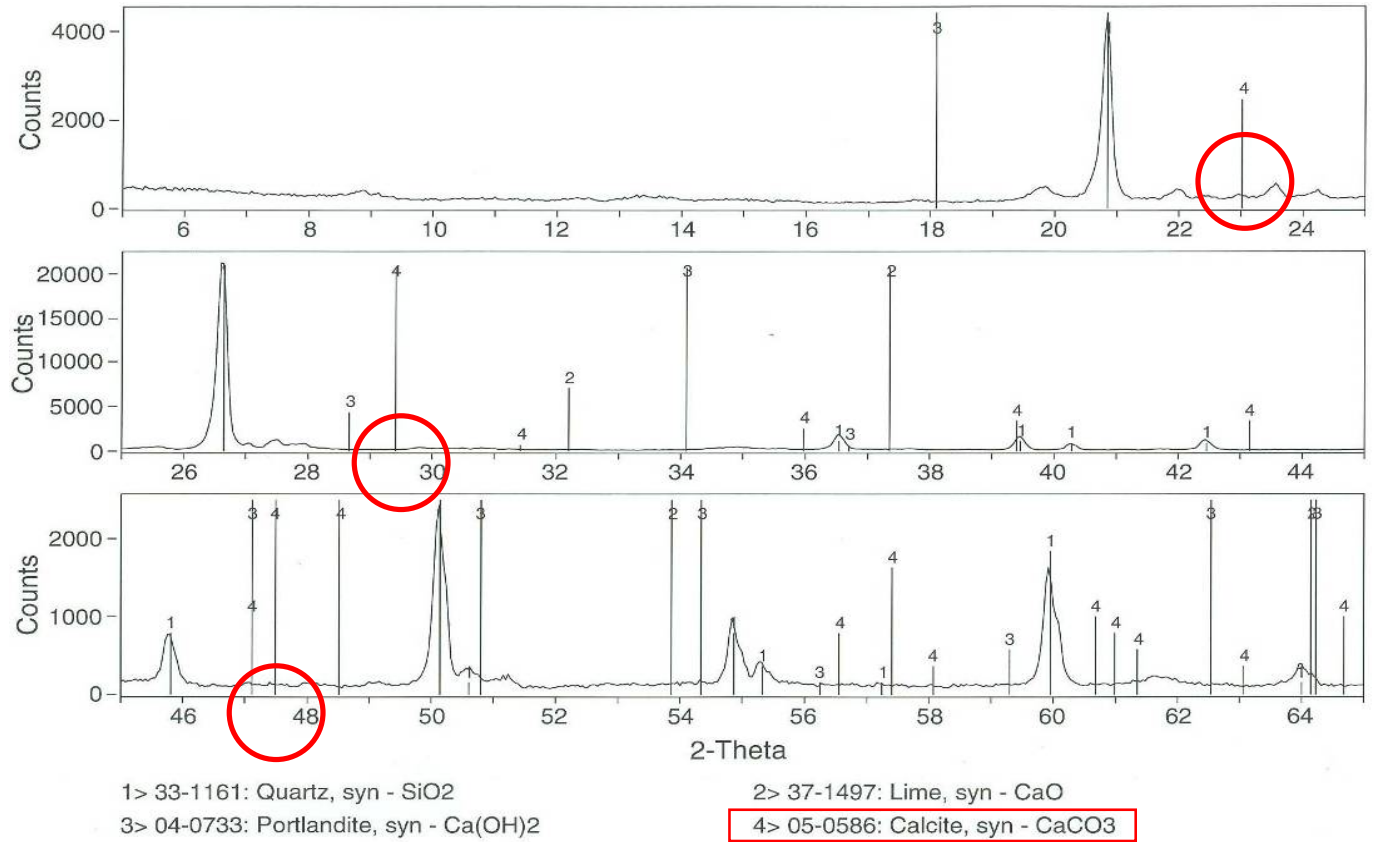

Figure 5.71 XRD pattern for lime-treated soil sample taken at a depth of 16 inches below top of subgrade at BH-4 (STA. 60 meters). Site (3) 
Figure $5.72 \sim$ Figure 5.74 show the results of TGA tests for the lime-treated and natural soil samples collected at $\mathrm{BH}-2,4$, and 6, respectively. The lime-treated and natural soil samples were taken approximately at depths of 4 and 30 inches below the top of the subgrade at each borehole. The figures show that the weight of the natural soil decreases uniformly with increasing temperature without a sharp decrease within a range of temperatures between 650 and $800{ }^{\circ} \mathrm{C}$. The TGA results for the natural soil samples confirm that the $\mathrm{CaCO}_{3}$ detected in the TGA tests results from the LKD added for the treatment. The calculated amount of $\mathrm{CaCO}_{3}$ is 10,7 , and $11 \%$ for the samples collected at BH-2 (STA. 20 meters), BH-4 (STA. 60 meters), and BH-6 (STA. 100 meters), respectively. From the TGA results at site (3), the amount of the added LKD would be more than $5 \%$. Since the increase in stiffness is not found at some of the locations (Figure 5.59) it must be concluded that most of the lime added was not chemically reactive.

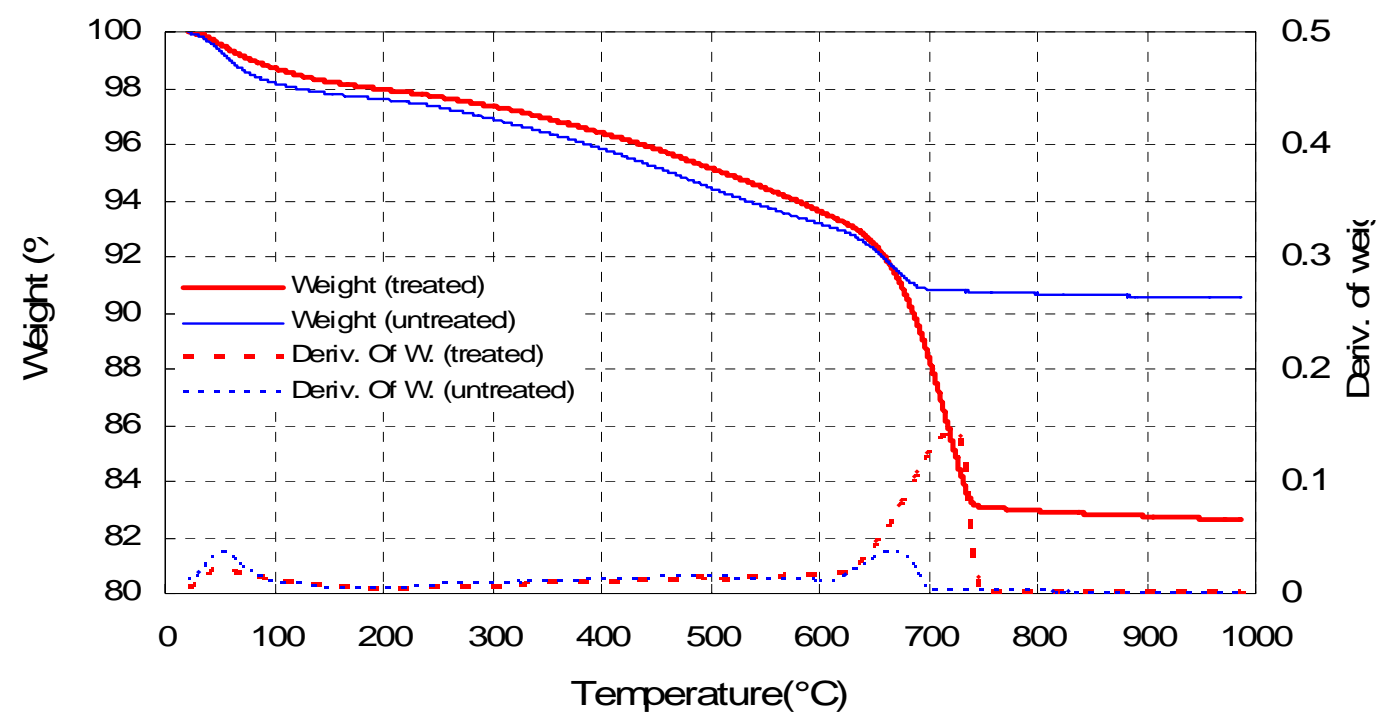

Figure 5.72 Weight loss and weight loss rate obtained from TGA from lime-treated and natural soil samples collected at BH-2 (STA. 40) at site (3) 


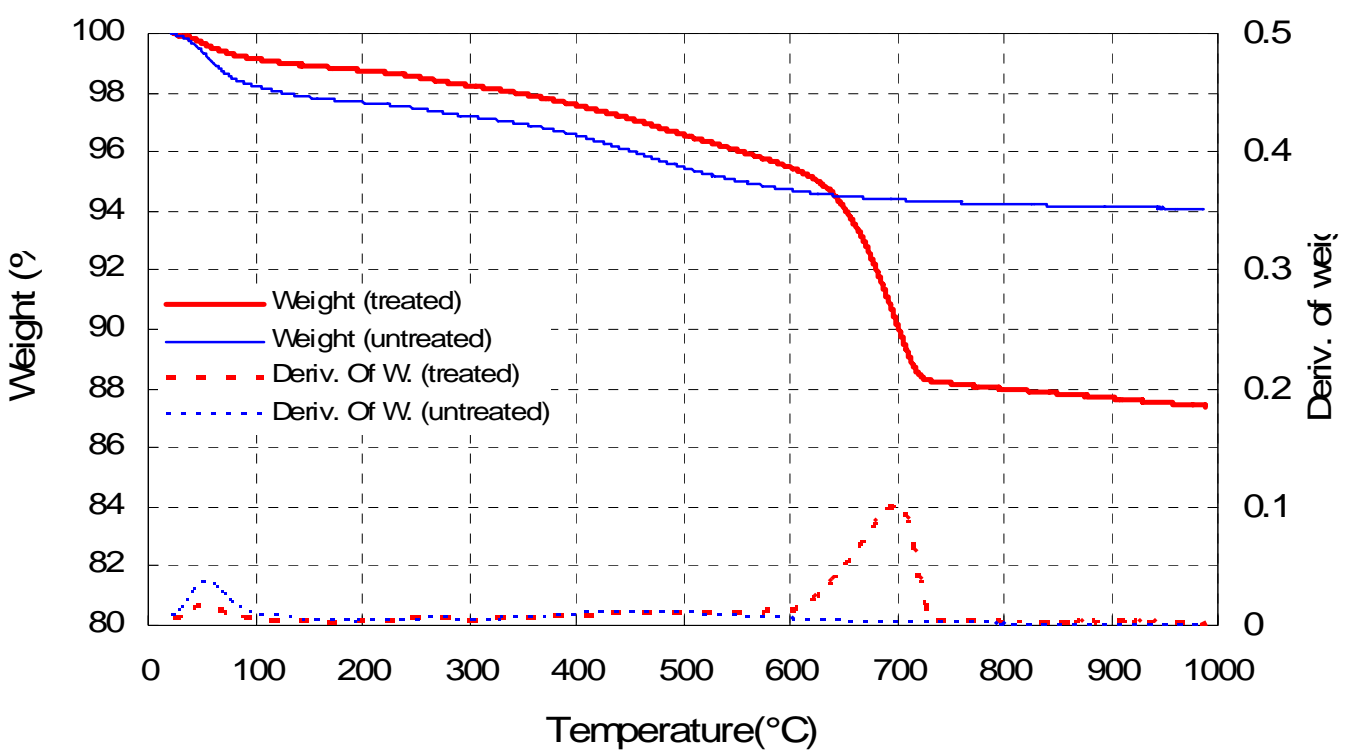

Figure 5.73 Weight loss and weight loss rate obtained from TGA from lime-treated and natural soil samples collected at BH-4 (STA. 60) at site (3)

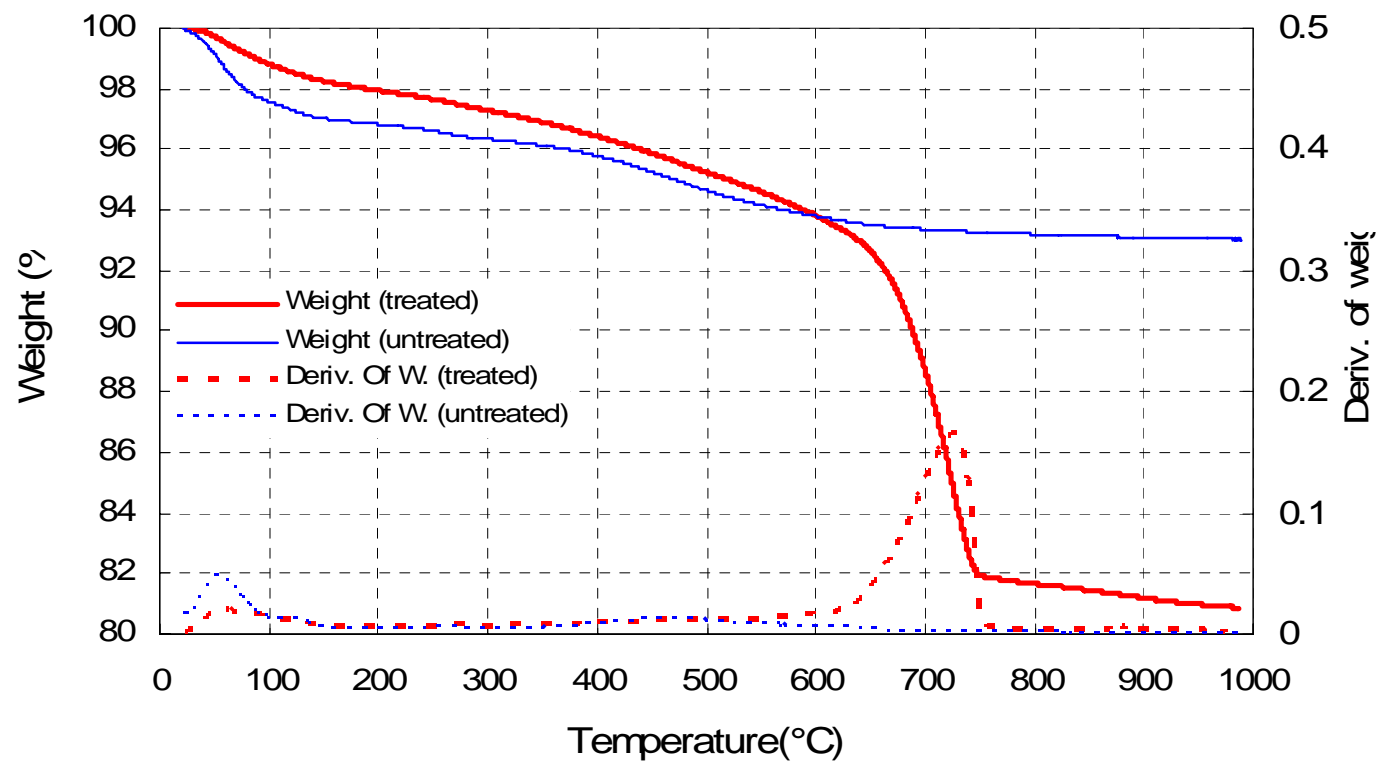

Figure 5.74 Weight loss and weight loss rate obtained from TGA from lime-treated and untreated soil samples collected at BH-6 (STA. 100) at site (3) 


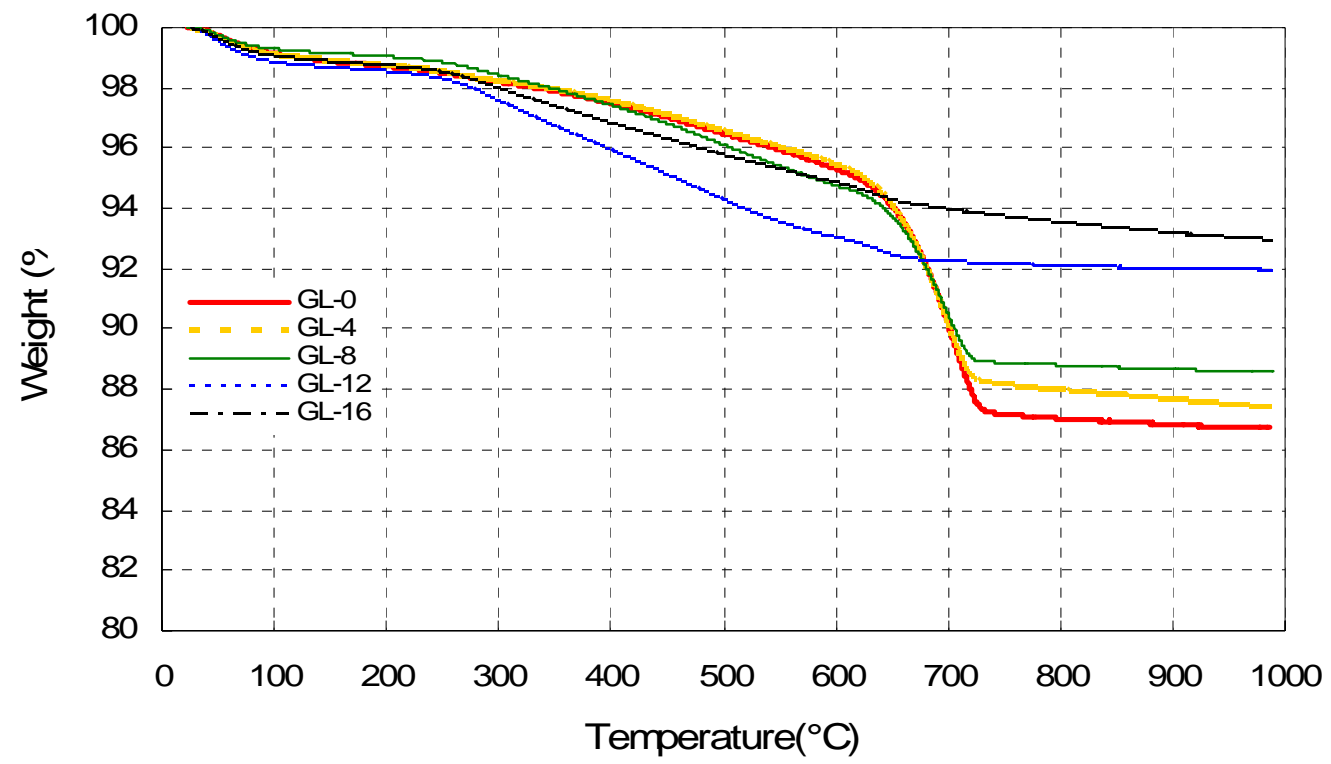

Figure 5.75 Weight loss and weight loss rate obtained from TGA from lime-treated soil samples collected at depths of $0,4,8,12$, and 16 inches, below top of subgrade at BH-4 (STA. 60 meters) at site (3)

Figure 5.75 shows TGA results of the lime-treated soil samples collected at depths of $0,4,8,12$, and 16 inches below the top of the subgrade at BH-6 (STA. 100 meters). The amount of $\mathrm{CaCO}_{3}$ decreases from $8 \%$ at the top of the lime-treated subgrade to $0 \%$ at 16-in. depth.

Based on the results of the laboratory and field tests at site (3), it appears that there is little correlation between the stiffness and/or strength of the subgrade and the added lime. Even though construction quality does affect the stiffness and/or strength of lime-treated soils, it is perhaps more likely at this site that the LKD added had very little chemically reactive lime. 


\subsection{Site (4)}

\section{Soil characterization properties}

Figure 5.76 shows the natural water content and soil index properties of the limetreated subgrade and natural (untreated) soil, obtained from laboratory tests using the samples collected at ten different borehole locations at the site. The water content of the lime-treated and untreated soils is determined from samples taken at 8-in and 30-in depth, respectively, below the top of the subgrade. The water content of the lime-treated subgrade is in the range of $10 \%$ to $18 \%$, while the natural soil is in the range of 10 to $13 \%$. In general, the water content of the lime-treated subgrade are a little higher than those of the natural soil.

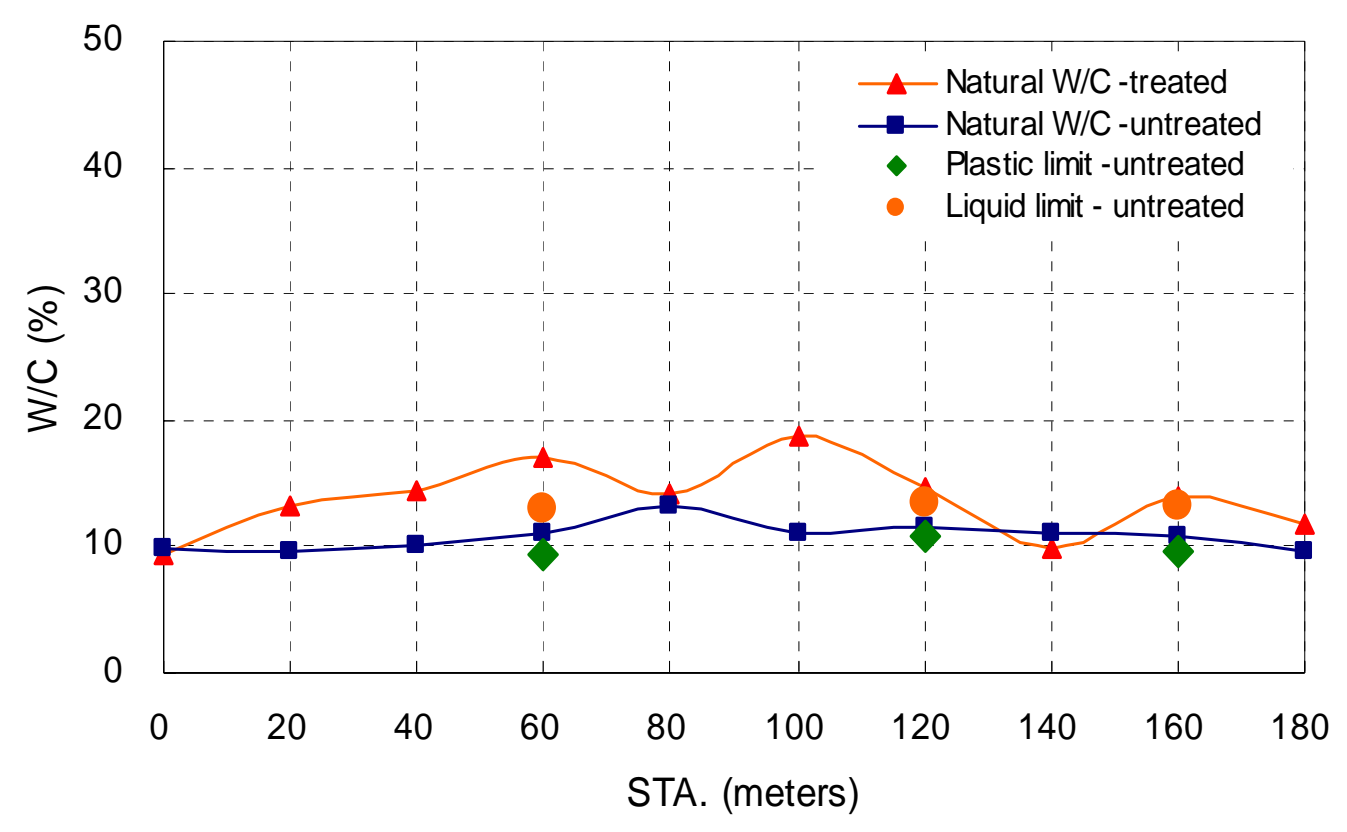

Figure 5.76 Natural water content and soil index properties. Site (4) 
Figure 5.77 shows the particle-size distribution from wet sieving tests from both the lime-treated and the natural soil. The amount passing the No. 200 sieve is $22 \%$ and $54 \%$ for the lime-treated and natural soil, respectively. Atterberg limits performed on the soils show that the lime-treated subgrade soil is non-plastic. The natural (untreated) soil has a Plastic Limit (PL) of 10, a Liquid Limit (LL) of 13, and a Plastic Index (PI) of 3. Based on the laboratory results, the lime-treated subgrade soil is classified as SM following USCS (Unified Soil Classification System), or A-1-b in accordance with the AASHTO classification. The natural soil is classified as ML and A-6, respectively.

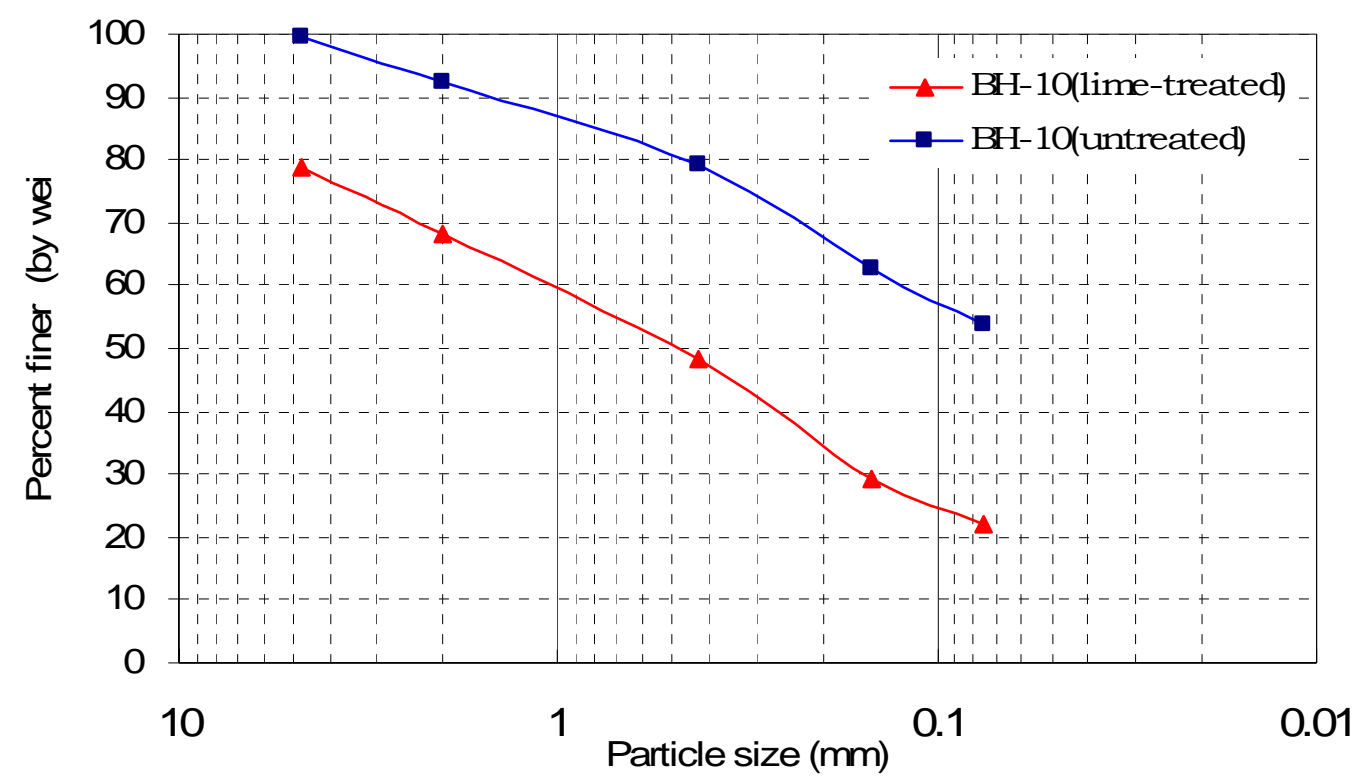

Figure 5.77 Particle-size distribution. Site (4)

Based on the soil index properties and particle-size distribution (Figure 5.76 and Figure 5.77), the lime treatment at the site appears to have been successful as the soil was modified from a low-plasticity clay to a silty sand. 


\section{Stiffness and/or strength properties}

The stiffness of the soil at site (4) has been determined by two methods: One through an indirect method using the results from the FWD tests; and the other method, directly from SPT and DCP tests. For the indirect method, the $\mathrm{M}_{\mathrm{R}}$ of the natural soil and the lime-treated subgrade soil layers is obtained from back-calculation of FWD deflection data. The $M_{R}$ of the lime-treated and the untreated natural subgrade layer is 111 and 22 ksi, respectively, resulting in an increase of the $M_{R}$ by a factor of $400 \%$.

Figure $5.78 \sim$ Figure 5.87 show DCPI (Dynamic Cone Penetration Index) and SPI (Standard Penetration Index) with depth of penetration at all the ten boreholes done at the site. In general there are two layers with a considerable difference of DCPI values: an upper layer with a low index and a lower layer with a larger index. This is the result of an increase in stiffness and/or strength of the upper layer due to the lime-treatment. As with the other sites, the DCPI measured just at the top of subgrade is large. This may be caused by the disturbance of the soil near the top of the subgrade during boring. 


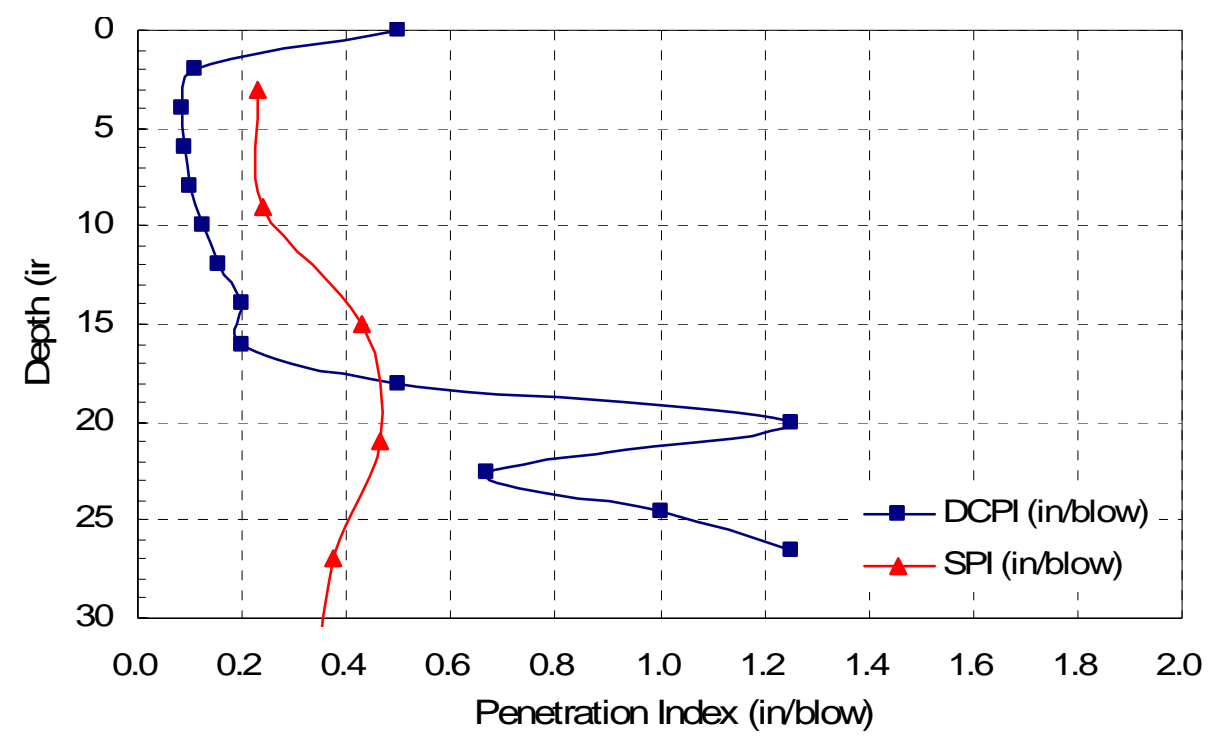

Figure 5.78 DCPT and SPT results with depth at BH-1 (STA. 0 meters). Site (4)

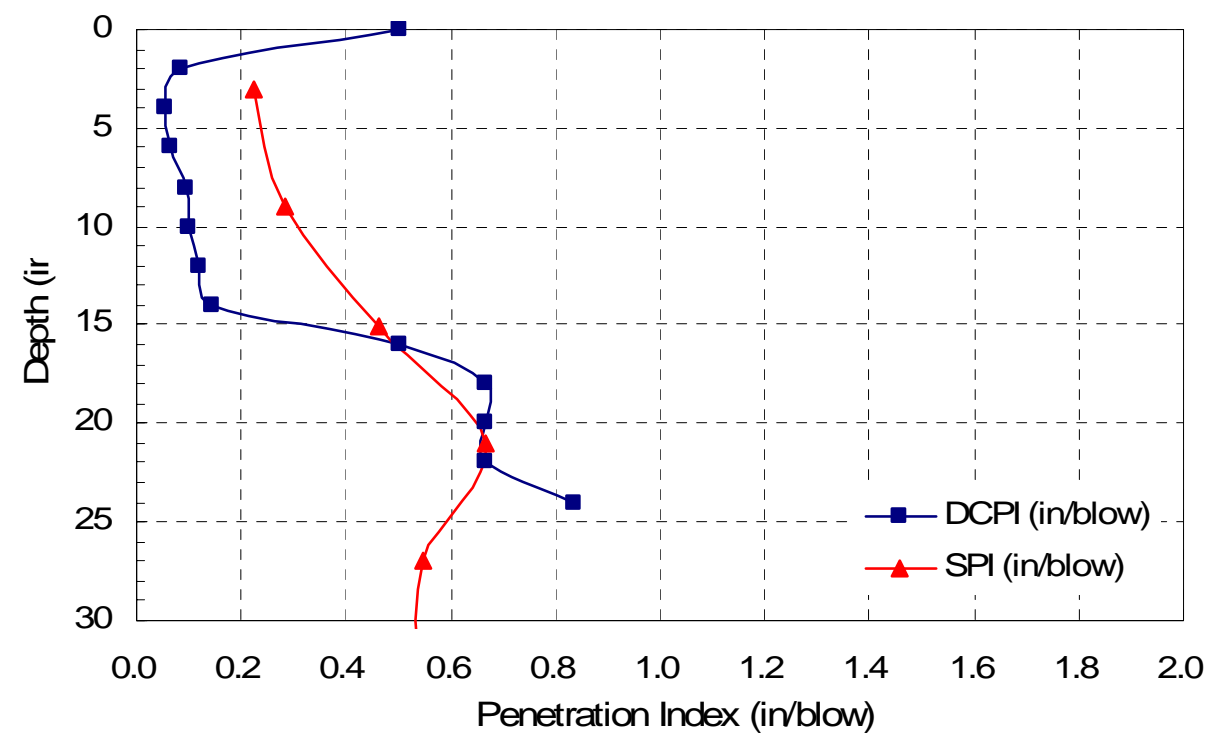

Figure 5.79 DCPT and SPT results with depth at BH-2 (STA. 20 meters). Site (4) 


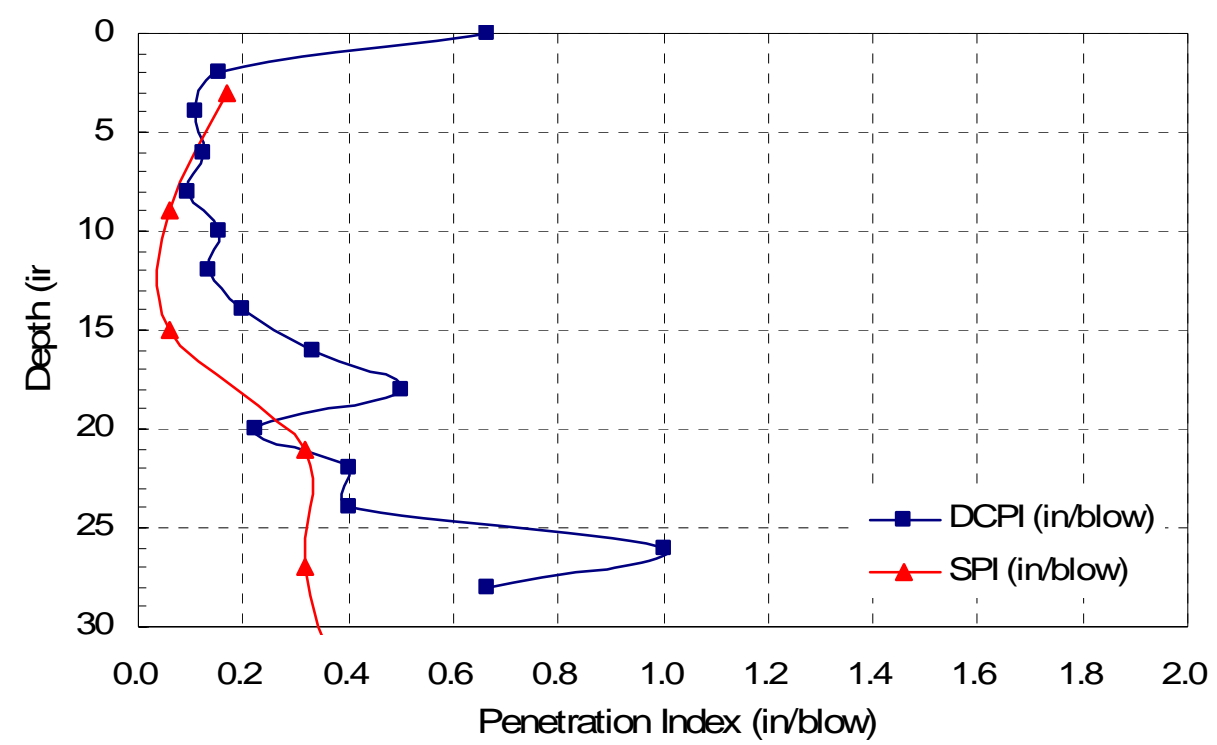

Figure 5.80 DCPT and SPT results with depth at BH-3 (STA. 40 meters). Site (4)

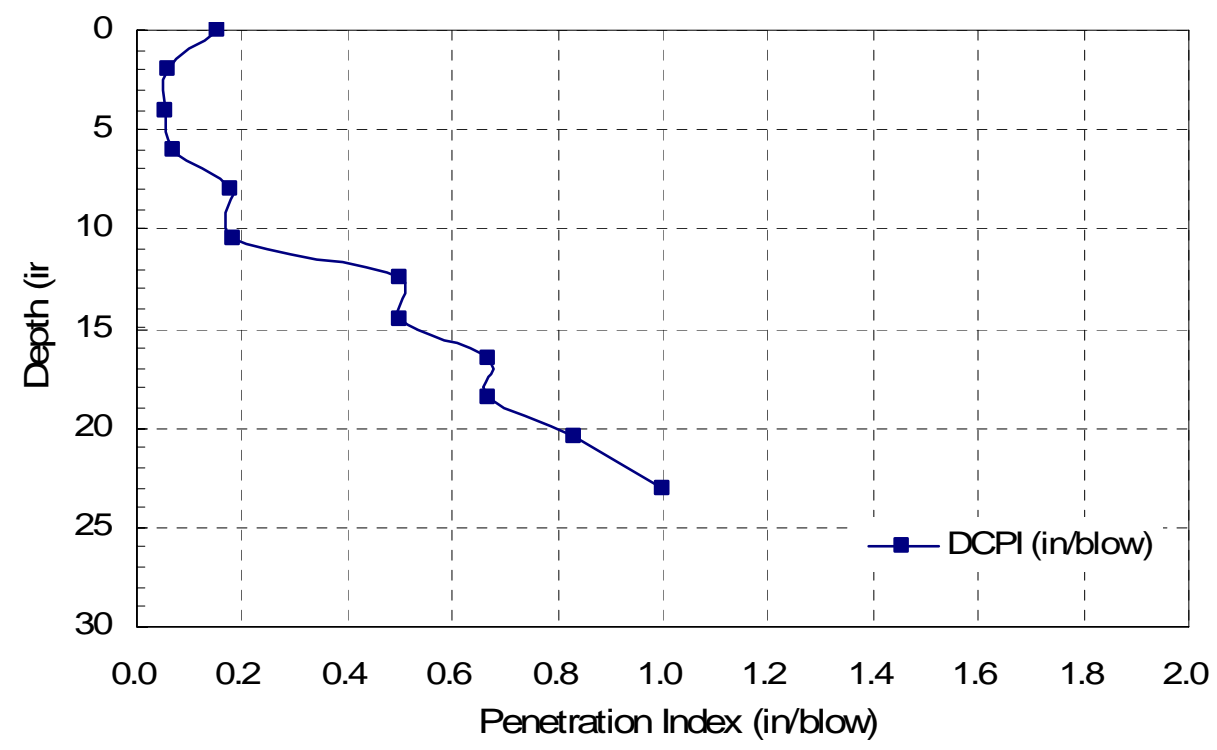

Figure 5.81 DCPT result with depth at BH-4 (STA. 60 meters). Site (4) 


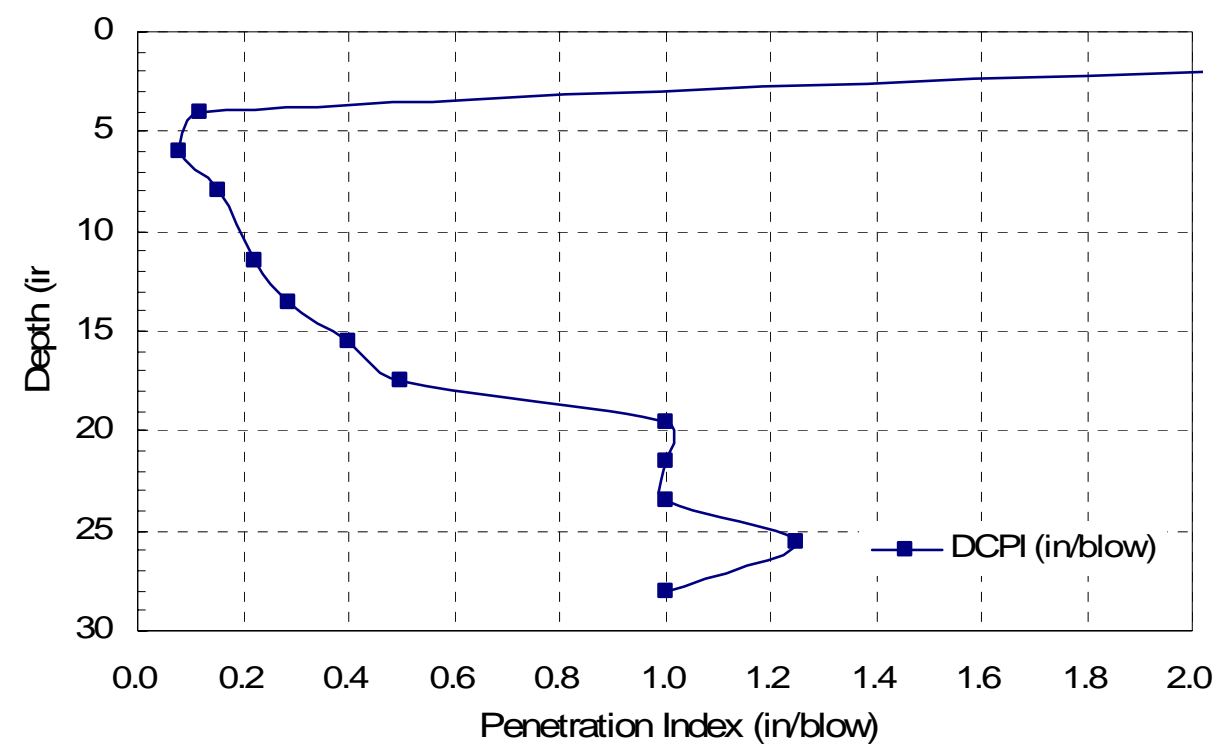

Figure 5.82 DCPT result with depth at BH-5 (STA. 80 meters). Site (4)

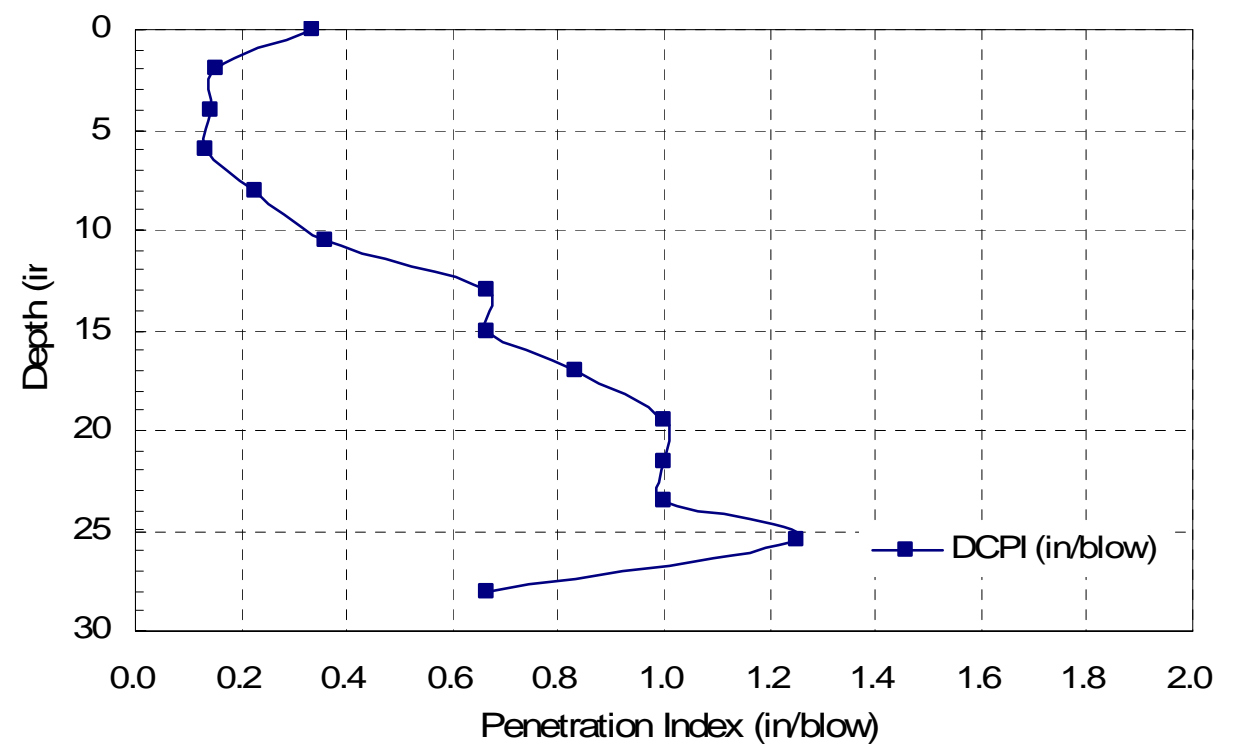

Figure 5.83 DCPT result with depth at BH-6 (STA. 100 meters). Site (4) 


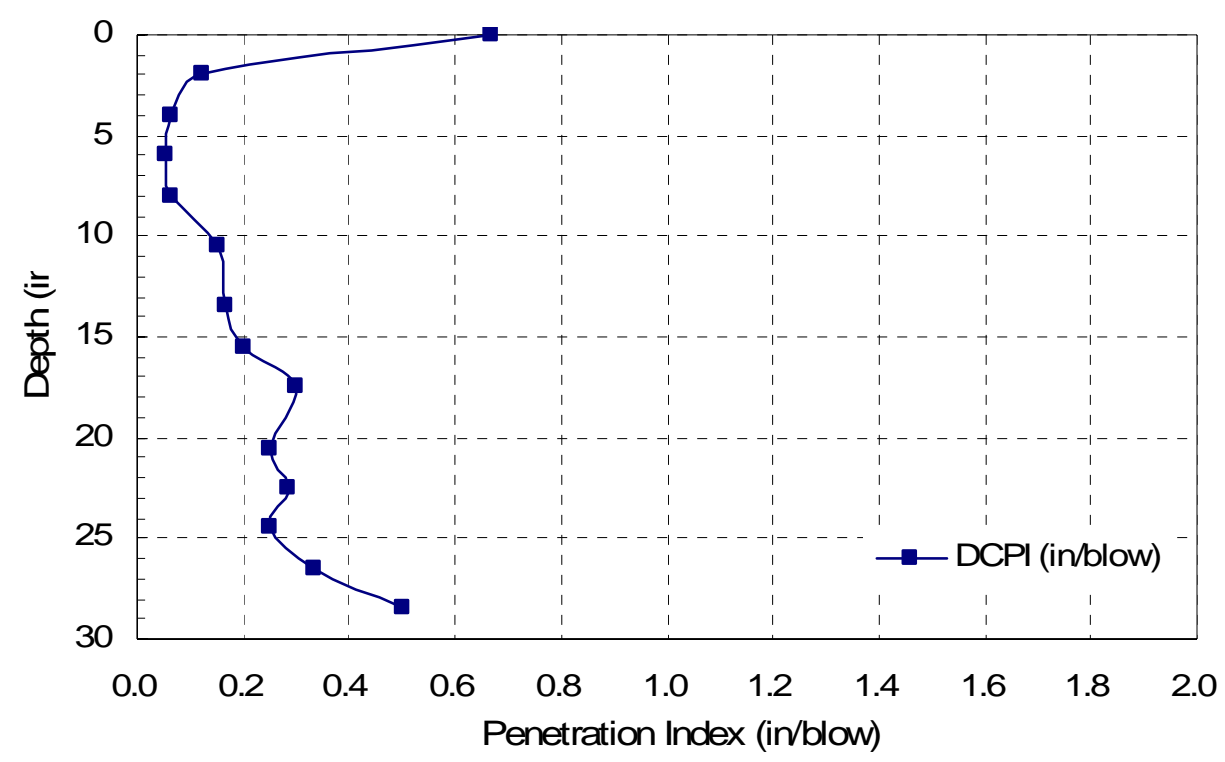

Figure 5.84 DCPT result with depth at BH-7 (STA. 120 meters). Site (4)

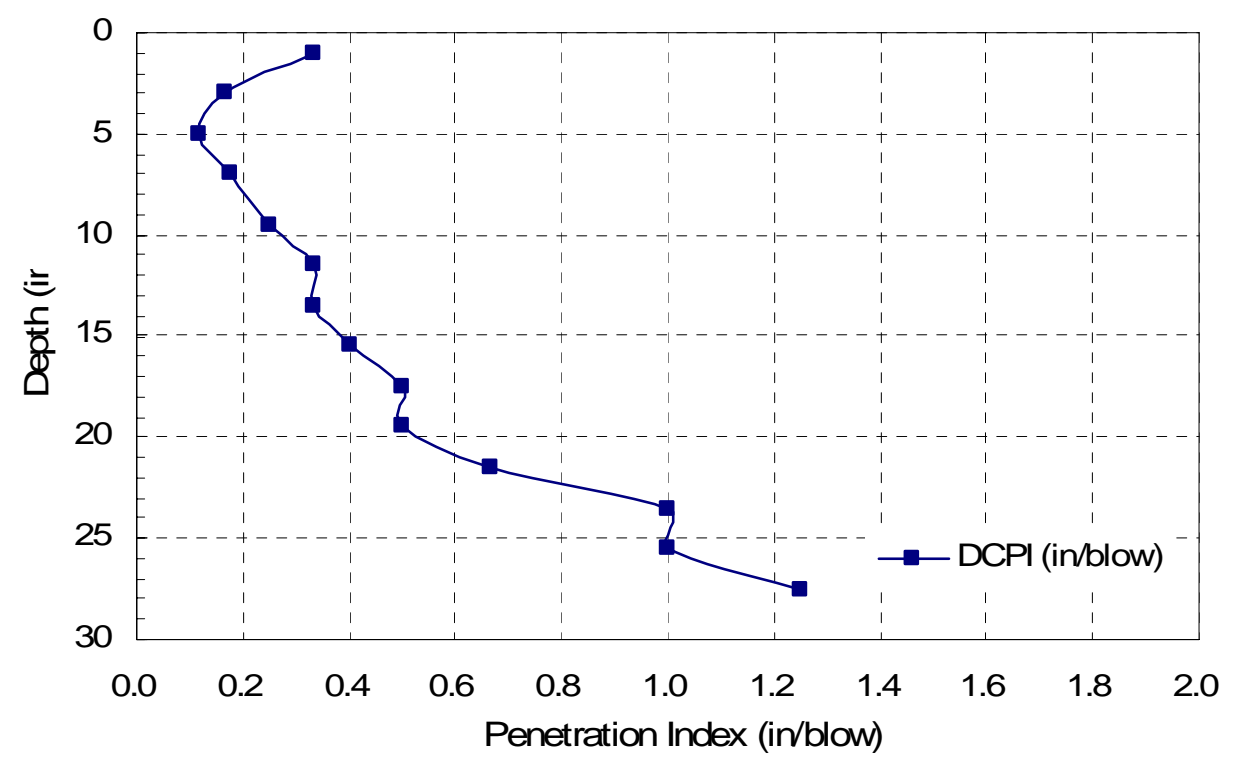

Figure 5.85 DCPT result with depth at BH-8 (STA. 140 meters). Site (4) 


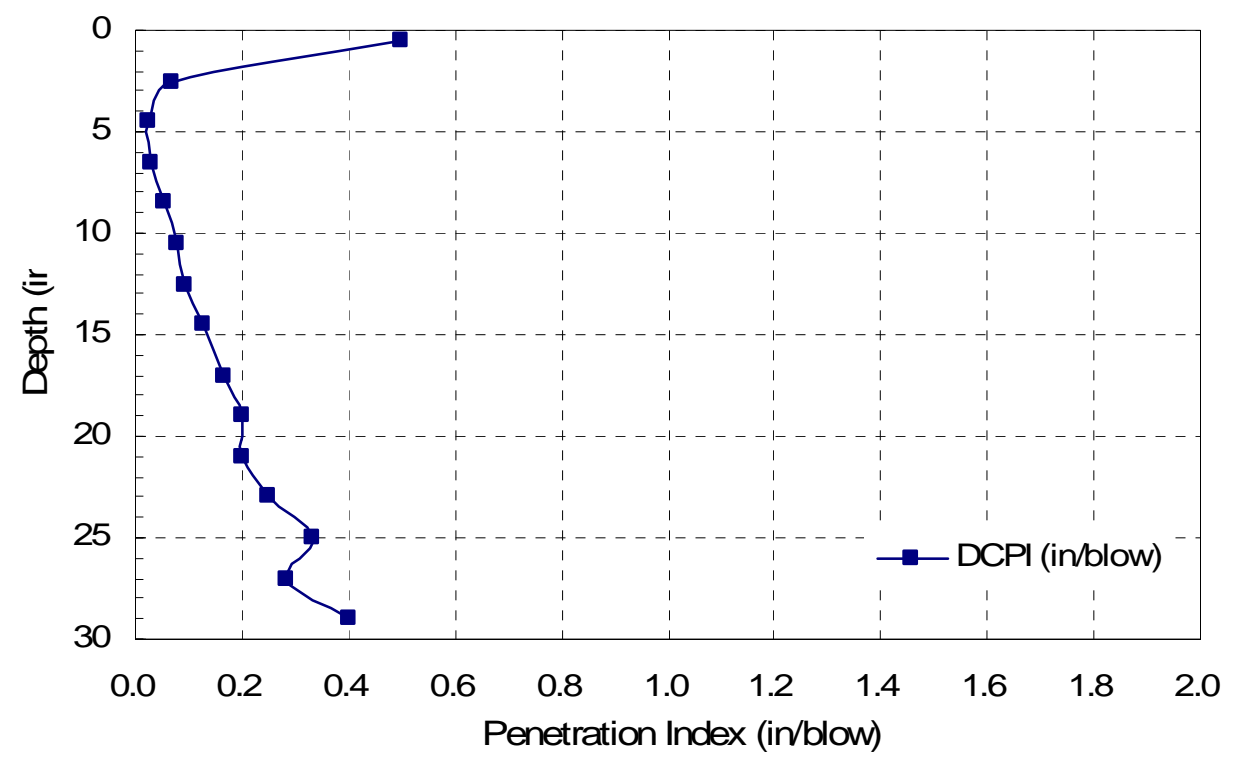

Figure 5.86 DCPT result with depth at BH-9 (STA. 160 meters). Site (4)

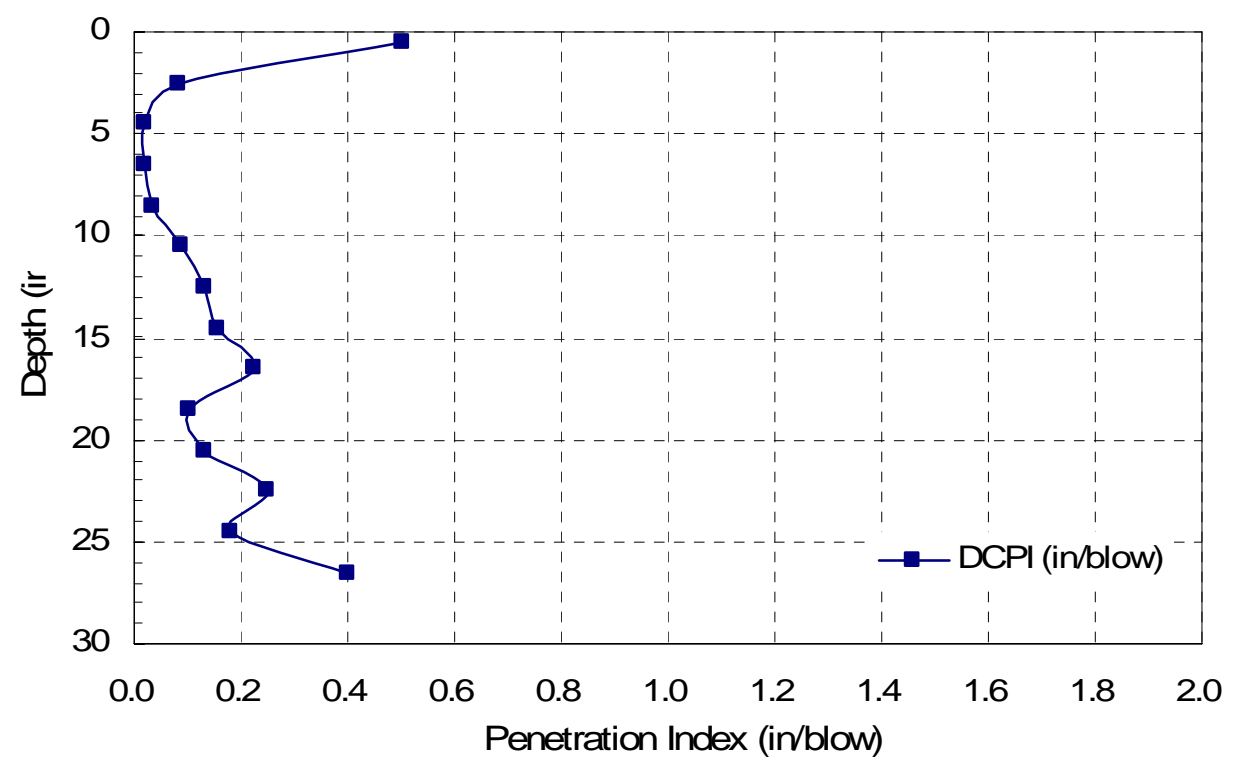

Figure 5.87 DCPT result with depth at BH-10 (STA. 180 meters). Site (4) 


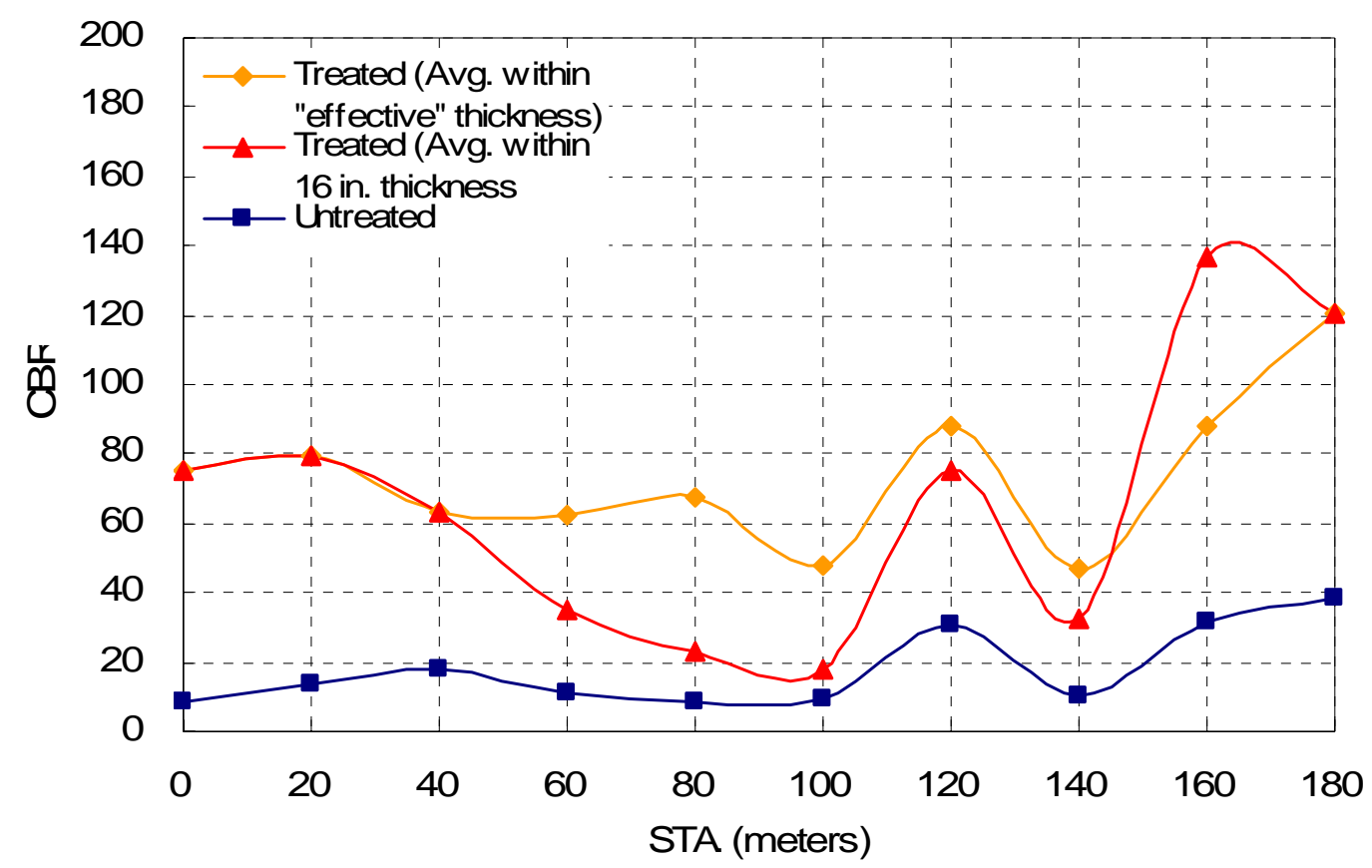

Figure 5.88 CBR of subgrade estimated from DCPT results. Site (4)

Figure 5.88 plots the longitudinal distribution of CBR for both the lime-treated and natural soil layers. The CBR values are obtained with a correlation of DCPI and CBR (Webster et al., 1992). From the figure, it is observed that: (1) the CBR of the natural subgrade soil layer ranges from 9 to 39; (2) the CBR of the lime-treated subgrade, calculated within the effective thickness of the layer, ranges between 47 and 121, which results in an increase of the CBR by a factor of $210 \%$ to $740 \%$; (3) the CBR of the limetreated subgrade soil layer, calculated within a thickness of 16 inches below the top of the subgrade, ranges between 18 and 137, which results in an increase of CBR of 100 to $740 \%$; and (4) the distance between the two curves of the treated soil is a measure of the difference between the design and the actual depth of treatment. In the figure, at $\mathrm{BH}-9$ (STA. 160 meters), the CBR value calculated as the average over the entire 16 inches is larger than the CBR value calculated within the effective thickness. This is possible 
because the effective thickness of the lime-treated subgrade soil layer is larger than 16 inches.

While Figure 5.88 shows that there is a substantial increase of the stiffness of the soil with treatment, it also shows a very large and significant variability.

\section{Lime content}

Figure 5.89 shows the $\mathrm{pH}$ values of both the lime-treated subgrade and natural soil, which were determined at the boreholes drilled at the site. The lime-treated subgrade soil has a $\mathrm{pH}$ ranging from 9.8 to 11.9 while the untreated soil has a $\mathrm{pH}$ ranging from 7.9 to 9.2. The increase of $\mathrm{pH}$ denotes the presence of lime.

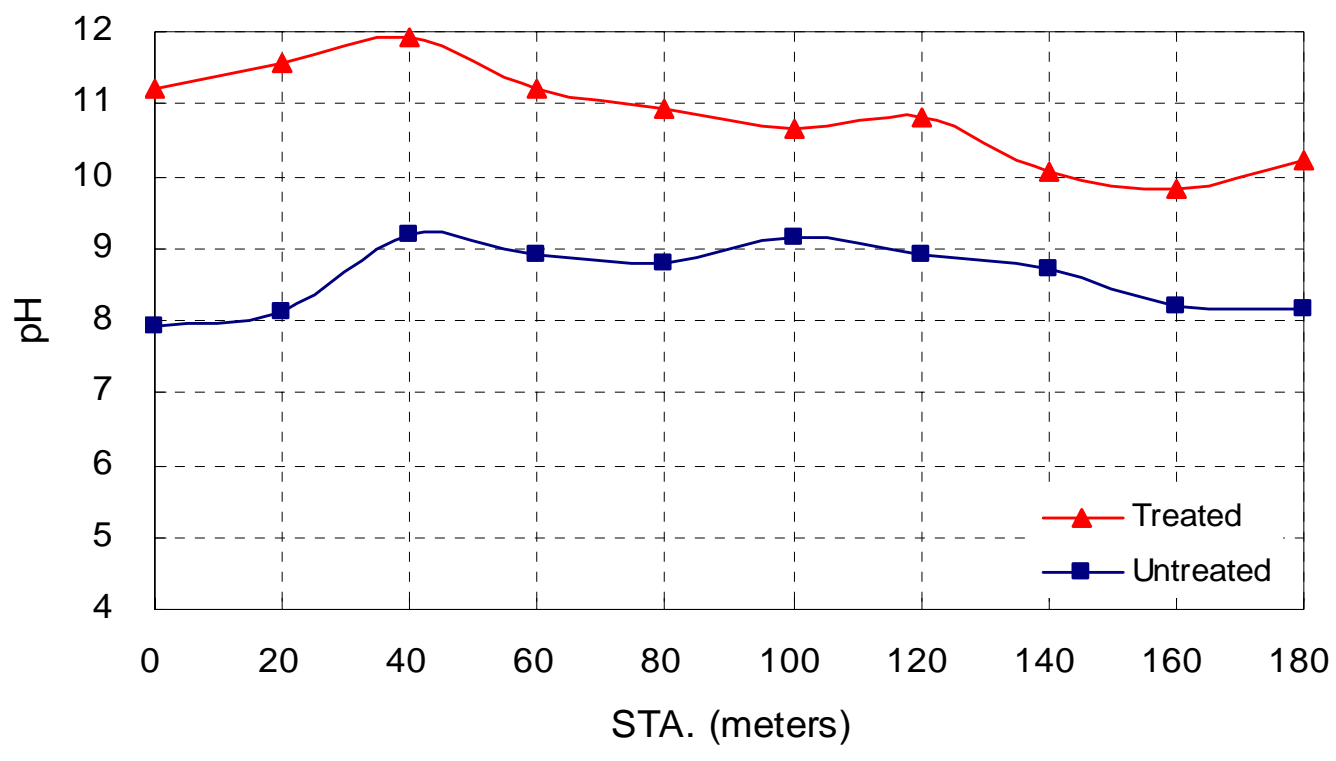

Figure $5.89 \mathrm{pH}$. Site (4)

Figure 5.90 Figure 5.92 show the results of XRD tests from the lime-treated soil samples taken at BH-3 (STA. 40 meters), BH-6 (STA. 100 meters), and BH-9 (STA. 160 
meters), respectively. The samples were taken approximately at a depth of 4 inches below the top of the subgrade. All the figures show that the XRD pattern has a strong peak at the critical refraction angles of calcium carbonate $\left(\mathrm{CaCO}_{3}\right)$.

Figure 5.93 Figure 5.97 show the XRD pattern for the lime-treated soil samples collected at depths of $0,4,8,12$, and 16 inches below the top of the subgrade at $\mathrm{BH}-9$ (STA. 160 meters). The XRD tests were done to investigate the existence of lime with depth in the subgrade. In all the figures, the XRD pattern has an obvious peak at the critical refraction angles of $\mathrm{CaCO}_{3}$, and it appears that the lime exists through the entire 16 inches of the lime treated subgrade soil layer.
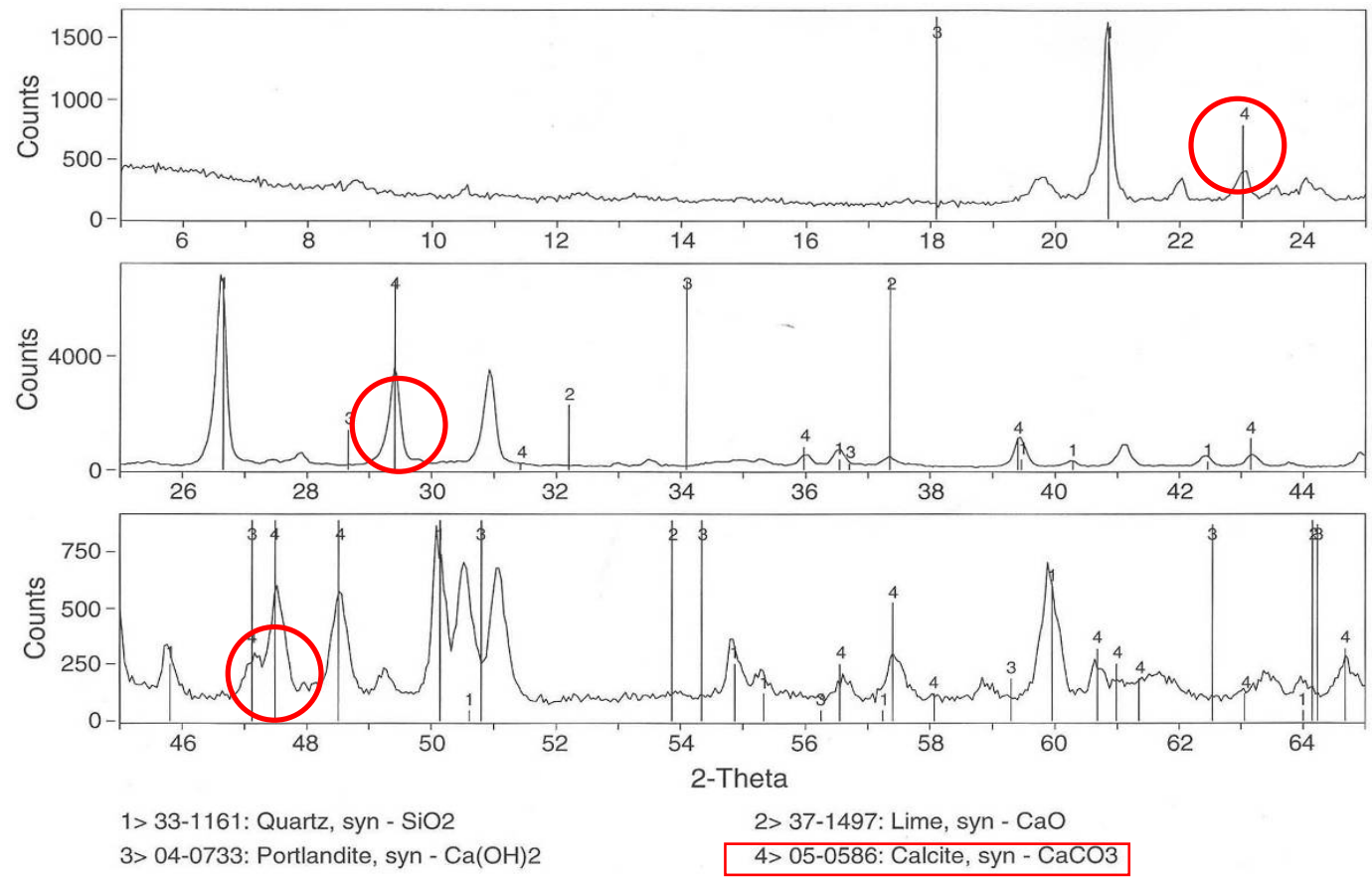

Figure 5.90 XRD pattern for lime-treated soil sample at BH-3 (STA. 40). Site (4) 

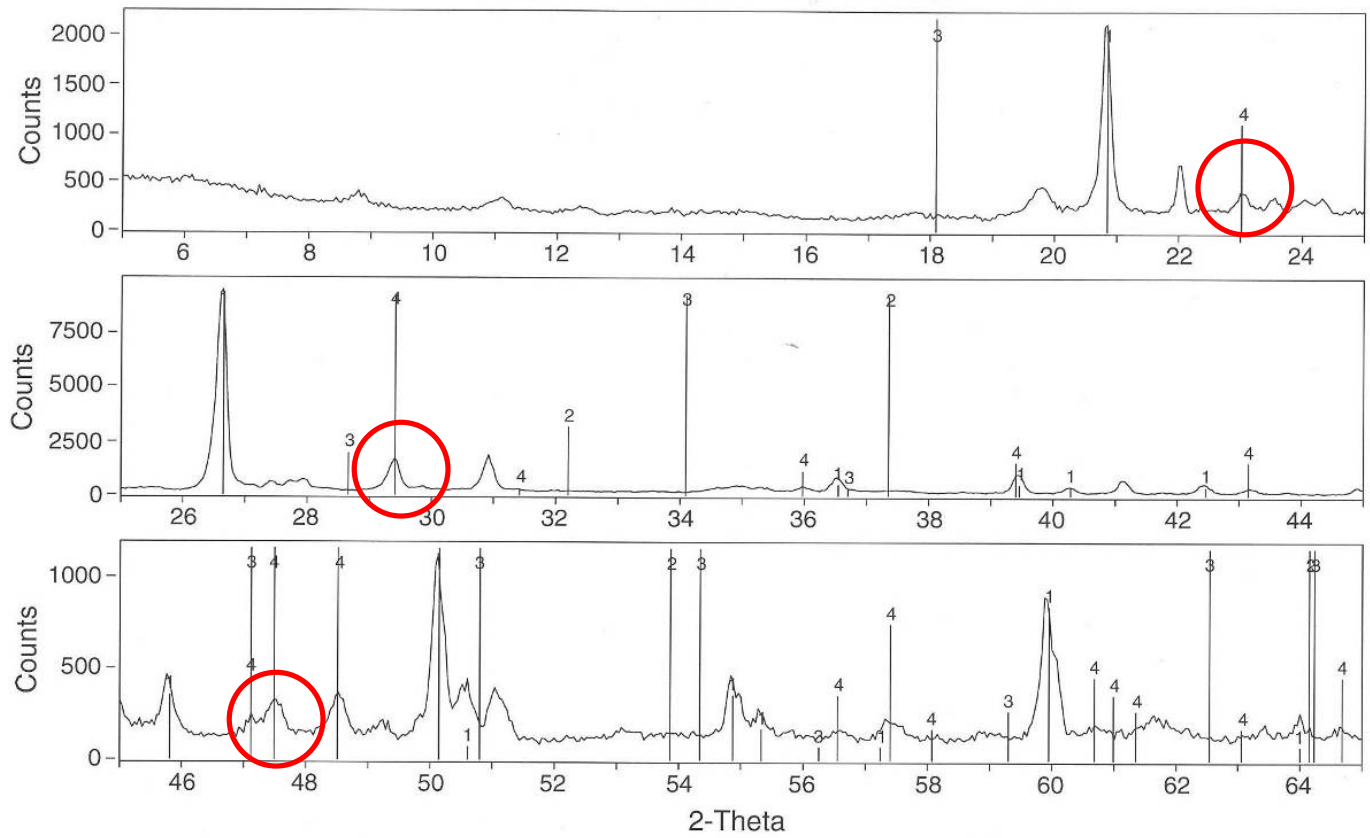

1> 33-1161: Quartz, syn - SiO2

3> 04-0733: Portlandite, syn - $\mathrm{Ca}(\mathrm{OH}) 2$

2> 37-1497: Lime, syn - CaO

4> 05-0586: Calcite, syn - CaCO3

Figure 5.91 XRD pattern for lime-treated soil sample at BH-6 (STA. 100). Site (4)
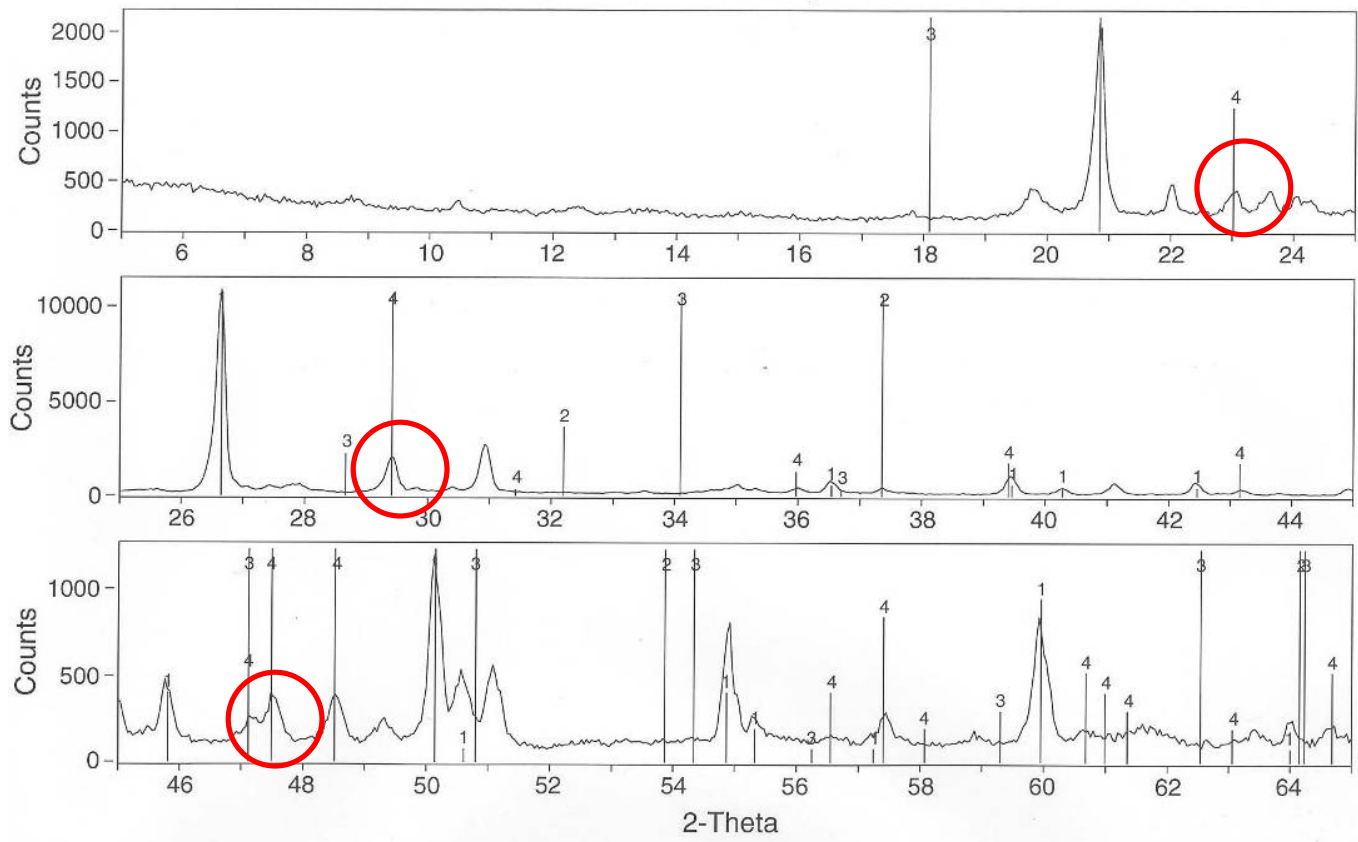

1> 33-1161: Quartz, syn - SiO2

2> 37-1497: Lime, syn - CaO

3> 04-0733: Portlandite, syn - $\mathrm{Ca}(\mathrm{OH}) 2$

4> 05-0586: Calcite, syn - $\mathrm{CaCO} 3$

Figure 5.92 XRD pattern for lime-treated soil sample at BH-9 (STA. 160). Site (4) 

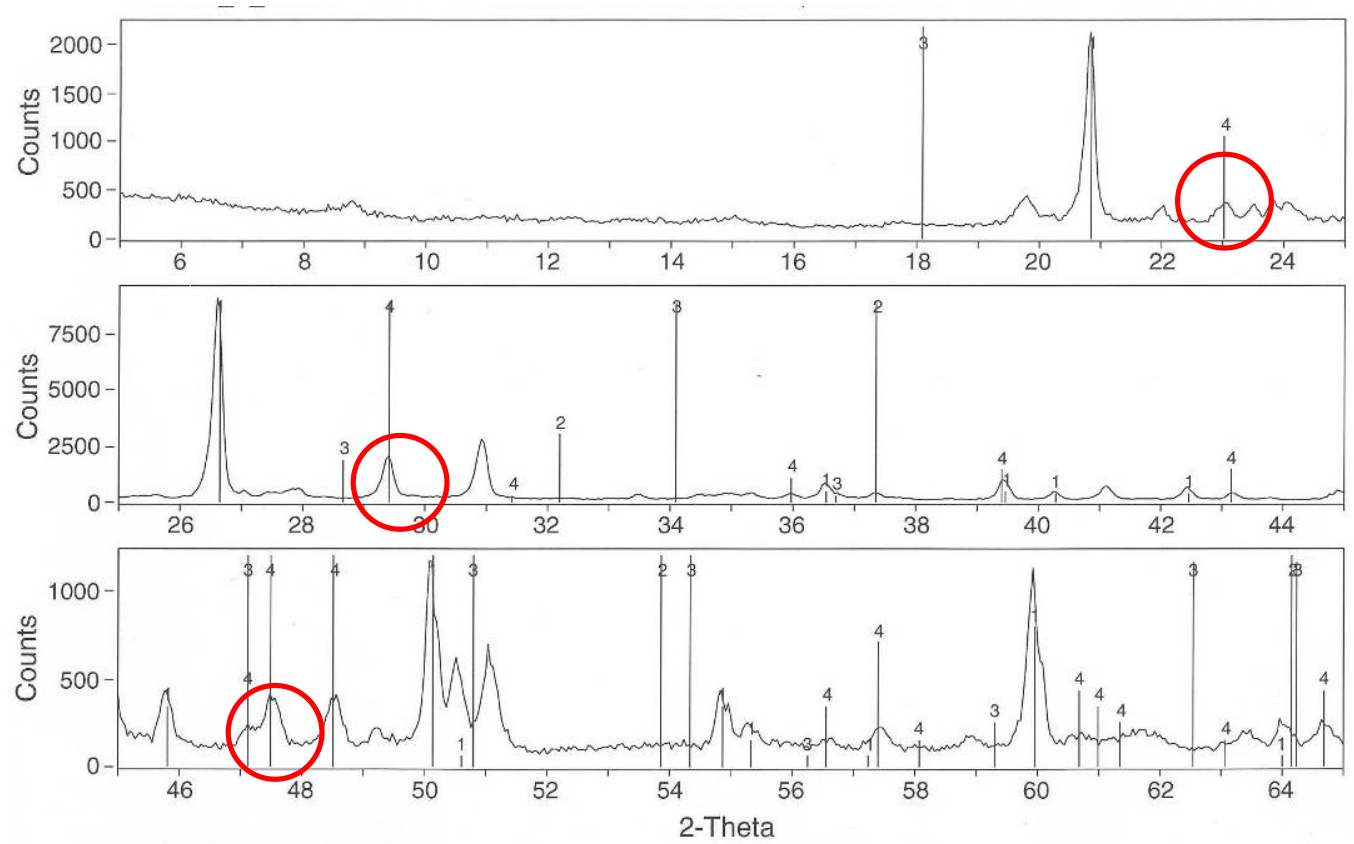

1> 33-1161: Quartz, syn - SiO2

2> 37-1497: Lime, syn - CaO

3>04-0733: Portlandite, syn - $\mathrm{Ca}(\mathrm{OH}) 2$

4> 05-0586: Calcite, syn - CaCO3

Figure 5.93 XRD pattern for lime-treated soil sample taken at a depth of 0 inch below top of subgrade at BH-9. Site (4)
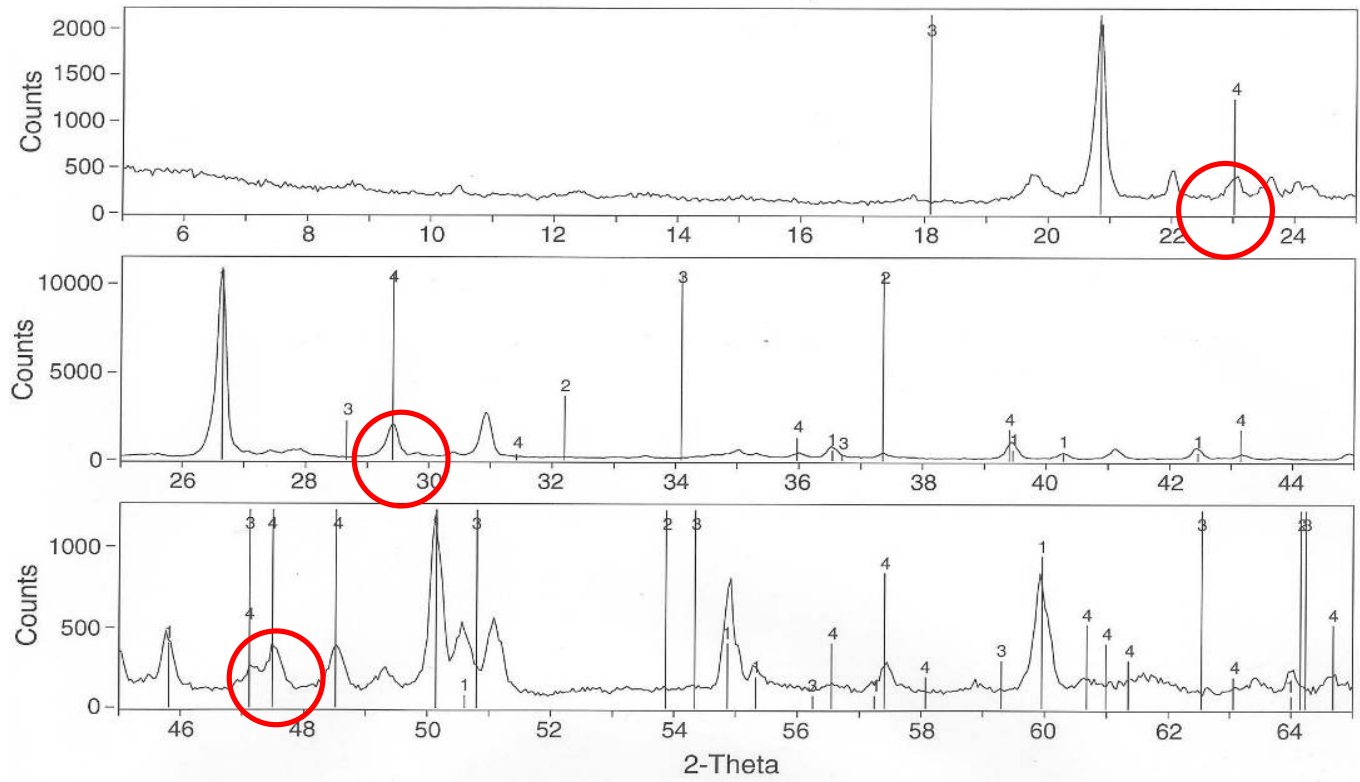

1> 33-1161: Quartz, syn - SiO2

2> 37-1497: Lime, syn - CaO

3> 04-0733: Portlandite, syn - $\mathrm{Ca}(\mathrm{OH}) 2$

4> 05-0586: Calcite, syn - $\mathrm{CaCO} 3$

Figure 5.94 XRD pattern for lime-treated soil sample taken at a depth of 4 inches below top of subgrade at BH-9. Site (4) 

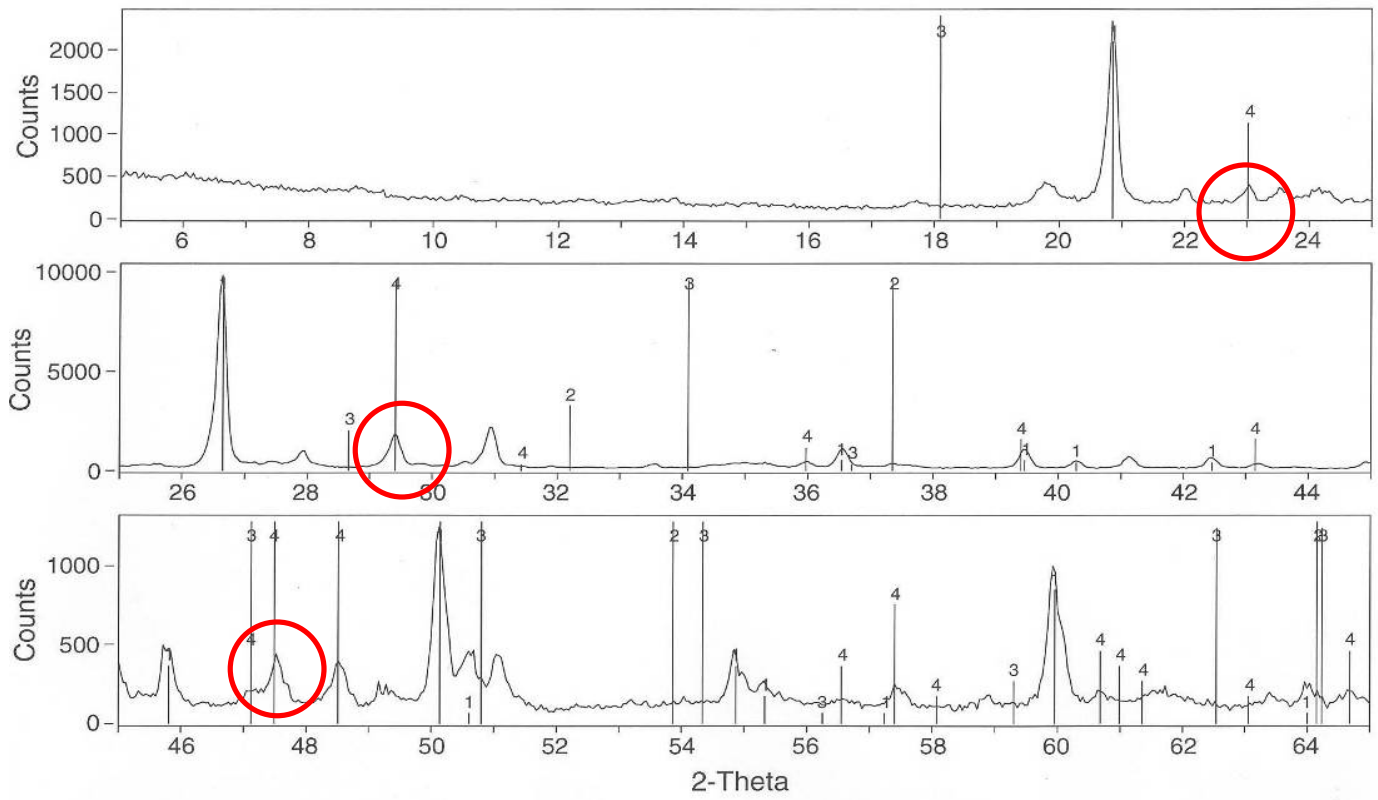

1> 33-1161: Quartz, syn - SiO2

3> 04-0733: Portlandite, syn - $\mathrm{Ca}(\mathrm{OH}) 2$

2> 37-1497: Lime, syn - CaO

4> 05-0586: Calcite, syn - $\mathrm{CaCO} 3$

Figure 5.95 XRD pattern for lime-treated soil sample taken at a depth of 8 inches below top of subgrade at BH-9. Site (4)
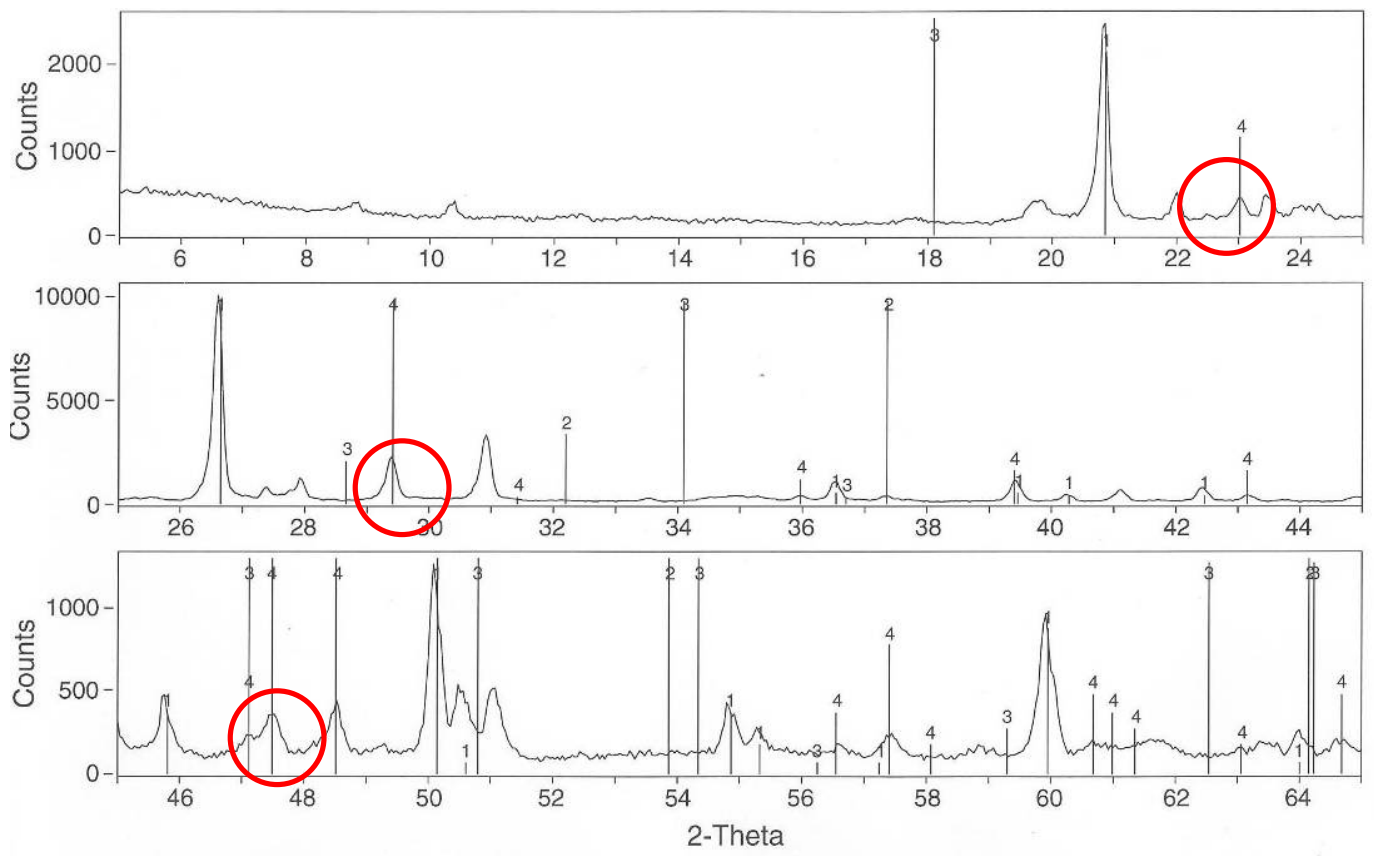

1> 33-1161: Quartz, syn - SiO2

3> 04-0733: Portlandite, syn - $\mathrm{Ca}(\mathrm{OH}) 2$

2> 37-1497: Lime, syn - CaO

4> 05-0586: Calcite, syn - $\mathrm{CaCO} 3$

Figure 5.96 XRD pattern for lime-treated soil sample taken at a depth of 12 inches below top of subgrade at BH-9. Site (4) 

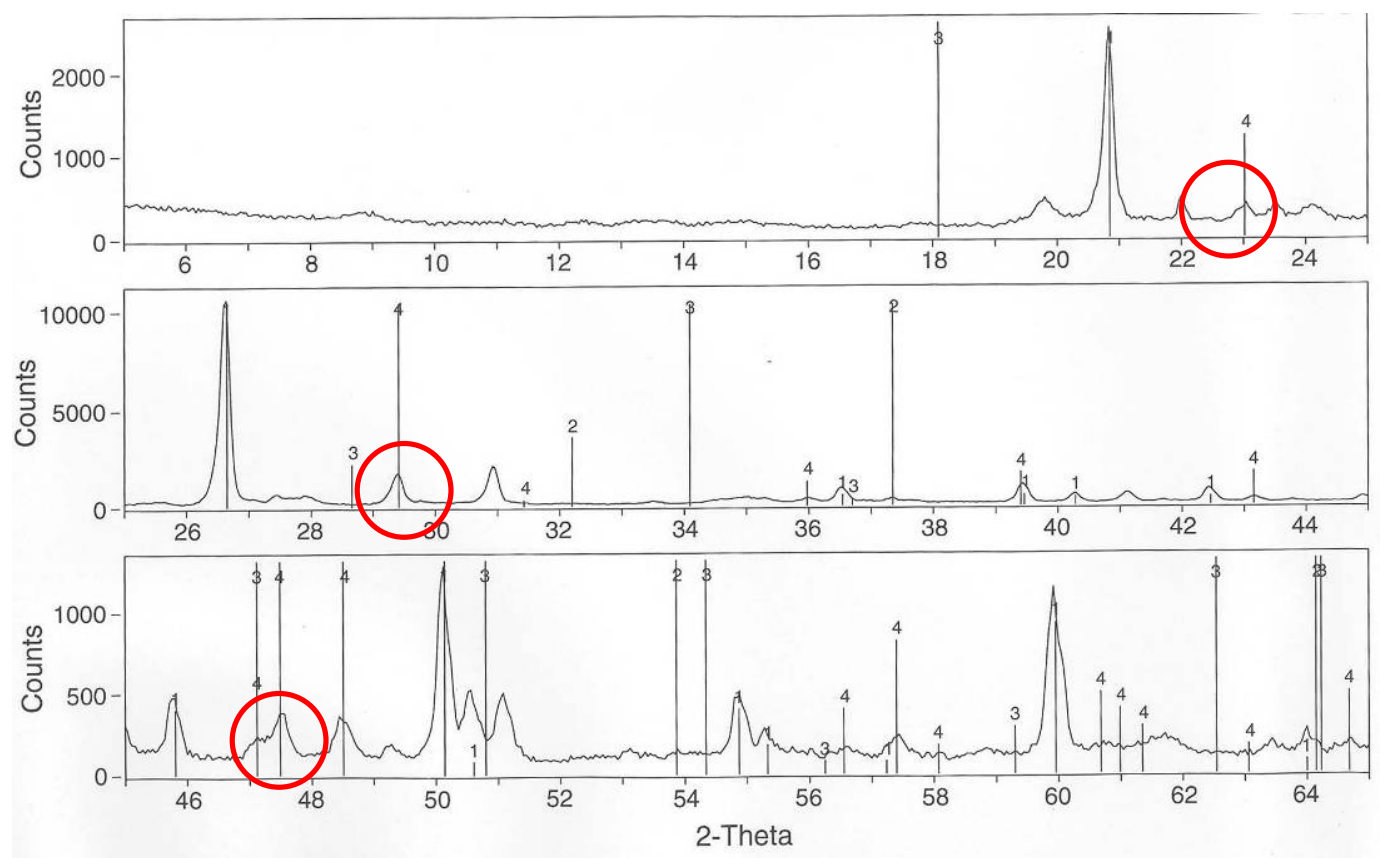

1> 33-1161: Quartz, syn - SiO2

3> 04-0733: Portlandite, syn - $\mathrm{Ca}(\mathrm{OH}) 2$

2> 37-1497: Lime, syn - CaO

4> 05-0586: Calcite, syn - CaCO3

Figure 5.97 XRD pattern for lime-treated soil sample taken at a depth of 16 inches below top of subgrade at BH-9. Site (4)

Figure $5.98 \sim$ Figure 5.100 show the results of TGA tests for the lime-treated samples collected at BH-3 (STA. 40 meters), BH-6 (STA. 100 meters), and BH-9 (STA. 160 meters), respectively. The samples were taken approximately at depths of 4 inches (lime-treated soil) and 30 inches (natural soil) below the top of the subgrade. The results indicate an amount of $\mathrm{CaCO}_{3}$ of $17.5,8.0$, and $10.5 \%$ in the samples collected at $\mathrm{BH}-3$, $\mathrm{BH}-4$, and $\mathrm{BH}-6$, respectively. Again, it has to be noted that not all calcium carbonate found in the soil corresponds to the hydration of calcium oxide. This indicates that the lime used at this site was very reach in calcium, but a significant percentage of the lime was not chemically reactive. 


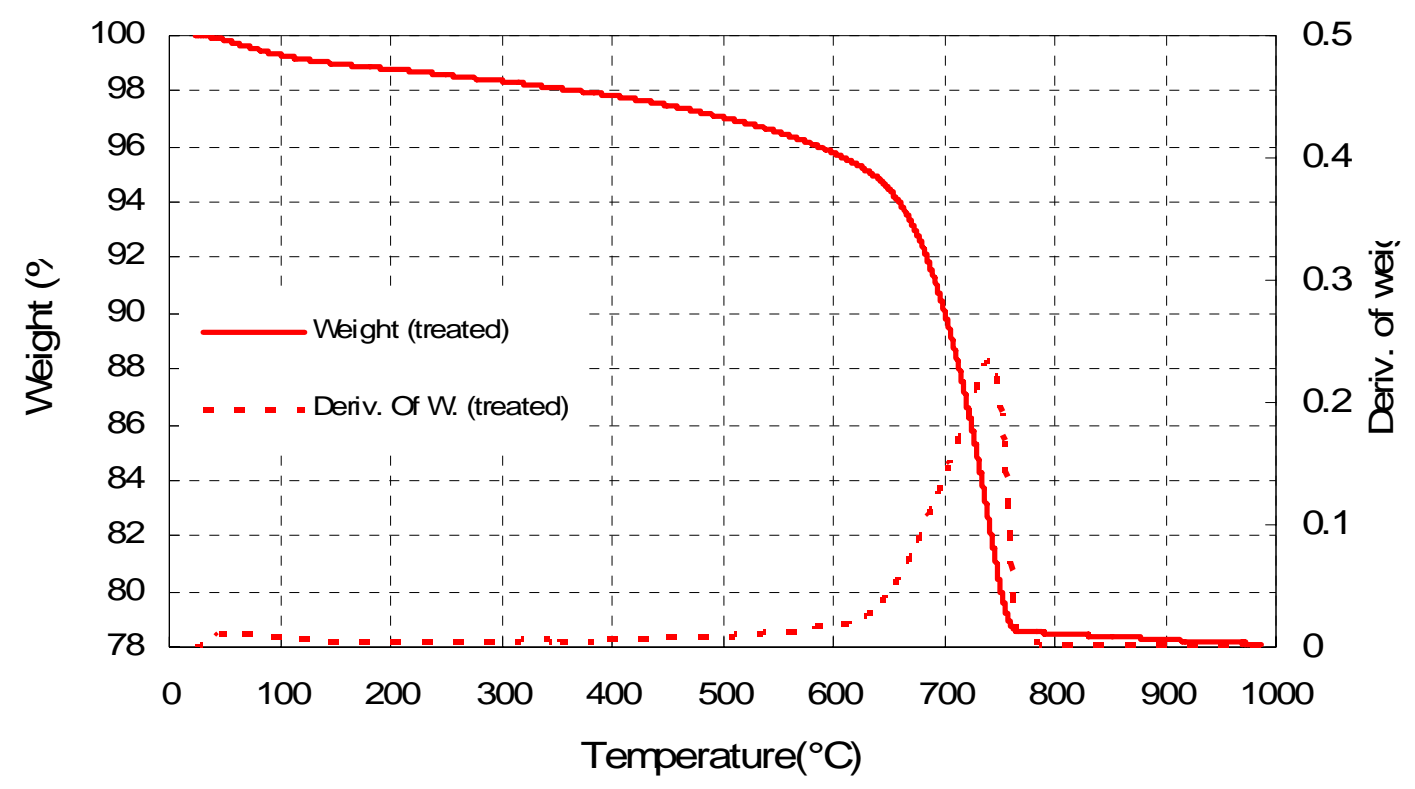

Figure 5.98 Weight loss obtained from TGA from lime-treated and natural soil samples collected at BH-3 (STA. 40 meters) at site (4)

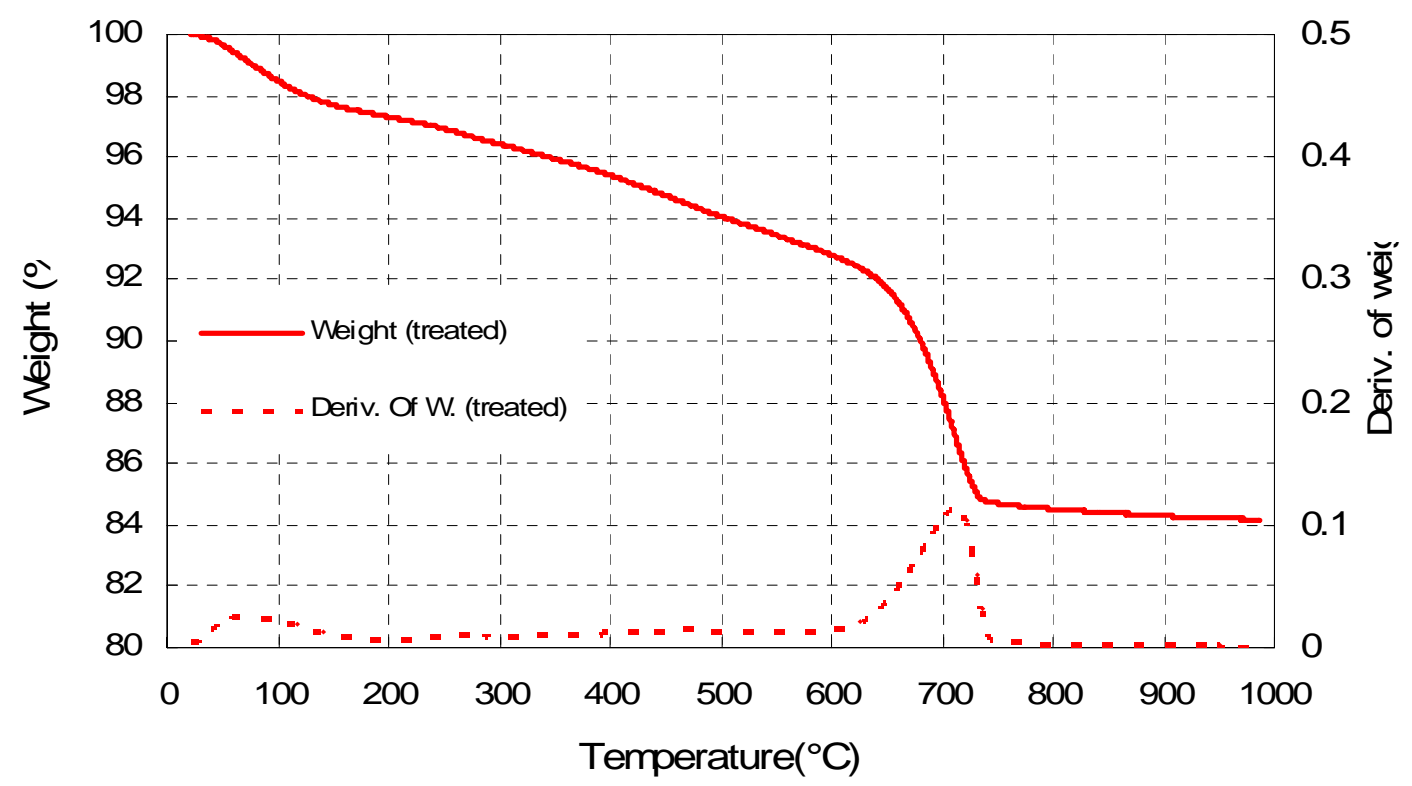

Figure 5.99 Weight loss obtained from TGA from lime-treated and natural soil samples collected at BH-6 (STA. 100 meters) at site (4) 


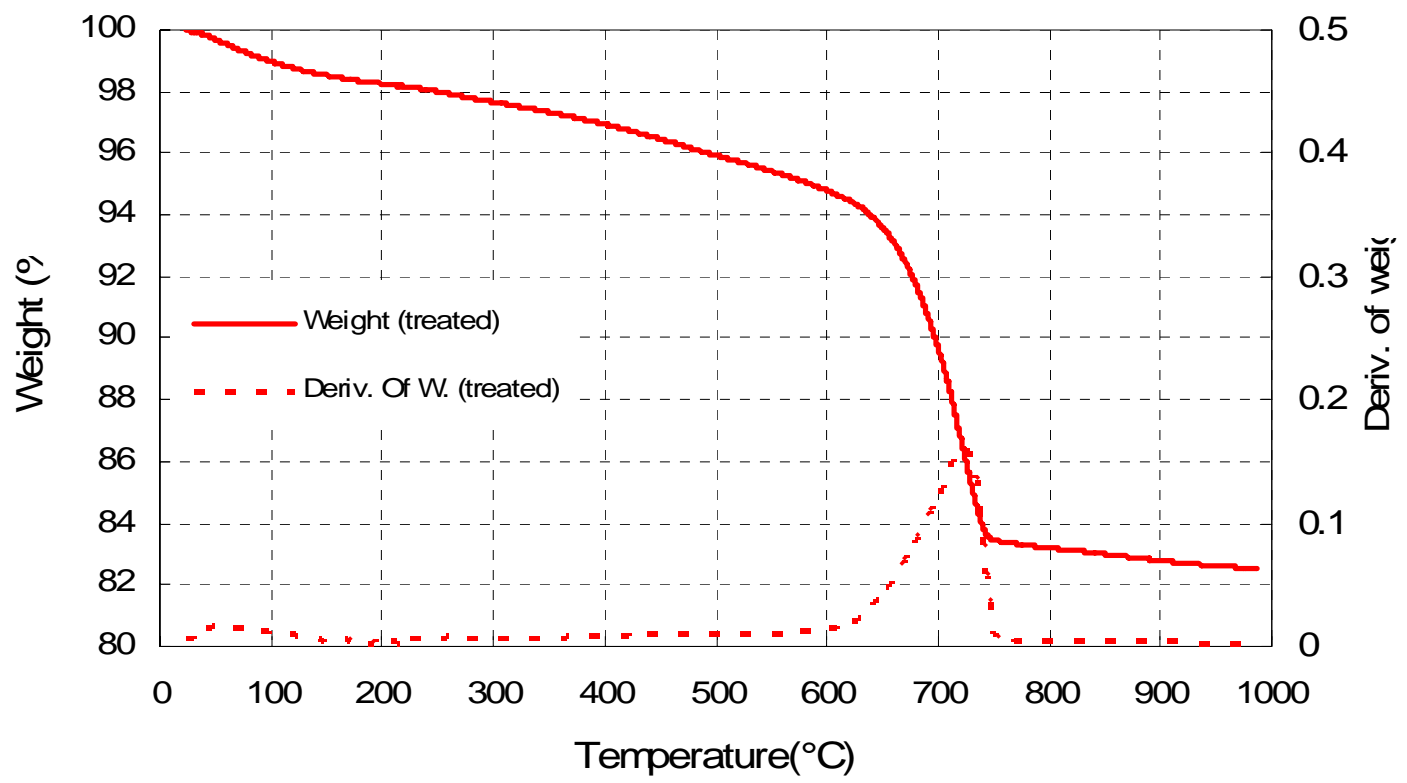

Figure 5.100 Weight loss obtained from TGA from lime-treated and natural soil samples collected at BH-9 (STA. 160 meters) at site (4)

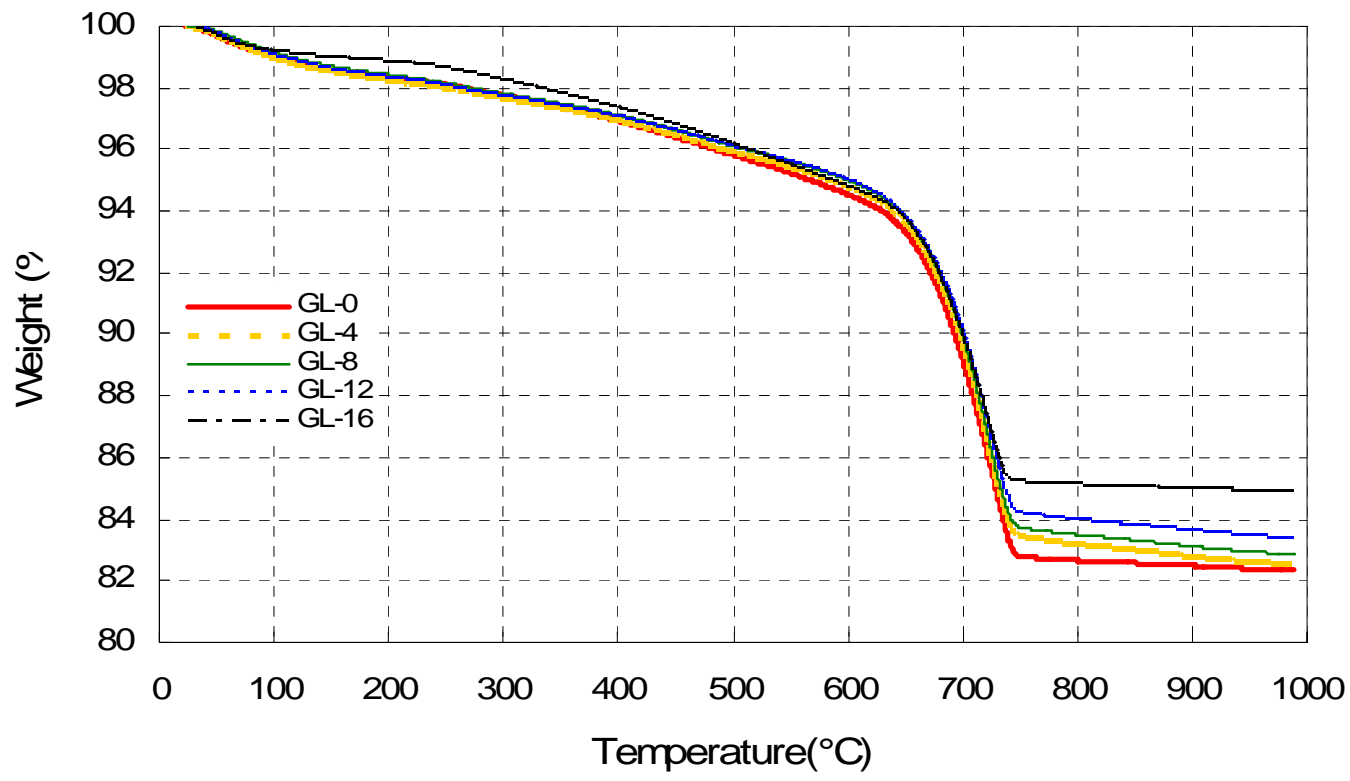

Figure 5.101 Weight loss and weight loss rate obtained from TGA from lime-treated soil samples collected at depths of $0,4,8,12$, and 16 inches, below top of subgrade at BH-9 (STA. 160 meters) at site (3) 
Figure 5.101 shows TGA results for the lime-treated soil samples that were collected at depths of $0,4,8,12$, and 16 inches below the top of the subgrade at BH-9 (STA. 160 meters). In the figure, the calculated amount of $\mathrm{CaCO}_{3}$ decreases from $11.5 \%$ at the top of the lime-treated subgrade to $9 \%$ at 16 -in. depth below the top. Note that a significant amount of $\mathrm{CaCO}_{3}$ is found even at 16-in. depth below the top of the limetreated subgrade. It appears that the lime was well mixed with the natural soil through the entire thickness of 16 inches during the construction.

The laboratory and field tests results suggest that the lime still remains in the subgrade after five years of service, and that the lime-treated subgrade still has the engineering properties gained with the addition of lime. 


\subsection{Site (5)}

\section{Soil characterization properties}

Figure 5.102 shows the natural water content and soil index properties of the lime-treated subgrade and natural (untreated) soil. The water content is determined from samples taken at 8 -in and 30-in depth below the top of the subgrade. The water content of the lime-treated subgrade is in the range of $19 \%$ to $26 \%$ while the natural soil in the range of $18 \%$ to $22 \%$. In essence, there is no significant difference in water content between the treated and untreated soils, or at least the differences are within the variations that one may expect in the field.

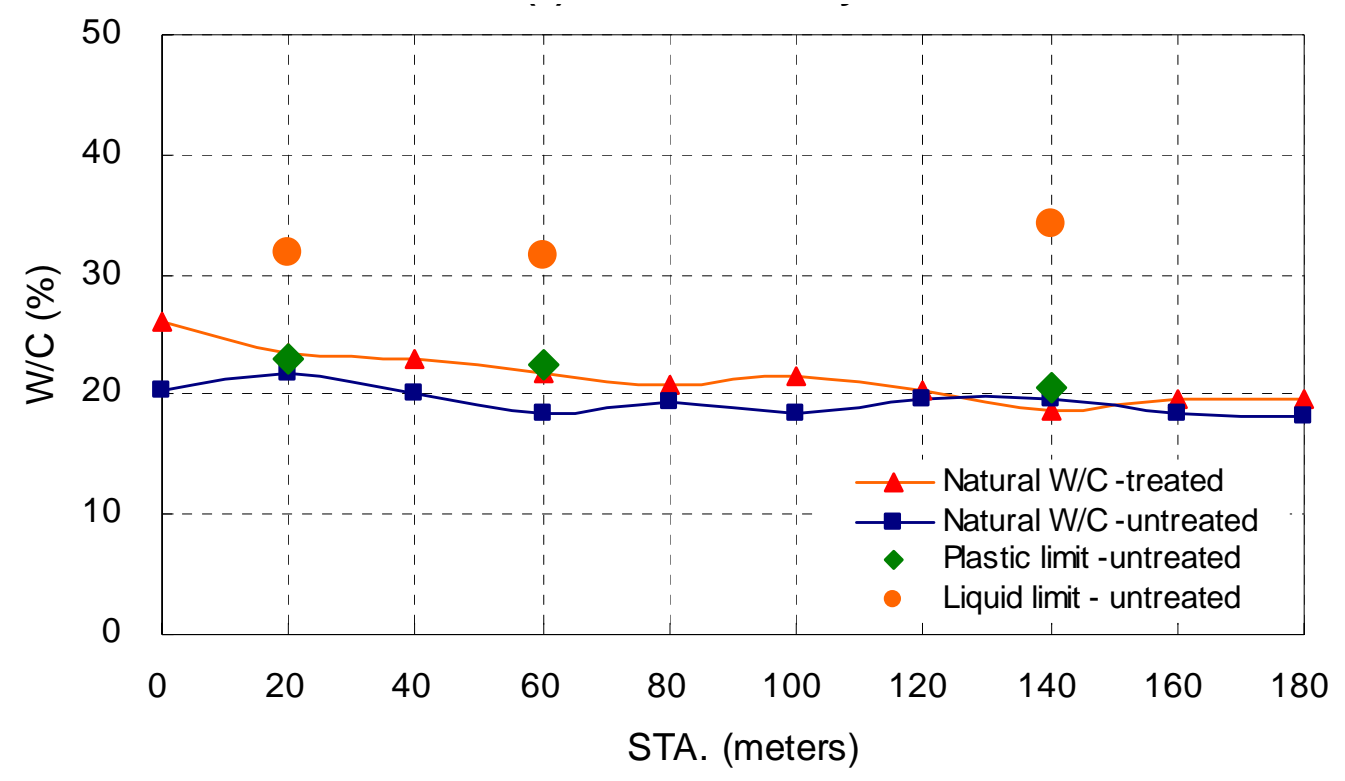

Figure 5.102 Natural water content and soil index properties. Site (5)

Figure 5.103 shows the particle-size distribution from wet sieving tests from both the lime-treated and the natural soil. The amount passing the No. 200 sieve is $65 \%$ and 
$98 \%$ for the lime-treated and natural soil, respectively. Atterberg limits performed on the soils show that the lime-treated subgrade soil is non-plastic, because the soil cannot be rolled into a 3-mm thread. The natural (untreated) soil has a Plastic Limit (PL) of 22, a Liquid Limit (LL) of 33, and a Plastic Index (PI) of 11. Based on the laboratory results, the lime-treated subgrade soil is classified as ML following USCS (Unified Soil Classification System), or A-4 in accordance with the AASHTO classification. The natural soil is classified as CL and A-6, respectively.

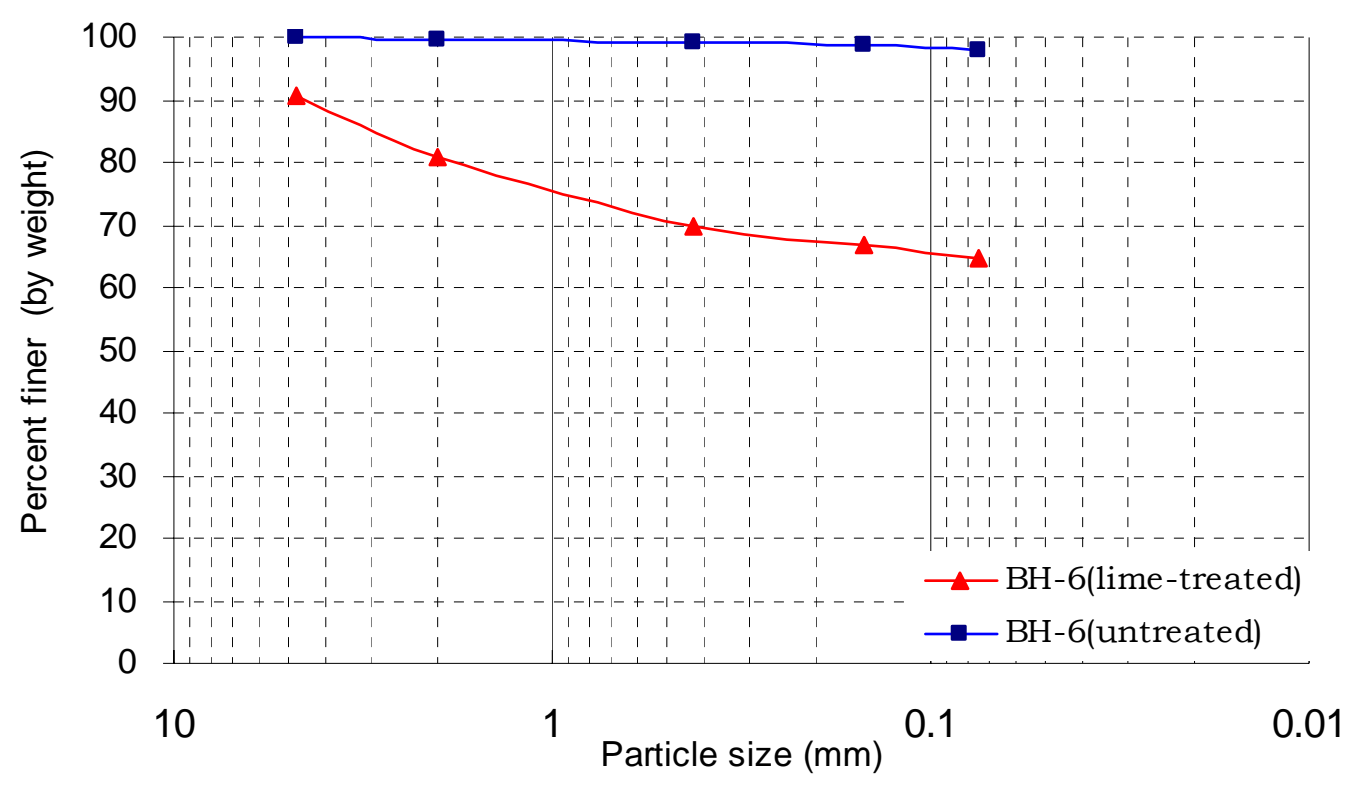

Figure 5.103 Particle-size distribution. Site (5)

Based on the soil index properties and particle-size distribution determined from the laboratory tests, the lime treatment at the site appears to have been successful as the soil was modified from low-plasticity clay to a non-plastic silt. 


\section{Stiffness and/or strength properties}

The stiffness of the soil at site (5) has been determined by two methods: One through an indirect method using the results from the FWD tests. The other method, directly from SPT and DCP tests. For the indirect method, the $\mathrm{M}_{R}$ of the natural soil and the lime-treated subgrade soil layers is obtained from back-calculation of FWD deflection data. The $\mathrm{M}_{\mathrm{R}}$ of the lime-treated and the untreated natural subgrade layer is 80 and $28 \mathrm{ksi}$, respectively, resulting in an increase of the $\mathrm{M}_{\mathrm{R}}$ by a factor of $190 \%$.

Figure $5.104 \sim$ Figure 5.113 show DCPI (Dynamic Cone Penetration Index) and SPI (Standard Penetration Index) with depth of penetration at all the ten boreholes done at the site. In most figures, the following observation can be found: (1) there are the two clear layers with a considerable difference of DCPI values due to an increase in stiffness and/or strength because of the lime-treatment; and (2) the DCPI measured just at the top of subgrade are larger than those immediately below. As mentioned in the previous sites, this is caused by disturbance during boring operations.

It is also interesting to note that at the transition between the two layers (treated and untreated; for example, at about 17 inches depth in Figure 5.108), and for a short depth, there is a substantial increase of DCPI values. This phenomenon is observed in the other plots on DCPI with depth. Our interpretation, which given the data available should be taken as provisional, is that the spikes indicate soil disturbance during construction at the contact between the treated and untreated layers. The disturbance might be caused by incomplete mixing of soil and lime during construction and/or insufficient compaction of the lime-treated subgrade. 


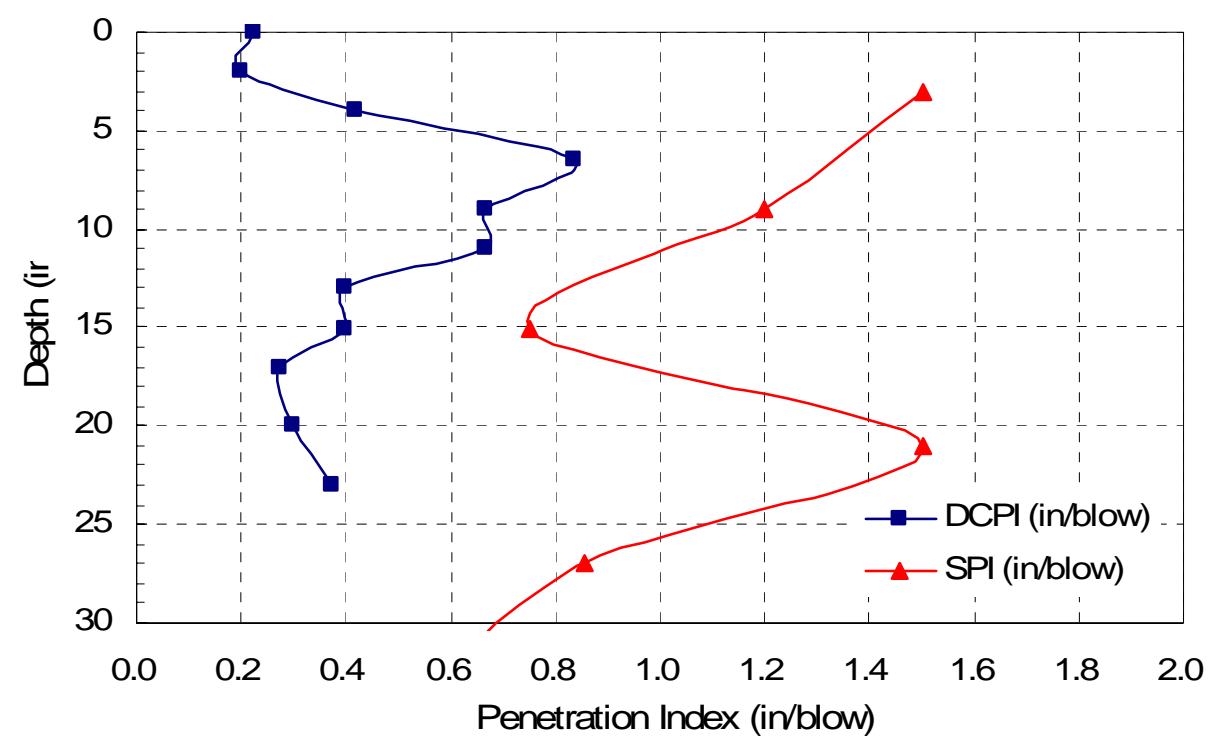

Figure 5.104 DCPT and SPT results with depth at BH-1 (STA. 0 meters). Site (5)

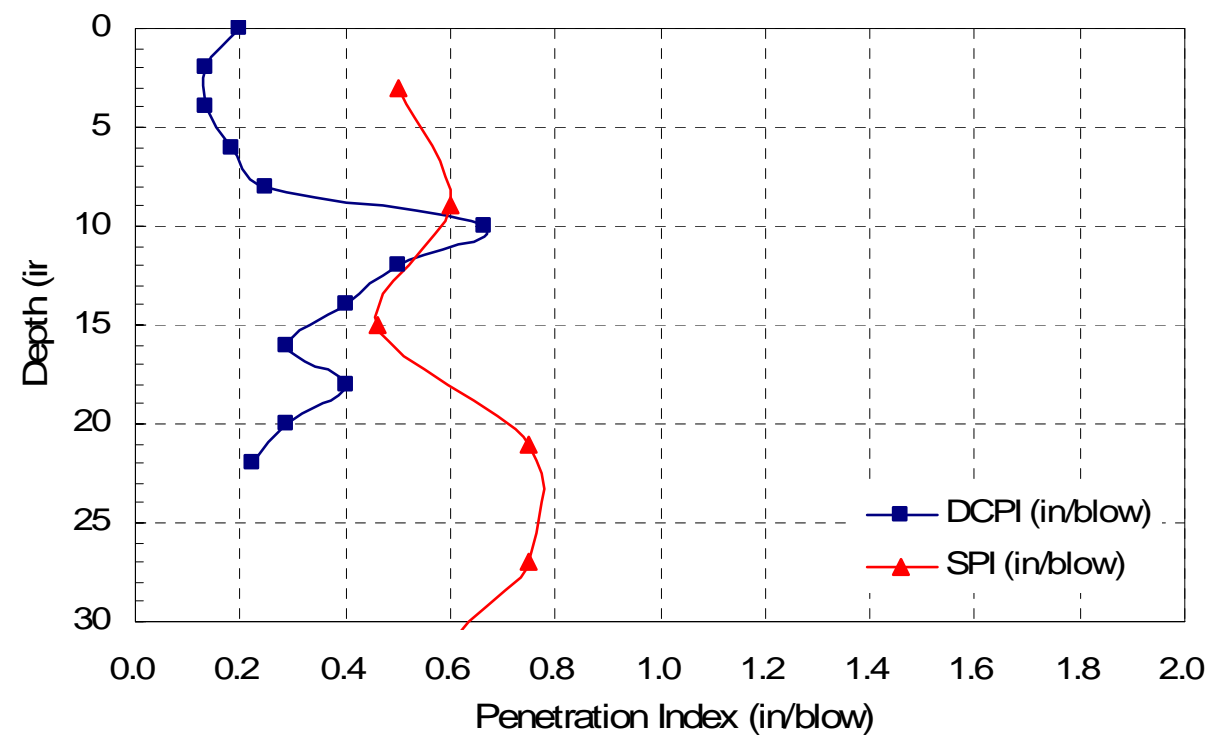

Figure 5.105 DCPT and SPT results with depth at BH-2 (STA. 20 meters). Site (5) 


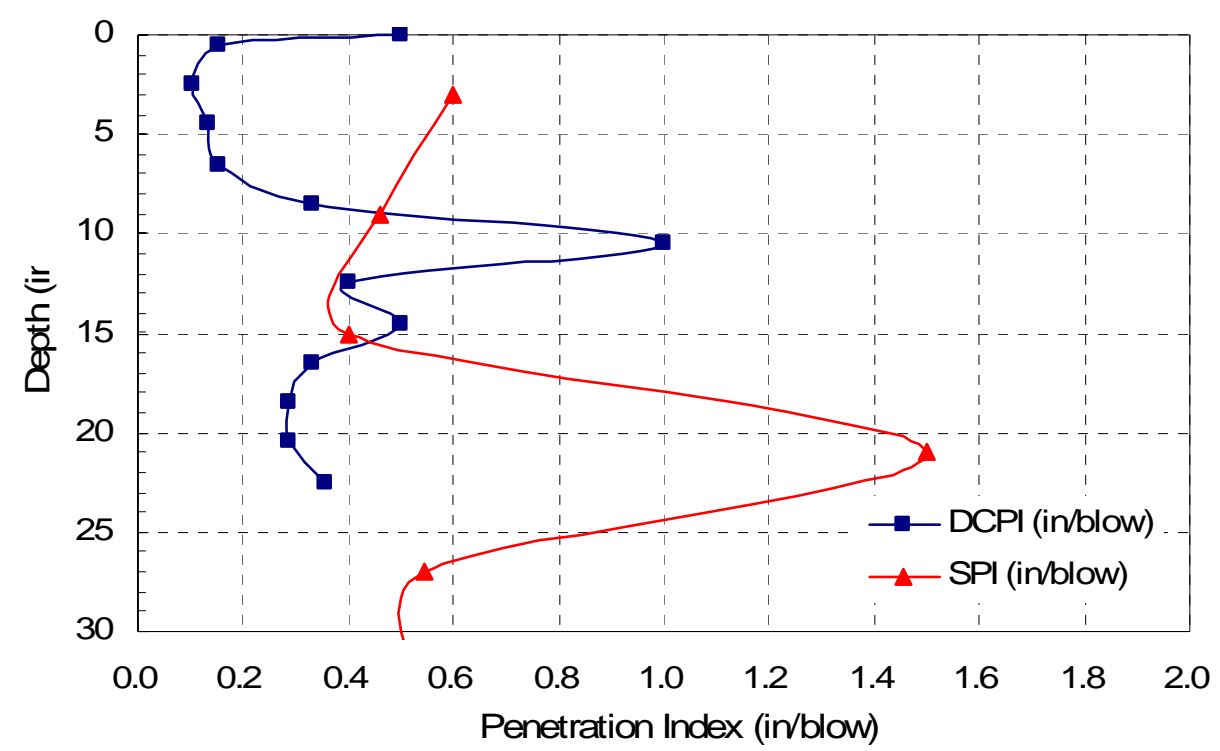

Figure 5.106 DCPT and SPT results with depth at BH-3 (STA. 40 meters). Site (5)

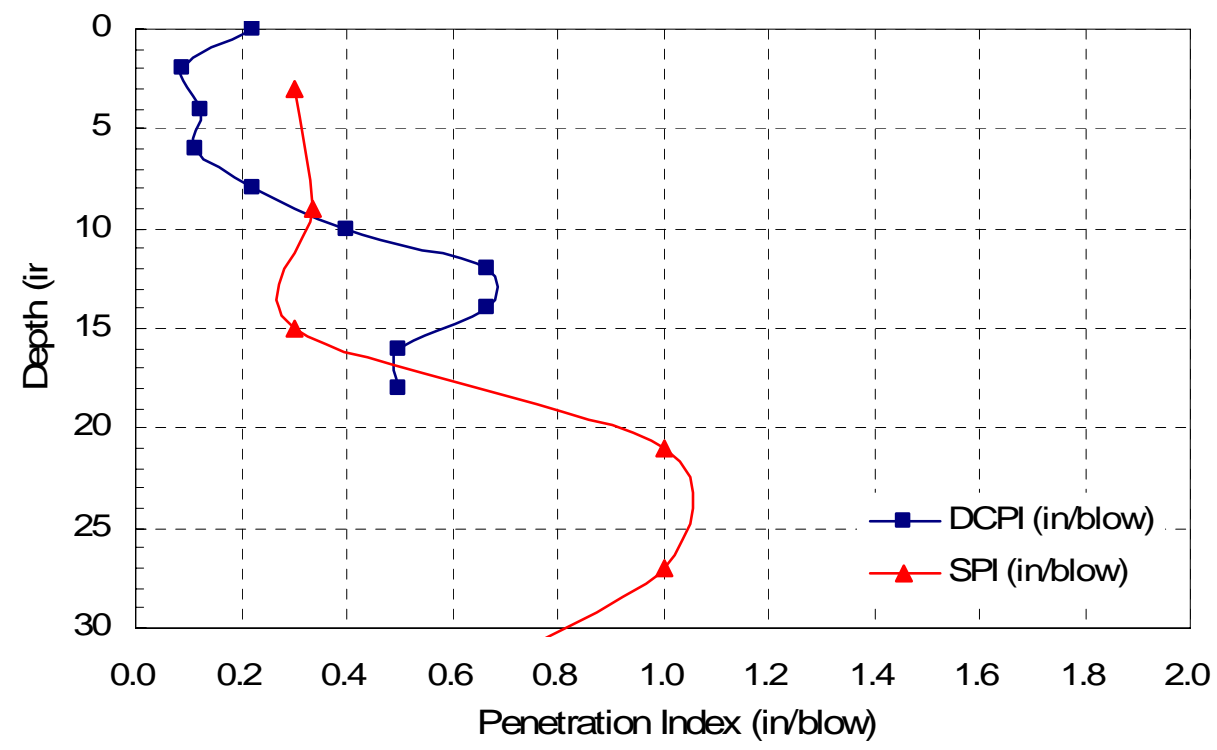

Figure 5.107 DCPT and SPT results with depth at BH-4 (STA. 60 meters). Site (5) 


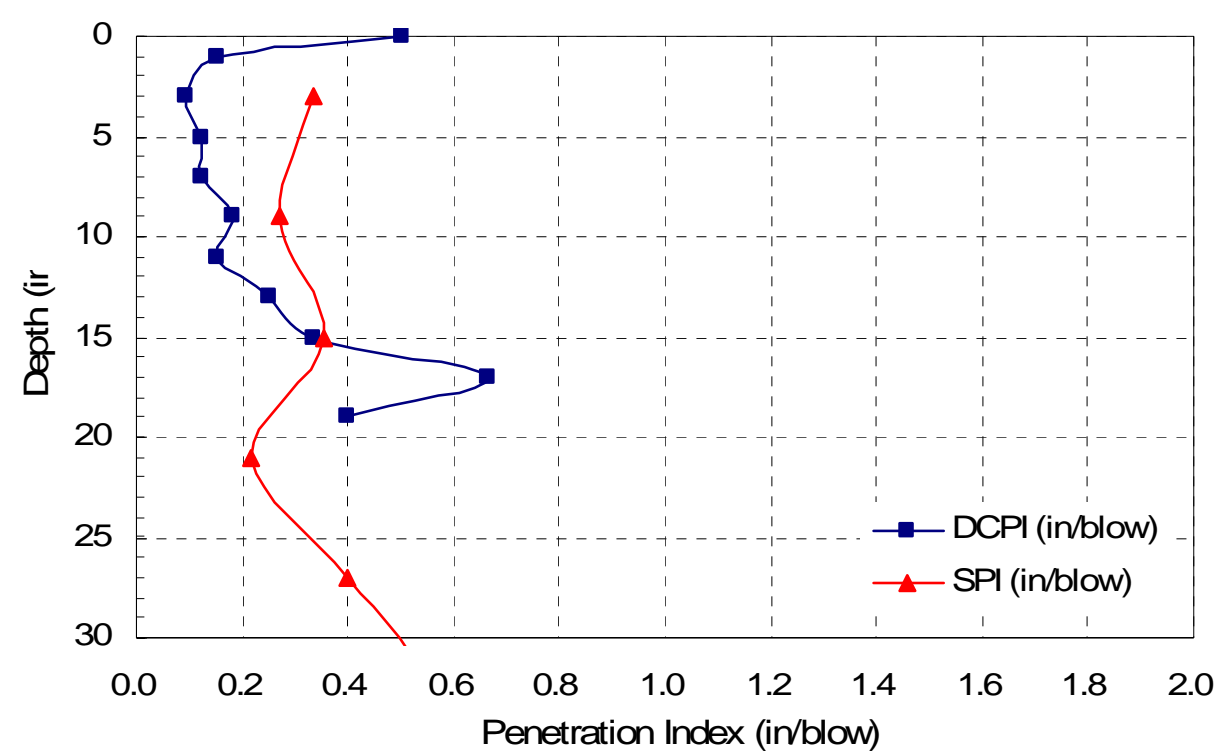

Figure 5.108 DCPT and SPT results with depth at BH-5 (STA. 80 meters). Site (5)

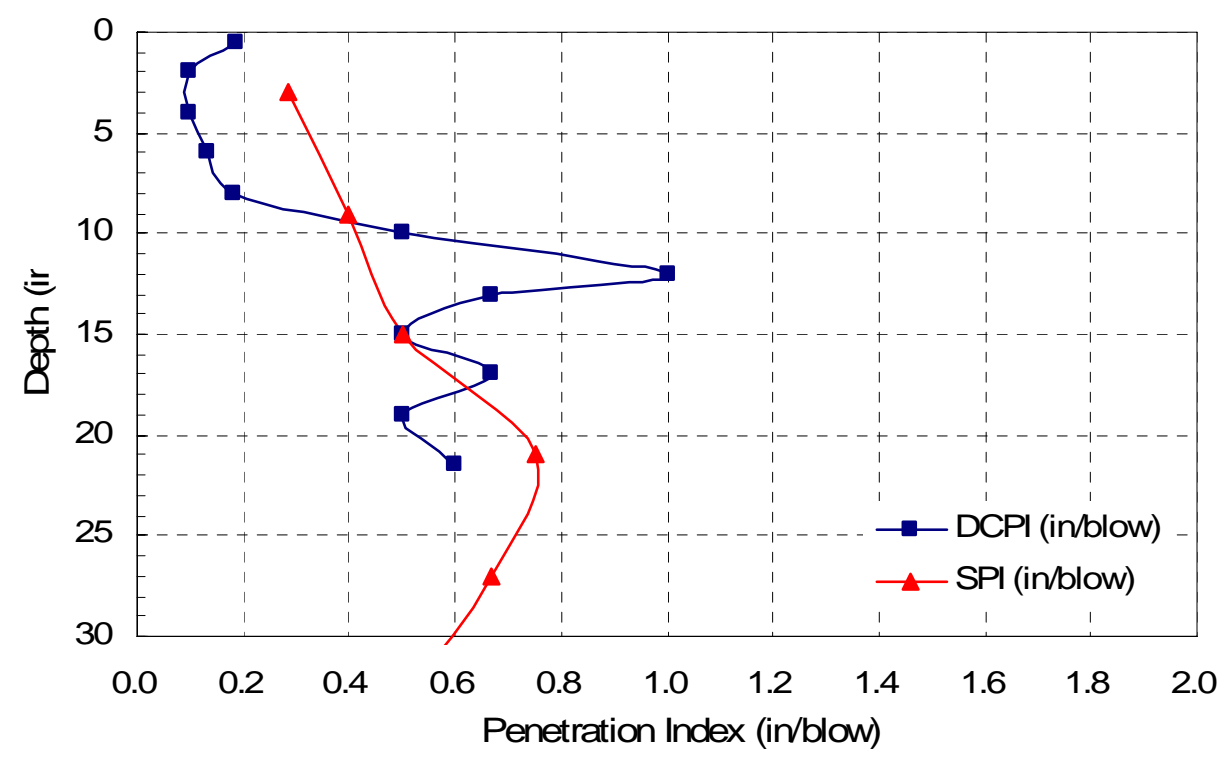

Figure 5.109 DCPT and SPT results with depth at BH-6 (STA. 100 meters). Site (5) 


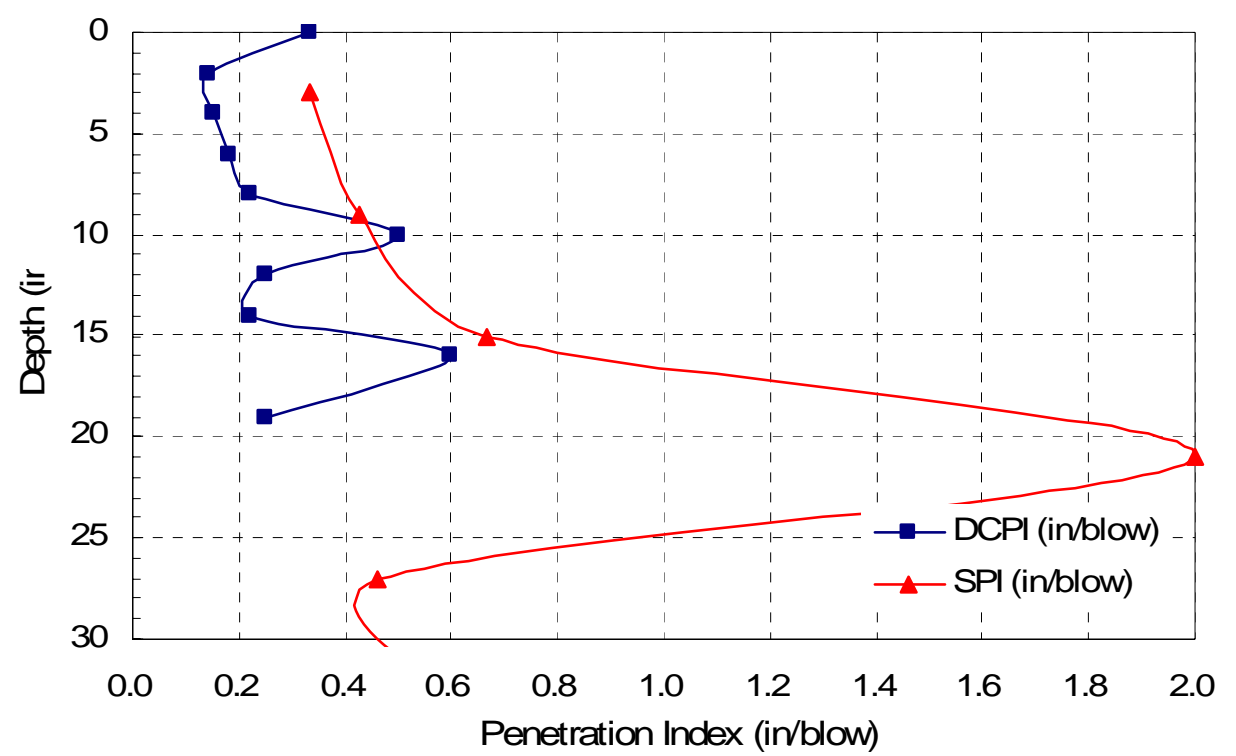

Figure 5.110 DCPT and SPT results with depth at BH-7 (STA. 120 meters). Site (5)

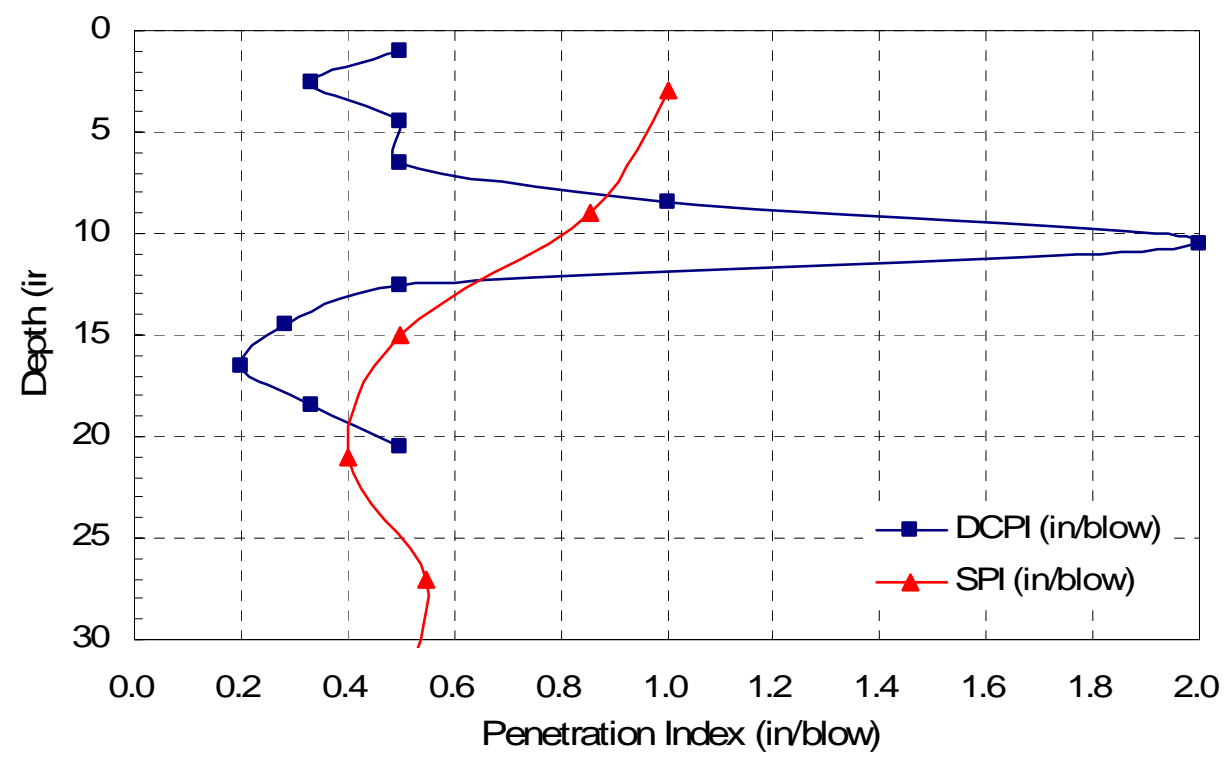

Figure 5.111 DCPT and SPT results with depth at BH-8 (STA. 140 meters). Site (5) 


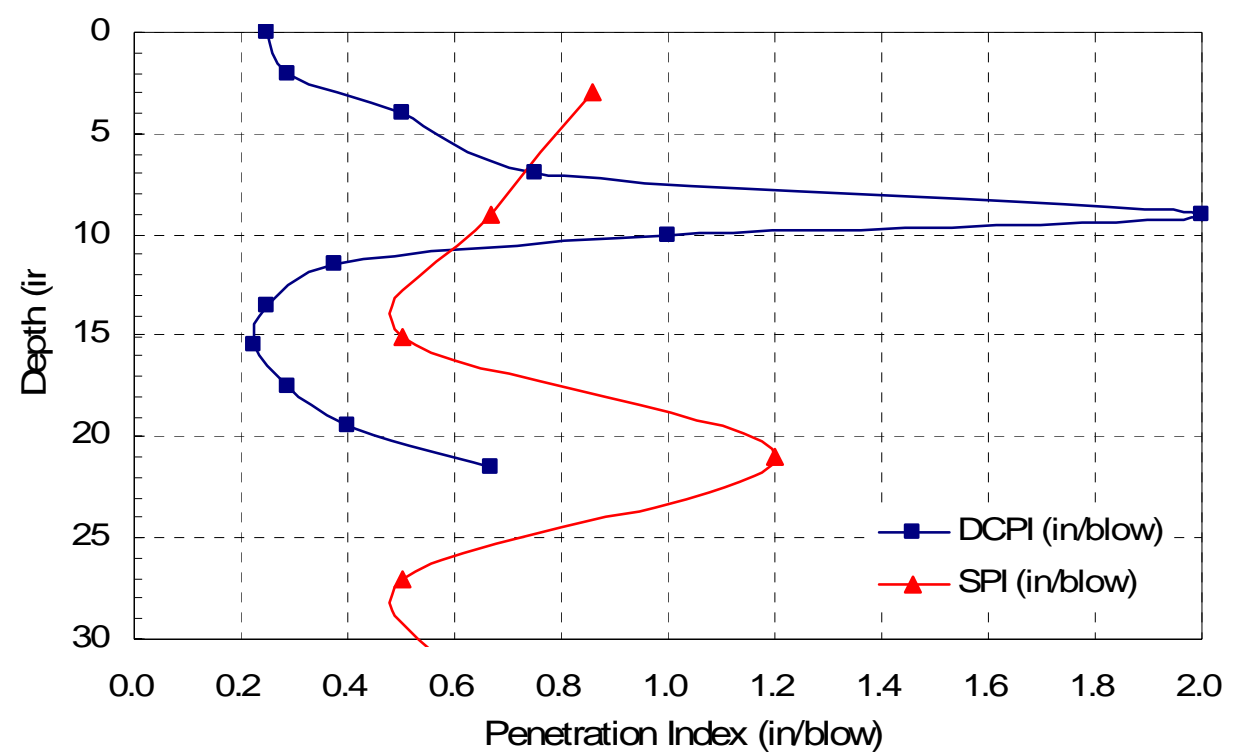

Figure 5.112 DCPT and SPT results with depth at BH-9 (STA. 160 meters). Site (5)

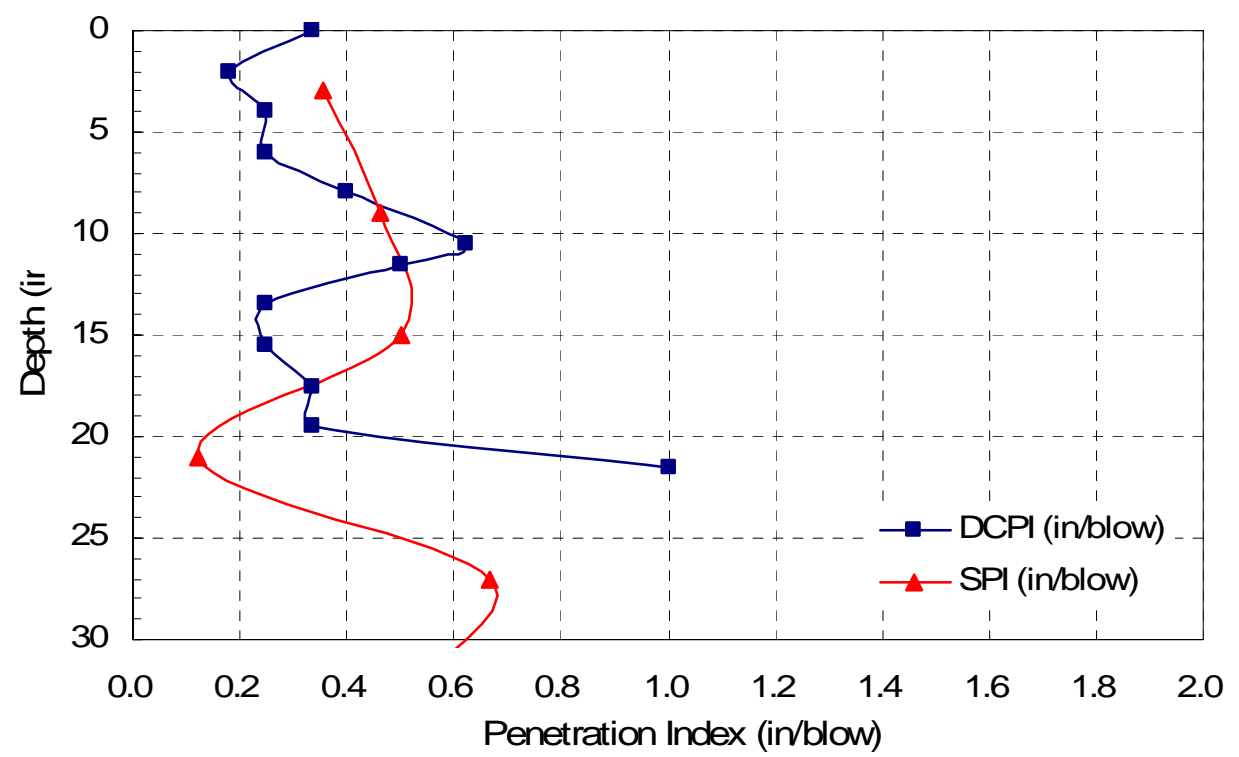

Figure 5.113 DCPT and SPT results with depth at BH-10 (STA. 180 meters). Site (5) 


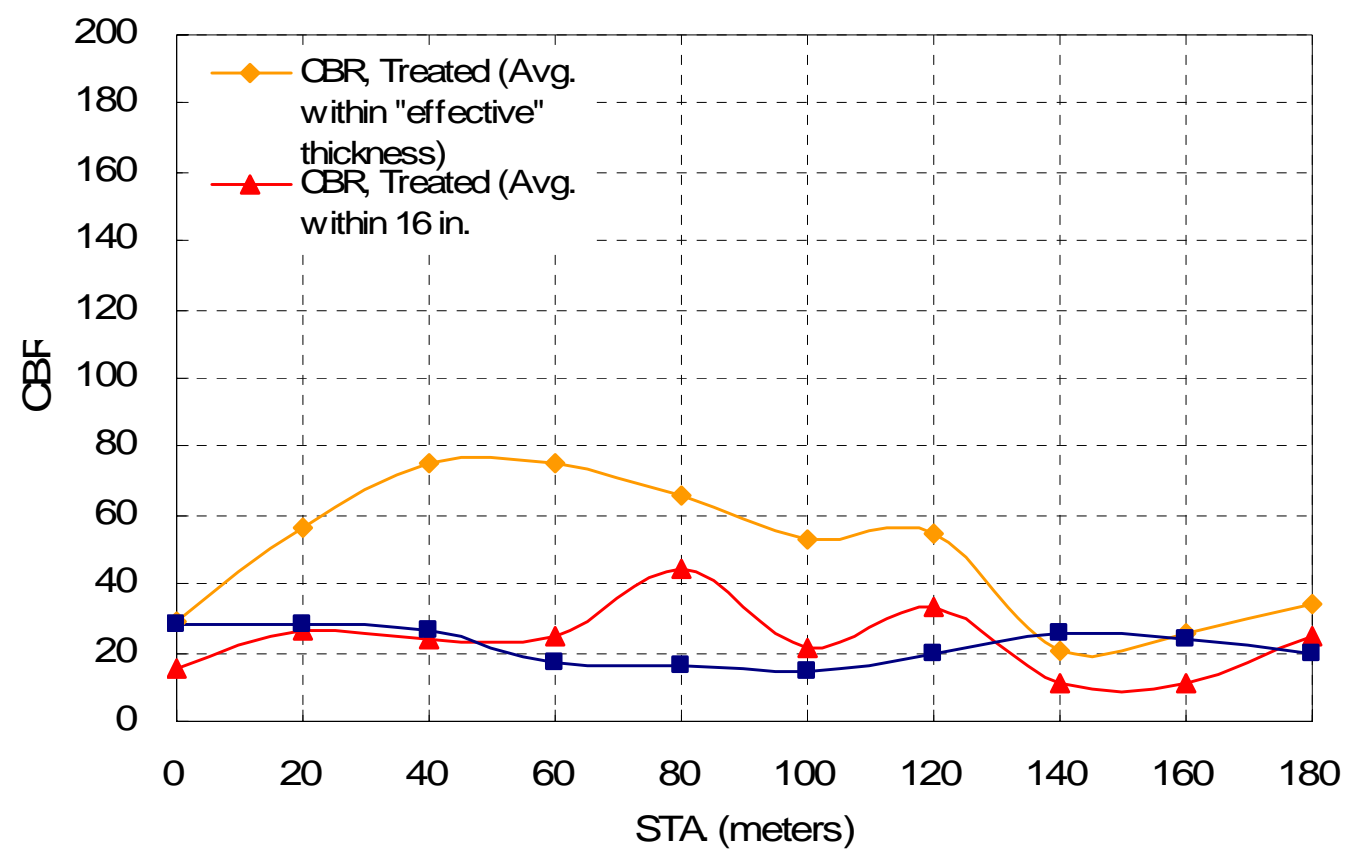

Figure 5.114 CBR of subgrade estimated from DCPT results. Site (5)

Figure 5.114 plots the longitudinal distribution of CBR for both lime-treated and natural soil layers. The CBR values are obtained with a correlation of DCPI and CBR (Webster et al., 1992). From the figure, it is observed between STA. 20 and 120 that: (1) the CBR of the natural soil layer ranges between 14 and 28; (2) the CBR of the limetreated subgrade soil layer, calculated within the effective thickness of the layer, ranges between 28 and 80, which results in an increase of the CBR by a factor of $100 \%$ to $350 \%$; (3) the CBR of the lime-treated subgrade soil layer, calculated within a thickness of 16 inches below the top of the subgrade, ranges between 18 and 43, which results in a maximum increase of CBR of $180 \%$; and (4) the distance between the two curves of the treated soil is a measure of the difference between the design and the actual depth of treatment.

While Figure 5.114 shows that there is a substantial increase of the stiffness of the 
soil with treatment, it also shows a very large and significant variability.

\section{Lime content}

Figure 5.115 shows the $\mathrm{pH}$ values of both the lime-treated subgrade and natural soil, which were determined at the boreholes drilled at the site. The lime-treated subgrade soil has a $\mathrm{pH}$ ranging from 9.1 to 10.6 while the untreated soil has a $\mathrm{pH}$ ranging from 6.4 to 7.3. The increase of $\mathrm{pH}$ denotes the presence of lime.

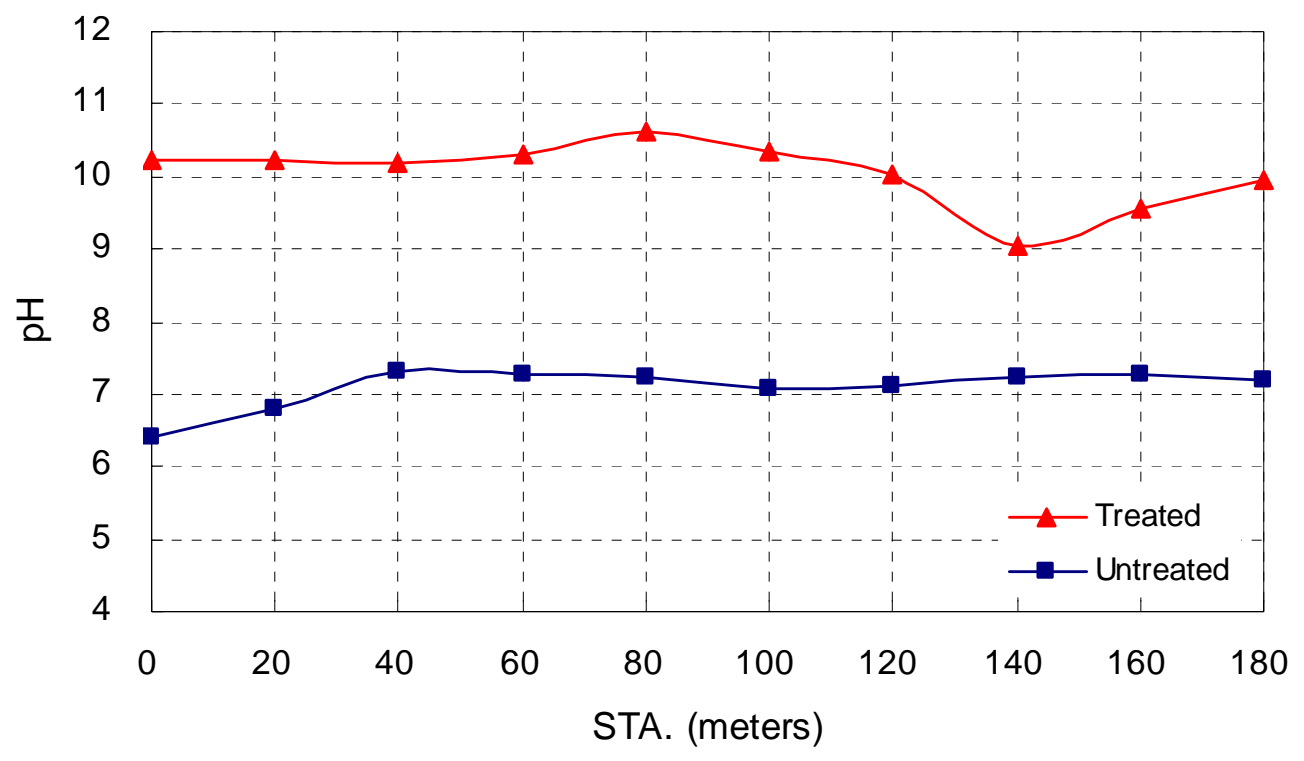

Figure $5.115 \mathrm{pH}$. Site (5)

Figure $5.116 \sim$ Figure 5.121 shows the results of XRD tests from the lime-treated and natural soil samples obtained from the field. The existence of calcium carbonate $\left(\mathrm{CaCO}_{3}\right)$ in the lime-treated subgrade is observed in the XRD results. The fact that the source of the $\mathrm{CaCO}_{3}$ is from the added lime is confirmed by the observation that the mineral was not found in the natural soil. As discussed in Chapter $4, \mathrm{CaCO}_{3}$ is created by 
the reaction of calcium hydroxide $\left(\mathrm{Ca}(\mathrm{OH})_{2}\right)$ with carbon dioxide $\left(\mathrm{CO}_{2}\right)$. Quantification of the amount of lime is done through thermo-gravimetric analyses (TGA). The figures shows that the XRD patterns of the lime-treated soil samples has a peak at the critical refraction angles of $\mathrm{Ca}(\mathrm{CO})_{3}$, but those of the untreated soil samples has no peak at the critical angles. The XRD patterns confirm the existence of $\mathrm{Ca}(\mathrm{CO})_{3}$ in the lime-treated soil samples, and that the $\mathrm{Ca}(\mathrm{CO})_{3}$ comes from the LKD added 11 years ago for the purpose of the modification of the soil using lime treatment.
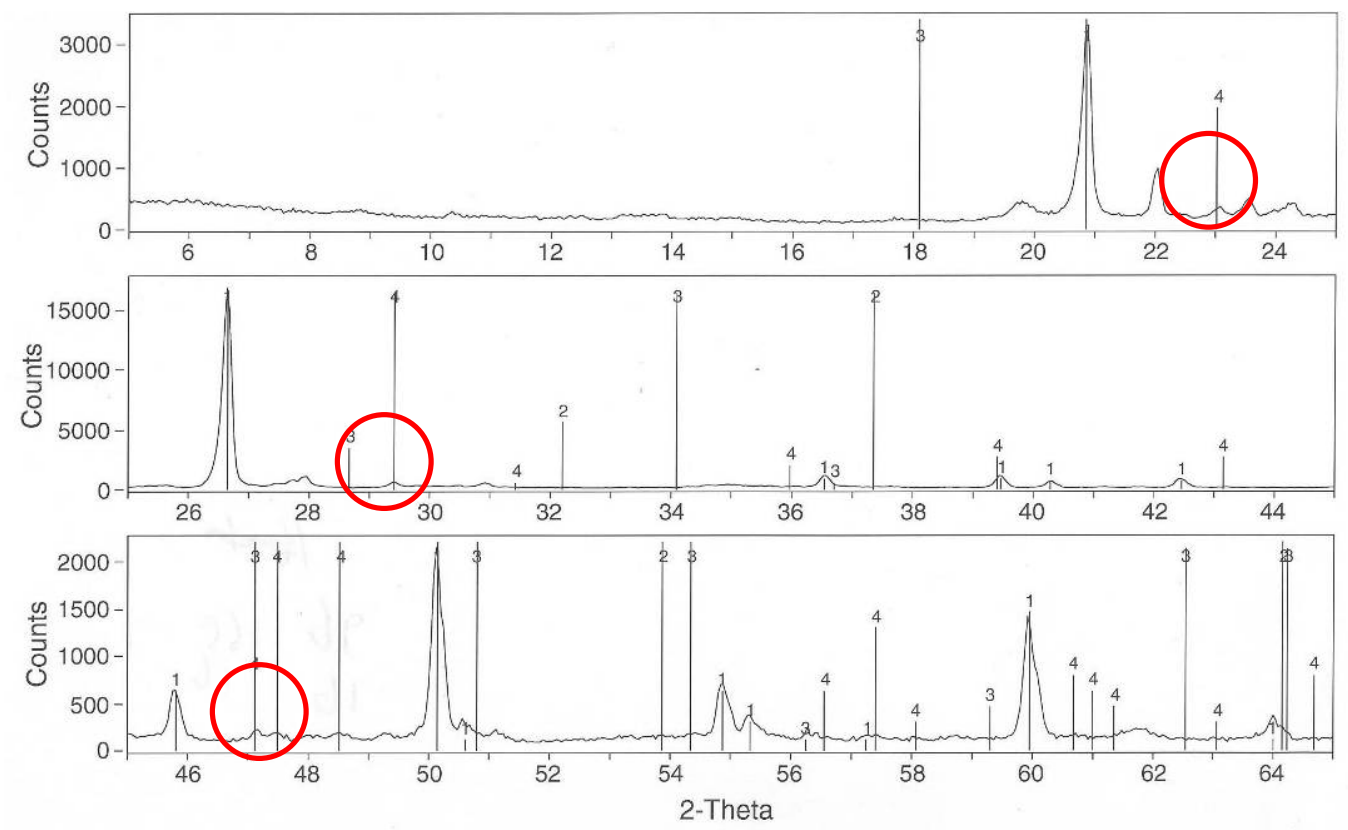

1> 33-1161: Quartz, syn - SiO2 3> 04-0733: Portlandite, syn - $\mathrm{Ca}(\mathrm{OH}) 2$

2> 37-1497: Lime, syn - CaO 4> 05-0586: Calcite, syn - $\mathrm{CaCO} 3$

Figure 5.116 XRD pattern for lime-treated soil sample at BH-3 (STA. 40 meters). Site (5) 

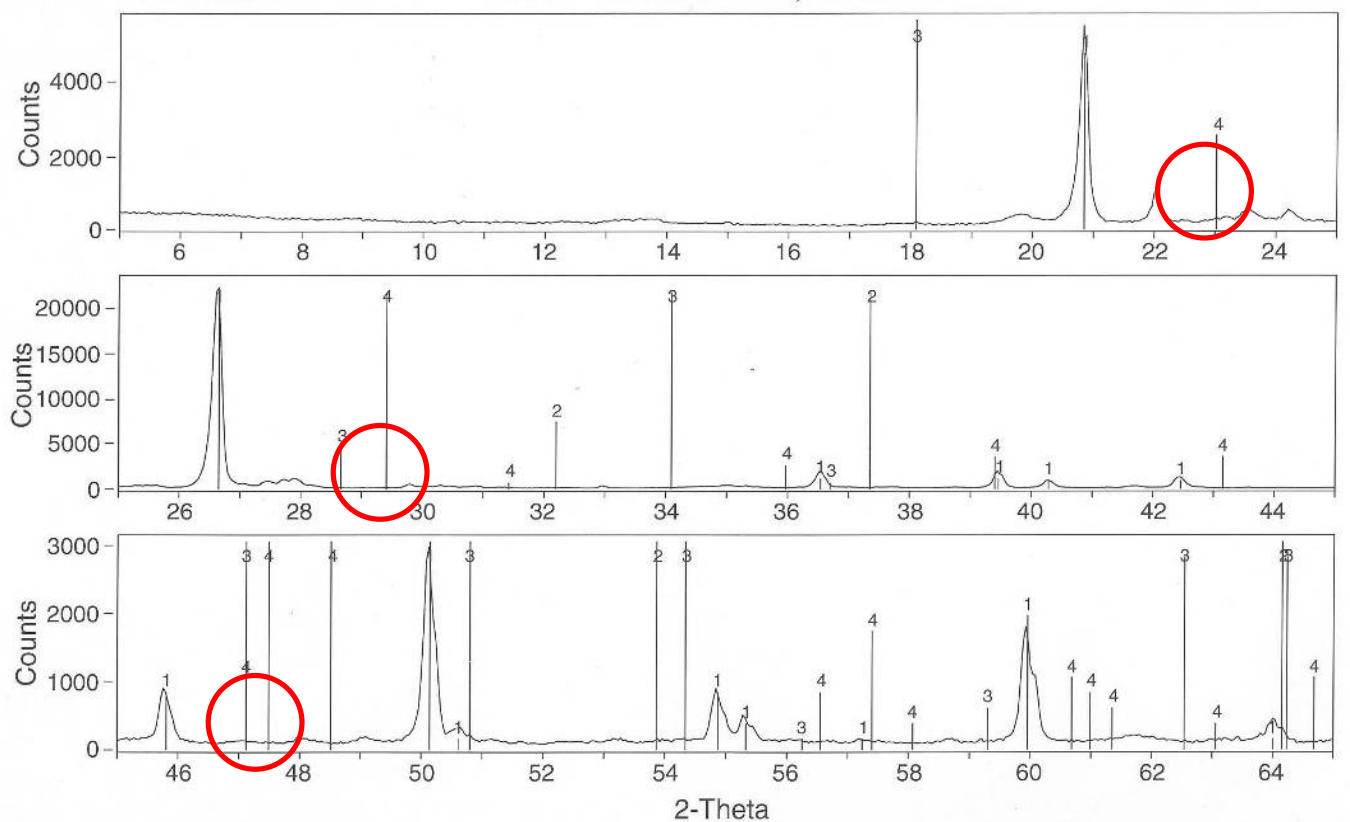

1> 33-1161: Quartz, syn - SiO2

3>04-0733: Portlandite, syn - $\mathrm{Ca}(\mathrm{OH}) 2$

2> 37-1497: Lime, syn - CaO

4>05-0586: Calcite, syn-cacos

Figure 5.117 XRD pattern for untreated soil sample at BH-3 (STA. 40 meters). Site (5)
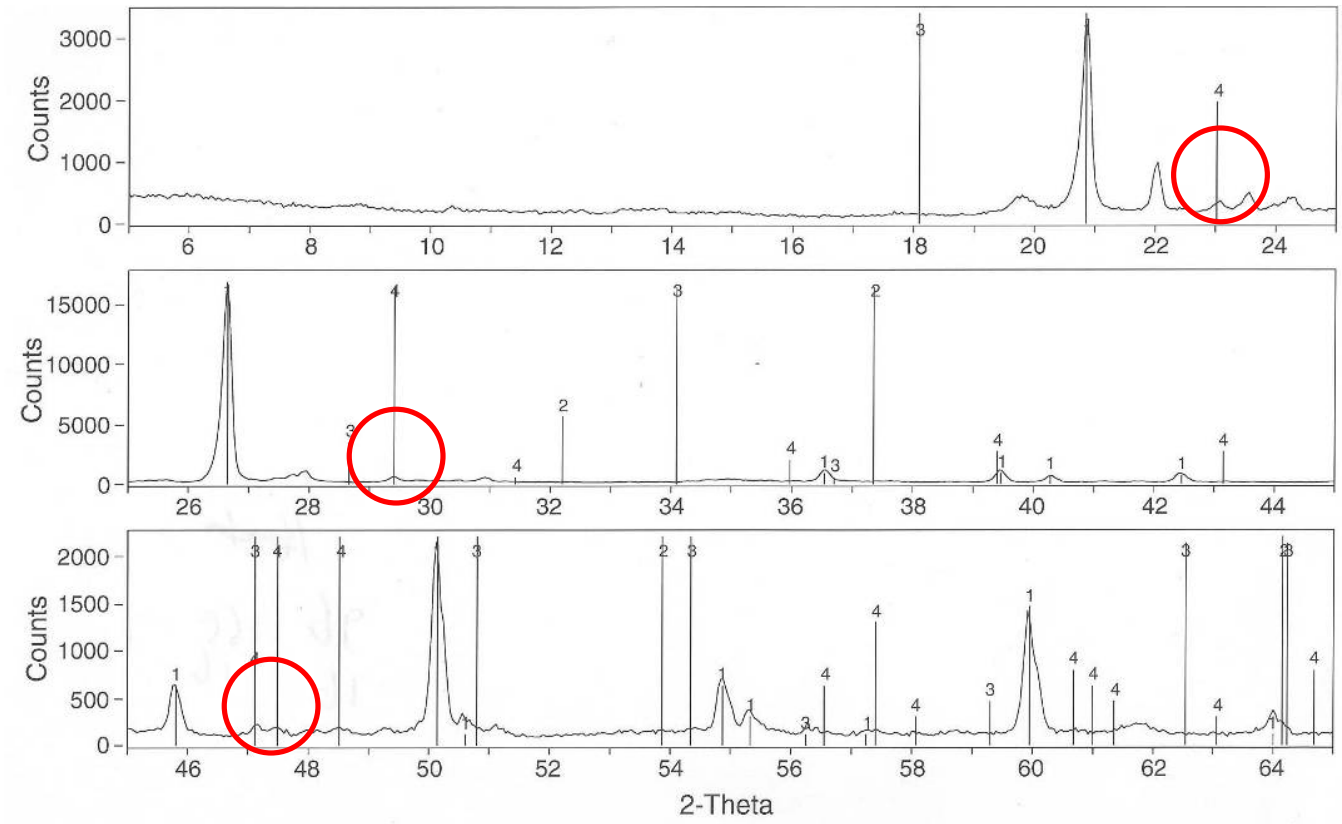

1> 33-1161: Quartz, syn - SiO2

2> 37-1497: Lime, syn - CaO

3> 04-0733: Portlandite, syn - $\mathrm{Ca}(\mathrm{OH}) 2$

4> 05-0586: Calcite, syn - $\mathrm{CaCO} 3$

Figure 5.118 XRD pattern for lime-treated soil sample at BH-5 (STA. 80 meters). Site (5) 

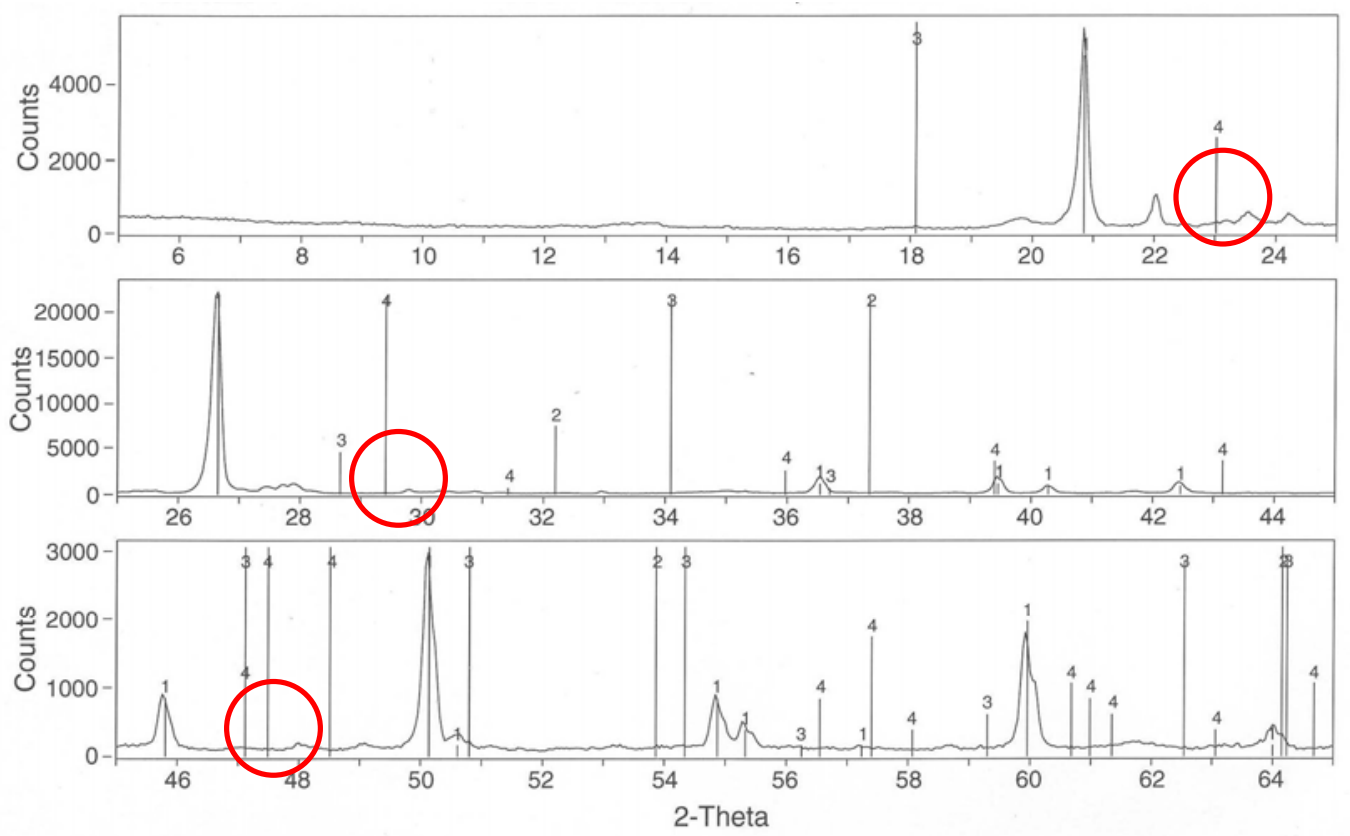

1> 33-1161: Quartz, syn - SiO2

2> 37-1497: Lime, syn - CaO

3> 04-0733: Portlandite, syn - $\mathrm{Ca}(\mathrm{OH}) 2$

4> 05-0586: Calcite, syn - CaCO3

Figure 5.119 XRD pattern for untreated soil sample at BH-5 (STA. 80 meters). Site (5)
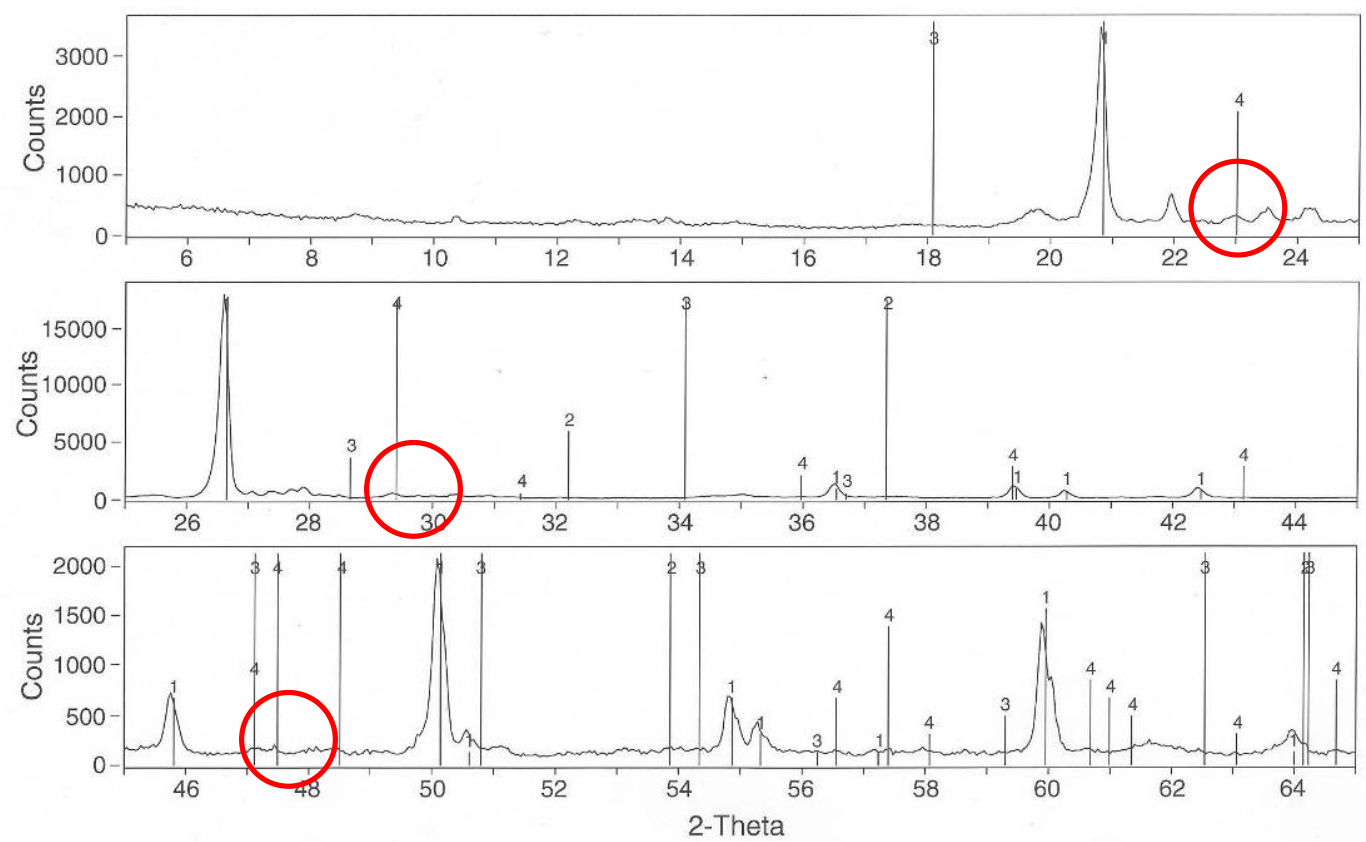

1> 33-1161: Quartz, syn - SiO2

3> 04-0733: Portlandite, syn - $\mathrm{Ca}(\mathrm{OH}) 2$

2> 37-1497: Lime, syn - CaO

4> 05-0586: Calcite, syn - CaCO3

Figure 5.120 XRD pattern for lime-treated soil sample at BH-7 (STA. 120 m). Site (5) 

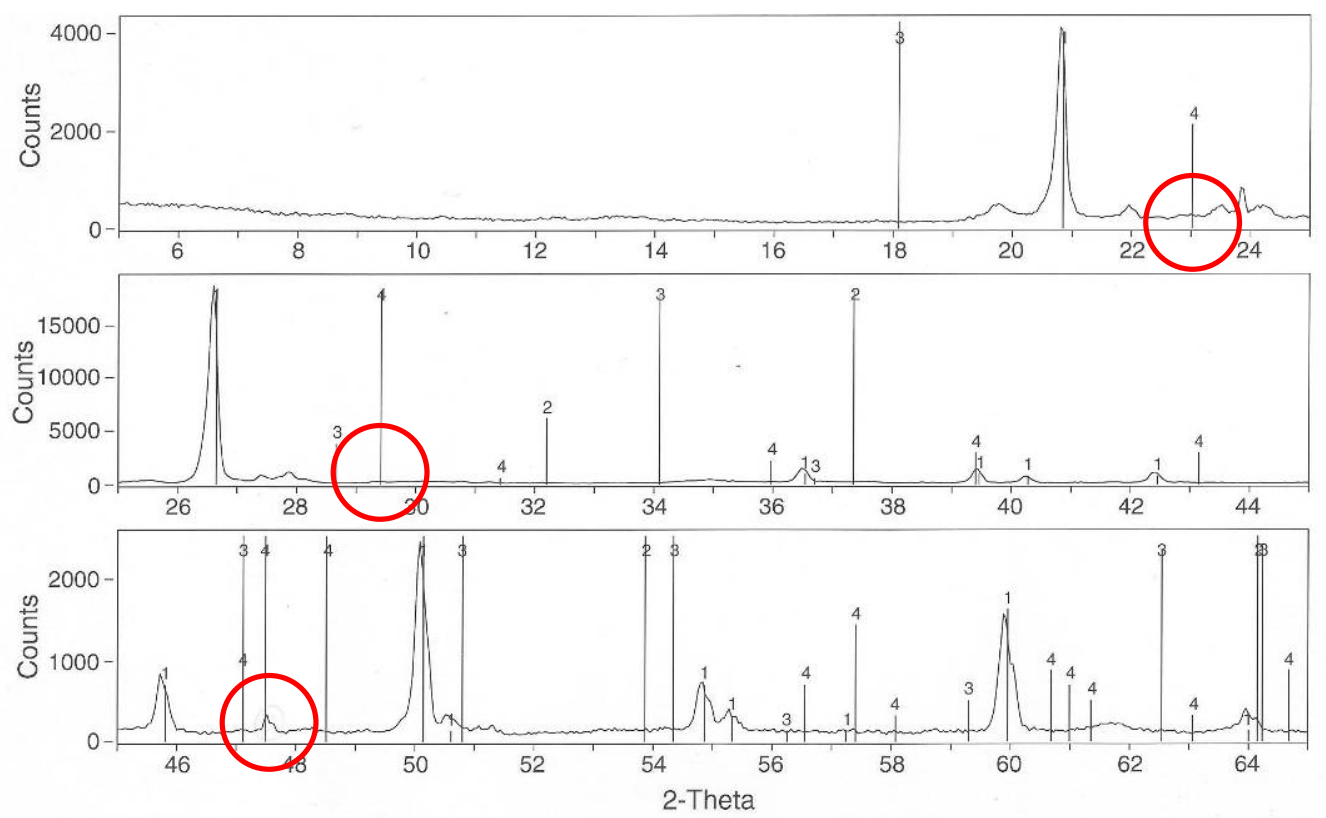

1> 33-1161: Quartz, syn - SiO2

3> 04-0733: Portlandite, syn - $\mathrm{Ca}(\mathrm{OH}) 2$

2> 37-1497: Lime, syn - CaO

4> 05-0586: Calcite, syn - $\mathrm{CaCO} 3$

Figure 5.121 XRD pattern for untreated soil sample at BH-7 (STA. $120 \mathrm{~m}$ ). Site (5)

Figure 5.122 Figure 5.124 show the results of TGA tests for the lime-treated and natural soil samples collected at $\mathrm{BH}-3,5$, and 7, respectively. The lime-treated and natural soil samples were taken approximately at depths of 4 and 30 inches respectively below the top of the subgrade. The figures show that the weight of the natural soil decreases uniformly with increasing temperature without the sharp decrease between 650 and $800{ }^{\circ} \mathrm{C}$ found in the lime-treated samples. This is confirmation that the $\mathrm{CaCO}_{3}$ detected in the TGA and XRD data from the lime-treated soil samples originated from the LKD added during construction. The amount of $\mathrm{CaCO}_{3}$, which includes both the lime used for the soil-lime reaction and any pre-existing $\mathrm{CaCO}_{3}$ in the $\mathrm{LKD}$, is $2,1.4$, and $1.9 \%$ for the samples collected at $\mathrm{BH}-3,5$, and 7 , respectively. 


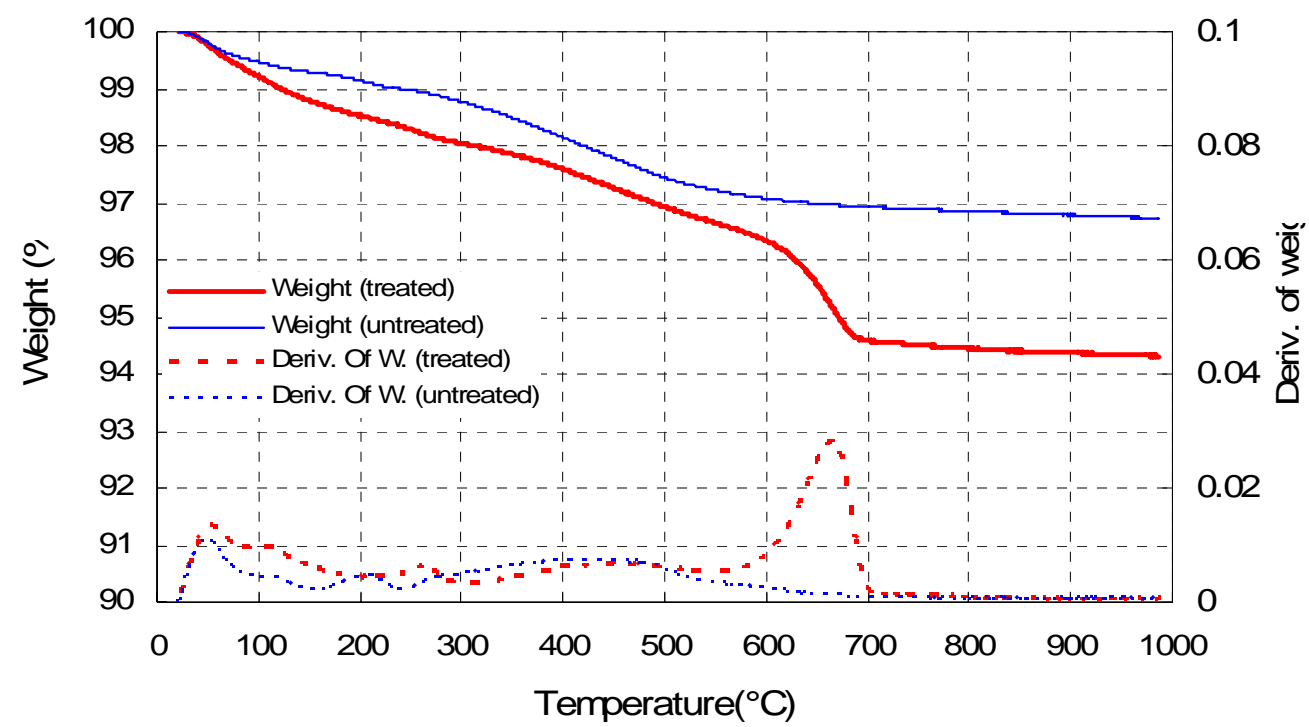

Figure 5.122 Weight loss and weight loss rate obtained from TGA from lime-treated and natural soil samples collected at BH-3 (STA. 40 meters) at site (5)

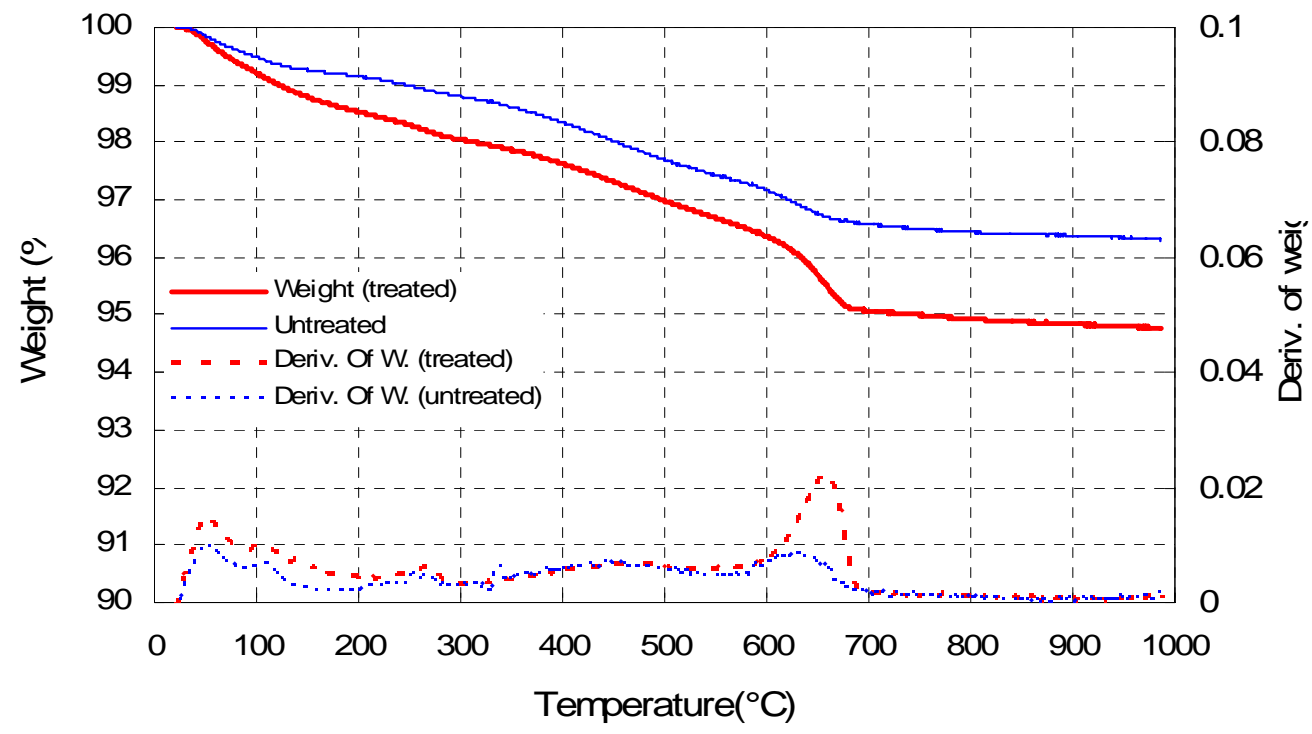

Figure 5.123 Weight loss and weight loss rate obtained from TGA from lime-treated and natural soil samples collected at BH-5 (STA. 80 meters) at site (5) 


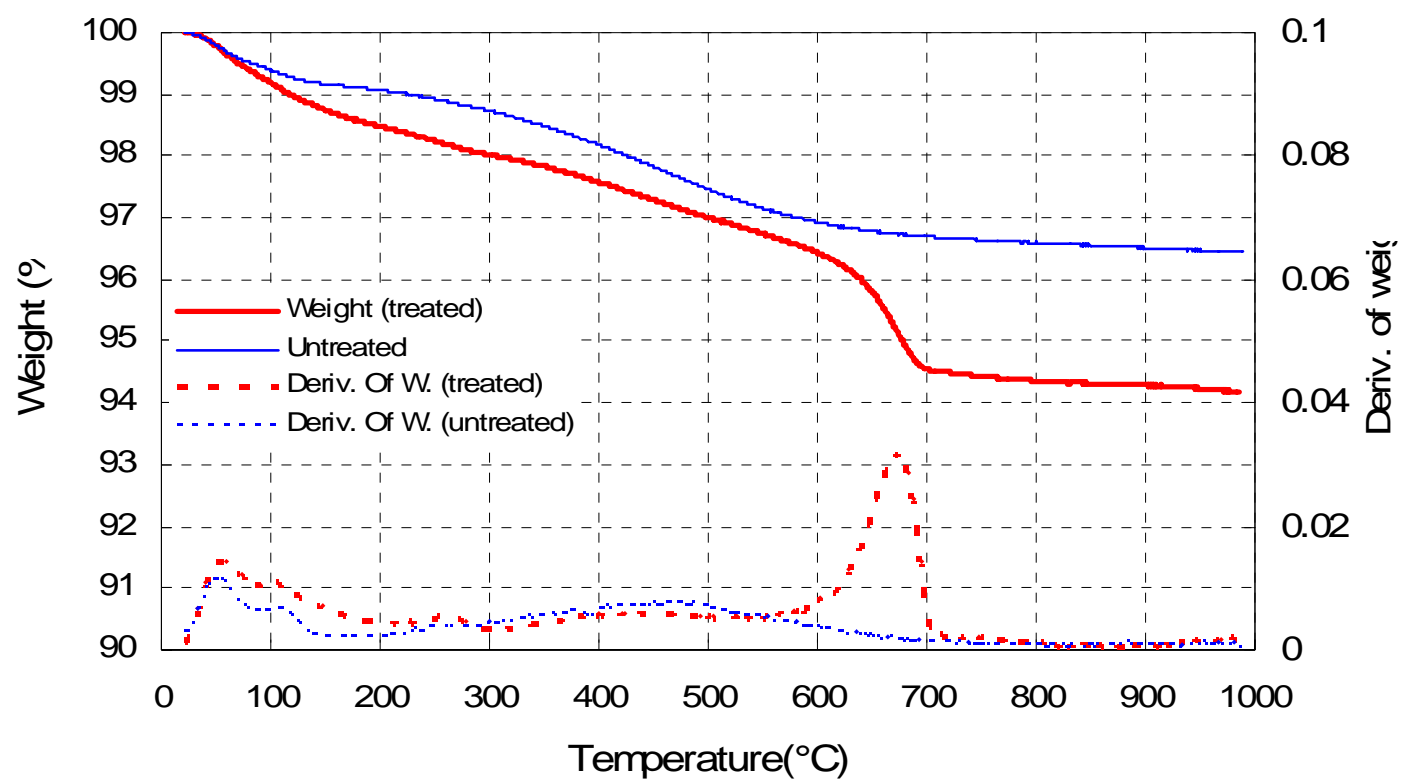

Figure 5.124 Weight loss and weight loss rate obtained from TGA from lime-treated and untreated soil samples collected at BH-7 (STA. 120 meters) at site (5)

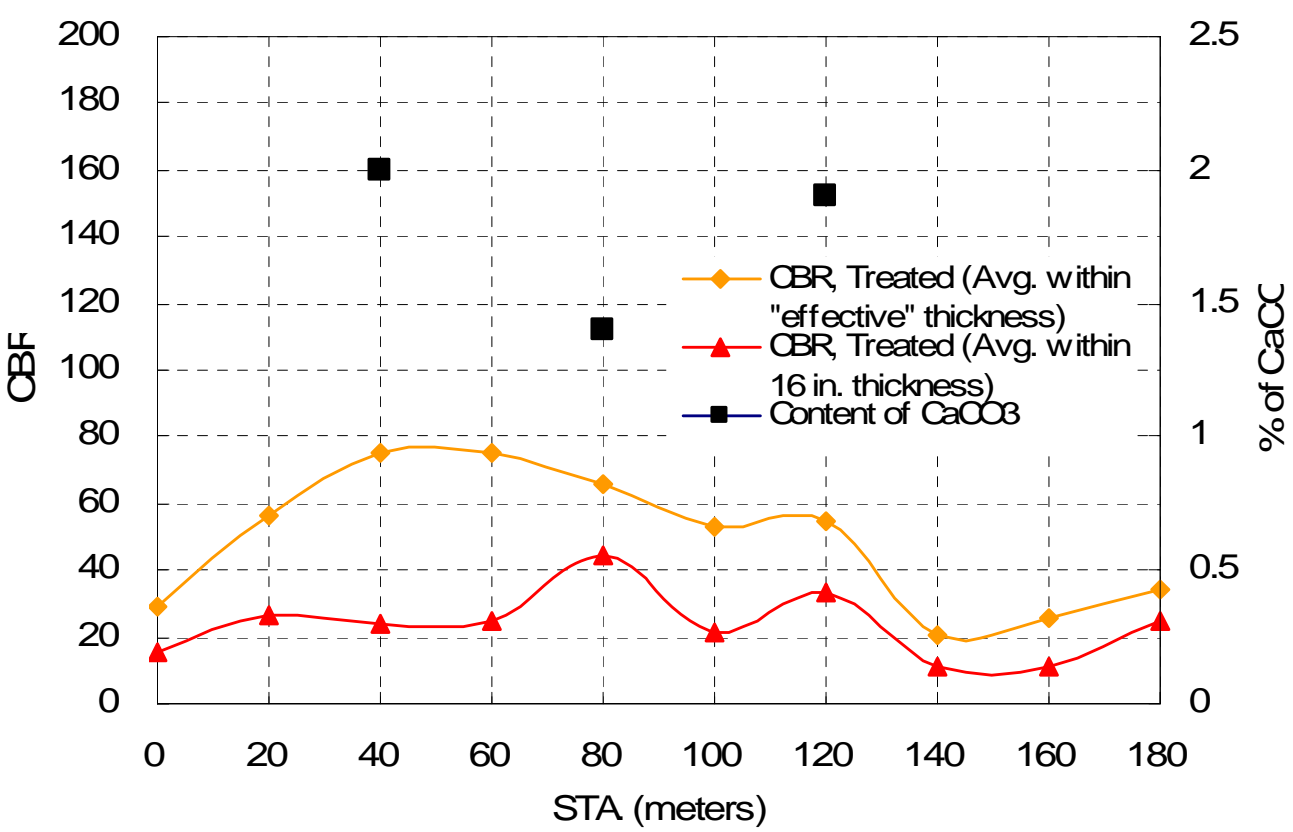

Figure 5.125 CBR and lime content of lime-treated subgrade soil at site (5)

The lime content is plotted together with CBR in Figure 5.125 in an attempt to 
determine whether there is a strong correlation between the two. The results suggest that there should be factors other than lime dosage that affect the stiffness; for example percentage of active lime, construction quality and compaction, to name a few.

The laboratory and field tests results strongly suggest that even after 11 years of service, the lime still remains in the soil and the soil still has the engineering properties gained with the addition of the lime. In addition, given the lime content found in the laboratory analyses, it appears that there has been no leaching of the lime from the subgrade. In other words, the tests show no degradation of the treatment with time. 


\subsection{Site (6)}

\section{Soil characterization properties}

Figure 5.126 shows the natural water content and soil index properties of the lime-treated subgrade and natural (untreated) soil from the samples collected at the boreholes. The samples were taken at 8-in depth (lime-treated soil) and 30-in depth (natural soil). The water content of the lime-treated subgrade is in the range of $19 \%$ to $28 \%$ while the natural soil below the subgrade is in the range of $19 \%$ to $23 \%$. In essence, there is no significant difference in water content between the treated and untreated soils.

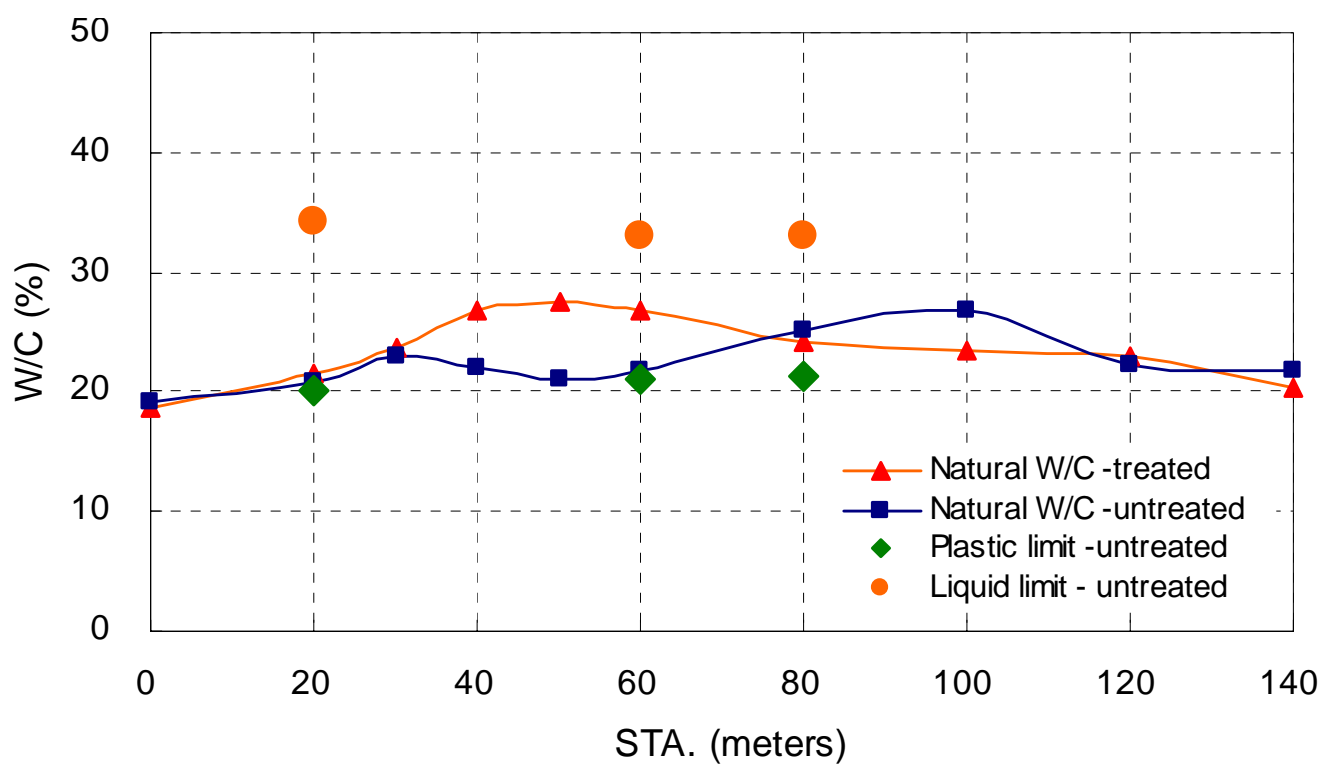

Figure 5.126 Natural water content and soil index properties. Site (6)

Figure 5.127 shows the particle-size distribution from wet sieving tests from both the lime-treated and the natural soil. The amount passing the No. 200 sieve is $35 \%$ and $75 \%$ for the lime-treated and natural soil, respectively. Atterberg limits performed on the 
soils show that the lime-treated subgrade soil is non-plastic. The natural (untreated) soil has a Plastic Limit (PL) of 21, a Liquid Limit (LL) of 33, and a Plastic Index (PI) of 12. Based on the laboratory results, the lime-treated subgrade soil is classified as SM following USCS (Unified Soil Classification System), or A-4 in accordance with the AASHTO classification. The natural soil is classified as ML and A-6, respectively.

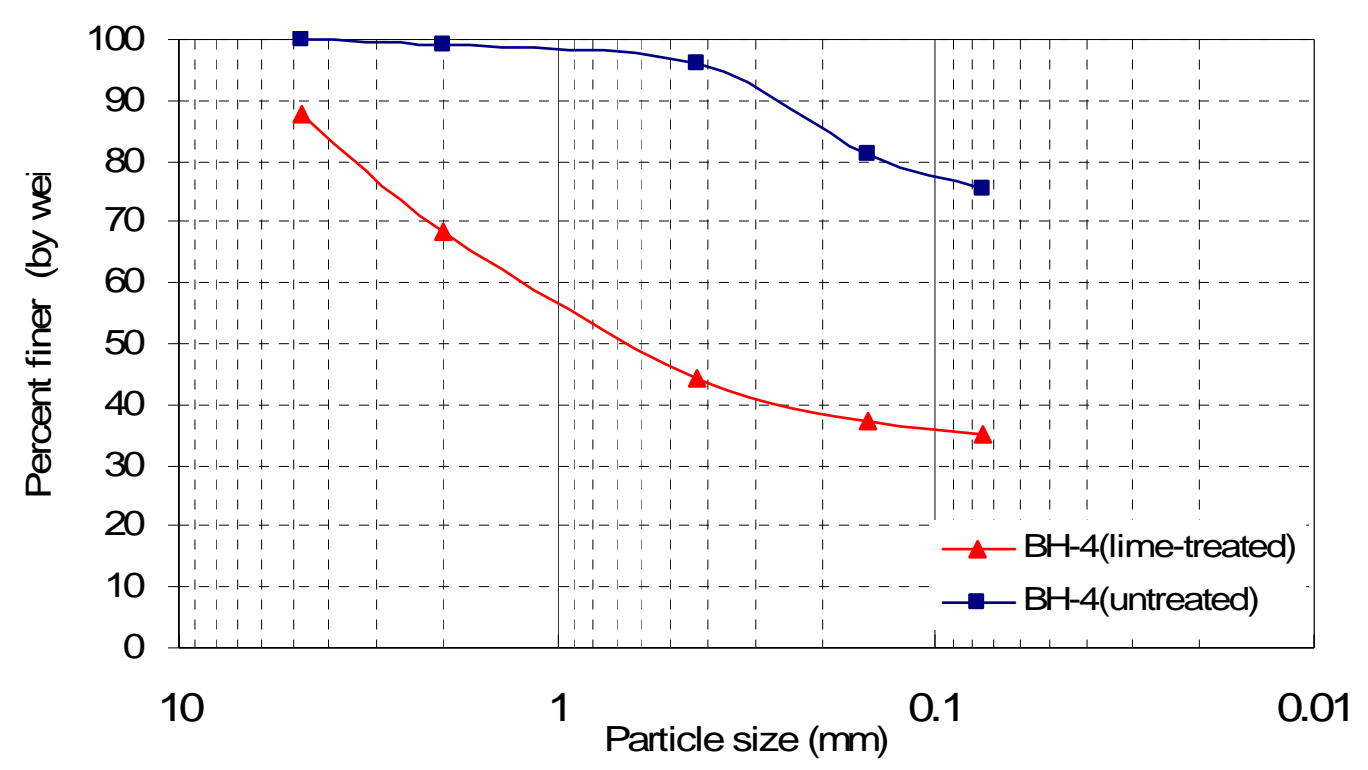

Figure 5.127 Particle-size distribution. Site (6)

Based on the soil index properties and particle-size distribution (Figure 5.126 and Figure 5.127), the lime treatment at the site appears to have been successful as the soil was modified from a low-plasticity silt to a silty sand.

\section{Stiffness and/or strength properties}

The $\mathrm{M}_{\mathrm{R}}$ of the lime-treated and the untreated natural subgrade layer, obtained from back-calculation of the FWD deflection data, is 72 and $17 \mathrm{ksi}$, respectively, 
resulting in an increase of the $\mathrm{M}_{\mathrm{R}}$ by a factor of $320 \%$.

Figure $5.128 \sim$ Figure 5.136 show DCPI (Dynamic Cone Penetration Index) and SPI (Standard Penetration Index) with depth of penetration. As previously discussed, the figures show two distinct layers: an upper layer with low values and a lower layer with larger values. Some disturbance at the top is also observed. In addition, the figures also show, as in site (5), that there is a substantial increase of DCPI values at the transition between the lime-treated subgrade and the natural soil. 


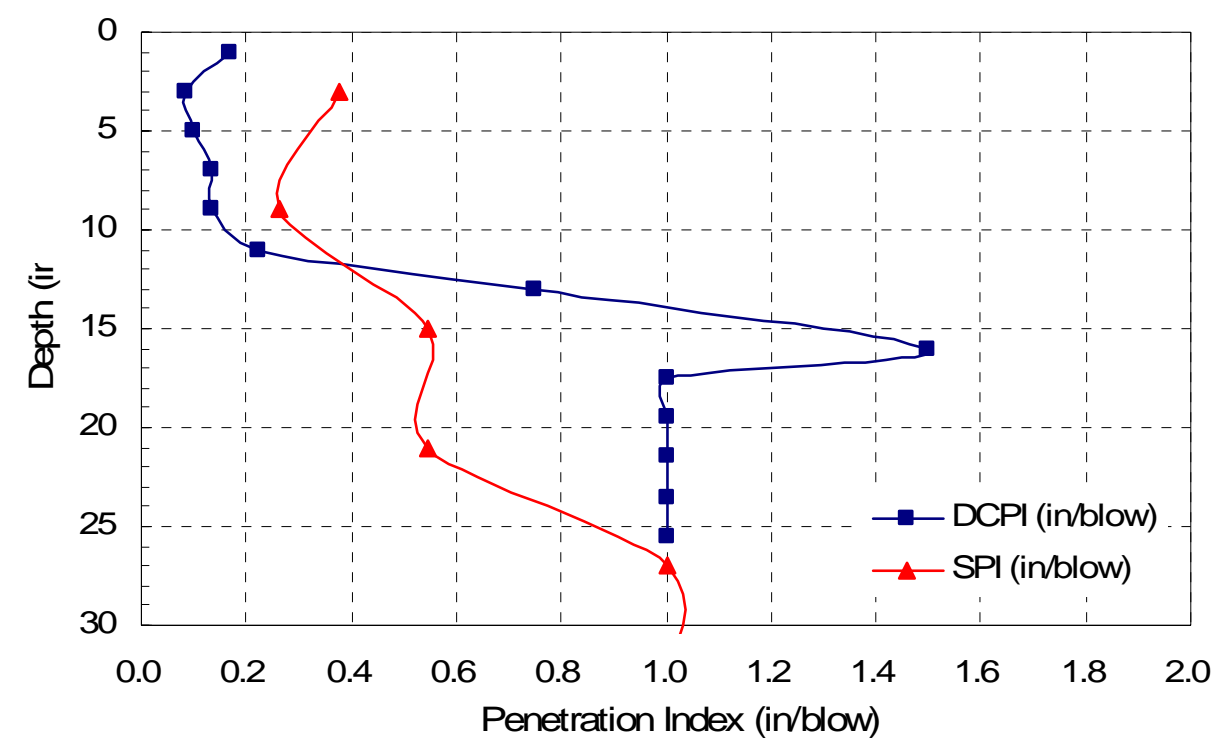

Figure 5.128 DCPT and SPT results with depth at BH-1 (STA. 0 meters). Site (6)

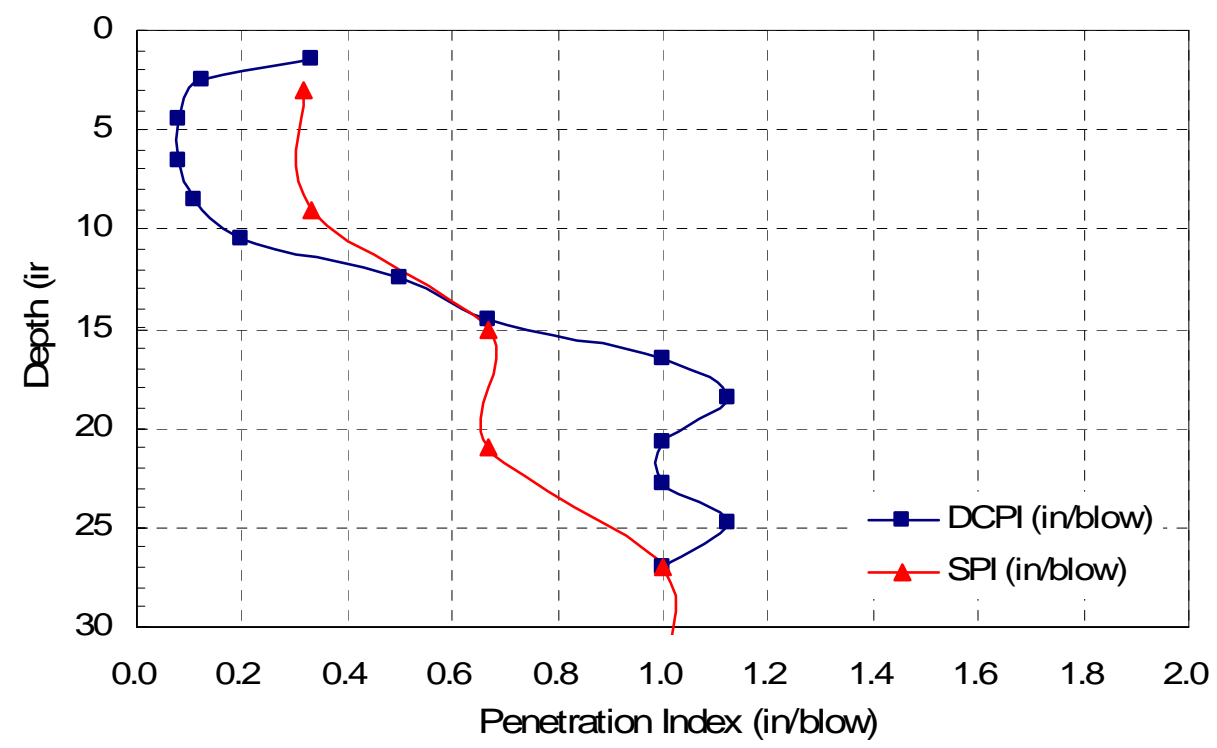

Figure 5.129 DCPT and SPT results with depth at BH-2 (STA. 10 meters). Site (6) 


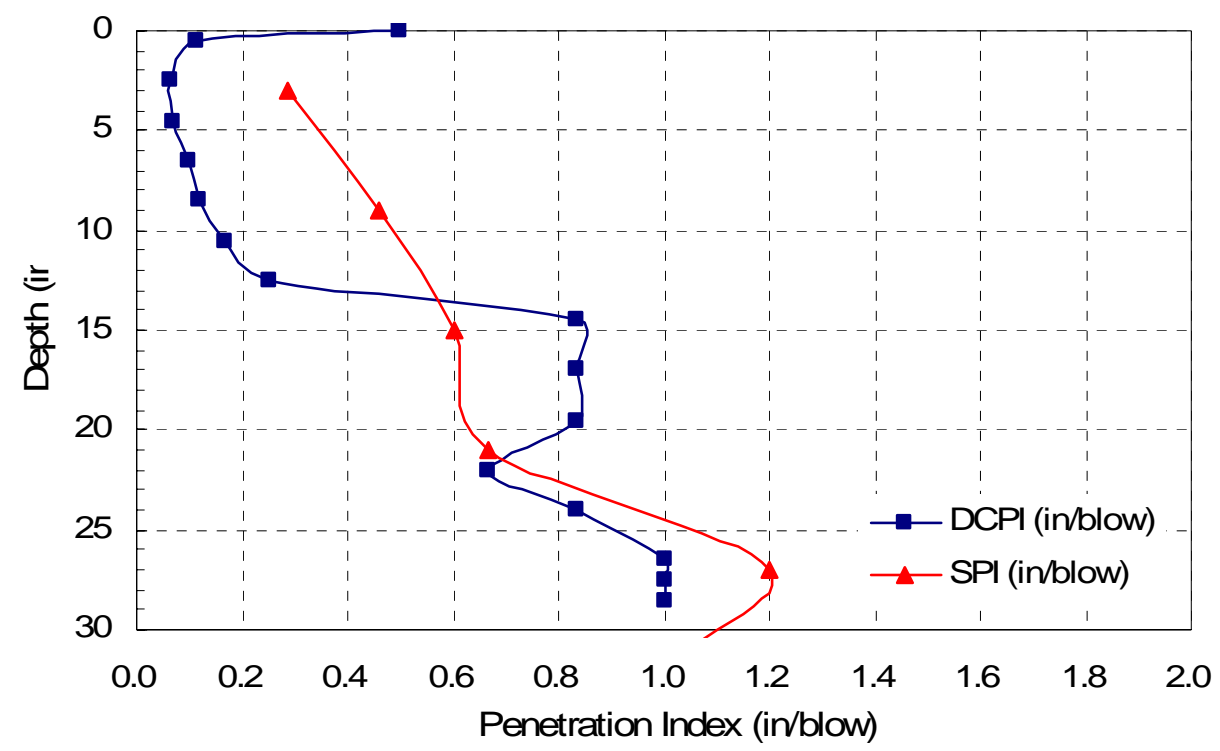

Figure 5.130 DCPT and SPT results with depth at BH-3 (STA. 20 meters). Site (6)

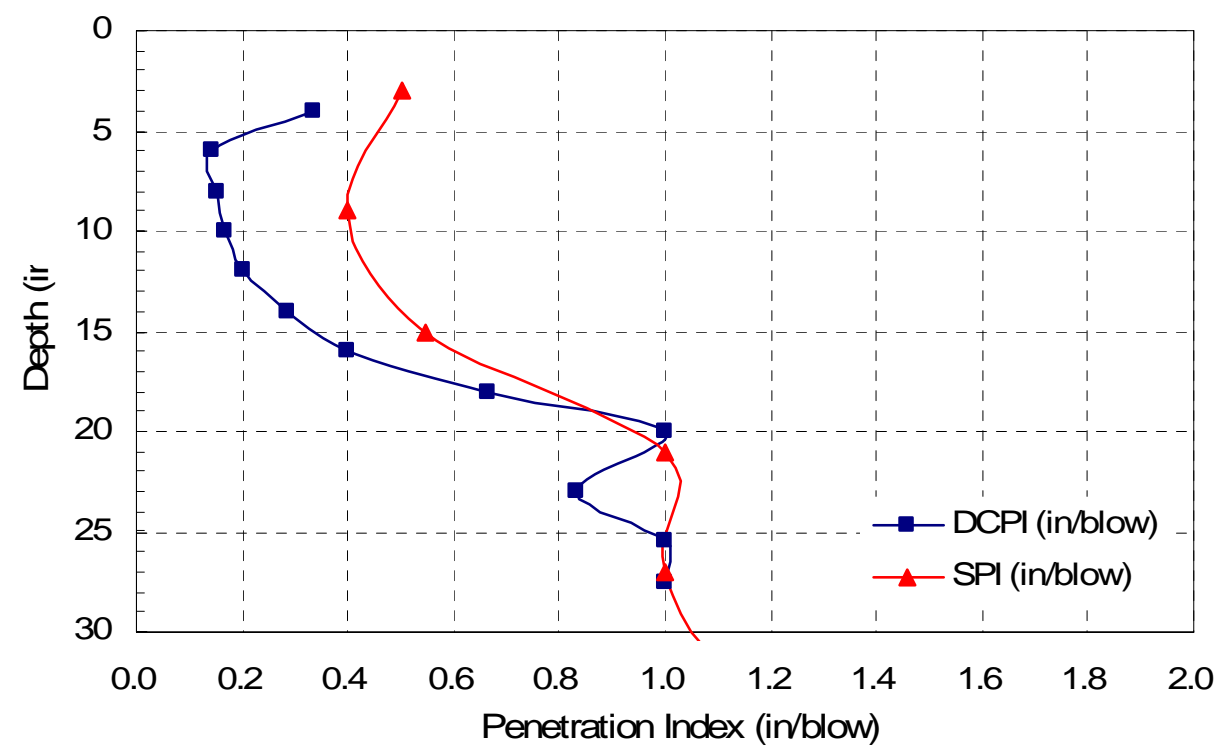

Figure 5.131 DCPT and SPT results with depth at BH-4 (STA. 30 meters). Site (6) 


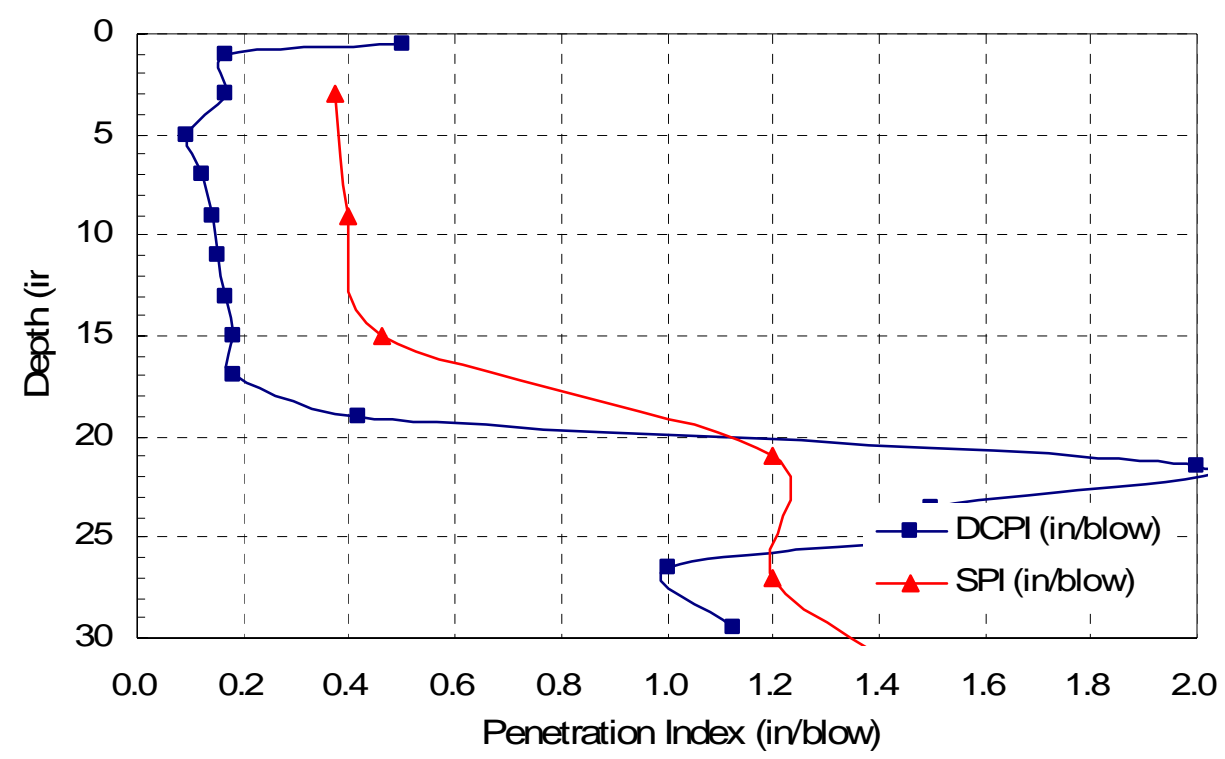

Figure 5.132 DCPT and SPT results with depth at BH-5 (STA. 40 meters). Site (6)

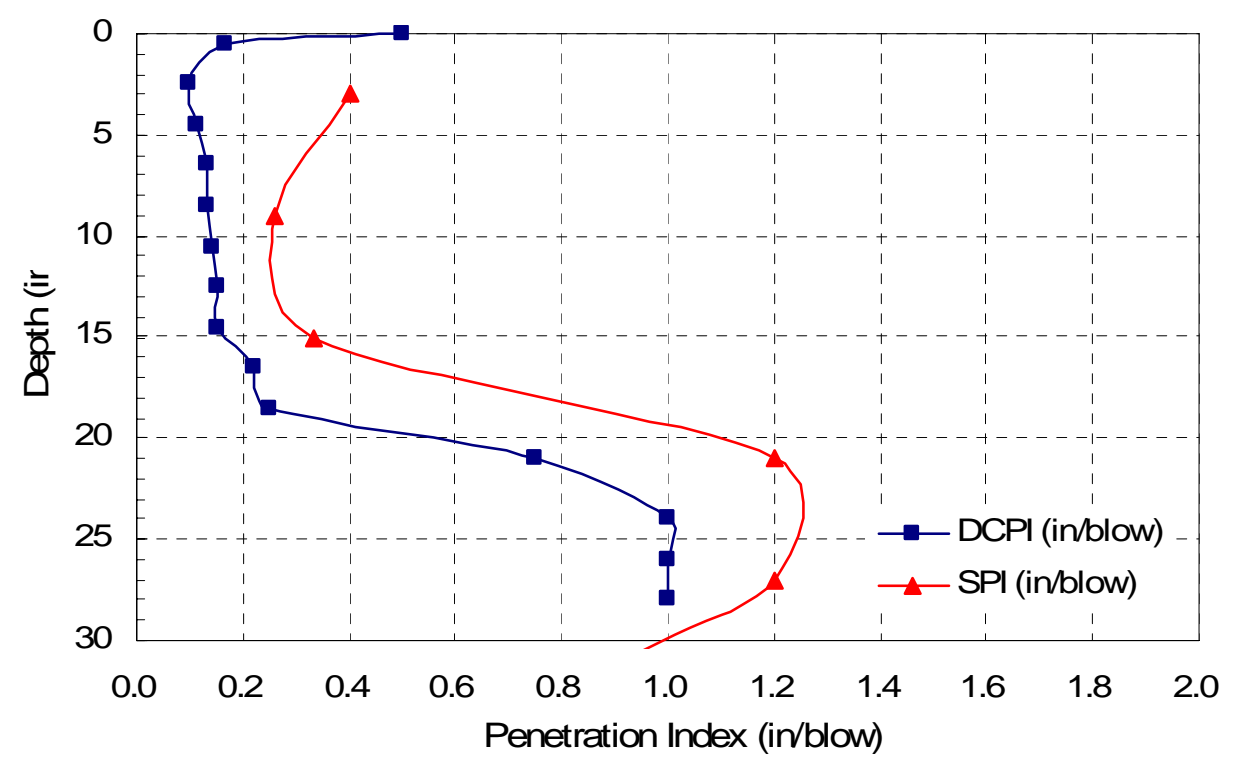

Figure 5.133 DCPT and SPT results with depth at BH-6 (STA. 60 meters). Site (6) 


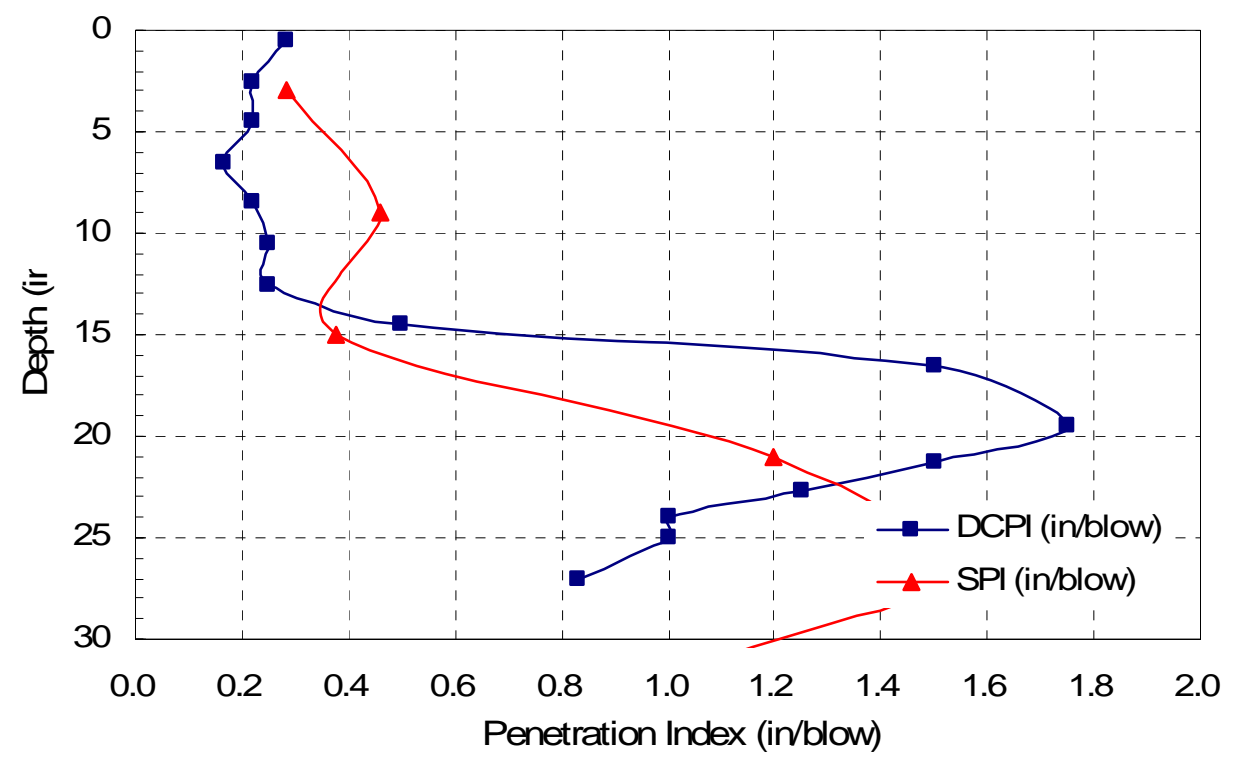

Figure 5.134 DCPT and SPT results with depth at BH-7 (STA. 80 meters). Site (6)

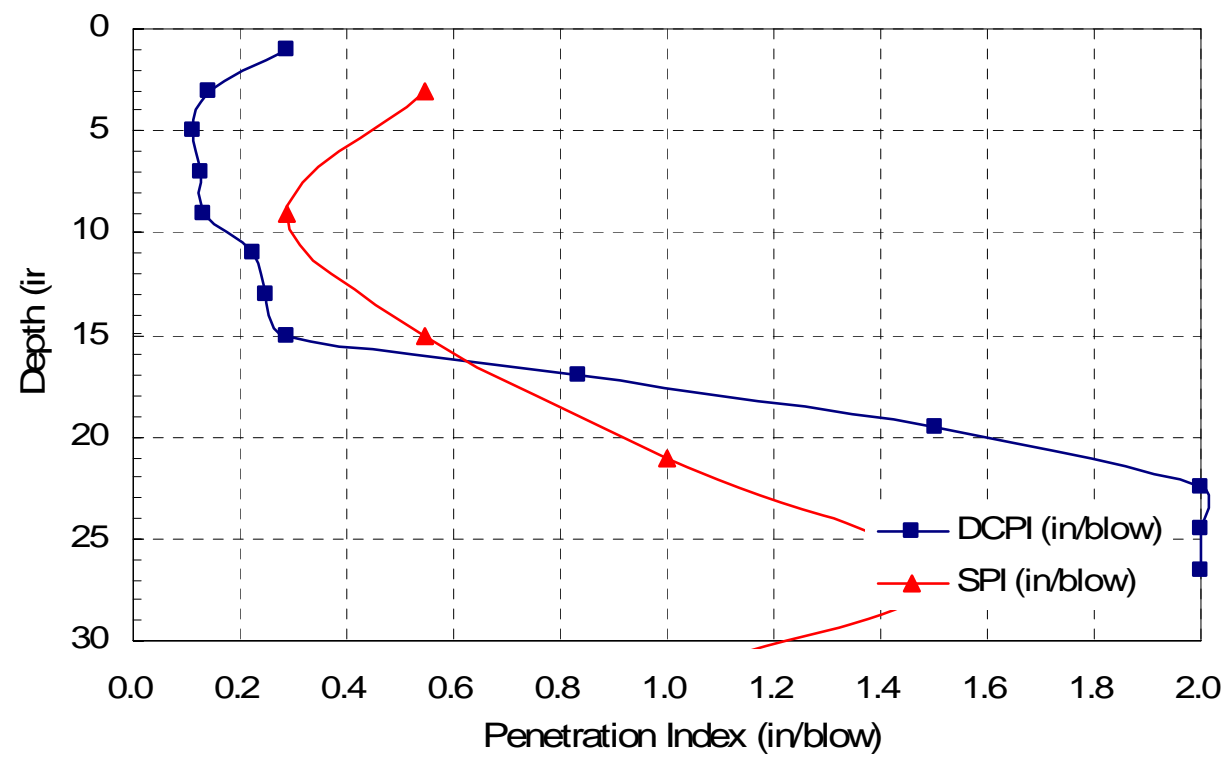

Figure 5.135 DCPT and SPT results with depth at BH-8 (STA. 100 meters). Site (6) 


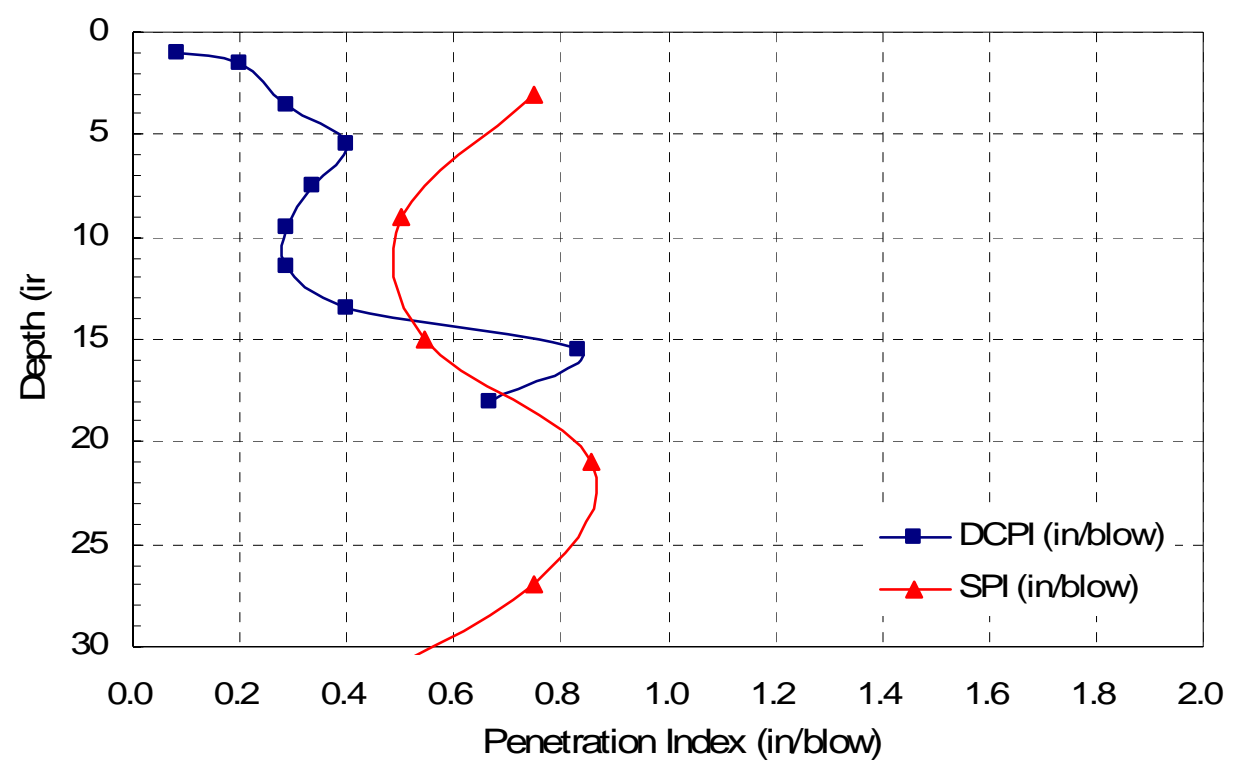

Figure 5.136 DCPT and SPT results with depth at BH-9 (STA. 120 meters). Site (6)

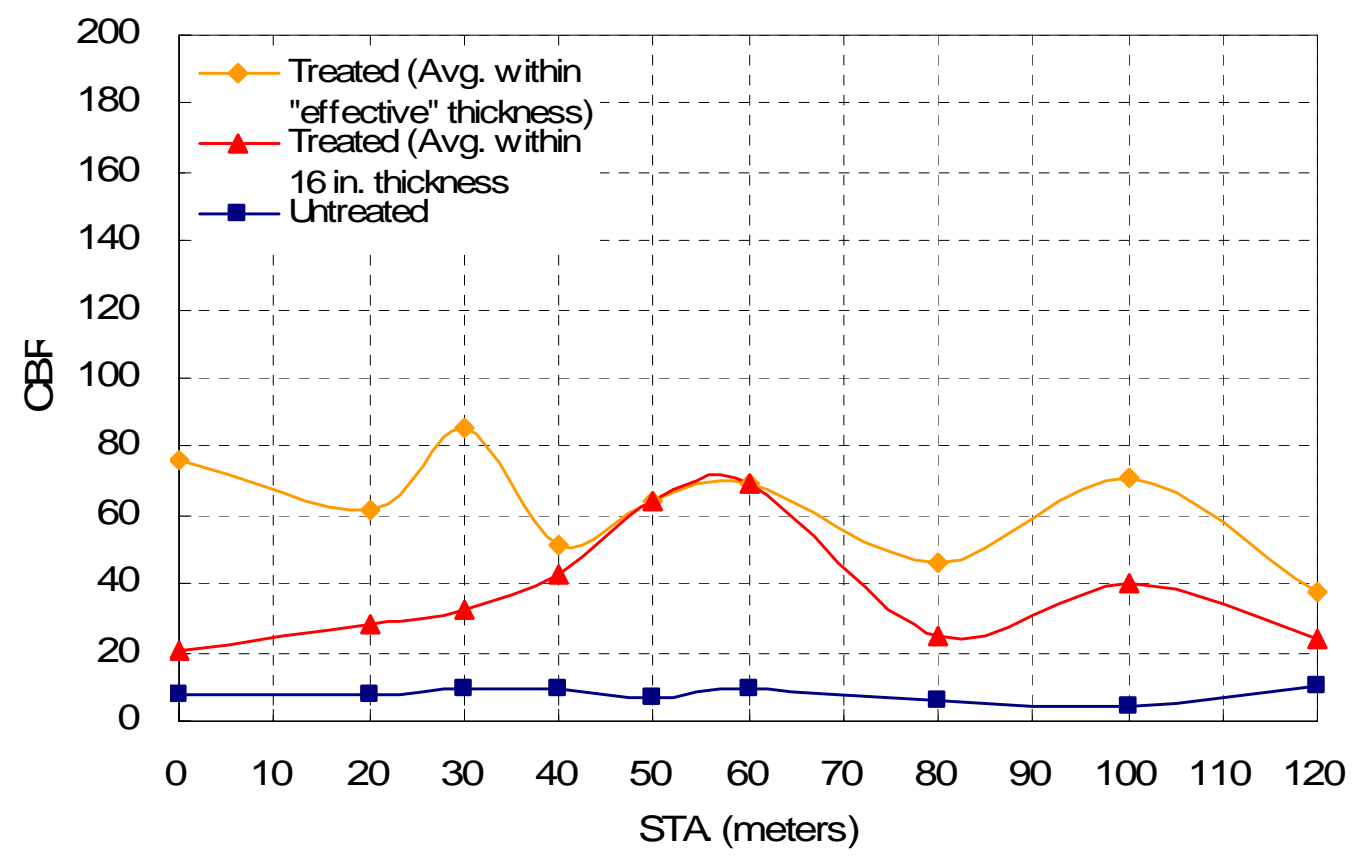

Figure 5.137 CBR of subgrade estimated from DCPT results. Site (6)

Figure 5.137 plots the longitudinal distribution of CBR for both lime-treated and natural soil layers. The CBR values are obtained with a correlation of DCPI and CBR 
(Webster et al., 1992). The CBR of the natural subgrade soil layer ranges from 4.2 to 10.6. The CBR of the lime-treated subgrade soil layer, calculated within the effective thickness, ranges between 38 and 86 , which results in an increase of the CBR by a factor of $250 \%$ to $1500 \%$. The CBR of the lime-treated subgrade soil layer, calculated within a thickness of 16 inches below the top of the subgrade, ranges between 21 and 70, which results in an increase of CBR of 130 to $880 \%$. The difference between the two curves for the limetreated soil is an indication of how homogeneous the results are along the site.

While Figure 5.137 shows that there is a substantial increase of the stiffness of the soil, it also shows a very large and significant variability.

\section{Lime content}

Figure 5.138 shows the $\mathrm{pH}$ values of both the lime-treated subgrade and natural soil, which were determined at the boreholes drilled at the site. The lime-treated subgrade soil has a $\mathrm{pH}$ ranging from 9.8 to 11.3 while the untreated soil has a $\mathrm{pH}$ ranging from 7.4 to 8.6. The increase of $\mathrm{pH}$ denotes the presence of lime. 


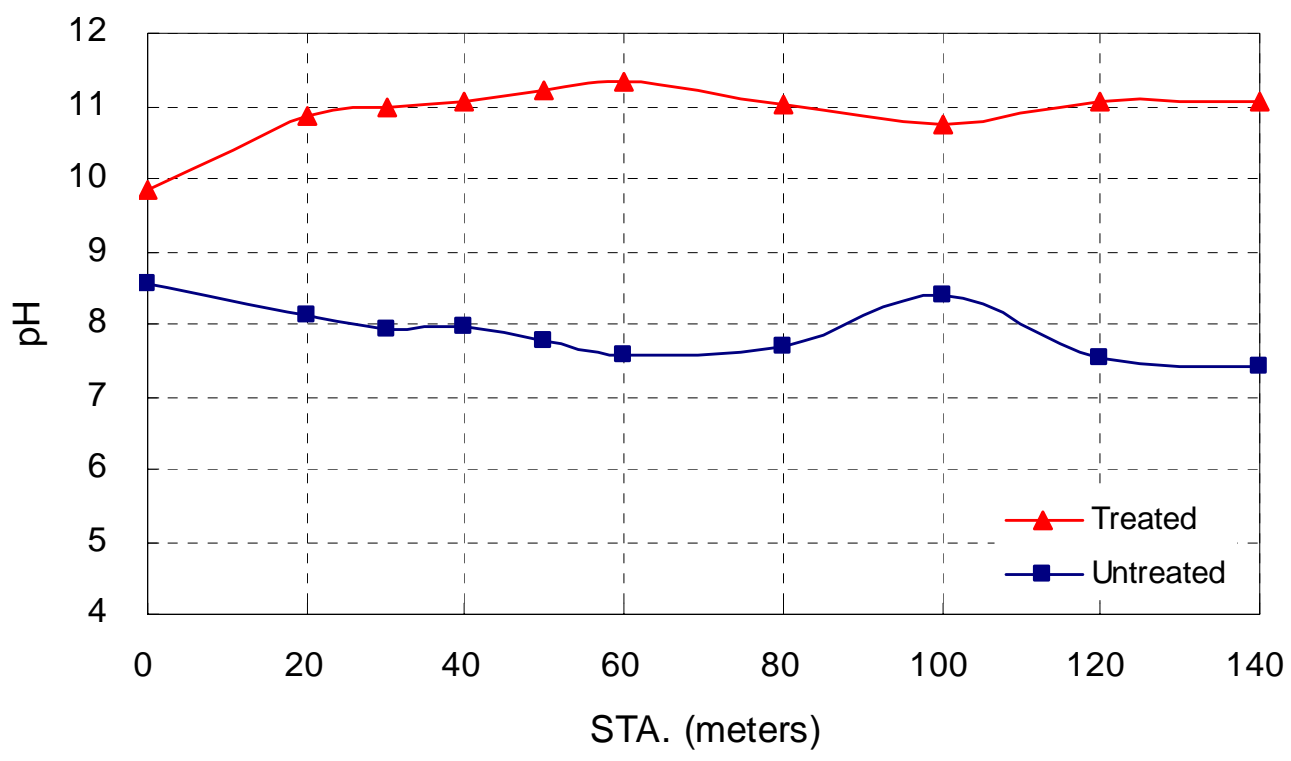

Figure $5.138 \mathrm{pH}$. Site (6)

Figure 5.139 Figure 5.144 show the results of XRD tests from the lime-treated and natural soil samples obtained in the field. The existence of calcium carbonate $\left(\mathrm{CaCO}_{3}\right)$ in the lime-treated subgrade is observed in the XRD results. The fact that the source of the $\mathrm{CaCO}_{3}$ is from the added lime is confirmed by the observation that the mineral was not found in the natural soil. The figures shows that the XRD patterns of the lime-treated soil samples have a peak at the critical refraction angles of $\mathrm{Ca}(\mathrm{CO})_{3}$, but those of the untreated soil samples have no peak at the critical angles. 

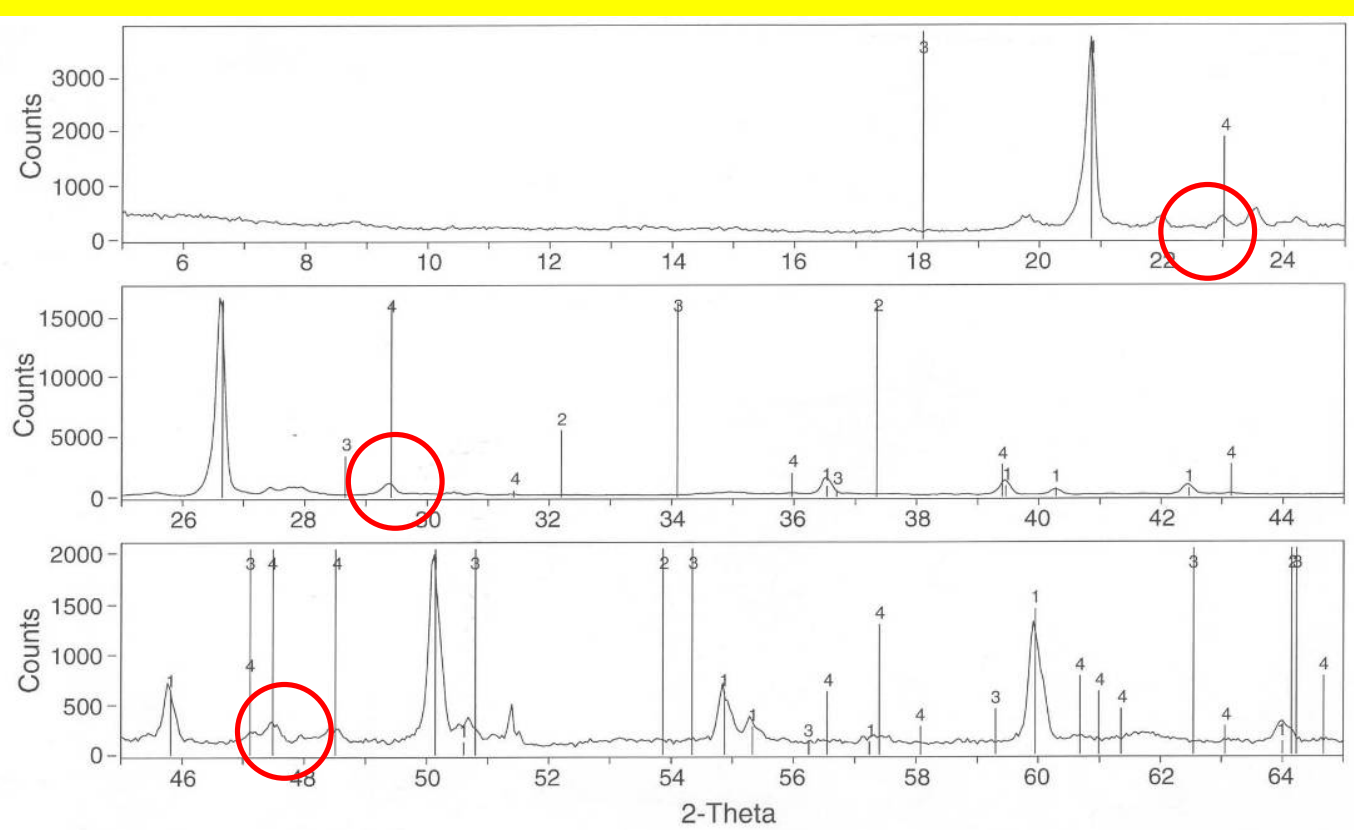

1> 33-1161: Quartz, syn - SiO2

3> 04-0733: Portlandite, syn - $\mathrm{Ca}(\mathrm{OH}) 2$

2> 37-1497: Lime, syn - CaO

4> 05-0586: Calcite, syn - $\mathrm{CaCO} 3$

Figure 5.139 XRD pattern for lime-treated soil sample at BH-1 (STA. 0 meters). Site (6)
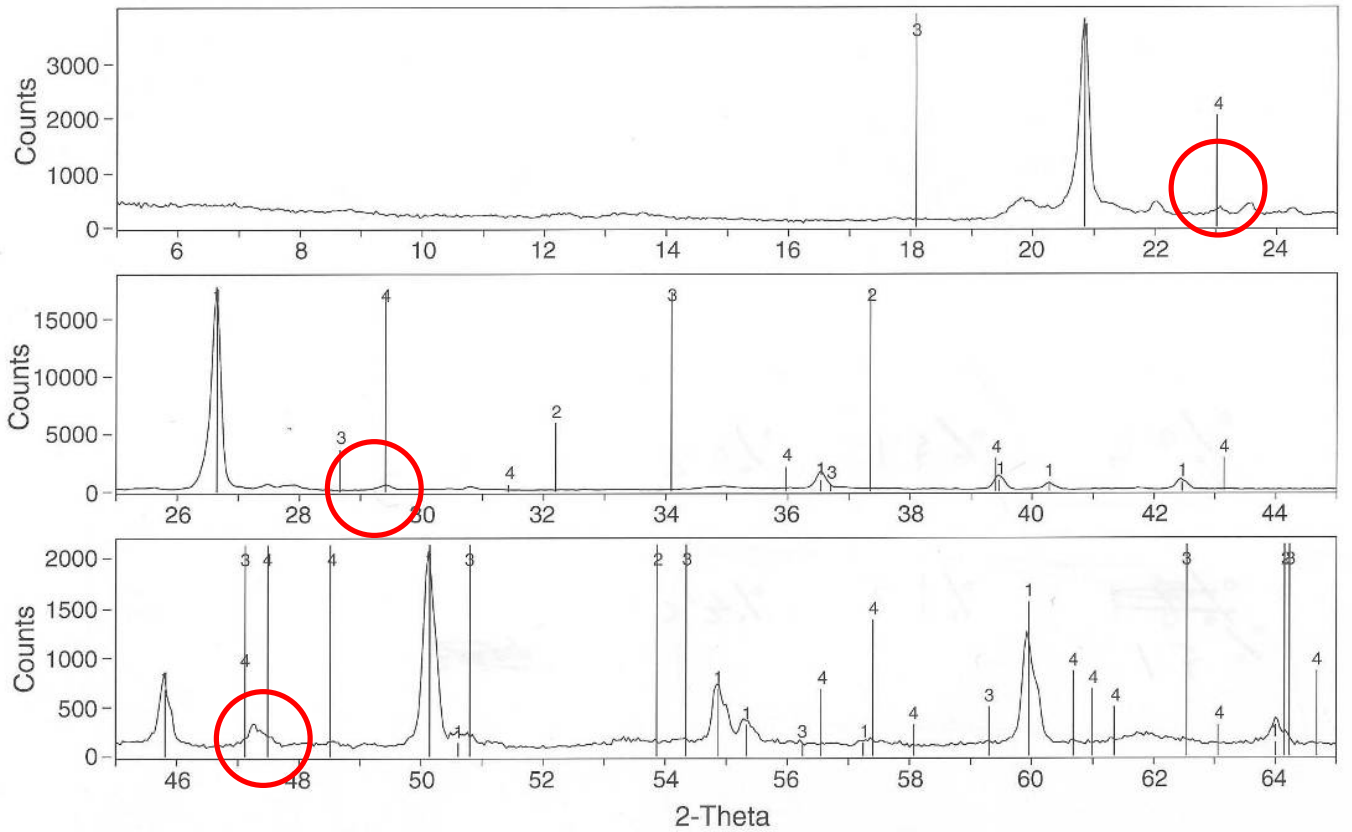

1> 33-1161: Quartz, syn - SiO2

2> 37-1497: Lime, syn - CaO

3> 04-0733: Portlandite, syn - $\mathrm{Ca}(\mathrm{OH}) 2 \quad$ 4> 05-0586: Calcite, syn - $\mathrm{CaCO} 3$

Figure 5.140 XRD pattern for untreated soil sample at BH-1 (STA. 0 meters). Site (6) 

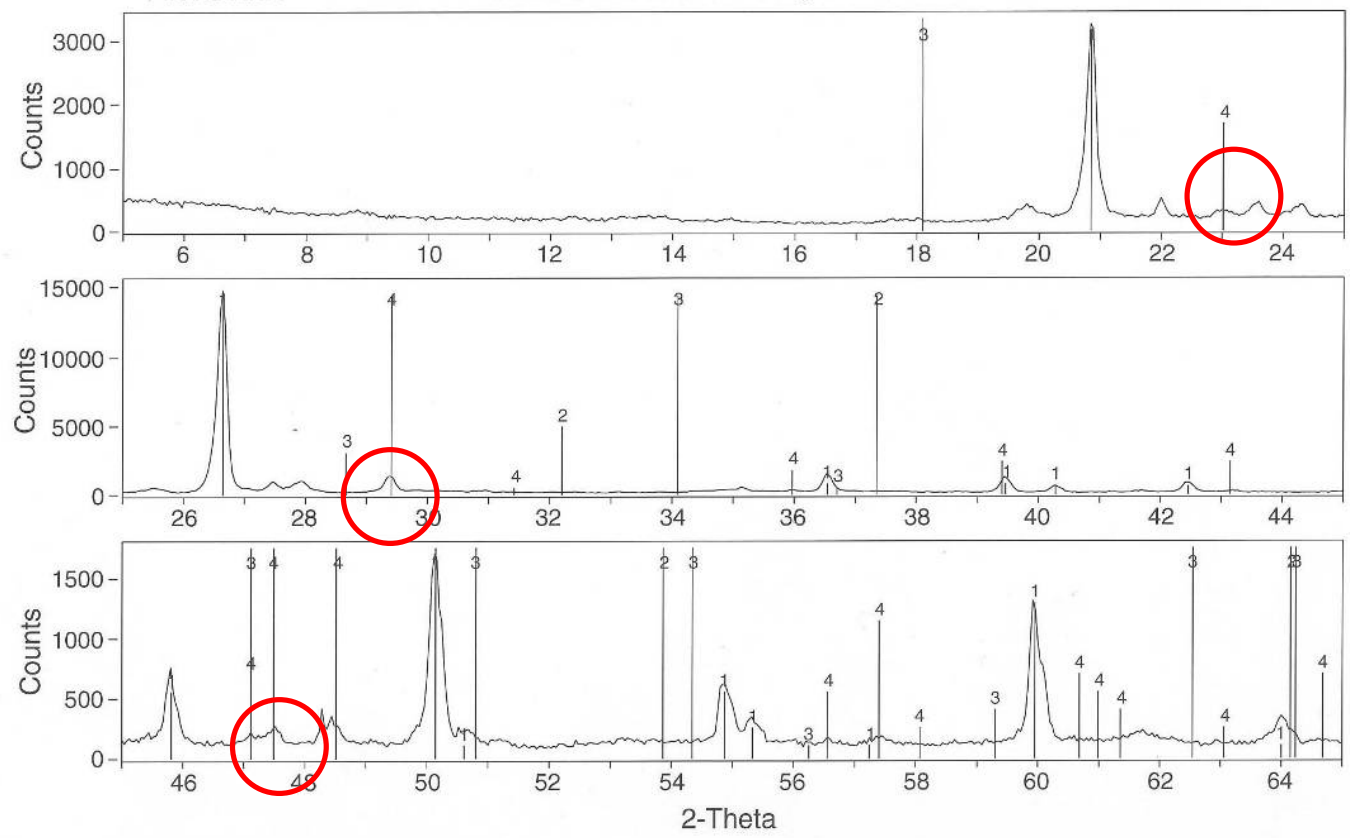

1> 33-1161: Quartz, syn - SiO2

2> 37-1497: Lime, syn - CaO

3> 04-0733: Portlandite, syn - $\mathrm{Ca}(\mathrm{OH}) 2$

4> 05-0586: Calcite, syn - CaCO3

Figure 5.141 XRD pattern for lime-treated soil sample at BH-3 (STA. 30 meters). Site (6)
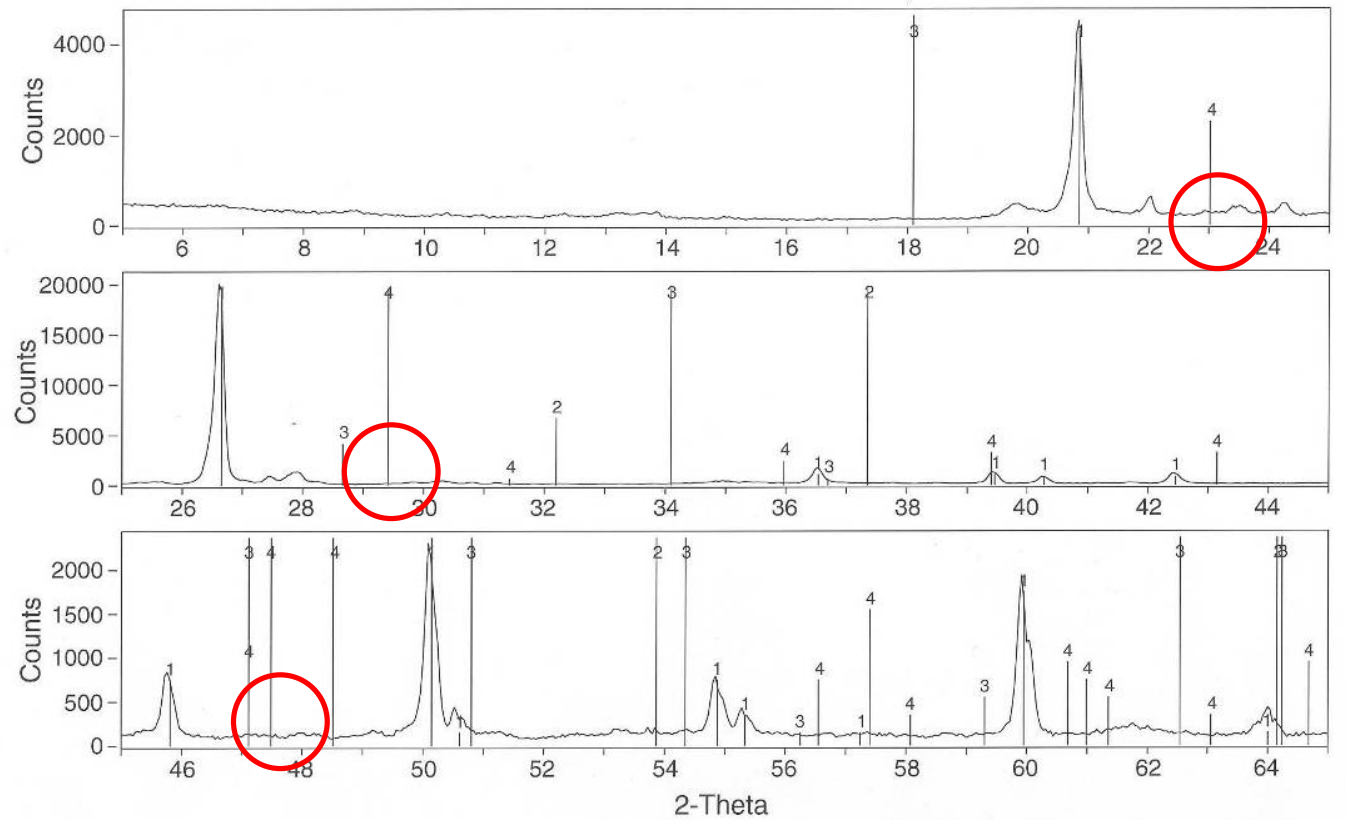

1> 33-1161: Quartz, syn - SiO2

3> 04-0733: Portlandite, syn - $\mathrm{Ca}(\mathrm{OH}) 2$

2> 37-1497: Lime, syn - CaO

4> 05-0.586: Calcite, syn - $\mathrm{CaCO} 3$

Figure 5.142 XRD pattern for untreated soil sample at BH-3 (STA. 30 meters). Site (6) 

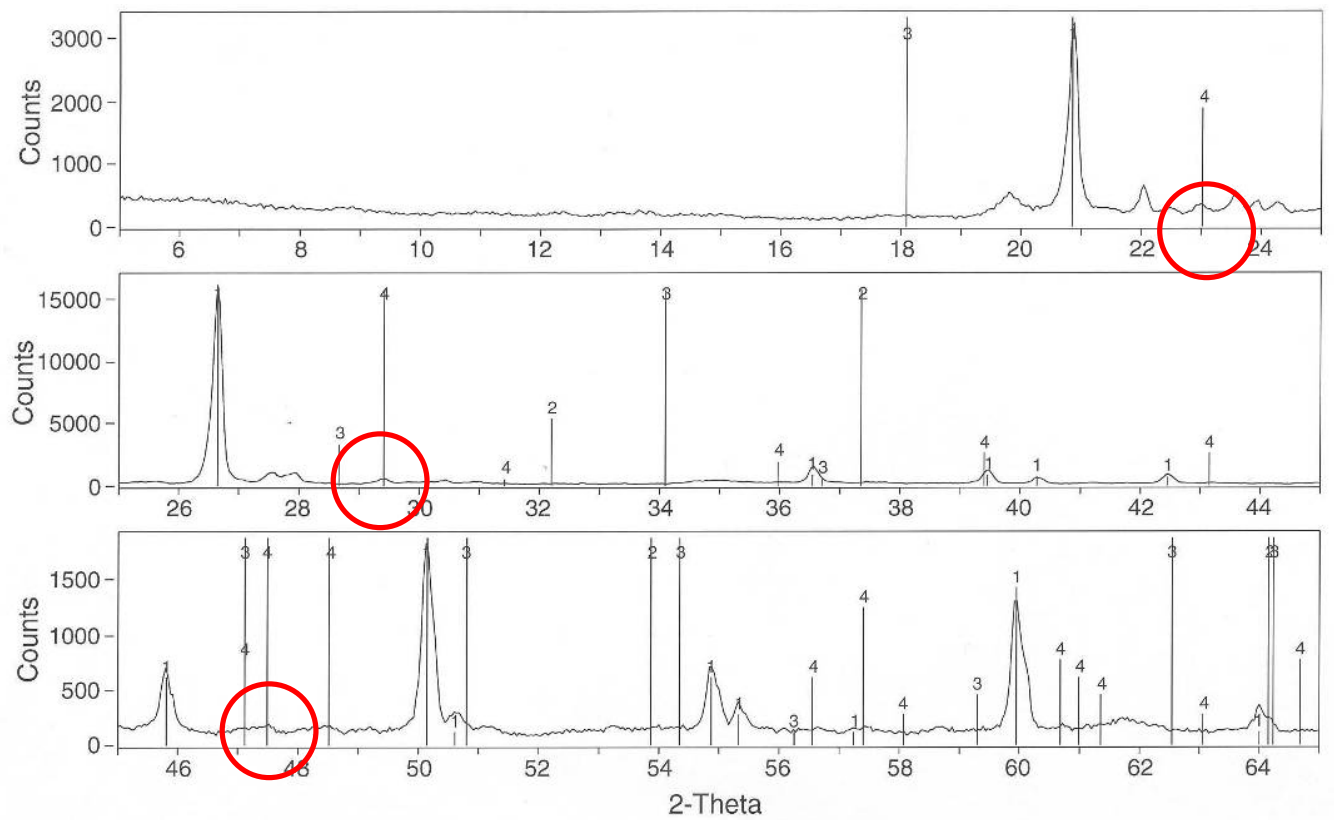

1> 33-1161: Quartz, syn - SiO2

3> 04-0733: Portlandite, syn - $\mathrm{Ca}(\mathrm{OH}) 2$

2> 37-1497: Lime, syn - CaO

4> 05-0586: Calcite, syn - CaCO3

Figure 5.143 XRD pattern for lime-treated soil sample at BH-7 (STA. 80 meters). Site (6)
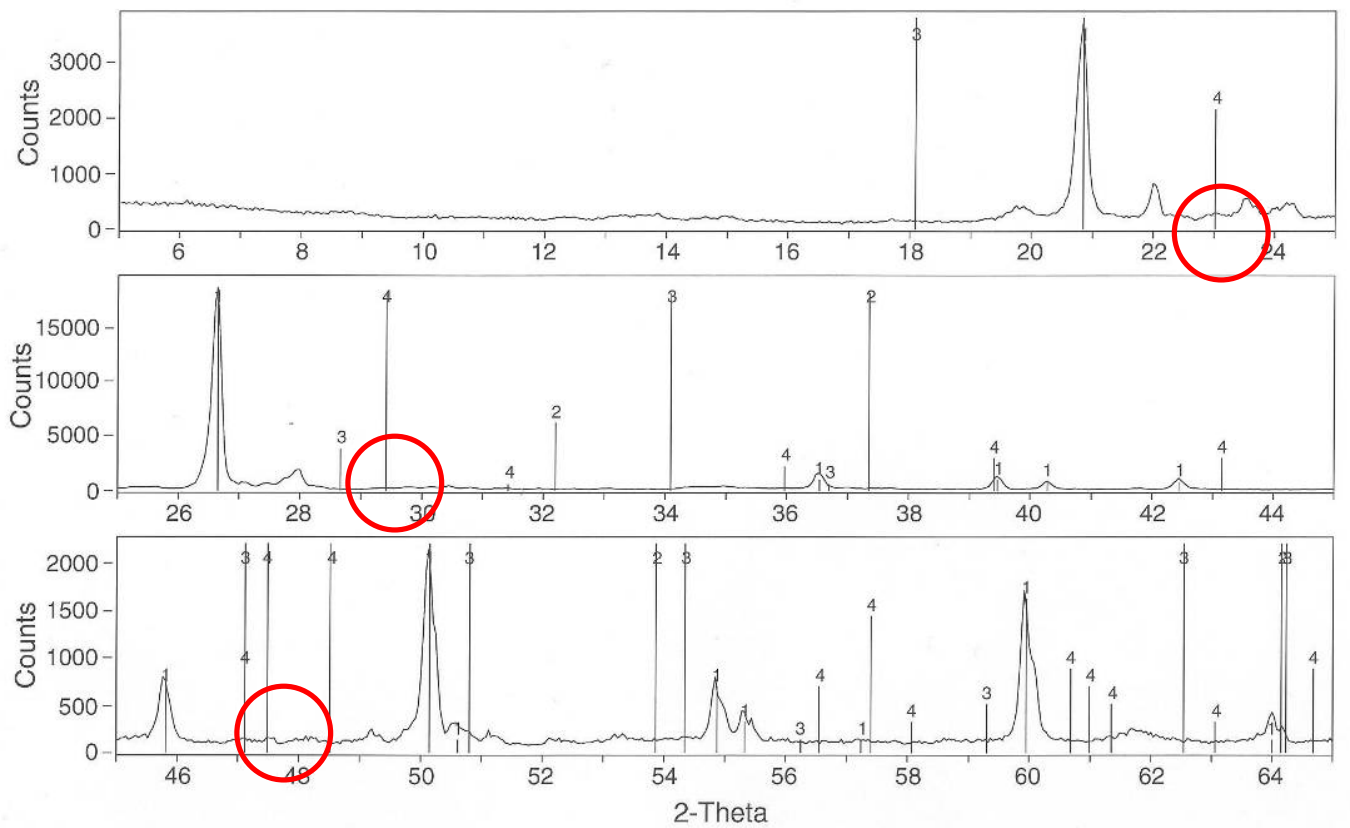

1> 33-1161: Quartz, syn - SiO2

2> 37-1497: Lime, syn - CaO

3> 04-0733: Portlandite, syn - $\mathrm{Ca}(\mathrm{OH}) 2 \quad$ 4> 05-0586: Calcite, syn - $\mathrm{CaCO} 3$

Figure 5.144 XRD pattern for untreated soil sample at BH-7 (STA. 80 meters). Site (6) 
Figure $5.145 \sim$ Figure 5.147 show the results of TGA tests for the lime-treated and natural soil samples collected at $\mathrm{BH}-1,3$, and 7, respectively. The lime-treated and natural soil samples were taken approximately at depths of 4 and 30 inches respectively below the top of the subgrade. The figures show that the weight of the natural soil decreases uniformly with increasing temperature without a sharp decrease within a range of temperatures between 650 and $800{ }^{\circ} \mathrm{C}$. From the TGA data of the natural soil samples, it is confirmed that the $\mathrm{CaCO}_{3}$, which is detected in the TGA data of the lime-treated soil samples, originates from the LKD added for the lime treatment. From the figures, the calculated amount of $\mathrm{CaCO}_{3}$, which includes both the lime used for the soil-lime reaction and any pre-existing $\mathrm{CaCO}_{3}$ in the $\mathrm{LKD}$, is $2.0,1.0$, and $2.0 \%$ at $\mathrm{BH}-3,5$, and 7 , respectively.

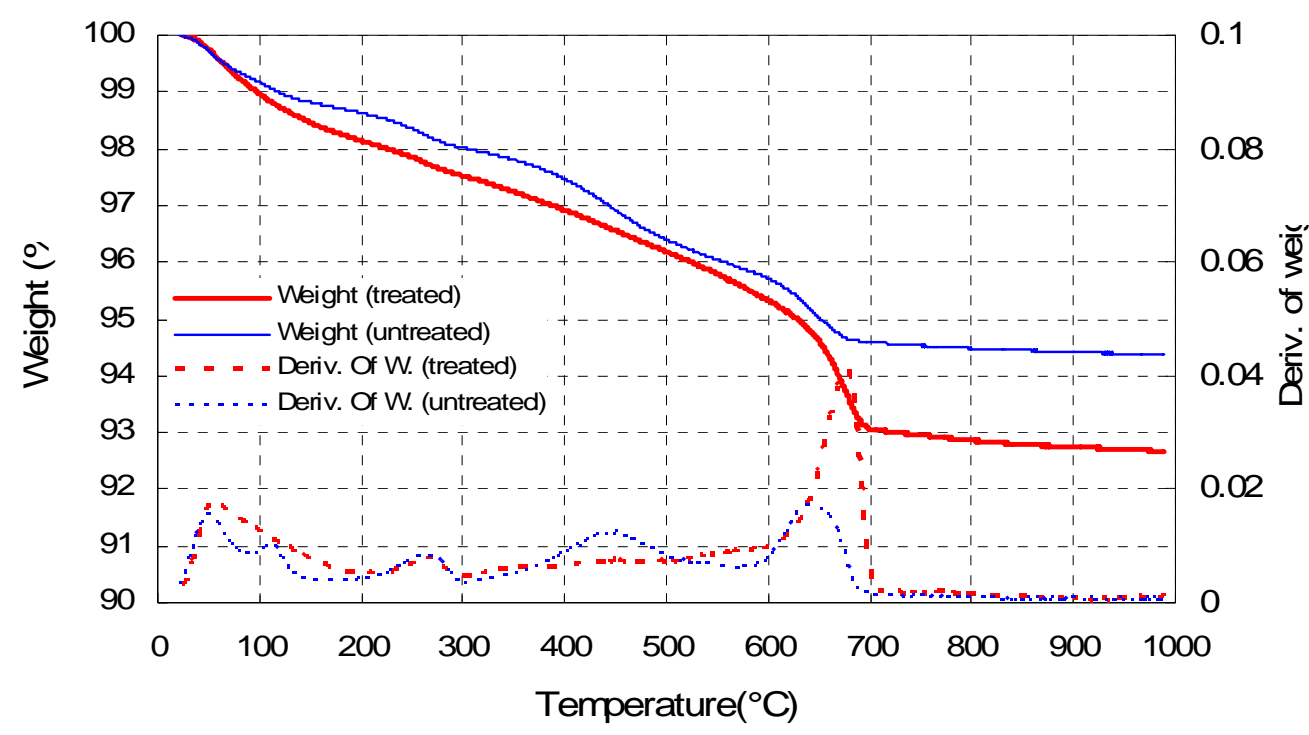

Figure 5.145 Weight loss and weight loss rate obtained from TGA from lime-treated and natural soil samples collected at BH-1 (STA. 0 meters) at site (6) 


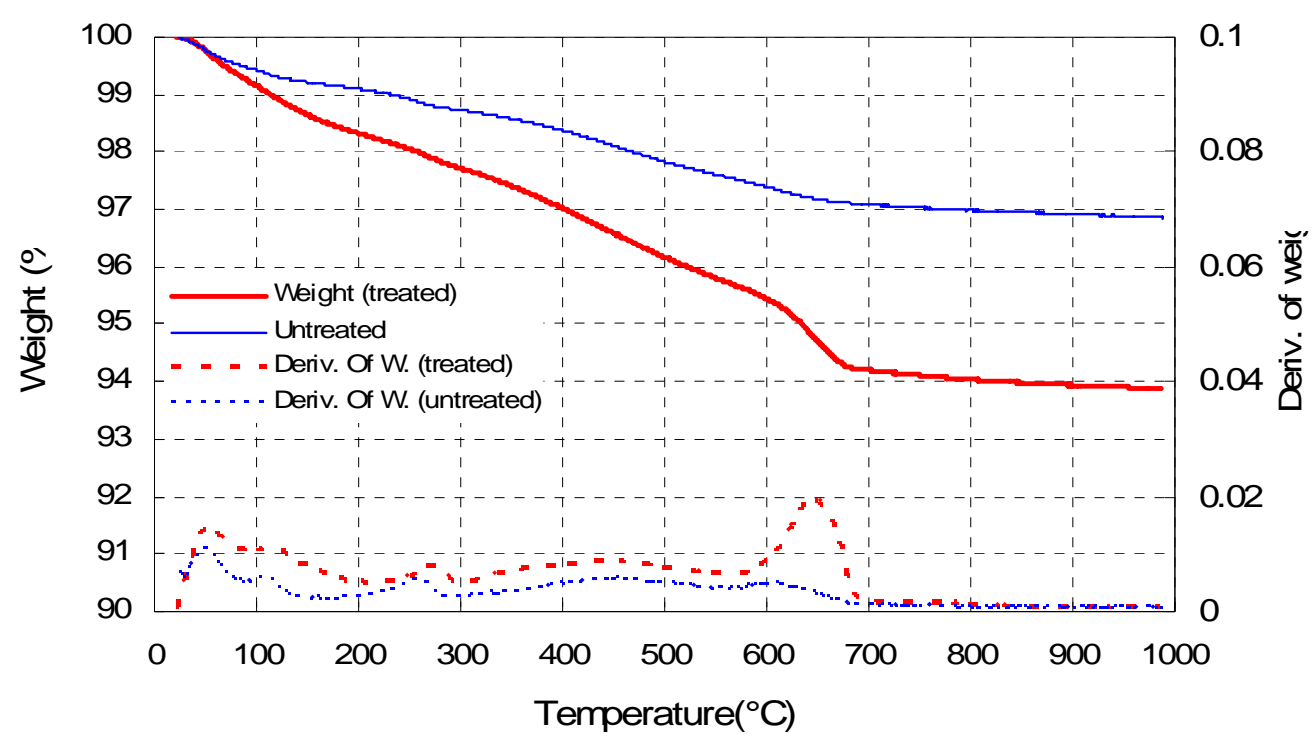

Figure 5.146 Weight loss and weight loss rate obtained from TGA from lime-treated and natural soil samples collected at BH-3 (STA. 30 meters) at site (6)

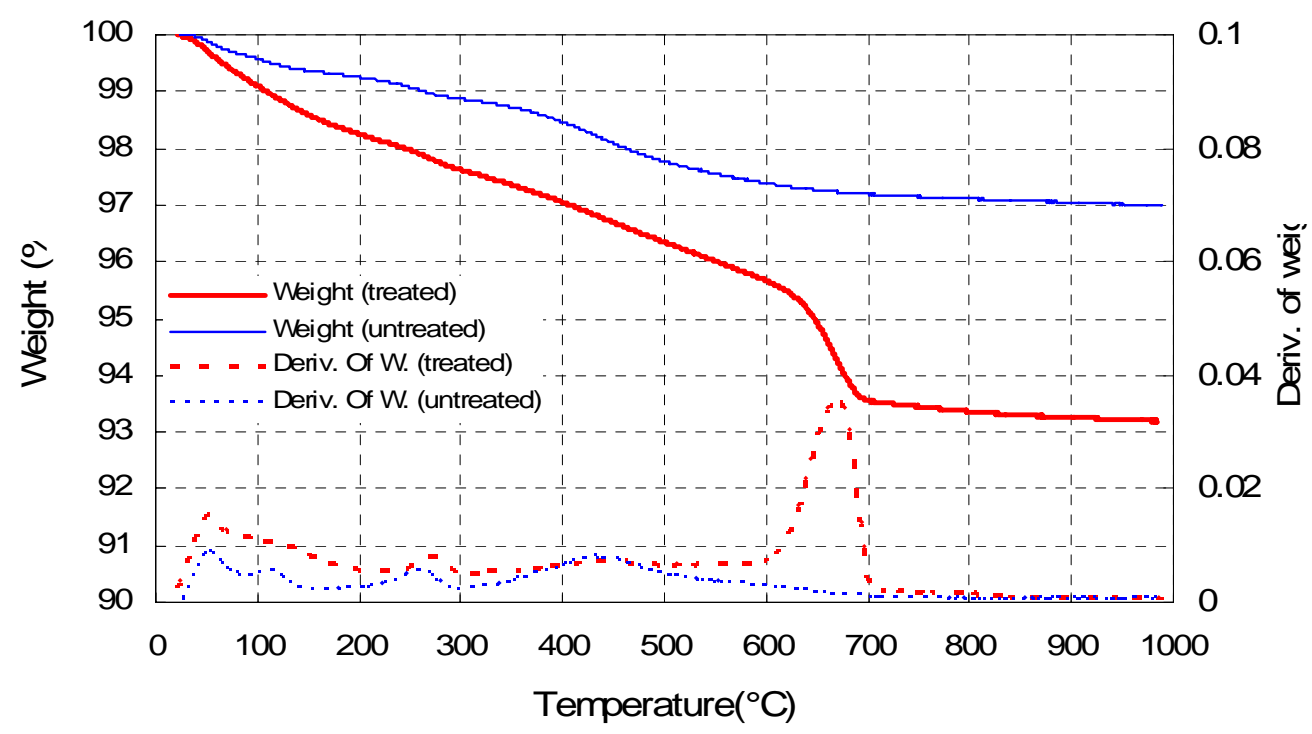

Figure 5.147 Weight loss and weight loss rate obtained from TGA from lime-treated and untreated soil samples collected at BH-7 (STA. 80 meters) at site (6)

The laboratory and field tests results strongly suggest that after five years of service, the lime still remains in the soil and the soil still has the engineering properties gained with the addition of the lime. There has been no leaching of the lime from the subgrade. 


\subsection{Summary}

Table 5.1 shows the summary of average or typical laboratory and field test results at each site. The table includes: (1) geographical location of the testing site; (2) year of lime treatment; (3) percent passing the No. 200 sieve of the natural and lime-treated soils; (4) natural water content of the natural and lime-treated soils; (4) soil type of the natural and lime-treated soils; (5) $\mathrm{pH}$ of the natural and lime-treated soils; (6) ratio of the CBR of the lime-treated subgrade layer calculated within the "effective" thickness to the CBR of the natural (untreated) soil layer; and ratio of the CBR of the lime-treated subgrade layer calculated within 16-in. thickness below the top of the subgrade to the CBR of the natural (untreated) soil layer, which are estimated from the DCPT result with depth; (7) ratio of the $M_{R}$ of the lime-treated subgrade soil layer to the $M_{R}$ of the natural soil layer, which are back-calculated from FWD test results: (8) content of $\mathrm{CaCO}_{3}$ in the lime-treated subgrade soil; and (9) the existence of "spike", which is a substantial increase of DCPI values at the contact between the treated and the untreated soil layers. 
Table 5.1 Summary of laboratory and field test results at each site

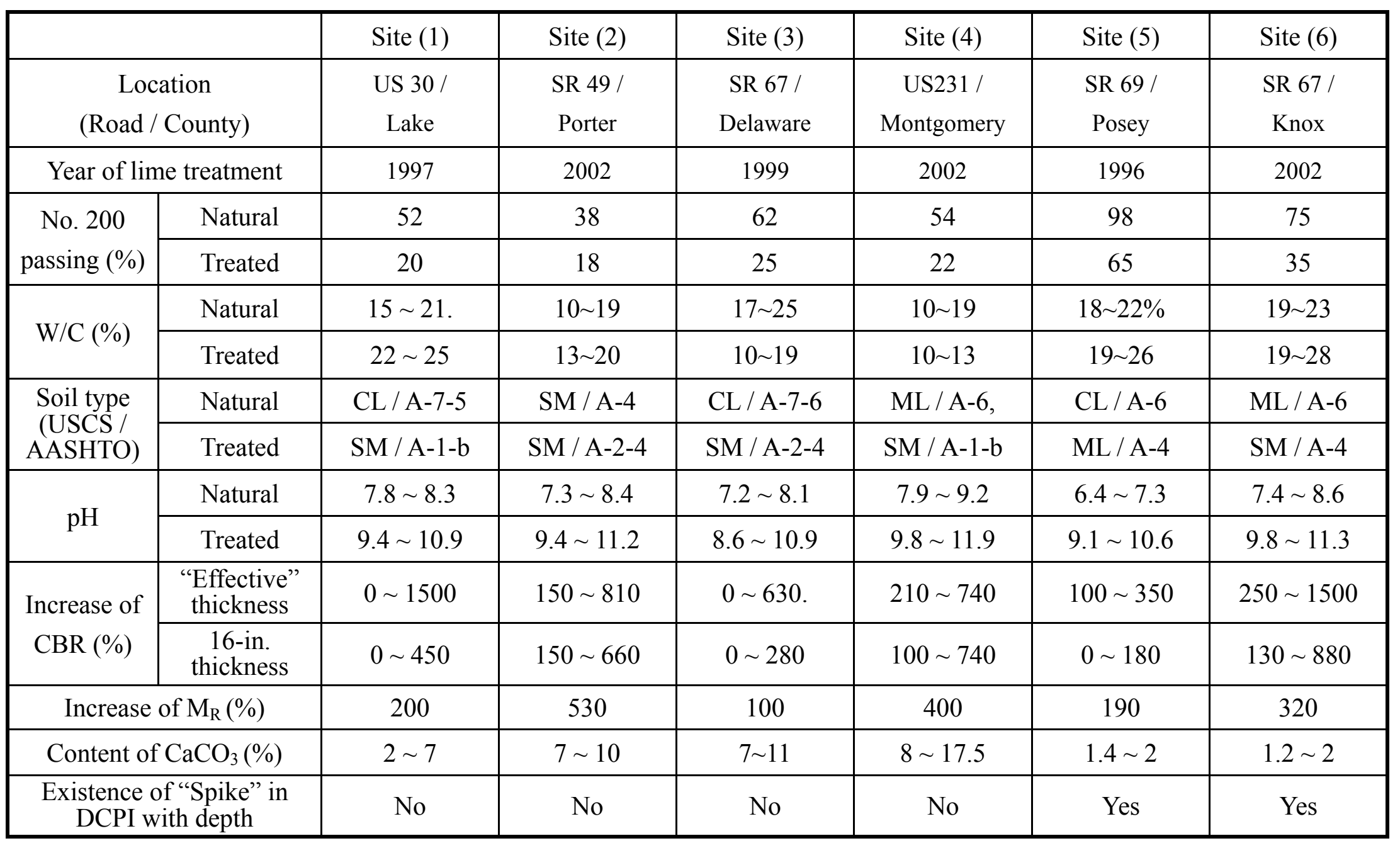




\section{CHAPTER 6. Summary and Conclusions}

This chapter includes the summary of the research study on post-construction evaluation of lime-treated subgrade soils, as well as the conclusions reached from the work. It is divided into three Sections: Summary, Conclusions and Recommendations and Implementation.

\subsection{Summary}

A comprehensive field investigation was carried out to determine the properties of subgrade soils treated with lime in pavements that had been in service for at least five years. Six sites were selected for the field tests. The testing sites were selected based on the following considerations: (1) location of the road project in the State of Indiana; (2) class of the road; (3) year when lime treatment was done; (4) type of lime used; (5) type of pavement; (6) availability of information necessary for post-construction evaluation; and (7) traffic and safety control.

The road projects chosen were: (1) Des. 62050 (R-22364) on US 30 in Lake County; (2) Des. 9901900 (R-25555) on SR 49 in Porter County; (3) Des. 9118711 (R23126) on SR 67 in Delaware County; (4) Des. 9133550 (R-25819) on US 231 in Montgomery County; (5) Des. 63260 (R-24568) on SR 69 in Posey County; and (6) Des. 9774201 (R-25919) on SR 67 in Knox County.

Sites (1) and (2) are located in Northern Indiana; sites (3) and (4) in Central Indiana, and sites (5) and (6) in Southern Indiana. The sites are considered representative 
of the roads encountered across the State. Lime treatment was done in all the sites before 2002. Sites (1) and (5) have PCC pavement while sites (2), (3), (4), and (6) have HMA pavement. Sites (1) and (4) are on US Highways while sites (2), (3), (5) and (6) are on Indiana State Roads. At each site, the design called for an improvement of the subgrade by mixing the natural soil with $5 \%$ of LKD over a depth of 16 inches.

In all the six sites selected, SPT, DCPT, and FWD tests were performed to evaluate the in-situ stiffness and/or strength properties of the lime-treated subgrade. Laboratory tests from soil samples taken from the SPT spoon were done to obtain index properties of the lime-treated subgrade and the lime content that remains in the soil.

FWD tests were conducted at each site to obtain the in-situ $M_{R}$ of the lime-treated subgrade and of the original, untreated soil. DCP tests were performed to complement FWD tests as well as to evaluate directly the stiffness of the lime-treated subgrade. The objective of SPT tests was mostly to obtain samples for laboratory tests, and to a smaller extent to compare SPT results with DCP data.

Ten borings, spaced at approximately $66 \mathrm{ft}(20 \mathrm{~m})$, were drilled at sites (2) to (6) to perform the DCP tests. Another ten borings were done near the DCP borings for SPT tests and for collection of soil samples for laboratory tests. The distance between a SPT borehole and the nearest DCPT was about 2 meters. At site (1), five borings for SPT and four for DCPT were conducted because of safety issues associated with the large traffic density of the road. The SPT were conducted and soil samplings were taken in ten boreholes at sites (2) to (6) and in five boreholes at site (1). All the field investigation was carried out while the roads were in service. Care was taken to ensure the safety of the vehicles circulating and the personnel in the field conducting the tests. 
FWD and DCP test results provide information on the strength and stiffness of the lime-treated subgrade, but not on the type of soil. The index properties of the lime-treated subgrade were evaluated from laboratory tests using the soil samples collected in the field. XRD (X-Ray Diffraction) and TGA (Thermogravimetric Analysis) tests were conducted to investigate mineralogy and chemical properties of the lime-treated subgrade and of the natural soil underneath.

\section{2. $\underline{\text { Conclusions }}$}

The long-term performance of the lime-treated subgrade at each site has been evaluated based on the results of the laboratory and field tests. The evaluation was done by comparing the soil indices and stiffness and/or strength properties of the lime-treated subgrade soil with those of the natural soil. In addition, the lime content of the subgrade and the natural soil were measured to establish the remaining lime in the treated subgrade and detect any leaching in the underlying soil.

Table 6.1 provides a summary of the most important engineering indices of the soils investigated. The first observation is that the lime treatment was successful for its intended purpose: to create during construction a stable soil platform. It is important to note that the treatment was not intended to increase the engineering properties of the subgrade, nor to reduce the pavement thickness or to improve its load capacity or durability. 
Table 6.1 Summary of laboratory and field test results at each site

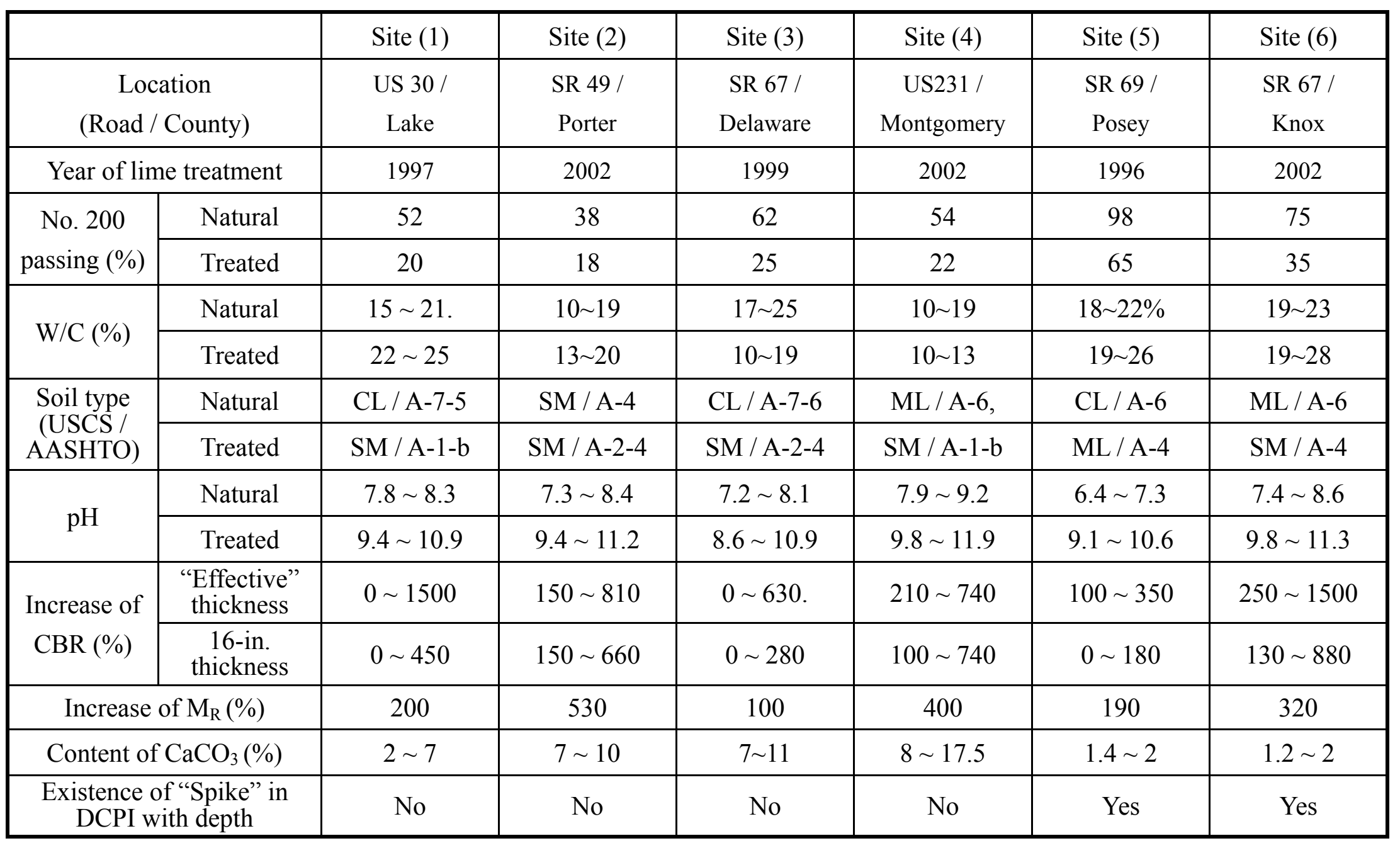


In all cases the fines content of the original soil was reduced. The reduction ranged from $20 \%$ to $40 \%$. The maximum reduction occurred at site (6) with $40 \%$ fewer fines, and the minimum at site (2) with a reduction of $20 \%$. In general the lime treatment changed the original soil from a silty/clayey soil to a non-plastic silty sand, with the exception of site (5) where the $30 \%$ reduction from the initial $98 \%$ fines content did not bring the percentage of fines below the $50 \%$ threshold; however the treated soil was nonplastic.

The water content at each site was fairly uniform, with no significant differences along the length investigated, which can be taken as an indication that there were no significant changes in the nature of the soil from point to point. In all cases the water content of the natural soil was close to its plastic limit. The water content of the treated soil was found, within experimental error, similar to that of the untreated soil.

$\mathrm{pH}$ measurements provide a qualitative measure of the presence of the lime in the soil, as the addition of LKD increases the $\mathrm{pH}$. As shown in Table 6.1 the treated subgrade always has a $\mathrm{pH}$ larger than the untreated soil. The $\mathrm{pH}$ increase ranges from 1 to 3.5 , bringing the natural soil from an initial $\mathrm{pH}$ of 7.5 to 8 , slightly basic, to 8.5 to 11 , moderately to highly basic. The fact that the $\mathrm{pH}$ is still high indicates that the lime remains in the subgrade after completion of construction of the roads, from 5 to 11 years ago.

Quantification of the lime content has been done with thermogravimetric (TGA) laboratory tests. The lime content at each site is given in Table 6.1, and ranges from $1.2 \%$ to $17.5 \%$, with typical values in the range of $5 \%$ to $7 \%$. The values are larger than expected because an addition of 5\% LKD would have resulted in lime quantities, for 
typical lime contents of LKD, in the range of $1.5 \%$ to $3 \%$. The TGA tests measure the total $\mathrm{CaCO}_{3}$, but it does not provide an indication of the source of the mineral. The source of the mineral can be either from hydration of the lime $\left(\mathrm{CaO}\right.$ and $\left.\mathrm{Ca}(\mathrm{OH})_{2}\right)$ after mixing with the soil, lime hydrated before mixture (e.g. from storage), or from $\mathrm{CaCO}_{3}$ that remained after heating in the kiln. Hence, even though the tests give a value of the total calcium carbonate, it is not possible to determine the percentage of the mineral that was the result of the reaction of the lime with the soil. An important result from the TGA tests, which was confirmed with X-ray diffraction tests, is that the lime was only present in the treated subgrade and not in the natural soil. This provides a strong indication, together with the $\mathrm{pH}$ measurements, that there was no leaching of the lime out of the subgrade, and thus the treatment remains after 5 to 11 years.

Figure 6.1 to Figure 6.6 are plots of the longitudinal CBR distribution at each site, which is obtained from correlations with DCPI. There are two key observations: (1) the addition of lime treatment to the natural soil has the potential to significantly increase the CBR of the natural soil, by as much as $500 \%$ to $1500 \%$, as indicated by both DCPI and FWD tests; and (2) the results obtained show a very large scatter, both along the length of the road and also with depth. 


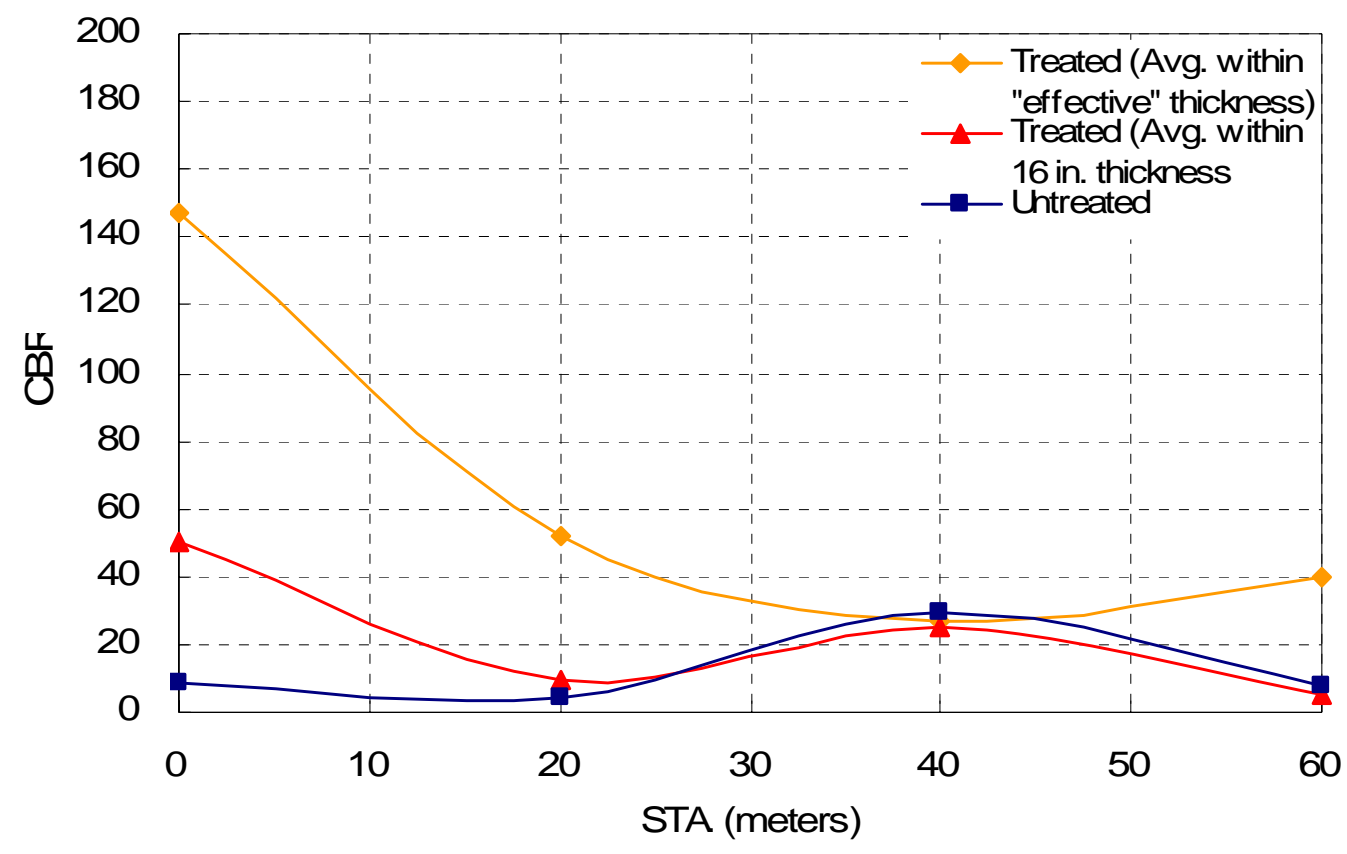

Figure 6.1 CBR of subgrade estimated from DCPT results. Site (1)

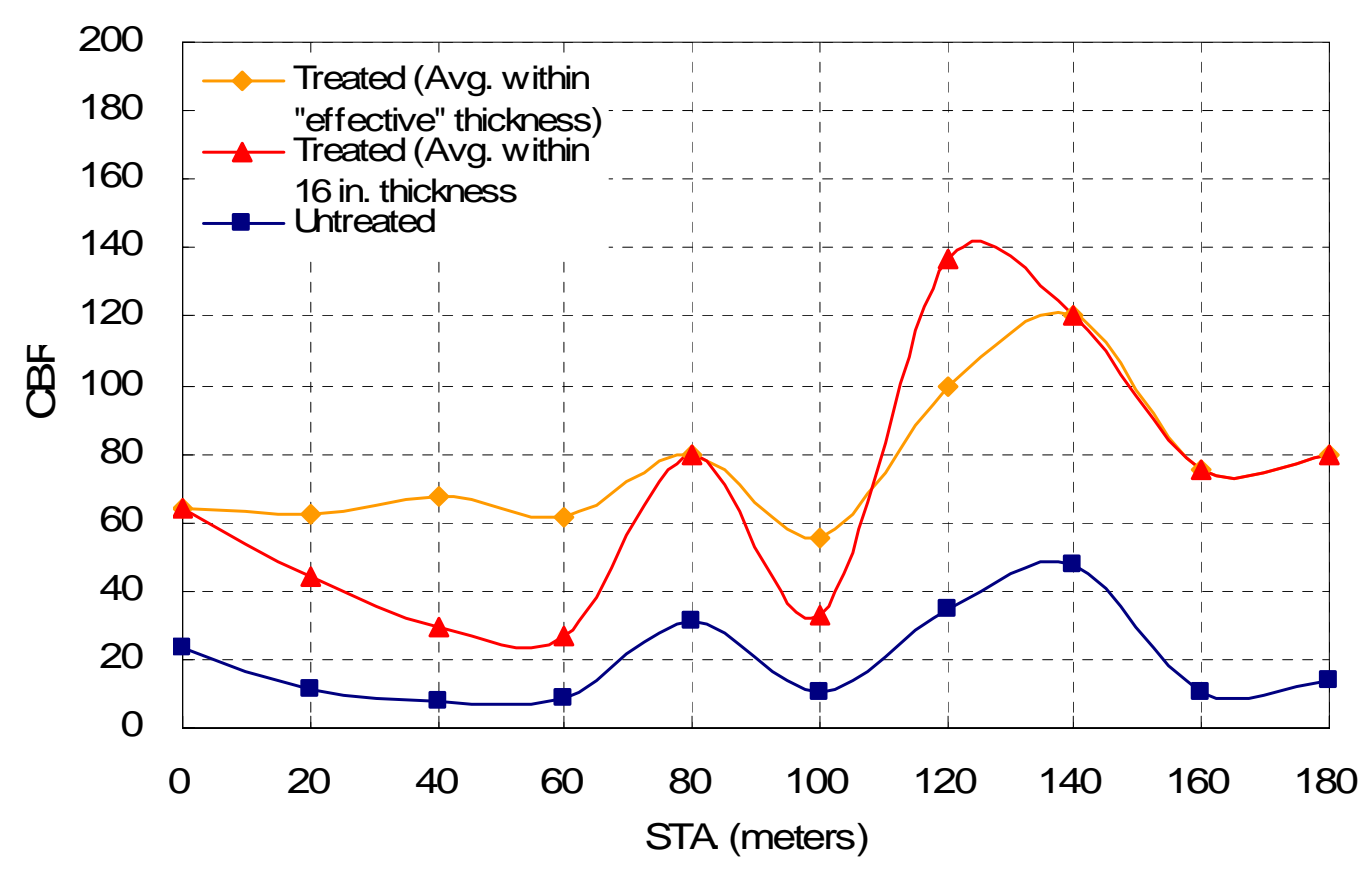

Figure 6.2 CBR of subgrade estimated from DCPT results. Site (2) 


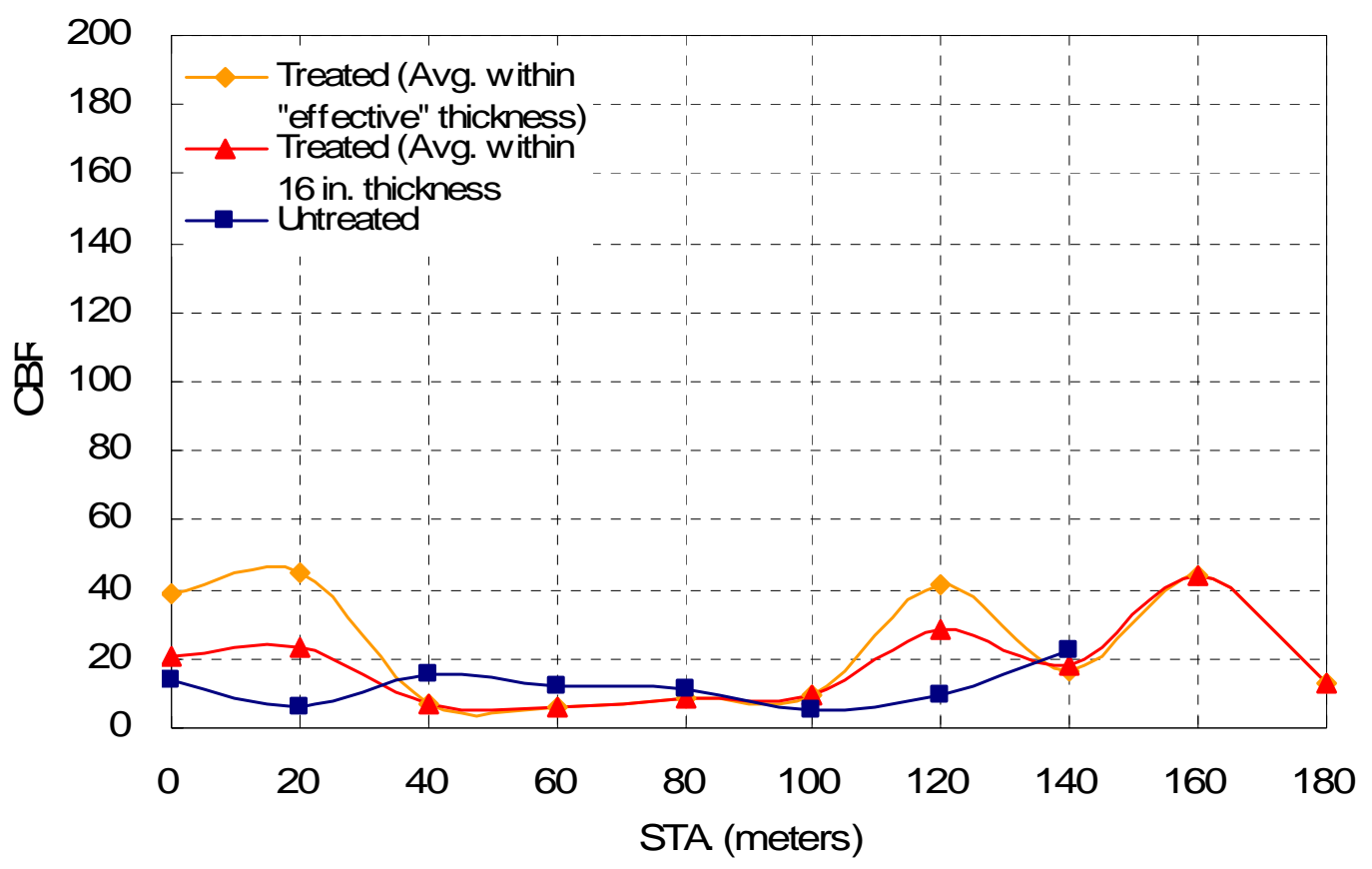

Figure 6.3 CBR of subgrade estimated from DCPT results. Site (3)

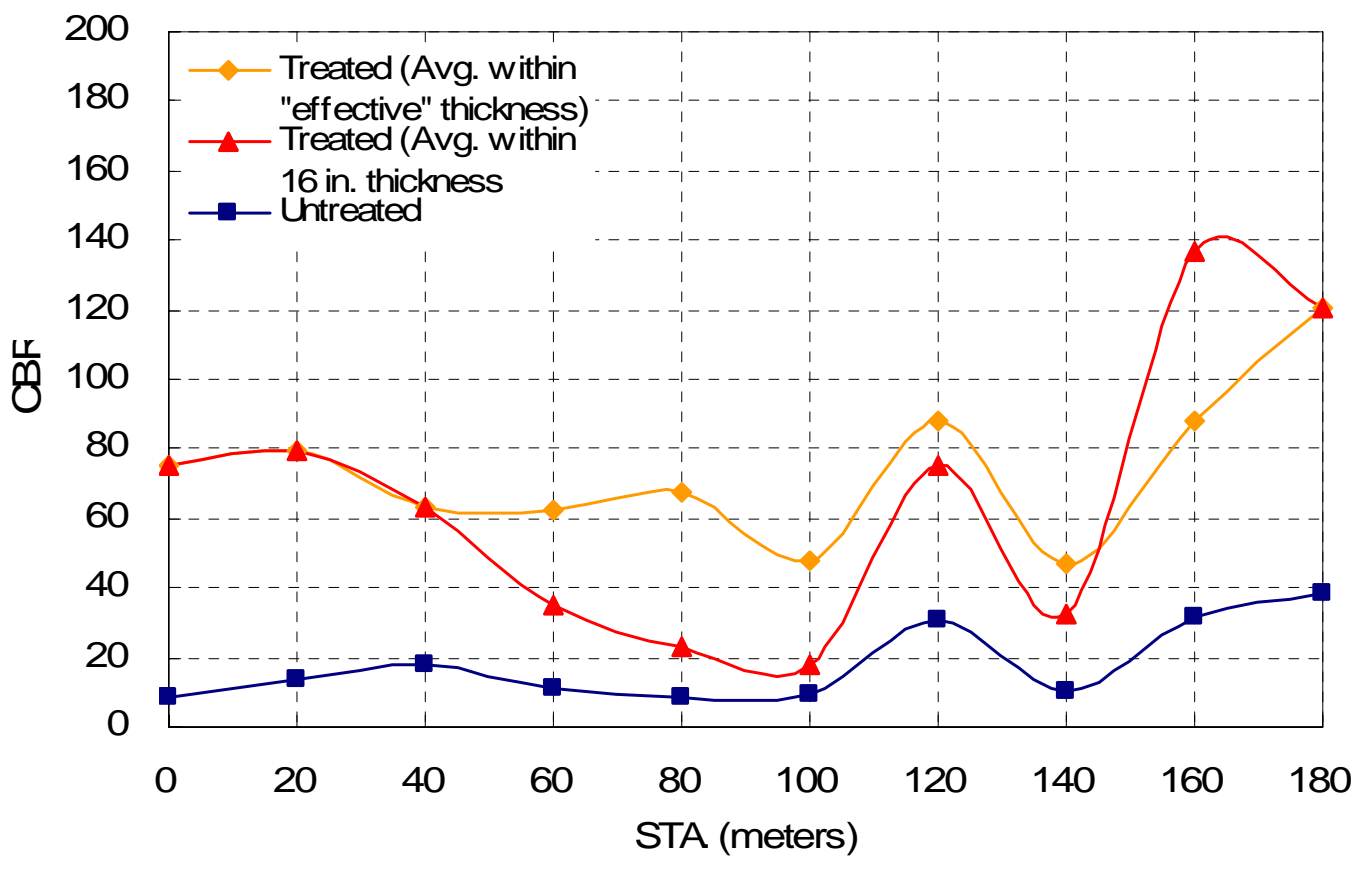

Figure 6.4 CBR of subgrade estimated from DCPT results. Site (4) 


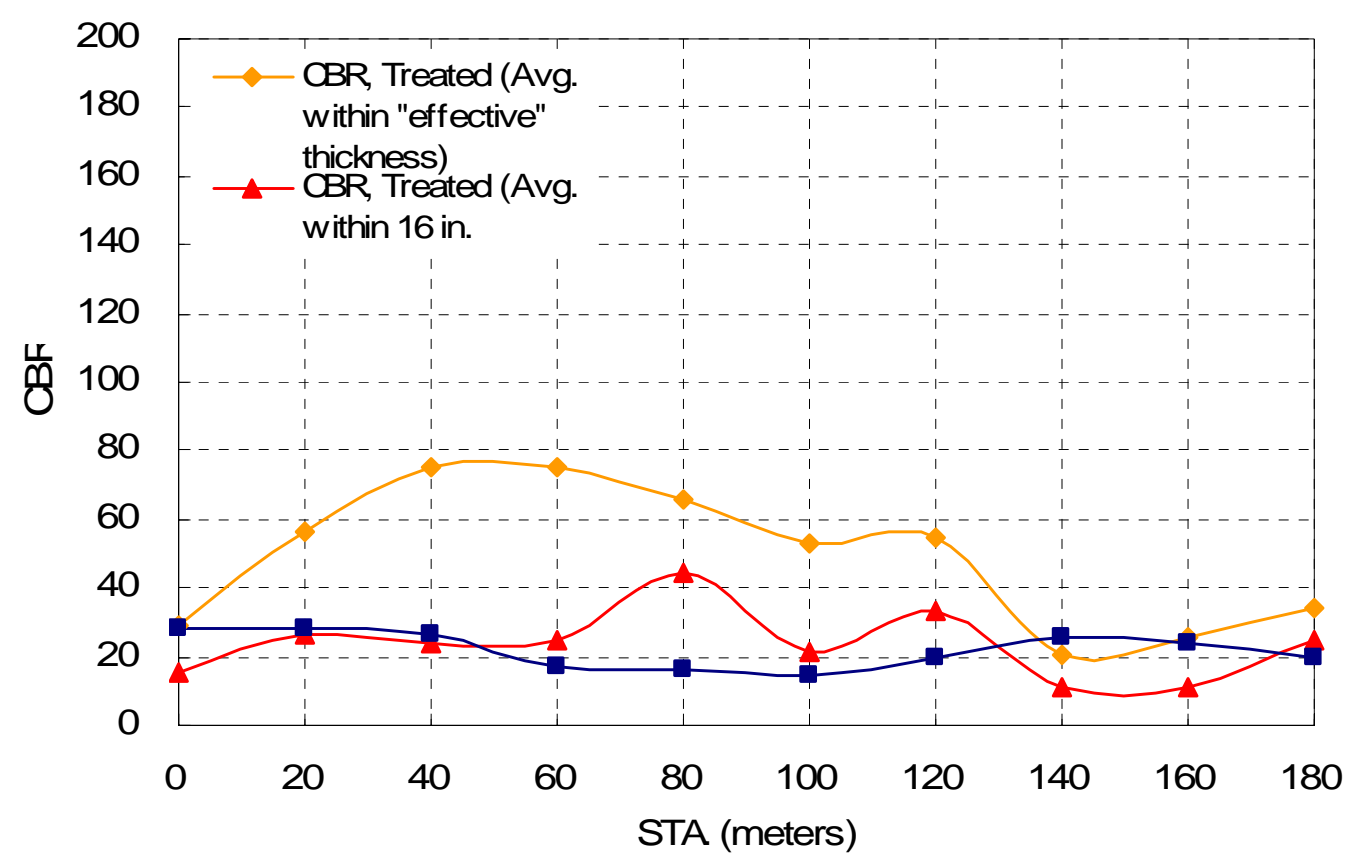

Figure 6.5 CBR of subgrade estimated from DCPT results. Site (5)

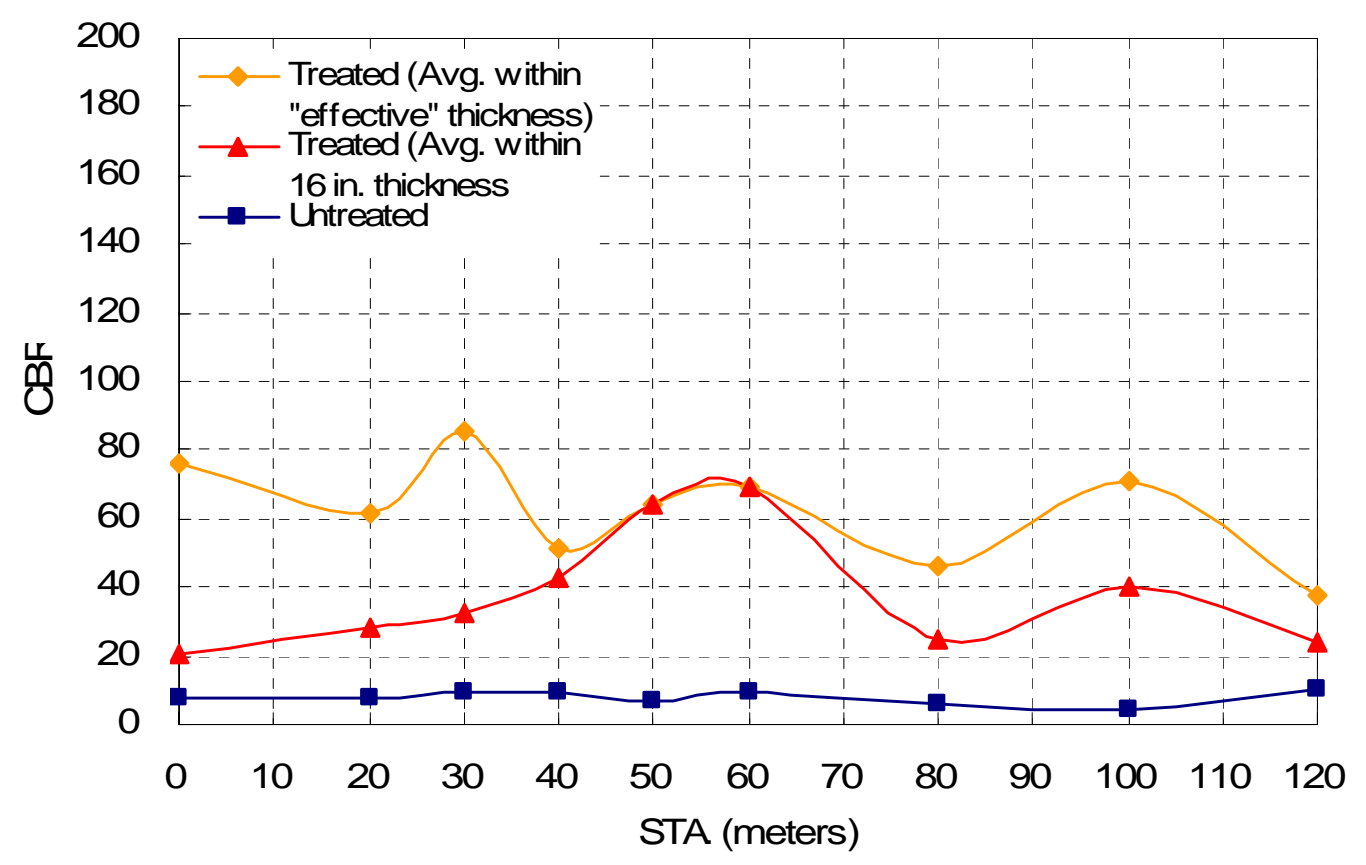

Figure 6.6 CBR of subgrade estimated from DCPT results. Site (6) 
Figure 6.1, which corresponds to the CBR at site (1), illustrates the two observations. At STA (0) the CBR of the effective thickness (this is the depth over which the DCPI are small and uniform) is very high, about 150 , which represents an extremely large increase with respect to the CBR of the natural soil, which was about 10 . The increase is $1500 \%$. The average of the CBR over the design depth of 16 inches at the same location is only 50. Compared with the value of the natural soil this still represents a large increase, about $500 \%$, but compared with the CBR of the effective thickness, it is a clear indication of the non-uniform results with depth. Inspection of the CBR of the effective and average thickness of the treated subgrade along the length of site (1) shows a large scatter along the length of the road. For example between STA. 30 meters and STA. 50 meters the treatment was not successful in improving the CBR (it has to be mentioned again that the treatment was successful as the soil was improved from a clayey soil to a silty sand, and surely the treated soil provided an acceptable working platform). The discussion can be applied to all other sites where similar trends are observed. It has to be noted that the CBR at site (3) showed no improvement with treatment.

Attempts to correlate CBR with lime content both at depth and along the road have shown no relation between lime and CBR values. While the results show that the addition of lime does improve the CBR, the fact that no clear relation is found is an indication that other factors, besides lime content, have a significant effect. These include: percentage of $\mathrm{CaO}$ and $\mathrm{Ca}(\mathrm{OH})_{2}$ (active lime) in the LKD before treatment, and construction quality. Support for the first factor is given by the fact that large amounts of $\mathrm{CaCO}_{3}$ have been found at different sites, but there is no strong correlation between the amount of lime found and improved properties; e.g. compare $\mathrm{CaCO}_{3}$ content between 
sites (1), (6) and (4), (5); also site (3) has a very large percentage of $\mathrm{CaCO}_{3}$ with little or no CBR improvement. Support for the second factor is given by the large scatter of DCPI values with depth. An additional observation that appears to support the finding of questionable construction quality is the presence of large DCPI values at the contact between the subgrade and the natural soil observed at sites (5) and (6); see Table 6.1 and for example Figure 5.111 for site (5) and Figure 5.132 for site (6). These "spikes" could be an indication of disturbance, large water content or poor mixture and/or compaction during construction.

In conclusion, the research has shown the following: (1) treatment with LKD decreases the plasticity of a soil and substantially increases the stiffness of the subgrade; (2) the long-term improvement of the stiffness of the subgrade is confirmed and the LKD remains in the soil even after 11 years of service of the roads; (3) the construction quality observed from the field tests is highly variable; and (4) LKD is found to be a good and reliable material, provided that a good quality control is maintained during construction.

\subsection{Recommendations and Implementation}

The research has shown the following: (1) the lime remains in the soil even after 11 years of service of the road after construction; (2) the addition of lime decreases the plasticity of the soil and increases its CBR; and (3) the construction quality observed from the field tests is highly questionable. An added comment regarding the last observation is that what was done during construction was adequate, and possibly acceptable, given that the intent of the treatment was only to obtain a stable working platform and not to improve the engineering properties of the soil. However within the 
realm of this research, the results denote a highly non-uniform construction quality.

The recommendations for implementation of the research are based on consensus among INDOT and FHWA personnel, and from industry. In the light of the positive results obtained from the research it is recommended to increase the CBR of LKD-treated subgrade soils by $20-30 \%$ the CBR of the natural, untreated, soil. This increase accounts for the immediate benefits of the engineering properties of the treated soil as well as the long-term benefits. It also considers that the quality control that INDOT has in place today at construction sites has improved over the years.

In the future a further increase of the CBR of the treated subgrade would be appropriate as field data from construction sites is gathered. Such increase needs to be linked to an improvement of quality control during all the phases of the subgrade treatment with LKD that should result in a uniform treatment of the soil along the road. Specifically good quality construction practices and quality control need to be achieved through all the stages of construction: delivery of the LKD at the site; uniform spread of LKD, uniform mixing, and uniform compaction. The problems that the research has identified as the source of the non-uniform engineering properties of treated subgrade layers are associated with low reactive lime content of the LKD delivered at the site, which could be related to a long-time storage of the product and/or partial hydration of the lime; and also to non-ideal construction practices including non-optimal spread, mixing and compaction. Such problems can be identified in the field through systematic testing and an effective quality program, which could include measurements of: (1) the $\mathrm{CaO}$ content of the lime at the site, e.g. using phenolphtaleine; (2) the lime delivered per unit surface; and (3) the density achieved after compaction. Such tests could be 
complemented by direct measurements of the engineering properties of the subgrade by conducting DCPI and plate load tests. In addition disturbed samples should be taken to the laboratory for identification and lime content tests. Once the road is in service periodic inspections will provide an assessment of the level of performance with time and also as a function of weather conditions. 


\section{LIST OF REFERENCES}

AASHTO M 216-05 (2005), "Standard Specification for Lime for Soil Stabilization," AASHTO.

AASHTO T 99-01 (2004), "Standard Method of Test for Moisture-Density Relationship of Soils Using a 2.5-kg (5.5-lb) Rammer and a 305-mm (12-in.) Drop”, AASHTO.

AASHTO T 99-01 (2004) "Standard Method of Test for Moisture-Density Relationship of Soils Using a 4.54-kg (10-1b) Rammer and a 457mm (18-in.) Drop", AASHTO.

AASHTO T 256-01 (2001) "Standard Method of Test for Pavement Deflection Measurements," AASHTO.

AASHTO T 307-99 (2003) "Standard Method of Test for the Resilient Modulus and Aggregate Materials", AASHTO.

ASTM C 5-03 (2003) "Standard Specification for Quicklime for Structural Purposes," Annual book of ASTM Standards, Vol.04.08, ASTM international, West Conshohocken, PA.

ASTM C 25-99 (1999) "Standard Test Method for Chemical Analysis of Lime stone, Quicklime, and Hydrated Lime," Annual book of ASTM Standards, ASTM international, West Conshohocken, PA.

ASTM C 50-00 (2000) "Standard Practice for Sampling, Sample Preparation, Packing, and Marking of Lime and Limestone Procedure," Annual book of ASTM Standards, 
ASTM international, West Conshohocken, PA.

ASTM C 110-05 (2005), "Standard Test Method for Unconfined Compressive Strength of Compacted Soil-Lime Mixtures," Annual book of ASTM Standards, Vol.04.08, ASTM international, West Conshohocken, PA.

ASTM C 977-03 (2003), "Standard Specification for Quicklime and Hydrated Lime for Soil Stabilization," Annual book of ASTM Standards, ASTM international, West Conshohocken, PA.

ASTM D 558-04 (2004), "Standard Test Method for Moisture-Density Relations of SoilCement Mixtures," Annual book of ASTM Standards, ASTM international, West Conshohocken, PA.

ASTM D 698-00 (2000), "Standard Test Method for Laboratory Compaction Characteristics of Soil Using Standard Effort $(12,400 \mathrm{ft}-\mathrm{lbf} / \mathrm{ft} 3(600 \mathrm{KN}-\mathrm{m} / \mathrm{m} 3))$, Annual book of ASTM Standards, ASTM international, West Conshohocken, PA.

ASTM D 1557-02 (2002), "Standard Test Method for Laboratory Compaction Characteristics of Soil Using Modified Effort (56,000ft-lbf/ft3 (2,700KN-m/m3))," Annual book of ASTM Standards, ASTM international, West Conshohocken, PA.

ASTM D 3155-98 (1998), "Standard Test Method for Lime Content of Uncured SoilLime Mixtures," Annual book of ASTM Standards, ASTM international, West Conshohocken, PA.

ASTM D 3551-02 (2002), "Standard Practice for Laboratory Preparation of Soil-Lime 
Mixtures Using a Mechanical Mixer," Annual book of ASTM Standards, ASTM international, West Conshohocken, PA.

ASTM D 4972-01 (2001), "Standard Test Method for pH of Soils," Annual book of ASTM Standards, ASTM international, West Conshohocken, PA.

ASTM D 5050-96 (1996), "Standard Guide for Commercial Use of Lime Kiln Dusts and Portland Cement Kiln Dust,” ASTM international, West Conshohocken, PA.

ASTM D 5102-04 (2004), “Standard Test Method for Unconfined Compressive Strength of Compacted Soil-Lime Mixtures," Annual book of ASTM Standards, ASTM international, West Conshohocken, PA.

ASTM D 6236-98 (1998), "Standard Guide for Coring and Logging Cement- or LimeStabilized Soil," Annual book of ASTM Standards, ASTM international, West Conshohocken, PA.

ASTM D 6276-99 (1999), "Standard Test Method for Using pH to Estimate the Soil-lime Proportion Requirement for Soil Stabilization,” Annual book of ASTM Standards, ASTM international, West Conshohocken, PA.

ASTM D 6951-03 (2003), "Standard Test Method for Use of the Dynamic Cone Penetrometer in Shallow Pavement Application,” Annual book of ASTM Standards, ASTM international, West Conshohocken, PA.

ASTM (2002), "Resilient Modulus Testing for Pavement Components", STP1437, ASTM international. 
Basma, A.A. and Tuncer, E.R. (1990), "Effect on Lime on Volume Change and Compressibility of Expansive Clays," Transportation Research Record 1295, TRB, National Research Council, Washington D.C.

Bhattacharja, S., Bhatty, J.I. and Todres, H.A. (2003), "Stabilization of Clay Soils by Portland Cement or Lime - A Critical Review of Literature," PCA R\&D Serial No. 2066, Portland Cement Association, Stokie, Illinois

Bhuiyan, J.U. and Little, D.N. (1995) "Evaluation of Calcareous Base Course Materials Stabilized with Low Percentage of Lime in South Texas," Transportation Research Record 1486, TRB, National Research Council, Washington D.C.

Boardman. D.I., Glendinining, S., Rogers, C.D.F., and Holt, C.C. (2001), "In Situ Monitoring of Lime-Stabilized Road Subgrade," Transportation Research Record 1757, pp 3-13, TRB, National Research Council, Washington D.C.

Christensen, A.P. (1969), “Cement Modification of Clay Soils", RD002, Portland Cement Association, Skokie, Illinois

Daita, R.K.M., Drnevich, V.P. and Kim, D.H. (2005), "Family of Compaction Curves for Chemically Modified Soils," FHWA/IN/JTRP-2005/7, Indiana Department of Transportation.

Diamond, S. and Kinter, E.B. (1965), "Mechanisms of Soil-Lime Stabilization: An Interpretive Review", Highway Research Record 92, pp 33-103, TRB, National Research Council, Washington D.C. 
Doty, R. and Alexander, M.L. (1968), “Determination of Strength Equivalency for Design of Lime-Stabilized Roadways," Report No. FHWA-CA-TL-78-37.

Dubbleton, M.J. and Ross, N.F. (1960), "Effect of Temperature in Gain of Strength of Soils Stabilized with Hydrated Lime and Portland Cement, RN/3665, B.S. 438, Road Research Laboratories, Great Britain.

Eades, J.E., Nichols, F.P., and Grim, R.E. (1963) "Formation of New Minerals with Lime Stabilization as Proven by Field Experiments in Virginia," Highway Research Bulletin 335.

Fernandez, J. (2002), "Kinetic Study of The Hydrothermal Reaction of Fly Ash with $\mathrm{Ca}(\mathrm{OH}) 2$ In The Preparation of Desulfurant Sorbents," Chem. Eng. Comm., Vol. 189(3).

Geiman, C.M., Filz, G.M. and Brandon, T.L. (2005), "Stabilization of Soft Clay Subgrades in Virginia : Phase I Laboratory test", VTRC05-CR16, Virginia Transportation Research Council.

George, K.P. and Uddin, W. (2000), “ Subgrade Characterization for Highway Pavement Design”, FHWA/MS-DOT-RD-00-131, Mississippi Department of Transportation.

Hassan, A. (1996), “The Effect of Material Parameters on Dynamic Cone Penetrometer Results for Fine Grained Soils and Granular Materials," Ph.D. Dissertation, Oklahoma State University, Stillwater, Oklahoma.

Holtz, W.G. (1969), "Volume Change in Expansive Clay Soils and Control by Lime 
Treatment," Presented at the Second International Research and Engineering Conference on Expansive Clay Soils, Texas A\&M University.

INDOT (2002), "Design Procedures for Soil Modification or Stabilization", Indiana Department of Transportation.

Kennedy, T.W., Smith, R., Holmgreeen R.J., and Tahmoressi, M. (1987), “An Evaluation of Lime and Cement Stabilization", Transportation Research Record 1119, TRB, National Research Council, Washington, D.C. pp 11-25.

Kim, D. and Siddiki, N. Z. (2004). "Lime Kiln Dust-Lime - A Comparative Study in Indiana, TRB 2004 Annual Meeting, Washington D. C.

Kim, D., Siddiki, N., Sommer, K., and Jackson, W. E. (2005), "Field Compaction Evaluation with DCPT, CLEGG Hammer, and Nuclear Gauge Test", TRB 2005 Annual Meeting, Washington, D.C., 2005.

Kim, D. and Siddiki, N. Z. (2006), Simplification of Resilient Modulus for Subgrades, FHWA/IN/JTRP-2005/23, Purdue University, IN.

Kleyn, E.G., and Savage, P.E. (1982), "The Application of the Pavement DCP to Determine the Bearing Properties and Performance of the Road Pavements," International Symposium on Bearing Capacity of Roads and Airfields, Trodheim, Norway.

Kota, P., Scullion, T. and Little, D.L.(1995), "Investigation of Performance of Heavily Stabilized Base in Houston, Texas, District," Transportation Research Record 1486, 
TRB, National Research Council, Washington D.C.

National Lime Association (2004), "Lime-treated soil construction manual: lime stabilization \& lime modification.” National Lime Association, Arlington, Virginia.

Little, D.N., Scullion, T., Kota, P.B.V.S., and Bhuiyan, J. (1995), "Identification of the Structural Benefits of Base and Subgrade Stabilization," Report No. FHWA/TX94/1287-2, Texas Department of Transportation.

Little, D.N., Thompson, M.R., Terrel, R.L., Epps, J.A., and Barenberg, E.J. (1987), “Soil Stabilization for Roadways and Airfields," Report ESL-TR-86-19, Air Force Services and Engineering Center, Tyndall Air Force Base, Florida.

Little, D.N. (1996), “Assessment of In Situ Structural Properties of Lime-stabilized Clay Subgrades," Transportation Research Record 1546, TRB, National Research Council, Washington D.C.

Little, D.N. (1999), "Evaluation of Structural Properties of Lime Stabilized Soils and Aggregates. Volume 1: Summary of Findings," National Lime Association, Arlington, Virginia.

Little, D.N. (2000), "Evaluation of Structural Properties of Lime Stabilized Soils and Aggregates. Volume 3: Mixture Design and Testing Protocol For Lime Stabilized soils," National Lime Association, Arlington, Virginia.

Little, D.N. (2001), "Example Problem Illustrating the Application of the National Lime Association Mixture Design and Testing Protocol(MDTP)," National Lime 
Association, Arlington, Virginia.

Livneh, M. (1987), "Validation of Correlations between a Number of Penetration Tests and In Situ California Bearing Ration Tests,” Transportation Research Record 1219, TRB, National Research Council, Washington D.C., pp. 56-67.

Livneh, M. and Ishai, I. (1988), “The Relationship Between In-Situ CBR Test and Various Penetration Tests," Proceedings of the First International Synapse on Penetration Testing, Orlando, Florida, ISOPT-1.

Livneh, M., Ishai, I. and Livneh, N.A. (1995), "Effect of Vertical Confinement on Dynamic Cone Penetrometer Strength Values in Pavement and Subgrade Evaluation,' Transportation Research Record 1473, TRB, National Research Council, Washington D.C., pp. 1-9.

Livneh, M. (2000), "Friction Correction Equation for the Dynamic Cone Penetrometer in Subsoil Strength Testing," Paper Presented at the 79th Transportation Research Board Annual Meeting, TRB, National Research Council, Washington D.C.

Malleal, J. and Quintus, H.V. (2004), "Consideration of Lime-stabilized Layers in Mechanistic-Empirical Pavement Design”, National Lime Association, Arlington, Virginia.

McElvaney, J. and Duatnika, I. (1991). "Strength Evaluation of Lime-stabilized Pavement Foundation Using the Dynamic Cone Penetrometer," Australian Rd. Res., Volume 21, No.1, pp. 40-52. 
Prusinski, J.R. and Sankar Bhattacharja (1999), "Effectiveness of Portland Cement and Lime in Stabilizing Clay Soils" Transportation Research Record, TRB, National Research Council, Washington D.C.

Sabatini, P.J., Bachus, R.C. and Mayne, P.W. (2002),"Geotechnical Engineering Circular NO. 5, Evaluation of soil and Rock Properties," FHWA-IF-02-034, Federal Highway Administration, Washington, D.C.

Smith, K.A. (1998), "Effect of Calcium Oxide Dose on Thermal Reactions, Lime Speciation, and Physical Properties of Alkaline Stabilized Biosolids,” Vol.70, No.2, Water Environment Research.

Stocker, P.T. (1975), "Diffusion and Diffuse Cementation in Lime and Cement Stabilized Clayey Soils - Chemical Aspects,” Australian Road Research, Vol.5, No.9

TxDOT Tex-101-E, "Preparing Soil and Flexible Base Materials for Testing," Texas Department of Transportation.

TxDOT Tex-113-E (2004), "Laboratory Compaction Characteristics and Moisturedensity Relationship of Base Materials" Texas Department of Transportation.

TxDOT Tex-121-E (2002), “Soil-Lime testing” Texas Department of Transportation.

Thompson, M.R. (1969), "Engineering Properties of Lime-Soil Mixtures," Journal of Materials, ASTM, Vol.4.

Transportation Research Board State of Art Report (1987), "Lime stabilization: reaction, properties, design, and construction", TRB, National Research Council, Washington 


\section{D.C.}

Uddin, M.K. and Buensuceso, B.R. (2002), "Lime Treated Clay: Salient Engineering Properties and a Conceptual Model", Soils and Foundation, Japanese Geotechnical Society, Vol. 42, No. 5, pp.79-89.

Viallar-Cociana, E. (2003), "Kinetics of the pozzolanic reaction between lime and sugar cane straw ash by electrical conductivity measurement: A kinetic-diffusive model," Cement and Concrete Research.

Webster, S. L., Grau, R. H., and Williams, T. P. (1992). Description and Application of Dual Mass Dynamic Cone Penetrometer. Final Report, Department of Army, Waterways Experiment Station, Vicksburg, MS.

Winterkorn, H. (1942), “Surface Chemical Factors Influencing the Stabilization of Soil with Cement," Proceeding, 22nd Annual Meeting of the Highway Research Board, National Research Council, Washington D.C.

Yusuf, F.A.M. and Little, D.N. (2001) "Evaluation of Structural Contribution of Lime Stabilization of Subgrade Soils in Mississippi," Transportation Research Record 1757, TRB, National Research Council, Washington D.C. 


\begin{abstract}
APPENDIX
This appendix contains boring logs, at each field testing site, which were obtained from the existing geotechnical data used for design of the corresponding road project. The boring logs were used for preliminary investigation on each site before field testing, as discussed in Chapter 3.
\end{abstract}




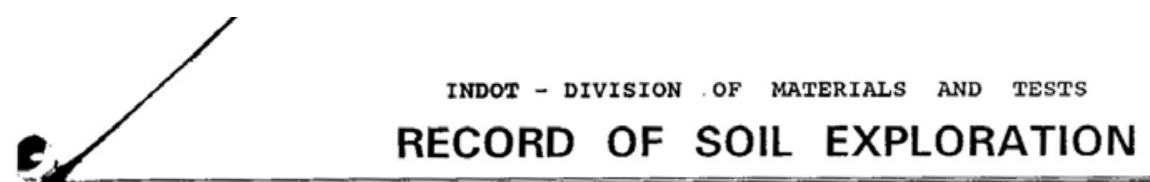

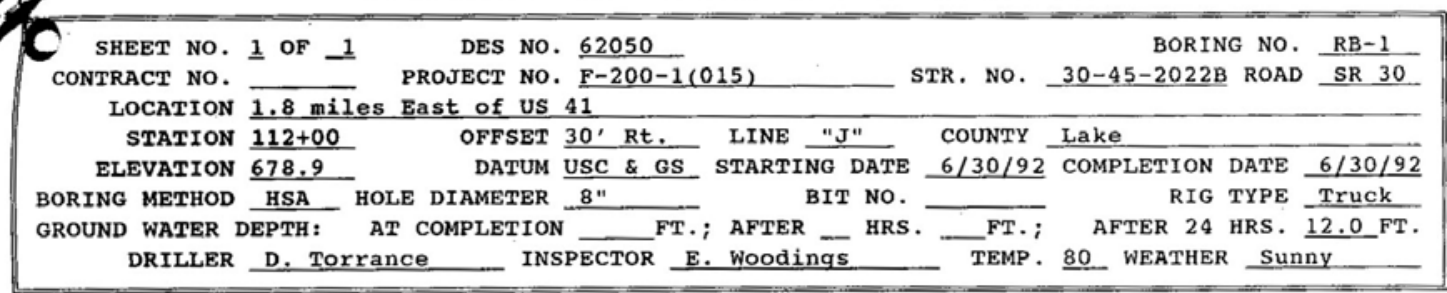

\begin{tabular}{|c|c|c|c|c|c|c|}
\hline & \multirow{2}{*}{ DESCRIPTION OF MATERIALS } & \multicolumn{4}{|c|}{ SAMPLE DATA } & \multirow{2}{*}{ REMARKS } \\
\hline & & TYPE/NO & DEPTH & *BLOW COUNT & \&RECOV & \\
\hline \begin{tabular}{ll|}
- & - \\
- & - \\
- & - \\
- & - \\
- & $5-$ \\
- & - \\
- & - \\
- & - \\
- & - \\
-10 & - \\
- & - \\
- & - \\
- & - \\
- & - \\
-15 & - \\
- & - \\
- & - \\
- & - \\
- & - \\
-20 & - \\
- & - \\
- & - \\
- & - \\
- & - \\
-25 & - \\
- & - \\
- & - \\
- & - \\
- & - \\
-30 & - \\
- & - \\
- & - \\
- & - \\
- & - \\
-35 & - \\
- & - \\
- & - \\
- & - \\
- & - \\
$-40-$
\end{tabular} & 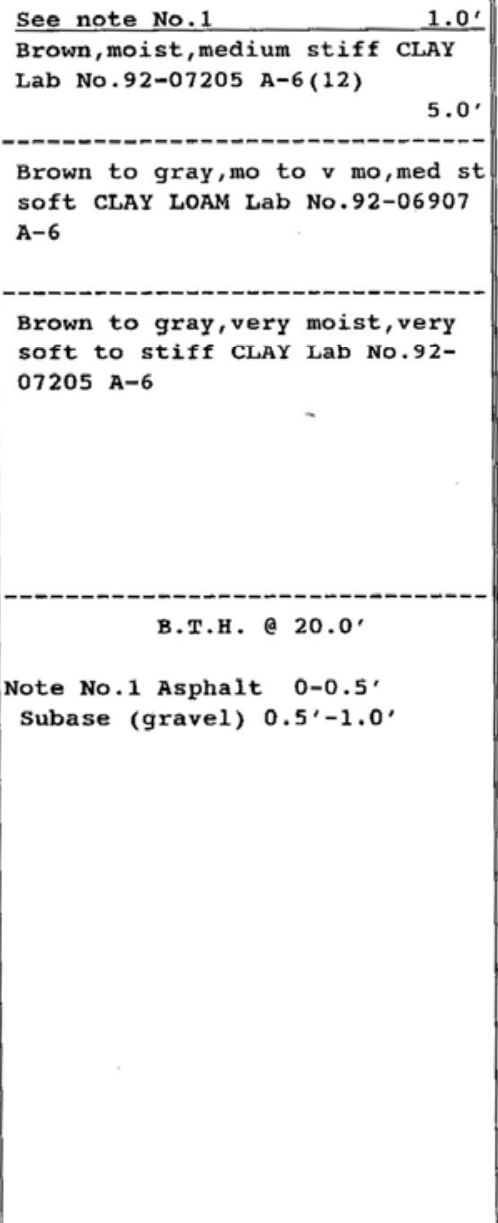 & $\begin{array}{l}\text { ss-3 } \\
\text { ss-4 } \\
\text { ss-5 }\end{array}$ & $\begin{array}{l}1.0-2.5 \\
3.5-5.0 \\
6.0-7.5 \\
8.5-10.0 \\
13 \cdot 5-15.0 \\
18.5-20.0\end{array}$ & $\begin{array}{l}4 / 4 / 4 \\
3 / 4 / 5 \\
3 / 4 / 4 \\
1 / 3 / 2 \\
0 / 2 / 3 \\
3 / 5 / 5\end{array}$ & 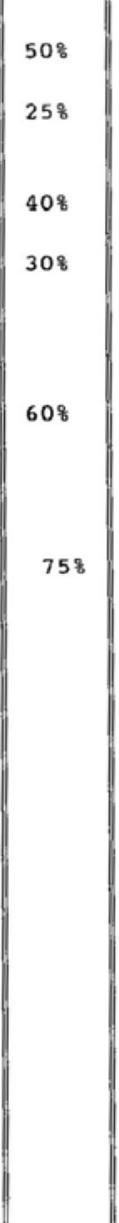 & Caved to $17.0^{\circ}$ \\
\hline
\end{tabular}

* Standard penetration test - 140 LB. hammer falling 30 inches

Figure A.1 Boring log for natural subgrade soil at site (1) 


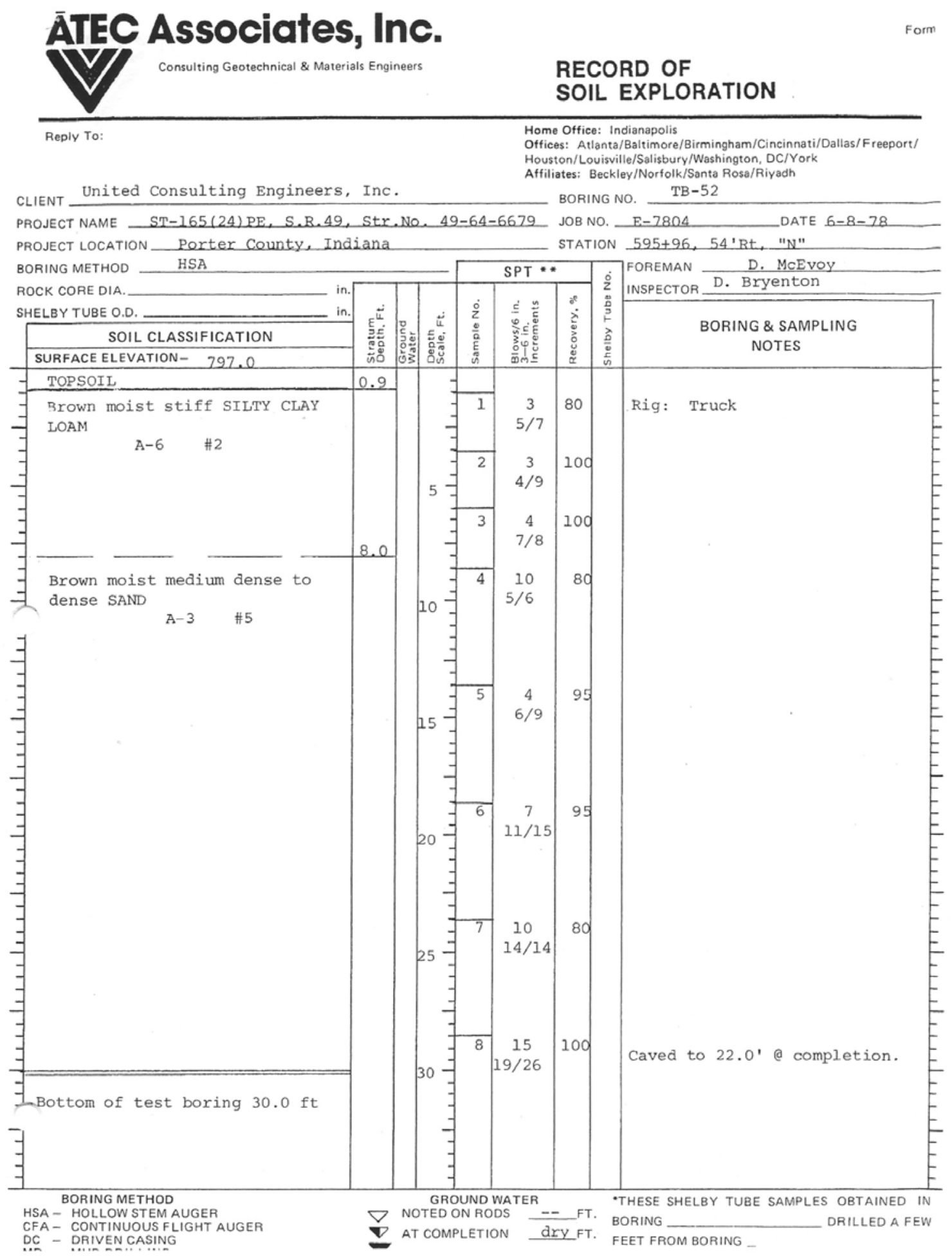

Fig A.2 Boring log for natural subgrade soil at site (2) 


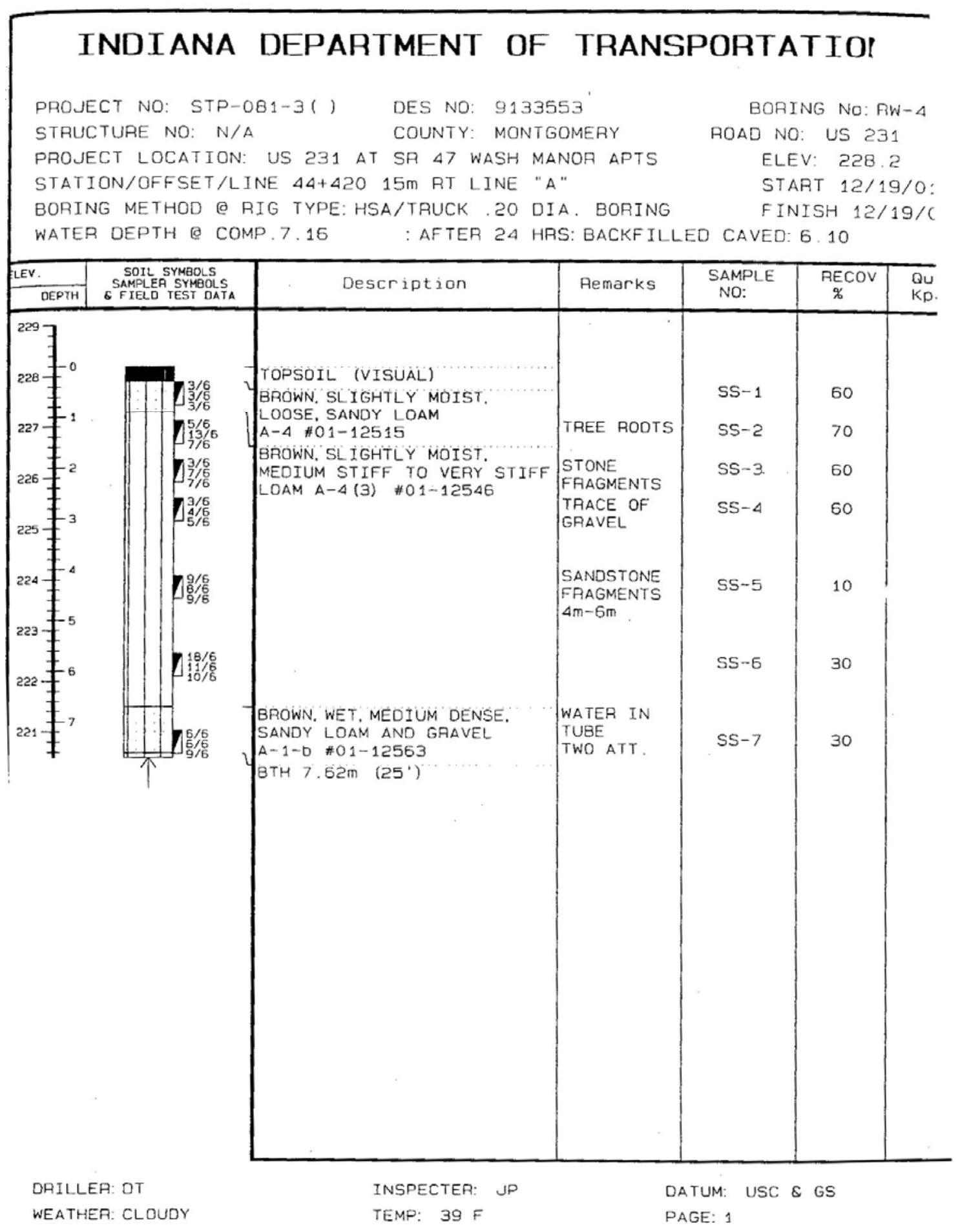

Figure A.3 Boring log for natural subgrade soil at site (4) 


\section{\AW ALT \& WITZIG ENGINEERING, INC.}

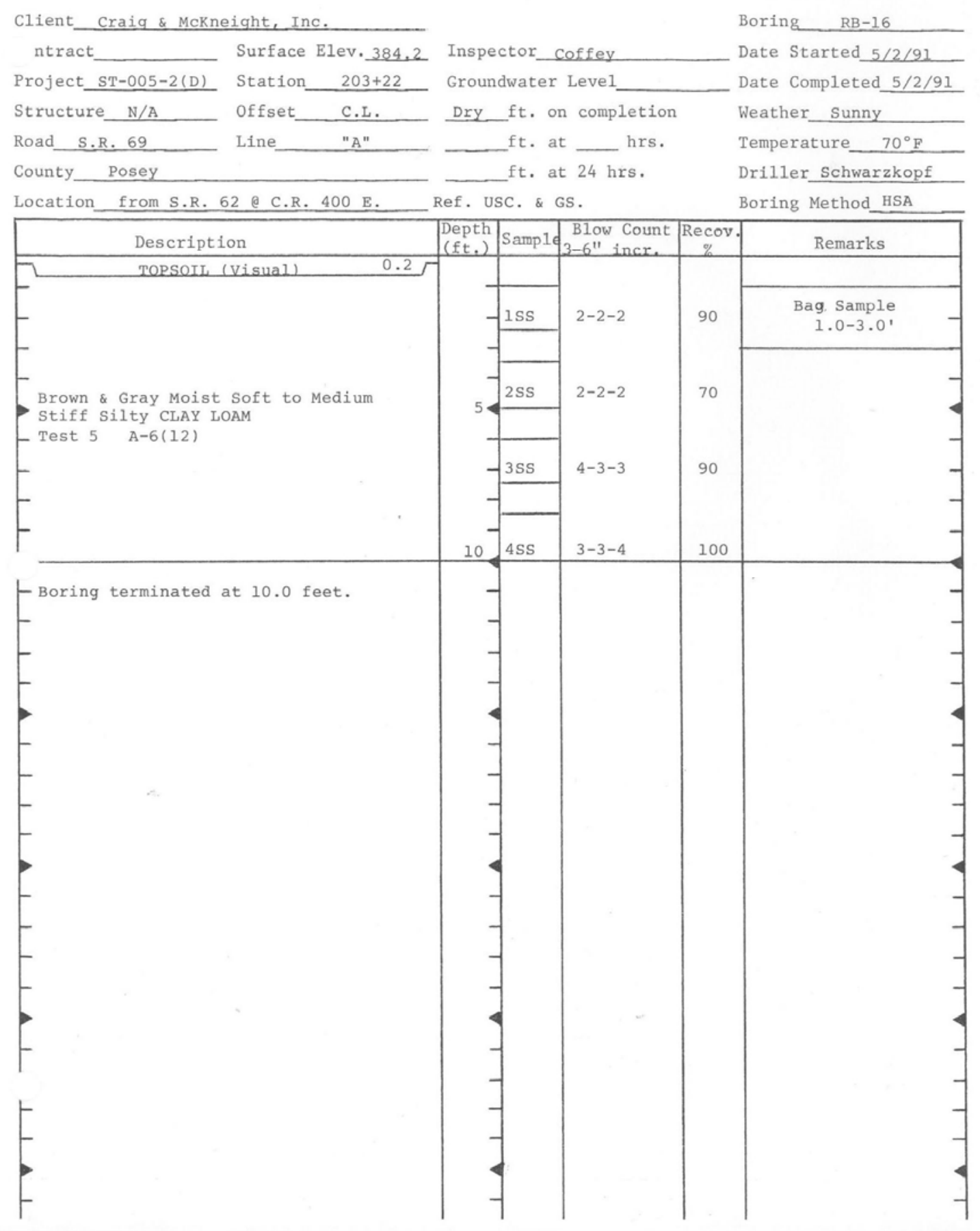

Figure A.4 Boring log for natural subgrade soil at site (5) 


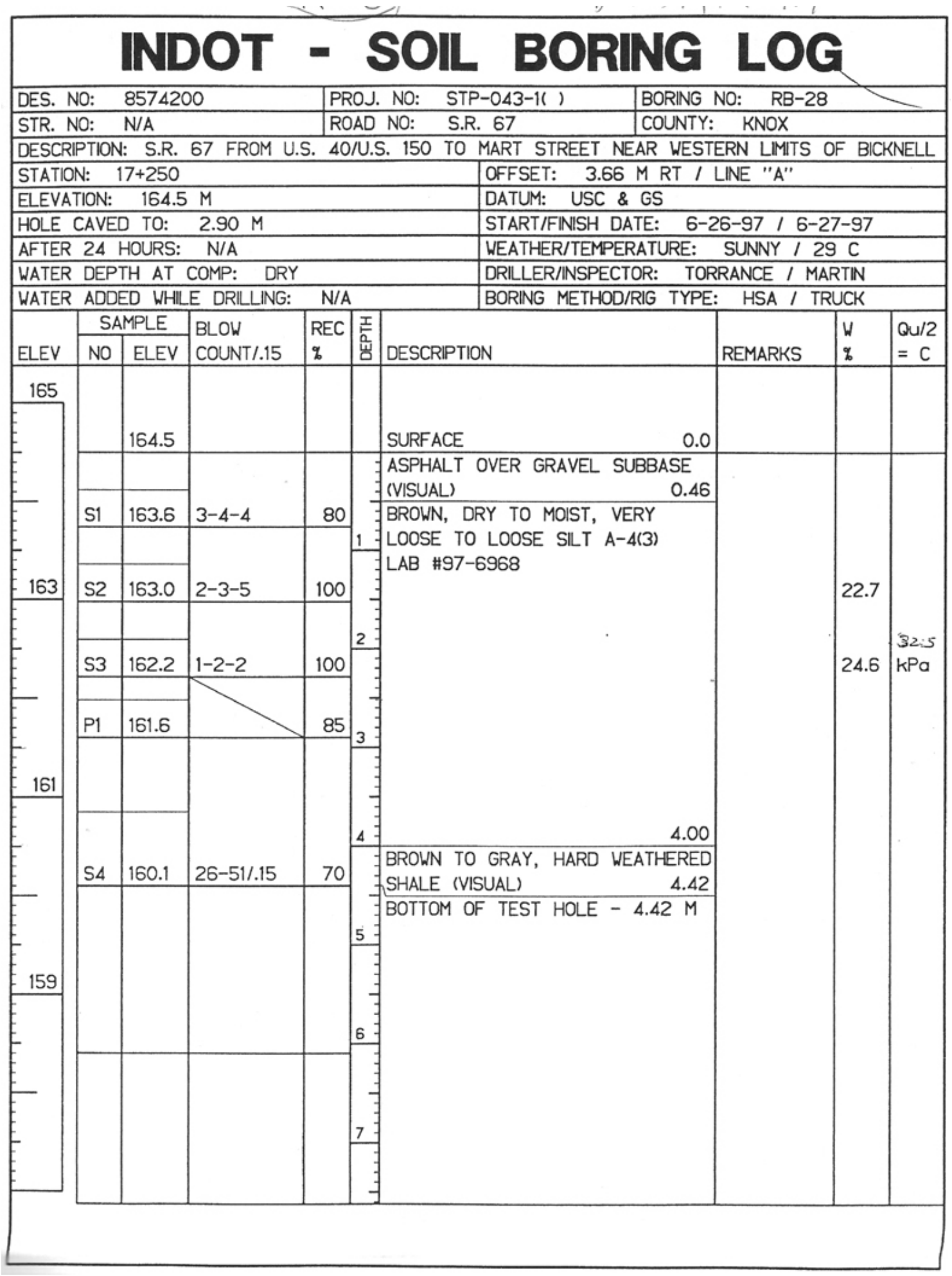

Figure A.5 Boring log for natural subgrade soil at site (6) 